Aus der Abteilung für Allgemeine Pflanzenpathologie und Pflanzenschutz des Departments für Nutzpflanzenwissenschaften der Georg-August-Universität Göttingen

\title{
Einfluss der Bestandesarchitektur auf die Ertragsbildung im Winterraps (Brassica napus L.)
}

\author{
Dissertation \\ zur Erlangung des Doktorgrades \\ der Fakultät für Agrarwissenschaften \\ der Georg-August-Universität Göttingen
}

vorgelegt von

Christian Comberg

geboren in Mettmann

Göttingen, im November 2014 
D 7

1. Referent: Prof. Dr. Andreas von Tiedemann

2. Referent: Prof. Dr. Heiko Becker

Tag der mündlichen Prüfung: 10. November 2014 


\section{Für Elisabeth}




\section{Inhalt}

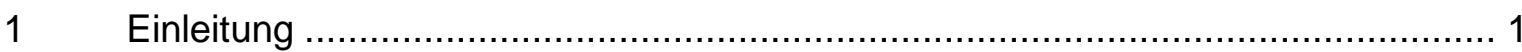

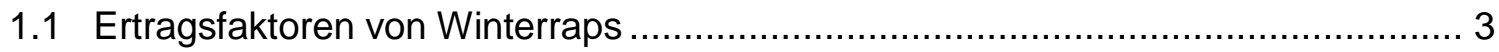

1.2 Wachstumsregulation in Winterraps durch Wachstumsregulatoren und Fungizide 8

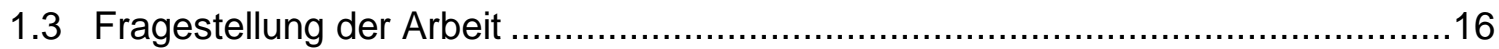

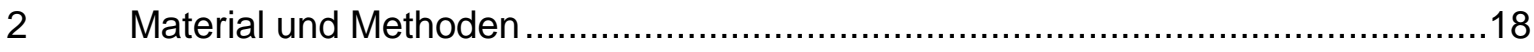

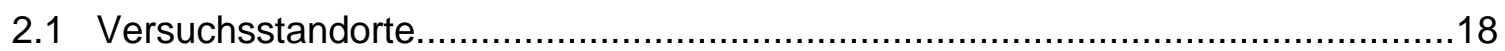

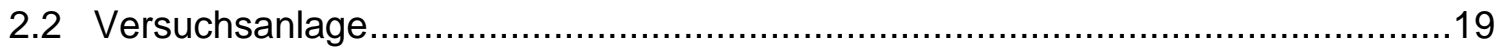

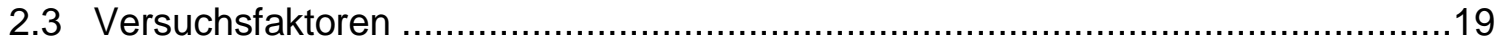

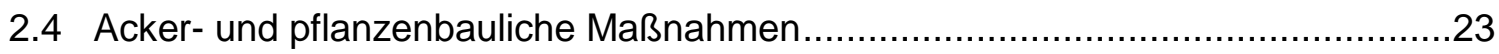

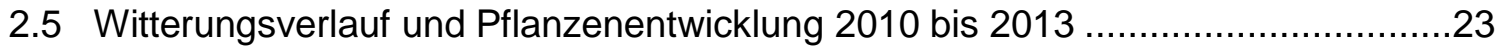

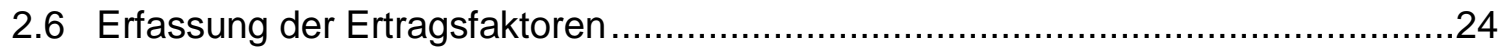

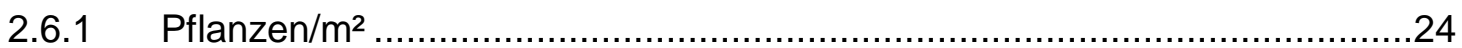

2.6.2 Schoten/Pflanze und Seitenriebe/Pflanze ...............................................25

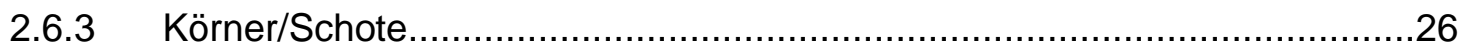

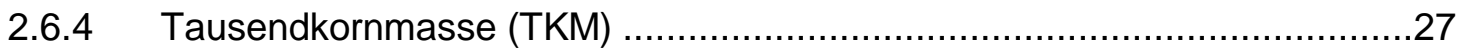

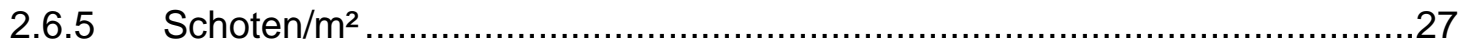

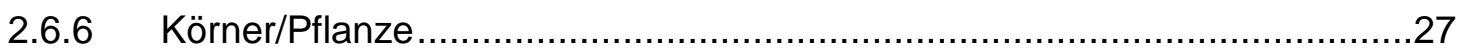

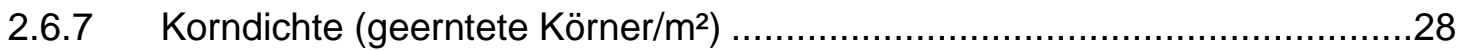

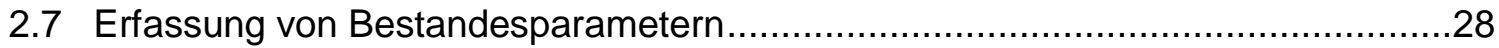

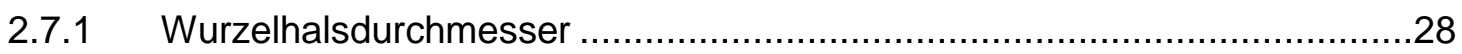

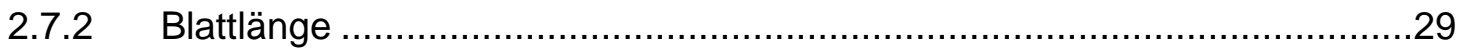

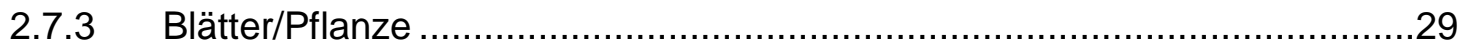

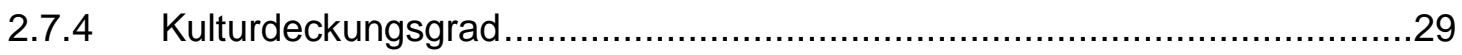

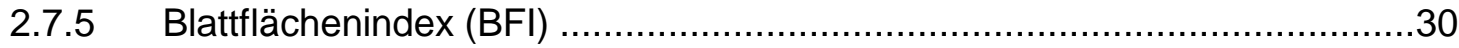

2.7.6 Photosynthetisch aktive Strahlung (PAR) ............................................ 32

2.7.7 Bestandeshöhe - Schotenansatzhöhe - Schotenschichtdicke ....................34

2.7.8 Grünfärbung des Pflanzenbestandes.................................................36 


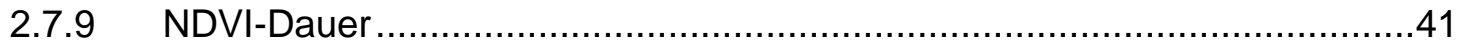

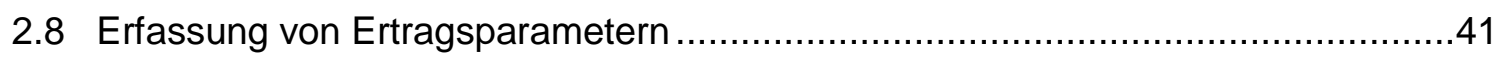

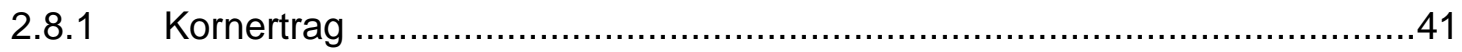

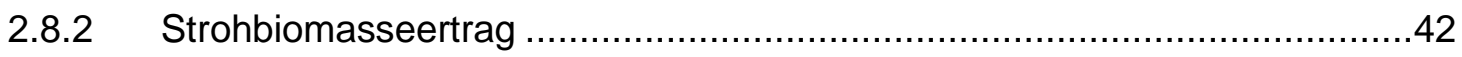

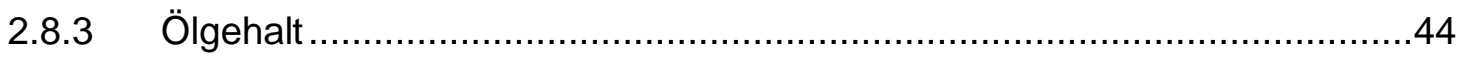

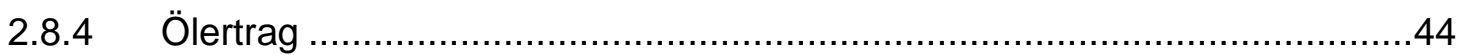

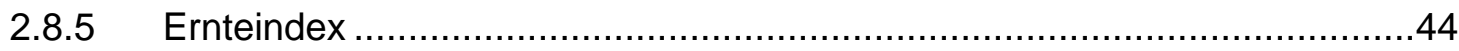

2.9 Erfassung des Befalls der Rapspflanzen mit der Wurzelhals- und Stängelfäule (Leptosphaeria maculans, anamorph: Phoma lingam) .....................................45

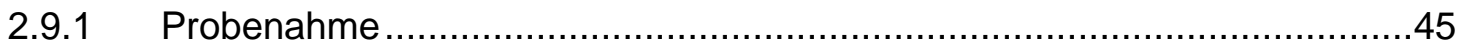

2.9.2 Visuelle Bonitur.......................................................................... 45

2.10 Erfassung des Befalls der Rapspflanzen mit der Kleinen Kohlfliege (Delia radicum)

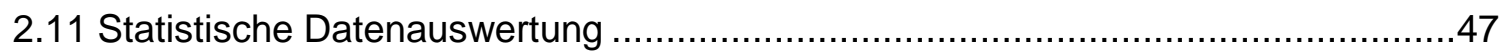

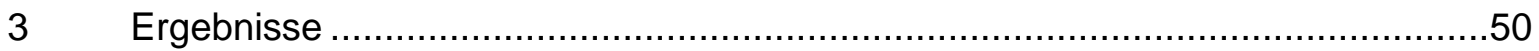

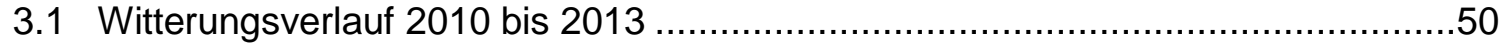

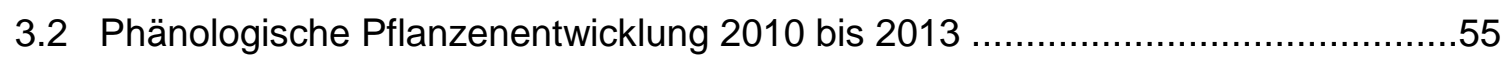

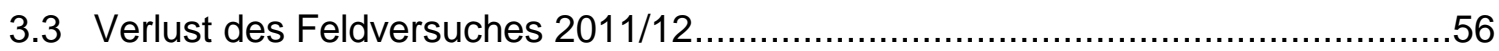

3.4 Einfluss der Anbaufaktoren Sorte, Saatstärke und Fungizidbehandlung auf Ertragsparameter und Ertragsfaktoren.....................................................59

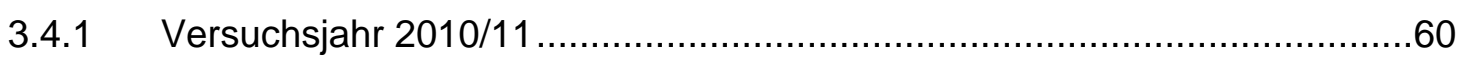

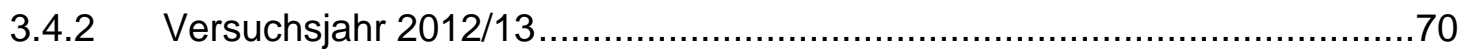

3.5 Einfluss der Anbaufaktoren Sorte, Saatstärke und Fungizidbehandlung auf

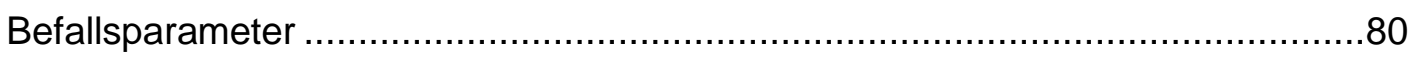

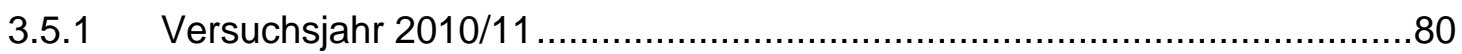

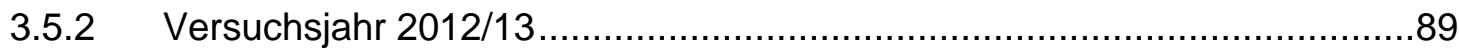

3.6 Einfluss von Bestandes- und Befallsparametern auf die Ertragshöhe ..................97

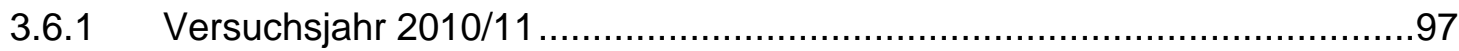

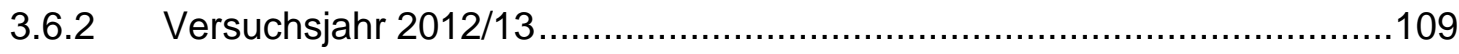


3.7 Effekte der Sorte, Saatstärke und Fungizidbehandlung auf Bestandes- und Befallsparameter, die die Ertragshöhe beeinflusst haben ...............................118

3.7.1 Versuchsjahr 2010/11 .....................................................................

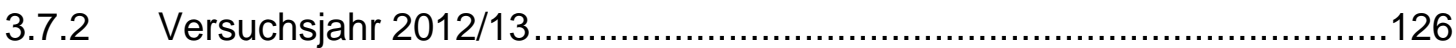

3.8 Einfluss von Bestandes- und Befallsparametern auf den Befall mit der Wurzelhalsund Stängelfäule

3.9 Effekte der Sorte, Saatstärke und Fungizidbehandlung auf Bestandes- und Befallsparameter, die den Befall mit der Wurzelhals- und Stängelfäule beeinflusst haben

3.10 Einfluss der Ertragsparameter und Ertragsfaktoren auf den Kornertrag 148

3.10.1 Versuchsjahr 2010/11 148

3.10.2 Versuchsjahr 2012/13 151

3.11 Summe der Effekte von Sorte, Saatstärke und Fungizidbehandlung auf ertragsrelevante Parameter 153

4 Diskussion. 154

4.1 Einfluss der Witterung auf die Ertragsbildung im Winterraps 154

4.2 Einfluss ausgewählter Bestandesparameter auf die Ertragsbildung im Winterraps.. 158

4.3 Einfluss der Anbaufaktoren Sorte und Saatstärke auf ertragsrelevante Bestandesparameter und den Ertrag.... 167

4.4 Einfluss der Fungizidbehandlungen auf ertragsrelevante Bestandesparameter und den Ertrag 170

4.5 Einfluss des Phomabefalls auf den Ertrag 174

4.6 Einfluss von ausgewählten Bestandesparametern und Anbaufaktoren auf den Phomabefall 176

4.7 Einfluss der Ertragsfaktoren auf die Ertragsbildung im Winterraps .181

4.8 Bewertung der statistischen Analyseverfahren 184

4.9 Abschließende Bewertung der Feldversuche 186

5 Schlussfolgerungen 189

6 Zusammenfassung. 191

$7 \quad$ Literaturverzeichnis 199 
$8 \quad$ Anhang

8.1 Anhang I: Infektionsversuche mit Botrytis cinerea an Winterraps......................220

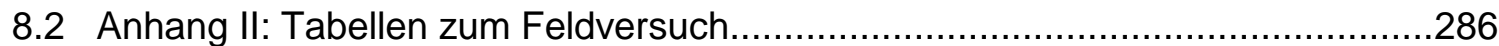

Danksagung

Erklärungen

Lebenslauf 


\section{Abkürzungen und Symbole}

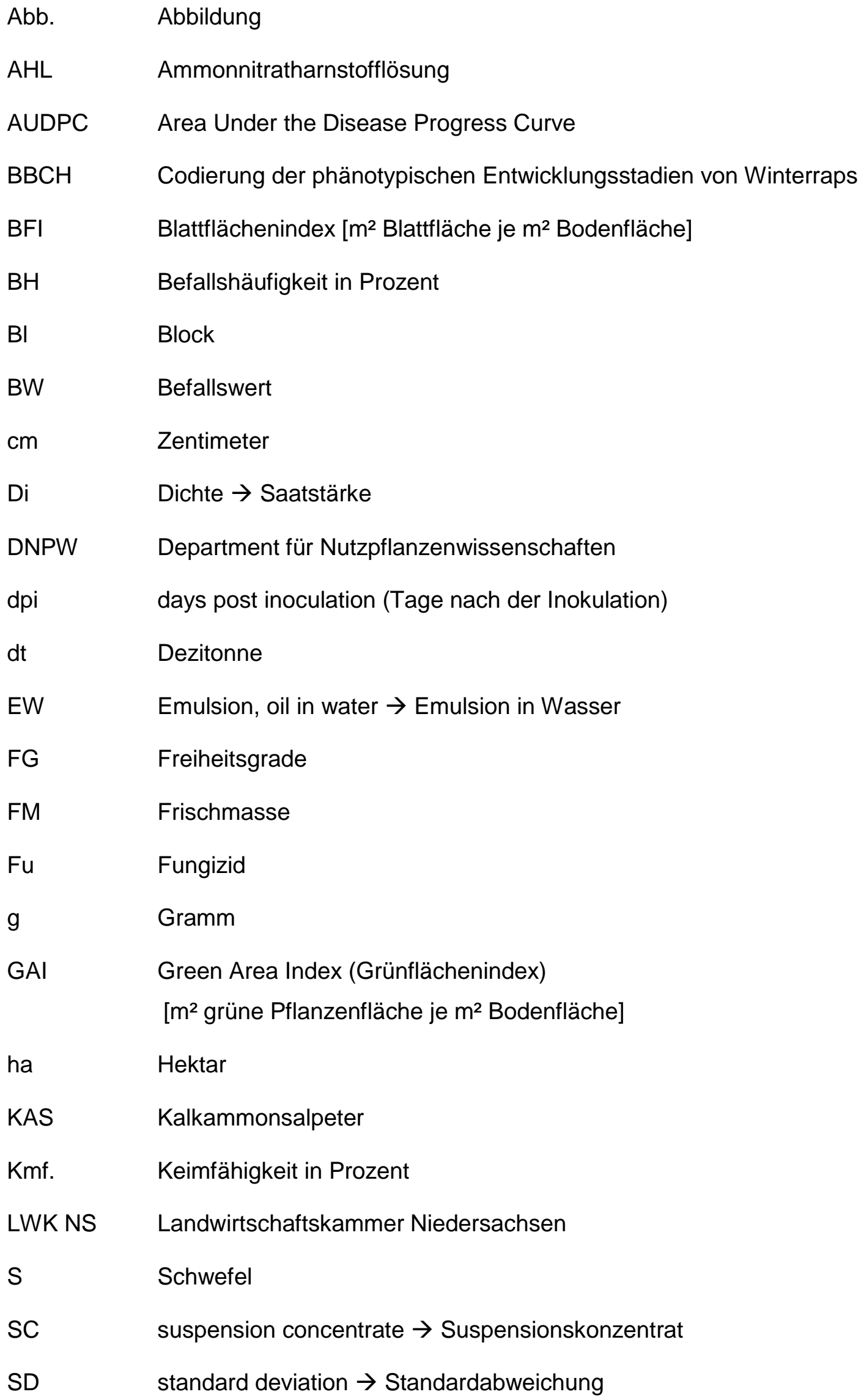


SE $\quad$ suspo-emulsion $\rightarrow$ Suspoemulsion

SL $\quad$ soluble concentrate $\rightarrow$ wasserbasiertes Konzentrat

So Sorte

SSA schwefelsaures Ammoniak

m Meter

mm Millimeter

n.b. nicht bestimmbar

n.e. nicht ermittelt

$\mathrm{nm} \quad$ Nanometer

PDA Personal Digital Assistent (kleiner, tragbarer Computer)

t Tonne

Tab. Tabelle

TKM Tausendkornmasse in Gramm

TM Trockenmasse

TSP Triplesuperphosphat

Var. Variante

vgl. vergleiche

WR Wachstumsregler

z.B. zum Beispiel

$\% \quad$ Prozent 


\section{Einleitung}

Mit der Einführung von erucasäurefreien und glucosinolatarmen Winterrapssorten (Doppel-Null-Sorten) Mitte der 80iger Jahre des vergangenen Jahrhunderts, begann der Siegeszug von Winterraps (Brassica napus L.) im deutschen Ackerbau. Die neuen Eigenschaften der Doppel-Null-Sorten erlaubten es, nun das Rapsöl als hochwertiges Speiseöl in der Humanernährung und das Rapsextraktionsschrot als wertvolles eiweißreiches Futtermittel in der Tierernährung einzusetzen. In Folge dessen stieg der Rapsanbau von etwa 297.000 ha im Jahr 1986 auf ca. 932.000 ha im Jahr 1995 (STATISTISCHES BUNDESAMT, 2013). Neben der Verbesserung der Qualitätseigenschaften, führte der Zuchtfortschritt auch zu einer kontinuierlichen Steigerung der Ertragsleistung der Winterrapssorten. Durch die gesteigerte Ertragsleistung und einer verbesserten Produktionstechnik verdoppelte sich der Kornertrag von durchschnittlich 1,61 t/ha im Jahr 1950 (BARTMER, 2007) auf 3,24 t/ha im Jahr 1995 (STATISTISCHES BUNDESAMT, 2013). Seit der Einführung von Hybridsorten Mitte der 90iger Jahre, erfuhr der Rapsanbau in Deutschland eine weitere Anbauausdehnung [bis zu 1,54 Millionen Hektar im Jahr 2007, (STATISTISCHES BUNDESAMT, 2013)], was neben weiteren Absatzmöglichkeiten für das Rapsöl als Biokraftstoff (Biodiesel) auch auf das erhöhte Ertragspotenzial von Hybridsorten zurückzuführen ist. So stiegen die Erträge in Deutschland seit 1996 jährlich um 45,4 kg/ha, was dazu führte, dass sich die durchschnittlichen Erträge immer mehr der 4 Tonnen je Hektar-Grenze angenähert bzw. diese bei günstigen Witterungsverhältnissen, wie in den Jahren 2004 und 2009, sogar überstiegen haben (Abb. 1).

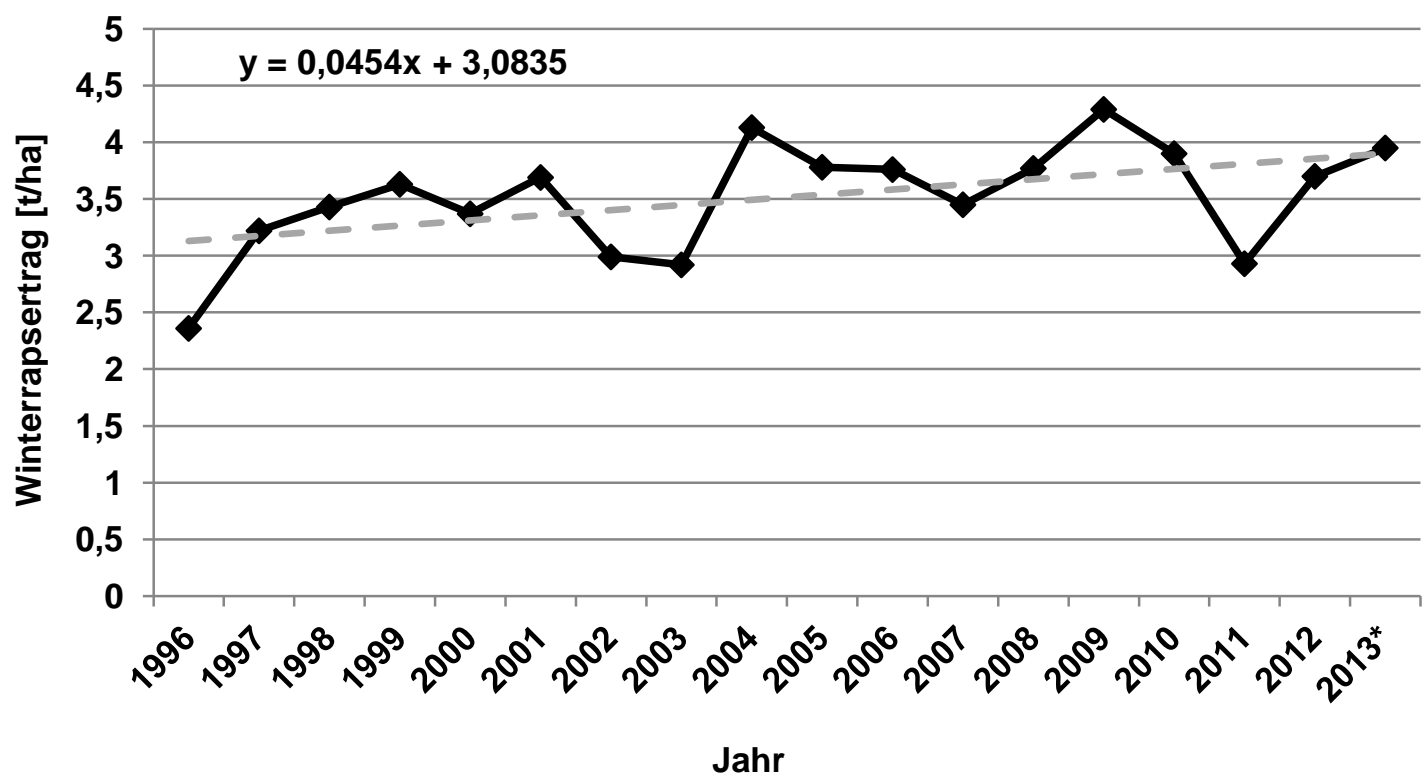

Abb. 1: Entwicklung der Winterrapserträge [t/ha] in Deutschland seit 1996. *vorläufig, (STATISTISCHES BUNDESAMT, 2013) 
In der landwirtschaftlichen Praxis konnte in den letzten Jahren vermehrt einen Rapsertrag von über 5 t/ha erzielt werden und vereinzelt waren sogar Spitzenerträge bis zu 6,5 t/ha möglich (SCHÖNBERGER, 2012). Doch damit wurde bisher das theoretische, genetische Ertragspotenzial moderner Hybridsorten von ca. 9 t/ha noch nicht ausgeschöpft (FRAUEN, 2012; SCHÖNBERGER, 2012). Um in Zukunft diese großen Ertragsreserven erschließen und den Kornertrag möglichst auf einem hohen Niveau stabilisieren zu können, muss die züchterische Optimierung von agronomischen Faktoren wie z.B. Winterfestigkeit, Standfestigkeit, Schotenplatzfestigkeit, Nährstoffeffizienz oder Krankheitsresistenz, sowie die Optimierung der Produktionstechnik weiter voranschreiten.

Damit die pflanzenbaulichen Anbaumaßnahmen weiter verbessert werden können, ist die Kenntnis über die Ertragsbildung im Winterraps von zentraler Bedeutung. Generell ist die Ertragsbildung eines Pflanzenbestandes abhängig von einem Komplex steuerbarer und nicht steuerbarer Einflussgrößen und ihrer Wechselbeziehungen (SCHEER, 1983). In der Vergangenheit haben viele verschiedene Untersuchungen zu steuerbaren Einflussgrößen wie Saatzeit (DEGENHARDT and KONDRA, 1981; MENDHAM et al., 1981a; SCARISBRICK et al., 1981; JeNKINS and LeITCH, 1986), Saatstärke (HENNING, 1979; STOY, 1983; SIERTS, 1987; LEACH et al., 1999; ANGADI et al., 2003), Düngung (SCOTT et al., 1973b; SCARISBRICK et al., 1980; MENDHAM et al., 1981b; WRIGHT et al., 1988), sowie Fungizidund Wachstumsreglereinsatz (SCARISBRICK et al., 1985; BAYLIS and HUTLEY-BULL, 1991; DEUKER-ISERMEYER et al., 1991; FISAHN, 1993; STAFFORD, 1996) grundlegende Ertragsbildungsprozesse aufgeklärt und somit zu einer verbesserten Produktionstechnik beigetragen. Ein Teil der älteren aber v.a. neuere Untersuchungen von MCWILLIAM et al. (1995), MCWILLIAM (1998), SCOTT et al. (1999) und LUNN et al. (2001) haben gezeigt, dass dünnere Pflanzenbestände mit einer dünneren/offeneren Schotenschicht ähnlich hohe Erträge oder sogar höhere Erträge erzielen können wie dichtere Pflanzenbestände mit einer dichteren Schotenschicht. Unter dem Begriff „Canopy Management" nennen die Autoren verschiedene Maßnahmen, wie solch lichtere Bestände "hergestellt“ werden können. Dabei wurde eine Einflussnahme auf die Bestandesarchitektur durch eine Kombination aus Saatstärke und Applikationen von Fungiziden mit wachstumsregulatorischer Nebenwirkung kaum in Betracht gezogen. Der Grund dafür ist darin zu sehen, dass zu dieser Thematik, insbesondere zu der Wechselbeziehung zwischen Saatstärke und wachstumsregulatorischer Fungizide nur sehr wenige Untersuchungen vorliegen. 


\subsection{Ertragsfaktoren von Winterraps}

Der Kornertrag von Winterraps ist das Produkt aus der Pflanzenzahl pro $\mathrm{m}^{2}$ (Pflanzendichte oder Bestandesdichte), der Anzahl an Schoten pro Pflanze, der Anzahl an Körnern pro Schote und der Einzel- bzw. Tausendkornmasse (TKM). Des Weiteren lassen sich aus den zuvor genannten vier primären Ertragsfaktoren auch sekundäre Ertragsfaktoren ableiten, um die Ertragsstruktur von Winterraps zu beschreiben (DiEPENBROCK, 2000) (Abb. 2).

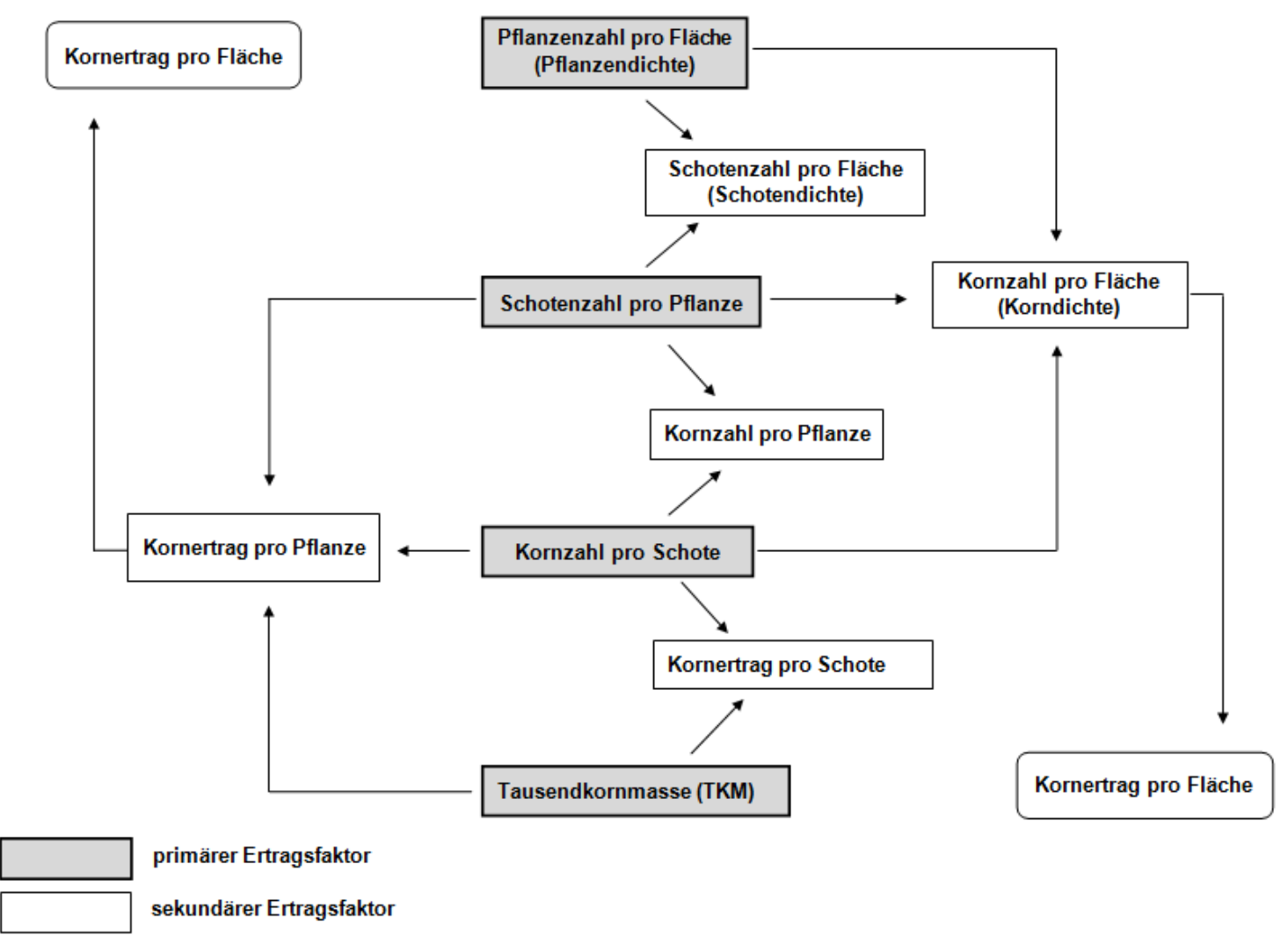

Abb. 2: Die Ertragsstruktur von Winterraps (DIEPENBROCK and GROSSE, 1995)

\section{Pflanzendichte (Bestandesdichte)}

Die Pflanzendichte hat den stärksten Einfluss auf den Kornertrag, da sie die Entwicklung der anderen drei primären Ertragsfaktoren steuert (DIEPENBROCK, 2000) und dadurch maßgeblich den Einzelpflanzenertrag beeinflusst (SCHÖNBERGER, 2012). Der Grund dafür ist in der intraspezifischen Konkurrenz zwischen den Rapspflanzen im Bestand um die Wachstumsfaktoren Licht, Wasser, Nährstoffe und Standraum zu sehen. Die innerartliche Konkurrenz kontrolliert maßgeblich das Wachstum und die Entwicklung jeder einzelnen Pflanze. Die Jahreswitterung hat einen besonders starken Einfluss auf die 
intraspezifischen Konkurrenzbeziehungen, sodass die Pflanzendichte eine über die Vegetationsperiode veränderliche Größe darstellt. Aus nominal gleichen HerbstBestandesdichten können in Abhängigkeit von den Auswinterungsverlusten verschiedene Frühjahrs-Bestandesdichten hervorgehen, wodurch sich die verschiedenen Ertragsfaktoren der Einzelpflanzen unterschiedlich stark entwickeln (BOIFFIN et al., 1981; GEISLER and StOY, 1987; SieRTS, 1987). StOY (1983) und SiERTS et al. (1987) konnten nachweisen, dass die umweltbedingten Pflanzenverluste umso mehr abnahmen, je gleichmäßiger die Pflanzen pro Flächeneinheit verteilt waren. Demnach ist die gleichmäßige Verteilung der Pflanzen pro $\mathrm{m}^{2}$ Boden eine Grundvoraussetzung sowohl für hohe als auch für stabile Kornerträge. Dabei nimmt der Anspruch an die gleichmäßige Verteilung mit abnehmender Bestandesdichte zu (MCWILLIAM et al., 1995; MCWILLIAM, 1998). Optimale Bestandesdichten variieren von Jahr zu Jahr, bedingt durch die jährlich schwankenden Umwelteinflüsse. Zudem wurden in der Vergangenheit durch sehr variable Bestandesdichten ähnlich hohe Erträge erzielt. Dabei bewegten sich die Bestandesdichten je nach Versuch z.B. zwischen 8 und 90 Pflanzen/m² (MENDHAM et al., 1981b), zwischen 40 und 200 Pflanzen/m² (MCGREGOR, 1987) oder zwischen 50 und 150 Pflanzen $/ \mathrm{m}^{2}$ (LEACH et al., 1999). Bei einem Versuch mit Sommerraps traten keine signifikanten Ertragsunterschiede bei einer Bestandesdichte von 40 bzw. 80 Pflanzen $/ \mathrm{m}^{2}$ auf (ANGADI et al., 2003). Dies zeigt, dass Winterrapsbestände eine hohe Kompensationsfähigkeit besitzen.

\section{Schoten pro Pflanze}

Die Anzahl an Schoten pro Pflanze ist das wichtigste Merkmal für den Einzelpflanzenertrag von Raps (FREUDHOFMAIER, 1991; DIEPENBROCK and GROSSE, 1995; DIEPENBROCK, 2000) und von allen Ertragskomponenten am variabelsten (DIEPENBROCK, 2000). Die Anzahl an Schoten pro Pflanze wird stärker durch die Reduktion von Seitentrieben, Knospen, Blüten und jungen Schoten bestimmt, was wiederum von der Assimilat-, Nährstoff- und Wasserversorgung (ALLEN and MORGAN, 1972; TAYO and MORGAN, 1979; ROOD and MAJOR, 1984) und hormonellen Faktoren (DE BOUILLE et al., 1989; ZANEWICH \& ROOD, 1993) abhängig ist, als durch die potenzielle Anzahl an Blüten und Schoten (HABEKOTTÉ, 1993). Somit ist dieser Ertragsfaktor stark umweltabhängig und eignet sich nicht als Selektionskriterium in der Ertragszüchtung (BECKER, 2011). Die Schotenzahl je Pflanze ist insbesondere von der Pflanzendichte, dem Saatzeitpunkt und der Menge an appliziertem Stickstoff (N)-Dünger abhängig. So konnte in verschiedenen Experimenten mit unterschiedlichen Pflanzendichten nachgewiesen werden, dass mit steigender Pflanzenzahl pro Flächeneinheit die Anzahl an fertilen Seitentrieben und damit 
auch die Anzahl an Schoten pro Pflanze abnahm (GEISLER and HENNING, 1981a; SCARISBRICK et al., 1982; GeISLER and StOY, 1987; SieRTS et al., 1987; CHAY and THURLING, 1989; LEACH et al., 1999). Diese negativen Korrelationen sind, wie oben angesprochen, auf steigende Konkurrenzbeziehungen zwischen den Rapspflanzen bei steigender Pflanzendichte zurückzuführen. Die Schotenzahl pro Pflanze nimmt allerdings nicht nur mit abnehmender Anzahl an Seitentrieben pro Pflanze ab, sondern auch direkt durch eine reduzierte Anlage von Schoten an den vorhandenen Seitentrieben. Dabei nehmen die Reduktionsprozesse vom Haupttrieb über die obersten Seitentriebe hin zu den untersten Seitentrieben zu (DIEPENBROCK, 2000).

Für die Schotenzahl pro Flächeneinheit (Schotendichte) wurde nachgewiesen, dass mit zunehmender Pflanzendichte die Schotendichte anstieg und ab einer bestimmten Pflanzendichte annähernd konstant blieb. Erst bei extrem hohen Pflanzendichten nahm die Schotendichte wieder ab (MendHAM et al., 1981b; GeISLER and STOY, 1987). Die vorherigen Autoren sowie (HABEKOTTÉ, 1993) konnten nachweisen, dass durch eine steigende Schotenzahl pro $\mathrm{m}^{2}$ der Kornertrag zunahm.

Bei einer verspäteten Aussaat nimmt die Anzahl an Schoten pro Pflanze ab (HODGSON, 1979; THURLING, 1974; JENKINS and LEITCH, 1986). Dabei sind die unteren Seitentriebe stärker betroffen als die oberen Seitentriebe oder der Haupttrieb (SCARISBRICK et al., 1981). Durch die verspätete Aussaat bilden die Pflanzen bis zur Blüte weniger Blattmasse aus, wodurch weniger Assimilate gebildet werden und somit weniger Assimilate während der Blüte zur Schotenbildung zur Verfügung stehen (MENDHAM et al., 1981a).

Eine N-Düngung im Herbst (MENDHAM et al., 1981b) oder im Frühjahr (ScOTT et al., 1973b; SCARISBRICK et al., 1980; WRIGHT et al., 1988) fördert die Schotenzahl pro Pflanze, da zu den angegebenen Zeiträumen v.a. das Blattwachstum angeregt und so die Kapazität der Quelle (Source) für die Assimilatproduktion verbessert wird.

JENKINS and LEITCH (1986) wiesen in ihren Versuchen nach, dass niedrige oder mittlere Schotenzahlen pro Pflanze, hervorgerufen durch eine verspätete Aussaat, durch eine erhöhte Kornzahl pro Schote oder eine erhöhte TKM kompensiert werden können.

Verschiedene Autoren stellten fest, dass bei einer gleichmäßigen Bestandesdichte, verschiedene Rapssorten ein unterschiedliches Verteilungsmuster der Schoten an Haupttrieb, oberen Seitentrieben und unteren Seitentrieben aufwiesen (RAKOW, 1978; GROSSE, 1989). Generell muss berücksichtigt werden, dass verschiedene Genotypen unter den gleichen Umweltbedingungen eine differenzierte Schotenentwicklung besitzen (DiEPENBROCK and GROSSE, 1995). 


\section{Körner pro Schote}

Winterraps ist in der Lage zwischen 30 (CLARKE, 1979; SCHULZ, 1987) und 40 (RAKOW, 1978; MORGAN, 1982) Körner pro Schote zu bilden. Allerdings werden so viele Körner pro Schote zur Ernte meist nicht vorgefunden, da in der Zeit nach der Blüte in einem Zeitraum von ca. zwei bis drei Wochen, eine Vielzahl der angelegten Kornanlagen wieder reduziert werden (PECHAN \& MORGAN, 1985). Bisher ist nur wenig über die Faktoren, die die Reduktionsprozesse steuern, bekannt (DIEPENBROCK, 2000). Grundsätzlich kommen wie bei einer Schotenreduktion eine verminderte Versorgung mit Assimilaten, Nährstoffen und Wasser, sowie hormonelle Faktoren in Frage (DIEPENBROCK \& GROSSE, 1995). Vergleichbar mit der Schotenzahl pro Pflanze nimmt die Kornzahl pro Schote vom Haupttrieb über die oberen primären Seitentriebe hin zu den unteren primären Seitentrieben ab. Dabei ist diese insertionsabhängige Körnerverteilung nicht so stark ausgeprägt wie die insertionsabhängige Schotenverteilung (RAKOW, 1978; STOY, 1983; SIERTS, 1987; GrosSE, 1989). Des Weiteren variiert die Anzahl Körner pro Schote innerhalb eines Triebes. So bilden die basalen Schoten am Haupttrieb mehr Körner pro Schote aus als die sich später entwickelnden apikalen Schoten (CLARKE, 1978). In den meisten Fällen sind diese Unterschiede eher auf eine geringere Samenanlage als auf eine Reduktion von Samenanlagen zurückzuführen (ScHULZ, 1987). Für gewöhnlich existiert eine negative Korrelation zwischen der Pflanzendichte und der Kornzahl pro Schote (SCARISBRICK et al., 1982; JENKINS and LEITCH, 1986; GEISLER and STOY, 1987; SIERTS, 1987; SIERTS et al., 1987). Bei einer hohen Pflanzendichte nimmt die Kornzahl pro Schote hauptsächlich an den unteren insertierten Seitentrieben ab, während sie am Haupttrieb annähernd konstant bleibt (STOY, 1983). Eine verspätete Aussaat von Winterraps führt häufig zu einer reduzierten Anzahl an Schoten pro Pflanze, die allerdings durch eine erhöhte Kornzahl pro Schote kompensiert werden kann. Dabei ist der Grad der Schotenverluste und deren Kompensation durch eine erhöhte Kornzahl pro Schote primär von den Umweltbedingungen im Herbst und Frühjahr abhängig (ScOTT et al., 1973a; MENDHAM et al., 1981a, 1981b; JENKINS and LEITCH, 1986).

Eine N-Düngung im Frühjahr kann (ALLEN and MORGAN, 1972; SCOTT et al., 1973b) muss aber nicht zwingend (MENDHAM et al., 1981b; WRIGHT et al., 1988) einen positiven Effekt auf die Kornzahl pro Schote haben. Höhere N-Gaben im Herbst reduzieren die Kornzahl pro Schote und fördern die Schotenzahl pro Flächeneinheit (MENDHAM et al., 1981b). 


\section{TKM}

Die TKM wird im Verlauf der Ertragsbildung als letzter Ertragsfaktor festgelegt. Wie bei den Ertragsfaktoren Schoten pro Pflanze und Körner pro Schote ist die Bildung der Kornmasse insertionsabhängig. Entsprechend sind die Körner aus Schoten die an unteren Seitentrieben ausgebildet wurden meist kleiner und nicht so schwer wie Körner, die an oberen Seitentrieben oder am Haupttrieb ausgebildet wurden (GEISLER and HENNING, 1981b; STOY, 1983). Von den drei Ertragsfaktoren Schoten pro Pflanze, Körner pro Schote und TKM reagiert die TKM am geringsten, die Körner pro Schote mittelmäßig und die Schoten pro Pflanze am stärksten auf die Insertionseffekte (CLARKE, 1979; HENNING, 1979; SCARISBRICK et al., 1981; StOY, 1983; SieRTS, 1987; Grosse, 1989). Umweltabhängige oder pflanzenbauliche Faktoren haben auf die TKM einen deutlich geringeren Einfluss als auf die anderen Ertragsfaktoren. ALLEN and MORGAN (1972), ScotT et al. (1973b), MENDHAM et al. (1981b) und WRIGHT et al. (1988) konnten keinen positiven Effekt einer N-Düngung im Herbst oder Frühjahr auf die TKM nachweisen. Ebenso traten keine signifikanten Unterschiede bei verschiedenen Bestandesdichten auf (StOY, 1983; JeNKINS and LeITCH, 1986; SieRTS et al., 1987; ChAY and THURLING, 1989). Einzig wenn der Winterraps deutlich zu spät ausgesät wurde, führte dies häufig zu einer leicht reduzierten TKM (SCOTT et al., 1973a; MENDHAM et al., 1981a; JENKINS and LEITCH, 1986). Da die TKM eine relativ hohe genetische Variabiliät aufweist, kann diese am ehesten durch die Wahl der Sorte beeinflusst werden. Ferner sind alle Maßnahmen, die die Abreife hinauszögern, förderlich für die TKM (SCHÖNBERGER, 2012).

Die TKM ist häufig negativ mit der Schotenzahl pro Pflanze bzw. der Kornzahl pro Schote korreliert (LEON and BECKER, 1995). Im Allgemeinen hat die TKM nur einen schwachen (DiEPENBROCK, 2000) bis gar keinen (RAKOW, 1978; Stoy, 1983; Grosse, 1989) Einfluss auf den Kornertrag von Winterraps.

Wie aus den vorherigen Erläuterungen hervorgeht, besitzt Winterraps eine hohe Variabilität in der Ausbildung des Flächenertrages, bedingt durch die hohe Kompensationsfähigkeit der einzelnen Ertragskomponenten. Weiterhin konnte GROSSE (1989) bei Versuchen mit zehn verschiedenen Sorten eine hohe genetische Variabilität zwischen den Ertragsfaktoren Schoten pro Pflanze, Körner pro Schote und TKM nachweisen. In seinen Versuchen erzielten die verwendeten Sorten bei ganz unterschiedlichen Konstellationen der Ertragsfaktoren ähnlich hohe Flächenerträge. Daher kann nicht von der Ausprägung einzelner Faktoren auf den Ertrag geschlossen werden. 


\subsection{Wachstumsregulation in Winterraps durch Wachstumsregulatoren und Fungizide}

Wachstumsregulatoren (WR) sind synthetische Wirkstoffe, die v.a. eingesetzt werden um das Längenwachstum von Pflanzen und damit einhergehend die apikale Dominanz des Haupttriebes zu hemmen. Die WR, die in Deutschland in der Kultur Winterraps zugelassen sind, inhibieren spezifische Schritte der Gibberellin-Biosynthese und verringern so den endogenen Gehalt an physiologisch aktiven Gibberellinen [Gibberellinsäuren, engl. gibberellic acids (GAs)] (GRAEBE, 1987; GROSSMANN et al., 1989). GAs und Auxine sind primär für die Zellstreckung und damit für das Längenwachstum höherer Pflanzen verantwortlich (RADEMACHER, 2000). Auxine stimulieren u.a. die Synthese von GAs und hemmen deren Abbau. Dies macht einen wesentlichen Teil der Auxin-Wirkung auf das Streckungswachstum aus (WEILER \& NOVER, 2008). Des Weiteren hemmen sie die Synthese von Cytokininen in der Wurzelspitze und deren akropetale Verlagerung in die Seitenknospen, wodurch diese nicht anfangen auszutreiben. Damit stellen Auxine die stoffliche Ursache der Apikaldominanz dar (NULTSCH, 2001). Die GA-Biosynthese leitet sich vom Terpenoidstoffwechselweg ab (GrossmanN et al., 1989) und verläuft bis zur Bildung des $\mathrm{GA}_{12}$-Aldehyds in allen Pflanzen gleich ab (KENDE \& ZEEVAART, 1997). Bei den weiteren Syntheseschritten bis zu physiologisch aktiven $\mathrm{GAs}$ wie z.B. $\mathrm{GA}_{1}, \mathrm{GA}_{3}, \mathrm{GA}_{4}$ oder $\mathrm{GA}_{7}$ treten artspezifische Unterschiede auf (KENDE \& ZEEVAART, 1997). Neben der Zellstreckung fördern GAs auch die Samenkeimung, die Induktion der Blütenentwicklung und zu einem gewissen Maß die Zellteilung. Das Wachstum in der Streckungszone junger Sprosse ist das Ergebnis des Wechselspiels von Auxinen und GAs. Nur das Zusammenwirken von Auxin und GA garantiert eine andauernde Zellstreckung. Ein Mangel an einem dieser Phytohormone resultiert in einem kleinwüchsigen Phänotyp (YANG et al., 1996).

Die Hemmstoffe der GA-Biosynthese können in drei Gruppen a) „Onium“-Wirkstoffe, b) Wirkstoffe mit stickstoffhaltiger Ringstruktur und c) Cyclohexandione eingeteilt werden. Wie oben erwähnt, inhibieren die Wirkstoffe dieser drei Gruppen die GA-Biosynthese jeweils an individuellen Stellen (Abb. 3). Je später die Inhibitoren in die Schritte der GABiosynthese eingreifen, desto weniger Konzentration wird benötigt, um die entsprechende wuchsretardierende Wirkung zu erzielen (RADEMACHER, 1991). 

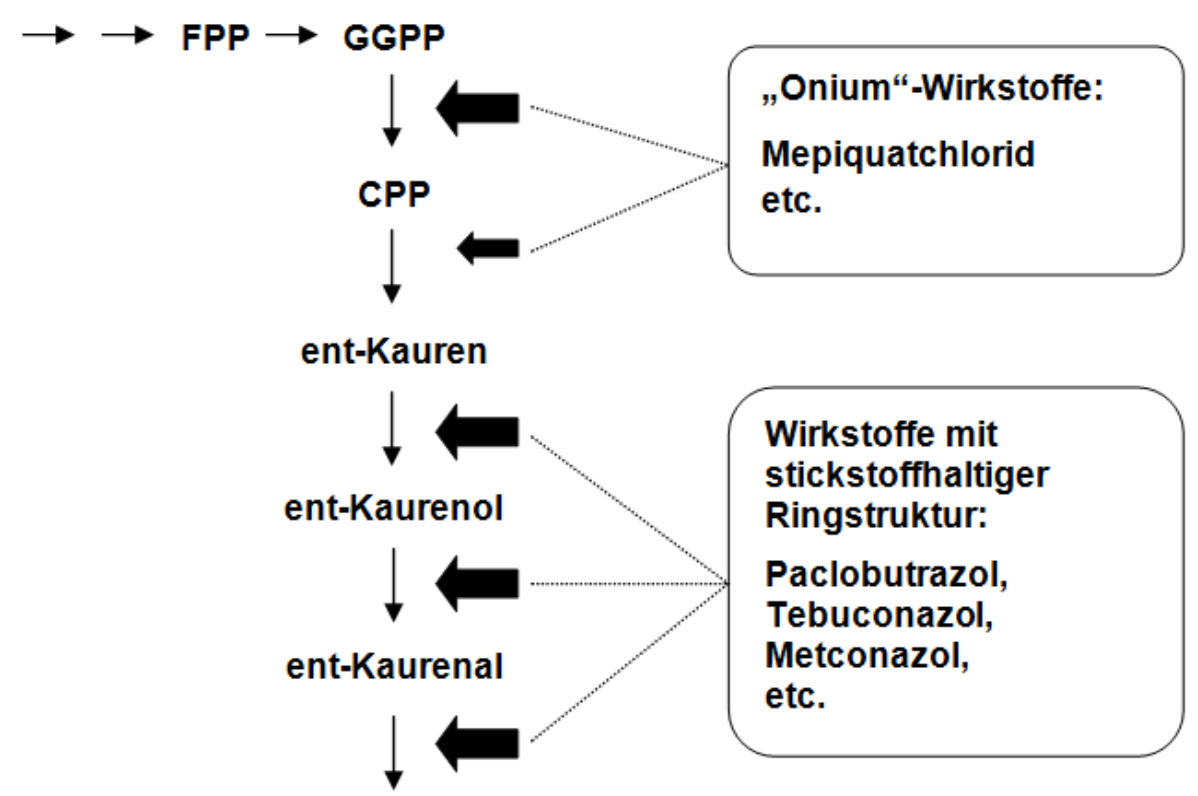

Wirkstoffe mit stickstoffhaltiger Ringstruktur:

Paclobutrazol, Tebuconazol, Metconazol, etc.

\section{ent-Kaurensäure}

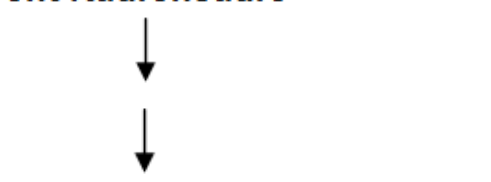

\section{GA $_{12}$-Aldehyd}

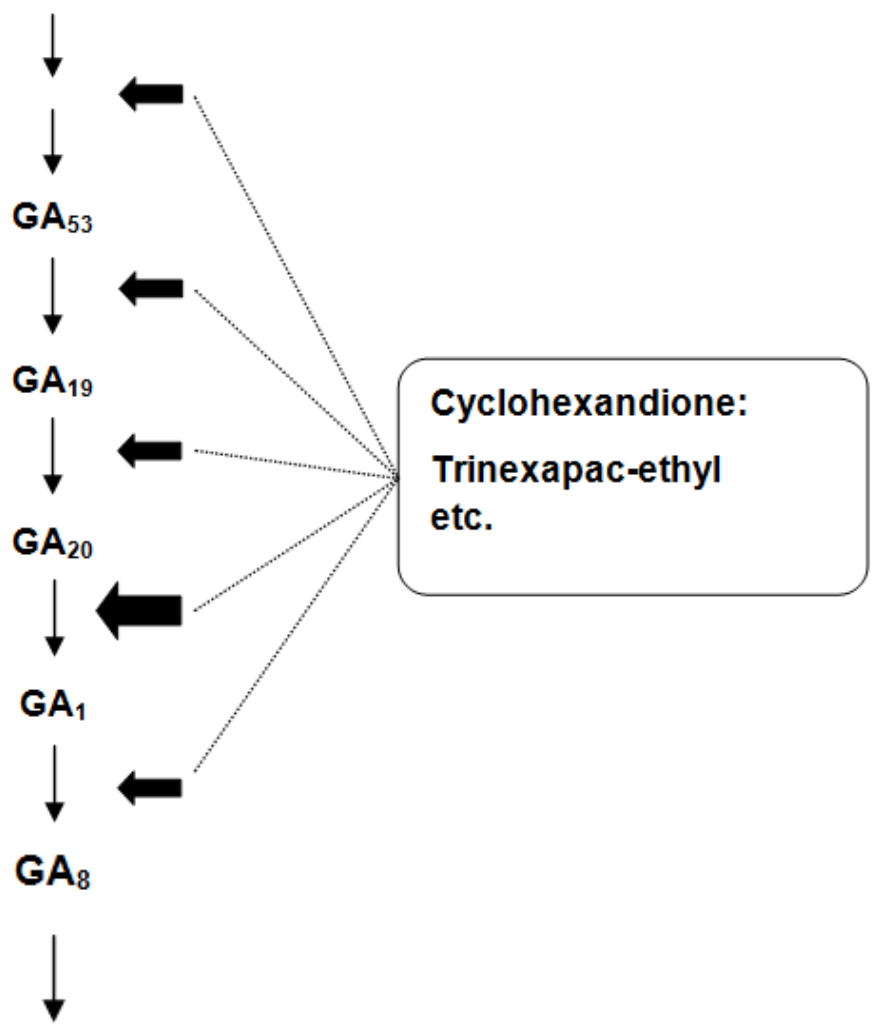

Abb. 3: Wesentliche Schritte der GA-Biosynthese, die zur Bildung von $\mathrm{GA}_{1}$ führen und Punkte an denen die WR, die im Raps eingesetzt werden, inhibieren (eine geringere Eingriffsstärke ist durch kleinere Pfeile gekennzeichnet). FPP $=$ Farnesylpyrophosphat; GGPP Geranylgeranylpyrophosphat; CPP = Copalyldiphosphat (RADEMACHER, 1991; 2000) 


\section{„Onium"-Wirkstoffe}

„Onium“-Wirkstoffe bestehen zur Hälfte aus einer positiv geladenen Ammonium-, Phosphonium- oder Sulfoniumgruppe und greifen in frühe Schritte der GA-Biosynthese direkt vor ent-Kauren ein (Abb. 3). Primär hemmen sie die Copalyldiphosphat (CPP)Synthase (früher bekannt unter ent-Kauren Synthase A), die die Umwandlung von Geranylgeranyldiphosphat (GGPP) zu CPP katalysiert. Ferner hemmen sie auch die entKauren-Synthase (früher bekannt unter ent-Kauren Synthase B), die für die Umwandlung von CPP zu ent-Kauren verantwortlich ist (RADEMACHER, 2000). Allerdings wird das zuletzt genannte Enzym nicht so stark gehemmt wie das erst genannte (SHECHTER \& WEST, 1969). Zu den bekanntesten Vertretern dieser Gruppe zählen das Chlormequatchlorid (TOLBERT, 1960a, 1960b), besser bekannt unter dem Namen Chlorcholinchlorid (CCC) und Mepiquatchlorid (ZEEH et al., 1974). Diese beiden Wirkstoffe wurden und werden hauptsächlich zur Halmkürzung und -festigung im Getreidebau eingesetzt. Seit 5 Jahren steht der Wirkstoff Mepiquatchlorid auch im Rapsanbau für die Wuchsregulierung zur Verfügung (ANONYMUS, 2009a).

\section{Wirkstoffe mit stickstoffhaltiger Ringstruktur}

Wuchsregulierende Substanzen, die aus einer stickstoffhaltigen Ringstruktur (N-haltiger Heterozyklus) aufgebaut sind, verhindern die oxidativen Schritte von ent-Kauren zu entKaurensäure, indem sie die Kaurenoxygenase, eine Cytochrom P-450 abhängige Monooxygenase, hemmen (Hedden \& GRAEBE, 1985; Graebe, 1987; GrossmanN et al., 1989). Am Stickstoffatom im heterozyklischen Ring befindet sich ein freies Elektronenpaar, das ausschließlich in der Peripherie des Wirkstoffmoleküls liegt. Dadurch ist es in der Lage mit pflanzlichen Cytochrom P-450 abhängigen Monooxygenasen zu interagieren (GROSSMANN et al., 1989). Es gibt verschiedene Wirkstoffe aus unterschiedlichen chemischen Gruppen, die alle als ein gemeinsames Strukturelement einen heterozyklischen Ring mit einem N-Atom enthalten. Dazu zählen z.B. die Pyrimidine, Imidazole oder die Triazole. Von diesen drei Gruppen sind allerdings nur Vertreter von den Triazolen zur Wachstumsregulation im Winterraps zugelassen. Im speziellen werden die Wirkstoffe Tebuconazol, Metconazol und neuerdings auch Paclobutrazol solo oder in Mischungen mit anderen Wirkstoffen eingesetzt (vgl. Tab. 2)

Dass Triazolderivate wie Paclobutrazol als reine Wachstumsregler fungieren (LEVER et al., 1982), ist eher die Seltenheit und beruht auf einer chemischen Optimierung des Wirkstoffs. Primär wirken sie als Fungizide, indem sie die $\mathrm{C}_{14}$-Demethylase, eine Cytochrom P-450-abhängige Monooxygenase, blockieren, wodurch ein wichtiger 
Zwischenschritt in der Ergosterolbiosynthese von Pilzen gehemmt wird (BUCHENAUER, 1977; KUCK et al., 1995; GISI et al., 2000; LEROUX et al., 2008). Ergosterol ist ein essentieller Bestandteil der pilzlichen Zellmembranen. Die Folgen von der Hemmung der Synthese von Ergosterol sind eine abnorme Ausbildung von pilzlichen Infektionsstrukturen und eine starke Hemmung des Myzelwachstums (AKERS et al., 1990; GoLD et al., 1992). Aufgrund ihres Wirkortes zählen die Triazol-Fungizide zu den Demethylaseinhibitoren (DMls). Diese gehören wiederum wegen ihres Wirkungsmodus zu den Sterolbiosyntheseinhibitoren Klasse 1 (SBI Klasse 1). Triazole wirken also sowohl im pilzlichen als auch im pflanzlichen Stoffwechsel, was auf die Interaktionen zwischen der N-haltigen Ringstruktur und bestimmten Cytochrom P-450 abhängigen Monooxygenasen zurückzuführen ist (SIEFERT and GROSSMANN, 1996). Ob Triazole als Fungizide oder WR fungieren bzw. beide Eigenschaften aufweisen, hängt von der stereochemischen Konfiguration der Substituenten an der Kohlenstoffkette ab (FLETCHER et al., 1986; BÜCHEL, 1986; FLETCHER and HOFSTRA, 1988). Aufgrund der asymmetrischen Kohlenstoffatome besitzen die meisten Triazole stereoisomere Formen (BUCHENAUER, 1995). Stereoisomere sind chemische Verbindungen, die die gleiche Summenformel und Atomsequenz besitzen, sich jedoch in der räumlichen Anordnung der Atome unterscheiden (CAMPBELL et al., 2003). Dies führt zu unterschiedlichen Eigenschaften der jeweiligen Stereoisomere (FLETCHER et al., 1986), die wiederum verschiedene Effekte im pflanzlichen oder pilzlichen Stoffwechsel auslösen. So inhibiert z.B. das (2S, 3S)-Isomer von Paclobutrazol besonders stark die GA-Biosynthese in höheren Pflanzen, wohingegen das (2R, 3R)-Isomer verstärkt die pilzliche Ergosterolbiosynthese hemmt (SUGAVANAM, 1984). Dieses Ergebnis entspricht den Ergebnissen von (HEDDEN \& GRAEBE, 1985; BURDEN et al., 1987a; FLETCHER et al., 2000), die nachweisen konnten, dass die RKonfiguration am chiralen C-Atom die fungizide Wirkung determiniert und die SKonfiguration stattdessen für den wuchsregulierenden Effekt verantwortlich ist. Auf der einen Seite können die kommerziell erhältlichen Wirkstoffe so chemisch optimiert sein, dass sie nur als WR oder Fungizid wirken (LÜRSSEN, 1988) und auf der anderen Seite können sie eine Mischung aus verschiedenen isomeren Formen darstellen, wodurch das entsprechende Triazol sowohl eine fungizide als auch eine wachstumsregulierende Eigenschaft besitzt (KRÄMER, 1986). Als Beispiele sind hier z.B. Paclobutrazol, als Triazol mit nur einer Eigenschaft (WR) sowie Tebuconazol und Metconazol als Triazole mit zwei Eigenschaften (Fungizid + WR) zu nennen. Normalerweise überwiegt bei den Triazolen mit zwei Eigenschaften die fungizide Wirkung. 
Triazole hemmen das Längenwachstum von Pflanzen nicht nur durch eine Inhibierung der GA-Biosynthese, sondern auch durch einen Eingriff in den Sterolmetabolismus. Dieser leitet sich wie die GA-Biosynthese vom Terpenoidstoffwechselweg ab ( (GROSSMANN et al., 1989). Phytosterole wie z.B. Stigmasterol, $\beta$-Sitosterol sind wichtige Bausteine pflanzlicher Membranen. Durch Blockierung der Obtusifoliol 14a-Demethylase, eine P-450 abhängige Monooxygenase, wird die pflanzliche Sterolbiosynthese gehemmt (BuCHENAUER \& RÖHNER, 1981; BuCHENAUER et al., 1984; BuRDEN et al., 1987b; TATON et al., 1988). Dies führt zu veränderten Membraneigenschaften und letztlich zu einer gehemmten Zellteilung in den subapikalen Meristembereichen der Pflanzen, was die Wuchshemmung bedingt (DAVIS et al., 1988; GrosSMANN et al., 1989; KHALIL and RAHMAN, 1995). Um die zuvor beschriebenen Effekte auslösen zu können, sind allerdings deutlich höhere Wirkstoffkonzentrationen nötig als bei der GA-Biosynthesehemmung (RADEMACHER et al., 1987; TATON et al., 1988; GROSSMANN et al., 1989). Demzufolge sind die pflanzlichen Wachstumsprozesse durch Triazolverbindungen auf zwei verschiedene Arten beeinflussbar: Während niedrige Wirkstoffkonzentrationen in die GA-Biosynthese eingreifen und so die internodiale Zellstreckung gehemmt wird, interagieren höhere Wirkstoffdosen mit der Sterolbiosynthese, wodurch die Zellteilungsprozesse in subapikalen Meristembereichen inhibiert werden (GROSSMANN et al., 1989; GROSSMANN, 1990).

Die bereits erwähnten positiven Effekte von Triazolderivaten auf das Pflanzenwachstum, stellen nur einen Teil einer ganzen Reihe an positiven Nebenwirkungen auf die Physiologie der Pflanze dar. So greifen Triazole z.B. auch in die Ethylen-, Abscisinsäureund Polyaminbiosynthese ein (BUCHENAUER, 1995; SIEFERT and GrossmanN, 1996). Zur Übersicht sind die weiteren physiologischen, sowie morphologischen Effekte von Triazolverbindungen und deren Auswirkungen auf das Pflanzenwachstum in Tab. 1 angegeben. 
Tab. 1: Weitere positive physiologische, sowie morphologische Nebenwirkungen von Triazolverbindungen und deren Einfluss auf das Pflanzenwachstum (BUCHENAUER, 1995; SIEFERT and GrossmanN, 1996).

\begin{tabular}{ll}
\hline Physiologische/morphologische Effekte & Auswirkungen auf Pflanzenwachstum \\
\hline Hemmung der Ethylenbildung & Seneszenzverzögerung \\
$\begin{array}{l}\text { Förderung der Polyaminbildung } \\
\text { Erhöhung der Cytokiningehalte durch } \\
\text { verringerten Abbau dieses Hormons }\end{array}$ & Seneszenzverzögerung, \\
kurzfristige Förderung \& langfristige & Seneszenzverzögerung \\
Hemmung der Abscisinsäurebildung & kurzfristig: Stomataschluss $\rightarrow$ \\
Steigerung der epicuticularen Wachsbildung & Transpirationsschutz, langfristig: \\
Erhöhung des Wurzel-/Sprossverhältnisses & Seneszenzverzögerung \\
$\begin{array}{l}\text { Förderung der Chlorophyllsynthese } \\
\text { Reduktion der Blattfläche } \rightarrow \text { Erhöhung der Blattdicke } \\
\rightarrow \text { Erhöhung der Parenchymzellzahl } \rightarrow \text { Erhöhung der }\end{array}$ & \\
$\begin{array}{l}\text { Chloroplastenzahl } \\
\text { Erhöhung der Nährstoffaufnahme }\end{array}$ & intensivere Grünfärbung \\
$\begin{array}{l}\text { Aktivierung von endogenen } \\
\text { antioxidativen Schutzmechanismen }\end{array}$ & $\begin{array}{l}\text { allgemein vitaler } \\
\text { Erhöhung der Toleranz gegenüber }\end{array}$ \\
\hline
\end{tabular}

In der Summe lassen sich die positiven Sekundäreffekte unter dem Begriff „Greening“Effekt zusammenfassen, da die meisten Nebenwirkungen die Seneszenz verzögern und dadurch die Assimilationsphase verlängert wird (HALLMANN et al., 2009). Nicht jede Triazolverbindung kann alle hier genannten Nebenwirkungen in der Pflanze auslösen. Das Wirkungsspektrum und die Wirkungsstärke hängt insbesondere von den unterschiedlichen molekülbedingten Bindungskapazitäten an die verschiedenen Cytochrom P-450 abhängigen Monooxygenasen im Stoffwechsel ab, sowie von der eingesetzten Wirkstoffkonzentration, dem Zeitpunkt und der Methode der Wirkstoffapplikation und der Pflanzenart (FLETCHER and HOFSTRA, 1988).

\section{Cyclohexandione}

Zu den Cyclohexandionen zählen z.B. die Wirkstoffe Prohexadion-Calcium (NAKAYAMA et al., 1990) und Trinexapac-ethyl (ADAMS et al., 1992) die beide zur Halmstabilisierung im Getreide eingesetzt werden. Im Winterraps ist dagegen nur Trinexapac-ethyl zugelassen. Verschiedene Untersuchungen konnten nachweisen, dass die Cyclohexandione erst relativ spät in die GA-Biosynthese eingreifen (NAKAYAMA et al., 1990; NAKAYAMA et al., 1991; RADEMACHER, 1991). Die späten Schritte in der GA-Biosynthese werden von löslichen Dioxygenasen katalysiert, die wiederum von dem Cosubstrat 2-Oxoglutarat 
(heutige Bezeichnung $\alpha$-Ketoglutarat) abhängig sind (GRAEBE, 1987). Bedingt durch die strukturelle Ähnlichkeit von Cyclohexandionen und 2-Oxoglutarat wird vermutet, dass die Retardantien und nicht 2-Oxoglutarat an die Dioxygenasen binden und so deren Funktion außer Kraft setzen (GRIGGs et al., 1991). Die wuchsregulierenden Stoffe und 2Oxoglutarat konkurrieren um die Bindungsstelle an den Dioxygenasen (GRIGGS et al., 1991; HedDEN, 1991). Indem die Dioxygenasen gehemmt werden, können fast alle Syntheseschritte nach $\mathrm{GA}_{12}$-Aldehyd nicht durchgeführt werden (vgl. Abb. 3). Dabei wird die $3 \beta$-Hydroxilierung von $\mathrm{GA}_{20} \mathrm{zu} \mathrm{GA}_{1}$ als primärer Angriffspunkt angesehen (GRIGGS et al., 1991; NAKAYAMA et al., 1991).

Unter praktischen Bedingungen wird der wuchsregulierende Effekt von einem Wirkstoff nicht zwangsläufig von der Art seiner Interaktion mit der GA-Biosynthese bestimmt (RADEMACHER, 2000), sondern vielmehr von der Applikationsart, der Pflanzenspezies, dem Entwicklungsstadium der Pflanze zum Behandlungszeitpunkt, der Aufwandmenge und den Witterungseinflüssen während und nach der Applikation beeinflusst (FLETCHER and HOFSTRA, 1988; HEDDEN et al., 1989; PAUL et al., 2001). Es wurde nachgewiesen, dass wüchsige Wetterbedingungen mit ausreichend hohen Temperaturen und einer ausreichend hohen Bodenfeuchte die wuchsregulierende Wirkung fördern (SCARISBRICK et al., 1985; PAUL et al., 2001; NÖTH, 2010; FABER, 2011; LANDWIRTSCHAFTSKAMMER NORDRHEIN-WESTFALEN, 2014).

Bei den WR die in Winterraps eingesetzt werden, handelt es sich bei den meisten Produkten offiziell um Fungizide, die einen wachstumsregulatorischen Nebeneffekt aufweisen. Nur im Fall von dem Produkt Moddus ${ }^{\circledR}$ handelt es sich um einen reinen WR. Die Fungizide bestehen aus ein bis zwei Wirkstoffen, wobei der fungizide und wachstumsregulierende Effekt in einem Wirkstoff vereint vorkommen kann (Metconazol, Tebuconazol) oder sich auf zwei verschiedene Wirkstoffe aufteilt (z.B. Paclobutrazol = WR Effekt, Difenoconazol = Fungizid Effekt). Zur Übersicht sind alle wichtigen wachstumsregulierenden Pflanzenschutzmittel, die in Deutschland für den Einsatz im Winterraps zugelassen sind, in der Tab. 2 alphabetisch aufgelistet. 
Tab. 2: Fungizide, mit wachstumsregulatorischer Nebenwirkung und Wachstumsregulatoren $\left(\right.$ Moddus $^{\circledR}$ ), die in Deutschland in der Kultur Winterraps zugelassen sind. Angegeben ist der Produktname, die Wirkstoffe der Produkte, die Wirkstoffgehalte, die Funktion der Wirkstoffe, der Zulassungsinhaber des jeweiligen Produktes, sowie die Einordnung der Produkte in die Gruppen von GA-Biosynthese-Inhibitoren (BUNDESAMT FÜR VERBRAUCHERSCHUTZ UND LeBENSMITTELSICHERHEIT (BVL), 2014; LANDWIRTSCHAFTSKAMMER NORDRHEIN-WESTFALEN, 2014).

\begin{tabular}{|c|c|c|c|c|c|}
\hline Produkt & Wirkstoffe & $\begin{array}{c}\text { Wirkstoffgehalte } \\
{[\mathrm{g} / \mathrm{l}]}\end{array}$ & $\begin{array}{c}\begin{array}{c}\text { Funktion } \\
\text { der } \\
\text { Wirkstoffe* }\end{array}\end{array}$ & $\begin{array}{c}\text { Gruppe von } \\
\text { GA- } \\
\begin{array}{c}\text { Biosynthese- } \\
\text { Inhibitor }\end{array} \\
\end{array}$ & $\begin{array}{l}\text { Zulassungs- } \\
\text { inhaber }\end{array}$ \\
\hline Ampera $^{\circledR}$ & $\begin{array}{l}\text { Prochloraz + } \\
\text { Tebuconazol }\end{array}$ & $\begin{array}{l}267 \\
133\end{array}$ & $\begin{array}{c}\mathrm{F} \\
\mathrm{F}+\mathrm{WR}\end{array}$ & $b$ & $\begin{array}{c}\text { Feinchemie } \\
\text { Schwebda } \\
\text { GmbH }\end{array}$ \\
\hline Caramba $^{\circledR}$ & Metconazol & 60 & $\mathrm{~F}+\mathrm{WR}$ & $b$ & BASF SE \\
\hline $\operatorname{Carax}^{\circledR}$ & $\begin{array}{l}\text { Metconazol + } \\
\text { Mepiquatchlorid }\end{array}$ & $\begin{array}{c}30 \\
210\end{array}$ & $\begin{array}{c}F+W R \\
W R\end{array}$ & $\begin{array}{l}\mathrm{b} \\
\mathrm{a}\end{array}$ & BASF SE \\
\hline Efilor $^{\circledR}$ & $\begin{array}{l}\text { Metconazol + } \\
\text { Boscalid }\end{array}$ & $\begin{array}{c}60 \\
133\end{array}$ & $\begin{array}{c}F+W R \\
F\end{array}$ & $b$ & $\begin{array}{c}\text { BASF SE } \\
\text { Baver }\end{array}$ \\
\hline Folicur $^{\circledR}$ & Tebuconazol & 250 & $\mathrm{~F}+\mathrm{WR}$ & $\mathrm{b}$ & $\begin{array}{c}\text { CropScience } \\
\text { AG }\end{array}$ \\
\hline Matador $^{\circledR}$ & $\begin{array}{l}\text { Triadimenol + } \\
\text { Tebuconazol }\end{array}$ & $\begin{array}{c}75 \\
225\end{array}$ & $\begin{array}{c}F+(W R) \\
F+W R\end{array}$ & $b$ & $\begin{array}{c}\text { Cheminova } \\
\text { Deutschland } \\
\text { GmbH }\end{array}$ \\
\hline Moddus $^{\circledR}$ & $\begin{array}{l}\text { Trinexapac- } \\
\text { ethyl }\end{array}$ & 250 & WR & c & $\begin{array}{c}\text { Syngenta } \\
\text { Agro GmbH } \\
\text { Feinchemie }\end{array}$ \\
\hline Orius $^{\circledR}$ & Tebuconazol & 200 & $\mathrm{~F}+\mathrm{WR}$ & $b$ & $\begin{array}{l}\text { Schwebda } \\
\text { GmbH }\end{array}$ \\
\hline Tilmor $^{\circledR}$ & $\begin{array}{l}\text { Tebuconazol + } \\
\text { Prothioconazol }\end{array}$ & $\begin{array}{c}160 \\
80\end{array}$ & $\stackrel{F+W R}{F}$ & $b$ & $\begin{array}{c}\text { Bayer } \\
\text { CropScience } \\
\text { AG }\end{array}$ \\
\hline Toprex $^{\circledR}$ & $\begin{array}{c}\text { Difenoconazol+ } \\
\text { Paclobutrazol } \\
\end{array}$ & $\begin{array}{l}250 \\
125 \\
\end{array}$ & $\begin{array}{c}\mathrm{F} \\
\mathrm{WR}\end{array}$ & $b$ & $\begin{array}{c}\text { Syngenta } \\
\text { Agro GmbH }\end{array}$ \\
\hline
\end{tabular}

Von den genannten Produkten werden die Triazolpräparate meist bevorzugt, da diese sowohl eine fungizide als auch eine wuchsregulierende Wirkung besitzen. Im Fall von Moddus $^{\circledR}$ müsste ein Triazolpräparat zugemischt werden, um bei einmaliger Applikation auch eine fungizide Wirkung $z u$ erhalten. Im Winterraps werden Fungizide mit wuchsretardierendem Nebeneffekt üblicherweise im Herbst im Vier- bis Sechsblattstadium (BBCH 14-16) und im Frühjahr ab dem Schossen (ab BBCH 30) bei einer Stängellänge von ca. $10-30 \mathrm{~cm}$ eingesetzt (SCHÖNBERGER, 2012; LANDWIRTSCHAFTSKAMMER NORDRHEIN-WESTFALEN, 2014). Ziel der Herbstbehandlung ist es, ein Überwachsen der Bestände zu verhindern und so die Winterhärte zu erhöhen. Eine Anwendung im Herbst 
kann komplett entfallen, wenn kein hoher Krankheitsdruck durch die Wurzelhals- und Stängelfäule vorliegt und die Pflanzen das Sechsblattstadium erst Ende September/Anfang Oktober erreichen. Dann ist die Gefahr der vorzeitigen Stängelstreckung nur noch sehr gering (SCHÖNBERGER, 2012). Der Einsatz im Frühjahr dient primär der Standfestigkeit (Verhinderung von Lager) und orientiert sich daher vielmehr an der Sprossstreckung nach Vegetationsbeginn und weniger an dem Auftreten von P. lingam. Bei wüchsigen Witterungsbedingungen im Frühjahr, einer lageranfälligen Sorte und hohem Krankheitsdruck, kann eine Nachbehandlung im Knospenstadium (BBCH 50-59) nötig sein. Andererseits kann bei kühlen und trockenen Bedingungen im Frühjahr, einer sehr standfesten Sorte und geringem Krankheitsdruck auf die Behandlung verzichtet werden (HANHART, 2014). Ferner können die Triazolwirkstoffe, bei einem Einsatz im Frühjahr, durch ihre vielfältigen physiologischen und morphologischen Nebenwirkungen die Bestandesarchitektur und das Blühverhalten beeinflussen. So berichteten JUNG et al. (1987) und DEUKER-ISERMEYER et al. (1991) von einer einheitlicheren Blüte und einer daraus resultierenden gleichmäßigeren Abreife der Bestände nach dem Einsatz von Triazolen. Die Bestandesarchitektur veränderte sich dahingehend, dass nach der Behandlung mit einem Triazol (Paclobutrazol), die Rapspflanzen mehr Seitentriebe ausgebildet hatten (BAYLIS and HUTLEY-BULL, 1991; ZHOU and XI, 1993). Dieser Effekt war nach Ansicht der Autoren darin begründet, dass Paclobutrazol die Apikaldominanz des Haupttriebes reduzierte.

\subsection{Fragestellung der Arbeit}

Ziel der vorliegenden Arbeit war es, in einem dreifaktoriellen Feldversuch am Standort Göttingen, den Zusammenhang zwischen der Bestandesarchitektur eines Rapsbestandes und dem Kornertrag zu analysieren, sowie den optimalen Bestandesaufbau zur Erzielung des möglichen Höchstertrages zu bestimmen. Im Mittelpunkt der Untersuchungen standen dabei zwei wesentliche Fragen:

1. Welche Bestandesparameter beeinflussen maßgeblich den Ertrag von Winterraps? und

2. Wie beeinflussen die drei anbautechnischen Faktoren Sorte, Saatstärke und Fungizide mit wachstumsregulatorischer Nebenwirkung die ertragsrelevanten Parameter? 
Die Bestandesarchitektur im Raps kann am stärksten durch die Aussaatstärke und durch Fungizidmaßnahmen, die einen wuchsregulierenden Nebeneffekt haben, beeinflusst werden. Je nach genetisch fixierter Pflanzenlänge und Wuchstyp der Sorte, kann diese auch einen Einfluss auf die Bestandesarchitektur ausüben. Durch den Einsatz von zwei Winterrapshybridsorten, zwei verschiedenen Aussaatstärken und acht verschiedenen wachstumsregulierenden Fungizidbehandlungen, sollten Rapsbestände mit einem unterschiedlichen Bestandesaufbau generiert werden, um so möglichst Unterschiede in den untersuchten Parametern hervorzurufen. Dies und die Untersuchung von einer Vielzahl von verschiedenen Parametern sollten dazu beitragen, mögliche ertragsrelevante Bestandesparameter zu identifizieren und gleichzeitig einen Rückschluss auf deren Beeinflussung durch die anbautechnischen Faktoren ermöglichen.

Die hier gewonnenen Erkenntnisse sollen dazu beitragen, das bestehende Anbausystem für Winterraps zu verbessern, um langfristig die Erträge von Winterraps zu steigern und auf einem hohen Niveau zu stabilisieren.

Nachdem ein komplettes Versuchsjahr (2011/12) wegen Auswinterungsschäden und einem zusätzlichen massiven Befall mit Botrytis cinerea aufgegeben werden musste, wurde in einem Nebenprojekt die Sortenanfälligkeit von Winterraps gegenüber $B$. cinerea, sowie die Temperaturansprüche von $B$. cinerea für eine Infektion von Winterraps unter kontrollierten Bedingungen näher untersucht (siehe Anhang Kapitel 8.1). 


\section{Material und Methoden}

\subsection{Versuchsstandorte}

In den Versuchsjahren 2010/11 und 2011/12 wurde der Feldversuch in Göttingen auf der Fläche "Große Lage“ vom Versuchsgut Reinshof der Universität Göttingen durchgeführt. Dabei lag die eigentliche Versuchsfläche in den beiden Versuchsjahren nicht an der gleichen Stelle. Die Versuchsfläche "Große Lage“ befindet sich am nordwestlichen Stadtrand von Göttingen zwischen den Ortsteilen Holtensen-Ost und Weende in der Talaue des Leinegrabens in direkter Nachbarschaft des Flusses Leine ca. $138 \mathrm{~m}$ über Normalhöhennull (NHN) (Gemarkung Weende, Flur 12, Koordinaten: 513'40.81'”N $\left.9^{\circ} 54^{\prime} 49.45^{\prime \prime} \mathrm{O}\right)$. Der vorliegende Bodentyp ist Auenboden, der aus jungen Flusssedimentablagerungen des Holozäns entstanden ist. Nach Klassifizierung durch die Reichsbodenschätzung bzw. deren Anpassungen handelt es sich in dem Versuchsflächenbereich um einen Lehmboden der Zustandsstufe 2, aus Alluvialböden mit der Bodenzahl 86 und der Ackerzahl 89 (L 2 Al 86/89) (ANONYMUS, 2012a).

Im letzten Versuchsjahr 2012/13 wurde der Feldversuch auf einer Fläche in der Nähe der Gemeinde Rosdorf im Landkreis Göttingen angelegt. Die Bezeichnung des Ackerschlages lautet „Dehne“ und dieser gehört ebenfalls zum Versuchsgut Reinshof der Universität Göttingen. Die Gemeinde Rosdorf grenzt im Südwesten an die Stadt Göttingen. Die Versuchsfläche befindet sich zwischen dem Ortsteil Mengershausen und der Gemeinde Rosdorf an der L573 (Gemarkung Rosdorf, Flur 26, Koordinaten: 51'29'47.76”N N 9॰53'17.19"O). Die Fläche liegt 168 m über NHN. Bei dem Bodentyp handelt es sich um eine Schwarzerde. Der Versuchsflächenbereich ist gekennzeichnet durch einen Lehmboden der Zustandsstufe 2, entstanden aus Löß mit einer Bodenzahl von 88 und einer Ackerzahl von 92 ( $L 2$ Lö 88/92). Der kalkhaltige und humose Lehmboden hat eine Mächtigkeit von 75-80 cm. (ANONYMUS, 2012b).

Beide Versuchsstandorte unterliegen üblicherweise einem Produktionsverfahren mit dreifeldriger Fruchtfolge, in der Zuckerrüben - Winterweizen - Wintergerste Zwischenfrucht Ölrettich angebaut werden. Neuerdings wird, je nach Biomassebedarf der Biogasanlage in Rosdorf, auch Silomais in die Fruchtfolge aufgenommen. Im Versuchsflächenbereich der beiden Schläge "Große Lage“ und „Dehne“ wurde erstmals Winterraps anstatt Zuckerrüben angebaut. 


\subsection{Versuchsanlage}

Bei den Feldversuchen in Göttingen von 2010/11 bis 2012/13 handelte es sich um dreifaktorielle Feldversuche mit zwei Winterrapshybridsorten, zwei Aussaatstärken und acht verschiedenen Fungizidbehandlungen (vgl. Kapitel 2.3). Im ersten Versuchsjahr (2010/11) waren die zwei Sorten und die zwei Aussaatstärken als vier Blöcke über die Versuchsfläche randomisiert (vgl. Tab. 10A im Anhang II). Innerhalb jedes Blockes waren die acht Fungizidbehandlungen in vierfacher Wiederholung vollrandomisiert. Die Parzellengröße betrug 22,5 m² (2,50 m breit und $9 \mathrm{~m}$ lang). In jedem Block wurde jede Parzelle bei einer Länge von $6 \mathrm{~m}$ in zwei Teilparzellen unterteilt. Dabei stellten die oberen $3 \mathrm{~m}$ die Boniturparzellen für sämtliche Bonituren und Probenahmen dar und die unteren $6 \mathrm{~m}$ dienten ausschließlich zur Ermittlung des Flächenertrages.

Im zweiten und dritten Versuchsjahr $(2011 / 12+2012 / 13)$ handelte es sich um eine teilrandomisierte Spalt-Spalt-Anlage in vierfacher Wiederholung, bei der die Sorten auf dem Großteilstück, die Aussaatstärken auf dem Mittelteilstück jeweils in Spalten randomisiert (Teilrandomisierung) und die Fungizidbehandlungen auf den Kleinteilstücken vollrandomisiert waren (vgl. Tab. 11A und 12A im Anhang II). In der Vegetationsperiode 2011/12 hatten die Parzellen eine Größe von $30 \mathrm{~m}^{2}$ (2,50 m breit und $12 \mathrm{~m}$ lang) und in der Vegetationsperiode 2012/13 waren sie $25 \mathrm{~m}^{2}$ groß (2,5 m breit und $10 \mathrm{~m}$ lang). In beiden Vegetationsperioden erfolgte ebenfalls eine Unterteilung der Gesamtparzellen in zwei Teilparzellen bei einer Länge von $6 \mathrm{~m}$. Wie schon zuvor erwähnt, stellte dabei die obere Teilparzelle die Boniturparzelle und die untere Teilparzelle die Ertragsparzelle dar. Die Teilparzellengröße für die Bestimmung des Flächenertrages war über alle drei Versuchsjahre identisch (15 $\mathrm{m}^{2}, 2,50 \mathrm{~m}$ breit und $6 \mathrm{~m}$ lang). Nur die Teilparzellengröße für die Bonituren und Probenahmen variierte je nach Versuchsjahr $\left(7,50 \mathrm{~m}^{2}, 15 \mathrm{~m}^{2}\right.$ und $\left.10 \mathrm{~m}^{2}\right)$.

\subsection{Versuchsfaktoren}

Der erste Versuchsfaktor stellte die Rapssorte dar. In den Versuchsjahren 2010/11 und 2011/12 wurden in dem Feldversuch in Göttingen die beiden Winterrapshybridsorten „NK Petrol“ und „SY Merlot“ verwendet. Im letzten Versuchsjahr 2012/13 wurde die Sorte „SY Merlot" durch die Sorte „SY Vesuvio" ersetzt. Diese ist in ihrem Längenwachstum sowie in der Anfälligkeit gegenüber Phoma lingam vergleichbar mit der Sorte „SY Merlot“ (persönliche Mitteilung Dr. Henke, Syngenta Agro $\mathrm{GmbH}, 18.03 .2013$ ). Alle drei genannten Sorten stammen von der Firma Syngenta Agro GmbH. Detaillierte 
Sortenprofile zu jeder Rapssorte befinden sich im Anhang II in den Tab. 13A-15A. Der zweite Versuchsfaktor war die Aussaatstärke. Es wurden entweder $30 \mathrm{Körner} / \mathrm{m}^{2}$ oder 60 Körner/m² ausgesät. Diese Saatstärken wurden in allen drei Versuchsjahren verwendet. Als dritter Versuchsfaktor dienten acht verschiedene Fungizidvarianten. Neben der fungiziden Wirkung haben diese Pflanzenschutzmittel auch eine wachstumsregulatorische Wirkung (vgl. Kapitel 1.2). Die acht verschiedenen Fungizidvarianten variierten in der Anzahl der Behandlungen pro Jahreszeit. Je nach Variante wurden im Herbst bzw. im Frühjahr keine, eine oder zwei Fungizidapplikationen durchgeführt. Fungizidvariante eins stellte die unbehandelte Kontrolle dar und in den Varianten zwei bis sieben wurde Toprex ${ }^{\circledR}$ (Difenoconazol + Paclobutrazol) eingesetzt (Tab. 3), wobei Difenoconazol ausschließlich eine fungizide Wirkung und Paclobutrazol ausschließlich eine wuchsregulierende Wirkung besitzt (ANONYMUS, 2013a). Nach dem ersten Versuchsjahr wurden die Varianten sechs und sieben den Versuchsfragen angepasst (Tab. 4). Bei der Variante acht handelte es sich um eine praxisübliche Variante, bei der entweder Carax ${ }^{\circledR}$ (Metconazol + Mepiquatchlorid) oder Folicur ${ }^{\circledR}$ (Tebuconazol) gespritzt wurde. Zur Vollblüte (BBCH 65; (MEIER, 2001) wurde in dieser Variante entweder Harvesan ${ }^{\circledR}$ (Flusilazol + Carbendazim) oder Ortiva ${ }^{\circledR}$ (Azoxystrobin) eingesetzt. In den anderen Varianten wurde zur Vollblütenspritzung Ortiva ${ }^{\circledR}$ verwendet. Die genauen Aufwandmengen der Fungizide aus der praxisüblichen Variante und deren Einsatzzeitpunkte können der Tab. 16A im Anhang II entnommen werden. Die Tab. 5 enthält weitere Einzelheiten zu den verwendeten Fungiziden wie z.B. Wirkstoffgehalte, Funktion der Wirkstoffe und Art der Formulierung.

Tab. 3: Fungizidvarianten im Feldversuch mit Winterraps im ersten Versuchsjahr 2010/11 am Standort Göttingen. Wenn nichts anderes angegeben ist, wurde Toprex ${ }^{\circledR}$ mit $0,5 \mathrm{l} / \mathrm{ha}$ und Ortiva ${ }^{\circledR}$ mit $1,0 \mathrm{l} /$ ha gespritzt.

\begin{tabular}{|c|c|c|c|c|c|}
\hline Variante & BBCH 14 & BBCH 16 & BBCH 33/35 & BBCH 53/55 & BBCH 65 \\
\hline 1 & \multicolumn{5}{|c|}{ unbehandelte Kontrolle } \\
\hline 2 & --- & --- & Toprex $^{\circledR}$ & --- & Ortiva $^{\circledR}$ \\
\hline 3 & Toprex $^{\circledR}$ & --- & Toprex $^{\circledR}$ & --- & Ortiva $^{\circledR}$ \\
\hline 4 & Toprex $^{\circledR}$ & Toprex $^{\circledR}$ & Toprex $^{\circledR}$ & --- & Ortiva $^{\circledR}$ \\
\hline 5 & Toprex $^{\circledR}$ & --- & Toprex $^{\circledR}$ & Toprex $^{\circledR}$ & Ortiva $^{\circledR}$ \\
\hline 6 & Toprex $^{\circledR}$ & --- & $\begin{array}{l}\text { 1,0 l/ha } \\
\text { Toprex }^{\circledR}\end{array}$ & --- & Ortiva $^{\circledR}$ \\
\hline 7 & Toprex ${ }^{\circledR}$ & --- & Toprex $^{\circledR}$ & --- & $\begin{array}{l}2,0 \mathrm{l} / \mathrm{ha} \\
\text { Ortiva }^{\circledR}\end{array}$ \\
\hline 8 & & & praxisüblich & & \\
\hline
\end{tabular}


Tab. 4: Fungizidvarianten im Feldversuch mit Winterraps im zweiten (2011/12) und dritten (2012/13) Versuchsjahr am Standort Göttingen. Toprex ${ }^{\circledR}$ wurde in allen Varianten mit $0,5 \mathrm{l} / \mathrm{ha}$ und Ortiva $^{\circledR}$ mit 1,0 l/ha gespritzt. Im Vergleich zum ersten Versuchsjahr haben sich die Varianten sechs und sieben verändert (fett hervorgehoben).

\begin{tabular}{cccccc}
\hline Variante & BBCH 14 & BBCH 16 & BBCH 33/35 & BBCH 53/55 & BBCH 65 \\
\hline 1 & & \multicolumn{3}{c}{ unbehandelte Kontrolle } \\
2 & --- & --- & Toprex $^{\circledR}$ & --- & Ortiva $^{\circledR}$ \\
3 & Toprex $^{\circledR}$ & --- & Toprex $^{\circledR}$ & --- & Ortiva $^{\circledR}$ \\
4 & Toprex $^{\circledR}$ & Toprex $^{\circledR}$ & Toprex $^{\circledR}$ & --- & Ortiva $^{\circledR}$ \\
5 & Toprex $^{\circledR}$ & --- & Toprex $^{\circledR}$ & Toprex $^{\circledR}$ & Ortiva $^{\circledR}$ \\
6 & Toprex $^{\circledR}$ & Toprex $^{\circledR}$ & Toprex $^{\circledR}$ & Toprex $^{\circledR}$ & Ortiva $^{\circledR}$ \\
7 & Toprex $^{\circledR}$ & --- & --- & --- & Ortiva $^{\circledR}$ \\
8 & & & praxisüblich & & \\
\hline
\end{tabular}


Tab. 5: Charakterisierung der im Feldversuch verwendeten Fungizide (ANONYMUS, 2013a, 2013b, 2013c, 2013d, 2013e).

\begin{tabular}{|c|c|c|c|c|c|c|}
\hline Produkt & Wirkstoffe & $\begin{array}{c}\text { Wirkstoffgehalte } \\
{[\mathrm{g} / \mathrm{l}]}\end{array}$ & $\begin{array}{c}\text { Funktion der } \\
\text { Wirkstoffe }^{*}\end{array}$ & Formulierung $^{\star \star}$ & Hersteller & Indikationen in Raps \\
\hline $\operatorname{Carax}^{\circledR}$ & $\begin{array}{l}\text { Metconazol+ } \\
\text { Mepiquatchlorid }\end{array}$ & $\begin{array}{c}30 \\
210\end{array}$ & $\begin{array}{c}F+W R \\
W R\end{array}$ & SL & BASF SE & $\begin{array}{l}\text { u.a. Standfestigkeit, Winterfestigkeit, } \\
\text { Wurzelhals- und Stängelfäule }\end{array}$ \\
\hline Folicur $^{\circledast}$ & Tebuconazol & 250 & $F+W R$ & $\mathrm{EW}$ & Bayer CropScience AG & $\begin{array}{l}\text { u.a. Standfestigkeit, Winterfestigkeit, } \\
\text { Wurzelhals- und Stängelfäule }\end{array}$ \\
\hline Harvesan $^{\circledR}$ & $\begin{array}{c}\text { Flusilazol } \\
\text { Carbendazim }\end{array}$ & $\begin{array}{l}250 \\
125\end{array}$ & $\begin{array}{l}\mathrm{F} \\
\mathrm{F}\end{array}$ & SE & $\begin{array}{l}\text { DuPont de Nemours } \\
\text { (Deutschland) GmbH }\end{array}$ & Weißstängeligkeit \\
\hline
\end{tabular}

${ }^{*}$ SC $=$ Suspensionskonzentrat; $\mathrm{SL}=$ wasserbasiertes Konzentrat; EW = Emulsion in Wasser; SE = Suspoemulsion (ANONYMUS, 2013f) 


\subsection{Acker- und pflanzenbauliche Maßnahmen}

Nach der Ernte der jeweiligen Vorfrucht (2010 \& 2012 Winterweizen, 2011 Wintergerste) erfolgten zuerst keine (2010) bzw. zwei (2011 \& 2012) Stoppelbearbeitungsgänge bevor die Fläche gepflügt wurde. Vor dem zweiten Stoppelbearbeitungsgang wurde organischer Dünger (2011) oder Mineraldünger (2012) als Grunddüngung ausgebracht (vgl. Tab. 18A \& 19A im Anhang II). Am 07.09.2010, am 24.08.2011 und am 29.08.2012 wurde der Versuch mit einer 2,50 m breiten Scheibenscharsämaschine (Fa. Hassia-Lemken, Alpen) blockweise (2010) bzw. spaltenweise (2011 \& 2012) nach Sorte und Aussaatstärke ausgesät. Die Ernte erfolgte mit einem handelsüblichen Mähdrescher (Modell Farmliner 3370, Fa. Deutz-Fahr, Köln). Dieser hat eine Schneidwerksbreite von 2,60 m. Zuerst wurden die Boniturparzellen und dann die Ertragsparzellen geerntet. Die Stickstoffdüngung richtete sich nach den ermittelten $\mathrm{N}_{\min }$-Gehalten. Der Einsatz von Herbiziden und Insektiziden erfolgte nach ortsüblichen Gegebenheiten bzw. nachdem Schadschwellen überschritten wurden. Die Applikation der Fungizide mit wachstumsregulatorischer Nebenwirkung erfolgte durch eine Versuchsparzellenspritze mit 250 I/ha Wasser (Düsentyp ID-120-03 Air-Injektor Flachstrahldüse). Die Blütenspritzung wurde mit einer herkömmlichen Feldspritze (Anbauspritze, $15 \mathrm{~m}$; Firma Rau) durchgeführt.

Zur weiteren Information ist im Anhang II eine detaillierte Auflistung aller durchgeführten acker- und pflanzenbaulichen Maßnahmen des jeweiligen Versuchsjahres (Tab. 17A-19A) zu finden. Zusätzlich sind dort eine Nährstoffanalyse des Gärsubstrates (Tab. 20A), und die Ergebnisse der Bodenproben des jeweiligen Versuchsjahres (Tab. 21A) einzusehen.

\subsection{Witterungsverlauf und Pflanzenentwicklung 2010 bis 2013}

Die Angaben zum Witterungsverlauf beruhen auf Daten, die mit einer eigenen, mobilen Wetterstation in unmittelbarer Nähe zum jeweiligen Feldversuch am Standort Göttingen erhoben wurden. Zum Einsatz kamen dabei Messinstrumente der Firma Davis Instruments aus Hayward, USA. Die Messstation wurde mit der Aussaat des Versuchs aufgebaut und erst nach der Ernte wieder abgebaut. Es werden in dieser Arbeit die Monatsmittelwerte für die Lufttemperatur in $1,50 \mathrm{~m}$ Höhe $\left[{ }^{\circ} \mathrm{C}\right]$ und die Summe für die Monatsniederschläge [mm] für den Zeitraum September bis Juli angegeben. Die unter 3.1 dargestellten Temperatur- und Niederschlagsabweichungen beziehen sich auf langjährige Durchschnittswerte der Referenzperiode 1981-2010, welche von der Wetterstation des 
Deutschen Wetterdienstes in Göttingen aufgezeichnet wurden (DEUTSCHER WETTERDIENST, 2013).

Für eine termingerechte Applikation sämtlicher Pflanzenschutz- und Düngemaßnahmen wurde in jeder Vegetationsperiode die Pflanzenentwicklung durch Bestimmung der Wachstumsstadien (BBCH-Stadien) erfasst. Dabei wurden die $\mathrm{BBCH}$-Stadien stets nach (MEIER, 2001) bestimmt.

\subsection{Erfassung der Ertragsfaktoren}

\subsubsection{Pflanzen $/ \mathrm{m}^{2}$}

Die Pflanzen $/ \mathrm{m}^{2}$ wurden jeweils einmal im Herbst und einmal bzw. zweimal (2012) im Frühjahr gezählt. An welchem Tag und zu welchem BBCH-Stadium die Durchführung erfolgte, kann der Tab. 6 entnommen werden.

Tab. 6: Zeitpunkt und BBCH-Stadium zu dem die Pflanzendichte (Pflanzen $/ \mathrm{m}^{2}$ ) in den Jahren 2010/11, 2011/12 und 2012/13 erfasst wurde.

\begin{tabular}{cccc}
\hline \multicolumn{1}{c}{ Herbst } & \multicolumn{2}{c}{ Frühjahr } \\
\hline Datum & BBCH-Stadium & Datum & BBCH-Stadium \\
\hline \multirow{2}{*}{18.10 .2010} & $14 / 15$ & 08.03 .2011 & $16 / 18$ \\
14.09 .2011 & $12 / 13$ & 20.03 .2012 & 30 \\
& & 18.04 .2012 & $57 / 61$ \\
27.09 .2012 & 13 & 19.04 .2013 & $51 / 52$ \\
\hline
\end{tabular}

Pro Boniturparzelle wurde an vier verschiedenen Stellen mit einem 0,25 $\mathrm{m}^{2}$-Zählrahmen die Pflanzendichte in Pflanzen $/ \mathrm{m}^{2}$ bestimmt. Für die Zählungen wurden in den Boniturparzellen ab dem zweiten Versuchsjahr rund einen Meter von der oberen und unteren Stirnseite entfernt, je ein roter Stab in den Boden gesteckt. An diesen Stäben wurde jeweils zur rechten und zur linken Seite der 0,25 $\mathrm{m}^{2}$-Zählrahmen ausgerichtet und die Pflanzen in dem Rahmen gezählt (Abb. 4). Durch die Stäbe war man im Frühjahr in der Lage wieder an der gleichen Stelle die Anzahl der Pflanzen $/ \mathrm{m}^{2}$ zu bestimmen. Zusätzlich ermöglichte dies die Erfassung der Pflanzenverluste über Winter (Auswinterung). Indem man die Pflanzenzahlen $/ \mathrm{m}^{2}$ aus dem Frühjahr von den Pflanzenzahlen $/ \mathrm{m}^{2}$ aus dem Herbst subtrahiert, erhält man die Anzahl an Pflanzen $/ \mathrm{m}^{2}$, die ausgewintert sind. 


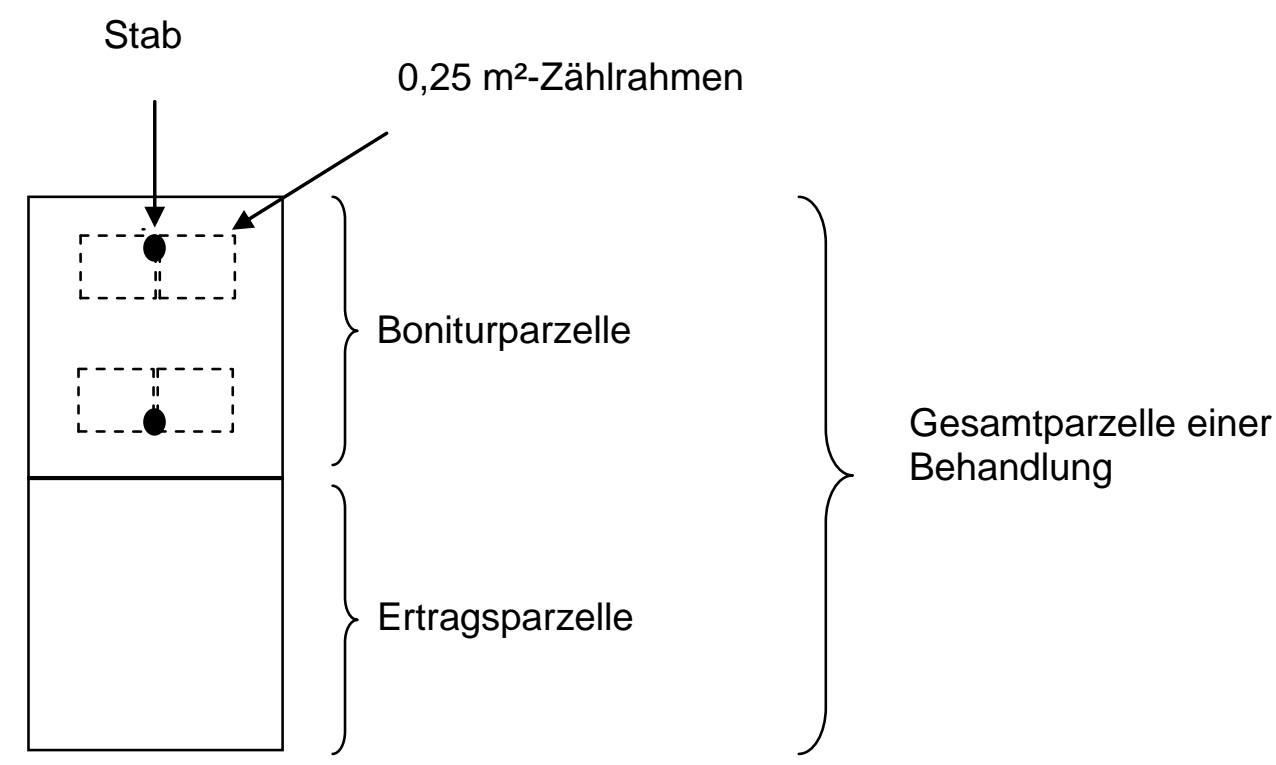

Abb. 4: Schematische Darstellung von der Ermittlung der Pflanzendichte (Pflanzen $\left./ \mathrm{m}^{2}\right)$ in der Boniturparzelle.

\subsubsection{Schoten/Pflanze und Seitenriebe/Pflanze}

Die Bestimmung der Schoten/Pflanze setzte eine Erfassung der Anzahl der Seitentriebe/Pflanze voraus. Daher wird an dieser Stelle für beide Parameter die methodische Ermittlung näher beschrieben. Es muss allerdings berücksichtigt werden, dass der Parameter Seitentriebe/Pflanze nicht zu den vier klassischen Ertragsfaktoren zählt. Für die Erfassung der Seitentriebe/Pflanze sowie der Schoten/Pflanze wurden im Versuchsjahr 2010/11 fünf Pflanzen pro Parzelle und 2012/13 zehn Pflanzen pro Parzelle geerntet. Die Probenahme erfolgte im ersten Jahr am 06.06.2011 (BBCH 77) und im dritten Jahr am 25.06.2013 (BBCH 77). Es war wichtig, dass die Pflanzen unterhalb des niedrigsten Seitentriebes abgeschnitten und nicht aus dem Randbereich der Boniturparzellen entnommen wurden. Zuerst wurden die Seitentriebe/Pflanze gezählt. Dabei wurden nur die Seitentriebe 1. Ordnung berücksichtigt. Der unterste Seitentrieb stellte den ersten Seitentrieb und der oberste den letzten Seitentrieb dar. Danach wurden die Schoten an den Seitentrieben sowie am Haupttrieb ermittelt. Nur Schoten mit deutlich erkennbarem Kornansatz, sowie aufgeplatzte Schoten wurden mit erfasst. Schoten an Seitentrieben 2. Ordnung wurden nicht separat gezählt, sondern den Seitentrieben 1. Ordnung zugerechnet. Die Gesamtzahl an Schoten/Pflanze ergab sich aus der Addition der Werte von jedem einzelnen Trieb. Aus den fünf bzw. zehn Einzelwerten pro Parzelle wurden Mittelwerte gebildet. Diese dienten der statistischen Auswertung. 


\subsubsection{Schoten/Trieb (absolut/relativ)}

Wie unter 2.6.2 beschrieben, wurden für den Parameter Schoten/Pflanze die Schoten pro Seiten- und Haupttrieb bestimmt. Die Daten zu den Werten Schoten/Pflanze und Schoten/Trieb ermöglichten es, den relativen Anteil an Schoten pro Trieb zu berechnen. Anhand der absoluten und relativen Zahlen zu der Anzahl Schoten/Trieb konnte man Aussagen darüber treffen, welche Triebe die meisten Schoten trugen. Die Bezeichnung Trieb 00 steht für den Haupttrieb, Trieb 01 für den obersten Seitentrieb, Trieb 02 für den zweitobersten Seitentrieb und entsprechend alle weiteren Triebe.

\subsubsection{Körner/Schote}

Zur Erfassung des Parameters Körner/Schote wurden pro Boniturparzelle aus dem mittleren Parzellenbereich ca. 10-15 Haupt- bzw. Seitentriebe entnommen. Die Probenahme erfolgte im Jahr 2010/11 am 06.07.11 (BBCH 85/87) und im Jahr 2012/13 am 08.07.13 (BBCH 81). Von den 10-15 Haupt- bzw. Seitentrieben wurden 200 Schoten mit einer Schere abgeschnitten und als Mischprobe jeweils in eine beschriftete Aluminiumschale (Fa. Contital, Modell R82L, Italien) gegeben. Die Schoten wurden anschließend für 24 Stunden bei $75^{\circ} \mathrm{C}$ in einen Trockenschrank gestellt (Fa. Memmert, Modell UFE 700, Deutschland). Dadurch entzog man den Schotenwänden das Wasser und konnte im nächsten Schritt die Schoten mit einem Handdreschgerät (Minibatt $=$ Minimähdrescher zur Probenahme, Fa. Reichardt $\mathrm{GmbH}$, Deutschland) besser ausdreschen. Die Rapskörner fielen beim Dreschvorgang in einen Becher, der direkt am Dreschgerät montiert war. Zusätzlich erfolgte der Drusch über einem Sieb (Masche 3,5 $\mathrm{mm}$ ), das in einer Aussaatschale stand, um einen möglichen Verlust von einzelnen Körnern zu verhindern (Abb. 5). Außerdem wurde jede gedroschene Probe aus dem Becher über dem Sieb ausgeschüttet, um eine grobe Vorreinigung durchzuführen und um zu kontrollieren, ob alle Schoten ausgedroschen wurden. Dann erfolgte eine gründliche Reinigung jeder einzelnen Dreschprobe mittels einer Kornreinigung (Fa. Pfeuffer, Modell MLN, Deutschland). Dabei wurden spezielle Rapssiebe verwendet und die aus der Bedienungsanleitung empfohlenen Grundeinstellungen berücksichtigt. Im letzten Schritt wurden die Körner aus jeweils 200 Schoten gezählt. Dazu wurde eine Kornzählmaschine (Numigral Seed Counter, Tripette et Renaud, Paris) verwendet. Aus der Anzahl Rapskörner pro 200 Schoten wurde die Zahl Körner je Schote errechnet. 


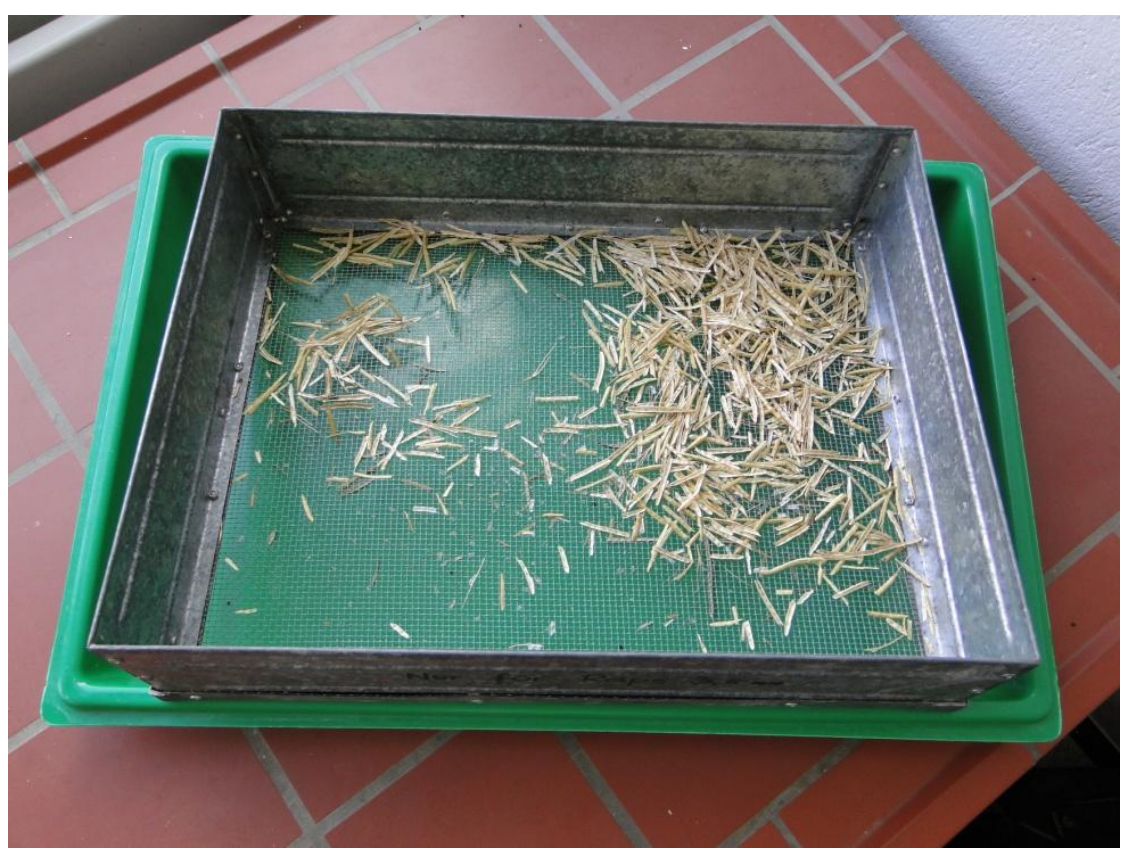

Abb. 5: Mittels eines Siebes mit einer Maschenweite von 3,5 mm wurden ausgedroschene Rapsproben grob gereinigt. So konnten größere Spreuanteile vorab aus der Kornprobe entfernt werden.

\subsubsection{Tausendkornmasse (TKM)}

Die Erfassung des Parameters Tausendkornmasse wurde nach der Ernte im Jahr 2011 und 2013 mit Hilfe von Rückstellproben der einzelnen Flächenertragsparzellen bestimmt. Nach der Reinigung der Rückstellproben von Spreuanteilen wurden mittels einer Kornzählmaschine (Numigral Seed Counter, Tripette et Renaud, Paris) von jeder Rückstellprobe 1000 Körner abgezählt und von diesen das Gewicht in Gramm ermittelt. Die Ernte erfolgte unter trockenen Bedingungen, sodass die Rapskörner für die Rückstellproben eine Restfeuchte von $\leq 9 \%$ hatten. Daher mussten die Proben für die TKM-Erfassung nicht getrocknet werden.

\subsubsection{Schoten $/ \mathrm{m}^{2}$}

Dieser Parameter wurde rechnerisch durch Multiplikation der Werte von Schoten/Pflanze und den Werten von Pflanzen $/ \mathrm{m}^{2}$ (Frühjahr) ermittelt.

\subsubsection{Körner/Pflanze}

Wie der vorherige Parameter wurde die Anzahl Körner/Pflanze durch Multiplikation der Werte von Schoten/Pflanze und den Werten von Körner/Schote berechnet. 


\subsubsection{Korndichte (geerntete Körner/m²)}

Mit den Werten von Körner/Pflanze und den Werten von Pflanzen $/ \mathrm{m}^{2}$ (Frühjahr) ließ sich die Korndichte, d.h. die geernteten Körner $/ \mathrm{m}^{2}$ berechnen.

\subsection{Erfassung von Bestandesparametern}

Die folgenden Parameter Wurzelhalsdurchmesser, Blattlänge und Anzahl Blätter/Pflanze wurden alle an den Pflanzenproben ermittelt, die auch für die Bonituren der Wurzelhalsund Stängelfäule verwendet wurden. Dabei wurde die Blattlänge und die Anzahl Blätter/Pflanze nur im Herbst und der Wurzelhalsdurchmesser sowohl im Herbst als auch im Frühsommer jeder Vegetationsperiode erfasst.

\subsubsection{Wurzelhalsdurchmesser}

Der Wurzelhals befindet sich unterhalb des Hypokotyls und stellt die Grenzzone zwischen Wurzel und Sprossachse dar (Abb. 6). In diesem Bereich wurde an der breitesten Stelle mit Hilfe einer digitalen Schieblehre (Fa. Max Bahr, Göttingen) der Durchmesser des Wurzelhalses in Millimeter gemessen. Pro Wurzelhals wurde eine Messung durchgeführt.

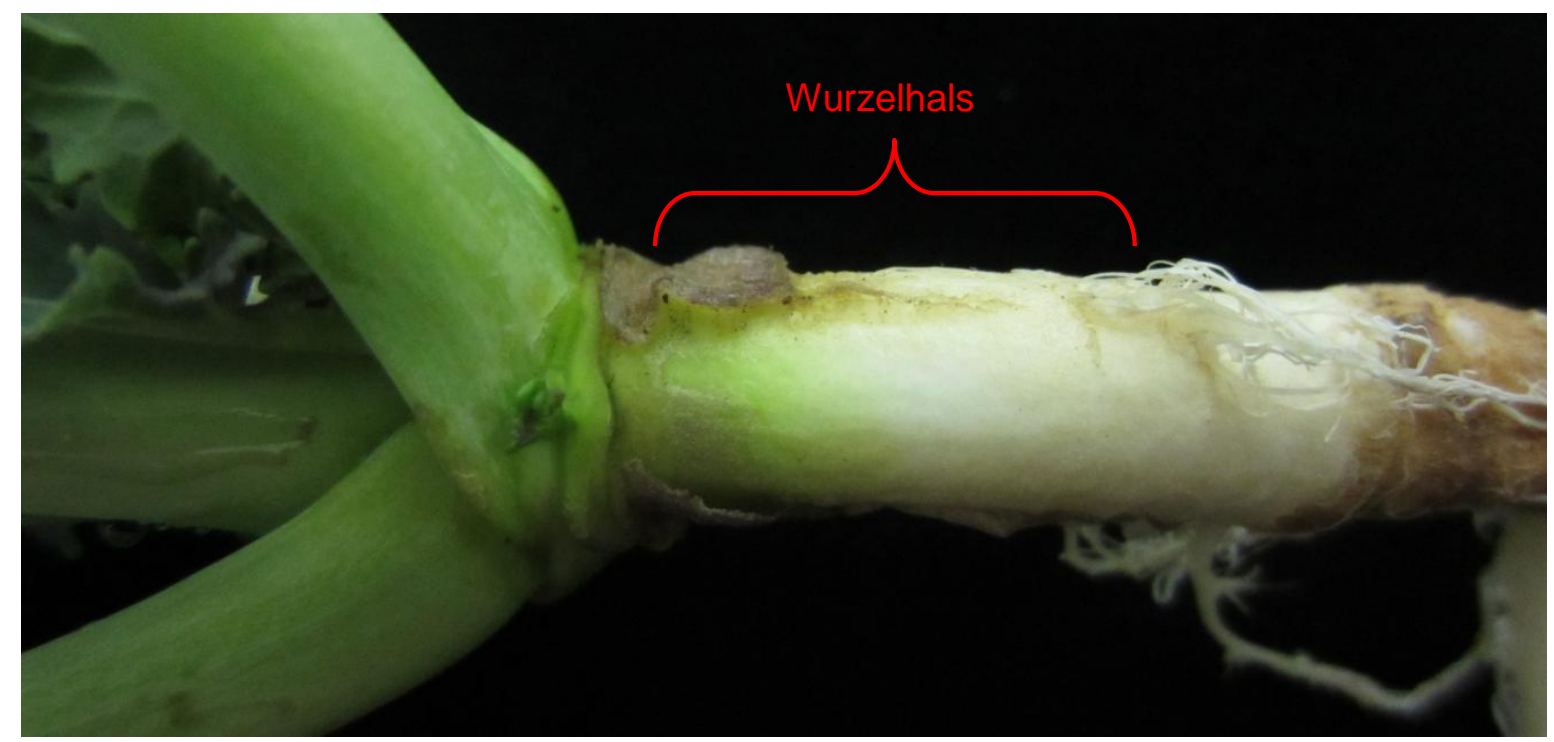

Abb. 6: Wurzelhals einer Rapspflanze im Sieben- bis Acht-Blatt-Stadium (BBCH 17/18). 


\subsubsection{Blattlänge}

Die Messung der Blattlänge erfolgte in Zentimeter von der untersten Ansatzstelle der Blattstiele am Hypokotyl bis zur Blattspitze des längsten Blattes mit einem Zollstock.

\subsubsection{Blätter/Pflanze}

Der Parameter Blätter/Pflanze konnte durch das Zählen der Blattansätze abgefallener Blätter und den noch vorhandenen Blättern bestimmt werden. Die Blattansätze waren gut durch die Anlage der Seitentriebe auffindbar (Abb. 7).

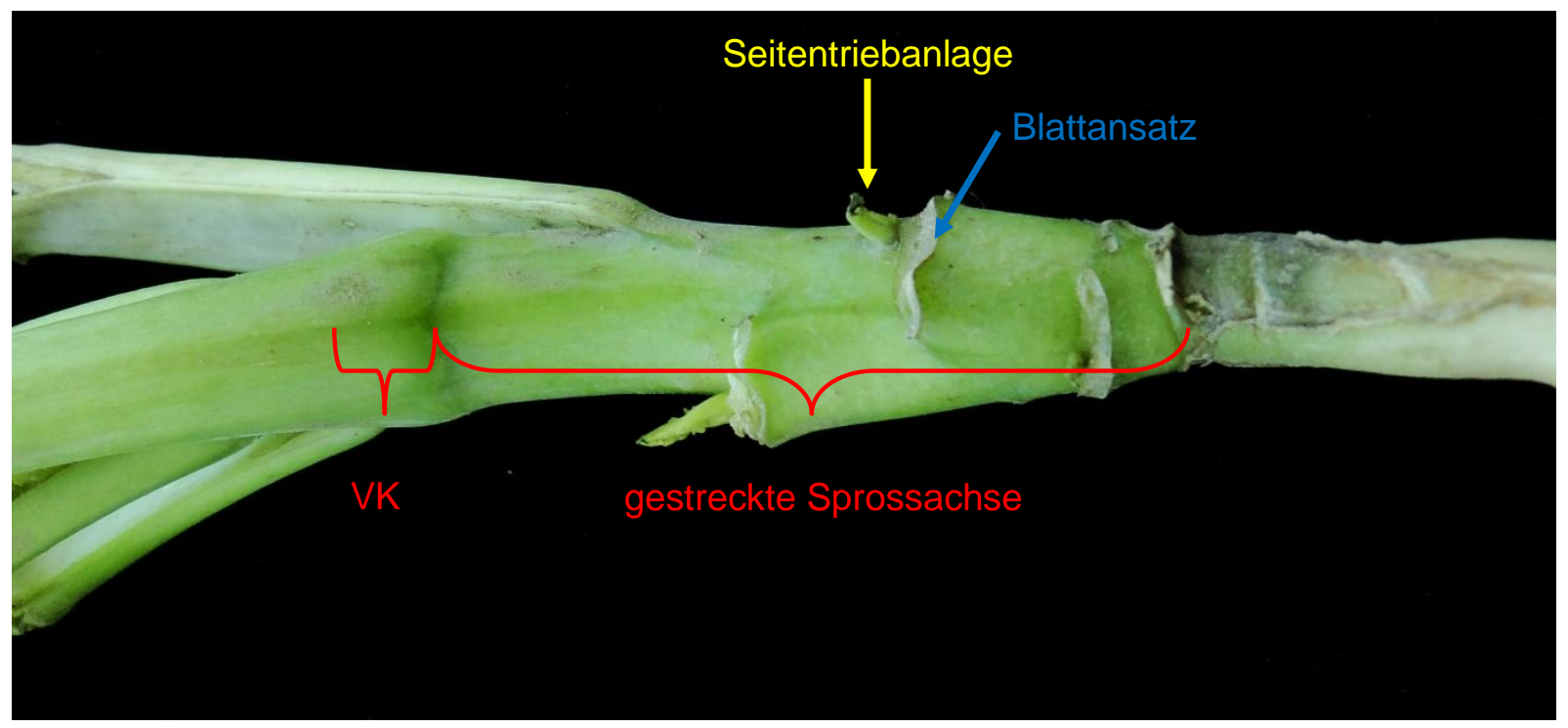

Abb. 7: Rapspflanze im Acht- bis Neun-Blatt-Stadium (BBCH 18/19) mit einem abgehobenen Vegetationskegel (VK) und Seitentriebanlage (gelber Pfeil) sowie Blattansatz (blauer Pfeil).

\subsubsection{Kulturdeckungsgrad}

Der Kulturdeckungsgrad, oder auch Bedeckungsgrad genannt, stellt das Verhältnis der vom Laubdach überdeckten Fläche zur Bestandsgrundfläche dar (HELMSCHROT, 1999) und variiert zwischen Null und Eins. Häufig wird er auch als prozentualer Kulturdeckungsgrad, also als der Anteil der Bestandsgrundfläche, der lückenlos durch photosynthetisch aktives Material überdeckt ist, angegeben und variiert dann zwischen 0\% und 100\% (ELVIDGE \& CHEN, 1995; LACAZE, 1996).

Zur Feststellung des Kulturdeckungsgrades wurden zu bestimmten BBCH-Stadien im Herbst bzw. Frühjahr Fotoaufnahmen gemacht (Tab. 7). Dazu wurde ein 0,5 m²-Zählrahmen jeweils einmal an den zwei roten Stäben in den Boniturparzellen zur 
Parzellenmitte hin ausgerichtet. Mit Hilfe einer Fotokamera (Fa. Sony ${ }^{\circledR}$ Modell: DSC-HX1, Japan) wurde in einer Höhe von ca. 1,85 m im 90-Winkel der Rahmen mit den darin eingefassten Rapspflanzen fotografiert. Pro Parzelle wurden zwei Bilder gemacht. Durch die Ausrichtung zur Parzellenmitte wurden mögliche Randeffekte ausgeschlossen. In jedem Versuchsjahr erfolgten die Aufnahmen immer von der linken Parzellenseite aus und wurden bei ähnlichen Wetterverhältnissen durchgeführt. Mit Hilfe der Software Assess 2.0 (Image Analysis Software for Disease Quantification, APS Press, USA) konnte am Computer der Kulturdeckungsgrad in Prozent ermittelt werden. Aus den zwei Kulturdeckungsgradwerten pro Parzelle wurde ein Mittelwert gebildet. Die Mittelwerte von jeder Parzelle gingen in die statistische Verrechnung ein. Aus der Tab. 7 geht hervor, dass im Frühjahr und Herbst des Jahres 2011 mehrmals zu verschiedenen BBCH-Stadien der Kulturdeckungsgrad ermittelt wurde. Dies diente vor allem zur besseren Einschätzung der Entwicklung des Kulturdeckungsgrades. Für die statistische Verrechnung wurden nur die Daten vom Kulturdeckungsgrad der unterstrichenen Erhebungstermine genutzt. Für das Kapitel Ergebnisse wurden nur die Daten der beiden Frühjahrstermine berücksichtigt.

Tab. 7: Zeitpunkt und BBCH-Stadium zu dem der Parameter Kulturdeckungsgrad [\%] in den Jahren 2010/11, 2011/12 und 2012/13 erfasst wurde. Die Daten der unterstrichenen Erhebungsterminen und $\mathrm{BBCH}$-Stadien flossen in die statistische Auswertung ein.

\begin{tabular}{|c|c|c|c|}
\hline \multicolumn{2}{|c|}{ Herbst } & \multicolumn{2}{|c|}{ Frühjahr } \\
\hline Datum & $\mathrm{BBCH}$ & Datum & $\mathrm{BBCH}$ \\
\hline $\begin{array}{c}\text { Herbst } 2010 \text { nicht } \\
\text { ermittelt }\end{array}$ & & $\begin{array}{l}11.03 .2011 \\
28.03 .2011 \\
\mathbf{0 4 . 0 4 . 2 0 1 1}\end{array}$ & $\begin{array}{c}15 / 19 \\
30 \\
\mathbf{3 2} / \mathbf{3 4}\end{array}$ \\
\hline $\begin{array}{l}27.09 .2011 \\
11.10 .2011 \\
25.10 .2011\end{array}$ & $\begin{array}{l}14 / 16 \\
17 / 18 \\
18 / 19\end{array}$ & $\begin{array}{l}\text { Frühjahr } 2012 \text { nicht } \\
\text { ermittelt, wegen } \\
\text { Auswinterung und } \\
\text { Botrytis-Befall } \\
\end{array}$ & \\
\hline$\underline{22.11 .2012}$ & $\underline{17 / 18}$ & $\underline{17.04 .2013}$ & $32 / 34$ \\
\hline
\end{tabular}

\subsubsection{Blattflächenindex (BFI)}

Der Blattflächenindex (BFI, englisch Leaf Area Index, LAI) beschreibt das Verhältnis der gesamten Blattoberfläche eines Bestandes zur gesamten Bestandesgrundfläche:

$$
\mathrm{BFI}=\frac{\text { Blattfläche des Bestandes }\left[\mathrm{m}^{2}\right]}{\text { Grundfläche des Bestandes }\left[\mathrm{m}^{2}\right]}
$$


Ein BFI von Null bedeutet, dass keine Blätter oder Nadeln vorkommen. Bei einem BFI von Eins entspricht die Blattfläche der horizontalen Bodenfläche und bei einem BFI von Zwei ist die Blattfläche doppelt so groß wie die Bodenfläche. Entsprechend kann man dies bis zum maximalen BFI von 16 fortsetzen. Dieser wird in den immergrünen Wäldern der Westküste der USA erreicht (WOHLRAB et al., 1992; DANSON, 1995; HILDEBRANDT, 1996).

Der BFI wurde mit Hilfe des Sensors LAI 2000 Plant Canopy Analyzer (Fa. Li-Cor ${ }^{\circledR}$, Lincoln, Nebraska, USA) im Versuchsjahr 2011/12 am 08.11.2011 (BBCH 18/19) und im Versuchsjahr 2012/13 am 23.11.2012 (BBCH 17/18) ermittelt. An der Linse des Sensors war eine Sichtkappe (View Cap) von $270^{\circ}$ befestigt (Abb. 8). Es wurden nur Messungen in den Versuchsvarianten V1 (unbehandelte Kontrolle), V3 (1x Toprex ${ }^{\circledR}$ im Herbst appliziert), V4 (2x Toprex $^{\circledR}$ im Herbst appliziert) und V8 (praxisüblich) durchgeführt, da sich die anderen Varianten zu diesem Zeitpunkt noch nicht von den genannten Varianten unterschieden. Wie in der Bedienungsanleitung beschrieben, wurden pro Parzelle jeweils 20 Messungen vorgenommen. Vier Messungen wurden über dem Bestand als Referenzmessungen und 16 Messungen unter den Blättern am Boden durchgeführt. Dabei erfolgten die Messungen im Uhrzeigersinn um die Parzelle herum, um eine gleichmäßige Verteilung der Messpunkte zu erzielen. Aus den 20 Messungen pro Parzelle hat der Sensor einen Mittelwert errechnet. Die Mittelwerte dienten der statistischen Analyse. Die Messungen erfolgten bei möglichst bewölktem Wetter, da dann die Messgenauigkeit am höchsten ist. Diese Voraussetzung war an den Tagen der jeweiligen Messung gegeben. Für die Endauswertung des Feldversuches wurden nur die BFI-Daten aus dem dritten Versuchsjahr berücksichtigt.

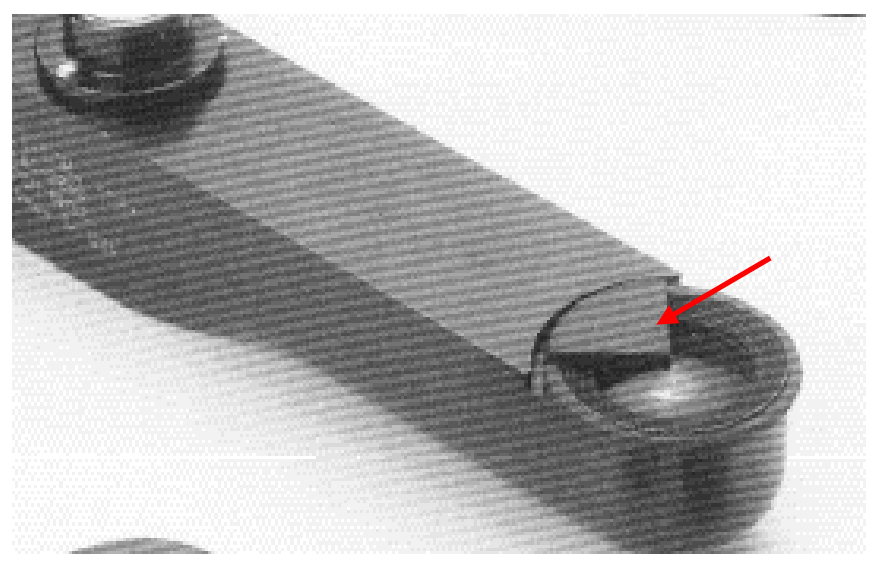

Abb. 8: Sensoreinheit des LAI 2000 Plant Canopy Analyzer (Fa. Li-Cor ${ }^{\circledR}$, Lincoln, Nebraska, USA). An der Linse ist eine Sichtkappe (View Cap) von $270^{\circ}$ befestigt (roter Pfeil). Foto: (ANONYMUS, 2013g) 


\subsubsection{Photosynthetisch aktive Strahlung (PAR)}

Die photosynthetisch aktive Strahlung (Photosynthetically Active Radiation $=$ PAR) stellt den Wellenlängenbereich des Sonnenlichtes von 400 bis $700 \mathrm{~nm}$ dar und wird in $\mu \mathrm{mol} / \mathrm{s} / \mathrm{m}^{2}\left(\equiv 1 \mu \mathrm{E} / \mathrm{s} / \mathrm{m}^{2} \equiv 6,022 \cdot 10^{17}\right.$ Photonen $\left./ \mathrm{s} / \mathrm{m}^{2}\right)$ angegeben. Aus Tab. 8 geht hervor, dass zu vier verschiedenen $\mathrm{BBCH}$-Stadien Lichtmessungen durchgeführt wurden. Bei der Messung der PAR im Rapsbestand wurden im ersten Versuchsjahr 2010/11 für die ersten drei Messtermine ein Punktsensor [LI-190 Quantum Sensor; (Abb. 9)] und ein dazu passender Datenspeicher (LI-250 Light Meter) von der Firma Li-Cor ${ }^{\circledast}$ aus Nebraska, USA genutzt. Beim letzten Messtermin im ersten Versuchsjahr sowie im dritten Versuchsjahr wurde der Punktsensor durch einen Stabsensor [LI-191 Line Quantum Sensor; Fa. Li$\mathrm{Cor}^{\oplus}$, Lincoln, Nebraska, USA (Abb. 10)] ersetzt. Der Stabsensor hat eine Länge von einem Meter und besteht u.a. aus Quarzglas $\left(\mathrm{SiO}_{2}\right)$ was das PAR-Licht aufnimmt und an einen Quantum-Sensor weiterleitet (ANONYMUS, 2014c). Im Vergleich zum Punktsensor sind die Messungen der PAR auf einer Länge von einem Meter genauer, da unterschiedliche Lichtverhältnisse in einem Pflanzenbestand (beschattet/unbeschattet) gleichzeitig erfasst werden und dafür ein Mittelwert ausgegeben wird.

Tab. 8: Erhebungstermine der photosynthetisch aktiven Strahlung (PAR) im Rapsbestand, gemessen unter den Blüten/Schoten (PAR_M1-4) und am Boden (PAR_B1-4) in den Versuchsjahren 2010/11 und 2012/13.

\begin{tabular}{cc}
\hline Datum & BBCH-Stadium \\
\hline $30.04-02.05 .2011$ & $63 / 65$ \\
$16.05-18.05 .2011$ & $67 / 69$ \\
$23 / 24 / 26.05 .2011$ & $73 / 74$ \\
$30.05-01.06 .2011$ & 75 \\
\hline 23.05 .2013 & 65 \\
04.06 .2013 & $67 / 69$ \\
11.06 .2013 & $73 / 74$ \\
18.06 .2013 & 75 \\
\hline
\end{tabular}




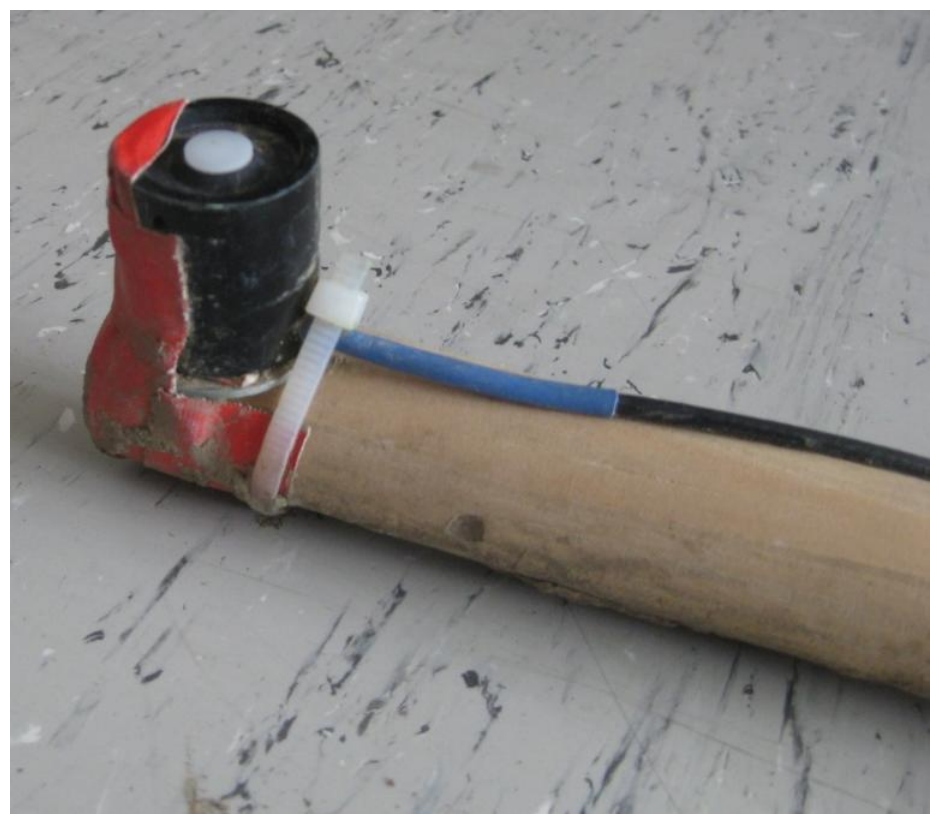

Abb. 9: Detailaufnahme des montierten Punktsensors (LI190 Quantum Sensor, Fa. Li-Cor ${ }^{\circledR}$, Lincoln, Nebraska, USA).

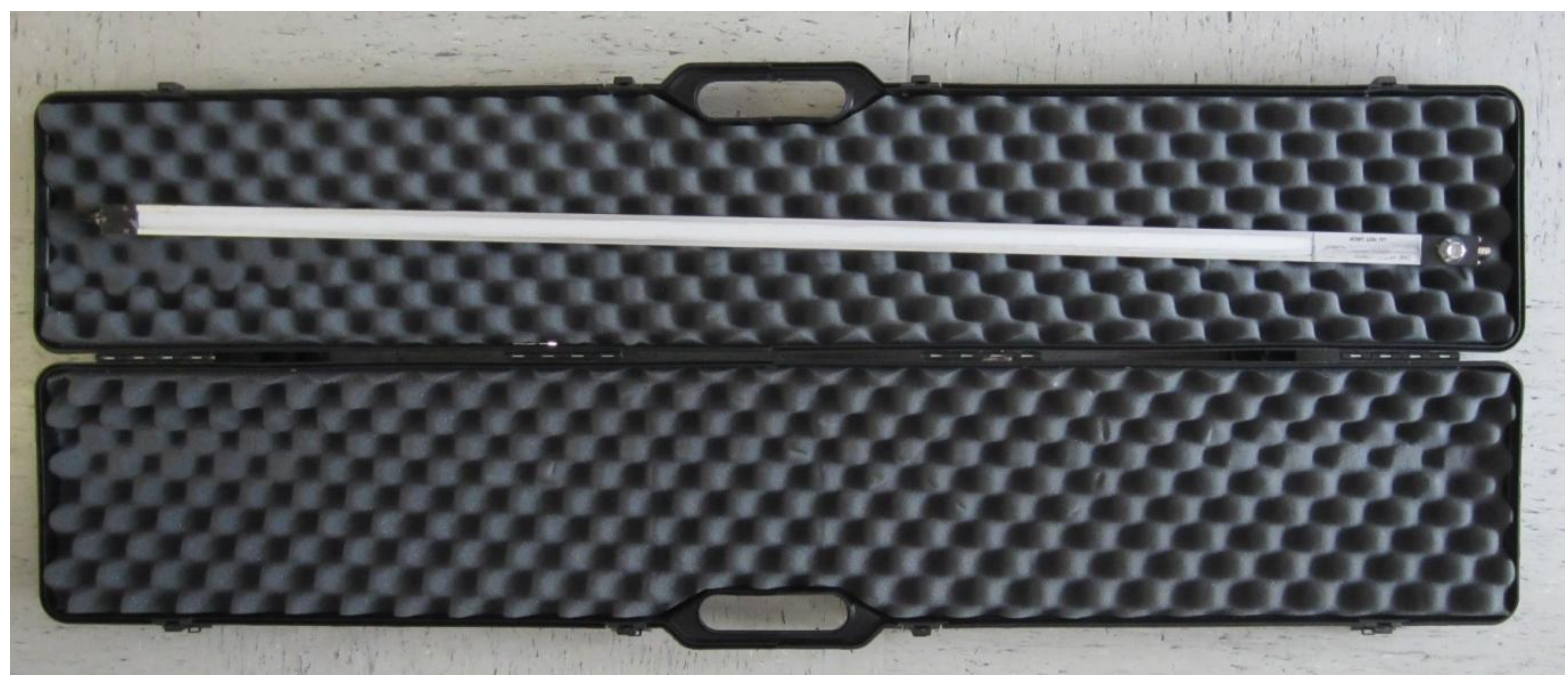

Abb. 10: Aufsicht auf den $1 \mathrm{~m}$ Stabsensor (LI-191 Line Quantum Sensor, Fa. Li-Cor ${ }^{\circledR}$, Lincoln, Nebraska, USA) in aufgeklappter Transportbox.

Im ersten Versuchsjahr wurden die Messungen zum jeweiligen $\mathrm{BBCH}$-Stadium an drei aufeinanderfolgenden Tagen durchgeführt. Aus diesen drei Werten wurde für die entsprechende Parzelle und dem entsprechenden $\mathrm{BBCH}$-Stadium ein Mittelwert gebildet. Im dritten Versuchsjahr wurde nur einmal pro Parzelle und pro $\mathrm{BBCH}$-Stadium die PAR gemessen. Die Messungen in den Parzellen erfolgten immer von der linken Parzellenseite aus. Die Ertragsparzellen waren für die Bestimmung dieses Parameters besser geeignet, 
da hier der Rapsbestand unbeeinflusst von Probenahmen war. Damit immer an der gleichen Stelle in den Ertragsparzellen die PAR gemessen werden konnte, wurde die Messstelle mit einem weißen Plastikstab markiert. An diesem Stab wurde der Punkt- bzw. Stabsensor ausgerichtet. Der Punktsensor war an einem Holzstab befestigt (Abb. 11), wodurch die Messung in der Parzellenmitte erfolgen konnte.

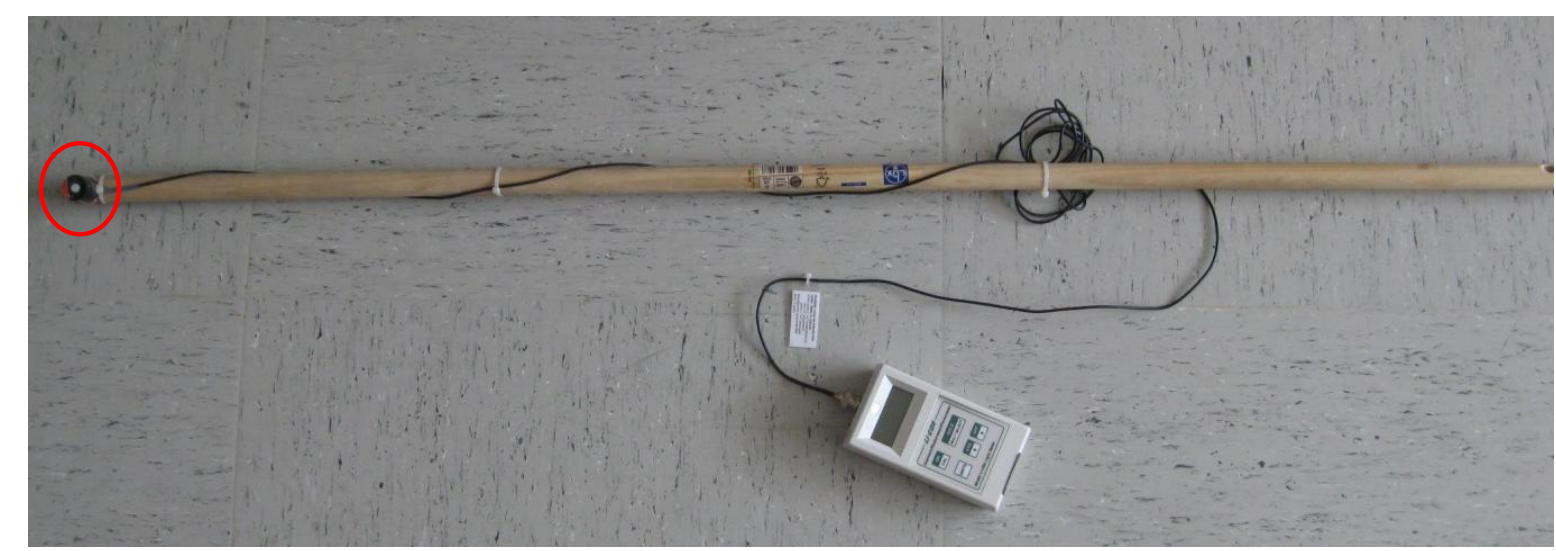

Abb. 11: Punktsensor (roter Kreis; LI-190 Quantum Sensor; Fa. Li-Cor ${ }^{\circledR}$, Lincoln, Nebraska, USA) montiert auf einem Holzstab mit Datenspeicher (LI-250 Light Meter, Fa. Li-Cor ${ }^{\circledR}$, Lincoln, Nebraska, USA).

Insgesamt wurde pro Parzelle jeweils einmal über dem Bestand, unter der Blüten- und Schotenschicht und am Boden eine Messung vorgenommen. Jeder Messvorgang dauerte 15 Sekunden. Durch die Messung der PAR über dem Bestand, konnten die absoluten Messwerte der PAR unter der Blüten- und Schotenschicht und am Boden in relative Werte umgerechnet werden. Diese Relativwerte wurden für die statistische Auswertung genutzt. Die Messungen erfolgten annähernd zur gleichen Tageszeit (ca. 11 bis 15 Uhr), um einen Einfluss des Sonnenstandes auf die Messwerte ausschließen zu können.

\subsubsection{Bestandeshöhe - Schotenansatzhöhe - Schotenschichtdicke}

Jeweils im Frühjahr wurden zu vier verschiedenen Wachstumsstadien die Bestandeshöhe und die Blüten- bzw. Schotenansatzhöhe in Zentimeter bestimmt (Tab. 9). 
Tab. 9: Zeitpunkt und BBCH-Stadium zu dem die Parameter Bestandeshöhe und Blüten- bzw. Schotenansatzhöhe in den Jahren 2010/11 und 2012/13 erfasst wurden.

\begin{tabular}{cc}
\hline Datum & BBCH-Stadium \\
\hline 11.05 .2011 & $65 / 67$ \\
18.05 .2011 & $67 / 69$ \\
24.05 .2011 & $73 / 74$ \\
30.05 .2011 & 75 \\
\hline 30.05 .2013 & $65 / 67$ \\
05.06 .2013 & $67 / 69$ \\
12.06 .2013 & $73 / 74$ \\
19.06 .2013 & 75 \\
\hline
\end{tabular}

In Göttingen wurden pro Boniturparzelle vier Messungen, wie in Abb. 12 dargestellt, vorgenommen

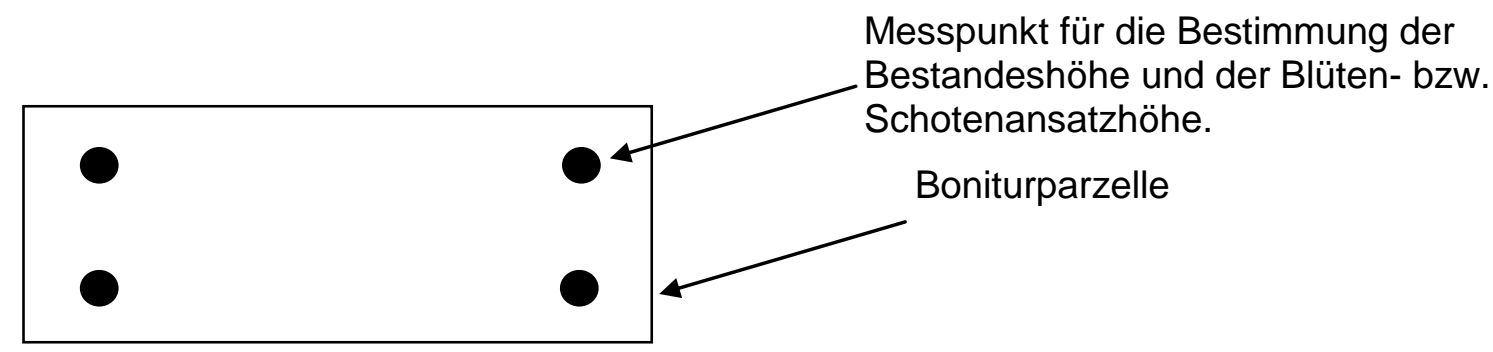

Abb. 12: Vereinfachte Darstellung der Messpunkte für die Bestandeshöhe und Blüten- bzw.

Schotenansatzhöhe in einer Boniturparzelle.

Die Bestandeshöhe wurde ermittelt, indem eine dünne Styroporplatte $(1 \mathrm{~cm})$ auf den Rapsbestand gelegt wurde und an der Unterkante der Styroporplatte die Höhe des Bestandes an einer Messlatte abgelesen wurde (Abb. 13). Die Blüten- bzw. Schotenansatzhöhe wurde unter Zuhilfenahme eines kleinen Rundstabes in $5 \mathrm{~cm}$ Schritten bestimmt, indem der Rundstab an der Grenze zwischen Blattschicht und Blütenbzw. Schotenschicht in Richtung Messlatte geschoben wurde. Durch Subtraktion der Werte der Blüten- bzw. Schotenansatzhöhe von der Bestandeshöhe wurde die Dicke [cm] der Blüten- bzw. Schotenschicht bestimmt. In die statistische Verrechnung gingen die Mittelwerte aus den vier Messwerten ein.

Zur Vereinfachung wird im Folgenden die Blüten- bzw. Schotenansatzhöhe als Schotenansatzhöhe und die Blüten- bzw. Schotenschicht als Schotenschichtdicke bezeichnet. 


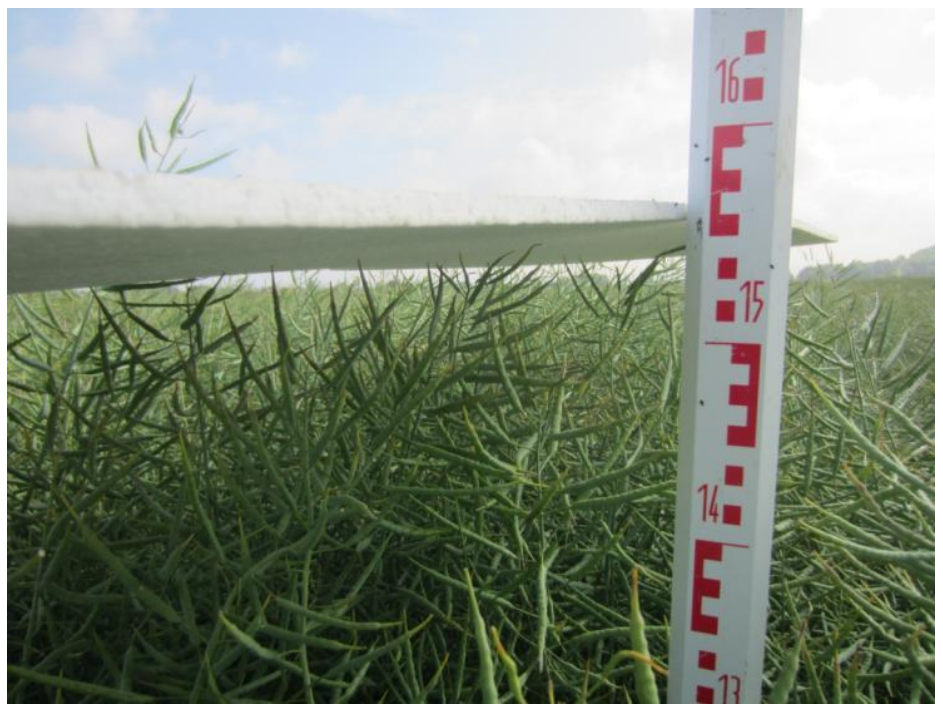

Abb. 13: Messung der Bestandeshöhe im Rapsbestand 2013 mit Hilfe einer Styroporplatte $(1 \mathrm{~cm})$ und einer Messlatte.

\subsubsection{Grünfärbung des Pflanzenbestandes}

\subsubsection{Normalized Difference Vegetation Index (NDVI)}

Der von ROUSE (1973) und ROUSE et al. (1974) eingeführte Vegetationsindex Normalized Difference Vegetation Index (NDVI), korreliert stark mit dem Blattflächenindex und der grünen pflanzlichen Biomasse (PEÑUELAS et al., 1994). Er eignet sich daher sehr gut, indirekt den Zustand eines Pflanzenbestandes zu beschreiben. So kann dieser z.B. genutzt werden, um die photosynthetische Leistungsfähigkeit, das NettoProduktionspotential oder den potenziellen Ertrag eines Pflanzenbestandes zu schätzen (Sellers, 1987; ThenKABAil et al., 2000; MA et al., 2001; RaUn et al., 2001). Der NDVI ist ein errechneter physikalischer Wert für eine bestimmte Fläche, der zwei Merkmale eines Pflanzenbestandes in sich vereint $(\mathrm{BOSCH}, 2012)$ :

1. Bedeckungsgrad von aktiven grünen Pflanzen

2. Vitalität eines Pflanzenbestandes (Grad der Aktivität von Chlorophyll).

Der NDVI wird nach folgender Formel berechnet:

$$
\mathrm{NDVI}=\frac{\mathrm{NIR}-\mathrm{Rot}}{\mathrm{NIR}+\text { Rot }}
$$

Dabei stellt NIR die Reflektion der Pflanzenoberfläche im nahinfraroten $(720-1300 \mathrm{~nm})$ und Rot die Reflektion der Pflanzenoberfläche im sichtbaren roten $(600-720 \mathrm{~nm})$ Wellenlängenbereich dar (ROUSE et al., 1974). 
Die Reflektion des sichtbaren roten Lichtes ist primär von der Chlorophylldichte im Palisadenparenchym des Blattes abhängig. Steigt diese, so erhöht sich die Absorption der Strahlung im roten und blauen Wellenlängenbereich des Lichtes und die Reflektion sinkt. Sinkt die Dichte, so nehmen die Absorption ab und die Reflektion zu. Damit einher geht eine Steigerung oder Verringerung der Photosyntheseleistung eines Blattes bzw. einer Pflanze. Die Reflektion von nahinfraroter Strahlung hängt vor allem von der Struktur der Schwammparenchymzellen und der Interzellularräume, die zwischen diesen Zellen liegen, ab. Demnach wird die Reflektion des sichtbaren Lichtes durch Blattpigmente (v.a. Chlorophyll) und die Reflektion des nahinfraroten Lichtes durch die interne Zellstruktur eines Blattes beeinflusst (CAMPBELL, 2002).

Der Wertebereich für den NDVI liegt zwischen Null und Eins. Dabei bedeutet ein NDVIWert von Null stark vereinfacht „keine Assimilation/totes Material“. Ein Wert von Eins bedeutet dagegen, dass eine grüne pflanzliche Oberfläche das ausgesendete Rotlicht zu $100 \%$ verwerten kann und keine entsprechende Reflektion an der Pflanzenoberfläche messbar ist. Allerdings handelt es sich bei einem Wert von Eins um einen theoretischen Wert, der in der Natur nicht erreicht wird (BOSCH, 2012).

\subsubsection{Messung des NDVI mittels GreenSeeker ${ }^{\circledR}$}

Mit Hilfe des GreenSeekers ${ }^{\circledR}$ Model 505 [Fa. NTech ${ }^{\circledR}$ Industries, Ukiah, Kalifornien, USA; (Abb. 14)] kann schnell, einfach und vor allem nicht-destruktiv der NDVI gemessen werden. Der GreenSeeker ${ }^{\circledR}$ ist ein Gerät mit einer optischen Sensoreinheit, die mittels einer LED-Lichtquelle aktiv Licht im sichtbaren (Rot, $660 \mathrm{~nm} \pm 12 \mathrm{~nm}$ ) und im nahinfraroten (NIR, 770nm $\pm 12 \mathrm{~nm}$ ) Wellenlängenbereich emittiert und gleichzeitig das vom Pflanzenbestand reflektierte Licht mit einer Photodiode detektiert (SOLIE et al., 2002; ANONYMUS, 2007; KIM et al., 2010) (Abb. 15). Das vom Pflanzenbestand zurückgestrahlte Licht wird durch spezielle Filter von störender Hintergrundbeleuchtung befreit und an einen Multiplex-Analog-Digital-Wandler weitergeleitet (SOLIE et al., 2002). Dieser setzt das gemessene Licht in digitale Daten um, woraus die Sensor-Software einen NDVI-Wert nach oben genannter Formel berechnet. Das von der LED-Lichtquelle erzeugte Scanfeld hat eine Breite von $61 \mathrm{~cm}$. Diese Breite verändert sich nicht, wenn man in einer Höhe von 81-122 cm über dem Pflanzenbestand misst (KIM et al., 2010). 


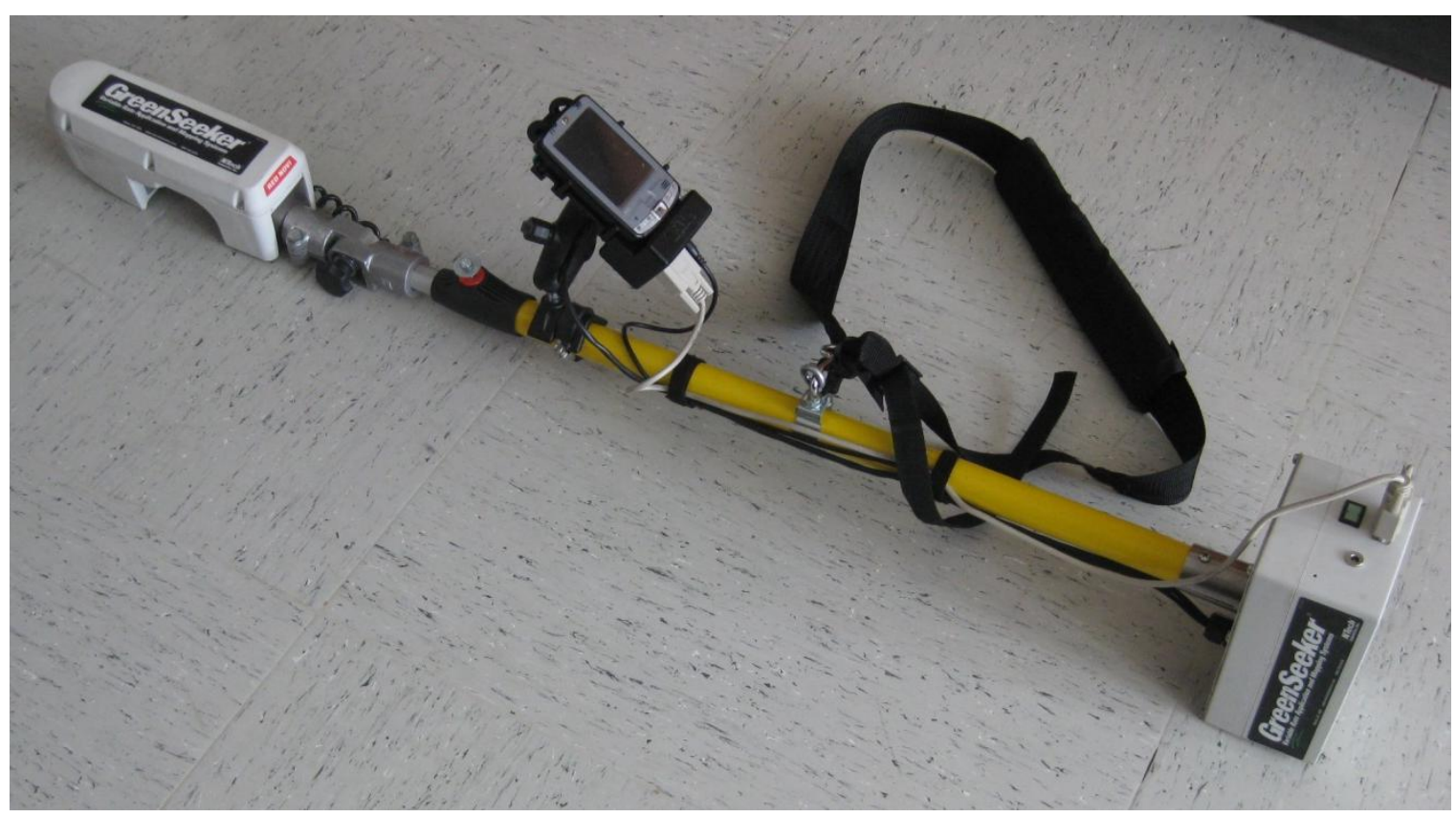

Abb. 14: GreenSeeker ${ }^{\circledR}$ von der Firma NTech ${ }^{\circledR}$ Industries. Links: Sensoreinheit, in der Mitte: Personal Digital Assistent (PDA), auf dem die Normalized Difference Vegetation Index (NDVI)Werte gespeichert werden und rechts: Akku.
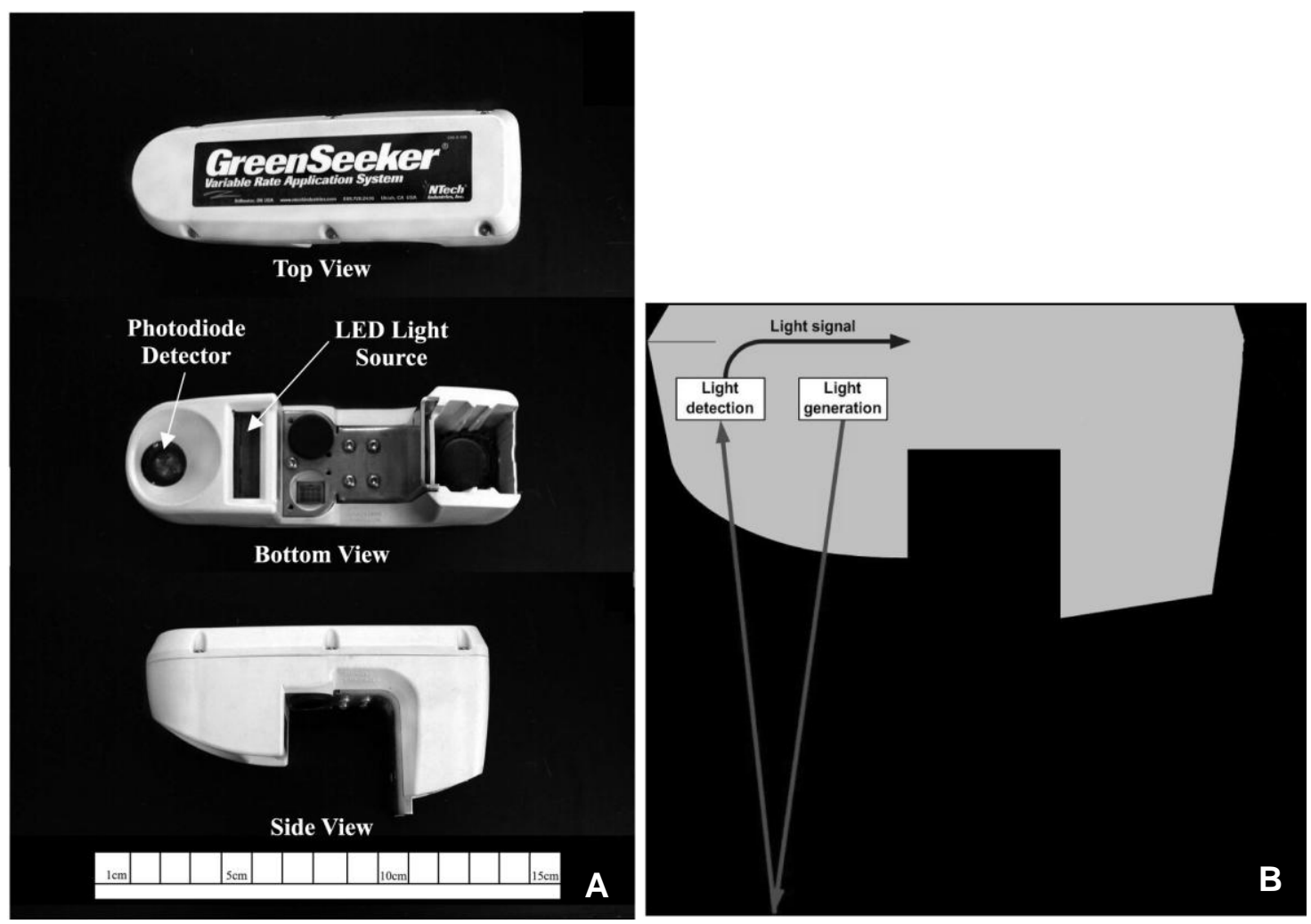

Abb. 15: A) Sensoreinheit des GreenSeekers ${ }^{\circledR}$ aus verschiedenen Blickwinkeln.

B) Schematische Darstellung des Strahlengangs der GreenSeeker ${ }^{\circledR}$ Sensoreinheit (INMAN et al., 2005). 
Die Erfassung von NDVI-Werten mit Hilfe des GreenSeekers ${ }^{\circledR}$ diente dazu, den Grünanteil des Pflanzenbestandes zu bestimmen. Dabei sollte untersucht werden, welchen Einfluss die Sorte, die Saatstärke und die Fungizidapplikationen auf den Grünanteil des Pflanzenbestandes hatten. Die Messungen wurden in der Regel wöchentlich ab dem BBCH-Stadium 62/63 (2010/11) bzw. 57/59 (2012/13) bis zur Ernte des Rapses durchgeführt.

Im Frühjahr/Sommer 2011 wurde der GreenSeeker ${ }^{\circledR}$ mit der Hand über den Bestand geführt. Im Frühjahr/Sommer 2013 wurde die Messmethode verbessert, indem der GreenSeeker $^{\circledR}$ in ein fahrbares Gestell (Abb. 16) eingespannt wurde. Die zwei Stützen links und rechts des Rades wurden während des Betriebes abmontiert und dienten nur als Standhilfe. Die gesamte GreenSeeker ${ }^{\circledR}$-Einheit konnte, je nach Bestandeshöhe, variabel an der senkrecht angebrachten Stange befestigt werden. So konnten die Messungen bei allen Parzellen immer in der gleichen Höhe über dem Pflanzenbestand durchgeführt werden. Am rechten Griff des fahrbaren Gestells befand sich ein Knopf, durch dessen Drücken eine Messung begonnen wurde. Sobald man diesen wieder losließ, wurde die entsprechende Messung beendet.

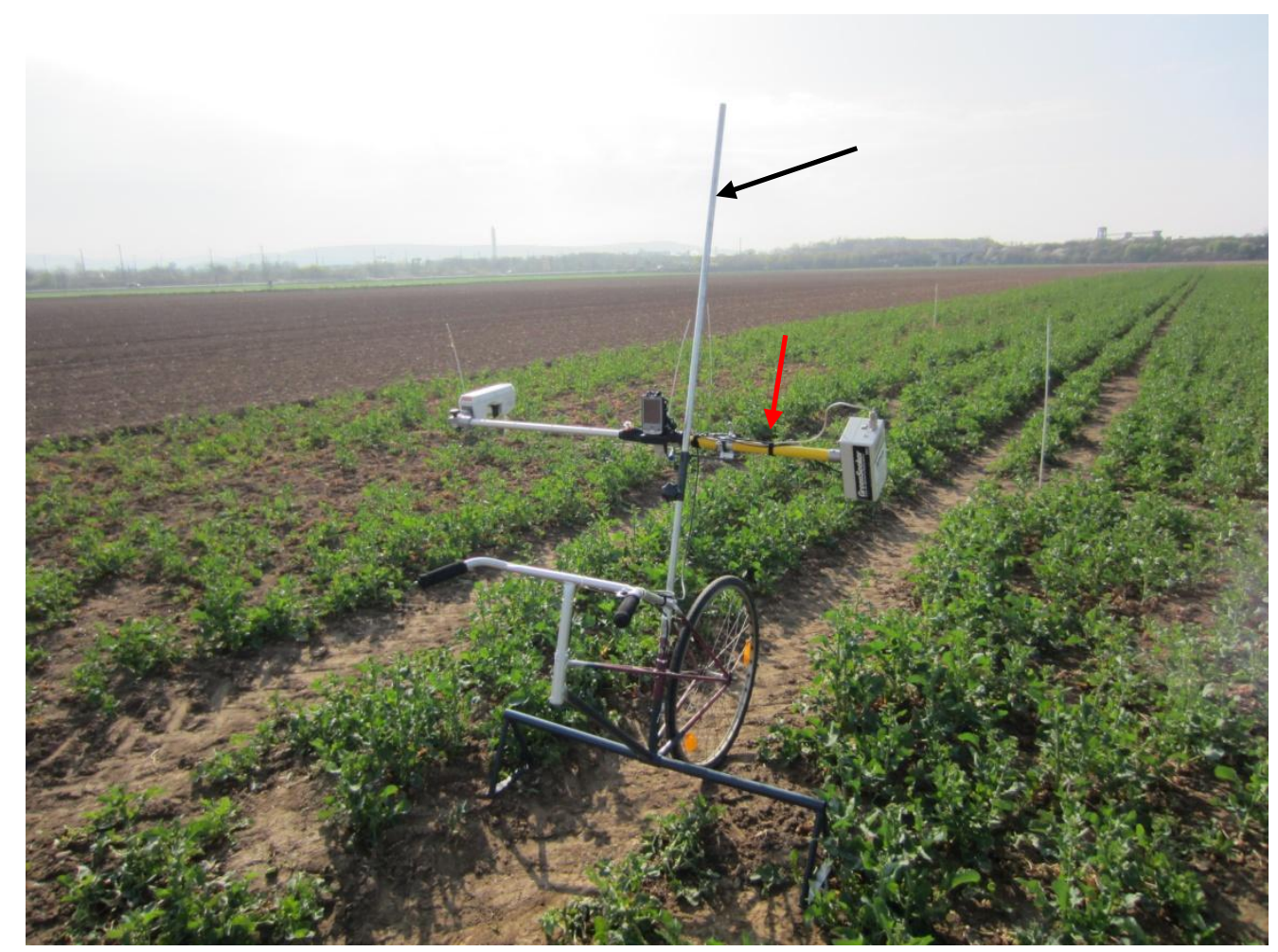

Abb. 16: GreenSeeker ${ }^{\circledR}$ (roter Pfeil) montiert an ein selbstkonstruiertes, fahrbares Gestell. Der GreenSeeker ${ }^{\circledR}$ kann individuell an der senkrechten Stange (schwarzer Pfeil) in der Höhe verstellt werden. 
Bei den Messungen wurden die Parzellen immer von der gleichen Parzellenseite aus, mit der gleichen Schrittzahl und dem gleichen Schritttempo abgeschritten. Ca. $50 \mathrm{~cm}$ nach dem Beginn einer Parzelle wurde die Messung gestartet und ca. $50 \mathrm{~cm}$ vor dem Ende einer Parzelle wurde sie beendet. So wurden mögliche Randeffekte ausgeschlossen und es wurden keine Pflanzen von der nächsten Parzelle mit gemessen. Alle 100 ms misst der GreenSeeker $^{\circledR}$ den NDVI und errechnet daraus einen Mittelwert. Die vom GreenSeeker ${ }^{\circledR}$ ermittelten Daten wurden auf einem Personal Digital Assistant (PDA) zwischengespeichert und am Computer für die weitere Verrechnung aufbereitet. Für die statistische Analyse wurden NDVI-Mittelwerte von bestimmten Messterminen genutzt. Das waren zum einen NDVI-Daten von vier Terminen aus der Zeit der Blüte bis zur mittleren Schotenentwicklung des Rapses (NDVI-Blüte 1-4, NDVI_B1-4) und zum anderen die Daten der letzten fünf Termine (NDVI-Abreife 1-5, NDVI_A1-5). In der Tab. 10 sind diese Messtermine sowie die entsprechenden $\mathrm{BBCH}-$ Stadien der jeweiligen Versuchsjahre angegeben.

Tab. 10: NDVI-Messtermine und dazugehörige BBCH-Stadien für die Versuchsjahre 2010/11 und 2012/13. Angegeben sind nur die Messtermine, von denen die Daten für die statistische Analyse genutzt wurden. Die ersten vier Messungen wurden während oder kurz nach der Blüte durchgeführt und daher unter dem Begriff „NDVI-Blüte 1-4“ (NDVI_B1-4) codiert. Die letzten Messungen erfolgten während der Abreife, sodass die entsprechende Codierung „NDVI-Abreife 1-5“(NDVI_A1-5) lautete.

\begin{tabular}{ccccc}
\hline Codierung & \multicolumn{2}{c}{ Vegetationsperiode 2010/11 } & \multicolumn{2}{c}{ Vegetationsperiode 2012/13 } \\
\hline & $\begin{array}{c}\text { NDVI } \\
\text { Messtermin }\end{array}$ & $\begin{array}{c}\text { BBCH- } \\
\text { Stadium }\end{array}$ & $\begin{array}{c}\text { NDVI } \\
\text { Messtermin }\end{array}$ & $\begin{array}{c}\text { BBCH- } \\
\text { Stadium }\end{array}$ \\
\hline NDVI_B1 & 03.05 .11 & $64 / 65$ & 16.05 .13 & $64 / 65$ \\
NDVI_B2 & 10.05 .11 & $65 / 66$ & 23.05 .13 & $65 / 66$ \\
NDVI_B3 & 17.05 .11 & 69 & 06.06 .13 & 69 \\
NDVI_B4 & 24.05 .11 & 73 & 12.06 .13 & 73 \\
NDVI_A1 & 15.06 .11 & 79 & 04.07 .13 & 79 \\
NDVI_A2 & 21.06 .11 & 81 & 11.07 .13 & 81 \\
NDVI_A3 & 28.06 .11 & 84 & 18.07 .13 & 84 \\
NDVI_A4 & 05.07 .11 & $85 / 87$ & 25.07 .13 & $85 / 87$ \\
NDVI_A5 & 12.07 .11 & 89 & 01.08 .13 & 89 \\
\hline
\end{tabular}




\subsubsection{NDVI-Dauer}

Bei dem Parameter NDVI-Dauer handelt es sich um die Integration der NDVI-Kurve über den entsprechenden Erhebungszeitraum. Die Berechnung der NDVI-Dauer basiert auf der Formel zur Berechnung der Area Under Disease Progress Curve [(AUDPC); (CAMPBELL and MADDEN, 1990; SHANER and FINNEY, 1977):

$$
A U D P C=\frac{y_{i}+y_{i+1}}{2} *\left(t_{i+1}-t_{i}\right),
$$

wobei $y_{i}$ in diesem Fall den NDVI-Wert zum Messzeitpunkt $i$ (Messtermine Tab. 10) und $t_{i}$ das Alter des Winterrapsbestandes in Tagen zum Messzeitpunkt i darstellt. Anstatt NDVIDauer könnte man es auch als Area Under Normalized Difference Vegetation Index Progress Curve (AUNDVIPC) bezeichnen.

Jeder NDVI-Messung im Frühjahr wurde die genaue Anzahl an Tagen nach der Aussaat (Alter des Bestandes) zugeordnet. Dabei wurde der Tag der Aussaat nicht mitgezählt. Die Fläche unter der NDVI-Kurve vom Tag der Aussaat bis zur ersten NDVI-Messung wurde für die Berechnung der gesamten Fläche unter der NDVI-Kurve nicht mit berücksichtigt, da für diesen Zeitraum der Verlauf der Kurve nicht bekannt war. Die NDVI-Dauer jeder einzelnen Versuchsparzelle ist damit ein dimensionsloses Maß für die Fläche unter der Kurve von der ersten bis zur letzten NDVI-Messung.

\subsection{Erfassung von Ertragsparametern}

\subsubsection{Kornertrag}

Vor der Ernte wurden die einzelnen Ertragsparzellen „gescheitelt“" ${ }^{11}$ um die Pflanzen jeder Parzelle genau zuordnen zu können. Das wurde in jedem Versuchsjahr im BBCH-Stadium 83/85 durchgeführt. Die Beerntung jeder Ertragsparzelle erfolgte mit einem Mähdrescher (Modell Farmliner 3370, Fa. Deutz-Fahr, Köln), der mit einem entsprechenden Rapsschneidwerk ausgestattet war. Dabei wurde die komplette Ertragsparzelle gedroschen. Das Erntegut wurde in Leinensäcken $(40 \times 50 \mathrm{~cm}$ ) aufgefangen, um die Erntemenge direkt am Feld durch Wiegen $z u$ bestimmen. Die Trockensubstanzbestimmung des Erntegutes erfolgte nachdem ein abgewogenes Aliquot der Ernteproben bei $105^{\circ} \mathrm{C}$ für $24 \mathrm{~h}$ getrocknet und dann zurückgewogen wurde. Die Proben wurden zurückgewogen, nachdem sie auf $40^{\circ} \mathrm{C}$ abgekühlt waren. Für die Ermittlung des Fremdbesatzes wurde ein abgewogenes Aliquot der Ernteproben mit Hilfe

\footnotetext{
${ }^{1}$ Scheiteln = Pflanzen am Parzellenrand mit einem Stock ca. bei halber Wuchshöhe in die Parzellenmitte drücken, um alle Pflanzen einer Parzelle bei der maschinellen Ernte erfassen zu können.
} 
eines Probenreinigers (Sample Cleaner, Model MLN, Fa. Pfeuffer, Kitzingen) gereinigt und dann zurückgewogen.

Diese Daten ermöglichten es, die Parzellenerträge auf Hektarerträge in Tonnen pro Hektar, bereinigt um den Besatz und standardisiert auf einen Wassergehalt von $9 \%$ umzurechnen.

\subsubsection{Strohbiomasseertrag}

Beim Dreschen der Ertragsparzellen wurde neben dem Kornertrag auch der Ertrag der Strohbiomasse bestimmt. Dazu wurde zum einen am Schüttlerauswurf eine Plane angebracht, um die Spreu aufzufangen und zum anderen ein flexibler Schüttgutbehälter (Big-Bag) über den Häckslerauswurf gezogen, um das zerkleinerte Rapsstroh aufzufangen (Abb. 17). Nach jeder gedroschenen Ertragsparzelle wurde der Inhalt der Plane in den Big-Bag überführt und dieser an einer Hängewaage (Modell IE-1700, Fa. CAS Deutschland AG, Braunschweig) befestigt, um das Gewicht der Frischmasse zu bestimmen. Die Hängewaage war an einer Vorrichtung, die in der Fronthydraulik eines Schleppers (Modell Agroplus 85, Fa. Deutz-Fahr, Köln) befestigt war, angebracht (Abb. 18). Nach dem Wiegevorgang wurde von jeder Strohbiomasseprobe eine Rückstellprobe von ca. 0,5 bis $1,0 \mathrm{~kg}$ für die Bestimmung der Trockensubstanz genommen. Die Rückstellproben wurden bei $105^{\circ} \mathrm{C}$ für $24 \mathrm{~h}$ getrocknet. Durch Differenzwägung vor und nach dem Trocknen, konnte der Trockensubstanzgehalt ermittelt werden. Die Strohbiomasseproben wurden zurückgewogen, nachdem sie auf $40^{\circ} \mathrm{C}$ abgekühlt waren. Mit Hilfe dieser Daten konnten die Hektarerträge der Strohbiomasse in Tonnen pro Hektar bei einem Wassergehalt von $0 \%$ berechnet werden.

Um den Strohbiomasseertrag genau ermitteln zu können, wurden die Rapspflanzen so niedrig abgemäht, wie es technisch möglich war. Die niedrigste Einstellung des Schneidwerkes hinterließ Rapsstoppeln mit einer Länge von ca. $15 \mathrm{~cm}$. 


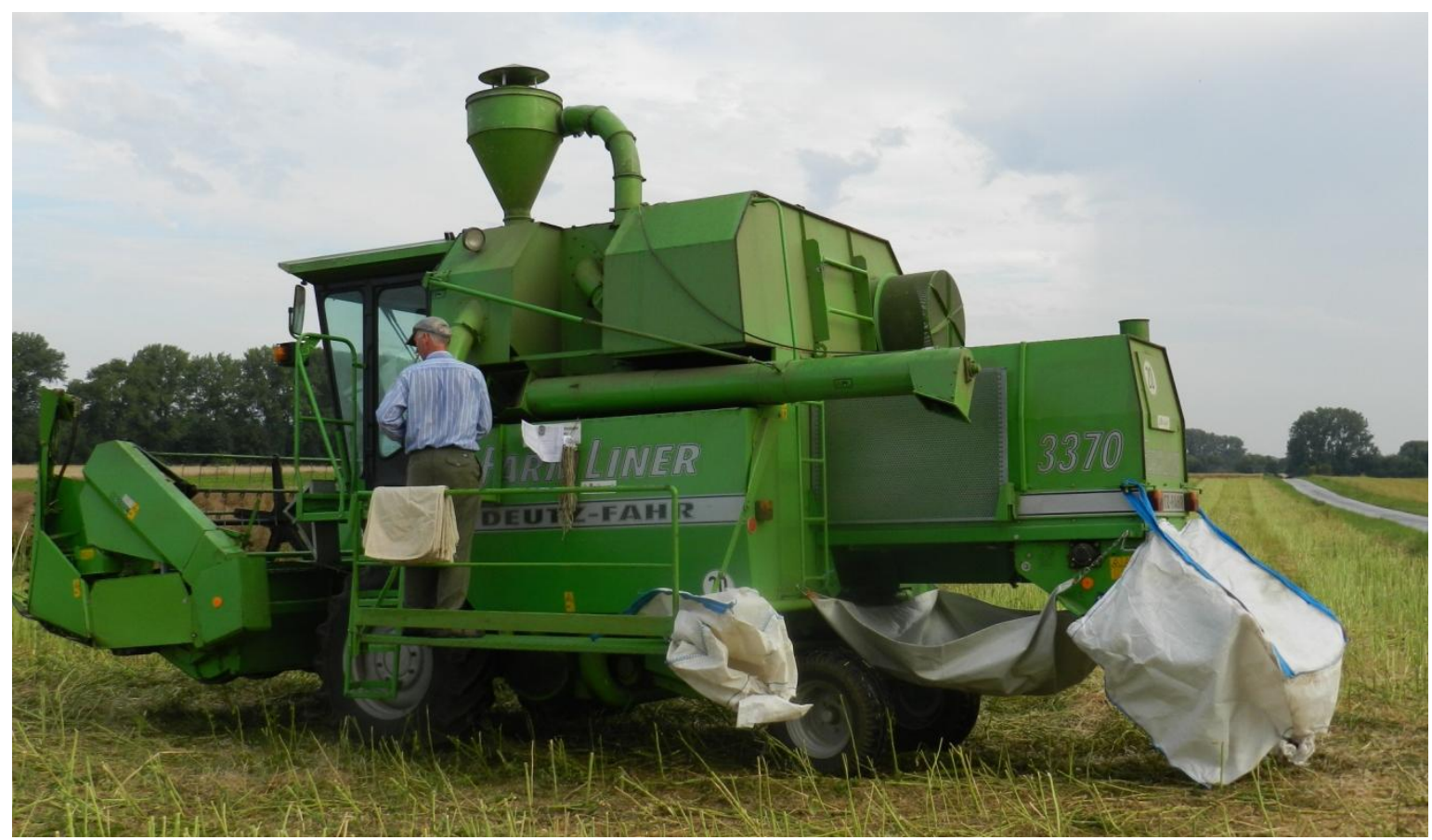

Abb. 17: Mähdrescher (Modell Farmliner 3370, Fa. Deutz-Fahr, Köln) für die Parzellenernte mit einer Auffangvorrichtung für Spreu (graue Plane) und einer Auffangvorrichtung für das gehäckselte Rapsstroh [weißer flexibler Schüttgutbehälter (Big-Bag)].

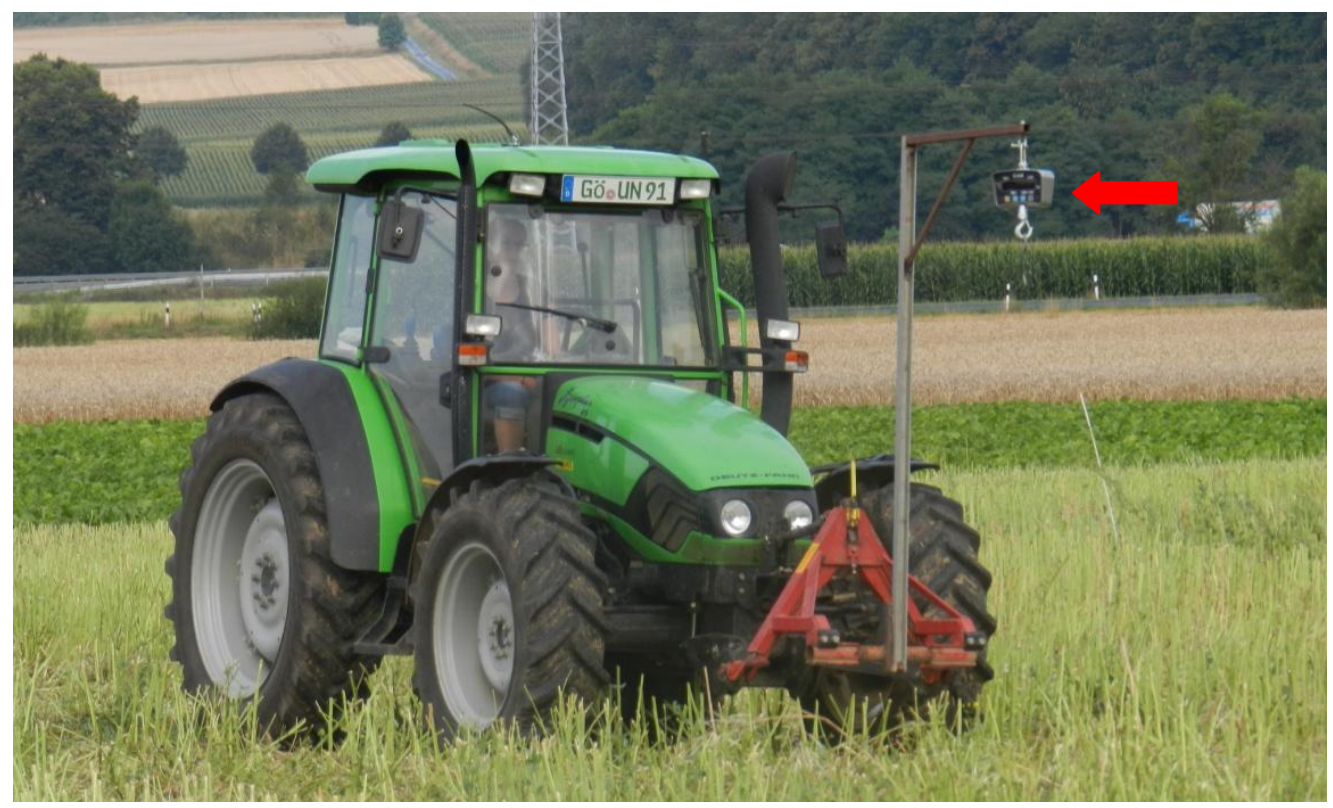

Abb. 18: Schlepper (Modell Agroplus 85, Fa. Deutz-Fahr, Köln) mit Anbauvorrichtung in der Fronthydraulik an der die Hängewaage (roter Pfeil) befestigt war. 


\subsection{3 Ölgehalt}

Die Mitarbeiter des Instituts für Pflanzenzüchtung der Universität Göttingen bestimmten mittels Nahinfrarotspektroskopie (NIRS) den Ölgehalt der Rapskornproben. Als Analysegerät stand das NIRS 6500 (Fa. Foss GmbH, Hillerød, Dänemark) zur Verfügung. Zur Kalibrierung des NIRS 6500 wurde die Kalibrierung „raps2010.epa“ von der VDLUFA Qualitätssicherung NIRS GmbH (Kassel, Deutschland) verwendet. Für die NIRS-Analyse wurde je Rückstellprobe ca. $17 \mathrm{~g}$ Rapskörner benötigt. Die analysierten Ölgehalte bezogen sich auf die Trockenmasse und wurden anschließend auf einen handelsüblichen Wassergehalt von $9 \%$ umgerechnet.

\subsection{4 Ölertrag}

Der Ölertrag in Tonnen pro Hektar wurde nach folgender Formel errechnet:

Ölertrag $=\frac{A * B}{100}$,

wobei A der Kornertrag in Tonnen pro Hektar und B der Ölgehalt in Prozent ist.

\subsubsection{Ernteindex}

Der Ernteindex stellt den prozentualen Anteil der Samenbiomasse an der gesamten oberirdischen Biomasse einer Pflanze dar und wurde nach folgender Formel berechnet:

$$
\text { Ernteindex }=\frac{100 * \mathrm{~A}}{\mathrm{~B}}
$$

wobei A der Kornertrag [t/ha] und B die gesamte oberirdische Biomasse [t/ha] ist. Die gesamte oberirdische Biomasse [t/ha] setzt sich zusammen aus dem Korn- [t/ha] und dem Strohbiomasseertrag $[\mathrm{t} / \mathrm{ha}]$. 


\subsection{Erfassung des Befalls der Rapspflanzen mit der Wurzelhals- und Stängelfäule (Leptosphaeria maculans, anamorph: Phoma lingam)}

\subsubsection{Probenahme}

In jedem Versuchsjahr wurde der Befall der Rapspflanzen mit der Wurzelhals- und Stängelfäule im Herbst zu Vegetationsende und im Frühsommer zu Beginn der Samenreife bonitiert (Tab. 11). Für die Befallsbeurteilung wurden aus jeder Boniturparzelle zufällig 25 Pflanzen entnommen. Im Herbst des Jahres 2010 waren es 20 Pflanzen je Boniturparzelle. Es wurde nur im Kernbereich der Parzelle beprobt. Nach der anschließenden Reinigung der Pflanzen, insbesondere des Wurzelbereiches, wurden diese bis zur Bonitur in einem Kühlraum bei $10^{\circ} \mathrm{C}$ zwischengelagert. Diese $20 \mathrm{bzw}$. 25 Pflanzen/Parzelle dienten je nach Probenahmezeitpunkt neben der Phomabonitur auch der Erfassung des Befalls mit der Kleinen Kohlfliege (Delia radicum), sowie der Messung des Wurzelhalsdurchmessers und der Blattlänge. Des Weiteren wurde die Anzahl Blätter/Pflanze erfasst.

Tab. 11: Zeitpunkt und BBCH-Stadium zu dem der Befall der Rapspflanzen mit der Wurzelhalsund Stängelfäule (Phoma lingam) in den Jahren 2010/11, 2011/12 und 2012/13 erfasst wurde. Im Frühsommer 2012 wurde keine Bonitur durchgeführt, da der Feldversuch ausgewintert war.

\begin{tabular}{cccc}
\hline \multicolumn{1}{c}{ Herbst } & \multicolumn{2}{c}{ Sommer } \\
\hline Datum & BBCH-Stadium & Datum & BBCH-Stadium \\
\hline 22.11 .2010 & $16 / 18$ & 29.06 .2011 & $83 / 84$ \\
21.11 .2011 & $18 / 19$ & --- & -- \\
20.11 .2012 & $17 / 18$ & 08.07 .2013 & $80 / 81$ \\
\hline
\end{tabular}

\subsubsection{Visuelle Bonitur}

Der Befall mit der Wurzelhals-und Stängelfäule wurde im Herbst an den Blättern und am Wurzelhals der Rapspflanzen untersucht. Im Frühsommer erfolgte die Bonitur am unteren Stängelabschnitt (ca. $30 \mathrm{~cm}$ ) sowie am Wurzelhals. An den erkrankten Blättern einer Rapspflanze wurde die Anzahl der Phoma-Blattläsionen bestimmt. Durch Addition der Einzelwerte pro Blatt wurde die Anzahl der Läsionen pro Pflanze ermittelt. Diese repräsentierte die Befallsstärke mit der Wurzelhals- und Stängelfäule. Aus den 20 bzw. 25 Einzelwerten pro Parzelle wurde für die statistische Verrechnung jeweils der mittlere Befallswert (BW) an Phomaläsionen/Pflanze gebildet. 
Bei der Beurteilung der Befallsstärke mit der Wurzelhals- und Stängelfäule am Wurzelhals sowie am unteren Stängelabschnitt wurde ein 9-stufiges Boniturschema verwendet, welches von (KRÜGER, 1982) entwickelt wurde (Tab. 12).

Tab. 12: Boniturschema für den Befall mit der Wurzelhals- und Stängelfäule (Phoma lingam) an Raps nach KRÜGER (1982), unterteilt in Wurzelhals- und Stängelbefall.

\begin{tabular}{|c|c|c|}
\hline \multirow[t]{2}{*}{ Befallswert } & \multicolumn{2}{|c|}{ Befallsstärke } \\
\hline & Wurzelhals & Stängel \\
\hline 1 & Kein Befall & Kein Befall \\
\hline 2 & Kleine Flecke an der Oberfläche & Kleine Flecke an der Oberfläche \\
\hline 3 & $\begin{array}{c}\text { Kleine Flecke mit geringer, nicht tiefgehender } \\
\text { Verkorkung und/oder Verbräunungen am } \\
\text { Wurzelhals }\end{array}$ & $\begin{array}{l}\text { Größere Flecke an der Oberfläche } \\
\text { mit geringer Verkorkung }\end{array}$ \\
\hline 4 & Zwischenstufe & Zwischenstufe \\
\hline 5 & $\begin{array}{c}\text { Umfassende aber nicht tiefe oder einseitig } \\
\text { tiefe Verkorkung } \\
\text { (bis } 50 \% \text { des Wurzelhalses befallen) }\end{array}$ & $\begin{array}{l}\text { Tiefer eingedrungene Befallsstellen } \\
\text { am Stängel }\end{array}$ \\
\hline 6 & Zwischenstufe & Zwischenstufe \\
\hline 7 & $\begin{array}{c}\text { Über } 50 \% \text { des Wurzelhalses stark verkorkt } \\
\text { und tief eingeschnürt }\end{array}$ & $\begin{array}{l}\text { Tief eingedrungene Befallsstellen, } \\
\text { Pyknidien meistens vorhanden }\end{array}$ \\
\hline 8 & Zwischenstufe & Zwischenstufe \\
\hline 9 & $\begin{array}{l}\text { Wurzelhals stark und sehr tief verkorkt, } \\
\text { Pflanzen abgestorben }\end{array}$ & $\begin{array}{l}\text { ausgedehnte, tief gehende } \\
\text { Befallsstellen am Stängel, Pflanze } \\
\text { abgestorben }\end{array}$ \\
\hline
\end{tabular}

Der mittlere BW einer Parzelle wurde nach folgender Formel berechnet:

$$
\text { Befallswert }=\frac{\left(\mathrm{n}_{1} * 1\right)+\left(\mathrm{n}_{2} * 2\right)+\cdots+\left(\mathrm{n}_{9} * 9\right)}{\mathrm{N}}
$$

$\mathrm{n}_{\mathrm{x}}$ : $\quad$ Anzahl Pflanzen mit jeweiligem Befallswert

1-9: $\quad$ Befallswert (siehe Tab. 12)

$\mathrm{N}: \quad$ Anzahl insgesamt bonitierter Pflanzen

Neben dem BW wurde auch die Befallshäufigkeit (BH), d.h. der prozentuale Anteil befallener Pflanzen in der Stichprobe, berechnet. 


\subsection{Erfassung des Befalls der Rapspflanzen mit der Kleinen Kohlfliege (Delia radicum)}

Zeitgleich mit der Phomabonitur im Herbst sowie im Frühsommer wurde der Befall mit der Kleinen Kohlfliege (Delia radicum) durch eine visuelle Bonitur des Larvenfraßes an der Wurzel erfasst (Abb. 19). Dabei bestimmte man den Anteil fraßgeschädigter Pflanzen (Befallshäufigkeit [\%]).

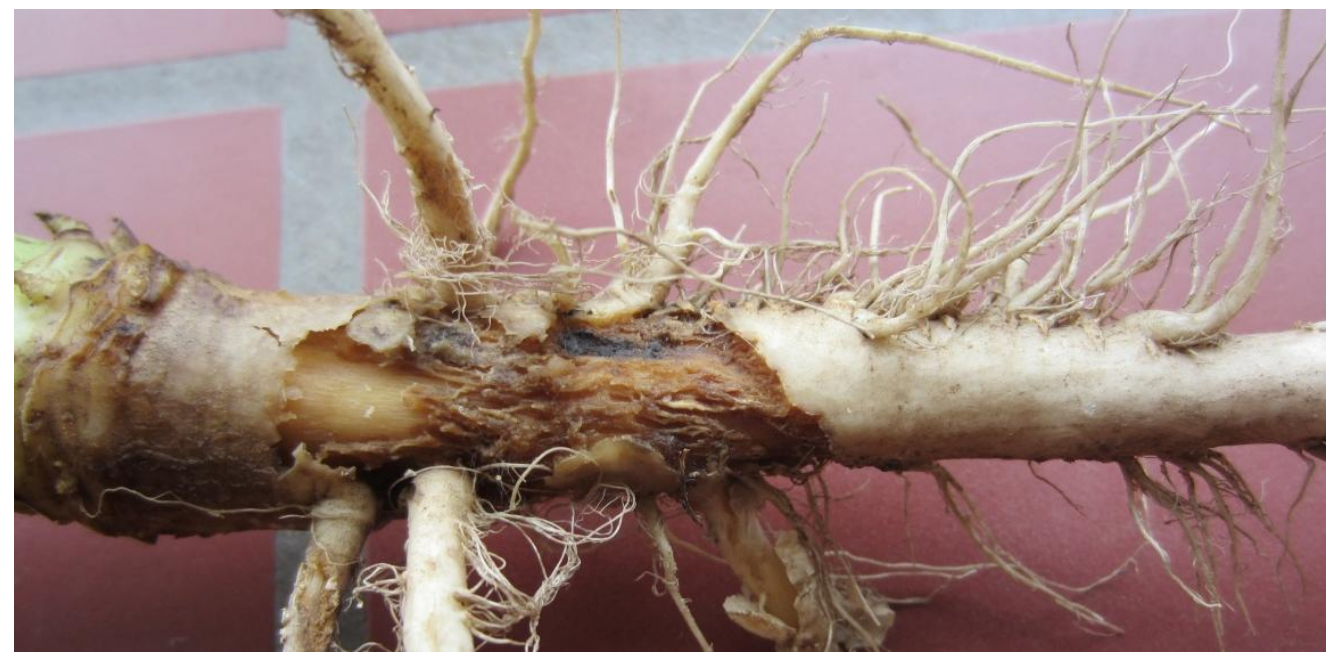

Abb. 19: Wurzelfraß durch Larven der Kleinen Kohlfliege (Delia radicum) an Winterraps

\subsection{Statistische Datenauswertung}

Die statistische Auswertung erfolgte mit Hilfe des Statistikprogramms SAS Version 9.2 und 9.3 (SAS Institute Inc., North Carolina, USA). Der Feldversuch in Göttingen wurde getrennt nach den beiden Untersuchungsjahren 2010/11 und 2012/13 als dreifaktorielle Spalt-Spalt-Anlage varianzanalytisch mit der SAS-Prozedur „proc mixed“ ausgewertet. Dabei lag im ersten Versuchsjahr noch keine Randomisation als Spalt-Spalt-Anlage vor (vgl. Kapitel 2.2). Als Freiheitsgradapproximationsmethode wurde diejenige nach KENWARD \& ROGER (1997) gewählt. Von jedem Versuchsglied gab es vier Wiederholungen $(n=4)$. Sofern nichts anderes angegeben ist, gingen die Daten aus den vier Wiederholungen in die statistische Analyse ein. Die Modellvoraussetzungen der Normalverteilung und der Varianzhomogenität der Daten wurden an Hand der Residuen mittels eines QQ-Plots bzw. eines Residuen-Plots grafisch beurteilt. Falls die Modellvoraussetzungen als gravierend verletzt angesehen wurden, wurden die Daten transformiert. Für den multiplen Mittelwertvergleich wurde der Tukey-Test verwendet. 
Unterschiedliche Buchstaben kennzeichnen signifikante Unterschiede zwischen den Mittelwerten bei einer Irrtumswahrscheinlichkeit von 5\% ( $\alpha \leq 0,05)$.

Im Versuchsjahr 2010/11 konnten aufgrund von Trockenheitsschäden in dem Block mit der Sorte NK Petrol und der Saatstärke $30 \mathrm{Körner} / \mathrm{m}^{2}$ von jeder Fungizidvariante nur drei anstatt 4 Wiederholungen für die Datenauswertung herangezogen werden. Ferner traten Probleme beim Drusch in der Parzelle 1 in dem Block mit der Sorte SY Merlot und der Saatstärke $60 \mathrm{Körner} / \mathrm{m}^{2}$ auf, sodass hier der Kornertrag und alle damit verbundenen Parameter nicht korrekt ermittelt werden konnten. Somit gingen in diesem Jahr von ursprünglich 128 Beobachtungen nur 119 in die Berechnungen ein. Im Versuchsjahr 2012/13 liefen wegen eines Saatfehlers in vier Parzellen nicht genügend Pflanzen auf, sodass diese Parzellen nicht mehr für den Versuch berücksichtigt werden konnten. Betroffen waren folgende Sorten- $x$ Saatstärken- $x$ Fungizid- Varianten:

1. SY Vesuvio $\times 30$ Körner $/ \mathrm{m}^{2} \times$ Fungizid 1 (Kontrolle)

2. SY Vesuvio $\times 30 \mathrm{Körner} / \mathrm{m}^{2} \times$ Fungizid 8 (praxisüblich)

3. NK Petrol $\times 30$ Körner $/ \mathrm{m}^{2} \times$ Fungizid 1 (Kontrolle)

4. NK Petrol x 30 Körner/m² x Fungizid 8 (praxisüblich).

Aus diesem Grund konnten nur 124 Beobachtungen von insgesamt 128 für die Auswertung berücksichtigt werden.

Bei einfachen, linearen Korrelations- bzw. Regressionsanalysen mit Daten aus dem Feldversuch in Göttingen, wurden der Pearson Korrelationskoeffizient $\left(r_{p}\right)$, der Spearmansche Rangkorrelationskoeffizient $\left(r_{s}\right)$ und das jeweilige Bestimmtheitsmaß $\left(R_{p}{ }^{2}\right.$ bzw. $R_{s}{ }^{2}$ ) ermittelt. Korrelationen wurden bei einer Irrtumswahrscheinlichkeit von $5 \%$ $(\alpha \leq 0,05)$ als signifikant betrachtet. Die Verrechnungen erfolgten in SAS durch die Prozedur „proc corr“ oder „proc reg“.

Eine multiple Regressionsanalyse wurde verwendet, um zu untersuchen, von welchen Bestandesparametern und Befallsparametern der Kornertrag bzw. der BW mit der Wurzelhals und Stängelfäule am Wurzelhals (nur 2010/11) primär beeinflusst wurden. Hierbei wurde die Anweisung "stepwise“ angewendet, wodurch die Parameter schrittweise in das Modell zur Beschreibung der Zielvariablen aufgenommen wurden. Außerdem wird bei jedem Aufnahmeschritt überprüft, ob die zuvor aufgenommenen erklärenden Variablen im Modell verbleiben oder wieder verworfen werden. Es wurden nur die Parameter in das Modell aufgenommen, die ein Signifikanzniveau von $\alpha \leq 0,05$ einhielten. Für diese Art von Analyse wurde in SAS die Prozedur „proc reg“ verwendet.

Eine Hauptkomponentenanalyse (principal component analysis, PCA) erfolgte in SAS durch die Prozedur „proc princomp“. Für die PCA wurden die Mittelwerte der Daten aus 
den (meist vier) Wiederholungen vom Standort Göttingen verwendet. Die Ergebnisse der PCA wurden für die Jahre getrennt durch zwei Biplots visualisiert. Dazu wurde das SASMakro „biplot“ eingesetzt (FRIENDLY, 2008).

Sämtliche Abbildungen wurden mit dem Softwareprogramm Origin 8.5 von der Firma OriginLab Corporation, Northampton, Massachusetts, USA erstellt. 


\section{Ergebnisse}

In dem Kapitel Ergebnisse werden zunächst der Witterungsverlauf in den Versuchsjahren 2010/11 bis 2012/13 (3.1), die phänologische Pflanzenentwicklung in den einzelnen Versuchsjahren (3.2) und die Gründe für den Verlust des Feldversuches 2011/12 (3.3) beschrieben. Zur Grundcharakterisierung der beiden Versuchsjahre wird im Kapitel 3.4 der Einfluss der Anbaufaktoren Sorte, Saatstärke und Fungizidbehandlung auf die Ertragsparameter und die Ertragsfaktoren sowie im Kapitel 3.5 der Einfluss der Anbaufaktoren auf die Befallsparameter vorgestellt. In den Kapiteln 3.6 und 3.8 werden die Bestandesparameter genannt, die laut einfacher und multipler Regression einen signifikanten Einfluss auf die Ertragshöhe bzw. auf Befall mit der Wurzelhals- und Stängelfäule hatten. Jeweils im Anschluss der zuvor genannten Kapitel, werden die Effekte der Anbaufaktoren Sorte, Saatstärke und Fungizidbehandlung auf die Bestandesparameter, die direkt oder indirekt die Ertragshöhe (3.7) bzw. den Befall mit der Wurzelhals- und Stängelfäule (3.9) beeinflusst haben, beschrieben. Im Kapitel 3.10 wird dargelegt, welchen Einfluss die Ertragsparameter und die Ertragsfaktoren auf den Kornertrag hatten. Im letzten Kapitel 3.11 wird von jedem Versuchsjahr der Haupteffekt vorgestellt, der am häufigsten einen signifikanten Einfluss auf die ertragsrelevanten Parameter hatte.

\subsection{Witterungsverlauf 2010 bis 2013}

\section{Vegetationsperiode 2010/11}

Die Vegetationsperiode von September 2010 bis Juli 2011 war durch extreme Witterungsereignisse gekennzeichnet (Abb. 20). Die kumulierte Niederschlagsmenge betrug für diese Periode $463 \mathrm{~mm}(-130 \mathrm{~mm})^{2}$ und die Durchschnittstemperatur lag bei $7,8^{\circ} \mathrm{C}\left(-0,6^{\circ} \mathrm{C}\right)$. Nach einem kühlen $\left(-2,8^{\circ} \mathrm{C}\right)$ und nassen $(+46,0 \mathrm{~mm})$ Herbst (Sep. - Nov.) im Jahr 2010, folgte ein sehr kalter $\left(-6,0^{\circ} \mathrm{C}\right)$ und trockener $(-41,2 \mathrm{~mm})$ Dezember. Die Vegetationsruhe setzte Ende November mit den ersten Schneefällen ein. Obwohl die Durchschnittstemperatur im Januar 2011 mit $2^{\circ} \mathrm{C}\left(+1,1^{\circ} \mathrm{C}\right)$ leicht erhöht war, traten regelmäßig Schneefälle auf, die die Niederschlagsmengen etwas erhöhten (+6,4 mm). Kontinuierlich steigende Temperaturen beendeten ab Mitte März die Vegetationsruhe.

\footnotetext{
${ }^{2}$ Die Temperatur- bzw. Niederschlagsangaben in Klammern kennzeichnen die Abweichungen von den langjährigen Durchschnittswerten im Zeitraum 1981-2010 für den Standort Göttingen. Die Daten wurden der Homepage des Deutschen Wetterdienstes (DWD) entnommen. DEUTSCHER WETTERDIENST (2013).
} 
Unterdurchschnittliche Niederschlagsmengen in den Monaten Februar bis Mai und z. T. ungewöhnlich hohe Temperaturen im April $\left(+2,4^{\circ} \mathrm{C}\right)$ führten zu einer ausgeprägten Frühjahrs- und Vorsommertrockenheit. Vor allem in der Hauptwachstumsphase des Rapses (März-Mai) fiel deutlich weniger Niederschlag $(-98,8 \mathrm{~mm})$ und die mittlere Temperatur war etwas erhöht $\left(+0,5^{\circ} \mathrm{C}\right)$. Ausreichende Niederschläge im Juni verbesserten die äußeren Umstände für die restliche Entwicklung der Rapspflanzen. Zur Abreife im Juli herrschten im Mittel kühlere Temperaturen $\left(-1,2^{\circ} \mathrm{C}\right)$ und im Vergleich zum langjährigen Mittel von 1981-2010 (DEUTSCHER WETTERDIENST, 2013) fielen 42,6 mm weniger Niederschlag. Zusammenfassend kann das Versuchsjahr 2010/11 als ein kühles und trockenes Jahr bezeichnet werden, in dem insbesondere in der Hauptwachstumsphase des Rapses wenig Niederschlag fiel und die Durchschnittstemperatur leicht erhöht war.
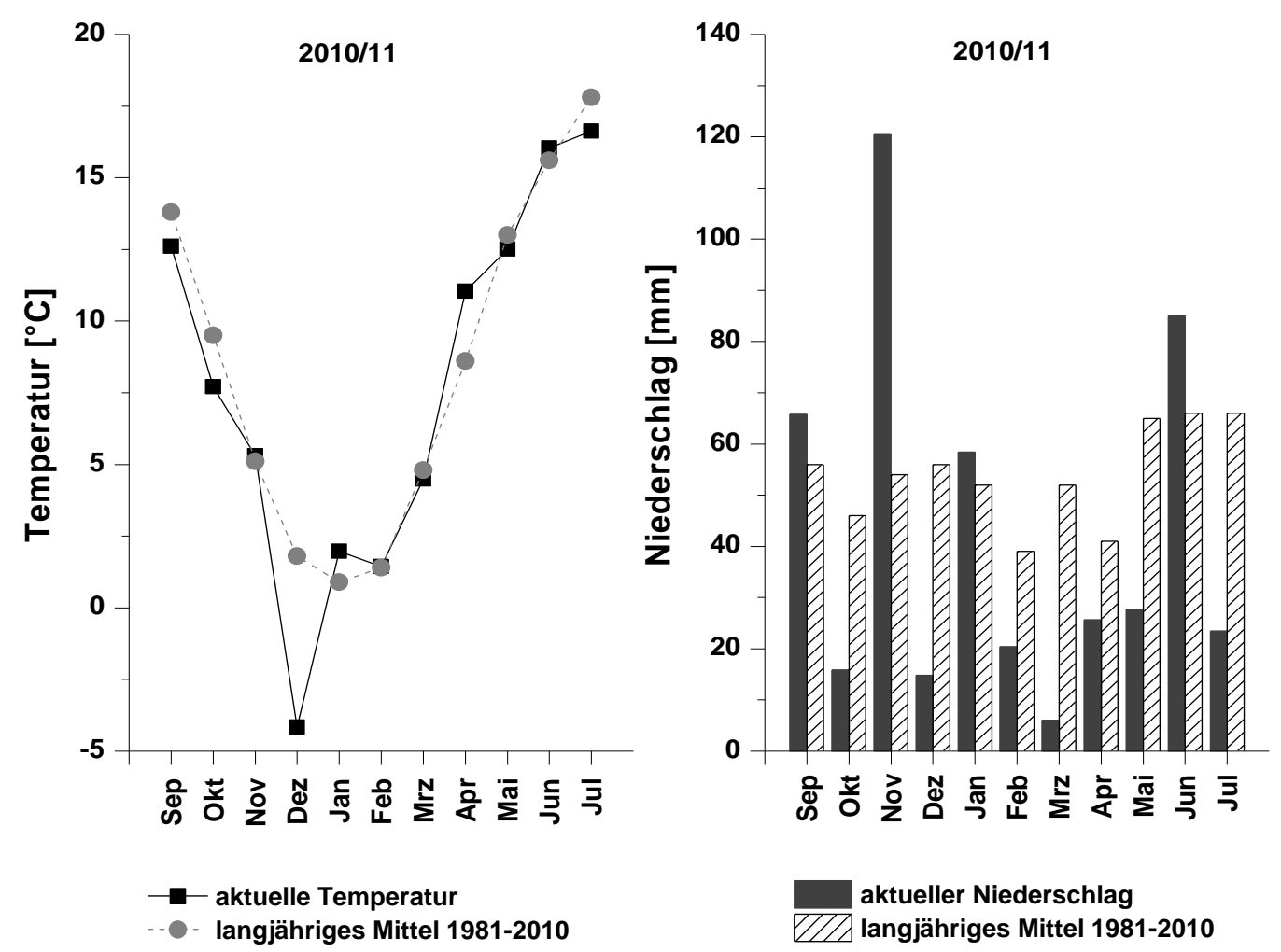

Abb. 20: Durchschnittliche monatliche Lufttemperatur $\left[{ }^{\circ} \mathrm{C}\right]$ und monatliche Niederschlagsmengen $[\Sigma$ mm] für die Vegetationsperiode von September 2010 bis Juli 2011 am Standort Göttingen im Vergleich zum langjährigen Mittel (1981-2010; (DEUTSCHER WETTERDIENST, 2013). 


\section{Vegetationsperiode $2011 / 12$}

Die Vegetationsperiode 2011/12 war wie die vorherige Vegetationsperiode von starken Witterungsschwankungen geprägt (Abb. 21). Der Herbst 2011 (Sep. - Nov.) war etwas zu kühl $\left(-0,7^{\circ} \mathrm{C}\right)$ und sehr trocken $(-68,8 \mathrm{~mm})$. Der Monat November war in ganz Deutschland der trockenste Monat seit Beginn der Wetteraufzeichnungen. Am Versuchsfeld wurden nur 2,8 mm Niederschlag gemessen. Im Dezember 2011 und Januar 2012 war die Witterung durch außergewöhnlich warm-feuchte Bedingungen $\left(+4,8^{\circ} \mathrm{C}\right.$ und $\left.+76,6 \mathrm{~mm}\right)$ gekennzeichnet, die keine Vegetationsruhe zuließen. Das zeigte sich an den Rapspflanzen Mitte Januar durch neu ausgetriebene Laubblätter. Nach dieser wüchsigen Phase folgte ab Ende Januar bis Mitte Februar eine Dauerfrostperiode ohne Schneefall mit Temperaturen zwischen $-1,7^{\circ} \mathrm{C}$ bis $-18,8^{\circ} \mathrm{C}$. Die kalten Temperaturen schlugen sich auch in der Durchschnittstemperatur für Februar nieder, die mit $-1,5^{\circ} \mathrm{C}$ um $2,9^{\circ} \mathrm{C}$ niedriger war als das langjährige Mittel von 1981-2010 (DEUTSCHER WETTERDIENST, 2013). Nach dieser Phase stiegen die Temperaturen stetig an und entsprachen im April dem langjährigen Mittel. Die Monate Februar bis April wiesen wie im Jahr davor sehr geringe Niederschläge auf $(-85,8 \mathrm{~mm})$. Der Verlauf der Witterung wurde nur bis April 2012 dargestellt, da der Feldversuch im April 2012, aufgrund von starken Auswinterungsschäden und starkem Befall mit $B$. cinerea, aufgegeben werden musste (vgl. Kapitel 3.3). 

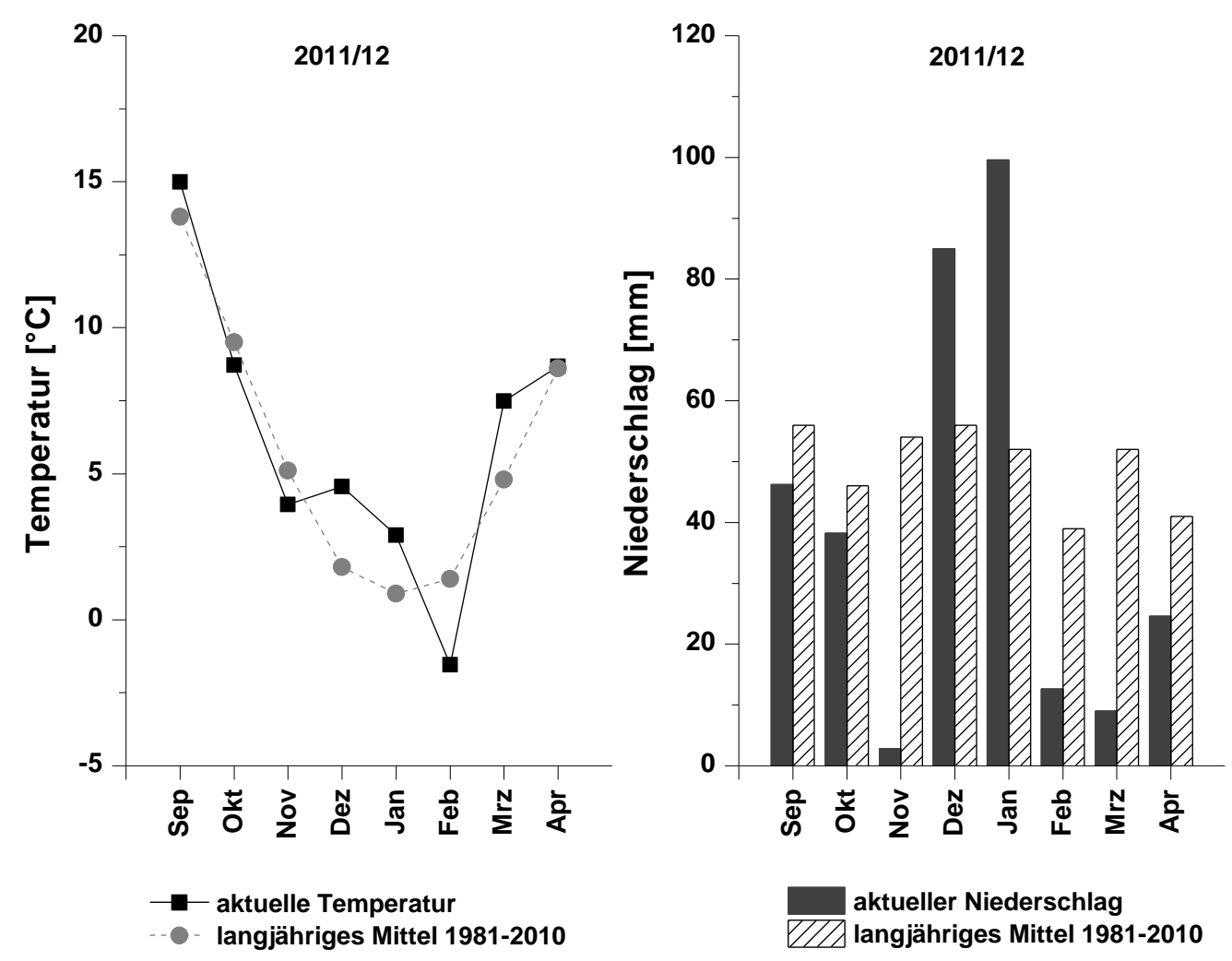

Abb. 21: Durchschnittliche monatliche Lufttemperatur $\left[{ }^{\circ} \mathrm{C}\right]$ und monatliche Niederschlagsmengen [ $\Sigma \mathrm{mm}$ ] für die Vegetationsperiode von September 2011 bis April 2012 am Standort Göttingen im Vergleich zum langjährigen Mittel (1981-2010; (DEUTSCHER WETTERDIENST, 2013).

\section{Vegetationsperiode 2012/13}

Von September 2012 bis Juli 2013 betrug die Summe der Niederschläge $433 \mathrm{~mm}$ und die mittlere Temperatur lag bei $7,6^{\circ} \mathrm{C}\left(-0,8^{\circ} \mathrm{C}\right)$. Im Vergleich zum langjährigen Mittel von 1981 2010 (DEUTSCHER WeTtERDIENST, 2013) waren damit $160 \mathrm{~mm}$ und im Vergleich zum Versuchsjahr 2010/11 $30 \mathrm{~mm}$ weniger Niederschlag gefallen. Allerdings fielen in den Monaten März bis Mai $157 \mathrm{~mm}$ Niederschlag und damit $98 \mathrm{~mm}$ mehr als im ersten Versuchsjahr. Diese Niederschlagsmenge entsprach annähernd dem langjährigen Mittel (158 mm). Weiterhin war die Durchschnittstemperatur für die Monate März bis Mai im Versuchsjahr $2012 / 13$ mit $6,5^{\circ} \mathrm{C}$ um $2,3^{\circ} \mathrm{C}$ niedriger als das langjährige Mittel, bzw. $2,8^{\circ} \mathrm{C}$ niedriger als im Versuchsjahr 2010/11.

Von September bis Dezember 2012 wichen die Durchschnittstemperaturen gar nicht oder nur minimal und die Niederschlagsmengen dafür sehr deutlich von dem langjährigen Mittel ab (Abb. 22). Dabei folgte auf einen viel zu trockenen Herbst (Sep. - Nov.; -64,2 $\mathrm{mm})$, ein feuchter Dezember (+ 17,8 mm). Anfang Dezember setzte mit dem ersten Schneefall die Vegetationsruhe ein. Von Januar bis März 2013 nahm die 
Durchschnittstemperatur kontinuierlich ab und lag im Januar knapp $\left(-0,4^{\circ} \mathrm{C}\right)$ bzw. im März deutlich $\left(-4,9^{\circ} \mathrm{C}\right)$ unter dem langjährigen Mittel. Außerdem war diese Zeit gekennzeichnet von häufigen Schneefällen, Dauerfrost und nur wenigen Tauphasen (Ende Januar/Anfang Februar und Anfang März). Die Niederschlagssumme für diese drei Monate war besonders gering (-66,6 mm). Mit ca. drei Wochen Vegetationsrückstand setzte zum Ende der ersten Aprildekade der Vegetationsbeginn ein. Auf einen etwas zu kühlen $\left(-0,5^{\circ} \mathrm{C}\right)$ und trockenen $(-8,2 \mathrm{~mm})$ April, folgte ein kühler $\left(-1,5^{\circ} \mathrm{C}\right)$ und viel zu nasser $(+43,4 \mathrm{~mm})$ Mai. Besonders in der letzten Maidekade und zum Monatswechsel Mai/Juni fielen kräftige Niederschläge. Die mittlere Temperatur wich im Juni mit $-0,6^{\circ} \mathrm{C}$ und im Juli mit $+0,3^{\circ} \mathrm{C}$ nur geringfügig von dem langjährigen Mittel ab. Aufgrund weniger Niederschlagsereignisse war es im Juni und Juli besonders trocken $(-82,4 \mathrm{~mm})$. Zusammenfassend kann das Versuchsjahr 2012/13, als ein kühles und besonders trockenes Jahr bezeichnet werden, in dem allerdings in der Hauptwachstumsphase des Rapses ausreichend Wasser zur Verfügung stand.
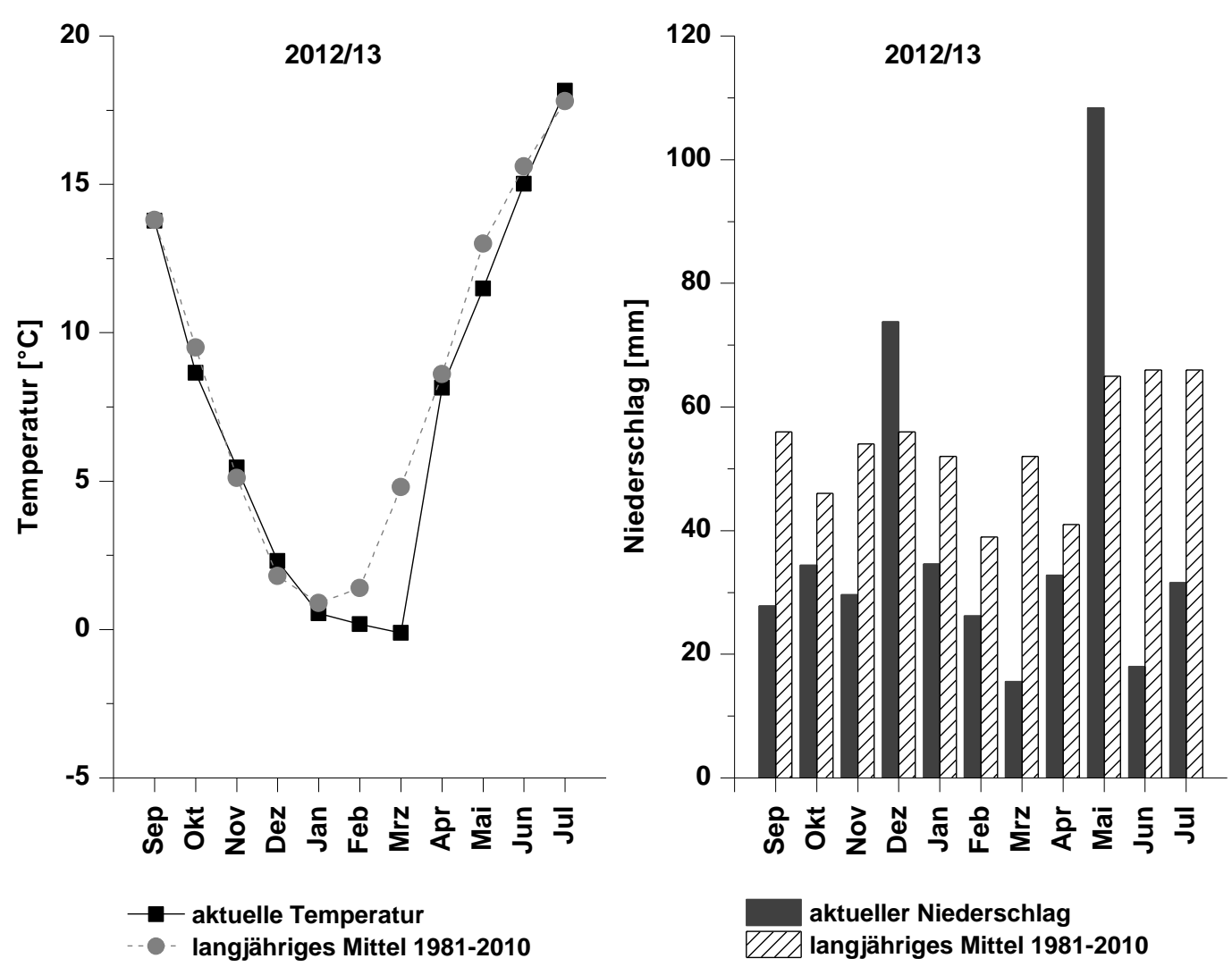

Abb. 22: Durchschnittliche monatliche Lufttemperatur $\left[{ }^{\circ} \mathrm{C}\right]$ und monatliche Niederschlagsmengen [ $\Sigma \mathrm{mm}$ ] für die Vegetationsperiode von September 2012 bis Juli 2013 am Standort Göttingen im Vergleich zum langjährigen Mittel (1981-2010; (DEUTSCHER WETTERDIENST, 2013). 


\subsection{Phänologische Pflanzenentwicklung 2010 bis 2013}

In Tab. 13 sind die Daten der Erfassung wichtiger Wachstumsstadien von Winterraps vergleichend für die einzelnen Versuchsjahre 2010/11, 2011/12 und 2012/13 gegenübergestellt. Das Versuchsjahr 2011/12 wurde aus Gründen der Vollständigkeit mit aufgeführt. Im ersten Versuchsjahr 2010/11 wurde das Sechs- bis Achtblatt-Stadium bedingt durch die verspätete Aussaat erst relativ spät, am 22.11.10, erreicht. Im Gegensatz dazu wurden im Versuchsjahr 2011/12 durch einen sehr warmen Herbst schon am 11.10.11 sechs bis acht Laubblätter pro Pflanze gezählt. Im dritten Versuchsjahr 2012/13 konnte das BBCH-Stadium 16/18 zu einem standorttypischen Termin (08.11.12) festgestellt werden. Im Vergleich der beiden Versuchsjahre 2010/11 und 2012/13 fällt auf, dass vom Frühjahr bis zur Ernte im Versuchsjahr 2012/13 die Wachstumsstadien immer ca. 2-3 Wochen später als im Versuchsjahr 2010/11 erreicht wurden. Dies ist auf den ca. drei Wochen späteren Vegetationsbeginn im Versuchsjahr 2012/13 zurückzuführen (vgl. Kapitel 3.1). Im ersten Versuchsjahr wurde ein unterschiedlicher Blühverlauf für die beiden verwendeten Winterrapssorten beobachtet. Die Sorte SY Merlot blühte und verblühte ca. 2 Tage früher als die Sorte NK Petrol. Dieser unterschiedliche Entwicklungsverlauf wurde bis zum $\mathrm{BBCH}$-Stadium 75 beobachtet. Im dritten Versuchsjahr beeinflussten die Winterrapssorten und die Fungizidbehandlungen die phänologische Entwicklung der Rapspflanzen. Die Sorte SY Vesuvio fing ca. 2-3 Tage früher an zu blühen als die Sorte NK Petrol. In den jeweiligen Sortenvarianten blühten die Pflanzen in den unbehandelten Kontrollen früher als die Pflanzen in den Fungizidvarianten, in denen zweimal im Frühjahr die Wirkstoffkombination aus Paclobutrazol und Difenoconazol (V5 und V6) eingesetzt wurde. (vgl. Tab. 4). Diese Fungizidvarianten verzögerten die Blüte stärker bei der Sorte SY Vesuvio als bei der Sorte NK Petrol. Bis zum Ende der Blüte traten nur noch Unterschiede in der phänologischen Entwicklung zwischen den genannten Fungizidvarianten und der unbehandelten Kontrolle auf. Danach verlief das Wachstum der Pflanzen sehr ähnlich. Im zweiten Versuchsjahr begann das Längenwachstum der Pflanzen (BBCH 30) im Vergleich zu den anderen beiden Versuchsjahren deutlich früher. Dieser zeitliche Vorsprung setzte sich bei den weiteren Wachstumsstadien fort. Zur Mitte der Knospenentwicklung wurde die phänologische Entwicklung nicht mehr erfasst, da der Feldversuch Ende April abgebrochen wurde (vgl. Kapitel 3.3). 
Tab. 13: Übersicht über die phänologische Entwicklung der Winterrapspflanzen in den Jahren 2010/11, 2011/12 und 2012/13. Aufgeführt sind die Daten, an denen wichtige Wachstumsstadien (BBCH-Stadien) erfasst wurden. Im Versuchsjahr 2011/12 wurde die phänologische Entwicklung nur bis zur Mitte der Knospenentwicklung erfasst (Anfang April), da danach der Feldversuch aufgrund von starken Auswinterungsschäden und Botrytis-Befall abgebrochen wurde.

\begin{tabular}{|c|c|c|c|}
\hline & \multicolumn{3}{|c|}{ Versuchsjahr } \\
\hline & 2010/11 & 2011/12 & $2012 / 13$ \\
\hline BBCH-Stadium & \multicolumn{3}{|c|}{ Datum der Erfassung } \\
\hline 00 & 07.09 .10 & 24.08 .11 & 29.08.12 \\
\hline 10 & 17.09 .10 & 01.09 .11 & 05.09 .12 \\
\hline $16 / 18$ & 22.11 .10 & 11.10 .11 & 08.11 .12 \\
\hline 30 & 28.03.11 & 15.03 .12 & 11.04 .13 \\
\hline $33 / 35$ & 06.04 .11 & $28.03 .12(33 / 52)$ & 18.04 .13 \\
\hline $53 / 55$ & 15.04 .11 & 02.04 .12 & 25.04 .13 \\
\hline 60 & $\begin{array}{l}\text { 19.04.11 (SY Merlot) } \\
\text { 21.04.11 (NK Petrol) }\end{array}$ & n. e. ${ }^{*}$ & $\begin{array}{c}\text { 07.05.13 (SY Vesuvio) } \\
10.05 .13 \text { (NK Petrol) }\end{array}$ \\
\hline 65 & 05.05 .11 & n. e.* & 21.05 .13 \\
\hline $69 / 71$ & $\begin{array}{r}20.05 .11 \text { (Merlot 71) } \\
\text { (Petrol 69) }\end{array}$ & n. e. ${ }^{*}$ & 06.06 .13 \\
\hline 75 & 01.06 .11 & n. e. ${ }^{*}$ & 14.06 .13 \\
\hline 80 & 20.06 .11 & n. e.* & 08.07 .13 \\
\hline 85 & 01.07 .11 & n. e.* & 24.07 .13 \\
\hline 89 & 12.07 .11 & n. e.* & 01.08 .13 \\
\hline 99 & 22.07 .11 & n. e.* & 06.08 .13 \\
\hline
\end{tabular}

${ }^{*}$ n. e. $=$ nicht ermittelt

\subsection{Verlust des Feldversuches 2011/12}

Im Versuchsjahr 2011/12 herrschten am Standort Göttingen seit der Aussaat im August 2011 bis Ende Januar 2012 wüchsige Bedingungen, sodass sich die Rapspflanzen im Feldversuch kontinuierlich weiter entwickelten. Dabei kam es auch zu einer leichten Streckung des Vegetationskegels der Rapspflanzen. Die wüchsige Witterung wurde Ende Januar durch einen abrupten Temperatursturz unter den Gefrierpunkt beendet. Es folgte eine strenge Frostperiode mit Temperaturen bis $-18,8^{\circ} \mathrm{C}$ bis Mitte Februar 2012 (vgl. Kapitel 3.1). Ohne eine Schneedecke waren die zu weit entwickelten Pflanzen dem Kahlfrost ungeschützt ausgesetzt. Dies führte zu starken Auswinterungsverlusten, wodurch sich die verschiedenen Pflanzendichten fast angeglichen haben (Abb. 23). 

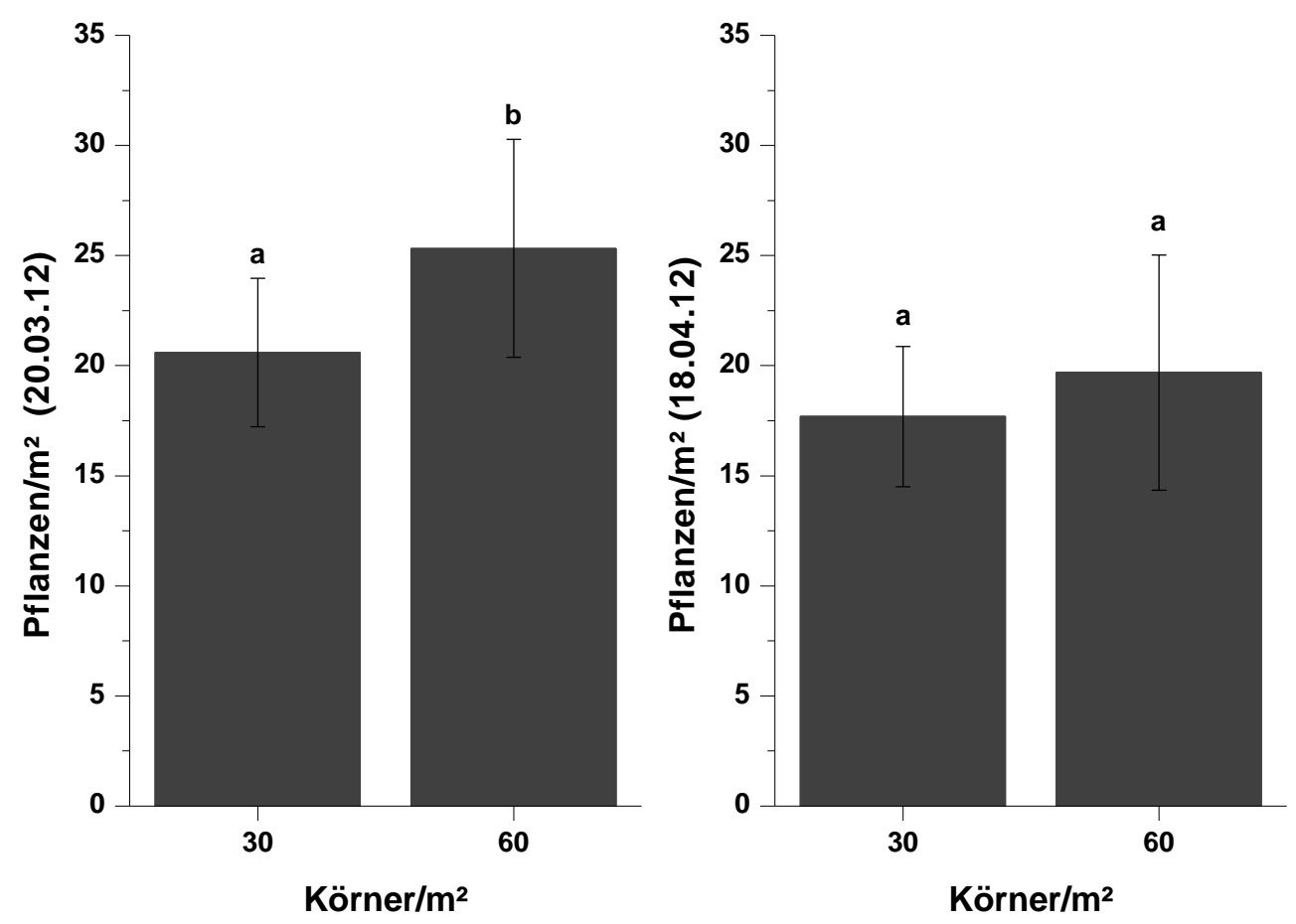

Abb. 23: Pflanzen $/ \mathrm{m}^{2}$ im Mittel über alle Parzellen der jeweiligen Saatstärkenvariante (30 bzw. 60 Körner/m²) nach zwei Zählungen (20.03.12 \& 18.04.12) im Versuchsjahr 2011/12 am Standort Göttingen. Verschiedene Buchstaben kennzeichnen signifikante Unterschiede zwischen den Saatstärken nach dem Tukey-Test $(p \leq 0,05, n=4)$, errechnet innerhalb des verwendeten gemischten Modells. Die Fehlerbalken stellen die jeweilige Standardabweichung dar.

In den Parzellen mit einer Aussaatstärke von 30 bzw. 60 Körner $/ \mathrm{m}^{2}$ wurden am 20.03.12 im Durchschnitt ca. 21 bzw. 25 Pflanzen $/ \mathrm{m}^{2}$ gezählt. Bei dieser Zählung wurde ein Befall mit $B$. cinerea an den Laubblättern und an der Stängelbasis der Rapspflanzen festgestellt. Sehr wahrscheinlich hat dieser Pilz nach der Frostperiode die Pflanzen über die absterbenden Laubblätter infiziert. Der Pilz wuchs durch die Petiolen in Richtung Stängel und führte dort zu einem Fäulnisprozess des Stängels. Der sofortige Einsatz eines Fungizides (1,0 I/ha Ortiva $^{\circledR}$, Azoxystrobin), erbrachte nicht den erhofften Bekämpfungserfolg. Dies bestätigte sich am 18.04.12 bei einer weiteren Zählung der Pflanzen $/ \mathrm{m}^{2}$ und einer gleichzeitigen Bonitur der BH mit B. cinerea. Jede gezählte Pflanze wurde kontrolliert, ob sie einen Befall mit B. cinerea aufwies. Unabhängig von der jeweiligen Fungizidvariante traten Befallshäufigkeiten zwischen $80 \%$ und $90 \%$ auf (Tab. 14). 
Tab. 14: Mittlere Befallshäufigkeit (BH) [\%] und Standardabweichung (SD) von Botrytis cinerea in Abhängigkeit von den Fungizidvarianten bonitiert am 18.04.12 im Versuchsjahr 2011/12. Verschiedene Buchstaben kennzeichnen signifikante Unterschiede zwischen den Fungizidvarianten nach dem Tukey-Test $(p \leq 0,05, n=4)$, errechnet innerhalb des verwendeten gemischten Modells. [T = 0,5 I/ha Toprex ${ }^{\circledR}$ (Difenoconazol + Paclobutrazol), C = 0,5 l/ha Carax ${ }^{\circledR}$ (Mepiquatchlorid + Metconazol) und $\mathrm{F}=0,8 \mathrm{l} /$ ha Folicur $^{\circledR}$ (Tebuconazol), $\mathrm{Fj}=$ Frühjahr]

\begin{tabular}{|c|c|c|c|c|c|c|}
\hline \multicolumn{6}{|c|}{ Fungizidvarianten } & \multirow[t]{2}{*}{$\begin{array}{c}\mathrm{BH}[\%] \pm \mathrm{SD} \\
\text { Botrytis cinerea }\end{array}$} \\
\hline \multicolumn{6}{|c|}{ BBCH-Stadium } & \\
\hline$\#$ & Beschreibung & 14 & 16 & $33 / 35$ & $53 / 55$ & \\
\hline 1 & unbehandelte Kontrolle & - & - & - & - & $85,6 \pm 6,6$ a \\
\hline 2 & ohne Herbst & - & - & $\mathrm{T}$ & - & $86,5 \pm 13,9$ a \\
\hline 3 & Standard & $\mathrm{T}$ & - & $\mathrm{T}$ & - & $79,9 \pm 12,5 \mathbf{a}$ \\
\hline 4 & Herbst intensiv & $\mathrm{T}$ & $\mathrm{T}$ & $\mathrm{T}$ & - & $84,1 \pm 8,9$ a \\
\hline 5 & Fj intensiv & $\mathrm{T}$ & - & $\mathrm{T}$ & $\mathrm{T}$ & $82,3 \pm 10,7 \mathbf{a}$ \\
\hline 6 & sehr intensiv & $\mathrm{T}$ & $\mathrm{T}$ & $\mathrm{T}$ & $\mathrm{T}$ & $88,0 \pm 5,4 \mathbf{a}$ \\
\hline 7 & ohne Fj & $\mathrm{T}$ & - & - & - & $84,3 \pm 13,0$ a \\
\hline 8 & praxisüblich & C & $\mathrm{C}$ & $\mathrm{F}$ & - & $80,1 \pm 9,7 \mathbf{a}$ \\
\hline
\end{tabular}

Dieser hohe Befall reduzierte die Pflanzendichte zusätzlich. In beiden Saatstärkevarianten hatte sich die Pflanzenzahl $/ \mathrm{m}^{2}$ auf ca. 20 Pflanzen $/ \mathrm{m}^{2}$ angeglichen (Abb. 23). Schließlich musste wegen der massiven Pflanzenverluste der komplette Feldversuch aufgegeben werden. Weitere Untersuchungen und Auswertungen waren unter diesen Umständen nicht mehr möglich. Somit standen für die Endauswertung des Feldversuches am Standort Göttingen nur die Ergebnisse aus den Versuchsjahren 2010/11 und 2012/13 zu Verfügung. 


\subsection{Einfluss der Anbaufaktoren Sorte, Saatstärke und Fungizidbehandlung auf Ertragsparameter und Ertragsfaktoren}

Von diesem Kapitel an werden ausschließlich Ergebnisse wiedergegeben, die auf Daten aus den Versuchsjahren 2010/11 und 2012/13 beruhen. Eine gemeinsame Verrechnung der Daten von beiden Versuchsjahren wurde in den statistischen Analysen (Varianz-, Korrelations- \& Regressionsanalysen) nicht durchgeführt, da in den zwei Versuchsjahren unterschiedliche Rapssorten und unterschiedliche Fungizidvarianten verwendet wurden (vgl. Kapitel 2.3). Zudem war die Witterung in den beiden Jahren v.a. in den Monaten März bis Mai sehr verschieden, sodass von einer differenzierten Wirksamkeit der in dieser Zeit applizierten Fungizide ausgegangen werden musste. Demnach werden in den folgenden Kapiteln die Ergebnisse getrennt nach den beiden Versuchsjahren besprochen. Zur Grundcharakterisierung der beiden Versuchsjahre werden in diesem Kapitel und im Kapitel 3.5 die Ergebnisse von dreifaktoriellen Varianzanalysen vorgestellt, die die Effekte der drei unabhängigen Versuchsfaktoren Sorte, Saatstärke und Fungizidbehandlung auf die Ertragsparameter, Ertragsfaktoren sowie Krankheitsparameter beschreiben. In Tab. 25A im Anhang II sind die Ergebnisse des globalen F-Tests für alle untersuchten Parameter aufgeführt. Auf Grundlage dieser Tabelle wurden für jeden Parameter alle signifikanten $(p \leq 0,05)$ Effekte ermittelt und für diese anschließend ein multipler Mittelwertvergleich (Tukey-Test) durchgeführt. Die Ergebnisse der Mittelwertvergleiche sind für das Versuchsjahr 2010/11 in Tab. 26A im Anhang und für das Versuchsjahr 2012/13 in Tab. 27A im Anhang angegeben. Im Folgenden werden, getrennt nach den Versuchsjahren 2010/11 und 2012/13, die signifikanten Effekte von Sorte und Saatstärke sowie die signifikanten und nicht signifikanten Effekte von der Interaktion aus Sorte $\mathrm{x}$ Saatstärke und von der Fungizidbehandlung für die Ertragsparameter und die Ertragsfaktoren vorgestellt. Die nicht signifikanten Effekte wurden der Vollständigkeit halber angegeben und dienen einer besseren Einordnung der Ergebnisse. Sie wurden direkt aus einer Excel-Tabelle übernommen, in der die kompletten Ergebnisse der Varianzanalysen gespeichert wurden.

Zu den Ertragsparametern zählen Kornertrag, Strohbiomasseertrag, Ölgehalt, Ölertrag sowie Ernteindex. Unter dem Begriff Ertragsfaktor werden die Pflanzen $/ \mathrm{m}^{2} \mathrm{im}$ Frühjahr, die Schoten/Pflanze, die Körner/Schote, die TKM, die Schoten $/ \mathrm{m}^{2}$, die Körner/Pflanze sowie die Korndichte zusammengefasst. Ferner wurde der Parameter Seitentriebe/Pflanze den Ertragsfaktoren zugeschrieben. Dieser stell eine Art Mischparameter dar, der einerseits als ein indirekter Ertragsfaktor und andererseits als ein Bestandesparameter definiert werden kann. 


\subsubsection{Versuchsjahr 2010/11}

\section{Kornertrag}

Aus der Tab. 15 geht hervor, dass der Kornertrag durch die Saatstärke, die Interaktion aus Sorte und Saatstärke und die Fungizidbehandlung signifikant beeinflusst wurde. Bei einer Aussaatstärke von $60 \mathrm{Körnern} / \mathrm{m}^{2}$ wurde ein signifikant höherer Ertrag (4,76 t/ha) erzielt als bei einer Aussaatstärke von 30 Körnern $/ \mathrm{m}^{2}$ (4,17 t/ha). Unter dem Einfluss der Sorten relativierte sich dieses Ergebnis. Die Winterrapssorten NK Petrol und SY Merlot erzielten bei einer hohen Aussaatstärke einen höheren Kornertrag (4,68 t/ha bzw. 4,85 t/ha) als bei einer niedrigen Aussaatstärke (4,40 t/ha bzw. 3,94 t/ha), allerdings war dieser Unterschied nur bei SY Merlot signifikant. Innerhalb einer Saatstärke traten keine signifikanten Unterschiede zwischen den zwei Rapssorten auf. Bei den Fungizidbehandlungen wurde der niedrigste Kornertrag (4,25 t/ha) in der Variante 8 und der höchste Kornertrag (4,74 t/ha) in der Variante 6 erzielt. Diese beiden Varianten unterschieden sich signifikant voneinander. Ansonsten traten keine weiteren signifikanten Unterschiede zwischen den einzelnen Fungizidbehandlungen auf.

\section{Strohbiomasseertrag}

Der Strohbiomasseertrag wurde durch die Saatstärke und die Fungizidbehandlung signifikant und durch die Interkation aus Sorte und Saatstärke nicht signifikant beeinflusst (Tab. 15). Bei einer Saatstärke von $60 \mathrm{Körnern} / \mathrm{m}^{2}$ war der Strohbiomasseertrag signifikant höher (6,04 t/ha) als bei einer Saatstärke von 30 Körnern/m² $(5,53 \mathrm{t} / \mathrm{ha})$. Von den Fungizidbehandlungen führte die Variante $2 \mathrm{zu}$ einem signifikant höheren Strohbiomasseertrag (6,27 t/ha) als die Varianten 4 (5,54 t/ha) und 8 (5,48 t/ha). Weitere signifikante Unterschiede wurden bei den Fungizidbehandlungen nicht festgestellt.

\section{ÖIgehalt}

Der Ölgehalt wurde durch die beiden Anbaufaktoren Sorte und Saatstärke signifikant beeinflusst (Tab. 15). Bei der Sorte SY Merlot war der Ölgehalt mit 44,01\% signifikant höher als bei Sorte NK Petrol (43,16\%). Ferner war der Ölgehalt bei einer Saatstärke von $60 \mathrm{Körnern} / \mathrm{m}^{2}$ signifikant höher $(43,80 \%)$ als bei einer Saatstärke von $30 \mathrm{Körnern} / \mathrm{m}^{2}$ (43,37\%). Obwohl die beiden zuvor genannten Haupteffekte jeweils einen signifikanten Effekt hatten, wurde für die Interaktion aus Sorte $x$ Saatstärke kein signifikanter Einfluss auf den Ölgehalt nachgewiesen. Gleiches traf auch auf die Fungizidbehandlungen zu. 


\section{Ölertrag}

Der Ölertrag wurde wie der Kornertrag durch die Aussaatstärke, die Interaktion zwischen Sorte $x$ Saatstärke und die Fungizidbehandlung signifikant beeinflusst (Tab. 15). So war der Ölertrag bei 60 Körnern/m² signifikant höher (2,09 t/ha) als bei 30 Körnern/m² $(1,81$ t/ha). Bei der Interaktion Sorte x Saatstärke erzielten NK Petrol und SY Merlot bei einer hohen Aussaatstärke einen höheren Ölertrag (2,03 t/ha bzw. 2,15 t/ha) als bei einer niedrigen Aussaatstärke (1,89 t/ha bzw. 1,73 t/ha). Bei SY Merlot war dieser Unterschied signifikant. Innerhalb einer Saatstärke traten keine signifikanten Unterschiede zwischen den zwei Rapssorten auf. Bei den Fungizidbehandlungen wurde der niedrigste Ölertrag $(1,85 \mathrm{t} / \mathrm{ha})$ in der Variante 8 und der höchste Ölertrag $(2,06 \mathrm{t} / \mathrm{ha})$ in der Variante 6 erzielt. Diese beiden Varianten unterschieden sich signifikant voneinander. Ansonsten traten keine weiteren signifikanten Unterschiede zwischen den einzelnen Fungizidbehandlungen auf.

\section{Ernteindex}

Der Ernteindex wurde durch die Fungizidbehandlung signifikant und durch Wechselwirkung zwischen Sorte und Saatstärke nicht signifikant beeinflusst (Tab. 15). Bei der Interaktion aus Sorte $x$ Saatstärke schwankten die Werte zwischen ca. 39,7\% (SY Merlot, 30 Körnern $/ \mathrm{m}^{2}$ ) und ca. 42,2\% (NK Petrol, 60 Körnern $/ \mathrm{m}^{2}$ ). Von den Fungizidbehandlungen führte die Variante $4 \mathrm{zu}$ einem signifikant höheren Ernteindex $(42,7 \%)$ als die Variante $2(39,2 \%)$. Weitere signifikante Unterschiede traten zwischen den verschiedenen Fungizidbehandlungen nicht auf.

\section{Pflanzen $/ \mathrm{m}^{2}$ im Frühjahr}

Für den Ertragsfaktor Pflanzen/m² im Frühjahr in BBCH 16/18 wurde ein signifikanter Einfluss der Sorte und der Saatstärke nachgewiesen (Tab. 15). Die Interaktion zwischen Sorte und Saatstärke und die Fungizidbehandlung hatten keinen signifikanten Einfluss auf die Pflanzendichte im Frühjahr in BBCH 16/18 (Tab. 15). Mit ca. 41 Pflanzen/m² bei NK Petrol und ca. 47 Pflanzen $/ \mathrm{m}^{2}$ bei $60 \mathrm{Körnern} / \mathrm{m}^{2}$, wurden in $\mathrm{BBCH} 16 / 18$ signifikant mehr Pflanzen $/ \mathrm{m}^{2}$ gezählt als bei SY Merlot (ca. 31 Pflanzen $/ \mathrm{m}^{2}$ ) bzw. bei $30 \mathrm{Körnern} / \mathrm{m}^{2}$ (ca. 24 Pflanzen $/ \mathrm{m}^{2}$ ). Im Schnitt winterten bei der niedrigen Saatstärke 6 Pflanzen $/ \mathrm{m}^{2}$ und bei der hohen Saatstärke 13 Pflanzen $/ \mathrm{m}^{2}$ aus. Obwohl die Mittelwerte der Pflanzenzahlen $/ \mathrm{m}^{2}$ bei der Interaktion aus Sorte $\mathrm{x}$ Saatstärke stark auf einen signifikanten Unterschied hindeuteten, wurde dieser nicht durch die statistische Varianzanalyse (globaler F-Test, Tab. 25A im Anhang II) belegt. 


\section{Schoten/Pflanze}

Die Saatstärke und die Interaktion zwischen Sorte und Saatstärke hatten einen signifikanten Effekt und die Fungizidbehandlung hatte keinen signifikanten Effekt auf den Ertragsfaktor Schoten/Pflanze (Tab. 15). Bei einer Aussaatstärke von $30 \mathrm{Körnern} / \mathrm{m}^{2}$ wurden im Durchschnitt 309 Schoten/Pflanze gebildet. Das waren ungefähr 102 Schoten/Pflanze mehr als bei einer Aussaatstärke von $60 \mathrm{Körnern} / \mathrm{m}^{2}$. Bei der Interaktion Sorte x Saatstärke zeigte sich, dass bei einer niedrigen Aussaatstärke SY Merlot signifikant mehr Schoten/Pflanze (ca. 346 Schoten/Pflanze) bildete als NK Petrol (ca. 273 Schoten/Pflanze). Bei einer hohen Aussaatstärke unterschied sich die Anzahl der Schoten/Pflanze zwischen den beiden Sorten nicht signifikant (SY Merlot ca. 204 und NK Petrol ca. 210 Schoten/Pflanze). Generell wurden bei einer niedrigen Saatstärke signifikant mehr Schoten/Pflanze gebildet als bei einer hohen Saatstärke.

\section{Körner/Schote}

Aus Tab. 15 geht hervor, dass der Ertragsfaktor Körner/Schote signifikant durch die Saatstärke und nicht signifikant durch die Interaktion aus Sorte x Saatstärke sowie die Fungizidbehandlung beeinflusst wurden. Die Rapspflanzen produzierten bei einer Aussaatstärke von $30 \mathrm{Körnern} / \mathrm{m}^{2} \mathrm{im}$ Schnitt $24 \mathrm{Körner} / S c h o t e$. Das waren ca. 2 Körner/Schote mehr als bei einer Aussaatstärke von $60 \mathrm{Körnern} / \mathrm{m}^{2}$. Bei der Interaktion aus Sorte x Saatstärke schwankte die Kornzahl/Schote zwischen ca. 21 (SY Merlot, 60 Körner $/ \mathrm{m}^{2}$ ) und 24 Körner/Schote (NK Petrol, 30 Körner $/ \mathrm{m}^{2}$ ). Bei den Fungizidbehandlungen lagen die Werte für die Kornzahl/Schote zwischen ca. 22 (Variante 2) und 23 Körner/Schote (Variante 5). Der Vollständigkeit halber sei darauf hingewiesen, dass die Interaktion aus Saatstärke und Fungizidbehandlung auch einen signifikanten Effekt auf die Anzahl Körner/Schote hatte (vgl. Tab. 25A im Anhang II, Globaltest). Einzelheiten werden dazu an dieser Stelle nicht näher beschrieben, stattdessen wird auf Tab. 26A im Anhang II verwiesen.

\section{TKM}

Für den Ertragsfaktor TKM wurden signifikante Einflüsse der Rapssorte, der Saatstärke, der Interaktion aus Sorte $x$ Saatstärke und der Fungizidbehandlung festgestellt (Tab. 15). SY Merlot erzielte im Mittel eine TKM von 5,71 g. NK Petrol erreichte dagegen nur 5,19 g. Bei der niedrigen Saatstärke wurde im Schnitt eine TKM von 5,57 g gebildet. Diese lag damit signifikant um 0,24 Gramm höher als bei der hohen Saatstärke. Alle Sorten $x$ Saatstärken - Kombinationen unterschieden sich signifikant voneinander. Die höchste 
TKM (5,88 g) wurde dabei in der Kombination aus SY Merlot und $30 \mathrm{Körner} / \mathrm{m}^{2}$ gebildet. Dahinter folgten die Kombinationen aus SY Merlot und $60 \mathrm{Körner} / \mathrm{m}^{2}$ (5,53 g), NK Petrol und $30 \mathrm{Körner} / \mathrm{m}^{2}(5,26 \mathrm{~g})$ sowie NK Petrol und $60 \mathrm{Körner} / \mathrm{m}^{2}(5,13 \mathrm{~g})$. Bei den verschiedenen Fungizidbehandlungen konnte eine TKM zwischen 5,35 g und 5,57 g ermittelt werden. Die Varianten $6(5,35 \mathrm{~g})$ und $4(5,37 \mathrm{~g})$ reduzierten im Vergleich zur Variante $1(5,57 \mathrm{~g})$ signifikant die TKM. Generell befand sich die TKM mit mehr als 5 Gramm auf einem recht hohen Niveau.

\section{Schoten $/ \mathrm{m}^{2}$}

Der berechnete Ertragsfaktor Schoten $/ \mathrm{m}^{2}$ wurde durch die Rapssorte und durch die Aussaatstärke signifikant und durch die Interaktion aus Sorte $\mathrm{x}$ Saatstärke und die Fungizidbehandlung nicht signifikant beeinflusst (Tab. 15). NK Petrol produzierte signifikant mehr Schoten $/ \mathrm{m}^{2}$ (ca. 9465 Schoten $/ \mathrm{m}^{2}$ ) als SY Merlot (ca. 7611 Schoten $/ \mathrm{m}^{2}$ ). Bei einer Saatstärke von 60 Körnern/m² konnten signifikant mehr Schoten $/ \mathrm{m}^{2}$ (ca. 9761 Schoten $/ \mathrm{m}^{2}$ ) ermittelt werden als bei einer Saatstärke von $30 \mathrm{Körnern} / \mathrm{m}^{2}$ (ca. 7315 Schoten $/ \mathrm{m}^{2}$ ). Bei der Interaktion Sorte $x$ Saatstärke variierte die Schotendichte zwischen ca. 6709 (SY Merlot, 30 Körner/m²) und ca. 11009 Schoten/m² (NK Petrol, 60 Körner/m²). Obwohl diese Differenz stark auf einen signifikanten Unterschied hindeutete, wurde diese nicht durch die statistische Varianzanalyse (globaler F-Test, Tab. 25A im Anhang II) bestätigt. Bei den Fungizidbehandlungen schwankte die Schotendichte zwischen ca. 7866 (Variante 1) und ca. 9275 Schoten $/ \mathrm{m}^{2}$ (Variante 8).

\section{Körner/Pflanze}

Der berechnete Ertragsfaktor Körner/Pflanze wurde durch die Saatstärke und die Interaktion Sorte $\mathrm{x}$ Saatstärke signifikant und durch die Fungizidbehandlung nicht signifikant beeinflusst (Tab. 15). Bei einer niedrigen Saatstärke wurden signifikant mehr Körner/Pflanze (ca. 7361 Körner/Pflanze) gebildet als bei einer hohen Saatstärke (ca. 4541 Körner/Pflanze). Dieses Ergebnis fand sich auch bei der Interaktion zwischen Sorte und Saatstärke wieder. Bei einer Saatstärke von $30 \mathrm{Körnern} / \mathrm{m}^{2}$ bildeten SY Merlot und NK Petrol signifikant mehr Körner/Pflanze (ca. 8066 Körner/Pflanze bzw. ca. 6656 Körner/Pflanze) als bei einer Saatstärke von 60 Körnern/m² (ca. 4261 Körner/Pflanze bzw. ca. 4819 Körner/Pflanze). Zwischen den Sorten traten innerhalb einer Saatstärke keine signifikanten Unterschiede auf. 


\section{Korndichte}

Der berechnete Ertragsfaktor Korndichte wurde durch die Sorte und die Saatstärke signifikant und durch die Interaktion zwischen Sorte $x$ Saatstärke sowie die Fungizidbehandlung nicht signifikant beeinflusst (Tab. 15). Die Korndichte bei NK Petrol war im Mittel mit 222.107 Körnern/m² um 54.771 Körnern $/ \mathrm{m}^{2}$ signifikant höher als bei SY Merlot (167.336 Körner $/ \mathrm{m}^{2}$ ). Bei einer Saatstärke von $60 \mathrm{Körnern} / \mathrm{m}^{2}$ wurde eine signifikant höhere Korndichte (ca. $215.321 \mathrm{Körner} / \mathrm{m}^{2}$ ) gebildet als bei $30 \mathrm{Körnern} / \mathrm{m}^{2}$ (174.122 Körner $/ \mathrm{m}^{2}$ ). Obwohl die Mittelwerte der Korndichten bei der Interaktion aus Sorte x Saatstärke stark auf einen signifikanten Unterschied hindeuteten, wurde dieser nicht durch die statistische Varianzanalyse (globaler F-Test, Tab. 25A im Anhang II) bestätigt.

\section{Seitentriebe/Pflanze}

Der indirekte Ertragsfaktor Seitentriebe/Pflanze wurde durch die Saatstärke und die Fungizidbehandlung signifikant und durch die Interaktion Sorte $x$ Saatstärke nicht signifikant beeinflusst (Tab. 15). Bei einer Aussaatstärke von 30 Körnern $/ \mathrm{m}^{2}$ bildeten die Rapspflanzen im Schnitt 9 Seitentriebe/Pflanze und damit ca. zwei Seitentriebe mehr als bei einer Aussaatstärke von $60 \mathrm{Körnern} / \mathrm{m}^{2}$. Dieser Unterschied war signifikant. Je nach Fungizidbehandlung wurden im Mittel zwischen 7 und 9 Seitentriebe/Pflanze gebildet. Durch Variante 4 (ca. 9 Seitentriebe/Pflanze) konnte die Anzahl an Seitentriebe/Pflanze im Vergleich zu Variante 1 (ca. 7 Seitentriebe/Pflanze) signifikant um ca. 2 Seitentriebe erhöht werden. Bei der Interaktion zwischen Sorte und Saatstärke schwankten die Werte auch zwischen 7 und 9 Seitentriebe/Pflanze. Allerdings waren hier die Unterschiede nicht statistisch absicherbar (vgl. Tab. 25A im Anhang II). 
Tab. 15: Einfluss der Sorte (So), der Saatstärke (Di), der Interaktion zwischen Sorte $x$ Saatstärke (So*Di) und der Fungizidbehandlung (Fu) auf die Ertragsparameter (Kornertrag, Strohbiomasseertrag, Ölgehalt, Ölertrag und Ernteindex) sowie die Ertragsfaktoren (Pflanzen $/ \mathrm{m}^{2} \mathrm{im}$ Frühjahr in BBCH 16/18, Schoten/Pflanze, Körner/Schote, TKM, Schoten/m², Körner/Pflanze Korndichte und Seitentriebe/Pflanze), die im Versuchsjahr 2010/11 im Feldversuch in Göttingen untersucht wurden. Mittelwerte, die mit unterschiedlichen Buchstaben kennzeichnet sind, unterscheiden sich signifikant (Tukey-Test, $p \leq 0,05$ ). Dargestellt sind die Mittelwerte, die Standardabweichung (SD), errechnet aus den Residuen des gegebenen Modells, und die Anzahl der Werte (n), die in die jeweilige Berechnung eingegangen sind. Für den Effekt der Sorte bzw. der Saatstärke wurden nur signifikante Ergebnisse wiedergegeben. Für die Interaktion Sorte $\mathrm{x}$ Saatstärke und die Fungizidbehandlung wurden sowohl signifikante als auch nicht signifikante Ergebnisse aufgeführt. Grundlage dieser Tabelle sind die Tabellen 25A und 26A im Anhang II aus denen hervorgeht, welche Effekte einen signifikanten Einfluss hatten ( $F-T e s t, p \leq 0,05$; Tab. 25A) und wie dieser sich auf den Mittelwertvergleich auswirkte (Tab. 26A). Die nicht signifikanten Ergebnisse wurden direkt aus einer Excel-Tabelle übernommen, in der die kompletten Ergebnisse der Varianzanalyse gespeichert wurden. [So $=$ Sorte $(\mathrm{M}=\mathrm{SY}$ Merlot, $\mathrm{P}=\mathrm{NK}$ Petrol); $\mathrm{Di}=$ Saatstärke (30 bzw. 60 Körner $\left./ \mathrm{m}^{2}\right)$; Fu = Fungizid $\left(1=\right.$ unbehandelte Kontrolle, $2=0,5 \mathrm{l} / \mathrm{ha} \mathrm{Toprex}^{\circledR}$ (Difenoconazol + Paclobutrazol) in $\mathrm{BBCH} 33 / 35,3=0,5 \mathrm{l} /$ ha Toprex $^{\circledR}$ in BBCH 14 und 33/35, $4=$ $0,5 \mathrm{l} /$ ha Toprex ${ }^{\circledR}$ in BBCH 14, 16 und 33/35, $5=0,5 \mathrm{l} /$ ha Toprex ${ }^{\circledR}$ in BBCH 14, 33/35 und 53/55, $6=$ 0,5 l/ha Toprex ${ }^{\circledR}$ in BBCH $14+1,0 \mathrm{l} /$ ha Toprex ${ }^{\circledR}$ in $\mathrm{BBCH} 33 / 35,7=$ wie Nr. 3 aber in BBCH 65 2,0 I/ha Ortiva ${ }^{\circledR}$ (Azoxystrobin), $8=$ praxisüblich $=0,6 \mathrm{l} /$ ha Folicur $^{\circledR}$ (Tebuconazol) in BBCH $14+0,7$ $\mathrm{l} /$ ha Carax $^{\circledR}$ (Mepiquatchlorid + Metconazol) in $\mathrm{BBCH} 33 / 35+0,8 \mathrm{l} /$ ha Harvesan ${ }^{\circledR}$ (Flusilazol + Carbendazim) in BBCH 65; Varianten 1-6 erhielten in BBCH 651 l/ha Ortiva $\left.{ }^{\circledR}\right)$ ].

\begin{tabular}{|c|c|c|c|c|c|c|c|c|}
\hline Parameter & Effekt & So & Di & $\mathbf{F u}$ & Mittelwert & SD & $\mathrm{n}$ & Buchstaben \\
\hline \multirow[t]{14}{*}{ Kornertrag [t/ha] } & $\mathrm{Di}$ & & 30 & & 4,17 & 0,31 & 64 & $b$ \\
\hline & Di & & 60 & & 4,76 & 0,28 & 64 & a \\
\hline & $\mathrm{So}^{*} \mathrm{Di}$ & $\mathrm{M}$ & 30 & & 3,94 & 0,32 & 32 & b \\
\hline & So* $\mathrm{Di}$ & M & 60 & & 4,85 & 0,29 & 32 & $a$ \\
\hline & $\mathrm{So}^{*} \mathrm{Di}$ & $\mathrm{P}$ & 30 & & 4,40 & 0,30 & 32 & $a b$ \\
\hline & So*Di & $P$ & 60 & & 4,68 & 0,28 & 32 & a \\
\hline & $\mathrm{Fu}$ & & & 1 & 4,35 & 0,21 & 16 & $\mathrm{ab}$ \\
\hline & $\mathrm{Fu}$ & & & 2 & 4,42 & 0,26 & 16 & $a b$ \\
\hline & $\mathrm{Fu}$ & & & 3 & 4,42 & 0,20 & 16 & $a b$ \\
\hline & $\mathrm{Fu}$ & & & 4 & 4,52 & 0,34 & 16 & $a b$ \\
\hline & $\mathrm{Fu}$ & & & 5 & 4,62 & 0,43 & 16 & $a b$ \\
\hline & $\mathrm{Fu}$ & & & 6 & 4,74 & 0,34 & 16 & a \\
\hline & $\mathrm{Fu}$ & & & 7 & 4,43 & 0,20 & 16 & $a b$ \\
\hline & $\mathrm{Fu}$ & & & 8 & 4,25 & 0,36 & 16 & $b$ \\
\hline Strohbiomasseertrag & $\mathrm{Di}$ & & 30 & & 5,53 & 0,57 & 64 & $\mathrm{~b}$ \\
\hline [t/ha] & $\mathrm{Di}$ & & 60 & & 6,04 & 0,47 & 64 & a \\
\hline
\end{tabular}




\begin{tabular}{|c|c|c|c|c|c|c|c|c|}
\hline & So* Di & $M$ & 30 & & 5,51 & 0,64 & 32 & $a$ \\
\hline & So* Di & $M$ & 60 & & 6,23 & 0,53 & 32 & a \\
\hline & So* $\mathrm{Di}$ & $\mathrm{P}$ & 30 & & 5,56 & 0,47 & 32 & a \\
\hline & So* Di & $\mathrm{P}$ & 60 & & 5,85 & 0,41 & 32 & a \\
\hline & $\mathrm{Fu}$ & & & 1 & 5,66 & 0,41 & 16 & $a b$ \\
\hline & $\mathrm{Fu}$ & & & 2 & 6,27 & 0,65 & 16 & $a$ \\
\hline & $\mathrm{Fu}$ & & & 3 & 5,58 & 0,53 & 16 & $a b$ \\
\hline & $\mathrm{Fu}$ & & & 4 & 5,54 & 0,41 & 16 & $b$ \\
\hline & $\mathrm{Fu}$ & & & 5 & 5,70 & 0,45 & 16 & $a b$ \\
\hline & $\mathrm{Fu}$ & & & 6 & 6,07 & 0,76 & 16 & $a b$ \\
\hline & $\mathrm{Fu}$ & & & 7 & 5,99 & 0,46 & 16 & $a b$ \\
\hline & $\mathrm{Fu}$ & & & 8 & 5,48 & 0,49 & 16 & $\mathrm{~b}$ \\
\hline \multirow[t]{16}{*}{ Ölgehalt [\%] } & So & $M$ & & & 44,01 & 0,37 & 64 & $a$ \\
\hline & So & $\mathrm{P}$ & & & 43,16 & 0,32 & 64 & b \\
\hline & $\mathrm{Di}$ & & 30 & & 43,37 & 0,30 & 64 & $\mathrm{~b}$ \\
\hline & $\mathrm{Di}$ & & 60 & & 43,80 & 0,39 & 64 & a \\
\hline & $\mathrm{So} \mathrm{Di}^{-}$ & $M$ & 30 & & 43,81 & 0,30 & 32 & $a$ \\
\hline & So*Di & $M$ & 60 & & 44,21 & 0,43 & 32 & a \\
\hline & So* $\mathrm{Di}$ & $\mathrm{P}$ & 30 & & 42,93 & 0,30 & 32 & a \\
\hline & So* $\mathrm{Di}$ & $\mathrm{P}$ & 60 & & 43,40 & 0,34 & 32 & a \\
\hline & $\mathrm{Fu}$ & & & 1 & 43,77 & 0,39 & 16 & a \\
\hline & $\mathrm{Fu}$ & & & 2 & 43,56 & 0,38 & 16 & a \\
\hline & $\mathrm{Fu}$ & & & 3 & 43,60 & 0,32 & 16 & a \\
\hline & $\mathrm{Fu}$ & & & 4 & 43,59 & 0,46 & 16 & a \\
\hline & $\mathrm{Fu}$ & & & 5 & 43,44 & 0,31 & 16 & a \\
\hline & $\mathrm{Fu}$ & & & 6 & 43,55 & 0,37 & 16 & a \\
\hline & $\mathrm{Fu}$ & & & 7 & 43,65 & 0,33 & 16 & a \\
\hline & $\mathrm{Fu}$ & & & 8 & 43,52 & 0,26 & 16 & a \\
\hline \multirow[t]{14}{*}{ Ölertrag [t/ha] } & $\mathrm{Di}$ & & 30 & & 1,81 & 0,13 & 64 & $\mathrm{~b}$ \\
\hline & $\mathrm{Di}$ & & 60 & & 2,09 & 0,12 & 64 & a \\
\hline & So*Di & $M$ & 30 & & 1,73 & 0,14 & 32 & $\mathrm{~b}$ \\
\hline & So* $\mathrm{Di}$ & $M$ & 60 & & 2,15 & 0,13 & 32 & a \\
\hline & So* Di & $P$ & 30 & & 1,89 & 0,13 & 32 & $a b$ \\
\hline & So*Di & $\mathrm{P}$ & 60 & & 2,03 & 0,11 & 32 & a \\
\hline & $\mathrm{Fu}$ & & & 1 & 1,91 & 0,09 & 16 & $a b$ \\
\hline & $\mathrm{Fu}$ & & & 2 & 1,93 & 0,11 & 16 & $a b$ \\
\hline & $\mathrm{Fu}$ & & & 3 & 1,93 & 0,09 & 16 & $a b$ \\
\hline & $\mathrm{Fu}$ & & & 4 & 1,97 & 0,15 & 16 & $a b$ \\
\hline & $\mathrm{Fu}$ & & & 5 & 2,01 & 0,18 & 16 & $a b$ \\
\hline & $\mathrm{Fu}$ & & & 6 & 2,06 & 0,14 & 16 & $a$ \\
\hline & $\mathrm{Fu}$ & & & 7 & 1,93 & 0,09 & 16 & $a b$ \\
\hline & $\mathrm{Fu}$ & & & 8 & 1,85 & 0,16 & 16 & $b$ \\
\hline
\end{tabular}




\begin{tabular}{|c|c|c|c|c|c|c|c|c|}
\hline \multirow[t]{12}{*}{ Ernteindex [\%] } & So* Di & $\mathrm{M}$ & 30 & & 39,66 & 2,89 & 32 & a \\
\hline & So*Di & $\mathrm{M}$ & 60 & & 41,51 & 2,58 & 32 & a \\
\hline & So* $\mathrm{Di}$ & $\mathrm{P}$ & 30 & & 41,98 & 1,66 & 32 & $\mathrm{a}$ \\
\hline & So*Di & $P$ & 60 & & 42,15 & 2,17 & 32 & a \\
\hline & $\mathrm{Fu}$ & & & 1 & 41,08 & 2,57 & 16 & $a b$ \\
\hline & $\mathrm{Fu}$ & & & 2 & 39,18 & 2,45 & 16 & $b$ \\
\hline & $\mathrm{Fu}$ & & & 3 & 41,97 & 2,23 & 16 & $a b$ \\
\hline & $\mathrm{Fu}$ & & & 4 & 42,65 & 2,39 & 16 & $\mathrm{a}$ \\
\hline & $\mathrm{Fu}$ & & & 5 & 42,47 & 2,51 & 16 & $a b$ \\
\hline & $\mathrm{Fu}$ & & & 6 & 41,71 & 2,82 & 16 & $a b$ \\
\hline & $\mathrm{Fu}$ & & & 7 & 40,21 & 2,24 & 16 & $a b$ \\
\hline & $\mathrm{Fu}$ & & & 8 & 41,33 & 2,37 & 16 & $a b$ \\
\hline Pflanzen $/ \mathrm{m}^{2}$ & So & $M$ & & & 30,91 & 4,70 & 64 & $b$ \\
\hline \multirow[t]{15}{*}{ im Frühjahr } & So & $P$ & & & 40,75 & 5,41 & 64 & $a$ \\
\hline & $\mathrm{Di}$ & & 30 & & 24,25 & 4,52 & 64 & b \\
\hline & $\mathrm{Di}$ & & 60 & & 47,41 & 5,56 & 64 & a \\
\hline & So* Di & $\mathrm{M}$ & 30 & & 19,50 & 3,31 & 32 & a \\
\hline & So* Di & $\mathrm{M}$ & 60 & & 42,31 & 5,83 & 32 & a \\
\hline & So* $\mathrm{Di}$ & $\mathrm{P}$ & 30 & & 29,00 & 5,53 & 32 & $\mathrm{a}$ \\
\hline & So*Di & $P$ & 60 & & 52,50 & 5,37 & 32 & a \\
\hline & $\mathrm{Fu}$ & & & 1 & 38,50 & 3,39 & 16 & a \\
\hline & $\mathrm{Fu}$ & & & 2 & 35,13 & 3,86 & 16 & $\mathrm{a}$ \\
\hline & $\mathrm{Fu}$ & & & 3 & 34,31 & 4,71 & 16 & $\mathrm{a}$ \\
\hline & $\mathrm{Fu}$ & & & 4 & 32,25 & 4,96 & 16 & a \\
\hline & $\mathrm{Fu}$ & & & 5 & 36,44 & 8,32 & 16 & $\mathrm{a}$ \\
\hline & $\mathrm{Fu}$ & & & 6 & 35,81 & 5,44 & 16 & $\mathrm{a}$ \\
\hline & $\mathrm{Fu}$ & & & 7 & 35,38 & 4,39 & 16 & $\mathrm{a}$ \\
\hline & $\mathrm{Fu}$ & & & 8 & 38,81 & 4,94 & 16 & a \\
\hline \multirow[t]{14}{*}{ Schoten/Pflanze } & $\mathrm{Di}$ & & 30 & & 309,25 & 50,40 & 64 & $\mathrm{a}$ \\
\hline & $\mathrm{Di}$ & & 60 & & 206,79 & 37,51 & 64 & $b$ \\
\hline & So*Di & $\mathrm{M}$ & 30 & & 345,57 & 61,76 & 32 & a \\
\hline & So*Di & $\mathrm{M}$ & 60 & & 203,63 & 42,26 & 32 & c \\
\hline & So* Di & $\mathrm{P}$ & 30 & & 272,93 & 30,53 & 32 & $b$ \\
\hline & So*Di & $P$ & 60 & & 209,96 & 32,76 & 32 & c \\
\hline & $\mathrm{Fu}$ & & & 1 & 217,40 & 36,20 & 16 & a \\
\hline & $\mathrm{Fu}$ & & & 2 & 254,78 & 49,24 & 16 & $\mathrm{a}$ \\
\hline & $\mathrm{Fu}$ & & & 3 & 259,22 & 39,23 & 16 & $\mathrm{a}$ \\
\hline & $\mathrm{Fu}$ & & & 4 & 279,02 & 25,35 & 16 & $\mathrm{a}$ \\
\hline & $\mathrm{Fu}$ & & & 5 & 276,98 & 65,09 & 16 & $\mathrm{a}$ \\
\hline & $\mathrm{Fu}$ & & & 6 & 261,59 & 53,08 & 16 & $\mathrm{a}$ \\
\hline & $\mathrm{Fu}$ & & & 7 & 257,50 & 49,91 & 16 & $\mathrm{a}$ \\
\hline & Fu & & & 8 & 257,70 & 29,09 & 16 & $a$ \\
\hline \multirow[t]{2}{*}{ Körner/Schote } & $\mathrm{Di}$ & & 30 & & 23,80 & 1,33 & 64 & $a$ \\
\hline & $\mathrm{Di}$ & & 60 & & 21,89 & 1,02 & 64 & $b$ \\
\hline
\end{tabular}




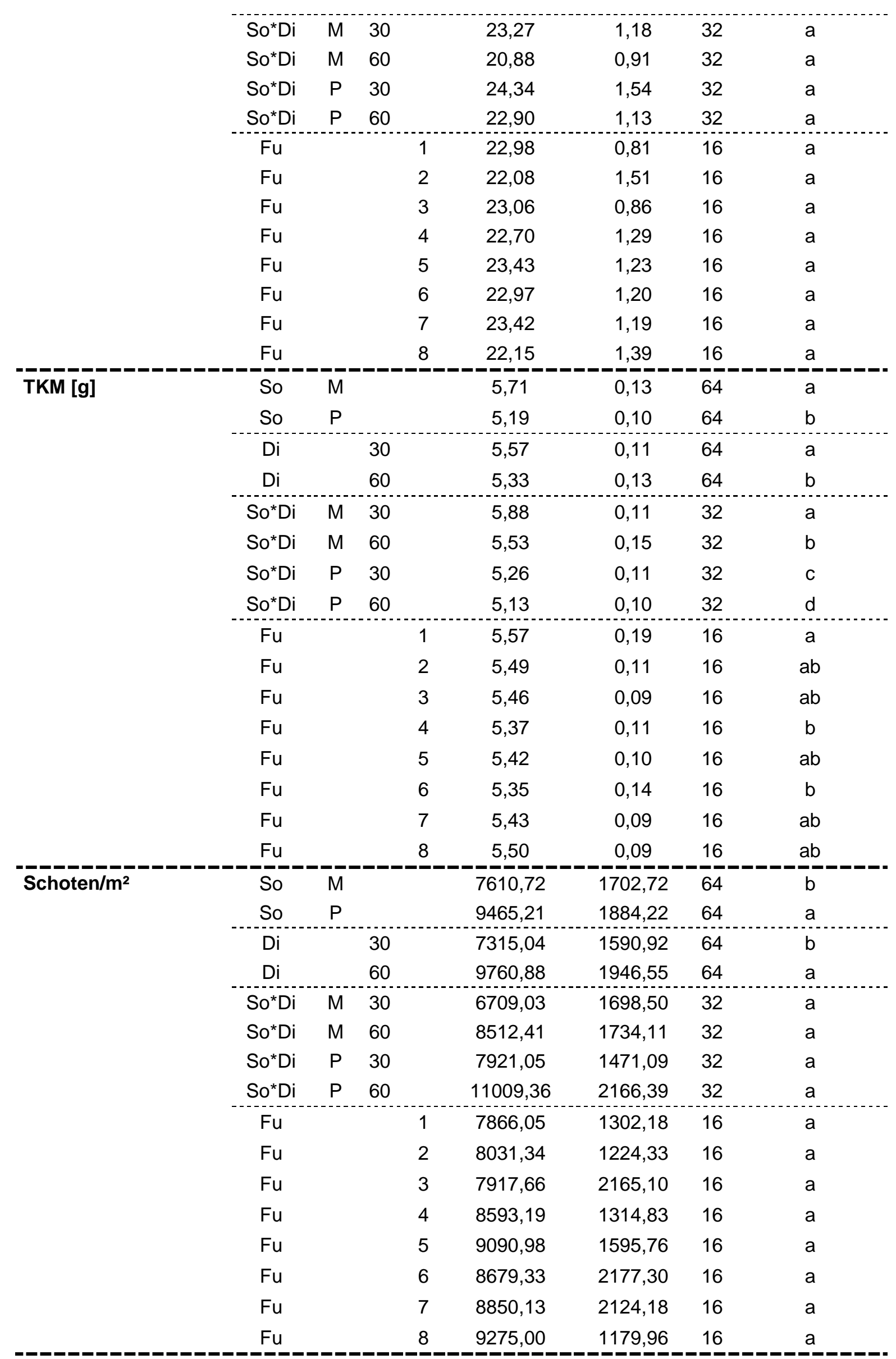




\begin{tabular}{|c|c|c|c|c|c|c|c|c|}
\hline \multirow[t]{14}{*}{ Körner/Pflanze } & $\mathrm{Di}$ & & 30 & & 7361,10 & 1307,34 & 64 & a \\
\hline & $\mathrm{Di}$ & & 60 & & 4540,45 & 922,35 & 64 & $\mathrm{~b}$ \\
\hline & So* Di & $M$ & 30 & & 8066,15 & 1562,94 & 32 & $a$ \\
\hline & So* $\mathrm{Di}$ & $M$ & 60 & & 4261,11 & 996,05 & 32 & $\mathrm{~b}$ \\
\hline & So* $\mathrm{Di}$ & $P$ & 30 & & 6656,05 & 891,42 & 32 & $\mathrm{a}$ \\
\hline & So* Di & $\mathrm{P}$ & 60 & & 4819,79 & 858,37 & 32 & $b$ \\
\hline & $\mathrm{Fu}$ & & & 1 & 4994,75 & 927,29 & 16 & $a$ \\
\hline & $\mathrm{Fu}$ & & & 2 & 5654,54 & 1318,57 & 16 & $\mathrm{a}$ \\
\hline & $\mathrm{Fu}$ & & & 3 & 6081,92 & 925,25 & 16 & $\mathrm{a}$ \\
\hline & $\mathrm{Fu}$ & & & 4 & 6378,08 & 783,94 & 16 & a \\
\hline & $\mathrm{Fu}$ & & & 5 & 6574,10 & 1560,10 & 16 & $\mathrm{a}$ \\
\hline & $\mathrm{Fu}$ & & & 6 & 6045,85 & 1184,57 & 16 & a \\
\hline & $\mathrm{Fu}$ & & & 7 & 6138,02 & 1323,50 & 16 & a \\
\hline & $\mathrm{Fu}$ & & & 8 & 5738,94 & 940,70 & 16 & a \\
\hline \multirow[t]{16}{*}{ Korndichte } & So & $M$ & & & 167336,08 & 41067,95 & 64 & $\mathrm{~b}$ \\
\hline & So & $\mathrm{P}$ & & & 222107,36 & 45734,11 & 64 & a \\
\hline & $\mathrm{Di}$ & & 30 & & 174122,37 & 39951,51 & 64 & $\mathrm{~b}$ \\
\hline & $\mathrm{Di}$ & & 60 & & 215321,08 & 46034,16 & 64 & $\mathrm{a}$ \\
\hline & So*Di & $M$ & 30 & & 156534,66 & 44324,33 & 32 & $a$ \\
\hline & So*Di & $M$ & 60 & & 178137,50 & 38248,03 & 32 & $\mathrm{a}$ \\
\hline & So*Di & $\mathrm{P}$ & 30 & & 191710,07 & 34187,93 & 32 & a \\
\hline & So*Di & $P$ & 60 & & 252504,65 & 53326,68 & 32 & a \\
\hline & $\mathrm{Fu}$ & & & 1 & 178781,98 & 32721,95 & 16 & $a$ \\
\hline & $\mathrm{Fu}$ & & & 2 & 178259,73 & 30096,87 & 16 & $a$ \\
\hline & $\mathrm{Fu}$ & & & 3 & 183043,50 & 49323,83 & 16 & $a$ \\
\hline & $\mathrm{Fu}$ & & & 4 & 195360,22 & 40474,35 & 16 & $a$ \\
\hline & $\mathrm{Fu}$ & & & 5 & 207958,69 & 58417,32 & 16 & $a$ \\
\hline & $\mathrm{Fu}$ & & & 6 & 198200,81 & 45877,66 & 16 & $a$ \\
\hline & $\mathrm{Fu}$ & & & 7 & 207518,40 & 53592,45 & 16 & $a$ \\
\hline & $\mathrm{Fu}$ & & & 8 & 208650,44 & 37007,76 & 16 & $a$ \\
\hline \multirow[t]{14}{*}{ Seitentriebe/Pflanze } & $\mathrm{Di}$ & & 30 & & 8,86 & 0,67 & 64 & $a$ \\
\hline & $\mathrm{Di}$ & & 60 & & 7,21 & 0,81 & 64 & $b$ \\
\hline & $\mathrm{So}{ }^{*} \mathrm{Di}$ & $M$ & 30 & & 9,09 & 0,73 & 32 & $a$ \\
\hline & So* $\mathrm{Di}$ & $M$ & 60 & & 7,19 & 0,93 & 32 & $a$ \\
\hline & So* Di & $P$ & 30 & & 8,63 & 0,59 & 32 & $a$ \\
\hline & So* Di & $P$ & 60 & & 7,23 & 0,68 & 32 & $a$ \\
\hline & $\mathrm{Fu}$ & & & 1 & 7,43 & 0,72 & 16 & $\mathrm{~b}$ \\
\hline & $\mathrm{Fu}$ & & & 2 & 8,11 & 0,69 & 16 & $a b$ \\
\hline & $\mathrm{Fu}$ & & & 3 & 8,12 & 1,00 & 16 & $a b$ \\
\hline & $\mathrm{Fu}$ & & & 4 & 8,65 & 0,71 & 16 & $a$ \\
\hline & $\mathrm{Fu}$ & & & 5 & 7,97 & 0,89 & 16 & $a b$ \\
\hline & $\mathrm{Fu}$ & & & 6 & 7,94 & 0,55 & 16 & $a b$ \\
\hline & $\mathrm{Fu}$ & & & 7 & 8,21 & 0,76 & 16 & $a b$ \\
\hline & $\mathrm{Fu}$ & & & 8 & 7,85 & 0,73 & 16 & $a b$ \\
\hline
\end{tabular}




\subsubsection{Versuchsjahr 2012/13}

\section{Kornertrag}

Im Versuchsjahr 2012/13 hatte die Fungizidbehandlung einen signifikanten und die Interaktion aus Sorte und Saatstärke einen nicht signifikanten Einfluss auf den Kornertrag (Tab. 16). Das Ertragsniveau lag ca. 1 t/ha über dem Niveau von 2010/11 und schwankte zwischen 5,15 t/ha und 5,87 t/ha. Die Varianten 4 (5,24 t/ha), 5 (5,47 t/ha) und $6(5,15$ t/ha), reduzierten den Kornertrag signifikant im Vergleich zu den Varianten 1 (5,79 t/ha), 2 $(5,87 \mathrm{t} / \mathrm{ha})$ und 7 (5,81 t/ha). Die Varianten 4 und 6 führten zudem zu einem signifikant niedrigeren Ertrag als die Varianten 3 (5,63 t/ha) und 8 (5,63 t/ha). Bei der Interaktion aus Sorte $x$ Saatstärke lagen die Werte für den Kornertrag zwischen 5,39 t/ha und 5,72 t/ha.

\section{Strohbiomasseertrag}

Der Strohbiomasseertrag wurde signifikant durch die Fungizidbehandlung und nicht signifikant durch die Wechselwirkung aus Sorte und Saatstärke beeinflusst (Tab. 16). Der Strohbiomasseertrag schwankte je nach Behandlung zwischen 5,41 t/ha und 6,48 t/ha. Die Varianten $4(5,41 \mathrm{t} / \mathrm{ha})$ und $6(5,49 \mathrm{t} / \mathrm{ha})$ reduzierten den Strohbiomasseertrag, im Vergleich zu den Varianten 1 (6,29 t/ha), 2 (6,23 t/ha) und 7 (6,48 t/ha), signifikant um ca. $0,7 \mathrm{t} / \mathrm{ha}$ bis $1,0 \mathrm{t} / \mathrm{ha}$. Weiterhin wurde durch Variante $8(5,74 \mathrm{t} / \mathrm{ha}) \mathrm{im}$ Vergleich zu Variante 7 der Strohbiomasseertrag signifikant um ca. 0,7 t/ha verringert. Bei der Interaktion Sorte x Saatstärke variierte der Strohbiomasseertrag zwischen 5,81 t/ha (NK Petrol, 30 Körner/m²) und 6,07 t/ha (NK Petrol, 60 Körner/m²).

\section{Ölgehalt}

Der Ölgehalt wurde von den drei Haupteffekten Sorte, Saatstärke und Fungizidbehandlung signifikant beeinflusst (Tab. 16). Die Interaktion aus Sorte und Saatstärke übte keinen signifikanten Einfluss auf den Ölgehalt aus (Tab. 16). SY Vesuvio erreichte mit 43,28\% einen signifikant höheren Ölgehalt als NK Petrol (42,32\%). Ferner führte eine niedrige Aussaatstärke zu einem signifikant höheren Ölgehalt $(43,02 \%)$ als eine hohe Aussaatstärke (42,57\%). Bei den Fungizidbehandlungen hatte die Variante 1 $(43,11 \%)$ einen signifikant höheren Ölgehalt als die Variante $6(42,41 \%)$. 


\section{Ölertrag}

Der Ölertrag wurde durch die Fungizidbehandlung signifikant und durch die Interaktion Sorte $x$ Saatstärke nicht signifikant beeinflusst (Tab. 16). Die Varianten 4 (2,23 t/ha), 5 $(2,32 \mathrm{t} / \mathrm{ha})$ und $6(2,18 \mathrm{t} / \mathrm{ha})$, reduzierten den Ölertrag signifikant im Vergleich zu den Varianten 1 (2,50 t/ha), 2 (2,53 t/ha) und 7 (2,50 t/ha). Die Varianten 4 und 6 führten zudem zu einem signifikant niedrigeren Ölertrag als die Varianten $3(2,41 \mathrm{t} / \mathrm{ha})$ und 8 $(2,41 \mathrm{t} / \mathrm{ha})$. Bei der Interaktion aus Sorte und Saatstärke lag der Ölertrag zwischen 2,29 t/ha (NK Petrol, $30 \mathrm{Körner} / \mathrm{m}^{2}$ ) und 2,43 t/ha (SY Merlot, $30 \mathrm{Körner} / \mathrm{m}^{2}$ ). Der Vollständigkeit halber wird hier darauf hingewiesen, dass die Interaktion aus Sorte $x$ Fungizidbehandlung und die Interkation aus Saatstärke x Fungizidbehandlung ebenfalls einen signifikanten Effekt auf den Ölertrag hatte (vgl. Tab. 25A im Anhang II, Globaltest). Einzelheiten werden dazu an dieser Stelle nicht näher beschrieben, stattdessen wird auf Tab. 27A im Anhang II verwiesen.

\section{Ernteindex}

Der Ernteindex wurde weder von den drei unabhängigen Haupteffekten Sorte, Saatstärke und Fungizidbehandlung noch von den daraus resultierenden Interaktionen signifikant beeinflusst (vgl. Tab. 16 und Tab. 25A im Anhang II). Bei der Interaktion zwischen Sorte und Saatstärke lagen die Werte zwischen ca. 45,9\% (NK Petrol, $30 \mathrm{Körner} / \mathrm{m}^{2}$ ) und ca. 46,4\% (SY Vesuvio, 30 Körner/m²). Bei den Fungizidapplikationen erzielte Variante 7 mit ca. $45,0 \%$ den niedrigsten und Variante 8 mit 47,2\% den höchsten Ernteindex.

\section{Pflanzen $/ \mathrm{m}^{2}$ im Frühjahr}

Die Anzahl Pflanzen/m² im Frühjahr in $\mathrm{BBCH}$ 51/52 wurde durch die Saatstärke und die Interaktion zwischen Sorte $x$ Saatstärke signifikant und durch die Fungizidbehandlung nicht signifikant beeinflusst (Tab. 16). Wie 2010/11 befanden sich bei einer hohen Saatstärke mit ca. 52 Pflanzen $/ \mathrm{m}^{2}$ signifikant mehr Pflanzen auf einem Quadratmeter als bei einer niedrigen Saatstärke (ca. 30 Pflanzen $/ \mathrm{m}^{2}$ ). Gemittelt über alle Parzellen der niedrigen Saatstärke traten keine Pflanzenverluste über Winter auf. Gemittelt über alle Parzellen der hohen Saatstärke winterten ca. 8 Pflanzen $/ \mathrm{m}^{2}$ aus. Damit traten im Jahr 2012/13 weniger Pflanzenverluste über Winter auf als im Jahr 2010/11. Bei der Sorte NK Petrol als auch bei der Sorte SY Vesuvio wurden bei der niedrigen Saatstärke signifikant weniger Pflanzen pro Quadratmeter in $\mathrm{BBCH} 51 / 52$ gezählt $(\mathrm{NK}$ Petrol = ca. 28 Pflanzen $/ \mathrm{m}^{2}$, SY Vesuvio = ca. 31 Pflanzen $/ \mathrm{m}^{2}$ ) als bei der hohen Saatstärke (NK Petrol = 
ca. 54 Pflanzen $/ \mathrm{m}^{2}$, SY Vesuvio = ca. 49 Pflanzen $/ \mathrm{m}^{2}$ ). Innerhalb einer Saatstärke unterschied sich die Pflanzendichte zwischen den beiden Sorten nicht signifikant.

\section{Schoten/Pflanze}

Der Ertragsfaktor Schoten/Pflanze wurde von der Saatstärke signifikant und von der Interaktion aus Sorte $\mathrm{x}$ Saatstärke sowie der Fungizidbehandlung nicht signifikant beeinflusst (Tab. 16). Bei $30 \mathrm{Körnern} / \mathrm{m}^{2}$ entwickelten sich im Schnitt 222 Schoten/Pflanze. Das waren ungefähr 87 Schoten/Pflanze mehr als bei einer Saatstärke von $60 \mathrm{Körnern} / \mathrm{m}^{2}$. Ähnliche Differenzen in der Anzahl der Schoten/Pflanze traten auch unter dem Einfluss der Sorten bei beiden Aussaatstärken auf. Allerdings waren diese nach dem globalen F-Test (Tab. 25A im Anhang II) nicht signifikant. Bei den verschiedenen Fungizidbehandlungen schwankte die Schotenzahl je Pflanze zwischen ca. 162 (Variante 3) und ca. 197 (Variante 4). Die Zahl der Schoten/Pflanze war im Jahr 2010/11 mit ca. 217 bis 279 Schoten/Pflanze deutlich höher als im Jahr 2012/13 (ca. 162 bis 197 Schoten/Pflanze).

\section{Körner/Schote}

Der Ertragsfaktor Körner/Schote wurde durch die Fungizidbehandlung signifikant und durch die Interaktion aus Sorte x Saatstärke nicht signifikant beeinflusst (Tab. 16). Bei der Variante 2 wurden signifikant mehr Körner/Schote gebildet (ca. 25 Körner/Schote) als bei der Variante 6 (ca. 23 Körner/Schote). Weitere signifikante Unterschiede sind bei den Fungizidvarianten nicht aufgetreten. Bei der Wechselwirkung zwischen Sorte und Saatstärke schwankte die Kornzahl/Schote zwischen ca. 24 Körner/Schote (SY Vesuvio, $60 \mathrm{Körner} / \mathrm{m}^{2}$ ) und ca. $25 \mathrm{Körner} / \mathrm{Schote}$ (SY Vesuvio, $30 \mathrm{Körner} / \mathrm{m}^{2}$ ). Im Vergleich der beiden Untersuchungsjahre wurden in 2010/11 je nach Fungizidvariante 22 bis 23 Körner je Schote und im Jahr 2012/13 23 bis 25 Körner je Schote gebildet.

\section{TKM}

Der Ertragsfaktor TKM wurde durch die Sorte und die Fungizidbehandlung signifikant sowie durch die Interaktion aus Sorte $\mathrm{x}$ Saatstärke nicht signifikant beeinflusst (Tab. 16). Die Sorte SY Vesuvio bildete im Durchschnitt eine höhere TKM (4,65 g) als die Sorte NK Petrol $(4,18 \mathrm{~g})$. Eine ähnliche Differenz zwischen den beiden Sorten konnte auch unter dem Einfluss der Aussaatstärken beobachtet werden. Allerdings waren diese laut globalem F-Test nicht statistisch signifikant (vgl. Tab. 25A im Anhang II). Bei den 
verschiedenen Fungizidbehandlungen lag die TKM zwischen 4,32 g (Variante 6) und 4,47 g (Variante 2 bzw. Variante 7). Dabei reduzierten die Varianten 5 (4,33 g) und 6, im Vergleich zu den Varianten 1 (4,46 g), 2, 7 (4,47 g) und 8 (4,46 g), signifikant die TKM. Im Vergleich der beiden Versuchsjahre war die TKM 2010/11 um ca. $1 \mathrm{~g}$ höher als 2012/13 (2010/11: ca. 5,35 bis $5,50 \mathrm{~g})$.

\section{Schoten $/ \mathrm{m}^{2}$}

Der berechnete Ertragsfaktor Schoten $/ \mathrm{m}^{2}$ wurde von keinem Anbaufaktor signifikant beeinflusst (Tab. 16). Im Jahr 2010/11 schwankte die Schotenzahl $/ \mathrm{m}^{2}$ je nach Fungizidvariante zwischen ca. 7866 und ca. 9275 Schoten $/ \mathrm{m}^{2}$ und im Jahr 2012/13 zwischen ca. 6195 und ca. 7045 Schoten $/ \mathrm{m}^{2}$. Damit wurden im Versuchsjahr 2010/11 deutlich mehr Schoten je Quadratmeter gebildet als im Versuchsjahr 2012/13.

\section{Körner/Pflanze}

Der berechnete Ertragsfaktor Körner/Pflanze wurde von der Saatstärke signifikant und von der Interaktion aus Sorte $\mathrm{x}$ Saatstärke sowie von der Fungizidbehandlung nicht signifikant beeinflusst (Tab. 16). Bei $30 \mathrm{Körnern} / \mathrm{m}^{2}$ wurden signifikant mehr Körner/Pflanze gebildet (ca. 5556 Körner/Pflanze) als bei $60 \mathrm{Körnern} / \mathrm{m}^{2}$ (ca. 3236 Körner/Pflanze). Obwohl signifikante Unterschiede zwischen den Saatstärken bestanden, konnten bei der Wechselwirkung aus Sorte x Saatstärke keine signifikanten Effekte ermittelt werden (vgl. globalen F-Test, Tab. 25A im Anhang II). Bei den verschiedenen Fungizidvarianten waren geringe Differenzen zwischen den Werten für die Kornzahl/Pflanze und verhältnismäßig hohe Standardabweichungen der Grund dafür, warum keine signifikanten Effekte auftraten. Im Jahr 2010/11 variierte die Anzahl Körner/Pflanze bei den Fungizidvarianten zwischen ca. 4995 und 6574 Körner/Pflanze. Im Jahr 2012/13 waren die Werte niedriger. Sie lagen zwischen ca. 4179 und ca. 4769 Körner/Pflanze.

\section{Korndichte}

Die Korndichte wurde wie der Ertragsfaktor Schoten $/ \mathrm{m}^{2}$ von keinem Versuchsfaktor signifikant beeinflusst (vgl. Tab. 16 und Tab. 25A im Anhang II). Bei der Interaktion aus Sorte x Saatstärke schwankten die Werte für die Korndichte zwischen ca. 149.241 (NK Petrol, 30 Körner $/ \mathrm{m}^{2}$ ) und 172.085 (NK Petrol, 60 Körner $/ \mathrm{m}^{2}$ ). Bei den Fungizidvarianten variierte die Korndichte zwischen ca. 151.379 Körnern $/ \mathrm{m}^{2}$ (Variante 6) und 173.038 
Körnern/m² (Variante 7). Im Vergleich der beiden Versuchsjahre war die Korndichte bei den Fungizidvarianten im Jahr 2010/11 deutlich höher (ca. 178.260 bis 208.650 Körner/m²).

\section{Seitentriebe/Pflanze}

Der Parameter Seitentriebe/Pflanze wurde durch die Saatstärke signifikant und durch die Interaktion zwischen Sorte x Saatstärke und die Fungizidbehandlung nicht signifikant beeinflusst (Tab. 16). Bei der niedrigen Saatstärke bildeten die Rapspflanzen ca. 8 Seitentriebe/Pflanze aus. Das waren ca. 2 Seitentriebe/Pflanze mehr als bei der hohen Aussaatstärke. Im Durchschnitt wurde bei beiden Saatstärken ein Seitentrieb je Pflanze weniger entwickelt als im Jahr 2010/11. Bei der Wechselwirkung aus Sorte und Saatstärke variierten die Seitentriebzahlen zwischen ca. 6 und 8 Seitentriebe/Pflanze, wobei die Unterschiede nicht statistisch abgesichert werden konnten. Bei den Fungizidbehandlungen lagen die Seitentriebzahlen bei ca. 7 bis 8 Seitentriebe/Pflanze. 
Tab. 16: Einfluss der Sorte (So), der Saatstärke (Di), der Interaktion zwischen Sorte $x$ Saatstärke (So*Di) und der Fungizidbehandlung (Fu) auf die Ertragsparameter (Kornertrag, Strohbiomasseertrag, Ölgehalt, Ölertrag und Ernteindex) sowie die Ertragsfaktoren (Pflanzen $/ \mathrm{m}^{2} \mathrm{im}$ Frühjahr in BBCH 16/18, Schoten/Pflanze, Körner/Schote, TKM, Schoten/m², Körner/Pflanze und Korndichte), die im Versuchsjahr 2012/13 im Feldversuch in Göttingen untersucht wurden. Mittelwerte, die mit unterschiedlichen Buchstaben kennzeichnet sind, unterscheiden sich signifikant (Tukey-Test, $p \leq 0,05$ ). Dargestellt sind die Mittelwerte, die Standardabweichung (SD), errechnet aus den Residuen des gegebenen Modells, und die Anzahl der Werte (n), die in die jeweilige Berechnung eingegangen sind. Kursive Buchstaben stellen Unterschiede zwischen den Mittelwerten auf Basis des Globaltests (F-Test, $p \leq 0,05)$ und nicht des Tukey-Tests dar. Für den Effekt der Sorte bzw. der Saatstärke wurden nur signifikante Ergebnisse wiedergegeben. Für die Interaktion Sorte $\times$ Saatstärke und die Fungizidbehandlung wurden sowohl signifikante als auch nicht signifikante Ergebnisse aufgeführt. Grundlage dieser Tabelle sind die Tabellen 25A und 27A im Anhang II aus denen hervorgeht, welche Effekte einen signifikanten Einfluss hatten ( $F-$ Test, $p \leq 0,05$; Tab. 25A) und wie dieser sich auf den Mittelwertvergleich auswirkte (Tab. 27A). Die nicht signifikanten Ergebnisse wurden direkt aus einer Excel-Tabelle übernommen, in der die kompletten Ergebnisse der Varianzanalyse gespeichert wurden. [So = Sorte ( $P=$ NK Petrol, $V=S Y$ Vesuvio); $\mathrm{Di}=$ Saatstärke $\left(30 \mathrm{bzw}\right.$. $\left.60 \mathrm{Körner} / \mathrm{m}^{2}\right) ; \mathrm{Fu}=$ Fungizid $(1=$ unbehandelte Kontrolle, $2=0,5 \mathrm{l} / \mathrm{ha}$ Toprex $^{\circledR}$ (Difenoconazol + Paclobutrazol) in $\mathrm{BBCH} 33 / 35,3=0,5 \mathrm{I} /$ ha Toprex ${ }^{\circledR}$ in BBCH 14 und $33 / 35,4=0,5 \mathrm{l} / \mathrm{ha}$ Toprex ${ }^{\circledR}$ in BBCH 14, 16 und 33/35, $5=0,5 \mathrm{l} / \mathrm{ha}$ Toprex ${ }^{\circledR}$ in BBCH 14, 33/35 und $53 / 55,6=0,5 \mathrm{l} /$ ha Toprex $^{\circledR}$ in BBCH 14, 16, 33/35 und 53/55, $7=0,5 \mathrm{l} /$ ha Toprex $^{\circledR}$ in BBCH 14, $8=$ praxisüblich $=0,5 \mathrm{l} / \mathrm{ha} \operatorname{Carax}^{\circledR}$ (Mepiquatchlorid + Metconazol) in $\mathrm{BBCH} 14$ und 33/35; alle Varianten erhielten in $\mathrm{BBCH} 651 \mathrm{l} /$ ha Ortiva $^{\circledR}$ (Azoxystrobin)].

\begin{tabular}{|c|c|c|c|c|c|c|c|c|}
\hline Parameter & Effekt & So & Di & $\mathrm{Fu}$ & Mittelwert & SD & $\mathbf{n}$ & Buchstaben \\
\hline \multirow[t]{12}{*}{ Kornertrag [t/ha] } & So*Di & $P$ & 30 & & 5,39 & 0,19 & 32 & $\mathrm{a}$ \\
\hline & So*Di & $P$ & 60 & & 5,72 & 0,21 & 32 & a \\
\hline & So*Di & $\mathrm{V}$ & 30 & & 5,57 & 0,25 & 32 & a \\
\hline & So* $\mathrm{Di}$ & V & 60 & & 5,61 & 0,22 & 32 & a \\
\hline & $\mathrm{Fu}$ & & & 1 & 5,79 & 0,26 & 16 & a \\
\hline & $\mathrm{Fu}$ & & & 2 & 5,87 & 0,19 & 16 & a \\
\hline & $\mathrm{Fu}$ & & & 3 & 5,63 & 0,21 & 16 & $a b$ \\
\hline & $\mathrm{Fu}$ & & & 4 & 5,24 & 0,23 & 16 & $\mathrm{~cd}$ \\
\hline & $\mathrm{Fu}$ & & & 5 & 5,47 & 0,15 & 16 & $\mathrm{bc}$ \\
\hline & $\mathrm{Fu}$ & & & 6 & 5,15 & 0,27 & 16 & d \\
\hline & $\mathrm{Fu}$ & & & 7 & 5,81 & 0,25 & 16 & a \\
\hline & Fu & & & 8 & 5,63 & 0,19 & 16 & $a b$ \\
\hline Strohbiomasseertrag & So* Di & $\mathrm{P}$ & 30 & & 5,81 & 0,48 & 32 & a \\
\hline \multirow[t]{3}{*}{ [t/ha] } & So* Di & $P$ & 60 & & 6,07 & 0,53 & 32 & a \\
\hline & So* Di & $\mathrm{V}$ & 30 & & 5,86 & 0,38 & 32 & a \\
\hline & So* $\mathrm{Di}$ & V & 60 & & 6,06 & 0,55 & 32 & a \\
\hline
\end{tabular}




\begin{tabular}{|c|c|c|c|c|c|c|c|c|}
\hline & $\mathrm{Fu}$ & & & 1 & 6,29 & 0,48 & 16 & $a b$ \\
\hline & $\mathrm{Fu}$ & & & 2 & 6,23 & 0,41 & 16 & $a b$ \\
\hline & $\mathrm{Fu}$ & & & 3 & 6,04 & 0,47 & 16 & $\mathrm{ac}$ \\
\hline & $\mathrm{Fu}$ & & & 4 & 5,41 & 0,44 & 16 & $c$ \\
\hline & $\mathrm{Fu}$ & & & 5 & 5,94 & 0,36 & 16 & $\mathrm{ac}$ \\
\hline & $\mathrm{Fu}$ & & & 6 & 5,49 & 0,69 & 16 & $c$ \\
\hline & $\mathrm{Fu}$ & & & 7 & 6,48 & 0,55 & 16 & $a$ \\
\hline & $\mathrm{Fu}$ & & & 8 & 5,74 & 0,50 & 16 & $\mathrm{bc}$ \\
\hline \multirow[t]{16}{*}{ Ölgehalt [\%] } & So & $P$ & & & 42,32 & 0,59 & 64 & $b$ \\
\hline & So & V & & & 43,28 & 0,57 & 64 & $a$ \\
\hline & $\mathrm{Di}$ & & 30 & & 43,02 & 0,59 & 64 & $a$ \\
\hline & $\mathrm{Di}$ & & 60 & & 42,57 & 0,57 & 64 & $b$ \\
\hline & $\mathrm{So}^{*} \mathrm{Di}$ & $P$ & 30 & & 42,48 & 0,58 & 32 & a \\
\hline & $\mathrm{So}^{*} \mathrm{Di}$ & $P$ & 60 & & 42,16 & 0,61 & 32 & $a$ \\
\hline & $\mathrm{So}^{*} \mathrm{Di}$ & $\mathrm{V}$ & 30 & & 43,57 & 0,60 & 32 & $a$ \\
\hline & So* $\mathrm{Di}$ & V & 60 & & 42,98 & 0,54 & 32 & $a$ \\
\hline & $\mathrm{Fu}$ & & & 1 & 43,11 & 0,43 & 16 & $a$ \\
\hline & $\mathrm{Fu}$ & & & 2 & 43,06 & 0,59 & 16 & $a b$ \\
\hline & $\mathrm{Fu}$ & & & 3 & 42,79 & 0,75 & 16 & $a b$ \\
\hline & $\mathrm{Fu}$ & & & 4 & 42,62 & 0,75 & 16 & $a b$ \\
\hline & $\mathrm{Fu}$ & & & 5 & 42,43 & 0,35 & 16 & $a b$ \\
\hline & $\mathrm{Fu}$ & & & 6 & 42,41 & 0,49 & 16 & $b$ \\
\hline & $\mathrm{Fu}$ & & & 7 & 43,06 & 0,64 & 16 & $a b$ \\
\hline & $\mathrm{Fu}$ & & & 8 & 42,89 & 0,62 & 16 & $a b$ \\
\hline \multirow[t]{12}{*}{ Ölertrag [t/ha] } & $\mathrm{So}^{*} \mathrm{Di}$ & $P$ & 30 & & 2,29 & 0,08 & 32 & $a$ \\
\hline & So* $\mathrm{Di}$ & $P$ & 60 & & 2,41 & 0,09 & 32 & $\mathrm{a}$ \\
\hline & $\mathrm{So}^{*} \mathrm{Di}$ & V & 30 & & 2,43 & 0,11 & 32 & $\mathrm{a}$ \\
\hline & So* $\mathrm{Di}$ & V & 60 & & 2,41 & 0,10 & 32 & $\mathrm{a}$ \\
\hline & $\mathrm{Fu}$ & & & 1 & 2,50 & 0,11 & 16 & $\mathrm{a}$ \\
\hline & $\mathrm{Fu}$ & & & 2 & 2,53 & 0,10 & 16 & $\mathrm{a}$ \\
\hline & $\mathrm{Fu}$ & & & 3 & 2,41 & 0,10 & 16 & $a b$ \\
\hline & $\mathrm{Fu}$ & & & 4 & 2,23 & 0,08 & 16 & $\mathrm{~cd}$ \\
\hline & $\mathrm{Fu}$ & & & 5 & 2,32 & 0,07 & 16 & $\mathrm{bc}$ \\
\hline & $\mathrm{Fu}$ & & & 6 & 2,18 & 0,11 & 16 & $d$ \\
\hline & $\mathrm{Fu}$ & & & 7 & 2,50 & 0,10 & 16 & $\mathrm{a}$ \\
\hline & $\mathrm{Fu}$ & & & 8 & 2,41 & 0,10 & 16 & $a b$ \\
\hline \multirow[t]{4}{*}{ Ernteindex [\%] } & So* $\mathrm{Di}$ & $\mathrm{P}$ & 30 & & 45,87 & 1,85 & 32 & a \\
\hline & So* $\mathrm{Di}$ & $\mathrm{P}$ & 60 & & 46,27 & 1,89 & 32 & a \\
\hline & So* $\mathrm{Di}$ & V & 30 & & 46,41 & 1,51 & 32 & $\mathrm{a}$ \\
\hline & So*Di & $\mathrm{V}$ & 60 & & 45,94 & 1,96 & 32 & $a$ \\
\hline
\end{tabular}




\begin{tabular}{|c|c|c|c|c|c|c|c|c|}
\hline & \multirow{2}{*}{\multicolumn{3}{|c|}{$\mathrm{Fu}$}} & & & & & \\
\hline & & & & 1 & 45,74 & 1,90 & 16 & a \\
\hline & $\mathrm{Fu}$ & & & 2 & 46,21 & 1,66 & 16 & $a$ \\
\hline & $\mathrm{Fu}$ & & & 3 & 45,99 & 1,58 & 16 & $a$ \\
\hline & $\mathrm{Fu}$ & & & 4 & 46,90 & 2,17 & 16 & $a$ \\
\hline & $\mathrm{Fu}$ & & & 5 & 45,69 & 1,31 & 16 & $a$ \\
\hline & $\mathrm{Fu}$ & & & 6 & 46,28 & 1,98 & 16 & $a$ \\
\hline & $\mathrm{Fu}$ & & & 7 & 44,97 & 1,87 & 16 & $a$ \\
\hline & $\mathrm{Fu}$ & & & 8 & 47,20 & 2,19 & 16 & $a$ \\
\hline Pflanzen $/ \mathrm{m}^{2}$ & $\mathrm{Di}$ & & 30 & & 29,63 & 4,88 & 64 & $\mathrm{~b}$ \\
\hline \multirow[t]{13}{*}{ im Frühjahr } & $\mathrm{Di}$ & & 60 & & 51,73 & 5,99 & 64 & $a$ \\
\hline & $\mathrm{So}^{*} \mathrm{Di}$ & $\mathrm{P}$ & 30 & & 27,64 & 4,82 & 32 & $\mathrm{~b}$ \\
\hline & $\mathrm{So}^{*} \mathrm{Di}$ & $P$ & 60 & & 54,03 & 5,69 & 32 & $a$ \\
\hline & So* $\mathrm{Di}$ & $\mathrm{V}$ & 30 & & 31,43 & 5,02 & 32 & $\mathrm{~b}$ \\
\hline & $\mathrm{So}^{*} \mathrm{Di}$ & V & 60 & & 49,44 & 6,37 & 32 & $a$ \\
\hline & $\mathrm{Fu}$ & & & 1 & 42,32 & 3,94 & 16 & a \\
\hline & $\mathrm{Fu}$ & & & 2 & 40,25 & 5,09 & 16 & $a$ \\
\hline & $\mathrm{Fu}$ & & & 3 & 39,94 & 5,25 & 16 & $a$ \\
\hline & $\mathrm{Fu}$ & & & 4 & 37,75 & 6,08 & 16 & $a$ \\
\hline & $\mathrm{Fu}$ & & & 5 & 42,19 & 6,04 & 16 & $a$ \\
\hline & $\mathrm{Fu}$ & & & 6 & 38,44 & 5,83 & 16 & $a$ \\
\hline & $\mathrm{Fu}$ & & & 7 & 42,06 & 7,34 & 16 & $a$ \\
\hline & $\mathrm{Fu}$ & & & 8 & 42,13 & 4,35 & 16 & $a$ \\
\hline \multirow[t]{14}{*}{ Schoten/Pflanze } & $\mathrm{Di}$ & & 30 & & 222,13 & 38,47 & 64 & $a$ \\
\hline & $\mathrm{Di}$ & & 60 & & 135,35 & 27,73 & 64 & b \\
\hline & $\mathrm{So}^{*} \mathrm{Di}$ & $P$ & 30 & & 224,59 & 35,62 & 32 & $a$ \\
\hline & So* $\mathrm{Di}$ & $P$ & 60 & & 132,13 & 26,82 & 32 & $a$ \\
\hline & So* $\mathrm{Di}$ & V & 30 & & 219,67 & 41,84 & 32 & $a$ \\
\hline & $\mathrm{So}^{*} \mathrm{Di}$ & $\mathrm{V}$ & 60 & & 138,58 & 29,03 & 32 & $a$ \\
\hline & $\mathrm{Fu}$ & & & 1 & 176,04 & 25,45 & 16 & $a$ \\
\hline & $\mathrm{Fu}$ & & & 2 & 188,29 & 32,63 & 16 & $a$ \\
\hline & $\mathrm{Fu}$ & & & 3 & 161,80 & 36,26 & 16 & $a$ \\
\hline & $\mathrm{Fu}$ & & & 4 & 196,93 & 31,51 & 16 & $a$ \\
\hline & $\mathrm{Fu}$ & & & 5 & 179,06 & 27,26 & 16 & $a$ \\
\hline & $\mathrm{Fu}$ & & & 6 & 180,63 & 40,94 & 16 & $a$ \\
\hline & $\mathrm{Fu}$ & & & 7 & 179,01 & 48,56 & 16 & $a$ \\
\hline & $\mathrm{Fu}$ & & & 8 & 168,17 & 19,43 & 16 & $a$ \\
\hline \multirow[t]{4}{*}{ Körner/Schote } & $\mathrm{So}^{*} \mathrm{Di}$ & $P$ & 30 & & 24,45 & 1,22 & 32 & $a$ \\
\hline & $\mathrm{So}^{*} \mathrm{Di}$ & $\mathrm{P}$ & 60 & & 24,13 & 0,85 & 32 & $a$ \\
\hline & So* $\mathrm{Di}$ & V & 30 & & 24,65 & 1,52 & 32 & $a$ \\
\hline & $\mathrm{So}^{*} \mathrm{Di}$ & V & 60 & & 23,70 & 1,17 & 32 & $a$ \\
\hline
\end{tabular}




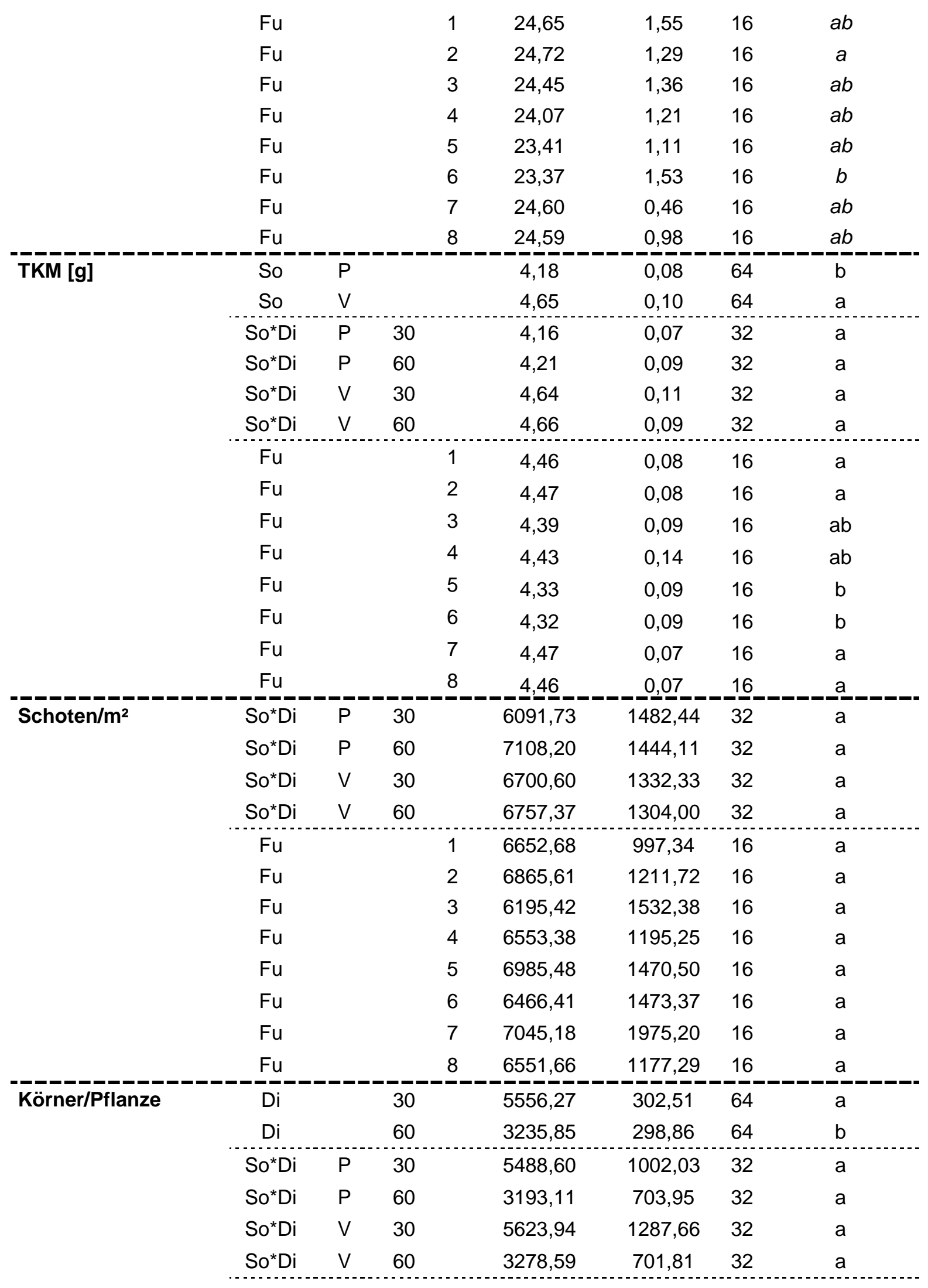




\begin{tabular}{|c|c|c|c|c|c|c|c|c|}
\hline & $\mathrm{Fu}$ & & & 1 & 4371,86 & 703,47 & 16 & a \\
\hline & $\mathrm{Fu}$ & & & 2 & 4679,70 & 704,94 & 16 & a \\
\hline & $\mathrm{Fu}$ & & & 3 & 4333,46 & 1447,37 & 16 & $\mathrm{a}$ \\
\hline & $\mathrm{Fu}$ & & & 4 & 4768,61 & 879,36 & 16 & a \\
\hline & $\mathrm{Fu}$ & & & 5 & 4212,15 & 636,55 & 16 & a \\
\hline & $\mathrm{Fu}$ & & & 6 & 4226,54 & 1000,81 & 16 & a \\
\hline & $\mathrm{Fu}$ & & & 7 & 4397,38 & 1328,76 & 16 & a \\
\hline & $\mathrm{Fu}$ & & & 8 & 4178,75 & 506,61 & 16 & a \\
\hline \multirow[t]{12}{*}{ Korndichte } & So*Di & $P$ & 30 & & 149240,57 & 37873,61 & 32 & a \\
\hline & So*Di & $P$ & 60 & & 172084,66 & 36773,06 & 32 & a \\
\hline & So*Di & V & 30 & & 165931,14 & 35276,41 & 32 & a \\
\hline & So* $\mathrm{Di}$ & V & 60 & & 160163,34 & 33812,72 & 32 & a \\
\hline & $\mathrm{Fu}$ & & & 1 & 164274,25 & 28190,24 & 16 & a \\
\hline & $\mathrm{Fu}$ & & & 2 & 169032,10 & 28591,98 & 16 & a \\
\hline & $\mathrm{Fu}$ & & & 3 & 154205,80 & 43319,91 & 16 & a \\
\hline & $\mathrm{Fu}$ & & & 4 & 158432,87 & 33621,00 & 16 & a \\
\hline & $\mathrm{Fu}$ & & & 5 & 163627,53 & 34687,12 & 16 & a \\
\hline & $\mathrm{Fu}$ & & & 6 & 151378,85 & 38853,53 & 16 & a \\
\hline & $\mathrm{Fu}$ & & & 7 & 173038,09 & 48040,36 & 16 & a \\
\hline & $\mathrm{Fu}$ & & & 8 & 160849,94 & 30433,02 & 16 & a \\
\hline \multirow[t]{14}{*}{ Seitentriebe/Pflanze } & $\mathrm{Di}$ & & 30 & & 7,86 & 0,94 & 64 & a \\
\hline & $\mathrm{Di}$ & & 60 & & 6,20 & 0,82 & 64 & b \\
\hline & So* Di & $\mathrm{P}$ & 30 & & 7,99 & 1,07 & 32 & a \\
\hline & So*Di & $P$ & 60 & & 6,31 & 0,83 & 32 & a \\
\hline & So*Di & V & 30 & & 7,72 & 0,80 & 32 & a \\
\hline & So*Di & $\mathrm{V}$ & 60 & & 6,10 & 0,82 & 32 & a \\
\hline & $\mathrm{Fu}$ & & & 1 & 6,79 & 0,82 & 16 & a \\
\hline & $\mathrm{Fu}$ & & & 2 & 6,96 & 0,76 & 16 & a \\
\hline & $\mathrm{Fu}$ & & & 3 & 6,78 & 1,00 & 16 & a \\
\hline & $\mathrm{Fu}$ & & & 4 & 7,64 & 1,05 & 16 & a \\
\hline & $\mathrm{Fu}$ & & & 5 & 7,26 & 0,88 & 16 & a \\
\hline & $\mathrm{Fu}$ & & & 6 & 7,47 & 0,96 & 16 & a \\
\hline & $\mathrm{Fu}$ & & & 7 & 6,74 & 1,01 & 16 & a \\
\hline & $\mathrm{Fu}$ & & & 8 & 6,61 & 0,58 & 16 & a \\
\hline
\end{tabular}




\subsection{Einfluss der Anbaufaktoren Sorte, Saatstärke und Fungizidbehandlung auf Befallsparameter}

In diesem Kapitel werden zur Grundcharakterisierung der beiden Versuchsjahre die Ergebnisse von dreifaktoriellen Varianzanalysen vorgestellt, die die Effekte der drei unabhängigen Versuchsfaktoren Sorte, Saatstärke und Fungizidbehandlung auf die Krankheitsparameter beschreiben. In Anlehnung an Kapitel 3.4 werden im Folgenden, getrennt nach den Versuchsjahren 2010/11 und 2012/13, die signifikanten Effekte von Sorte und Saatstärke sowie die signifikanten und nicht signifikanten Effekte von der Interaktion aus Sorte $x$ Saatstärke und von der Fungizidbehandlung für die Befallsparameter vorgestellt. Die nicht signifikanten Effekte wurden der Vollständigkeit halber angegeben und dienen einer besseren Einordnung der Ergebnisse. Sie wurden direkt aus einer Excel-Tabelle übernommen, in der die kompletten Ergebnisse der Varianzanalysen gespeichert wurden.

$\mathrm{Zu}$ den Befallsparametern zählen die $\mathrm{BH}$ und der BW mit der Wurzelhals- und Stängelfäule ( $P$. lingam) am Wurzelhals und an Laubblättern im Herbst sowie am Wurzelhals und am unteren Stängel im Frühjahr. Die BH mit der Kleinen Kohlfliege (D. radicum) im Herbst und Frühjahr stellt zwei weitere Befallsparameter dar.

\subsubsection{Versuchsjahr 2010/11}

\section{BH mit der Wurzelhals- und Stängelfäule an Laubblättern im Herbst}

Die BH mit der Wurzelhals- und Stängelfäule an Laubblättern im Herbst in BBCH 16/18 wurde signifikant durch die Interaktion Sorte $\mathrm{x}$ Saatstärke und die Fungizidbehandlung beeinflusst (Tab. 17). Die Pflanzen der Sorte NK Petrol waren im Herbst in BBCH 16/18 bei der niedrigen Saatstärke häufiger $(\mathrm{BH}=80,31 \%)$ mit der Wurzelhals- und Stängelfäule an Laubblättern befallen als bei der hohen Saatstärke (BH $=70,94 \%)$. Bei SY Merlot traten bei einer niedrigen $(\mathrm{BH}=72,19 \%)$ bzw. hohen $(\mathrm{BH}=75,00 \%)$ Saatstärke keine signifikanten Unterschiede in Bezug auf die $\mathrm{BH}$ mit der Wurzelhals und Stängelfäule an Laubblättern im Herbst in BBCH 16/18 auf. Weiterhin waren die Sorten zu dem angegebenen Wachstumsstadium nicht signifikant verschieden mit der Wurzelhals- und Stängelfäule befallen. Bei den Fungizidbehandlungen stellte sich heraus, dass die Variante $4(\mathrm{BH}=52,81 \%)$ die $\mathrm{BH}$ mit der Wurzelhals- und Stängelfäule an Laubblättern im Herbst in $\mathrm{BBCH} 16 / 18 \mathrm{im}$ Vergleich zu allen anderen Varianten [V1 $(\mathrm{BH}=82,81 \%)$; V2 $(\mathrm{BH}=86,88 \%) ; \mathrm{V3}(\mathrm{BH}=69,69 \%) ; \mathrm{V} 5(\mathrm{BH}=75,31 \%) ; \mathrm{V} 6(\mathrm{BH}=73,75 \%) ; \mathrm{V} 7(\mathrm{BH}=$ 
68,13\%); V8 $(\mathrm{BH}=87,50 \%)]$ signifikant reduzierte. Weiterhin verringerten die Varianten 3, 6 und 7 die $\mathrm{BH}$ mit der Wurzelhals- und Stängelfäule an Laubblättern signifikant im Vergleich zur Variante 8. Außerdem reduzierte die Variante 7 signifikant die $\mathrm{BH}$ mit der Wurzelhals- und Stängelfäule an Laubblättern im Vergleich zur Variante 1 und 2. Die Variante 3 reduzierte die $\mathrm{BH}$ mit der Wurzelhals- und Stängelfäule an Laubblättern signifikant im Vergleich zur Variante 2. Der Vollständigkeit halber sei darauf hingewiesen, dass die Interaktion aus Sorte x Fungizidbehandlung auch einen signifikanten Einfluss auf die BH mit der Wurzelhals- und Stängelfäule an Laubblättern im Herbst hatte (vgl. Tab. 25A im Anhang II). Einzelheiten werden dazu an dieser Stelle nicht näher beschrieben, stattdessen wird auf Tab. 26A im Anhang II verwiesen.

\section{BW mit der Wurzelhals- und Stängelfäule an Laubblättern im Herbst}

Der BW mit der Wurzelhals- und Stängelfäule an Laubblättern im Herbst in BBCH 16/18 wurde signifikant durch die Fungizidbehandlung und nicht signifikant durch die Interaktion zwischen Sorte und Saatstärke beeinflusst (Tab. 17). Die Variante 4 (BW =0,78) reduzierte den BW mit der Wurzelhals- und Stängelfäule an Laubblättern im Herbst in $\mathrm{BBCH}$ 16/18 im Vergleich zu allen anderen Varianten [V1 (BW = 3,60); V2 (BW = 4,11); V3 (BW = 2,04); V5 (BW = 2,29); V6 (BW = 1,93); V7 (BW = 1,91); V8 (BW = 3,58)] signifikant am stärksten. Dahinter folgten die Varianten 3, 5, 6 und 7, die im Vergleich zu den Varianten 1, 2 und 8, den BW mit der Wurzelhals- und Stängelfäule an Laubblättern im Herbst signifikant verringerten. Bei der Interaktion aus Sorte und Saatstärke schwankten die BW zwischen 2,35 (NK Petrol, 60 Körner/m²) und 2,92 (NK Petrol, 30 Körner $/ \mathrm{m}^{2}$ ). Auch hier sei der Vollständigkeit halber darauf hingewiesen, dass die Interaktion aus Sorte $x$ Fungizidbehandlung und die Interaktion aus Saatstärke $x$ Fungizidbehandlung jeweils einen signifikanten Effekt auf den BW mit der Wurzelhalsund Stängelfäule an Laubblättern im Herbst ausübten (vgl. Tab. 25A im Anhang II). Einzelheiten werden dazu an dieser Stelle nicht näher beschrieben, stattdessen wird auf Tab. 26A im Anhang II verwiesen.

\section{BH und BW mit der Wurzelhals- und Stängelfäule am Wurzelhals im Herbst}

Da die $\mathrm{BH}$ und der BW mit der Wurzelhals- und Stängelfäule am Wurzelhals im Herbst in $\mathrm{BBCH}$ 16/18 unabhängig von den Versuchsfaktoren insgesamt sehr niedrig waren, konnten keine signifikanten Effekte der drei Versuchsfaktoren statistisch abgesichert werden (vgl. Tab. 17 und Tab. 25A im Anhang II). Bei der Interaktion Sorte x Saatstärke schwankten die BH bzw. der BW zwischen 1,56\% bzw. 1,07 (SY Merlot, 30 Körner/m²) 
und 2,81\% bzw. 1,12 (NK Petrol, $60 \mathrm{Körner} / \mathrm{m}^{2}$ ). Bei den verschiedenen Fungizidbehandlungen pendelte die $\mathrm{BH}$ bzw. der BW zwischen 0,94\% bzw. 1,03 (Variante 1) und 3,13\% bzw. 1,13 (Variante 6). Bei dem zu Grunde gelegten Boniturschema stellte ein BW von 1 kein Befall dar.

\section{BH mit der Wurzelhals- und Stängelfäule am unteren Stängel im Frühjahr}

Die BH mit der Wurzelhals- und Stängelfäule am unteren Stängel im Frühjahr in BBCH 83/84 wurde signifikant durch die Sorte, die Saatstärke, die Interaktion aus Sorte und Saatstärke und die Fungizidbehandlung beeinflusst (Tab. 17). Rapspflanzen der Sorte SY Merlot waren häufiger im Frühjahr in $\mathrm{BBCH}$ 83/84 am unteren Stängel mit der Wurzelhalsund Stängelfäule befallen $(\mathrm{BH}=93,94 \%)$ als Rapspflanzen der Sorte NK Petrol $(\mathrm{BH}=$ 80,25\%). Des Weiteren waren die Pflanzen öfter bei einer Saatstärke von 30 Körnern $/ \mathrm{m}^{2}$ mit der Wurzelhals- und Stängelfäule am unteren Stängel im Frühjahr in BBCH 83/84 befallen $(\mathrm{BH}=92,13 \%)$ als bei einer Saatstärke von $60 \mathrm{Körnern} / \mathrm{m}^{2}(82,06 \%)$. Für die Interaktion zwischen Sorte und Saatstärke konnte nachgewiesen werden, dass NK Petrol bei einer Saatstärke von 60 Körnern $/ \mathrm{m}^{2}$ mit $71,00 \%$ eine signifikant geringere $\mathrm{BH}$ mit der Wurzelhals- und Stängelfäule am unteren Stängel im Frühjahr in BBCH 83/84 aufwies, als bei einer Saatstärke von $30 \mathrm{Körnern} / \mathrm{m}^{2}(\mathrm{BH}=89,5 \%)$ und als SY Merlot bei einer Saatstärke von 30 bzw. 60 Körnern $/ \mathrm{m}^{2}$ (BH =94,75\% bzw. 93,13\%). Bei den Fungizidbehandlungen variierte die $\mathrm{BH}$ mit der Wurzelhals- und Stängelfäule am unteren Stängel im Frühjahr in BBCH 83/84 zwischen 78,43\% (Variante 4) und 97,29 \% (Variante 8). Die Varianten 4, $6(\mathrm{BH}=82,14 \%)$ und $7(\mathrm{BH}=84,96 \%)$ führten im Vergleich zur Variante $1(\mathrm{BH}=94,05 \%)$ und 8 zu einer signifikant reduzierten $\mathrm{BH}$ mit der Wurzelhalsund Stängelfäule am unteren Stängel im Frühjahr in $\mathrm{BBCH}$ 83/84. Weitere signifikante Unterschiede bestanden zwischen den Varianten 4 und 2 ( $\mathrm{BH}=87,09 \%)$, wobei Variante 4 geringer befallen war als Variante 2. Weiterhin hatte die Interaktion aus Sorte und Fungizidbehandlung einen signifikanten Einfluss auf die $\mathrm{BH}$ mit der Wurzelhals- und Stängelfäule am unteren Stängel im Frühjahr (vgl. Tab. 25A im Anhang II, Globaltest). Einzelheiten werden dazu an dieser Stelle nicht näher beschrieben, stattdessen wird auf Tab. 26A im Anhang II verwiesen.

\section{BW mit der Wurzelhals- und Stängelfäule am unteren Stängel im Frühjahr}

Der BW mit der Wurzelhals- und Stängelfäule am unteren Stängel im Frühjahr in BBCH 83/84 wurde signifikant durch die Fungizidbehandlung und nicht signifikant durch die Interaktion aus Sorte und Saatstärke beeinflusst (Tab. 17). Bei den Fungizidvarianten lag 
der BW mit der Wurzelhals- und Stängelfäule am unteren Stängel im Frühjahr in BBCH 83/84 zwischen 2,82 (Variante 4) und 4,16 (Variante 8). Durch die Varianten 2 (BW = 3,16), $3(\mathrm{BW}=3,14), 4,5(\mathrm{BW}=3,10), 6(\mathrm{BW}=3,00)$ und $7(\mathrm{BW}=3,26)$ konnte der BW mit der Wurzelhals- und Stängelfäule am unteren Stängel im Frühjahr in $\mathrm{BBCH} 83 / 84$, im Vergleich zu den Varianten $1(B W=4,10)$ und 8 , signifikant reduziert werden. Bei der Interaktion Sorte $x$ Saatstärke schwankte der BW mit der Wurzelhals- und Stängelfäule am unteren Stängel im Frühjahr zwischen 3,15 (NK Petrol, 60 Körner/m²) und 3,73 (NK Petrol, $30 \mathrm{Körner} / \mathrm{m}^{2}$ ). Wie bei anderen Befallsparametern zuvor, wird auch hier der Vollständigkeit halber darauf hingewiesen, dass die Wechselwirkung aus Saatstärke $\mathrm{x}$ Fungizidbehandlung ebenfalls den BW mit der Wurzelhals- und Stängelfäule am unteren Stängel im Frühjahr signifikant beeinflusste (vgl. Tab. 25A im Anhang II, Globaltest). Einzelheiten werden dazu an dieser Stelle nicht näher beschrieben, stattdessen wird auf Tab. 26A im Anhang II verwiesen.

\section{BH mit der Wurzelhals- und Stängelfäule am Wurzelhals im Frühjahr}

Da die $\mathrm{BH}$ mit der Wurzelhals- und Stängelfäule am Wurzelhals im Frühjahr in $\mathrm{BBCH}$ 83/84 unabhängig von den Versuchsfaktoren insgesamt sehr hoch war, konnten keine signifikanten Effekte der drei Versuchsfaktoren statistisch abgesichert werden (vgl. Tab. 17 und Tab. 25A im Anhang II). Bei der Interaktion aus Sorte und Saatstärke schwankte die BH zwischen 92,50\% (NK Petrol, 60 Körner/m²) und 100\% (SY Merlot, 30 Körner $/ \mathrm{m}^{2}$ ). Bei den verschiedenen Fungizidbehandlungen pendelte die $\mathrm{BH}$ zwischen 96,65\% (Variante 7) und 99,65\% (Variante 8).

\section{BW mit der Wurzelhals- und Stängelfäule am Wurzelhals im Frühjahr}

Der BW mit der Wurzelhals- und Stängelfäule am Wurzelhals im Frühjahr in BBCH 83/84 wurde signifikant durch die Saatstärke, die Interaktion zwischen Sorte x Saatstärke und die Fungizidbehandlung beeinflusst (Tab. 17). In den Parzellen mit der niedrigen Saatstärke war der BW mit der Wurzelhals- und Stängelfäule am Wurzelhals im Frühjahr in $\mathrm{BBCH} 83 / 84$ signifikant höher $(\mathrm{BW}=5,53)$ als in den Parzellen mit der hohen Saatstärke $(B W=4,30)$. Für die Wechselwirkung aus Sorte $x$ Saatstärke konnte festgestellt werden, dass SY Merlot und NK Petrol jeweils bei einer Saatstärke von 30 Körnern $/ \mathrm{m}^{2}$ stärker mit der Wurzelhals- und Stängelfäule am Wurzelhals im Frühjahr in $\mathrm{BBCH} 83 / 84$ befallen waren (BW $=5,27$ bzw. 5,79) als bei einer Saatstärke von 60 Körnern $/ \mathrm{m}^{2}$ (BW = 4,58 bzW. 4,02). SY Merlot wies bei der hohen Saatstärke einen höheren BW (BW = 4,58) auf als NK Petrol $(B W=4,02)$ und NK Petrol war bei der 
niedrigen Saatstärke stärker befallen $(B W=5,79)$ als SY Merlot $(B W=5,27)$. Allerdings waren diese Unterschiede nicht signifikant verschieden. Im Vergleich zu Variante 1 (BW = $5,32)$ und $8(B W=5,38)$ reduzierten die Fungizidvarianten $3(B W=4,70), 4(B W=4,49)$, $6(B W=4,62)$ und $7(B W=4,73)$ signifikant den BW mit der Wurzelhals- und Stängelfäule am Wurzelhals im Frühjahr in $\mathrm{BBCH}$ 83/84. Weiterhin war der BW mit der Wurzelhalsund Stängelfäule am Wurzelhals im Frühjahr in den Fungizidvarianten 4 und 6 signifikant geringer als in der Fungizidvariante $2(B W=5,15)$.

\section{BH mit der Kleinen Kohlfliege im Herbst}

Die BH mit der Kleinen Kohlfliege im Herbst in BBCH 16/18 wurde durch die Fungizidbehandlung signifikant und durch die Interaktion aus Sorte und Saatstärke nicht signifikant beeinflusst (Tab. 17). Die Fungizidvariante 4 war signifikant häufiger $(\mathrm{BH}=$ 9,60\%) mit der Kleinen Kohlfliege im Herbst in $\mathrm{BBCH}$ 16/18 befallen als die Varianten 3 $(\mathrm{BH}=1,56 \%), 5(\mathrm{BH}=1,56 \%)$ und $8(\mathrm{BH}=1,25 \%)$. Da Variante 4 eine recht hohe Standardabweichung aufwies konnten die Unterschiede zu den Varianten $1(\mathrm{BH}=3,13 \%)$, $2(\mathrm{BH}=3,13), 6(\mathrm{BH}=1,88 \%)$ und $7(\mathrm{BH}=2,50 \%)$ nicht statistisch abgesichert werden. Bei der Wechselwirkung aus Sorte und Saatstärke variierte die $\mathrm{BH}$ mit der Kleinen Kohlfliege im Herbst in BBCH 16/18 zwischen 1,41\% (SY Merlot, $60 \mathrm{Körner} / \mathrm{m}^{2}$ ) und 4,69\% (SY Merlot, 30 Körner/m²).

\section{BH mit der Kleinen Kohlfliege im Frühjahr in BBCH 83/84}

Die BH mit der Kleinen Kohlfliege im Frühjahr in $\mathrm{BBCH}$ 83/84 wurde signifikant durch die Sorte, die Saatstärke, die Interaktion zwischen Sorte $x$ Saatstärke und die Fungizidbehandlung beeinflusst (Tab. 17). Rapspflanzen der Sorte SY Merlot waren häufiger im Frühjahr in BBCH 83/84 mit der Kleinen Kohlfliege befallen (83,38\%) als Rapspflanzen der Sorte NK Petrol (76,23\%). Zudem waren die Pflanzen öfter bei der niedrigen Saatstärke mit der Kleinen Kohlfliege befallen (84,60\%) als bei der hohen Saatstärke (75,00\%). Diese Ergebnisse fanden sich auch weitestgehend bei der Interaktion aus Sorte und Saatstärke wieder. So wies NK Petrol bei einer Saatstärke von 60 Körnern $/ \mathrm{m}^{2}$ mit $69,13 \%$ eine signifikant geringere $\mathrm{BH}$ mit der Kleinen Kohlfliege im Frühjahr in $\mathrm{BBCH} 83 / 84$ auf als bei einer Saatstärke von $30 \mathrm{Körnern} / \mathrm{m}^{2}(83,33 \%)$ und als SY Merlot bei einer Saatstärke von 30 bzw. 60 Körnern/m² (85,88\% bzw. 80,88\%). Bei den Fungizidbehandlungen war die Variante 8 nicht so oft mit der Kleinen Kohlfliege im Frühjahr befallen (73,84\%) wie die Varianten $4(\mathrm{BH}=83,76 \%)$ und $5(\mathrm{BH}=84,99 \%)$. 
Tab. 17: Einfluss der Sorte (So), der Saatstärke (Di), der Interaktion zwischen Sorte $x$ Saatstärke (So*Di) und der Fungizidbehandlung $(\mathrm{Fu})$ auf die Befallsparameter $(\mathrm{BH}$ und $\mathrm{BW}$ mit der Wurzelhals- und Stängelfäule ( $P$. lingam) am Wurzelhals und an Laubblättern im Herbst sowie am Wurzelhals und am unteren Stängel im Frühjahr, BH mit der Kleinen Kohlfliege (D. radicum) im Herbst und Frühjahr), die im Versuchsjahr 2010/11 im Feldversuch in Göttingen untersucht wurden. Mittelwerte, die mit unterschiedlichen Buchstaben kennzeichnet sind, unterscheiden sich signifikant (Tukey-Test, $p \leq 0,05$ ). Dargestellt sind die Mittelwerte, die Standardabweichung (SD), errechnet aus den Residuen des gegebenen Modells, und die Anzahl der Werte (n), die in die jeweilige Berechnung eingegangen sind. Kursive Buchstaben stellen Unterschiede zwischen den Mittelwerten auf Basis des Globaltests (F-Test, $p \leq 0,05$ ) und nicht des Tukey-Tests dar. Für den Effekt der Sorte bzw. der Saatstärke wurden nur signifikante Ergebnisse wiedergegeben. Für die Interaktion Sorte $x$ Saatstärke und die Fungizidbehandlung wurden sowohl signifikante als auch nicht signifikante Ergebnisse aufgeführt. Grundlage dieser Tabelle sind die Tabellen 25A und 26A im Anhang aus denen hervorgeht, welche Effekte einen signifikanten Einfluss hatten ( $F$-Test, $p \leq 0,05$; Tab. 25A) und wie dieser sich auf den Mittelwertvergleich auswirkte (Tab. 26A). Die nicht signifikanten Ergebnisse wurden direkt aus einer Excel-Tabelle übernommen, in der die kompletten Ergebnisse der Varianzanalyse gespeichert wurden. [So = Sorte $(\mathrm{M}=\mathrm{SY}$ Merlot, $\mathrm{P}=\mathrm{NK}$ Petrol); $\mathrm{Di}$ = Saatstärke (30 bzw. $\left.60 \mathrm{Körner} / \mathrm{m}^{2}\right) ; \mathrm{Fu}=$ Fungizid ( $1=$ unbehandelte Kontrolle, $2=0,5 \mathrm{l} / \mathrm{ha}$ Toprex $^{\circledR}$ (Difenoconazol + Paclobutrazol) in $\mathrm{BBCH} 33 / 35,3=0,5 \mathrm{l} /$ ha Toprex ${ }^{\circledR}$ in BBCH 14 und $33 / 35,4=0,5 \mathrm{l} / \mathrm{ha}$ Toprex ${ }^{\circledR}$ in BBCH 14, 16 und 33/35, $5=0,5 \mathrm{l} / \mathrm{ha}$ Toprex ${ }^{\circledR}$ in BBCH 14, 33/35 und $53 / 55,6=0,5 \mathrm{l} /$ ha Toprex $^{\circledR}$ in BBCH $14+1,0 \mathrm{l} /$ ha Toprex $^{\circledR}$ in BBCH 33/35, $7=$ wie Nr. 3 aber in BBCH 65 2,0 I/ha Ortiva ${ }^{\circledR}$ (Azoxystrobin), 8 = praxisüblich = 0,6 $\mathrm{l} /$ ha Folicur $^{\circledR}$ (Tebuconazol) in $\mathrm{BBCH} 14+0,7 \mathrm{l} /$ ha Carax $^{\circledR}$ (Mepiquatchlorid + Metconazol) in BBCH 33/35 + 0,8 I/ha Harvesan ${ }^{\circledR}$ (Flusilazol + Carbendazim) in $\mathrm{BBCH} 65$; Varianten 1-6 erhielten in $\mathrm{BBCH} 651 \mathrm{l} /$ ha Ortiva ${ }^{\circledR}$ )].

\begin{tabular}{|c|c|c|c|c|c|c|c|c|}
\hline Parameter & Effekt & So & Di & $\mathrm{Fu}$ & Mittelwert & SD & $\mathbf{n}$ & Buchstaben \\
\hline BH [\%] mit der & So* $\mathrm{Di}$ & $M$ & 30 & & 72,19 & 10,19 & 32 & $a b$ \\
\hline Wurzelhals- & So* $\mathrm{Di}$ & $M$ & 60 & & 75,00 & 12,74 & 32 & $a b$ \\
\hline und Stängelfäule & So* $\mathrm{Di}$ & $\mathrm{P}$ & 30 & & 80,31 & 9,67 & 32 & $a$ \\
\hline an Laubblättern & $\mathrm{So}^{*} \mathrm{Di}$ & $\mathrm{P}$ & 60 & & 70,94 & 8,28 & 32 & $b$ \\
\hline im Herbst & $\mathrm{Fu}$ & & & 1 & 82,81 & 12,01 & 16 & $a b c$ \\
\hline \multirow[t]{7}{*}{ in BBCH 16/18 } & $\mathrm{Fu}$ & & & 2 & 86,88 & 11,86 & 16 & $a b$ \\
\hline & $\mathrm{Fu}$ & & & 3 & 69,69 & 10,27 & 16 & $\mathrm{~cd}$ \\
\hline & $\mathrm{Fu}$ & & & 4 & 52,81 & 10,41 & 16 & e \\
\hline & $\mathrm{Fu}$ & & & 5 & 75,31 & 8,94 & 16 & ad \\
\hline & $\mathrm{Fu}$ & & & 6 & 73,75 & 7,52 & 16 & $b d$ \\
\hline & $\mathrm{Fu}$ & & & 7 & 68,13 & 14,88 & 16 & $d$ \\
\hline & $\mathrm{Fu}$ & & & 8 & 87,50 & 7,80 & 16 & a \\
\hline BW mit der & So* $\mathrm{Di}$ & $M$ & 30 & & 2,38 & 0,85 & 32 & $\bar{a}$ \\
\hline Wurzelhals- & So* $\mathrm{Di}$ & $M$ & 60 & & 2,48 & 1,07 & 32 & a \\
\hline und Stängelfäule & So* $\mathrm{Di}$ & $P$ & 30 & & 2,92 & 0,63 & 32 & $a$ \\
\hline an Laubblättern & $\mathrm{So}^{*} \mathrm{Di}$ & $P$ & 60 & & 2,35 & 0,61 & 32 & $a$ \\
\hline
\end{tabular}




\begin{tabular}{|c|c|c|c|c|c|c|c|c|}
\hline im Herbst & $\mathrm{Fu}$ & & & 1 & 3,60 & 1,11 & 16 & a \\
\hline \multirow[t]{7}{*}{ in $\mathrm{BBCH} 16 / 18$} & $\mathrm{Fu}$ & & & 2 & 4,11 & 1,21 & 16 & $\mathrm{a}$ \\
\hline & $\mathrm{Fu}$ & & & 3 & 2,04 & 0,70 & 16 & $b$ \\
\hline & $\mathrm{Fu}$ & & & 4 & 0,78 & 0,34 & 16 & c \\
\hline & $\mathrm{Fu}$ & & & 5 & 2,29 & 0,89 & 16 & $b$ \\
\hline & $\mathrm{Fu}$ & & & 6 & 1,93 & 0,35 & 16 & $b$ \\
\hline & $\mathrm{Fu}$ & & & 7 & 1,91 & 0,81 & 16 & $b$ \\
\hline & $\mathrm{Fu}$ & & & 8 & 3,58 & 0,74 & 16 & a \\
\hline $\mathrm{BH}[\%]$ mit der & So*Di & $M$ & 30 & & 1,56 & 1,73 & 32 & a \\
\hline Wurzelhals- & So*Di & M & 60 & & 1,88 & 2,65 & 32 & a \\
\hline und Stängelfäule & So* $\mathrm{Di}$ & $\mathrm{P}$ & 30 & & 2,50 & 3,20 & 32 & $a$ \\
\hline am Wurzelhals & So* $\mathrm{Di}$ & $P$ & 60 & & 2,81 & 3,28 & 32 & a \\
\hline im Herbst & $\mathrm{Fu}$ & & & 1 & 0,94 & 1,19 & 16 & a \\
\hline \multirow[t]{7}{*}{ in $\mathrm{BBCH} 16 / 18$} & $\mathrm{Fu}$ & & & 2 & 2,19 & 2,20 & 16 & $a$ \\
\hline & $\mathrm{Fu}$ & & & 3 & 2,19 & 3,63 & 16 & a \\
\hline & $\mathrm{Fu}$ & & & 4 & 1,88 & 2,39 & 16 & a \\
\hline & $\mathrm{Fu}$ & & & 5 & 2,19 & 2,84 & 16 & a \\
\hline & $\mathrm{Fu}$ & & & 6 & 3,13 & 3,05 & 16 & a \\
\hline & $\mathrm{Fu}$ & & & 7 & 2,50 & 3,86 & 16 & a \\
\hline & $\mathrm{Fu}$ & & & 8 & 2,50 & 2,60 & 16 & a \\
\hline BW mit der & So*Di & $M$ & 30 & & 1,07 & 0,10 & 32 & a \\
\hline Wurzelhals- & So* Di & $M$ & 60 & & 1,10 & 0,15 & 32 & $\mathrm{a}$ \\
\hline und Stängelfäule & So* $\mathrm{Di}$ & $\mathrm{P}$ & 30 & & 1,09 & 0,14 & 32 & $a$ \\
\hline am Wurzelhals & So*Di & $P$ & 60 & & 1,12 & 0,14 & 32 & $\mathrm{a}$ \\
\hline im Herbst & $\mathrm{Fu}$ & & & 1 & 1,03 & 0,05 & 16 & a \\
\hline \multirow[t]{7}{*}{ in $\mathrm{BBCH} 16 / 18$} & $\mathrm{Fu}$ & & & 2 & 1,11 & 0,11 & 16 & $a$ \\
\hline & $\mathrm{Fu}$ & & & 3 & 1,10 & 0,18 & 16 & a \\
\hline & $\mathrm{Fu}$ & & & 4 & 1,11 & 0,13 & 16 & a \\
\hline & $\mathrm{Fu}$ & & & 5 & 1,09 & 0,13 & 16 & a \\
\hline & $\mathrm{Fu}$ & & & 6 & 1,13 & 0,15 & 16 & a \\
\hline & $\mathrm{Fu}$ & & & 7 & 1,12 & 0,19 & 16 & a \\
\hline & $\mathrm{Fu}$ & & & 8 & 1,07 & 0,08 & 16 & a \\
\hline BH mit der & So & $\bar{M}$ & & & 93,94 & 3,83 & 64 & a \\
\hline Wurzelhals- & So & $\mathrm{P}$ & & & 80,25 & 7,80 & 64 & $b$ \\
\hline und Stängelfäule & $\mathrm{Di}$ & & 30 & & 92,13 & 4,28 & 64 & a \\
\hline am unteren Stängel & $\mathrm{Di}$ & & 60 & & 82,06 & 7,20 & 64 & $\mathrm{~b}$ \\
\hline im Frühjahr & So* Di & $M$ & 30 & & 94,75 & 3,20 & 32 & a \\
\hline \multirow[t]{3}{*}{ in $\mathrm{BBCH} 83 / 84$} & So* $\mathrm{Di}$ & M & 60 & & 93,13 & 4,43 & 32 & a \\
\hline & So*Di & $\mathrm{P}$ & 30 & & 89,50 & 5,47 & 32 & a \\
\hline & So* Di & $\mathrm{P}$ & 60 & & 71,00 & 9,26 & 32 & $\mathrm{~b}$ \\
\hline
\end{tabular}




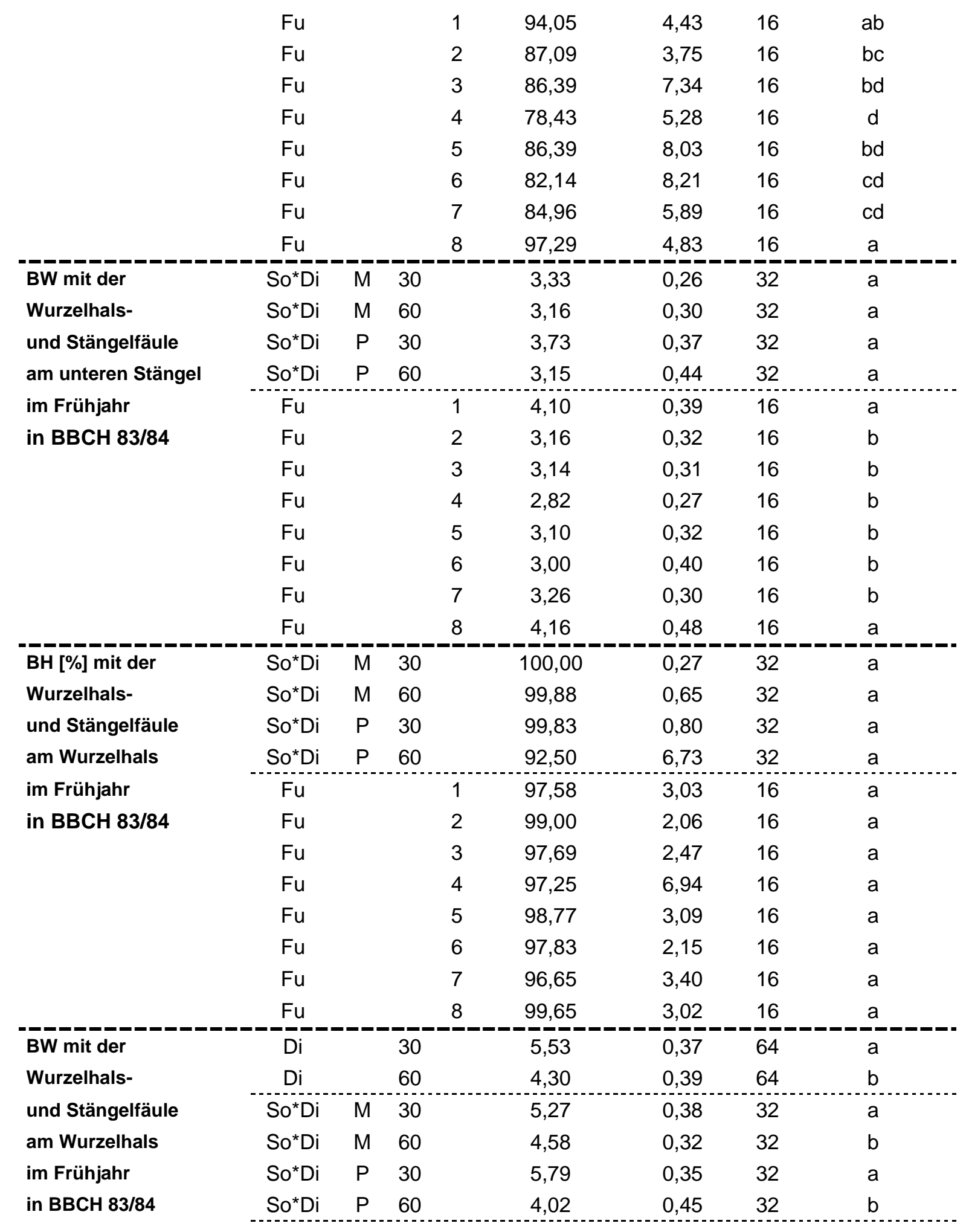




\begin{tabular}{|c|c|c|c|c|c|c|c|c|}
\hline & $\mathrm{Fu}$ & & & 1 & 5,32 & 0,50 & 16 & a \\
\hline & $\mathrm{Fu}$ & & & 2 & 5,15 & 0,44 & 16 & $a b$ \\
\hline & $\mathrm{Fu}$ & & & 3 & 4,70 & 0,35 & 16 & $\mathrm{bc}$ \\
\hline & $\mathrm{Fu}$ & & & 4 & 4,49 & 0,40 & 16 & $c$ \\
\hline & $\mathrm{Fu}$ & & & 5 & 4,94 & 0,39 & 16 & ac \\
\hline & $\mathrm{Fu}$ & & & 6 & 4,62 & 0,25 & 16 & c \\
\hline & $\mathrm{Fu}$ & & & 7 & 4,73 & 0,38 & 16 & $\mathrm{bc}$ \\
\hline & $\mathrm{Fu}$ & & & 8 & 5,38 & 0,34 & 16 & a \\
\hline $\mathrm{BH}[\%] \mathrm{mit}$ der & So* $\mathrm{Di}$ & $M$ & 30 & & 4,69 & 10,26 & 32 & a \\
\hline Kleinen Kohlfliege & So*Di & $M$ & 60 & & 1,41 & 2,44 & 32 & a \\
\hline im Herbst & So* $\mathrm{Di}$ & $P$ & 30 & & 3,28 & 4,10 & 32 & a \\
\hline \multirow[t]{9}{*}{ in BBCH 16/18 } & So* $\mathrm{Di}$ & $\mathrm{P}$ & 60 & & 2,66 & 2,47 & 32 & a \\
\hline & $\mathrm{Fu}$ & & & 1 & 3,13 & 3,39 & 16 & $a b$ \\
\hline & $\mathrm{Fu}$ & & & 2 & 3,13 & 3,75 & 16 & $a b$ \\
\hline & $\mathrm{Fu}$ & & & 3 & 1,56 & 2,62 & 16 & $b$ \\
\hline & $\mathrm{Fu}$ & & & 4 & 9,06 & 14,61 & 16 & a \\
\hline & $\mathrm{Fu}$ & & & 5 & 1,56 & 2,97 & 16 & $b$ \\
\hline & $\mathrm{Fu}$ & & & 6 & 1,88 & 2,16 & 16 & $a b$ \\
\hline & $\mathrm{Fu}$ & & & 7 & 2,50 & 2,57 & 16 & $a b$ \\
\hline & $\mathrm{Fu}$ & & & 8 & 1,25 & 3,40 & 16 & $b$ \\
\hline $\mathrm{BH}$ [\%] mit der & So & $M$ & & & 83,38 & 7,56 & 64 & $a$ \\
\hline Kleinen Kohlfliege & So & $P$ & & & 76,23 & 6,95 & 64 & $b$ \\
\hline im Frühjahr & $\mathrm{Di}$ & & 30 & & 84,60 & 6,73 & 64 & a \\
\hline \multirow[t]{13}{*}{ in $\mathrm{BBCH} 83 / 84$} & $\mathrm{Di}$ & & 60 & & 75,00 & 7,73 & 64 & $b$ \\
\hline & So* $\mathrm{Di}$ & $\mathrm{M}$ & 30 & & 85,88 & 7,00 & 32 & a \\
\hline & $\mathrm{So}^{*} \mathrm{Di}$ & $M$ & 60 & & 80,88 & 8,20 & 32 & a \\
\hline & So* $\mathrm{Di}$ & $P$ & 30 & & 83,33 & 6,51 & 32 & a \\
\hline & So* $\mathrm{Di}$ & $\mathrm{P}$ & 60 & & 69,13 & 7,37 & 32 & $b$ \\
\hline & $\mathrm{Fu}$ & & & 1 & 76,82 & 7,78 & 16 & $a b$ \\
\hline & $\mathrm{Fu}$ & & & 2 & 80,43 & 7,25 & 16 & $a b$ \\
\hline & $\mathrm{Fu}$ & & & 3 & 79,07 & 9,17 & 16 & $a b$ \\
\hline & $\mathrm{Fu}$ & & & 4 & 83,76 & 6,28 & 16 & $a$ \\
\hline & $\mathrm{Fu}$ & & & 5 & 84,99 & 6,33 & 16 & $a$ \\
\hline & $\mathrm{Fu}$ & & & 6 & 81,74 & 8,14 & 16 & $a b$ \\
\hline & $\mathrm{Fu}$ & & & 7 & 77,76 & 8,32 & 16 & $a b$ \\
\hline & $\mathrm{Fu}$ & & & 8 & 73,84 & 5,90 & 16 & $b$ \\
\hline
\end{tabular}




\subsubsection{Versuchsjahr 2012/13}

\section{BH und BW mit der Wurzelhals- und Stängelfäule an Laubblättern im Herbst}

Die $\mathrm{BH}$ und der BW mit der Wurzelhals- und Stängelfäule an Laubblättern im Herbst in $\mathrm{BBCH}$ 17/18 wurden signifikant durch die Fungizidbehandlung und nicht signifikant durch die Interaktion aus Sorte und Saatstärke beeinflusst (Tab. 18). Fungizidvariante 1 und 2 wiesen signifikant höhere $\mathrm{BH}(18,40 \%$ bzw. $21,50 \%)$ und BW $(0,25$ bzw. 0,33) mit der Wurzelhals- und Stängelfäule an Laubblättern im Herbst in $\mathrm{BBCH} 17 / 18$ auf als alle anderen Varianten [3 $(\mathrm{BH}=5,25 \%$; $\mathrm{BW}=0,06), 4(\mathrm{BH}=2,25 \% ; \mathrm{BW}=0,03), 5(\mathrm{BH}=$ $3,00 \%$; $\mathrm{BW}=0,04), 6(\mathrm{BH}=2,75 \%$; $\mathrm{BW}=0,03), 7(\mathrm{BH}=2,00 \%$; $\mathrm{BW}=0,02), 8(\mathrm{BH}=$ $3,32 \% ; B W=0,04)$ ]. Diese Werte waren deutlich niedriger als im Jahr 2010/11, in dem die $\mathrm{BH}$ und der BW mit der Wurzelhals- und Stängelfäule an Laubblättern im Herbst zwischen $52,81 \%$ bzw. 0,78 (Variante 4) und 87,50\% bzw. 3,58 (Variante 8) schwankten. Bei der Interaktion aus Sorte und Saatstärke pendelte die BH bzw. der BW mit der Wurzelhalsund Stängelfäule an Laubblättern im Herbst in $\mathrm{BBCH} 17 / 18$ zwischen 3,88\% bzw. 0,05 (SY Vesuvio, $60 \mathrm{Körner} / \mathrm{m}^{2}$ ) und 10,03\% bzw. 0,13 (NK Petrol, $30 \mathrm{Körner} / \mathrm{m}^{2}$ ). Der Vollständigkeit halber sei darauf hingewiesen, dass die Interaktion zwischen Sorte und Fungizidbehandlung auch einen signifikanten Effekt auf die $\mathrm{BH}$ mit der Wurzelhals- und Stängelfäule an Laubblättern im Herbst hatte (vgl. Tab. 25A im Anhang II, Globaltest). Einzelheiten werden dazu an dieser Stelle nicht näher beschrieben, stattdessen wird auf Tab. 27A im Anhang II verwiesen.

\section{BH und BW mit der Wurzelhals- und Stängelfäule am Wurzelhals im Herbst}

Da die $\mathrm{BH}$ und der BW mit der Wurzelhals- und Stängelfäule am Wurzelhals im Herbst in $\mathrm{BBCH}$ 17/18 unabhängig von den Versuchsfaktoren insgesamt sehr niedrig waren, konnten keine signifikanten Effekte der drei Versuchsfaktoren statistisch abgesichert werden (vgl. Tab. 18 und Tab. 25A im Anhang II). Bei der Interaktion Sorte x Saatstärke schwankten die BH bzw. der BW zwischen 0,25\% bzw. 1,00 (NK Petrol, 60 Körner $/ \mathrm{m}^{2}$ ) und 1,14\% bzw. 1,02 (SY Vesuvio, $30 \mathrm{Körner} / \mathrm{m}^{2}$ ). Bei den verschiedenen Fungizidbehandlungen pendelte die BH bzw. der BW zwischen 0\% bzw. 1,00 (Variante 2 und 3) und 1,50\% bzw. 1,03 (Variante 4). Bei dem zu Grunde gelegten Boniturschema stellte ein BW von 1 keinen Befall dar. Im Vergleich zwischen den Versuchsjahren waren die an sich niedrigen Werte für die $\mathrm{BH}$ und den BW mit der Wurzelhals- und Stängelfäule am Wurzelhals im Herbst im Jahr 2012/13 noch etwas niedriger als im Jahr 2010/11 (vgl. diesen Befallsparameter in Tab. 17 und Tab. 18). 


\section{BH mit der Wurzelhals- und Stängelfäule am unteren Stängel im Frühjahr}

Die BH mit der Wurzelhals- und Stängelfäule am unteren Stängel im Frühjahr in $\mathrm{BBCH}$ 80/81 wurde signifikant durch die Fungizidbehandlung und nicht signifikant durch die Wechselwirkung aus Sorte und Saatstärke beeinflusst (Tab. 18). Die Fungizidvarianten 4 $(\mathrm{BH}=10,50 \%), 5(\mathrm{BH}=9,75 \%)$ und $6(\mathrm{BH}=10,75 \%)$ reduzierten im Vergleich zu den Varianten $1(\mathrm{BH}=23,57 \%)$ und $2(\mathrm{BH}=21,25 \%)$ signifikant die $\mathrm{BH}$ mit der Wurzelhals und Stängelfäule am unteren Stängel im Frühjahr in $\mathrm{BBCH}$ 80/81. Des Weiteren waren die Rapspflanzen in der Variante $3(\mathrm{BH}=11,75 \%)$ signifikant geringer mit der Wurzelhalsund Stängelfäule am unteren Stängel im Frühjahr in $\mathrm{BBCH} 80 / 81$ befallen als die Rapspflanzen in Variante 1. Bei der Interaktion aus Sorte und Saatstärke variierten die BH zwischen 9,25\% (NK Petrol, 60 Körner/m²) und 17,95\% (SY Vesuvio, $30 \mathrm{Körner} / \mathrm{m}^{2}$ ). Aufgrund einer verhältnismäßig hohen Standardabweichung konnten diese Unterschiede nicht statistisch abgesichert werden.

\section{BW mit der Wurzelhals- und Stängelfäule am unteren Stängel im Frühjahr}

Der BW mit der Wurzelhals- und Stängelfäule am unteren Stängel im Frühjahr in BBCH 80/81 wurde signifikant durch die Saatstärke und die Fungizidbehandlung beeinflusst (Tab. 18). Die Interaktion zwischen Sorte und Saatstärke hatte auf diesen Befallsparameter keinen signifikanten Einfluss (Tab. 18). Bei der niedrigen Saatstärke war der BW mit der Wurzelhals- und Stängelfäule am unteren Stängel in BBCH 80/81 signifikant höher $(B W=1,33)$ als bei der hohen Saatstärke $(B W=1,22)$. Bei den Fungizidbehandlungen reduzierte die Variante $6(\mathrm{BW}=1,15)$ im Vergleich zu den Varianten 1 (BW $=1,39)$ und $8(B W=1,37)$ signifikant den $B W$ mit der Wurzelhals- und Stängelfäule am unteren Stängel im Frühjahr in $\mathrm{BBCH}$ 80/81. Des Weiteren verringerte die Variante $5(B W=1,17)$ im Vergleich zur Variante $1(B W=1,39)$ signifikant den BW mit der Wurzelhals- und Stängelfäule am unteren Stängel im Frühjahr. Für die Interaktion aus Sorte x Saatstärke wurden BW zwischen 1,19 (NK Petrol, 60 Körner/m²) und 1,34 (SY Vesuvio, $30 \mathrm{Körner} / \mathrm{m}^{2}$ ) ermittelt. Insgesamt zeigen die Ergebnisse der $\mathrm{BH}$ und des BW mit der Wurzelhals- und Stängelfäule am unteren Stängel im Frühjahr in BBCH 80/81, dass der Befall mit $P$. lingam am unteren Stängel im Frühjahr recht gering war. Mit $\mathrm{BH}$ von $9,75 \%$ bis $23,57 \%$ und $\mathrm{BW}$ von 1,15 bis 1,39 war der Befall mit $P$. lingam am unteren Stängel im Frühjahr im Versuchsjahr 2012/13 deutlich niedriger als im Versuchsjahr $2010 / 11(\mathrm{BH}=78,43 \%$ bis $97,29 \%$ bzw. $\mathrm{BW}=2,82$ bis 4,16$)$. 


\section{BH mit der Wurzelhals- und Stängelfäule am Wurzelhals im Frühjahr}

Die BH mit der Wurzelhals- und Stängelfäule am Wurzelhals im Frühjahr in BBCH 80/81 wurde signifikant durch die Fungizidbehandlung und nicht signifikant durch die Wechselwirkung aus Sorte und Saatstärke beeinflusst (Tab. 18). Mit 25,50\% (Variante 4) und 27,00\% (Variante 6) waren in den Varianten 4 und 6 signifikant weniger Rapspflanzen mit der Wurzelhals- und Stängelfäule am Wurzelhals in $\mathrm{BBCH} 80 / 81$ befallen als in den Varianten 2 (39,75\%) und 8 (40,70\%). Weitere signifikante Effekte wurden bei den Fungizidbehandlungen nicht ermittelt. Bei der Interaktion zwischen Sorte und Saatstärke schwankten die Werte für die BH zwischen 31,63\% (SY Vesuvio, $60 \mathrm{Körner} / \mathrm{m}^{2}$ ) und $34,60 \%$ (NK Petrol, 30 Körner/m²).

\section{BW mit der Wurzelhals- und Stängelfäule am Wurzelhals im Frühjahr}

Der BW mit der Wurzelhals- und Stängelfäule am Wurzelhals im Frühjahr in BBCH 80/81 wurde signifikant durch die Sorte und die Fungizidbehandlung und nicht signifikant durch die Interaktion aus Sorte x Saatstärke beeinflusst (Tab. 18). Rapspflanzen der Sorte SY Vesuvio waren nicht so stark mit der Wurzelhals- und Stängelfäule am Wurzelhals im Frühjahr in $\mathrm{BBCH}$ 80/81 befallen (BW = 1,59) als die Pflanzen der Sorte NK Petrol (BW = 1,76). Bei den Fungizidbehandlungen reduzierten die Varianten $4(1,42)$ und $6(1,43)$ im Vergleich zu den Varianten 1 (BW = 1,79), 2 (BW = 1,82), $7(B W=1,73)$ und 8 (BW = 2,03) signifikant den BW mit der Wurzelhals- und Stängelfäule am Wurzelhals im Frühjahr in $\mathrm{BBCH}$ 80/81. Ferner waren die Rapspflanzen der Variante 7 nicht so stark mit der Wurzelhals- und Stängelfäule am Wurzelhals im Frühjahr befallen $(1,73)$ wie die Rapspflanzen der Variante 8 (2,03). Bei der Interaktion zwischen Sorte und Saatstärke lagen die BW zwischen 1,59 (SY Vesuvio, $60 \mathrm{Körner} / \mathrm{m}^{2}$ ) und 1,82 (NK Petrol, 30 Körner $/ \mathrm{m}^{2}$ ). Die hier beschriebenen BW sowie die zuvor erläuterten Werte für die $\mathrm{BH}$ zeigen, dass der Befall mit $P$. lingam am Wurzelhals im Frühjahr in $\mathrm{BBCH}$ 80/81 geringfügig höher war als der Befall mit $P$. lingam am unteren Stängel im Frühjahr in $\mathrm{BBCH}$ 80/81. Insgesamt war der Befall mit $P$. lingam am Wurzelhals im Frühjahr noch auf einem recht niedrigen Niveau. Im Vergleich zum Versuchsjahr 2010/11, in dem die BH bzw. der BW mit der Wurzelhals-und Stängelfäule am Wurzelhals im Frühjahr zwischen 96,65\% und 99,65\% bzw. zwischen 4,49 und 5,38 schwankte, war der Befall mit $P$. lingam am Wurzelhals im Frühjahr im Jahr 2012/13 deutlich geringer. Der Vollständigkeit halber wird darauf hingewiesen, dass die Interaktion zwischen Saatstärke und Fungizidbehandlung ebenfalls einen signifikanten Effekt auf den BW mit der Wurzelhalsund Stängelfäule am Wurzelhals im Frühjahr hatte (vgl. Tab. 25A im Anhang II, 
Globaltest). Einzelheiten werden dazu an dieser Stelle nicht näher beschrieben, stattdessen wird auf Tab. 27A im Anhang II verwiesen.

\section{BH mit der Kleinen Kohlfliege im Herbst}

Im Versuchsjahr 2012/13 konnte die BH mit der Kleinen Kohlfliege im Herbst in BBCH 17/18 nicht ermittelt werden, da die Probenahme der Rapspflanzen und trockenen Bedingungen erfolgte und so nicht immer die komplette Pfahlwurzel geerntet werden konnte. Somit konnte nicht an jeder Pflanze eine genaue Beurteilung des Larvenfraßes von der Kleinen Kohlfliege an der Pfahlwurzel erfolgen, woraufhin diese Bonitur komplett entfallen ist.

\section{BH mit der Kleinen Kohlfliege im Frühjahr}

Die BH mit der Kleinen Kohlfliege im Frühjahr in $\mathrm{BBCH}$ 80/81 wurde weder von den drei unabhängigen Anbaufaktoren Sorte, Saatstärke und Fungizidbehandlung noch von den daraus resultierenden Interaktionen signifikant beeinflusst (vgl. Tab. 18 und Tab. 25A im Anhang II). Bei der Interaktion aus Sorte und Saatstärke schwankten die Werte für die BH mit der Kleinen Kohlfliege im Frühjahr in BBCH 80/81 zwischen 62,00\% (NK Petrol, 60 Körner/m²) und 72,89\% (SY Vesuvio, 30 Körner $/ \mathrm{m}^{2}$ ). Bei den Fungizidbehandlungen variierte die $\mathrm{BH}$ mit der Kleinen Kohlfliege im Frühjahr in $\mathrm{BBCH}$ 80/81 zwischen 62,10\% (Variante 8) und 69,00\% (Variante 3). 
Tab. 18: Einfluss der Sorte (So), der Saatstärke (Di), der Interaktion zwischen Sorte $x$ Saatstärke (So*Di) und der Fungizidbehandlung $(\mathrm{Fu})$ auf die Befallsparameter $(\mathrm{BH}$ und $\mathrm{BW}$ mit der Wurzelhals- und Stängelfäule ( $P$. lingam) am Wurzelhals und an Laubblättern im Herbst sowie am Wurzelhals und am unteren Stängel im Frühjahr, BH mit der Kleinen Kohlfliege (D. radicum) im Herbst und Frühjahr), die im Versuchsjahr 2012/13 im Feldversuch in Göttingen untersucht wurden. Mittelwerte, die mit unterschiedlichen Buchstaben kennzeichnet sind, unterscheiden sich signifikant (Tukey-Test, $p \leq 0,05$ ). Dargestellt sind die Mittelwerte, die Standardabweichung (SD), errechnet aus den Residuen des gegebenen Modells, und die Anzahl der Werte (n), die in die jeweilige Berechnung eingegangen sind. Für den Effekt der Sorte bzw. der Saatstärke wurden nur signifikante Ergebnisse wiedergegeben. Für die Interaktion Sorte $\mathrm{x}$ Saatstärke und die Fungizidbehandlung wurden sowohl signifikante als auch nicht signifikante Ergebnisse aufgeführt. Grundlage dieser Tabelle sind die Tabellen 25A und 27A im Anhang II aus denen hervorgeht, welche Effekte einen signifikanten Einfluss hatten ( $F$-Test, $p \leq 0,05$; Tab. 25A) und wie dieser sich auf den Mittelwertvergleich auswirkte (Tab. 27A). Die nicht signifikanten Ergebnisse wurden direkt aus einer Excel-Tabelle übernommen, in der die kompletten Ergebnisse der Varianzanalyse gespeichert wurden. [So = Sorte $(\mathrm{P}=\mathrm{NK}$ Petrol, $\mathrm{V}=\mathrm{SY}$ Vesuvio $) ; \mathrm{Di}=$ Saatstärke (30 bzw. 60 Körner $\left./ \mathrm{m}^{2}\right) ; \mathrm{Fu}=$ Fungizid $\left(1=\right.$ unbehandelte Kontrolle, $2=0,5 \mathrm{l} /$ ha Toprex $^{\circledR}$ (Difenoconazol + Paclobutrazol) in $\mathrm{BBCH} 33 / 35,3=0,5 \mathrm{l} /$ ha Toprex ${ }^{\circledR}$ in $\mathrm{BBCH} 14$ und 33/35, $4=0,5 \mathrm{l} /$ ha Toprex $^{\circledR}$ in BBCH 14, 16 und 33/35, $5=0,5 \mathrm{l} /$ ha Toprex ${ }^{\circledR}$ in BBCH 14, 33/35 und 53/55, $6=0,5 \mathrm{l} /$ ha Toprex $^{\circledR}$ in $\mathrm{BBCH} 14,16,33 / 35$ und $53 / 55,7=0,5 \mathrm{l} /$ ha Toprex $^{\circledR}$ in $\mathrm{BBCH} 14,8=$ praxisüblich $=0,5 \mathrm{l} / \mathrm{ha}$ $\operatorname{Carax}^{\circledR}$ (Mepiquatchlorid + Metconazol) in $\mathrm{BBCH} 14$ und 33/35; alle Varianten erhielten in $\mathrm{BBCH} 65$ $1 \mathrm{l} /$ ha Ortiva $^{\circledR}$ (Azoxystrobin)].

\begin{tabular}{|c|c|c|c|c|c|c|c|c|}
\hline Parameter & Effekt & So & Di & $\mathrm{Fu}$ & Mittelwert & SD & $n$ & Buchstaben \\
\hline BH [\%] mit der & So*Di & $\mathrm{P}$ & 30 & & 10,03 & 5,24 & 32 & $a$ \\
\hline Wurzelhals- & So* Di & $P$ & 60 & & 8,38 & 4,01 & 32 & a \\
\hline und Stängelfäule & So* Di & $\mathrm{V}$ & 30 & & 6,96 & 5,87 & 32 & $a$ \\
\hline an Laubblättern & So* Di & $\mathrm{V}$ & 60 & & 3,88 & 6,17 & 32 & a \\
\hline im Herbst & $\mathrm{Fu}$ & & & 1 & 18,40 & 7,76 & 16 & a \\
\hline \multirow[t]{7}{*}{ in $\mathrm{BBCH} 17 / 18$} & $\mathrm{Fu}$ & & & 2 & 21,50 & 10,94 & 16 & a \\
\hline & $\mathrm{Fu}$ & & & 3 & 5,25 & 4,40 & 16 & $b$ \\
\hline & $\mathrm{Fu}$ & & & 4 & 2,25 & 2,55 & 16 & $b$ \\
\hline & $\mathrm{Fu}$ & & & 5 & 3,00 & 3,52 & 16 & $b$ \\
\hline & $\mathrm{Fu}$ & & & 6 & 2,75 & 2,29 & 16 & $b$ \\
\hline & $\mathrm{Fu}$ & & & 7 & 2,00 & 2,94 & 16 & $b$ \\
\hline & $\mathrm{Fu}$ & & & 8 & 3,32 & 2,94 & 16 & $b$ \\
\hline BW mit der & So* $\mathrm{Di}$ & $P$ & 30 & & 0,13 & 0,09 & 32 & a \\
\hline Wurzelhals- & So*Di & $\mathrm{P}$ & 60 & & 0,11 & 0,05 & 32 & a \\
\hline und Stängelfäule & So*Di & $\mathrm{V}$ & 30 & & 0,10 & 0,08 & 32 & a \\
\hline an Laubblättern & So* Di & V & 60 & & 0,05 & 0,09 & 32 & $\mathrm{a}$ \\
\hline
\end{tabular}




\begin{tabular}{|c|c|c|c|c|c|c|c|c|}
\hline im Herbst & $\mathrm{Fu}$ & & & 1 & 0,25 & 0,12 & 16 & $a$ \\
\hline \multirow[t]{7}{*}{ in $\mathrm{BBCH} 17 / 18$} & $\mathrm{Fu}$ & & & 2 & 0,33 & 0,17 & 16 & $\mathrm{a}$ \\
\hline & $\mathrm{Fu}$ & & & 3 & 0,06 & 0,05 & 16 & $\mathrm{~b}$ \\
\hline & $\mathrm{Fu}$ & & & 4 & 0,03 & 0,05 & 16 & $\mathrm{~b}$ \\
\hline & $\mathrm{Fu}$ & & & 5 & 0,04 & 0,06 & 16 & $\mathrm{~b}$ \\
\hline & $\mathrm{Fu}$ & & & 6 & 0,03 & 0,03 & 16 & $b$ \\
\hline & $\mathrm{Fu}$ & & & 7 & 0,02 & 0,04 & 16 & $\mathrm{~b}$ \\
\hline & $\mathrm{Fu}$ & & & 8 & 0,04 & 0,04 & 16 & $\mathrm{~b}$ \\
\hline $\mathrm{BH}[\%] \mathrm{mit}$ der & So*Di & $P$ & 30 & & 0,43 & 0,94 & 32 & $a$ \\
\hline Wurzelhals- & So* Di & $\mathrm{P}$ & 60 & & 0,25 & 0,92 & 32 & $a$ \\
\hline und Stängelfäule & So*Di & V & 30 & & 1,14 & 2,23 & 32 & a \\
\hline am Wurzelhals & So* $\mathrm{Di}$ & $\mathrm{V}$ & 60 & & 0,25 & 1,21 & 32 & a \\
\hline im Herbst & $\mathrm{Fu}$ & & & 1 & 0,36 & 0,83 & 16 & a \\
\hline \multirow[t]{7}{*}{ in $\mathrm{BBCH} 17 / 18$} & $\mathrm{Fu}$ & & & 2 & 0,00 & 0,22 & 16 & a \\
\hline & $\mathrm{Fu}$ & & & 3 & 0,00 & 0,22 & 16 & $a$ \\
\hline & $\mathrm{Fu}$ & & & 4 & 1,50 & 2,25 & 16 & a \\
\hline & $\mathrm{Fu}$ & & & 5 & 1,00 & 2,77 & 16 & a \\
\hline & $\mathrm{Fu}$ & & & 6 & 0,50 & 1,29 & 16 & $a$ \\
\hline & $\mathrm{Fu}$ & & & 7 & 0,75 & 0,97 & 16 & a \\
\hline & $\mathrm{Fu}$ & & & 8 & 0,03 & 0,22 & 16 & a \\
\hline BW mit der & So*Di & $P$ & 30 & & 1,00 & 0,01 & 32 & $a$ \\
\hline Wurzelhals- & So* Di & $\mathrm{P}$ & 60 & & 1,00 & 0,01 & 32 & a \\
\hline und Stängelfäule & So*Di & V & 30 & & 1,02 & 0,04 & 32 & $a$ \\
\hline am Wurzelhals & So*Di & $\mathrm{V}$ & 60 & & 1,00 & 0,01 & 32 & a \\
\hline im Herbst & $\mathrm{Fu}$ & & & 1 & 1,00 & 0,01 & 16 & a \\
\hline \multirow[t]{7}{*}{ in $\mathrm{BBCH} 17 / 18$} & $\mathrm{Fu}$ & & & 2 & 1,00 & 0,00 & 16 & a \\
\hline & $\mathrm{Fu}$ & & & 3 & 1,00 & 0,00 & 16 & a \\
\hline & $\mathrm{Fu}$ & & & 4 & 1,03 & 0,005 & 16 & $a$ \\
\hline & $\mathrm{Fu}$ & & & 5 & 1,02 & 0,04 & 16 & a \\
\hline & $\mathrm{Fu}$ & & & 6 & 1,01 & 0,01 & 16 & a \\
\hline & $\mathrm{Fu}$ & & & 7 & 1,01 & 0,01 & 16 & a \\
\hline & $\mathrm{Fu}$ & & & 8 & 1,00 & 0,00 & 16 & a \\
\hline BH mit der & So* $\mathrm{Di}$ & $P$ & 30 & & 16,70 & 7,82 & 32 & $a$ \\
\hline Wurzelhals- & So*Di & $\mathrm{P}$ & 60 & & 9,25 & 6,07 & 32 & a \\
\hline und Stängelfäule & So* Di & $\mathrm{V}$ & 30 & & 17,95 & 7,82 & 32 & a \\
\hline am unteren Stängel & So* Di & $\mathrm{V}$ & 60 & & 16,00 & 8,76 & 32 & a \\
\hline im Frühjahr & $\mathrm{Fu}$ & & & 1 & 23,57 & 13,21 & 16 & a \\
\hline \multirow[t]{7}{*}{ in $\mathrm{BBCH} 80 / 81$} & $\mathrm{Fu}$ & & & 2 & 21,25 & 9,17 & 16 & $a b$ \\
\hline & $\mathrm{Fu}$ & & & 3 & 11,75 & 5,46 & 16 & $\mathrm{bc}$ \\
\hline & $\mathrm{Fu}$ & & & 4 & 10,50 & 5,72 & 16 & c \\
\hline & $\mathrm{Fu}$ & & & 5 & 9,75 & 5,06 & 16 & c \\
\hline & $\mathrm{Fu}$ & & & 6 & 10,75 & 7,58 & 16 & c \\
\hline & $\mathrm{Fu}$ & & & 7 & 15,00 & 7,39 & 16 & ac \\
\hline & $\mathrm{Fu}$ & & & 8 & 17,24 & $-6,44$ & 16 & -ac \\
\hline
\end{tabular}




\begin{tabular}{|c|c|c|c|c|c|c|c|}
\hline BW mit der & $\mathrm{Di}$ & & 30 & 1,33 & 0,18 & 64 & a \\
\hline Wurzelhals- & $\mathrm{Di}$ & & 60 & 1,22 & 0,14 & 64 & $b$ \\
\hline und Stängelfäule & So*Di & $\mathrm{P}$ & 30 & 1,33 & 0,18 & 32 & a \\
\hline am unteren Stängel & So*Di & $P$ & 60 & 1,19 & 0,13 & 32 & a \\
\hline im Frühjahr & So*Di & $\mathrm{V}$ & 30 & 1,34 & 0,18 & 32 & a \\
\hline \multirow[t]{9}{*}{ in $\mathrm{BBCH} 80 / 81$} & So* $\mathrm{Di}$ & $\mathrm{V}$ & 60 & 1,25 & 0,15 & 32 & a \\
\hline & $\mathrm{Fu}$ & & 1 & 1,39 & 0,22 & 16 & a \\
\hline & $\mathrm{Fu}$ & & 2 & 1,36 & 0,21 & 16 & ac \\
\hline & $\mathrm{Fu}$ & & 3 & 1,25 & 0,13 & 16 & ac \\
\hline & $\mathrm{Fu}$ & & 4 & 1,18 & 0,14 & 16 & ac \\
\hline & $\mathrm{Fu}$ & & 5 & 1,17 & 0,09 & 16 & $\mathrm{bc}$ \\
\hline & $\mathrm{Fu}$ & & 6 & 1,15 & 0,10 & 16 & c \\
\hline & $\mathrm{Fu}$ & & 7 & 1,33 & 0,22 & 16 & $\mathrm{ac}$ \\
\hline & $\mathrm{Fu}$ & & 8 & 1,37 & 0,16 . & -16 & $a b$ \\
\hline $\mathrm{BH}[\%] \mathrm{mit}$ der & So*Di & $P$ & 30 & 34,60 & 6,93 & 32 & $a$ \\
\hline Wurzelhals- & So* Di & $\mathrm{P}$ & 60 & 33,00 & 11,66 & 32 & a \\
\hline und Stängelfäule & So*Di & $\mathrm{V}$ & 30 & 31,73 & 9,56 & 32 & a \\
\hline am Wurzelhals & So* Di & $\mathrm{V}$ & 60 & 31,63 & 10,12 & 32 & a \\
\hline im Frühjahr & $\mathrm{Fu}$ & & 1 & 37,20 & 9,02 & 16 & $a b$ \\
\hline \multirow[t]{7}{*}{ in $\mathrm{BBCH} 80 / 81$} & $\mathrm{Fu}$ & & 2 & 39,75 & 7,56 & 16 & $a$ \\
\hline & $\mathrm{Fu}$ & & 3 & 29,75 & 8,12 & 16 & $a b$ \\
\hline & $\mathrm{Fu}$ & & 4 & 25,50 & 12,09 & 16 & $b$ \\
\hline & $\mathrm{Fu}$ & & 5 & 28,25 & 11,12 & 16 & $a b$ \\
\hline & $\mathrm{Fu}$ & & 6 & 27,00 & 10,93 & 16 & $b$ \\
\hline & $\mathrm{Fu}$ & & 7 & 33,75 & 7,38 & 16 & $a b$ \\
\hline & $\mathrm{Fu}$ & & 8 & 40,70 & 11,98 & 16 & a \\
\hline BW mit der & So & $P$ & & 1,76 & 0,26 & 64 & a \\
\hline Wurzelhals- & So & $\mathrm{V}$ & & 1,59 & 0,18 & 64 & $b$ \\
\hline und Stängelfäule & So*Di & $\mathrm{P}$ & 30 & 1,82 & 0,20 & 32 & a \\
\hline am Wurzelhals & So* Di & $P$ & 60 & 1,71 & 0,30 & 32 & a \\
\hline im Frühjahr & So* Di & $\mathrm{V}$ & 30 & 1,59 & 0,15 & 32 & a \\
\hline \multirow[t]{9}{*}{ in $\mathrm{BBCH} 80 / 81$} & So* Di & $\mathrm{V}$ & 60 & 1,59 & 0,21 & 32 & $\mathrm{a}$ \\
\hline & $\mathrm{Fu}$ & & 1 & 1,79 & 0,20 & 16 & $a b$ \\
\hline & $\mathrm{Fu}$ & & 2 & 1,82 & 0,21 & 16 & $a b$ \\
\hline & $\mathrm{Fu}$ & & 3 & 1,62 & 0,18 & 16 & $\mathrm{bc}$ \\
\hline & $\mathrm{Fu}$ & & 4 & 1,42 & 0,16 & 16 & $\mathrm{c}$ \\
\hline & $\mathrm{Fu}$ & & 5 & 1,57 & 0,25 & 16 & $\mathrm{bc}$ \\
\hline & $\mathrm{Fu}$ & & 6 & 1,43 & 0,18 & 16 & $c$ \\
\hline & $\mathrm{Fu}$ & & 7 & 1,73 & 0,28 & 16 & $b$ \\
\hline & $\mathrm{Fu}$ & & 8 & 2,03 & 0,33 & 16 & $a$ \\
\hline $\mathrm{BH}[\%] \mathrm{mit}$ der & So*Di & $P$ & 30 & & & & \\
\hline Kleinen Kohlfliege & So* Di & $\mathrm{P}$ & 60 & nicht & ermittelt & & \\
\hline im Herbst & So*Di & $\mathrm{V}$ & 30 & & & & \\
\hline in $\mathrm{BBCH} 17 / 18$ & So* Di & $\mathrm{V}$ & 60 & & & & \\
\hline
\end{tabular}




\begin{tabular}{|c|c|c|c|c|c|c|c|c|}
\hline & $\mathrm{Fu}$ & & & 1 & & & & \\
\hline & $\mathrm{Fu}$ & & & 2 & & & & \\
\hline & $\mathrm{Fu}$ & & & 3 & & & & \\
\hline & $\mathrm{Fu}$ & & & 4 & nicht & ermittelt & & \\
\hline & $\mathrm{Fu}$ & & & 5 & & & & \\
\hline & $\mathrm{Fu}$ & & & 6 & & & & \\
\hline & $\mathrm{Fu}$ & & & 7 & & & & \\
\hline & $\mathrm{Fu}$ & & & 8 & & & & \\
\hline $\mathrm{BH}[\%] \mathrm{mit}$ der & So* $\mathrm{Di}$ & $\mathrm{P}$ & 30 & & 68,19 & 8,02 & 32 & a \\
\hline Kleinen Kohlfliege & So* $\mathrm{Di}$ & $P$ & 60 & & 62,00 & 9,10 & 32 & $a$ \\
\hline im Frühjahr & So* $\mathrm{Di}$ & V & 30 & & 72,89 & 6,59 & 32 & $a$ \\
\hline \multirow[t]{9}{*}{ in $\mathrm{BBCH} 80 / 81$} & So* $\mathrm{Di}$ & $\mathrm{V}$ & 60 & & 66,50 & 8,69 & 32 & a \\
\hline & $\mathrm{Fu}$ & & & 1 & 68,21 & 6,16 & 16 & $a$ \\
\hline & $\mathrm{Fu}$ & & & 2 & 68,75 & 10,14 & 16 & $a$ \\
\hline & $\mathrm{Fu}$ & & & 3 & 69,00 & 7,81 & 16 & $a$ \\
\hline & $\mathrm{Fu}$ & & & 4 & 67,75 & 7,12 & 16 & $a$ \\
\hline & $\mathrm{Fu}$ & & & 5 & 68,25 & 8,94 & 16 & $a$ \\
\hline & $\mathrm{Fu}$ & & & 6 & 68,25 & 9,24 & 16 & $a$ \\
\hline & $\mathrm{Fu}$ & & & 7 & 66,75 & 8,42 & 16 & $a$ \\
\hline & $\mathrm{Fu}$ & & & 8 & 62,10 & 7,77 & 16 & $a$ \\
\hline
\end{tabular}




\subsection{Einfluss von Bestandes- und Befallsparametern auf die Ertragshöhe}

In diesem Kapitel werden, getrennt für die Versuchsjahre 2010/11 und 2012/13, die Bestandes- und Befallsparameter vorgestellt, die am Standort Göttingen einen wesentlichen Einfluss auf den Kornertrag hatten. Zur Ermittlung der Bestandes- und Befallsparameter, die den stärksten Zusammenhang mit dem Kornertrag aufwiesen, wurden drei verschiedene statistische Analyseverfahren angewendet. Dazu zählten die einfache, lineare Regression, die multiple Regression und die Hauptkomponentenanalyse (principal component analysis, PCA). Die Ergebnisse der einzelnen Analysen werden im Folgenden nacheinander vorgestellt und sollen in der Diskussion in Bezug auf ihren Beitrag und Nutzen bewertet werden. Zu den Bestandes- und Befallsparametern zählen alle Parameter, die nicht im Kapitel Material und Methoden als Ertragsparameter bzw. Ertragsfaktoren definiert wurden. Der Parameter Pflanzen $/ \mathrm{m}^{2}$ im Frühjahr stellt sowohl einen Ertragsfaktor als auch einen wichtigen Bestandesparameter dar. Daher wurden dieser und der Parameter Pflanzen $/ \mathrm{m}^{2}$ im Herbst bei den folgenden Betrachtungen mit berücksichtigt.

\subsubsection{Versuchsjahr 2010/11}

\section{Einfache, lineare Regression}

Die Ergebnisse der einfachen, linearen Regressionsrechnung zwischen allen untersuchten Parametern und der Zielvariablen Kornertrag sind für das Versuchsjahr 2010/11 im Anhang II in der Tab. 22A aufgeführt. Davon werden alle signifikanten (nach Pearson und Spearman) Wechselbeziehungen hier in Tab. 19 wiedergegeben. Durch die einfache, lineare Regression konnte für das Versuchsjahr 2010/11 ermittelt werden, dass der Bestandesparameter Grünfärbung des Pflanzenbestandes in $\mathrm{BBCH} 73$ (NDVI_B4) den stärksten positiven $\left(r_{p}=0,539\right)$ und der Bestandesparameter Anteil an PAR am Boden in BBCH 75 (PAR_B4) den stärksten negativen Einfluss $\left(r_{p}=-0,663\right)$ auf den Kornertrag hatte. Weitere recht hohe, positive Zusammenhänge bestanden mit den Parametern Anzahl an Pflanzen/m² im Frühjahr in BBCH 16/18 (Di_Fj; $r_{p}=0,482$ ), Anzahl an Pflanzen $/ \mathrm{m}^{2}$ im Herbst in $\mathrm{BBCH}$ 14/15 (Di_He; $r_{p}=0,480$ ) und dem Kulturdeckungsgrad im Frühjahr in $\mathrm{BBCH} 32 / 34$ (KDG_Fj; $r_{p}=0,470$ ). Die Parameter Anteil an PAR unter den Schoten in BBCH 75 (PAR_M4; $\left.r_{p}=-0,524\right)$, Wurzelhalsdurchmesser im Frühjahr in $\mathrm{BBCH} 83 / 84$ (WHD_Fj; $\left.r_{p}=-0,476\right)$ und Anteil an 
PAR am Boden in BBCH 67/69 (PAR_B2; $r_{p}=-0,463$ ) zählten zu den Parametern, die nach PAR_B4 noch eine verhältnismäßig hohe negative Korrelation mit dem Kornertrag aufwiesen. Von allen erhobenen Krankheits- oder Schädlingsparametern hatten die Parameter BW mit der Wurzelhals- und Stängelfäule am Wurzelhals im Frühjahr in BBCH 83/84 (BW_Wh_Fj) und die BH mit der Wurzelhals- und Stängelfäule am unteren Stängel im Frühjahr in BBCH 83/84 (BH_St_Fj) einen signifikant negativen Effekt auf den Kornertrag, wobei dieser bei dem Parameter BW_Wh_Fj stärker ausgeprägt war $\left(r_{p}=\right.$ -0,363). Beim Vergleich der genannten Korrelationskoeffizienten fiel auf, dass PAR_B4 mit -0,663 den höchsten negativen Korrelationskoeffizienten aufwies. Die anderen erwähnten positiven und negativen $r_{p}$-Werte zeigten, unabhängig von ihrem Vorzeichen, keine großen Unterschiede. Das verdeutlichen auch die entsprechenden Bestimmtheitsmaße $\left(\mathrm{R}_{\mathrm{p}}^{2}\right)$.

Tab. 19: Signifikante, einfache, lineare Regressionen zwischen verschiedenen Bestandes- bzw. Befallsparametern und der Zielvariablen Kornertrag (Feldversuch Göttingen 2010/11). Dargestellt ist die Anzahl der Werte (n), die in jede Regressionsrechnung eingeflossen sind, der Korrelationskoeffizient nach Pearson $\left(r_{p}\right)$, das Bestimmtheitsmaß nach Pearson $\left(R_{p}{ }^{2}\right)$ und die Überschreitungswahrscheinlichkeit ( $p$-Wert) für die Pearson-Korrelation $\left(p_{p}\right)$. Korrelationen bzw. Bestimmtheitsmaße sind signifikant bei einem Wert $p_{p} \leq 0,05$ (hoch signifikant bei $p_{p} \leq 0,01$, höchst signifikant bei $\left.p_{p} \leq 0,001\right)$. Die Tabelle ist aufsteigend nach den $r_{p}$-Werten sortiert.

\begin{tabular}{lcccc}
\hline Parameter & $\mathbf{n}$ & $\mathbf{r}_{\mathbf{p}}$ & $\mathbf{R}_{\mathbf{p}}{ }^{2}$ & $\mathbf{p}_{\mathbf{p}}$ \\
\hline Anteil an PAR am Boden in BBCH 75 & 119 & $-0,663$ & 0,439 & 0,000 \\
Anteil an PAR unter den Schoten in BBCH 75 & 119 & $-0,524$ & 0,275 & 0,000 \\
Wurzelhalsdurchmesser in BBCH 83/84 & 118 & $-0,476$ & 0,226 & 0,000 \\
Anteil an PAR am Boden in BBCH 67/69 & 119 & $-0,463$ & 0,215 & 0,000 \\
Anteil an PAR am Boden in BBCH 73/74 & 119 & $-0,405$ & 0,164 & 0,000 \\
Seitentriebe/Pflanze & 119 & $-0,375$ & 0,141 & 0,000 \\
BW mit der Wurzelhals- und Stängelfäule & 119 & $-0,363$ & 0,132 & 0,000 \\
am Wurzelhals in BBCH 83/84 & 119 & $-0,356$ & 0,126 & 0,000 \\
Anteil an PAR am Boden in BBCH 63/65 & 119 & $-0,354$ & 0,125 & 0,000 \\
Anteil an PAR unter den Schoten in BBCH 67/69 & 119 & $-0,323$ & 0,104 & 0,000 \\
absolute Anzahl an Schoten am 2. Seitentrieb & 119 & $-0,315$ & 0,099 & 0,000 \\
Grünfärbung des Pflanzenbestandesin BBCH 65/66 & 119 & $-0,300$ & 0,090 & 0,001 \\
absolute Anzahl an Schoten am 1. Seitentrieb & 119 & $-0,284$ & 0,080 & 0,002 \\
Anteil an PAR unter den Schoten in BBCH 73/74 & 119 & $-0,279$ & 0,078 & 0,002 \\
\hline absolute Anzahl an Schoten am Haupttrieb & & & &
\end{tabular}




\begin{tabular}{lllll}
\hline absolute Anzahl an Schoten am 3. Seitentrieb & 119 & $-0,278$ & 0,077 & 0,002 \\
Grünfärbung des Pflanzenbestandes in BBCH 89 & 119 & $-0,271$ & 0,074 & 0,003 \\
Wurzelhalsdurchmesser in BBCH 16/18 (He)* & 119 & $-0,206$ & 0,043 & 0,024 \\
BH mit der Wurzelhals- und Stängelfäule & 119 & $-0,198$ & 0,039 & 0,031 \\
am unteren Stängel in BBCH 83/84 & 119 & $-0,194$ & 0,038 & 0,035 \\
absolute Anzahl an Schoten am 4. Seitentrieb & 119 & 0,226 & 0,051 & 0,014 \\
relativer Anteil an Schoten am Haupttrieb & 119 & 0,237 & 0,056 & 0,009 \\
Schotenansatzhöhe in BBCH 75 & 119 & 0,273 & 0,075 & 0,003 \\
Bestandeshöhe in BBCH 75 & 119 & 0,280 & 0,078 & 0,002 \\
Bestandeshöhe in BBCH 65/67 & 119 & 0,304 & 0,093 & 0,001 \\
Grünfärbung des Pflanzenbestandes in BBCH 84 & 119 & 0,307 & 0,094 & 0,001 \\
relativer Anteil an Schoten am 4. Seitentrieb & 119 & 0,313 & 0,098 & 0,001 \\
Schotenschichtdicke in BBCH 65/67 & 119 & 0,333 & 0,111 & 0,000 \\
Schotenschichtdicke in BBCH 73/74 & 119 & 0,367 & 0,135 & 0,000 \\
Grünfärbung des Pflanzenbestandes in BBCH 79 & 119 & 0,470 & 0,221 & 0,000 \\
Kulturdeckungsgrad in BBCH 32/34 & 119 & 0,480 & 0,230 & 0,000 \\
Pflanzen/m² in BBCH 14/15 (He) & 119 & 0,482 & 0,232 & 0,000 \\
Pflanzen/m² in BBCH 16/18 (Fj) & 119 & 0,539 & 0,290 & 0,000 \\
\hline Grünfärbung des Pflanzenbestandesin BBCH 73 & & &
\end{tabular}

${ }^{*} \mathrm{He}=$ Herbst, $\mathrm{Fj}=$ Frühjahr

\section{Multiple Regression - Kornertrag}

Für die Ermittlung der Bestandesparameter, die den stärksten Zusammenhang mit der jeweiligen Zielvariablen hatten, wurden multiple Regressionsanalysen durchgeführt. Die dabei erhaltenen Regressionsmodelle bestanden jeweils aus mehreren x-Variablen (erklärende Variablen oder Prädiktoren), die die Varianz der y-Variable (Zielvariable) bei einem Signifikanzniveau von $p \leq 0,05$ erklärten. Von jedem Modell dienten die ersten beiden erklärenden Variablen für eine hierarchische Darstellung. Diese zwei Variablen wurden in einem nächsten Schritt als neue Zielvariablen in jeweils einer weiteren multiplen Regressionsanalyse verwendet. Aus den neu erhaltenen Regressionsmodellen gingen wieder die ersten beiden Prädiktoren in die hierarchische Abbildung bzw. in die nächste multiple Regression ein. Diese beschriebene Vorgehensweise ermöglichte es, die Abhängigkeiten zwischen den einzelnen Parametern aufzuschlüsseln. Wegen einer besseren Übersicht und weil die ersten zwei Prädiktoren den stärksten Zusammenhang mit der jeweiligen Zielvariablen hatten, wurden nur diese in der hierarchischen Abbildung aufgeführt. Für insgesamt drei Hierarchieebenen wurden die Abhängigkeiten untersucht. 
Die partiellen $\mathrm{R}^{2}$-Werte, die das Maß für die Güte des Zusammenhangs zwischen zwei Parametern darstellen, wurden in Prozent umgerechnet und in den Abbildungen wiedergegeben.

Bei der multiplen Regression kann das Problem der Multikollinearität auftreten. Multikollinearität liegt vor, wenn zwei oder mehr erklärende Variablen stark voneinander abhängig sind. In diesem Fall ist eine Modellinterpretation nicht mehr eindeutig möglich, da der Beitrag eines Prädiktors zur Erklärung der Varianz der Zielvariablen nicht genau identifiziert werden kann. Weiterhin kann dies dazu führen, dass signifikante Prädiktoren als nicht signifikant bewertet werden und dadurch nicht in das Regressionsmodell aufgenommen werden (FIELD, 2006). In statistischen Analyseprogrammen werden für die Diagnose der Multikollinearität die Kennwerte Toleranz und Variance Inflation Factor (VIF) berechnet. Ein geringer Toleranzwert $(<0,2)$ bzw. ein hoher VIF-Wert $(>10)$ deuten auf lineare Abhängigkeiten mit anderen Prädiktoren hin (MYERS, 1990; MENARD, 1995). Wenn das Problem der Multikollinearität bei einer multiplen Regression auftrat, wurde die Regressionsanalyse noch einmal durchgeführt, wobei einer oder mehrere abhängige Prädiktoren ausgeschlossen wurden. Die Ergebnisse aller durchgeführten multiplen Regressionen, befinden sich auszugsweise im Anhang II in den Tabellen 28A - 67A.

Die hierarchische Darstellung in Abb. 24 beruht auf signifikanten Regressionsmodellen, die im Anhang II in den Tabellen $28 \mathrm{~A}$ bis $41 \mathrm{~A}$ zu finden sind und zeigt für das Jahr 2010/11, die Zusammenhänge zwischen bestimmten Parametern ausgehend von der Zielvariablen Kornertrag. Der Kornertrag wurde am stärksten durch den Parameter Anteil an PAR am Boden in BBCH 75 (PAR_B4) mit 43,7\% (partielles $\mathrm{R}^{2}=0,437$ ) beeinflusst, gefolgt von dem Parameter Grünfärbung des Pflanzenbestandes in BBCH 73 (NDVI_B4) mit 6,6\%. PAR_B4 war dabei negativ und NDVI_B4 positiv mit dem Kornertrag korreliert. Aus Abb. 25 wird ersichtlich, dass die Parameter NDVI_B4 und PAR_B4 negativ miteinander korreliert waren $\left(r_{p}=-0,481\right)$. Eine Hierarchieebene weiter zeigt sich, dass der Parameter PAR_B4 vor allem von dem Parameter Anteil an PAR unter den Schoten in BBCH 75 (PAR_M4; 78,5\%) abhängig war. Beide Parameter waren positiv miteinander korreliert. Mit 2,2\% hatte der Parameter NDVI_B4 den zweitstärksten Einfluss auf PAR_B4, wobei dieser in einer negativen Beziehung zu PAR_B4 stand. Der Kulturdeckungsgrad im Frühjahr in $\mathrm{BBCH}$ 32/34 (KDG_Fj) zeigte den größten Zusammenhang (40,6\%) mit dem Parameter PAR_M4. Den zweitgrößten Zusammenhang mit PAR_M4, wies der Parameter absolute Anzahl an Schoten am 1. Seitentrieb (abs_01; 5,6\%) auf. KDG_Fj war negativ und abs_01 war positiv mit PAR_M4 korreliert. Mit 65,6\% hatte die Anzahl an Pflanzen/m² im Frühjahr in BBCH 16/18 (Di_Fj) 
den größten Einfluss auf den KDG_Fj (Daten in Abb. 24 nicht angegeben, vgl. Tab. 40A/41A im Anhang II). Dabei war Di_Fj positiv mit KDG_Fj korreliert. NDVI_B4 wurde am stärksten $(29,3 \%)$ durch den Wurzelhalsdurchmesser im Frühjahr in $\mathrm{BBCH} 83 / 84$ (WHD_Fj) beeinflusst. An zweiter Stelle folgte der BW mit der Wurzelhals- und Stängelfäule am Wurzelhals im Frühjahr in BBCH 83/84 (BW_Wh_Fj; 3,9\%). Beide Prädiktoren waren negativ mit NDVI_B4 korreliert. Auf der nächsten Hierarchieebene zeigt sich, dass der WHD_Fj besonders von der Pflanzendichte im Herbst in BBCH 14/15 (Di_He; 56,3\%) abhängig war, gefolgt von der Schotenschichtdicke in BBCH 73/74 (Schi_3; 8,1\%). Dabei wiesen beide Parameter einen negativen Zusammenhang mit WHD_Fj auf. BW_WH_Fj wurde am stärksten von der Pflanzendichte im Frühjahr in BBCH 16/18 (Di_Fj; 32,5\%) beeinflusst. Als nächste erklärende Variable für den Parameter BW_Wh_Fj wurde der Parameter BW mit der Wurzelhals- und Stängelfäule am unteren Stängel im Frühjahr in BBCH 83/84 (BW_St_Fj; 20,9\%) ermittelt. Letzterer war positiv und Di_Fj war negativ mit BW_Wh_Fj korreliert. 


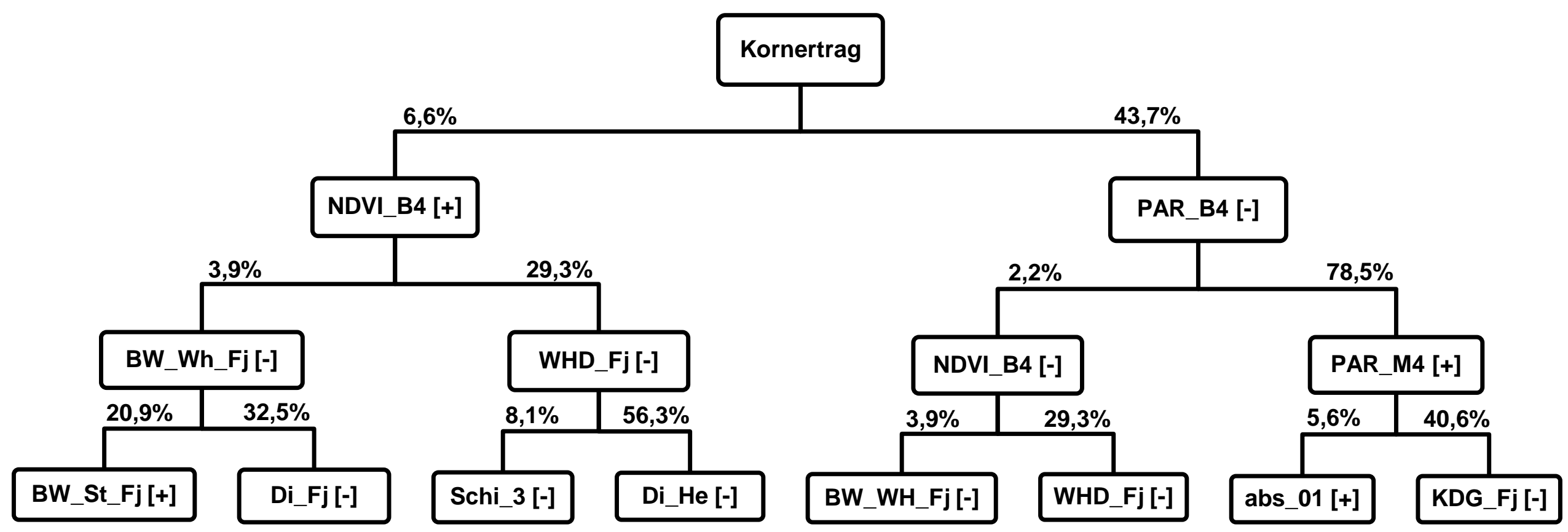

Abb. 24: Hierarchische Darstellung von Parametern, die im Versuchsjahr 2010/11 die Zielvariable Kornertrag maßgeblich beeinflusst haben bzw. von denen sie selbst beeinflusst wurden. Die Prozentzahlen stellen das partielle $R^{2}$ dar und drücken das Maß der Güte des Zusammenhangs mit der jeweiligen Zielvariable aus. Auf jeder Hierarchieebene ist der erste und zweite Prädiktor für die entsprechende Zielvariable dargestellt. Alle weiteren Prädiktoren, die eine Zielvariable beschreiben, wurden in dieser Darstellung nicht berücksichtigt. Diese Abbildung beruht auf den Ergebnissen mehrerer multipler Regressionen, wovon die Ergebnisse auszugsweise im Anhang II in den Tabellen 28A - 41A zu finden sind. Ein Parameter wurde als Prädiktor für die jeweilige Zielvariable in das Regressionsmodell aufgenommen, wenn dieser ein Signifikanzniveau von $p \leq 0,05$ einhielt. $[+]=$ positiv bzw. $[-]=$ negativ mit der Zielvariable korreliert. Erklärungen der Parameterabkürzungen: NDVI_B4 = Grünfärbung des Pflanzenbestandes in BBCH 73; PAR_B4 = Anteil photosynthetisch aktiver Strahlung am Boden [\%] in BBCH 75; PAR_M4 = Anteil photosynthetisch aktiver Strahlung unter den Schoten [\%] in BBCH 75; KDG_Fj = Kulturdeckungsgrad [\%] im Frühjahr in $\mathrm{BBCH}$ 32/34; abs_01 = absolute Anzahl an Schoten am 1. Seitentrieb; BW_Wh_Fj = Befallswert mit der Wurzelhals- und Stängelfäule am Wurzelhals im Frühjahr in $\mathrm{BBCH}$ 83/84; BW_St_Fj = Befallswert mit der Wurzelhals- und Stängelfäule am unteren Stängel im Frühjahr in BBCH 83/84; WHD_Fj = Wurzelhalsdurchmesser [mm] im Frühjahr in BBCH 83/84; Di_He = Pflanzen $/ \mathrm{m}^{2} \mathrm{im}$ Herbst in BBCH 14/15; Di_Fj $=$ Pflanzen $/ \mathrm{m}^{2}$ im Frühjahr in BBCH 16/18; Schi_3 = Schotenschichtdicke [cm] in BBCH 73/74. 


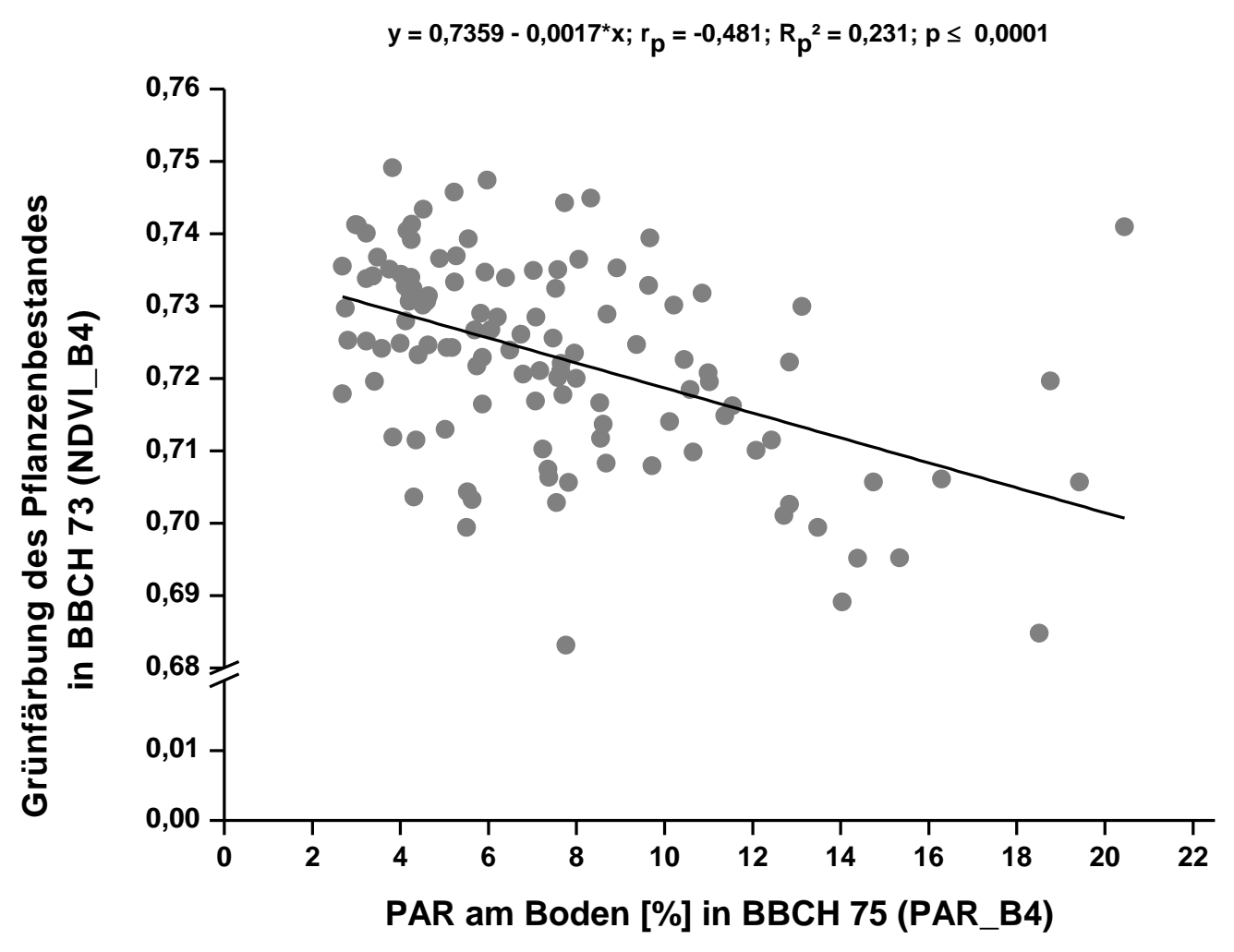

Abb. 25: Einfache, lineare Regression zwischen dem Anteil an PAR am Boden in BBCH 75 (PAR_B4) und der Grünfärbung des Pflanzenbestandes in BBCH 73 (NDVI_B4), berechnet aus den Daten, die im Versuchsjahr 2010/11 im Feldversuch in Göttingen erhoben wurden. Zur Ermittlung des $p$-Wertes wurde der globale F-Test verwendet $(p \leq 0,05) . \quad\left(r_{p}=\right.$ Korrelationskoeffizient nach Pearson, $R_{p}{ }^{2}=$ Bestimmtheitsmaß nach Pearson, $n=120$ )

\section{Hauptkomponentenanalyse (PCA)}

Die PCA ist ein dimensionsreduzierendes Verfahren, bei dem möglichst wenige Informationen verloren gehen sollen. Die PCA errechnet sogenannte Hauptkomponenten $(\mathrm{HK})$, die ein Maximum an gemeinsamer Varianz aller Variablen (hier Parameter) wiedergeben sollen. Dabei nimmt die erste HK den größten Anteil der Varianz im gesamten Datensatz auf, die zweite HK das Maximum der verbleibenden Varianz usw. (SCHNELL, 1994). Ziel ist es, mit wenigen HK (neuen latenten Variablen) alle Ausgangsvariablen zu beschreiben (Datenreduktion). Nach (KRZANOWSKI, 1990) sollten die ausgewählten HK insgesamt mindestens 75-80 \% der Varianz erreichen. Die HK sind Linearkombinationen der Ausgangsvariablen ( $\mathrm{x}$; hier Ausgangsparameter). Sie setzen sich aus der Summe der Variablen (x), multipliziert mit ihren jeweiligen Faktorladungen (a) zusammen, wie aus dem Beispiel für die erste HK hervorgeht. 
Beispiel: erste $H K=a_{1} x_{1}+a_{2} x_{2}+a_{3} x_{3}+\ldots a_{p} x_{p}$

$a=$ Ladungen; $x=$ Variablen (Parameter); $p=$ Anzahl der Variablen (SCHNELL, 1994)

Die Faktorladungen (a) sind eine Maßgröße für den Zusammenhang zwischen ursprünglichen Variablen und der jeweiligen HK, d.h. sie sind Korrelationskoeffizienten zwischen HK und Variablen (BACKHAUS et al., 1996). Dabei stehen negative bzw. positive Faktorladungen für eine negative bzw. positive Korrelation. Die Ergebnisse der PCA können als Biplot dargestellt werden. In einem Biplot werden die Zeilen und Spalten einer Matrix in einem zweidimensionalen Diagramm dargestellt (GoWER and HAND, 1996). Die Zeilen entsprechen hier den Kombinationen aus den drei Versuchsfaktoren Sorte, Saatstärke und Fungizidvariante [Beobachtungen, (Mittelwerte der meist 4 Wiederholungen)] und die Spalten repräsentieren die erhobenen bzw. berechneten Parameter. Die 32 verschiedenen Kombinationen aus den drei Versuchsfaktoren sind in blau durch zwei Buchstaben und eine Zahl dargestellt. Der erste Buchstabe stellt die Abkürzung der Winterrapssorte dar [M = SY Merlot (nur 2010/11), P = NK Petrol, V = SY Vesuvio (nur 2012/13)], der zweite Buchstabe ist die Abkürzung für die Saatstärke ( $I$ = low $=30 \mathrm{Körner} / \mathrm{m}^{2}, \mathrm{~h}=$ high $=60 \mathrm{Körner} / \mathrm{m}^{2}$ ) und die Zahl steht für die Fungizidvarianten (vgl. Tab. 3 bzw. Tab. 4). Die 69 Parameter werden durch rote Striche, die vom Ursprung ausgehen, dargestellt. An den Strichenden sind Parameterabkürzungen angegeben, die in der Abbildungsunterschrift vom Biplot erklärt werden. Die Abszisse stellt bei der PCA die erste HK und die Ordinate die zweite HK dar. Der Winkel zwischen zwei Parametern (Striche) oder einem Parameter und einer HK approximiert die Korrelation zwischen den Parametern oder einem Parameter und einer HK. Ein Winkel von $90^{\circ}$ oder $270^{\circ}$ bedeutet keine Korrelation, einer von $0^{\circ}$ oder $360^{\circ}$ bedeutet perfekte positive Korrelation und einer von $180^{\circ}$ perfekte negative Korrelation. Die Länge der Striche gibt die Stärke des Einflusses eines Parameters auf einen anderen Parameter oder auf eine HK an. Nahe beieinander liegende Kombinationen aus den drei Versuchsfaktoren (blaue BuchstabenZahlen-Kombinationen) besitzen ähnliche Ausprägungen auf allen Parametern, die sich in der Nähe der Kombinationen aus den drei Versuchsfaktoren befinden (ANONYMUS, 2014b; SCHNELL, 1994).

In Abb. 26 ist der Biplot der PCA mit den Ergebnissen zu allen Parametern aus dem Versuchsjahr 2010/11 dargestellt. Für eine einfachere Beschreibung des Biplots wird dieser in vier Quadranten eingeteilt. Der 1. Quadrant liegt links oben, der 2. Quadrant rechts oben, der 3. Quadrant rechts unten und der 4. Quadrant links unten. Beide HK erklären zusammen 57,11\% der Varianz der Daten im kompletten Datensatz (1. HK = $37,52 \%$ und 2. HK = 19,59\%). Anhand der Faktorladungen (Tab. 68A im Anhang II) wird deutlich, dass in die erste HK insbesondere die Parameter Kulturdeckungsgrad im 
Frühjahr in BBCH 32/34 (BG_2, 4 Quadrant; -0,187) und Anteil an PAR am Boden in BBCH 75 (P_B4, 2. Quadrant; 0,179) eingegangen waren. Diese Parameter wiesen zugleich auch die längsten Strichlängen und die geringste Winkeldifferenz auf. Die zweite HK wurde vor allem durch die Parameter Wurzelhalsdurchmesser im Herbst in BBCH 16/18 (WD_1, 1. Quadrant; -0,228) und Grünfärbung des Pflanzenbestandes in BBCH 84 (N_A3, 3. Quadrant; 0,213) beeinflusst. Weiterhin flossen mit hohen negativen sowie positiven Faktorladungen folgende Parameter in die erste HK ein: die Pflanzendichte im Frühjahr in $\mathrm{BBCH}$ 16/18 (D_2, 3. Quadrant; -0,176), die Pflanzendichte im Herbst in BBCH 14/15 (D_1; 3 Quadrant; -0,164), der Anteil an PAR am Boden in BBCH 67/69 (P_B2, 2. Quadrant, 0,177) und der Anteil an PAR unter den Schoten in BBCH 75 (P_M4, 2. Quadrant; 0,175). Im Vergleich zu den anderen Parametern, hatten alle Parameter von PAR einen recht starken Einfluss auf die erste HK (vgl. Tab. 68A). Die zweite HK wurde durch folgende Parameter zusätzlich stärker negativ oder positiv beeinflusst: NDVI_Dauer (NI, 3 Quadrant; -0,197), Ölgehalt (OG, 3. Quadrant; -0,193), Schotenansatzhöhe in BBCH 73/74 (Sh3, 1. Quadrant; 0,204) und Anzahl Körner/Schote (KS, 2. Quadrant; 0,193). Insgesamt waren die Faktorladungen der einzelnen Parameter für die erste HK und zweite HK eher niedrig, sodass die jeweilige HK nicht durch einige wenige, sondern durch eine Vielzahl von Parametern erklärt wurde. Daher beschrieben die erste und zweite HK auch nicht sehr viel Varianz im kompletten Datensatz der ganzen Parameter. Dieser Umstand zeigte sich im Biplot durch eine sternförmige Anordnung der einzelnen Striche (Parameter).

Im 1. Quadranten lagen alle Messtermine des Parameters Schotenansatzhöhe (Sh1-4) und des Parameters Bestandeshöhe (H_1-4) nah beieinander. Diese waren demnach eng miteinander korreliert und beeinflussten sich auch annähernd gleich stark (Strichlänge). Da sie etwa im $45^{\circ}$-Winkel standen, gingen sie zu gleichen Werten in die entsprechende HK ein. Dabei beeinflussten sie die zweite HK positiv und die erste HK negativ. Diese Parameter waren mit den Parametern der Grünfärbung des Pflanzenbestandes in $\mathrm{BBCH}$ 79, 81, 84, 85/87 und 89 (N_A1-5) negativ korreliert. Der Parameter Kornertrag (Yd) lag im 4. Quadranten und war u.a. mit dem Ölertrag (OE), der Grünfärbung des Pflanzenbestandes in $\mathrm{BBCH} 73$ (N_B4), dem Strohbiomasseertrag (DM), der Schotenschichtdicke in $\mathrm{BBCH} 73 / 74$ (Si3) und 75 (Si4), der relativen Anzahl an Schoten am Haupttrieb (r_0), der Pflanzendichte im Herbst in BBCH 14/15 (D_1), der Pflanzendichte im Frühjahr in BBCH 16/18 (D_2), dem Kulturdeckungsgrad im Frühjahr in BBCH 32/34 (BG_2) und den Schoten/m² (Sm2) positiv korreliert. Allerdings beeinflussten die Parameter OE, N_B4, D_1, D_2 und BG_2 den Kornertrag stärker als die Parameter Sm2, r_0, Si3, Si4 und DM. Die Parameter, die im 2. Quadranten lagen, waren negativ mit dem Kornertrag aber auch mit allen anderen Parametern im 4. Quadranten korreliert. Die 
Parameter mit einem längeren Strich, wie z.B. Wurzelhalsdurchmesser im Frühjahr in BBCH 32/34 (WD_2) oder Anteil an PAR am Boden in BBCH 75 (P_B4) beeinflussten den Kornertrag stärker negativ als Parameter mit einem kürzeren Strich, wie z.B. absolute Anzahl an Schoten am 1., 2., 3. und 4. Seitentrieb (a_1, a_2, a_3 und a_4) oder BW mit der Wurzelhals- und Stängelfäule am Wurzelhals im Frühjahr in $\mathrm{BBCH}$ 83/84 (PW_2). PW_2 war mit allen Parametern im 2. Quadranten positiv und mit allen Parametern im 4. Quadranten negativ korreliert. Von den positiv korrelierten Parametern hatten vor allem die Parameter Wurzelhalsdurchmesser im Frühjahr in $\mathrm{BBCH}$ 83/84 (WD_2), Seitentriebe/Pflanze (StP), Schoten/Pflanze (SP), Anteil an PAR unter den Schoten in BBCH 75 (P_M4) und Anteil an PAR am Boden in BBCH 67/69 (P_B2) und BBCH 75 (P_B4) einen stärkeren Einfluss auf PW_2. Von den negativ korrelierten Parametern beeinflussten insbesondere BG_2, D_2 und D_1 den Parameter PW_2.

Die Kombinationen aus den drei Versuchsfaktoren konnten entsprechend der Sorten $\mathrm{x}$ Saatstärkenkombinationen in vier Gruppen eingeteilt werden (vgl. schwarze Ellipsen). Auf der 1. PCA-Achse differenzierten insbesondere die Sorten $x$ Saatstärkenkombinationen NK Petrol x $60 \mathrm{Körner} / \mathrm{m}^{2}$ (Ph) und SY Merlot x $30 \mathrm{Körner} / \mathrm{m}^{2}$ (Ml). Die Kombinationen der Versuchsfaktoren von $\mathrm{Ph}$ lagen im 1. und 4. Quadranten und hatten alle ähnliche Ausprägungen (und somit hohe Werte) bei folgenden Parametern: BG_2, relative Anzahl an Schoten am 3. und 4. Seitentrieb (r_3 und r_4) Sm2, Korndichte (KD), Blätter/Pflanze (BP) und weitere. Die Kombinationen der Versuchsfaktoren von Ml befanden sich im 2. und 3. Quadranten und hatten alle ähnliche Ausprägungen (und somit hohe Werte) bei folgenden Parametern: P_B4, P_M4, P_B2, P_M2, StP, SP, Grünfärbung des Pflanzenbestandes in $\mathrm{BBCH}$ 65/66 (N_B2) etc. Auf der 2. PCA-Achse unterschieden sich die Sorten x Saatstärkenkombinationen NK Petrol x 30 Körner $/ \mathrm{m}^{2}(\mathrm{Pl})$ und SY Merlot x 60 Körner/m² (Mh) voneinander. Dabei lagen alle Kombinationen der Versuchsfaktoren von $\mathrm{PI}$ im 1. und 2. Quadranten und wurden vor allem durch die Parameter Wurzelhalsdurchmesser im Herbst in BBCH 16/18 (WD_1), Körner/Schote (KS), BW mit der Wurzelhals- und Stängelfäule am unteren Stängel im Frühjahr in BBCH 83/84 (PW_S) und BW sowie $\mathrm{BH}$ mit der Wurzelhals- und Stängelfäule an Laubblättern (Blattläsionen) im Herbst in BBCH 16/18 (PW_P und PH_P) charakterisiert. Die Kombinationen der Versuchsfaktoren von Mh lagen im 3. und 4. Quadranten und wiesen u.a. ähnliche Ausprägungen (und somit hohe Werte) bei den Parametern relative Anzahl an Schoten am 1. Seitentrieb (r_1), Grünfärbung des Pflanzenbestandes in $\mathrm{BBCH} 79$ (N_A1) und 84 (N_A3) und Ölgehalt (OG) auf. 


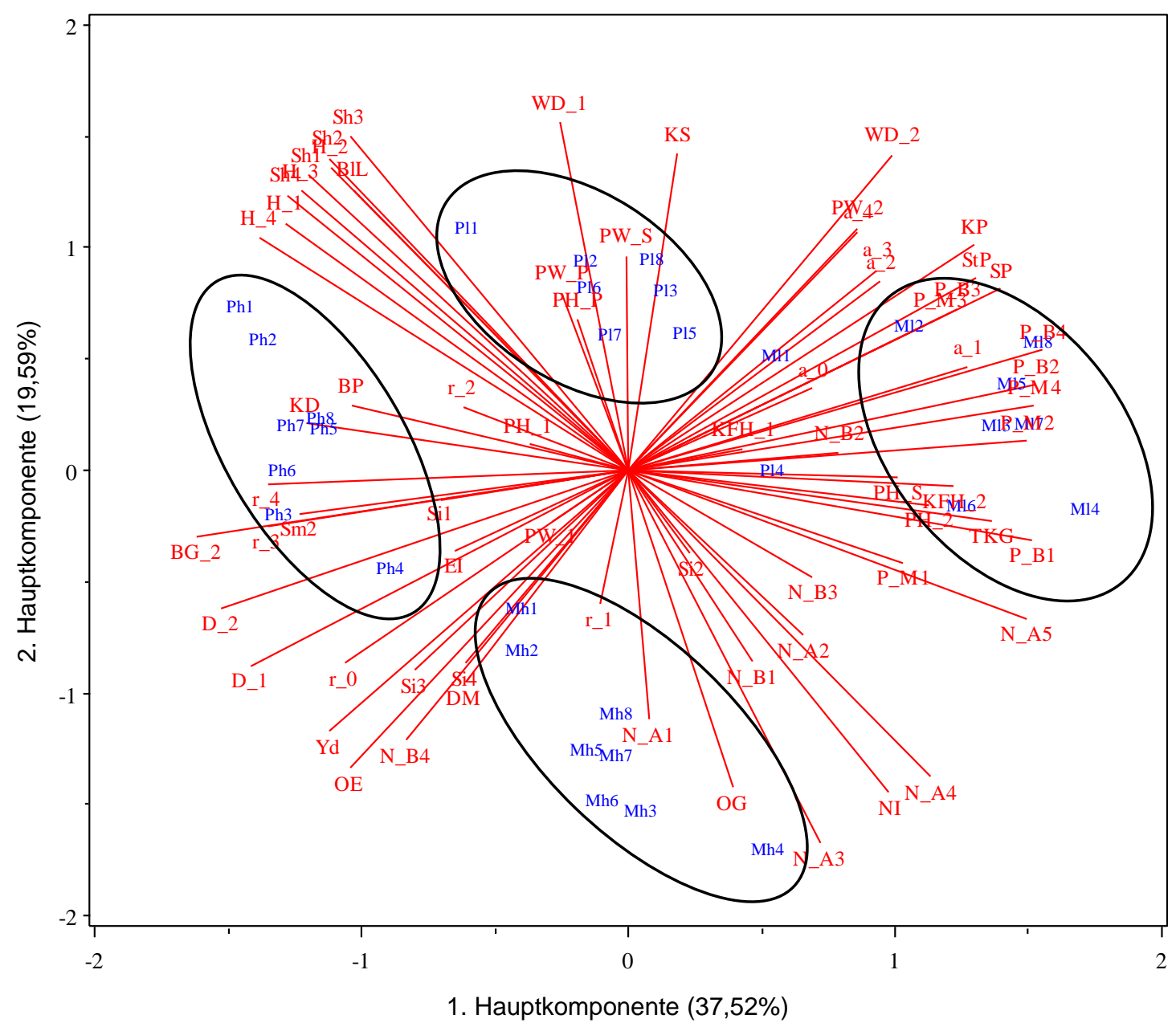

Abb. 26: Biplot zur Visualisierung der Hauptkomponentenanalyse, die mit Daten von allen Parametern aus dem Versuchsjahr 2010/11 vom Feldversuch am Standort Göttingen durchgeführt wurde. Die Prozentzahlen geben jeweils an, wie viel Varianz die jeweilige HK im gesamten Datensatz erklärt. In blau (Buchstaben- und Zahlenkombinationen) sind die 32 Beobachtungen (Mittelwerte aus meist 4 Wiederholungen) entsprechend der verschiedenen Kombinationen aus den drei Versuchsfaktoren Sorte, Saatstärke und Fungizidvariante dargestellt. Der erste Buchstabe repräsentiert die Winterrapssorte $(\mathrm{M}=\mathrm{SY}$ Merlot, $\mathrm{P}=\mathrm{NK}$ Petrol), der zweite Buchstabe steht für die Saatstärke $\left(I=\right.$ low $=30 \mathrm{Körner} / \mathrm{m}^{2}, \mathrm{~h}=$ high $\left.=60 \mathrm{Körner} / \mathrm{m}^{2}\right)$ und die Zahl steht für die einzelnen Fungizidvarianten (vgl. Tab. 3 bzw. Tab. 4). Die schwarzen Ellipsen bedeuten, dass die Kombinationen aus den drei Versuchsfaktoren entsprechend der Sorten $x$ Saatstärkenkombinationen in vier Gruppen eingeteilt werden konnten. Die roten Striche symbolisieren die 69 Parameter, die in dem Versuchsjahr erhoben wurden. An den Strichenden ist jeweils eine Parameterabkürzung angegeben. Erklärung der Parameterabkürzungen: $Y d=$ Kornertrag [t/ha], DM = SBME = Strohbiomasseertrag [t/ha]; OG = Ölgehalt [\%]; OE = Ölertrag [t/ha]; El = Ernteindex [\%]; D_2 = Di_Fj = Pflanzen/m² im Frühjahr in BBCH 16/18; SP = SpP = Schoten pro Pflanze; TKG = TKM = Tausendkornmasse [g]; KS = KpS = Körner pro Schote; Sm2= Spm2 = Schoten pro $\mathrm{m}^{2} ; \mathrm{KP}=\mathrm{KpP}=$ Körner pro Pflanze; KD = Korn_Di = Korndichte; BG_2 = KDG_Fj $=$ Kulturdeckungsgrad [\%] im Frühjahr; WD_2 $=$ WHD_Fj $=$ Wurzelhalsdurchmesser [mm] 
im Frühjahr in $\mathrm{BBCH}$ 83/84; StP $=\mathrm{StpP}=$ Seitentriebe pro Pflanze; H_1-4 = Hoe_1-4 = Bestandeshöhe [cm] in BBCH 65/67 (1), 67/69 (2), 73/74 (3) und 75 (4); Sh1-4 = Sah_1-4 = Schotenansatzhöhe [cm] in 65/67 (1), 67/69 (2), 73/74 (3) und 75 (4); Si1-4 = Schi_1-4 = Schotenschichtdicke [cm] in BBCH 65/67 (1), 67/69 (2), 73/74 (3) und 75 (4); a_0-4 = abs_00-04 = absolute Anzahl an Schoten am Haupttrieb (00), am 1. Seitentrieb (01), am 2. Seitentrieb (02) usw.; r_0-4 = rel_00-04 = relative Anzahl an Schoten am Haupttrieb (00), am 1. Seitentrieb (01), am 2. Seitentrieb (02) usw.; P_M1-4 = PAR_M1-4 = Anteil an photosynthetisch aktiver Strahlung [\%] unter den Schoten in BBCH 63/65 (1), $67 / 69$ (2), 73/74 (3) und 75 (4); P_B1-4 = PAR_B1-4 = Anteil an photosynthetisch aktiver Strahlung [\%] am Boden in BBCH 63/65 (1), 67/69 (2), 73/74 (3) und 75 (4); NI = NDVI_Dauer = Integration der NDVI-Kurve über den entsprechenden Erhebungszeitraum; N_B1-4 = NDVI_B1-4 = Grünfärbung des Pflanzenbestandes in BBCH 64/65 (1), 65/66 (2), 69 (3) und 73 (4); N_A1-5 = NDVI_A1-5 = Grünfärbung des Pflanzenbestandes in BBCH 79 (1), 81 (2), 84 (3), 85/87 (4) und 89 (5); D_1 = DI_He = Pflanzen $/ \mathrm{m}^{2}$ im Herbst in BBCH 14/15; WD_1 = WHD_He = Wurzelhalsdurchmesser im Herbst [mm] in BBCH 16/18; BIL = Blattlae $=$ Blattlänge $[\mathrm{cm}] ; \mathrm{BP}=\mathrm{BpP}=$ Blätter pro Pflanze; PW_S $=$ BW_St_Fj $=$ Befallswert mit der Wurzelhals- und Stängelfäule am unteren Stängel im Frühjahr in BBCH 83/84; PH_S =BH_St_Fj = Befallshäufigkeit [\%] mit der Wurzelhals- und Stängelfäule am unteren Stängel im Frühjahr in BBCH 83/84; PW_2 = BW_Wh_Fj = Befallswert mit der Wurzelhals- und Stängelfäule am Wurzelhals im Frühjahr in $\mathrm{BBCH}$ 83/84; $\mathrm{PH} \_2=\mathrm{BH} \_W h \_F j=$ Befallshäufigkeit [\%] mit der Wurzelhals- und Stängelfäule am Wurzelhals im Frühjahr in $\mathrm{BBCH}$ 83/84; PW_P = BW_He = Befallswert mit der Wurzelhals- und Stängelfäule an Laubblättern (Blattläsionen) im Herbst in $\mathrm{BBCH}$ 16/18; $\mathrm{PH} \_\mathrm{P}=\mathrm{BH} \_\mathrm{He}=$ Befallshäufigkeit [\%] mit der Wurzelhals- und Stängelfäule an Laubblättern (Blattläsionen) im Herbst in BBCH 16/18; PW_1 = BW_Wh_He = Befallswert mit der Wurzelhals- und Stängelfäule am Wurzelhals im Herbst in BBCH 16/18; PH_1 = BH_Wh_He = Befallshäufigkeit [\%] mit der Wurzelhals- und Stängelfäule am Wurzelhals im Herbst in $\mathrm{BBCH}$ 16/18; KFH_2 = BH_Kf_Fj = Befallshäufigkeit [\%] mit der Kleinen Kohlfliege im Frühjahr in BBCH 83/84; $\mathrm{KFH} \_1=\mathrm{BH} \_\mathrm{Kf} \_H e=$ Befallshäufigkeit [\%] mit der Kleinen Kohlfliege im Herbst in BBCH 16/18. 


\subsubsection{Versuchsjahr 2012/13}

\section{Einfache, lineare Regression}

Die Ergebnisse der einfachen, linearen Regressionsrechnung zwischen allen untersuchten Parametern und der Zielvariablen Kornertrag sind für das Versuchsjahr 2012/13 im Anhang II in Tab. 24A aufgeführt. Aus dieser Tabelle wurden alle signifikanten (nach Pearson und Spearman) Ergebnisse der Bestandes- und Befallsparameter entnommen und in Tab. 20 wiedergegeben. Durch die einfache, lineare Regression konnte für das Versuchsjahr 2012/13 ermittelt werden, dass der Parameter Schotenansatzhöhe in BBCH 75 (Sah_4) den stärksten positiven $\left(r_{p}=0,547\right)$ und der Parameter Grünfärbung des Pflanzenbestandes in BBCH 64/65 (NDVI_B1) den stärksten negativen Einfluss $\left(r_{p}=-0,367\right)$ auf den Kornertrag hatte. Neben Sah_4 wiesen auch die anderen Messtermine, zu denen die Schotenansatzhöhe bestimmt wurde [BBCH 65/67 (1), $\mathrm{BBCH} 67 / 69$ (2) und $\mathrm{BBCH}$ 73/74(3)] sowie die Bestandeshöhe, einen verhältnismäßig hohen positiven Zusammenhang mit dem Kornertrag auf. Dabei folgte hinter Sah_4 die Schotenansatzhöhe in BBCH 73/74 (Sah_3; $r_{p}=0,546$ ), die Schotenansatzhöhe in BBCH 67/69 (Sah_2; $r_{p}=0,536$ ) und die Schotenansatzhöhe in BBCH 65/67 (Sah_1; $r_{p}=0,527$ ). Von den vier Messterminen der Bestandeshöhe, hatte die Bestandeshöhe in BBCH 65/67 (Hoe_1) den größten Einfluss $\left(r_{p}=0,494\right)$ auf den Kornertrag. Dahinter reihten sich die anderen Messtermine ein (Hoe_2: $r_{p}=0,492 ;$ Hoe_3: $r_{p}=0,475$ und Hoe_4: $\left.r_{p}=0,448\right)$. Die Parameter Grünfärbung des Pflanzenbestandes in BBCH 79 und 81 (NDVI_A1 und NDVI_A2) wiesen mit $r_{p}=-0,337$ und $r_{p}=-0,279$ die zweit- und drittstärkste negative Korrelation mit dem Kornertrag auf. Die Parameter $\mathrm{BH}$ bzw. BW mit der Wurzelhals- und Stängelfäule am unteren Stängel im Frühjahr in BBCH 80/81 (BH_St_Fj: $r_{p}=0,240$ bzw. BW_St_Fj: $r_{p}=0,251$ ) und die Parameter BH und BW mit der Wurzelhals- und Stängelfäule an Laubblättern (Blattläsionen) im Herbst in $\mathrm{BBCH}$ 17/18 (BH_He: $r_{p}=0,251$ bzw. BW_He: $\left.r_{p}=0,244\right)$ zeigten einen leichten positiven Zusammenhang mit dem Kornertrag. Beim Vergleich der genannten Korrelationskoeffizienten fiel auf, dass die positiven Korrelationskoeffizienten deutlich höher waren als die negativen. Das verdeutlichen auch die entsprechenden Bestimmtheitsmaße $\left(R_{p}{ }^{2}\right)$. Demnach hatten die Parameter mit den höchsten positiven Korrelationskoeffizienten einen stärkeren Einfluss auf den Kornertrag als die Parameter mit den höchsten negativen Korrelationskoeffizienten. 
Tab. 20: Signifikante, einfache, lineare Regressionen zwischen verschiedenen Bestandes- bzw. Befallsparametern und der Zielvariablen Kornertrag (Feldversuch Göttingen 2012/13). Dargestellt ist die Anzahl der Werte (n), die in jede Regressionsrechnung eingeflossen sind, der Korrelationskoeffizient nach Pearson $\left(r_{p}\right)$, das Bestimmtheitsmaß nach Pearson $\left(R_{p}{ }^{2}\right)$ und die Überschreitungswahrscheinlichkeit ( $p$-Wert) für die Pearson-Korrelation $\left(p_{p}\right)$. Korrelationen bzw. Bestimmtheitsmaße sind signifikant bei einem Wert $p_{p} \leq 0,05$ (hoch signifikant bei $p_{p} \leq 0,01$, höchst signifikant bei $\left.p_{p} \leq 0,001\right)$. Die Tabelle ist aufsteigend nach den $r_{p}$-Werten sortiert.

\begin{tabular}{|c|c|c|c|c|}
\hline Parameter & $n$ & $r_{p}$ & $\mathbf{R}_{\mathrm{p}}^{2}$ & $p_{p}$ \\
\hline Grünfärbung des Pflanzenbestandes in BBCH 64/65 & 124 & $-0,367$ & 0,135 & 0,000 \\
\hline Grünfärbung des Pflanzenbestandes in BBCH 79 & 124 & $-0,337$ & 0,114 & 0,000 \\
\hline Grünfärbung des Pflanzenbestandes in BBCH 81 & 124 & $-0,279$ & 0,078 & 0,002 \\
\hline Anteil an PAR am Boden in BBCH 63/65 & 124 & $-0,272$ & 0,074 & 0,002 \\
\hline Anteil an PAR am Boden in BBCH 73/74 & 124 & $-0,255$ & 0,065 & 0,004 \\
\hline Schotenschichtdicke in BBCH 75 & 124 & $-0,244$ & 0,059 & 0,006 \\
\hline Seitentriebe/Pflanze & 124 & $-0,225$ & 0,051 & 0,012 \\
\hline Grünfärbung des Pflanzenbestandes in BBCH 84 & 124 & $-0,221$ & 0,049 & 0,014 \\
\hline Anteil an PAR unter den Schoten in BBCH 67/69 & 124 & $-0,220$ & 0,048 & 0,014 \\
\hline Anteil an PAR unter den Schoten in BBCH 63/65 & 124 & $-0,213$ & 0,045 & 0,018 \\
\hline NDVI_Dauer & 124 & $-0,209$ & 0,043 & 0,020 \\
\hline Schotenschichtdicke in BBCH 73/74 & 124 & $-0,194$ & 0,037 & 0,031 \\
\hline Anteil an PAR unter den Schoten in BBCH 73/74 & 124 & $-0,187$ & 0,035 & 0,037 \\
\hline Pflanzen/m² in BBCH $51 / 52(F j)^{*}$ & 124 & 0,215 & 0,046 & 0,017 \\
\hline $\begin{array}{l}\text { BH mit der Wurzelhals- und Stängelfäule } \\
\text { am unteren Stängel in } \mathrm{BBCH} 80 / 81\end{array}$ & 124 & 0,240 & 0,058 & 0,007 \\
\hline $\begin{array}{l}\text { BW mit der Wurzelhals- und Stängelfäule } \\
\text { an Laubblättern in } \mathrm{BBCH} 17 / 18(\mathrm{He})^{\star}\end{array}$ & 124 & 0,244 & 0,059 & 0,006 \\
\hline $\begin{array}{l}\text { BH mit der Wurzelhals- und Stängelfäule } \\
\text { an Laubblättern in } \mathrm{BBCH} 17 / 18(\mathrm{He})^{\star}\end{array}$ & 124 & 0,251 & 0,063 & 0,005 \\
\hline $\begin{array}{l}\text { BW mit der Wurzelhals- und Stängelfäule } \\
\text { am unteren Stängel in } \mathrm{BBCH} 80 / 81\end{array}$ & 124 & 0,251 & 0,063 & 0,005 \\
\hline relativer Anteil an Schoten am 4. Seitentrieb & 124 & 0,281 & 0,079 & 0,002 \\
\hline Kulturdeckungsgrad in BBCH 17/18 (He)* & 124 & 0,293 & 0,086 & 0,001 \\
\hline relativer Anteil an Schoten am 1. Seitentrieb & 124 & 0,295 & 0,087 & 0,001 \\
\hline relativer Anteil an Schoten am 3. Seitentrieb & 124 & 0,341 & 0,116 & 0,000 \\
\hline Kulturdeckungsgrad in $\mathrm{BBCH} 32 / 34$ & 124 & 0,345 & 0,119 & 0,000 \\
\hline relativer Anteil an Schoten am 2. Seitentrieb & 124 & 0,349 & 0,121 & 0,000 \\
\hline BFI & 60 & 0,438 & 0,192 & 0,000 \\
\hline Bestandeshöhe in BBCH 75 & 124 & 0,448 & 0,201 & 0,000 \\
\hline Bestandeshöhe in BBCH 73/74 & 124 & 0,475 & 0,225 & 0,000 \\
\hline Bestandeshöhe in BBCH 67/69 & 124 & 0,492 & 0,242 & 0,000 \\
\hline Bestandeshöhe in BBCH 65/67 & 124 & 0,494 & 0,244 & 0,000 \\
\hline
\end{tabular}




\begin{tabular}{lrlll}
\hline Schotenansatzhöhe in BBCH 65/67 & 124 & 0,527 & 0,277 & 0,000 \\
Schotenansatzhöhe in BBCH 67/69 & 124 & 0,536 & 0,287 & 0,000 \\
Schotenansatzhöhe in BBCH 73/74 & 124 & 0,546 & 0,298 & 0,000 \\
Schotenansatzhöhe in BBCH 75 & 124 & 0,547 & 0,299 & 0,000 \\
\hline
\end{tabular}

${ }^{*} \mathrm{He}=$ Herbst, $\mathrm{Fj}=$ Frühjahr

\section{Multiple Regression - Kornertrag}

Die hierarchische Darstellung in Abb. 27 basiert auf signifikanten Regressionsmodellen, die durch mehrere, multiple Regressionsanalysen berechnet wurden. Diese Regressionsmodelle sind im Anhang II in den Tabellen 54A bis 67A zu finden. Im Versuchsjahr 2012/13 wurde der Kornertrag vor allem durch die Schotenansatzhöhe in BBCH 75 (Sah_4; 30,6\%) und die Grünfärbung des Pflanzenbestandes in BBCH 89 (NDVI_A5; 16,6\%) positiv beeinflusst (Abb. 27). Sah_4 und NDVI_A5 waren negativ $\left(r_{p}=-0,605\right)$ miteinander korreliert (Abb. 28). Der stärkste Prädiktor für Sah_4 war die Bestandeshöhe in BBCH 65/67 (Hoe_1; 96,2\%). An zweiter Stelle folgte der Prädiktor Schotenschichtdicke in BBCH 65/67 (Schi_1; 1,7\%). Hoe_1 war positiv und Schi_1 war negativ mit Sah_4 korreliert. Auf der nächsten Hierarchieebene zeigt sich, dass Hoe_1 zum größten Anteil durch den Parameter Schotenansatzhöhe in BBCH 65/67 (Sah_1; 95,5\%) und zum restlichen Anteil durch den Parameter Schi_1 (4,5\%) erklärt wurde. Das war nicht verwunderlich, da sich die Bestandeshöhe rechnerisch aus der Schotenansatzhöhe und der Schotenschichtdicke ergab. Der stärkste Prädiktor für Schi_1 war die Grünfärbung des Pflanzenbestandes in BBCH 65/66 (NDVI_B2; 16,6\%), gefolgt von dem Parameter $\mathrm{BH}$ mit der Wurzelhals- und Stängelfäule am unteren Stängel im Frühjahr in BBCH 80/81 (BH_St_Fj; 3,6\%). NDVI_B2 war negativ und BH_St_Fj war positiv mit Schi_1 korreliert. NDVI_A5 wurde maßgeblich durch die Bestandeshöhe in BBCH 73/74 (Hoe_3; 46,0\%) beeinflusst. Die Schotenschichtdicke in BBCH 73/74 (Schi_3) hatte mit $6,3 \%$ den zweitstärksten Einfluss auf NDVI_A5. Beide Bestandesparameter waren negativ mit der Zielvariablen NDVI_A5 korreliert. Hoe_3 war hauptsächlich von der Schotenansatzhöhe in BBCH 73/74 (Sah_3; 94,9\%) abhängig. Die restlichen 5,1\% wurden von der Schotenschichtdicke in BBCH 73/74 (Schi_3) erklärt. Dass Hoe_3 zu 100\% durch zwei Parameter erklärt wurde, liegt an dem gleichen Grund, der schon zuvor bei Hoe_1 genannt wurde. Schi_3 war insbesondere von NDVI_B2 $(29,1 \%)$ abhängig. Den nächst größeren Einfluss hatte Sah_3 mit 13,5\%. Beide Prädiktoren waren negativ mit der Zielvariablen Schi_3 korreliert. 


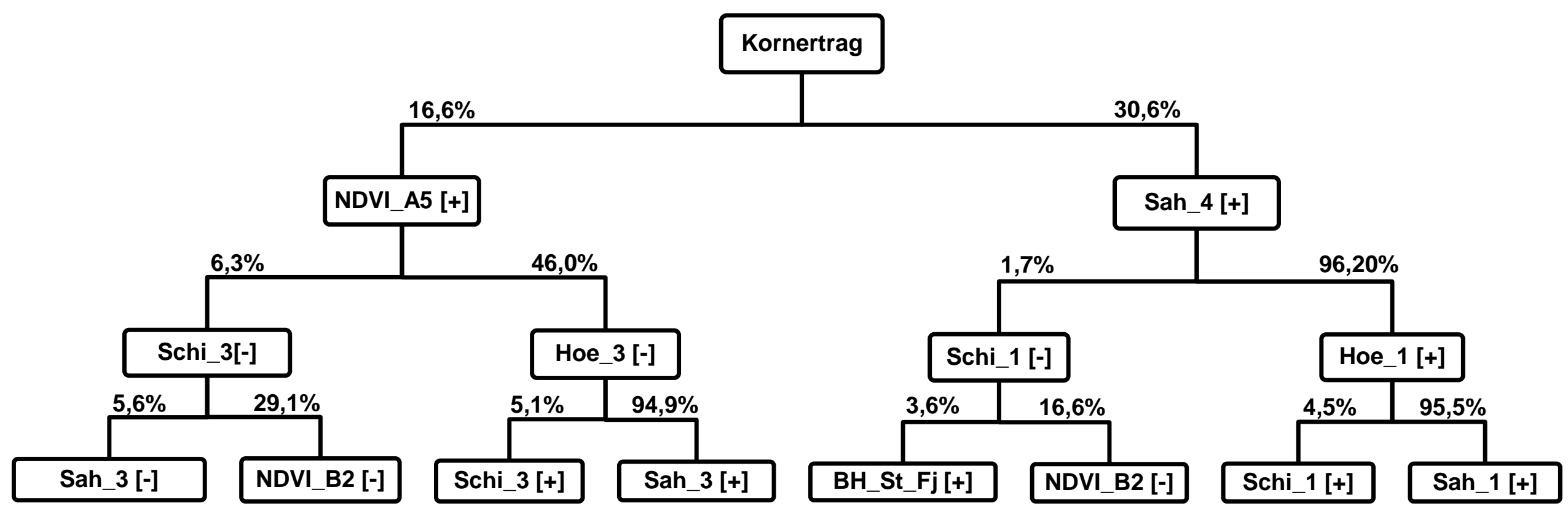

Abb. 27: Hierarchische Darstellung von Parametern, die im Versuchsjahr 2012/13 die Zielvariable Kornertrag maßgeblich beeinflusst haben bzw. von denen sie selbst beeinflusst wurden. Die Prozentzahlen stellen das partielle $R^{2}$ dar und drücken das Maß der Güte des Zusammenhangs mit der jeweiligen Zielvariable aus. Auf jeder Hierarchieebene ist der erste und zweite Prädiktor für die entsprechende Zielvariable dargestellt. Alle weiteren Prädiktoren, die eine Zielvariable beschreiben, wurden in dieser Darstellung nicht berücksichtigt. Diese Abbildung beruht auf den Ergebnissen mehrerer multipler Regressionen, wovon die Ergebnisse auszugsweise im Anhang II in den Tabellen 54A - 67A zu finden sind. Ein Parameter wurde als Prädiktor für die jeweilige Zielvariable in das Regressionsmodell aufgenommen, wenn dieser ein Signifikanzniveau von $p \leq 0,05$ einhielt. [+] = positiv bzw. [-] = negativ mit der Zielvariable korreliert. Erklärungen der Parameterabkürzungen: NDVI_B2 und A5 = Grünfärbung des Pflanzenbestandes in BBCH 65/66 (B2) und 89 (A5); Sah_1, 3 und 4 = Schotenansatzhöhe [cm] in BBCH 65/67, 73/74 und 75; Schi_1 und 3 = Schotenschichtdicke [cm] in BBCH 65/67 und 73/74; Hoe_1 und $3=$ Bestandeshöhe [cm] in BBCH 65/67 und 73/74; BH_St_Fj = Befallshäufigkeit [\%] mit der Wurzelhals- und Stängelfäule am unteren Stängel im Frühjahr in BBCH 80/81. 


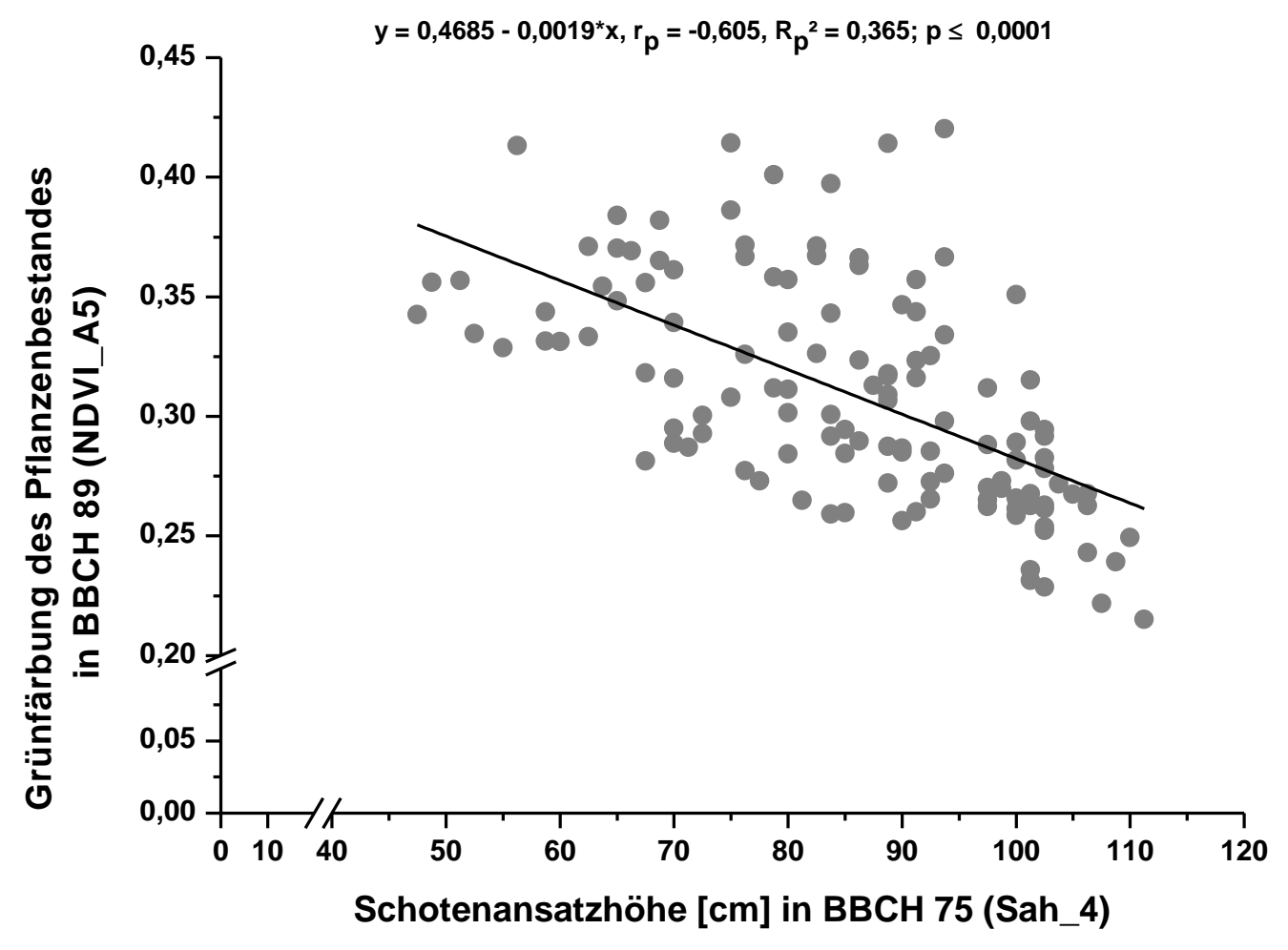

Abb. 28: Einfach, lineare Regression zwischen der Schotenansatzhöhe in BBCH 75 (Sah_4) und der Grünfärbung des Pflanzenbestandes in BBCH 89 (NDVI_A5), berechnet aus den Daten, die im Versuchsjahr 2012/13 im Feldversuch in Göttingen erhoben wurden. Zur Ermittlung des p-Wertes wurde der globale F-Test verwendet $(p \leq 0,05)$. $\left(r_{p}=\right.$ Korrelationskoeffizient nach Pearson, $R_{p}^{2}$ $=$ Bestimmtheitsmaß nach Pearson, $n=124$ ) 


\section{PCA}

In Abb. 29 ist der Biplot zu der PCA mit den Daten aus dem Versuchsjahr 2012/13 dargestellt. Die erste HK erklärt 27,95\% der Varianz der Daten im kompletten Datensatz und die zweite HK erklärt 23,58\%. Anhand der Faktorladungen (Tab. 68A im Anhang II) wird deutlich, dass die Parameter Grünfärbung des Pflanzenbestandes in BBCH 79 (N_A1, 1. Quadrant; -0.214) und Bestandeshöhe in $\mathrm{BBCH} 75$ (H_4, 3. Quadrant; 0,209) am stärksten negativ bzw. positiv in die erste HK eingegangen waren. Dahinter folgten für den negativen Bereich die Parameter NDVI-Dauer (NI, 1. Quadrant; -0,213) und Grünfärbung des Pflanzenbestandes in BBCH 81 (N_A2, 1. Quadrant; -0,203) und für den positiven Bereich die Parameter Bestandeshöhe in BBCH 67/69 (H_2, 3. Quadrant; 0,208) und 65/67 (H_1, 3. Quadrant; 0,208). Im Allgemeinen hatten alle Messtermine von dem Parameter Grünfärbung des Pflanzenbestandes zur Abreife (N_A1-5 = NDVI_A1-5, BBCH 79, 81, 84, 85/87 und 89) und die verschiedenen Messtermine von den Parametern Bestandeshöhe (H_1-4 = Hoe_1-4) und der Schotenansatzhöhe (Sh1-4 = Sah_1-4, BBCH 65/67, 67/69, 73/74 und 75) einen hohen Einfluss auf die erste HK (vgl. Tab. 68A). Die zweite HK wurde vor allem durch die Parameter relative Anzahl an Schoten am 2. Seitentrieb (r_2, 4. Quadrant; -0,227) und Seitentriebe/Pflanze (StP, 2. Quadrant, 0,220) beschrieben. Weiterhin flossen mit recht hohen negativen und positiven Faktorladungen folgende Parameter in die zweite HK ein: die Pflanzendichte im Frühjahr in BBCH 51/52 (D_2, 4. Quadrant; -0,218), die relative Anzahl an Schoten am 1. Seitentrieb (r_1, 4 Quadrant; -0,215), die Körner/Pflanze (KP, 2. Quadrant; 0,215) und die Schoten/Pflanze (SP, 2. Quadrant, 0,211). Insgesamt waren die Faktorladungen der einzelnen Parameter für die erste HK und zweite HK eher niedrig, sodass die jeweilige HK nicht durch einige wenige, sondern durch eine Vielzahl von Parametern erklärt wurde. Daher beschrieben die erste und zweite HK auch nicht sehr viel Varianz im kompletten Datensatz der ganzen Parameter. Dieser Umstand zeigte sich im Biplot durch eine sternförmige Anordnung der einzelnen Striche (Parameter).

Im 1. Quadranten lagen alle Messtermine von dem Parameter N_A1-5 nah beieinander, was deren hohe Korrelation untereinander beschreibt. Diesen Parametern gegenüber, lagen im 3. Quadranten alle Messtermine von den Parametern H_1-4 und Sh1-4. Diese waren so stark miteinander korreliert, dass sich die Striche teilweise überlagern und die Parameterabkürzungen nur noch erahnt werden können. Wie im Jahr 2010/11 waren die Parameter N_A1-5 mit den Parametern H_1-4 und Sh_1-4 negativ korreliert. Der Parameter Kornertrag (Yd) lag im 3. Quadranten und war u.a. mit dem Strohbiomassertrag (DM), dem Ölertrag (OE), der relativen Anzahl an Schoten am 3. Seitentrieb (r_3) und allen Messterminen von der Bestandeshöhe (H_1-4) und der Schotenansatzhöhe (Sh1-4) positiv korreliert. Hierbei beeinflussten die Parameter Sh1-4 und H_1-4 den Kornertrag stärker als 
die Parameter r_3, OE oder DM. Die Parameter, die im 1. Quadranten lagen, waren alle negativ mit dem Kornertrag korreliert. Dazu zählten z.B. der BW und die BH mit der Wurzelhals- und Stängelfäule am Wurzelhals im Herbst in $\mathrm{BBCH}$ 17/18 (PW_1 und PH_1), die Grünfärbung des Pflanzenbestandes in BBCH 64/65 (N_B1) und 65/66 (N_B2) und die Grünfärbung des Pflanzenbestandes in $\mathrm{BBCH} 79,81,84,85 / 87$ und 89 (N_A1-5). Des Weiteren kann dem Biplot entnommen werden, dass die Parameter Pflanzendichte im Frühjahr in $\mathrm{BBCH}$ 51/52 (D_2), Pflanzendichte im Herbst in $\mathrm{BBCH} 13$ (D_1), relative Anzahl an Schoten am Haupttrieb ( $\left.r \_0\right)$, relative Anzahl an Schoten am 1. Seitentrieb $\left(r \_1\right)$, relative Anzahl an Schoten am 2. Seitentrieb (r_2) und Kulturdeckungsgrad im Frühjahr in BBCH 32/34 (BG_2) negativ mit den Parametern Seitentriebe/Pflanze (StP), Schoten/Pflanze (SP), Körner/Pflanze (KP), Wurzelhalsdurchmesser im Herbst in BBCH 17/18 (WD_1), Wurzelhalsdurchmesser im Frühjahr in $\mathrm{BBCH}$ 80/81 (WD_2) sowie absolute Anzahl an Schoten am Haupttrieb (a_0), und am 1. bis 4. Seitentrieb (a_1-4) korreliert waren.

Die Kombinationen aus den drei Versuchsfaktoren können entsprechend der Fungizidvarianten und der Saatstärken in zwei Gruppen eingeteilt werden. Auf der 1. PCAAchse unterschieden sich die Fungizidvarianten 4, 5 und 6 (1. und 4. Quadrant) von den Varianten 1, 2, 3, 7 und $8^{3}$ (2. und 3. Quadrant). Auf der 2. PCA-Achse wurde die niedrige Saatstärke (1. und 2. Quadrant) von der hohen Saatstärke (3. und 4. Quadrant) aufgetrennt. Die Sorten bildeten keine deutlichen Gruppen. Da die Fungizidvarianten in den jeweiligen Quadranten breit verstreut lagen, wiesen sie für eine Vielzahl von Parametern ähnliche Ausprägungen auf. Die Kombinationen der Versuchsfaktoren mit der niedrigen Saatstärke von 30 Körner $/ \mathrm{m}^{2}$ zeigten u.a. bei den Parametern SP, KP, StP, WD_1 und WD_2 ähnliche Ausprägungen. Bei den Kombinationen der Versuchsfaktoren mit der hohen Saatstärke von 60 Körner/m² lagen z.B. ähnliche Ausprägungen bei den Parametern r_0, r_1, r_2, D_1, D_2 und BG_2 vor.

\footnotetext{
${ }^{3}$ Fungizidvarianten: $1=$ unbehandelte Kontrolle, $2=0,5 \mathrm{l} / \mathrm{ha}$ Topre ${ }^{\circledR}$ in $\mathrm{BBCH} 33 / 35 ; 3=0,5 \mathrm{l} / \mathrm{ha}$ Toprex $^{\circledR}$ in BBCH 14 und 33/35; $4=0,5 \mathrm{I} /$ ha Toprex ${ }^{\circledR}$ in BBCH 14, 16 und 33/35; $5=0,5 \mathrm{l} /$ ha Toprex ${ }^{\circledR}$ in $\mathrm{BBCH} 14,33 / 35$ und $53 / 55 ; 6=0,5 \mathrm{l} / \mathrm{ha}$ Toprex $^{\circledR}$ in $\mathrm{BBCH} 14,16,33 / 35$ und $53 / 55 ; 7=0,5 \mathrm{l} / \mathrm{ha}$ Toprex ${ }^{\circledR}$ in BBCH 14 und $8=$ praxisüblich: 0,5 l/ha Carax ${ }^{\circledR}$ in BBCH 14 und 35/55; In allen Varianten wurde zur Vollblüte in BBCH 65 1,0 I/ha Ortiva ${ }^{\circledR}$ gespritzt.
} 


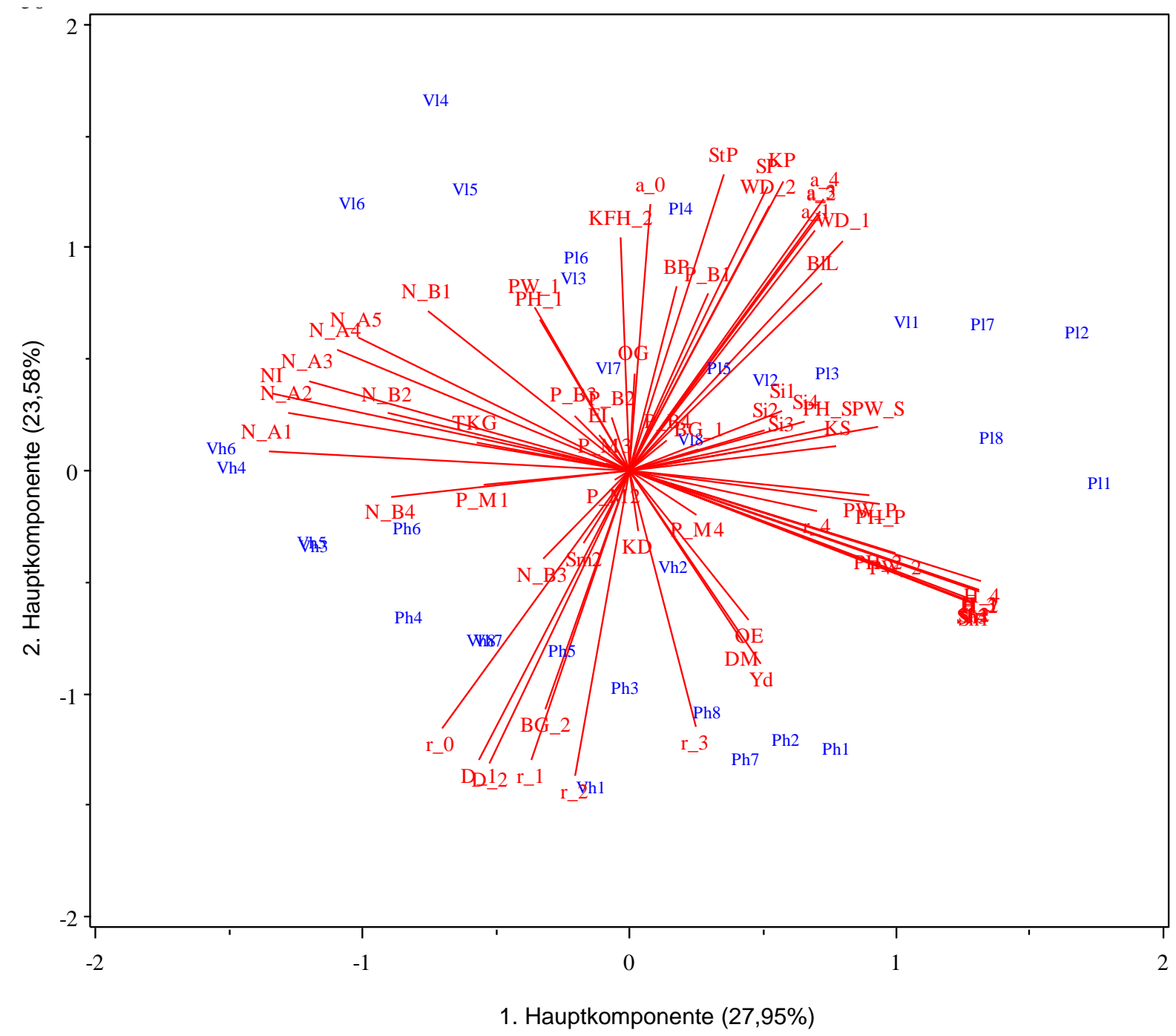

Abb. 29: Biplot zur Visualisierung der Hauptkomponentenanalyse, die mit Daten von allen Parametern aus dem Versuchsjahr 2012/13 vom Feldversuch am Standort Göttingen durchgeführt wurde. Die Prozentzahlen geben jeweils an, wie viel Varianz die jeweilige HK im gesamten Datensatz erklärt. In blau, sowie zwei Buchstaben- und einer Zahlenkombination sind die 32 Beobachtungen (Mittelwerte aus meist 4 Wiederholungen) entsprechend der verschiedenen Kombinationen aus den drei Versuchsfaktoren Sorte, Saatstärke und Fungizidvariante dargestellt. Der erste Buchstabe repräsentiert die Winterrapssorte $(\mathrm{P}=\mathrm{NK}$ Petrol; $\mathrm{V}=\mathrm{SY}$ Vesuvio), der zweite Buchstabe steht für die Saatstärke $\left(I=\right.$ low $=30 \mathrm{Körner} / \mathrm{m}^{2}, \mathrm{~h}=$ high $\left.=60 \mathrm{Körner} / \mathrm{m}^{2}\right)$ und die Zahl steht für die einzelnen Fungizidvarianten (vgl. Tab. 3 bzw. Tab. 4). Die roten Striche symbolisieren die 69 Parameter, die in dem Versuchsjahr erhoben wurden. An den Strichenden ist jeweils eine Parameterabkürzung angegeben. Erklärung der Parameterabkürzungen: $\mathrm{Yd}=$ Kornertrag $[\mathrm{t} / \mathrm{ha}], \mathrm{DM}=\mathrm{SBME}=$ Strohbiomasseertrag [t/ha]; OG = Ölgehalt [\%]; OE = Ölertrag [t/ha]; El = Ernteindex [\%]; D_2 = Di_Fj $=$ Pflanzen $/ \mathrm{m}^{2} \mathrm{im}$ Frühjahr in $\mathrm{BBCH} 51 / 52 ; \mathrm{SP}=\mathrm{SpP}=$ Schoten pro Pflanze; TKG $=\mathrm{TKM}=$ Tausendkornmasse [g]; KS = KpS = Körner pro Schote; Sm2= Spm2 = Schoten pro $\mathrm{m}^{2} ; \mathrm{KP}=\mathrm{KpP}=$ Körner pro Pflanze; $\mathrm{KD}=$ Korn_Di $=$ Korndichte; BG_2 $=\mathrm{KDG} \_\mathrm{Fj}=$ Kulturdeckungsgrad [\%] $\mathrm{im}$ Frühjahr in $\mathrm{BBCH}$ 32/34; WD_2 $=$ WHD_Fj $=$ Wurzelhalsdurchmesser $[\mathrm{mm}]$ im Frühjahr in $\mathrm{BBCH}$ 80/81; StP $=$ StpP $=$ Seitentriebe pro Pflanze; H_1-4 = Hoe_1-4 = Bestandeshöhe [cm] in BBCH 65/67 
(1), 67/69 (2), 73/74 (3) und 75 (4); Sh1-4 = Sah_1-4 = Schotenansatzhöhe [cm] in 65/67 (1), 67/69 (2), 73/74 (3) und 75 (4); Si1-4 = Schi_1-4 = Schotenschichtdicke [cm] in BBCH 65/67 (1), 67/69 (2), 73/74 (3) und 75 (4); a_0-4 = abs_00-04 = absolute Anzahl der Schoten am Haupttrieb (00), am 1. Seitentrieb (01), am 2. Seitentrieb (02) usw.; r_0-4 = rel_00-04 = relative Anzahl der Schoten am Haupttrieb (00), am 1. Seitentrieb (01), am 2. Seitentrieb (02) usw.; P_M1-4 = PAR_M1-4 = Anteil an photosynthetisch aktiver Strahlung [\%] unter den Schoten in BBCH 63/65 (1), 67/69 (2), 73/74 (3) und 75 (4); P_B1-4 = PAR_B1-4 = Anteil an photosynthetisch aktiver Strahlung [\%] am Boden in BBCH 63/65 (1), 67/69 (2), 73/74 (3) und 75 (4); NI = NDVI_Dauer = Integration der NDVI-Kurve über den entsprechenden Erhebungszeitraum; N_B1-4 = NDVI_B1-4 = Grünfärbung des Pflanzenbestandes in BBCH 64/65 (1), 65/66 (2), 69 (3) und 73 (4); N_A1-5 = NDVI_A1-5 = Grünfärbung des Pflanzenbestandes in BBCH 79 (1), 81 (2), 84 (3), 85/87 (4) und 89 (5); D_1 = DI_He = Pflanzen/m² im Herbst in BBCH 13; WD_1 = WHD_He = Wurzelhalsdurchmesser im Herbst [mm] in BBCH 17/18; $\mathrm{BIL}=$ Blattlae = Blattlänge $[\mathrm{cm}] ; \mathrm{BP}=\mathrm{BpP}=$ Blätter pro Pflanze; PW_S = BW_St_Fj $=$ Befallswert mit der Wurzelhals- und Stängelfäule am unteren Stängel im Frühjahr in BBCH 80/81; PH_S = BH_St_Fj = Befallshäufigkeit [\%] mit der Wurzelhals- und Stängelfäule am unteren Stängel im Frühjahr in BBCH 80/81; PW_2 = BW_Wh_Fj = Befallswert mit der Wurzelhals- und Stängelfäule am Wurzelhals im Frühjahr in BBCH 80/81; PH_2 = BH_Wh_Fj = Befallshäufigkeit [\%] mit der Wurzelhals- und Stängelfäule am Wurzelhals im Frühjahr in $\mathrm{BBCH}$ 80/81; PW_P $=$ BW_He $=$ Befallswert mit der Wurzelhals- und Stängelfäule an Laubblättern (Blattläsionen) im Herbst in $\mathrm{BBCH} 17 / 18$; $\mathrm{PH} P \mathrm{P}=$ $\mathrm{BH} \_\mathrm{He}=$ Befallshäufigkeit [\%] mit der Wurzelhals- und Stängelfäule an Laubblättern (Blattläsionen) im Herbst in BBCH 17/18; PW_1 = BW_Wh_He = Befallswert mit der Wurzelhals- und Stängelfäule am Wurzelhals im Herbst in BBCH 17/18; $\mathrm{PH} \_1=\mathrm{BH}$ _Wh_He = Befallshäufigkeit [\%] mit der Wurzelhalsund Stängelfäule am Wurzelhals im Herbst in $\mathrm{BBCH}$ 17/18; KFH_2 $=\mathrm{BH} \_\mathrm{Kf} \_\mathrm{Fj}=$ Befallshäufigkeit [\%] mit der Kleinen Kohlfliege im Frühjahr in $\mathrm{BBCH}$ 80/81; KFH_1 = BH_Kf_He = Befallshäufigkeit [\%] mit der Kleinen Kohlfliege im Herbst in $\mathrm{BBCH}$ 17/18. 


\subsection{Effekte der Sorte, Saatstärke und Fungizidbehandlung auf Bestandes- und Befallsparameter, die die Ertragshöhe beeinflusst haben}

In diesem Kapitel werden, getrennt nach den Versuchsjahren 2010/11 und 2012/13, die Ergebnisse von dreifaktoriellen Varianzanalysen vorgestellt, die die Effekte der drei unabhängigen Versuchsfaktoren Sorte, Saatstärke und Fungizidbehandlung auf die Bestandes- und Krankheitsparameter beschreiben. Dabei werden nur signifikante Ergebnisse der Varianzanalysen für die Bestandes- und Befallsparameter genannt, die einen direkten oder indirekten Einfluss auf den Kornertrag hatten (vgl. Kapitel 3.6). Bevor die Ergebnisse zu einem Parameter beschrieben werden, wird dieser durch eine Überschrift angekündigt. Der Überschrift kann zusätzlich entnommen werden, ob der Parameter direkt (1. Hierarchieebene bei multipler Regression) oder indirekt (2. oder 3. Hierarchieebene bei multipler Regression) ertragsrelevant war.

\subsubsection{Versuchsjahr 2010/11}

\section{Pflanzen/m² im Herbst in BBCH 14/15 (Di_He); (indirekt ertragsrelevant)}

Der Bestandesparameter Pflanzen/m² im Herbst in BBCH 14/15 wurde signifikant durch die Sorte und die Saatstärke beeinflusst (Tab. 21). In den Parzellen mit der Sorte NK Petrol wurden in $\mathrm{BBCH}$ 14/15 signifikant mehr Pflanzen $/ \mathrm{m}^{2}$ gezählt (ca. 48 Pflanzen $/ \mathrm{m}^{2}$ ) als in den Parzellen mit der Sorte SY Merlot (ca. 40 Pflanzen $/ \mathrm{m}^{2}$ ). Bei $60 \mathrm{Körnern} / \mathrm{m}^{2}$ war die Pflanzendichte in BBCH 14/15 signifikant höher (ca. 56 Pflanzen $/ \mathrm{m}^{2}$ ) als bei $30 \mathrm{Körnern} / \mathrm{m}^{2}$ (ca. 33 Pflanzen/m²).

Tab. 21: Einfluss der Sorte ((So), $M=$ SY Merlot bzw. $P=$ NK Petrol) und der Saatstärke ((Di), 30 Körner $/ \mathrm{m}^{2}$ bzw. $60 \mathrm{Körner} / \mathrm{m}^{2}$ ) auf die Anzahl Pflanzen $/ \mathrm{m}^{2}$ im Herbst in BBCH 14/15 (Di_He) im Versuchsjahr 2010/11 am Standort Göttingen. Dargestellt sind die Mittelwerte und die Standardabweichung (SD). Verschiedene Buchstaben kennzeichnen signifikante Unterschiede zwischen den Mittelwerten nach dem Tukey-Test $(p \leq 0,05, n=4)$, errechnet innerhalb des verwendeten gemischten Modells. Großbuchstaben kennzeichnen Unterschiede zwischen den Sorten und kleingeschriebene Buchstaben zwischen den Saatstärken.

\begin{tabular}{lcccccc}
\hline Parameter & Effekt & So & Di & Mittelwert & SD & Buchstaben \\
\hline Pflanzen $/ \mathbf{m}^{2}$ & So & M & & 40,3 & 5,7 & B \\
im Herbst in & So & P & 47,9 & 6,4 & A \\
BBCH 14/15 (Di_He) & $\cdots \ldots \ldots \ldots \ldots \ldots . .$. \\
& Di & & 30 & 32,7 & 5,1 & b \\
& Di & & 60 & 55,5 & 6,9 & a \\
\hline
\end{tabular}




\section{Pflanzen/m² im Frühjahr in BBCH 16/18 (Di_Fj); (indirekt ertragsrelevant)}

Die Effekte der Anbaufaktoren Sorte, Saatstärke und Fungizidbehandlung auf die Anzahl Pflanzen/m² im Frühjahr in BBCH 16/18 wurden in Kapitel 3.4.1 vorgestellt und werden daher an dieser Stelle nicht noch einmal erwähnt.

\section{Kulturdeckungsgrad im Frühjahr in BBCH 32/34 (KDG_Fj); (indirekt ertragsrelevant)}

Der Kulturdeckungsgrad im Frühjahr in $\mathrm{BBCH}$ 32/34 wurde zum einen durch die Sorte und zum anderen durch die Saatstärke signifikant beeinflusst (Tab. 22). Unabhängig voneinander führte die Sorte NK Petrol und die Aussaatstärke von 60 Körnern $/ \mathrm{m}^{2}$ zu einem höheren Kulturdeckungsgrad (NK Petrol $=49,47 \%, 60 \mathrm{Körner} / \mathrm{m}^{2}=51,80 \%$ ) als die Sorte SY Merlot $(37,20 \%)$ und die Aussaatstärke von 30 Körnern/m² (34,87\%).

Tab. 22: Einfluss der Sorte ((So), $M=S Y$ Merlot bzw. $P=N K$ Petrol) und der Saatstärke ((Di), 30 Körner $/ \mathrm{m}^{2}$ bzw. 60 Körner/m²) auf den Kulturdeckungsgrad [\%] im Frühjahr in BBCH 32/34 (KDG_Fj) im Versuchsjahr 2010/11 am Standort Göttingen. Dargestellt sind die Mittelwerte und die Standardabweichung (SD). Verschiedene Buchstaben kennzeichnen signifikante Unterschiede zwischen den Mittelwerten nach dem Tukey-Test $(p \leq 0,05, n=4)$, errechnet innerhalb des verwendeten gemischten Modells. Großbuchstaben kennzeichnen Unterschiede zwischen den Sorten und kleingeschriebene Buchstaben zwischen den Saatstärken.

\begin{tabular}{lcccccc}
\hline Parameter & Effekt & So & Di & Mittelwert & SD & Buchstaben \\
\hline Kulturdeckungsgrad & So & M & & 37,20 & 4,74 & B \\
[\%] in BBCH 32/34 & So & P & 49,47 & 6,29 & A \\
(KDG_Fj) & Di & & 30 & 34,87 & 6,11 & b \\
& Di & & 60 & 51,80 & 4,93 & a \\
\hline
\end{tabular}

\section{Anteil an PAR unter den Schoten in BBCH 75 (PAR_M4) (indirekt ertragsrelevant)}

Der Bestandesparameter Anteil an PAR unter den Schoten in $\mathrm{BBCH} 75$ wurde von den drei Anbaufaktoren Sorte, Saatstärke und Fungizidbehandlung signifikant beeinflusst. In den Parzellen, in denen die Sorte SY Merlot gesät war, wurde signifikant mehr PAR unter den Schoten gemessen (18,97\%) als in den Parzellen, in denen die Sorte NK Petrol (14,89\%) gesät war (Tab. 23). Unabhängig davon wurde in den Parzellen mit der niedrigen Aussaatstärke mehr PAR unter den Schoten gemessen $(19,88 \%)$ als in den Parzellen mit der hohen Aussaatstärke (13,98\%). 
Tab. 23: Einfluss der Sorte ((So), $M=S Y$ Merlot bzw. $P=N K$ Petrol) und der Saatstärke ((Di), $30 \mathrm{Körner} / \mathrm{m}^{2}$ bzw. $\left.60 \mathrm{Körner} / \mathrm{m}^{2}\right)$ auf den Anteil an PAR [\%] unter den Schoten in $\mathrm{BBCH} 75$ (PAR_M4) im Versuchsjahr 2010/11 am Standort Göttingen. Dargestellt sind die Mittelwerte und die Standardabweichung (SD). Verschiedene Buchstaben kennzeichnen signifikante Unterschiede zwischen den Mittelwerten nach dem Tukey-Test $(p \leq 0,05, n=4)$, errechnet innerhalb des verwendeten gemischten Modells. Großbuchstaben kennzeichnen Unterschiede zwischen den Sorten und kleingeschriebene Buchstaben zwischen den Saatstärken.

\begin{tabular}{lcccccc}
\hline Parameter & Effekt & So & Di & Mittelwert & SD & Buchstaben \\
\hline Anteil an PAR [\%] & So & M & 18,97 & 3,24 & A \\
unter den Schoten & So & P & 14,89 & 2,57 & B \\
in BBCH 75 & Di & & 30 & 19,88 & 3,53 & $\mathrm{a}$ \\
(PAR_M4) & $\mathrm{Di}$ & & 60 & 13,98 & 2,33 & $\mathrm{~b}$ \\
\hline
\end{tabular}

Bei den Fungizidbehandlungen zeigte sich, dass bei der Variante 4 signifikant mehr PAR unter den Schoten in BBCH 75 gemessen wurde (19,12\%) als in der Variante 1 (14,67\%; Abb. 30). Weitere Unterschiede waren zwischen den einzelnen Fungizidbehandlungen nicht aufgetreten. 


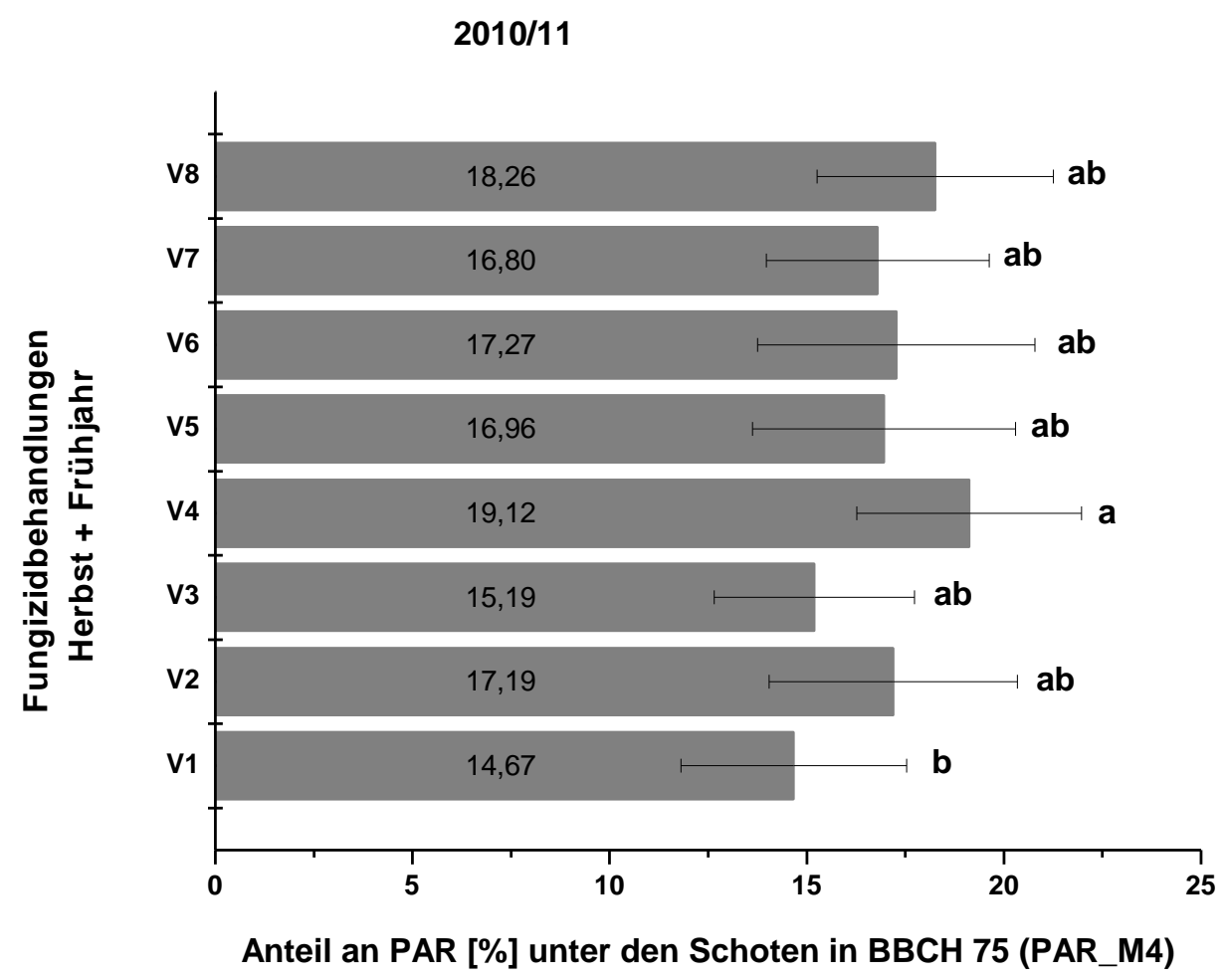

Abb. 30: Einfluss der im Herbst und im Frühjahr durchgeführten Fungizidbehandlungen auf den Anteil an PAR [\%] unter den Schoten in BBCH 75 (PAR_M4) im Versuchsjahr 2010/11 am Standort Göttingen. Verschiedene Buchstaben kennzeichnen signifikante Unterschiede zwischen den Fungizidbehandlungen nach dem Tukey-Test $(p \leq 0,05, n=4)$, errechnet innerhalb des verwendeten gemischten Modells. Die Fehlerbalken stellen die jeweilige Standardabweichung dar. $V=$ Variante: $V 1$ $=$ unbehandelte Kontrolle, V2 $=0,5 \mathrm{l} /$ ha Toprex $^{\circledR}$ (Difenoconazol + Paclobutrazol) in BBCH 33/35, V3 = 0,5 I/ha Toprex ${ }^{\circledR}$ in BBCH 14 und 33/35, V4 = 0,5 I/ha Toprex ${ }^{\circledR}$ in BBCH 14, 16 und 33/35, V5 = 0,5 I/ha Toprex ${ }^{\circledR}$ in $\mathrm{BBCH} 14,33 / 35$ und 53/55, V6 $=0,5 \mathrm{l} /$ ha Toprex $^{\circledR}$ in $\mathrm{BBCH} 14+1,0 \mathrm{l} /$ ha Toprex $^{\circledR}$ in $\mathrm{BBCH} 33 / 35$, V7 = wie Nr. 3 aber in $\mathrm{BBCH} 65$ 2,0 l/ha Ortiva ${ }^{\circledR}$ (Azoxystrobin), V8 = praxisüblich = 0,6 I/ha Folicur ${ }^{\circledR}$ (Tebuconazol) in $\mathrm{BBCH} 14+0,7 \mathrm{l} /$ ha Carax ${ }^{\circledR}$ (Mepiquatchlorid + Metconazol) in $\mathrm{BBCH}$ $33 / 35+0,8 \mathrm{I} /$ ha Harvesan ${ }^{\circledR}$ (Flusilazol + Carbendazim) in $\mathrm{BBCH} 65$; Varianten 1-6 erhielten in $\mathrm{BBCH}$ $651 \mathrm{l} /$ ha Ortiva ${ }^{\circledR}$. 


\section{Anteil an PAR am Boden in BBCH 75 (PAR_B4); (direkt ertragsrelevant)}

Der Bestandesparameter Anteil an PAR am Boden in BBCH 75 wurde signifikant von der Sorte und von der Saatstärke beeinflusst (Tab. 24). Im Wachstumsstadium 75 wurde in den Rapsbeständen der Sorte SY Merlot mehr PAR am Boden gemessen (8,92\%) als in den Rapsbeständen der Sorte NK Petrol (5,96\%). Des Weiteren wurde bei einer Aussaatstärke von 30 Körnern/m² mehr PAR am Boden ermittelt (9,71\%) als bei einer Aussaatstärke von 60 Körnern/m².

Tab. 24: Einfluss der Sorte ((So), $M=S Y$ Merlot bzw. $P=N K$ Petrol) und der Saatstärke ((Di), $30 \mathrm{Körner} / \mathrm{m}^{2}$ bzw. $60 \mathrm{Körner} / \mathrm{m}^{2}$ ) auf den Anteil an PAR [\%] am Boden in BBCH 75 (PAR_B4) im Versuchsjahr 2010/11 am Standort Göttingen. Dargestellt sind der Mittelwerte und die Standardabweichung (SD). Verschiedene Buchstaben kennzeichnen signifikante Unterschiede zwischen den Mittelwerten nach dem Tukey-Test $(p \leq 0,05, n=4)$, errechnet innerhalb des verwendeten gemischten Modells. Großbuchstaben kennzeichnen Unterschiede zwischen den Sorten und kleingeschriebene Buchstaben zwischen den Saatstärken.

\begin{tabular}{lcccccc}
\hline Parameter & Effekt & So & Di & Mittelwert & SD & Buchstaben \\
\hline Anteil an PAR [\%] & So & $\mathrm{M}$ & 8,92 & 2,18 & $\mathrm{~A}$ \\
am Boden & So & $\mathrm{P}$ & 5,96 & 1,45 & $\mathrm{~B}$ \\
in BBCH 75 & $\mathrm{Di}$ & & 30 & 9,71 & 2,44 & $\mathrm{a}$ \\
(PAR_B4) & $\mathrm{Di}$ & & 60 & 5,17 & 1,19 & $\mathrm{~b}$ \\
\hline
\end{tabular}

\section{Absolute Anzahl an Schoten am 1. Seitentrieb (abs_01) (indirekt ertragsrelevant)}

Der Bestandesparameter absolute Anzahl an Schoten am 1. Seitentrieb wurde von der Saatstärke und der Interaktion zwischen Sorte $x$ Saatstärke signifikant beeinflusst. Es konnte festgestellt werden, dass bei einer niedrigen Saatstärke mehr Schoten am 1. Seitentrieb gebildet wurden (ca. 24 Schoten) als bei einer hohen Saatstärke (ca. 18 Schoten; Tab. 25). SY Merlot bildete bei einer Saatstärke von 30 Körnern $/ \mathrm{m}^{2}$ signifikant mehr Schoten am 1. Seitentrieb (ca. 28 Schoten) als bei einer Saatstärke von 60 Körnern $/ \mathrm{m}^{2}$ (ca. 17 Schoten; Tab. 25). NK Petrol bildete ebenfalls bei einer niedrigen Saatstärke mehr Schoten am 1. Seitentrieb (ca. 20 Schoten), allerdings war diese Anzahl nicht signifikant verschieden von der Anzahl an Schoten am 1. Seitentrieb die bei einer hohen Saatstärke angesetzt wurden (ca. 18 Schoten). 
Tab. 25: Einfluss der Saatstärke ((Di), $\left.30 \mathrm{Körner} / \mathrm{m}^{2} \mathrm{bzw} .60 \mathrm{Körner} / \mathrm{m}^{2}\right)$ und der Interaktion zwischen Sorte und Saatstärke ((So*Di), M = SY Merlot bzw. P = NK Petrol) auf die absolute Anzahl an Schoten am 1. Seitentrieb (abs_01) im Versuchsjahr 2010/11 am Standort Göttingen. Dargestellt sind die Mittelwerte und die Standardabweichung (SD). Verschiedene Buchstaben kennzeichnen signifikante Unterschiede zwischen den Mittelwerten nach dem Tukey-Test $(p \leq 0,05, n=4)$, errechnet innerhalb des verwendeten gemischten Modells. Großbuchstaben kennzeichnen Unterschiede zwischen den Saatstärken und kleingeschriebene Buchstaben zwischen der Interaktion Sorte x Saatstärke.

\begin{tabular}{lcccccc}
\hline Parameter & Effekt & So & Di & Mittelwert & SD & Buchstaben \\
\hline absolute Anzahl & $\mathrm{Di}$ & & 30 & 24,2 & 6,8 & $\mathrm{~A}$ \\
an Schoten am & $\mathrm{Di}$ & & 60 & 17,6 & 5,7 & $\mathrm{~B}$ \\
1. Seitentrieb & $\mathrm{So} \ldots \mathrm{Di}$ & $\mathrm{M}$ & 30 & 28,2 & 8,1 & $\mathrm{a}$ \\
(abs_01) & $\mathrm{So}{ }^{*} \mathrm{Di}$ & $\mathrm{M}$ & 60 & 17,3 & 5,2 & $\mathrm{~b}$ \\
& $\mathrm{So}{ }^{*} \mathrm{Di}$ & $\mathrm{P}$ & 30 & 20,1 & 4,7 & $\mathrm{ab}$ \\
& $\mathrm{So}^{*} \mathrm{Di}$ & $\mathrm{P}$ & 60 & 17,9 & 6,3 & $\mathrm{~b}$ \\
\hline
\end{tabular}

\section{Grünfärbung des Pflanzenbestandes in BBCH 73 (NDVI_B4); (direkt ertragsrelevant)}

Von den unabhängigen Variablen, übten die Saatstärke und die Fungizidbehandlung jeweils einen signifikanten Effekt auf den Bestandesparameter Grünfärbung des Pflanzenbestandes in $\mathrm{BBCH} 73$ aus. So war die Grünfärbung des Pflanzenbestandes in $\mathrm{BBCH} 73$ in den Parzellen mit der hohen Saatstärke signifikant höher $(\mathrm{NDVI}=0,730)$ als in den Parzellen mit der niedrigen Saatstärke (NDVI = 0,716; Tab. 26).

Tab. 26: Einfluss der Saatstärke ((Di), $\left.30 \mathrm{Körner} / \mathrm{m}^{2} \mathrm{bzw} .60 \mathrm{Körner} / \mathrm{m}^{2}\right)$ auf die Grünfärbung des Pflanzenbestandes in BBCH 73 (NDVI_B4) im Versuchsjahr 2010/11 am Standort Göttingen. Dargestellt sind die Mittelwerte und die Standardabweichung (SD). Verschiedene Buchstaben kennzeichnen signifikante Unterschiede zwischen den Saatstärken nach dem Tukey-Test $(p \leq 0,05$, $n=4$ ), errechnet innerhalb des verwendeten gemischten Modells.

\begin{tabular}{lcccccc}
\hline Parameter & Effekt & So & Di & Mittelwert & SD & Buchstaben \\
\hline Grünfärbung des & $\mathrm{Di}$ & 30 & 0,716 & 0,010 & $\mathrm{~b}$ \\
Pflanzenbestandes & $\mathrm{Di}$ & 60 & 0,730 & 0,008 & $\mathrm{a}$ \\
in BBCH 73 (NDVI_B4) & & & & & & \\
\hline
\end{tabular}


Im Vergleich der Fungizidbehandlungen führte die Variante 4 (NDVI = 0,727) und 6 (NDVI = $0,727)$ zu einem signifikant grüner gefärbten Pflanzenbestand im Wachstumsstadium 73 als die Variante 1 (NDVI = 0,715; Abb. 31). Weitere signifikante Unterschiede traten nicht auf. Obwohl Variante 3 den gleichen mittleren NDVI-Wert aufwies wie die Varianten 4 und 6 $(0,727)$, unterschied sich Variante 3 nicht signifikant von der unbehandelten Kontrolle (V1). Das liegt daran, dass die hier dargestellten NDVI-Werte auf drei Nachkommastellen gerundet wurden. Aus den Rohdaten geht hervor, dass der NDVI-Wert von Variante 3 etwas niedriger war als der NDVI-Wert von Variante 4 und 6.

\section{0/2011}

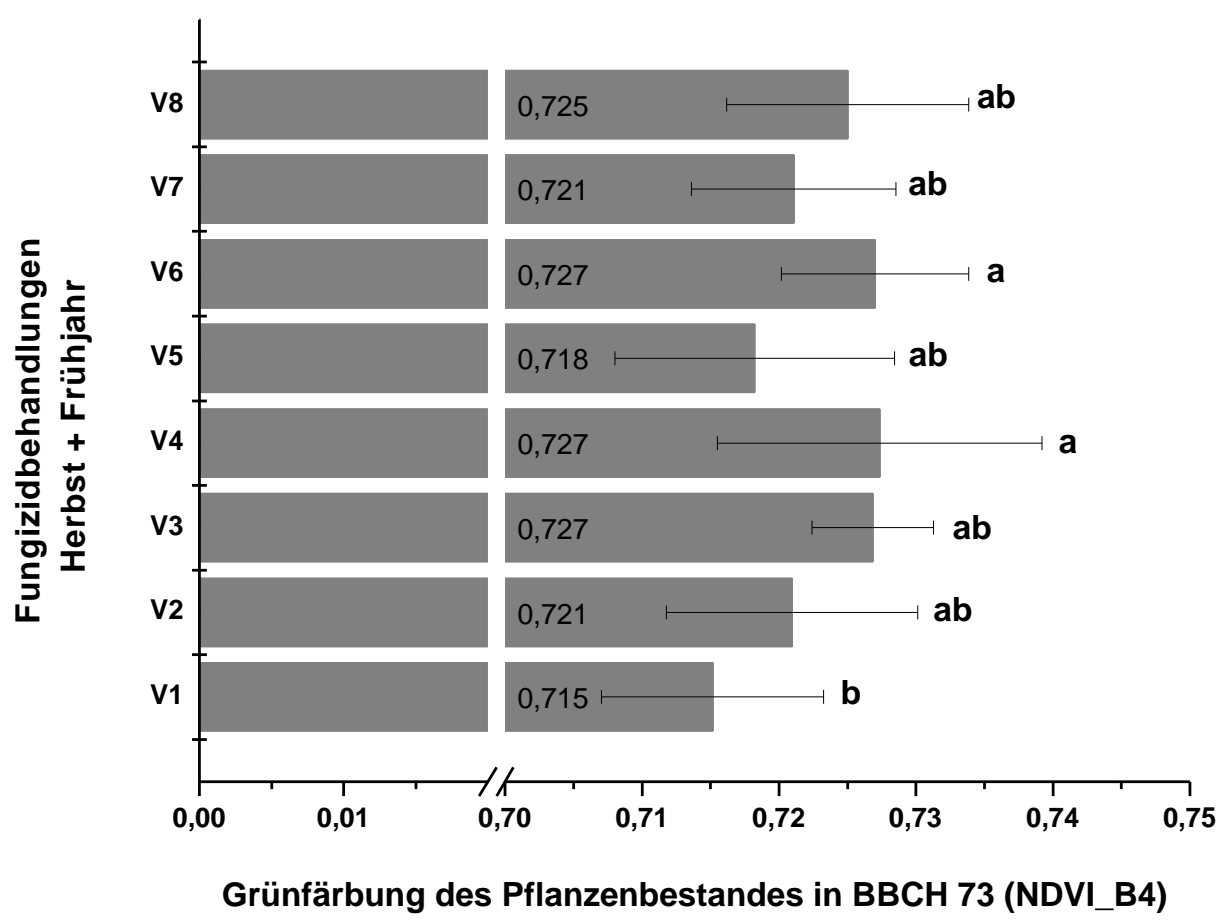

Abb. 31: Einfluss der im Herbst und im Frühjahr durchgeführten Fungizidbehandlungen auf die Grünfärbung des Pflanzenbestandes in BBCH 73 (NDVI_B4) im Versuchsjahr 2010/11 am Standort Göttingen. Verschiedene Buchstaben kennzeichnen signifikante Unterschiede zwischen den Fungizidbehandlungen nach dem Tukey-Test $(p \leq 0,05, n=4)$, errechnet innerhalb des verwendeten gemischten Modells. Die Fehlerbalken stellen die jeweilige Standardabweichung dar. $V=$ Variante: $V 1$ $=$ unbehandelte Kontrolle, V2 $=0,5 \mathrm{l} /$ ha Toprex $^{\circledR}$ (Difenoconazol + Paclobutrazol) in BBCH 33/35, V3 = 0,5 I/ha Toprex ${ }^{\circledR}$ in BBCH 14 und 33/35, V4 = 0,5 I/ha Toprex ${ }^{\circledR}$ in BBCH 14, 16 und 33/35, V5 = 0,5 I/ha Toprex ${ }^{\circledR}$ in BBCH 14, 33/35 und 53/55, V6 $=0,5$ l/ha Toprex ${ }^{\circledR}$ in BBCH $14+1,0$ l/ha Toprex ${ }^{\circledR}$ in $\mathrm{BBCH} 33 / 35$, V7 = wie Nr. 3 aber in $\mathrm{BBCH} 65$ 2,0 l/ha Ortiva ${ }^{\circledR}$ (Azoxystrobin), V8 = praxisüblich = 0,6 I/ha Folicur ${ }^{\circledR}$ (Tebuconazol) in $\mathrm{BBCH} 14+0,7 \mathrm{I} /$ ha Carax ${ }^{\circledR}$ (Mepiquatchlorid + Metconazol) in $\mathrm{BBCH}$ $33 / 35+0,8 \mathrm{I} /$ ha Harvesan $^{\circledR}$ (Flusilazol + Carbendazim) in $\mathrm{BBCH} 65$; Varianten 1-6 erhielten in $\mathrm{BBCH}$ $651 \mathrm{l} /$ ha Ortiva ${ }^{\circledR}$. 


\section{Schotenschichtdicke in BBCH 73/74 (Schi_3); (indirekt ertragsrelevant)}

Der Bestandesparameter Schotenschichtdicke in $\mathrm{BBCH} 73 / 74$ wurde von den drei Versuchsfaktoren Sorte, Saatstärke und Fungizidbehandlung nicht signifikant beeinflusst (vgl. Tab. 25A im Anhang II).

\section{Wurzelhalsdurchmesser im Frühjahr in BBCH 83/84 (WHD_Fj); (indirekt ertragsrelevant)}

Der Bestandesparameter Wurzelhalsdurchmesser im Frühjahr in $\mathrm{BBCH}$ 83/84 wurde von der Saatstärke signifikant beeinflusst (Tab. 27). Bei einer Saatstärke von 30 Körnern $/ \mathrm{m}^{2}$ war der Durchmesser vom Wurzelhals der Rapspflanzen in $\mathrm{BBCH} 83 / 84$ signifikant größer $(15,66$ $\mathrm{mm})$ als bei einer Saatstärke von 60 Körnern/m² $(12,72 \mathrm{~mm})$.

Tab. 27: Einfluss der Saatstärke ((Di), $30 \mathrm{Körner} / \mathrm{m}^{2}$ bzw. $\left.60 \mathrm{Körner} / \mathrm{m}^{2}\right)$ auf den Wurzelhalsdurchmesser [mm] in BBCH 83/84 (WHD_Fj) im Versuchsjahr 2010/11 am Standort Göttingen. Dargestellt sind die Mittelwerte und die Standardabweichung (SD). Verschiedene Buchstaben kennzeichnen signifikante Unterschiede zwischen den Saatstärken nach dem Tukey-Test ( $p \leq 0,05, n=4)$, errechnet innerhalb des verwendeten gemischten Modells.

\begin{tabular}{lccccc}
\hline Parameter & Effekt & Di & Mittelwert & SD & Buchstaben \\
\hline Wurzelhalsdurchmesser [mm] & $\mathrm{Di}$ & 30 & 15,66 & 0,81 & $\mathrm{a}$ \\
in BBCH 83/84 (WHD_Fj) & $\mathrm{Di}$ & 60 & 12,72 & 0,65 & $\mathrm{~b}$ \\
\hline
\end{tabular}

BW mit der Wurzelhals- und Stängelfäule am Wurzelhals bzw. am unteren Stängel im Frühjahr in BBCH 83/84 (BW_Wh_Fj bzW. BW_St_Fj); (indirekt ertragsrelevant)

Die Effekte der Versuchsfaktoren Sorte, Saatstärke und Fungizidbehandlung auf den BW mit der Wurzelhals- und Stängelfäule am Wurzelhals bzw. am unteren Stängel im Frühjahr in $\mathrm{BBCH}$ 83/84 wurden in Kapitel 3.5.1 vorgestellt und werden daher an dieser Stelle nicht noch einmal erwähnt. 


\subsubsection{Versuchsjahr 2012/13}

Schotenansatzhöhe in BBCH 65/67 (Sah_1), in BBCH 73/74 (Sah_3) und in BBCH 75 (Sah_4)

Die Schotenansatzhöhe in $\mathrm{BBCH}$ 65/67, in $\mathrm{BBCH} 73 / 74$ und in $\mathrm{BBCH} 75$ wurde durch die Sorte, die Fungizidbehandlung und die Interaktion zwischen Sorte x Fungizidbehandlung signifikant beeinflusst. Aus der Tab. 27A im Anhang II geht hervor, dass zum einen die Schotenansatzhöhe von Messtermin zu Messtermin zunahm und zum anderen die signifikanten Effekte von den Sorten, den Fungizidbehandlungen und der Interaktion zwischen Sorten x Fungizidbehandlungen sich von Messtermin zu Messtermin nur geringfügig bis gar nicht geändert hatten. Die grundlegende Tendenz der Effekte blieb immer gleich. Aus diesem Grund und weil die Schotenansatzhöhe in $\mathrm{BBCH} 75$ von allen drei Wachstumsstadien den stärksten Zusammenhang mit dem Kornertrag aufwies, werden an dieser Stelle nur die signifikanten Effekte der Versuchsfaktoren zu dem Bestandesparameter Schotenansatzhöhe in $\mathrm{BBCH} 75$ explizit beschrieben. Für nähere Informationen zu der Schotenansatzhöhe in $\mathrm{BBCH} 65 / 67$ und in $\mathrm{BBCH} 73 / 74$ wird auf die Tab. 27A im Anhang II verwiesen.

\section{Schotenansatzhöhe in BBCH 75 (Sah_4) (direkt ertragsrelevant)}

Die Schotenansatzhöhe in $\mathrm{BBCH} 75$ wurde durch die Sorte, die Fungizidbehandlung und durch die Interaktion zwischen Sorte x Fungizidbehandlung signifikant beeinflusst. Die Schotenansatzhöhe in $\mathrm{BBCH} 75$ war bei NK Petrol mit 93,60 cm signifikant höher als bei SY Vesuvio $(77,68 \mathrm{~cm}$; Tab. 28).

Tab. 28: Einfluss der Sorte ((So), $P=N K$ Petrol bzw. $V=S Y$ Vesuvio) auf die Schotenansatzhöhe [cm] in BBCH 75 (Sah_4) im Versuchsjahr 2012/13 am Standort Göttingen. Dargestellt sind die Mittelwerte und die Standardabweichung (SD). Verschiedene Buchstaben kennzeichnen signifikante Unterschiede zwischen den Sorten nach dem Tukey-Test $(p \leq 0,05, n=4)$, errechnet innerhalb des verwendeten gemischten Modells.

\begin{tabular}{lccccc}
\hline Parameter & Effekt & So & Mittelwert & SD & Buchstaben \\
\hline Schotenansatzhöhe [cm] & So & P & 93,60 & 3,07 & a \\
in BBCH 75 (Sah_4) & So & V & 77,68 & 2,63 & b \\
\hline
\end{tabular}


Bei den verschiedenen Fungizidvarianten schwankte die Schotenansatzhöhe in BBCH 75 je nach Variante zwischen 66,48 cm und 101,46 cm (Abb. 32). Im Vergleich zur Variante 1 $(101,46 \mathrm{~cm})$ reduzierte die Variante $6(66,48 \mathrm{~cm})$ die Schotenansatzhöhe in BBCH 75 am stärksten, gefolgt von der Variante $4(70,78 \mathrm{~cm})$, der Variante $5(79,92 \mathrm{~cm})$, der Variante 3 $(84,38 \mathrm{~cm})$ und den Varianten $8(92,58 \mathrm{~cm}), 7(94,14 \mathrm{~cm})$ und $2(95,39 \mathrm{~cm})$. Dabei unterschieden sich alle aufgeführten Varianten signifikant von der unbehandelten Kontrolle. Des Weiteren unterschieden sich fast alle Varianten in Bezug auf die Schotenansatzhöhe in $\mathrm{BBCH} 75$ signifikant voneinander. Nur die Varianten 2, 7 und 8 waren nicht signifikant verschieden.

$2012 / 13$

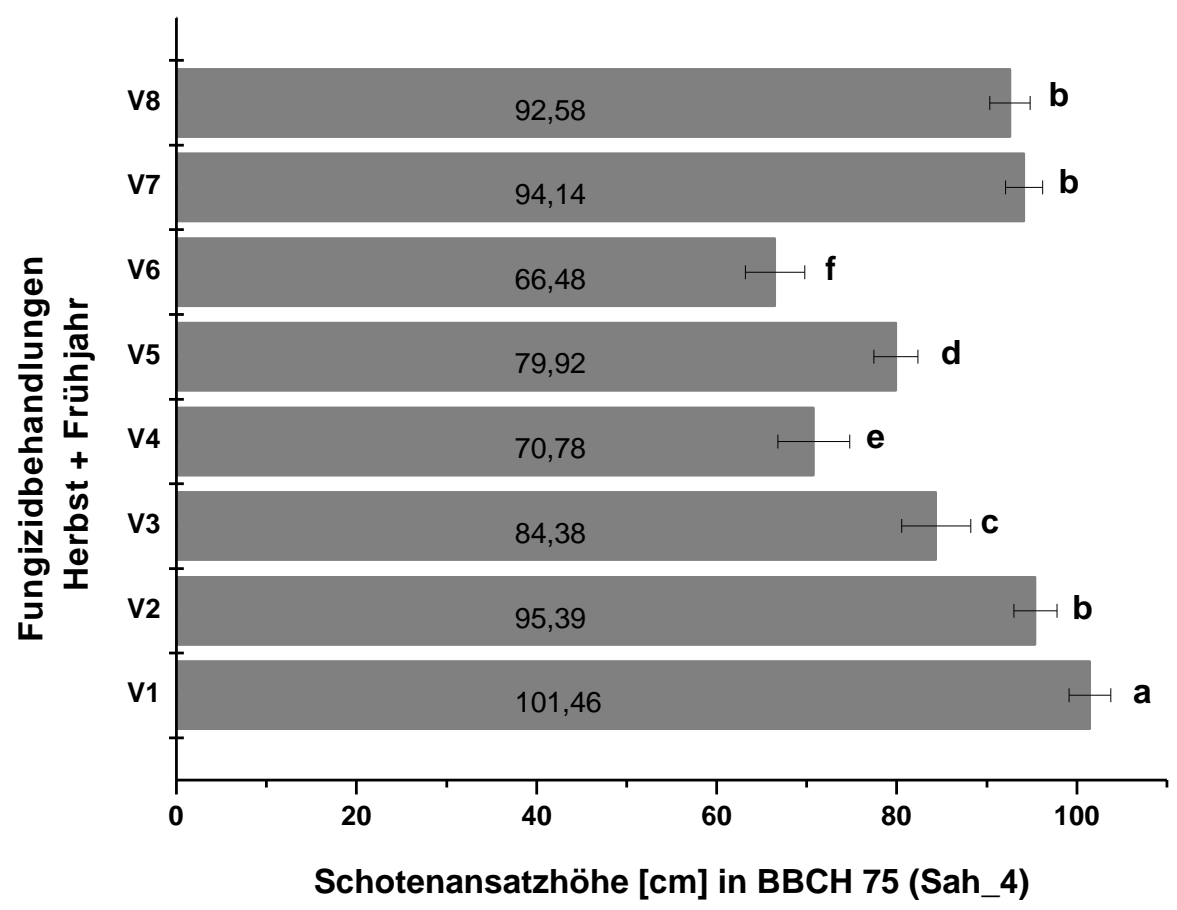

Abb. 32: Einfluss der im Herbst und im Frühjahr durchgeführten Fungizidbehandlungen auf die Schotenansatzhöhe [cm] in BBCH 75 (Sah_4) im Versuchsjahr 2012/13 am Standort Göttingen. Verschiedene Buchstaben kennzeichnen signifikante Unterschiede zwischen den Fungizidbehandlungen nach dem Tukey-Test $(p \leq 0,05, n=4)$, errechnet innerhalb des verwendeten gemischten Modells. Die Fehlerbalken stellen die jeweilige Standardabweichung dar. V = Variante: $V 1$ $=$ unbehandelte Kontrolle, V2 $=0,5 \mathrm{l} /$ ha Toprex $^{\circledR}$ (Difenoconazol + Paclobutrazol) in BBCH 33/35, V3 = 0,5 I/ha Toprex ${ }^{\circledR}$ in BBCH 14 und 33/35, V4 = 0,5 I/ha Toprex ${ }^{\circledR}$ in BBCH 14, 16 und 33/35, V5 = 0,5 I/ha Toprex ${ }^{\circledR}$ in BBCH 14, 33/35 und 53/55, V6 $=0,5$ l/ha Toprex ${ }^{\circledR}$ in BBCH 14, 16, 33/35 und 53/55, V7 $=0,5 \mathrm{l} / \mathrm{ha}$ Toprex $^{\circledR}$ in $\mathrm{BBCH} 14, \mathrm{~V} 8=$ praxisüblich $=0,5 \mathrm{l} /$ ha Carax $^{\circledR}$ (Mepiquatchlorid + Metconazol) in $\mathrm{BBCH} 14$ und 33/35; alle Varianten erhielten in $\mathrm{BBCH} 651$ l/ha Ortiva ${ }^{\circledR}$ (Azoxystrobin). 
Die zuvor beschriebenen Effekte der einzelnen Fungizidvarianten konnten auch bei der Interaktion zwischen Sorte und Fungizidbehandlung festgestellt werden (vgl. Tab. 27A im Anhang II). Unter dem Einfluss der Sorte NK Petrol verringerten, im Vergleich zur unbehandelten Kontrolle (Variante 1; 106,79 cm), die Varianten $6(75,31 \mathrm{~cm})$ und $4(80,00$ $\mathrm{cm})$ die Schotenansatzhöhe in $\mathrm{BBCH} 75$ am stärksten, gefolgt von den Varianten $5(89,22$ $\mathrm{cm})$ und $3(92,97 \mathrm{~cm})$. Variante $8(100,02 \mathrm{~cm})$ reduzierte im Vergleich zur unbehandelten Kontrolle die Schotenansatzhöhe in $\mathrm{BBCH} 75$ am geringsten. Alle genannten Varianten unterschieden sich signifikant von der unbehandelten Kontrolle. Weiterhin unterschieden sich signifikant voneinander, die Varianten 4 und 6 von den Varianten 3, 5 und 8 sowie die Varianten 3 und 5 von Variante 8. Die Varianten $2(101,41 \mathrm{~cm})$ und $7(103,13 \mathrm{~cm})$ unterschieden sich in Bezug auf die Schotenansatzhöhe in BBCH 75 nicht signifikant von Variante 1. Unter dem Einfluss der Sorte SY Vesuvio reduzierten, im Vergleich zur unbehandelten Kontrolle (Variante 1; 96,14 cm), die Varianten $6(57,66 \mathrm{~cm})$ und $4(61,56 \mathrm{~cm})$ die Schotenansatzhöhe in BBCH 75 am stärksten, gefolgt von den Varianten $5(70,62 \mathrm{~cm})$ und $3(75,78 \mathrm{~cm})$. Die Varianten $8(85,15 \mathrm{~cm}), 7(85,16 \mathrm{~cm})$ und $2(89,37 \mathrm{~cm})$ reduzierten, im Vergleich zur unbehandelten Kontrolle, die Schotenansatzhöhe in $\mathrm{BBCH} 75$ am geringsten. Alle aufgezählten Varianten unterschieden sich signifikant von der Variante 1 sowie untereinander, wobei zwischen den Varianten 2, 7 und 8 keine signifikanten Differenzen in Bezug auf die Schotenansatzhöhe in $\mathrm{BBCH} 75$ auftraten.

\section{Bestandeshöhe in BBCH 65/67 (Hoe_1) und in BBCH 73/74 (Hoe_3)}

Die Bestandeshöhe in $\mathrm{BBCH}$ 65/67 und in $\mathrm{BBCH} 73 / 74$ wurde durch die Sorte und die Fungizidbehandlung signifikant beeinflusst. Wie bei den verschiedenen Messterminen von der Schotenansatzhöhe, nahm die Bestandeshöhe vom ersten zum dritten Messtermin zu. Die signifikanten Effekte von den Sorten und den Fungizidbehandlungen änderten sich mit der Zunahme der Bestandeshöhe nicht (vgl. Tab. 27A im Anhang II). Aus diesem Grund und da der Parameter Bestandeshöhe in $\mathrm{BBCH}$ 65/67 einen stärkeren Zusammenhang mit seiner Zielvariablen aufwies als der Parameter Bestandeshöhe in 73/74, werden hier nur die signifikanten Effekte der Versuchsfaktoren zum Parameter Bestandeshöhe in BBCH 65/67 ausführlich beschrieben. Nähere Informationen zu der Bestandeshöhe in $\mathrm{BBCH}$ 73/74 finden sich in Tab. 27A im Anhang II.

\section{Bestandeshöhe in BBCH 65/67 (Hoe_1); (indirekt ertragsrelevant)}

Die Rapspflanzen der Sorte NK Petrol waren im Wachstumsstadium 65/67 signifikant höher $(140,16 \mathrm{~cm})$ als die Rapspflanzen der Sorte SY Vesuvio (121,96 cm; Tab. 29). 
Tab. 29: Einfluss der Sorte ((So), P = NK Petrol bzw. V = SY Vesuvio) auf die Bestandeshöhe [cm] in BBCH 65/67 (Hoe_1) im Versuchsjahr 2012/13 am Standort Göttingen. Dargestellt sind die Mittelwerte und die Standardabweichung (SD). Verschiedene Buchstaben kennzeichnen signifikante Unterschiede zwischen den Sorten nach dem Tukey-Test $(p \leq 0,05, n=4)$, errechnet innerhalb des verwendeten gemischten Modells.

\begin{tabular}{lccccc}
\hline Parameter & Effekt & So & Mittelwert & SD & Buchstaben \\
\hline Bestandeshöhe [cm] & So & P & 140,16 & 3,12 & a \\
in BBCH 65/67 (Hoe_1) & So & V & 121,96 & 3,44 & b \\
\hline
\end{tabular}

Die Abb. 33 zeigt, dass die Bestandeshöhe in BBCH 65/67 bei den acht verschiedenen Fungizidvarianten zwischen 111,91 cm (Variante 6) und 146,36 cm (Variante 1) lag. Im Vergleich zur Variante 1 reduzierten die Varianten 6 und $4(116,28 \mathrm{~cm})$ die Bestandeshöhe in BBCH 65/67 am stärksten, gefolgt von den Varianten $5(125,56 \mathrm{~cm})$ und $3(129,23 \mathrm{~cm})$. Am geringsten reduzierten die Varianten $8(137,39 \mathrm{~cm}), 7(140,09 \mathrm{~cm})$ und $2(141,63 \mathrm{~cm})$ die Bestandeshöhe in $\mathrm{BBCH}$ 65/67. Dabei unterschieden sich alle aufgeführten Varianten signifikant von Variante 1. Weiterhin unterschieden sich die Varianten 4 und 6 signifikant von den Varianten 2, 3, 5, 7 und 8. Die Varianten 3 und 5 waren in Bezug auf die Bestandeshöhe in $\mathrm{BBCH}$ 65/67 signifikant verschieden von den Varianten 2, 7 und 8. 


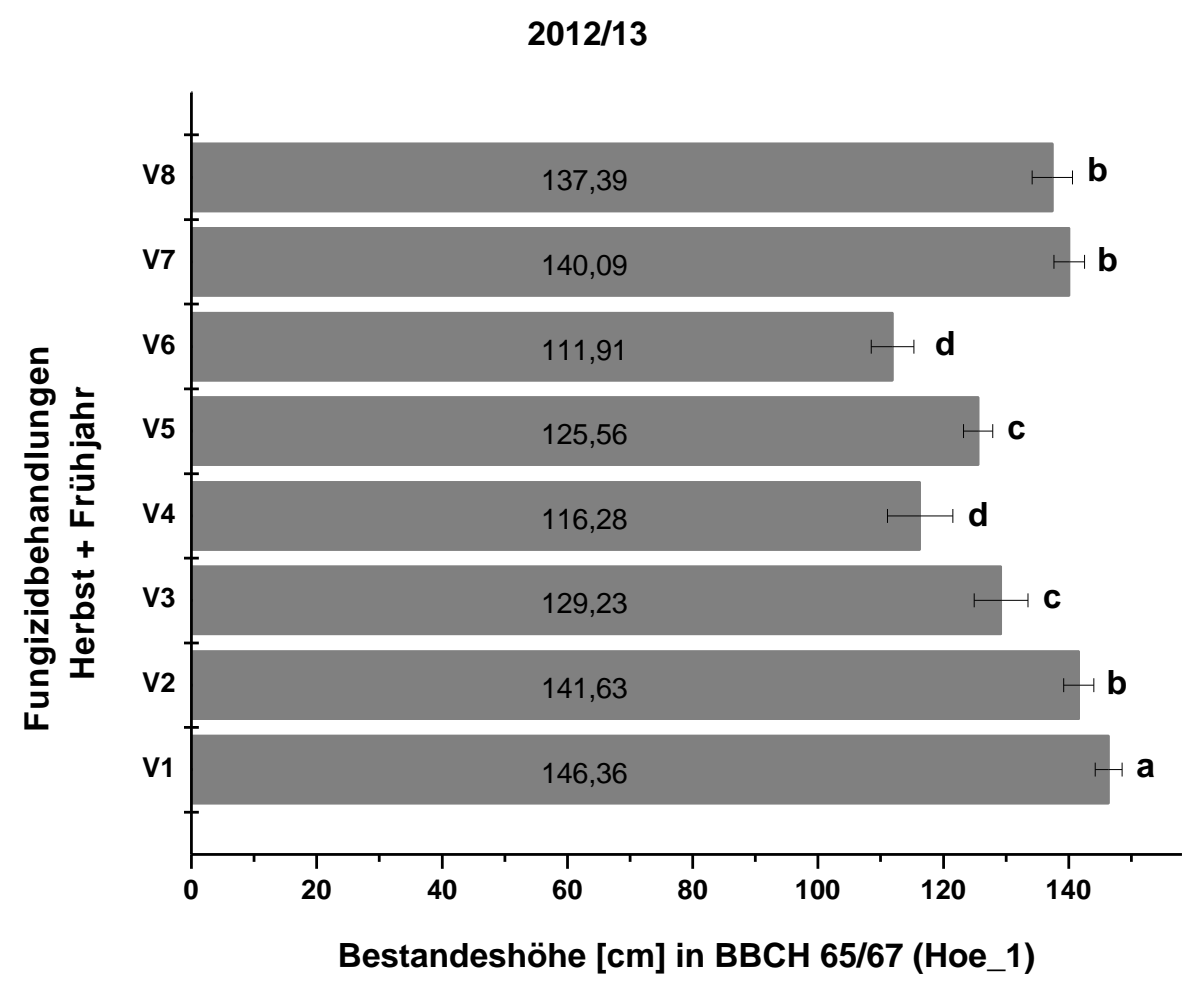

Abb. 33: Einfluss der im Herbst und im Frühjahr durchgeführten Fungizidbehandlungen auf die Bestandeshöhe [cm] in BBCH 65/67 (Hoe_1) im Versuchsjahr 2012/13 am Standort Göttingen. Verschiedene Buchstaben kennzeichnen signifikante Unterschiede zwischen den Fungizidbehandlungen nach dem Tukey-Test $(p \leq 0,05, n=4)$, errechnet innerhalb des verwendeten gemischten Modells. Die Fehlerbalken stellen die jeweilige Standardabweichung dar. V = Variante: V1 $=$ unbehandelte Kontrolle, V2 $=0,5 \mathrm{l} / \mathrm{ha}$ Topre $^{\circledR}{ }^{\circledR}$ (Difenoconazol + Paclobutrazol) in BBCH 33/35, V3 = 0,5 I/ha Toprex ${ }^{\circledR}$ in BBCH 14 und 33/35, V4 = 0,5 I/ha Toprex ${ }^{\circledR}$ in BBCH 14, 16 und 33/35, V5 = 0,5 I/ha Toprex ${ }^{\circledR}$ in BBCH 14, 33/35 und 53/55, V6 $=0,5 \mathrm{l} /$ ha Toprex ${ }^{\circledR}$ in BBCH 14, 16, 33/35 und 53/55,

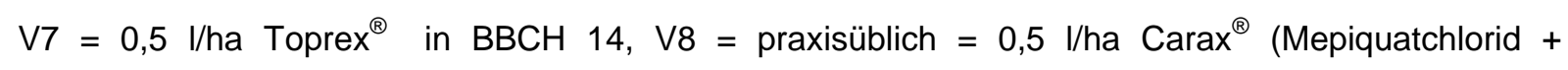
Metconazol) in BBCH 14 und 33/35; alle Varianten erhielten in $\mathrm{BBCH} 651$ l/ha Ortiva ${ }^{\circledR}$ (Azoxystrobin).

\section{Schotenschichtdicke in BBCH 65/67 (Schi_1); (indirekt ertragsrelevant)}

Für die Schotenschichtdicke in BBCH 65/67 wurden keine signifikanten Effekte der Sorte, der Saatstärke oder der Fungizidbehandlung ermittelt. Für weitere Einzelheiten siehe Tab. 25A im Anhang II. 


\section{Schotenschichtdicke in BBCH 73/74 (Schi_3); (indirekt ertragsrelevant)}

Die Schotenschichtdicke in BBCH 73/74 wurde einzig durch die Sorte signifikant beeinflusst (Tab. 30). NK Petrol wies mit $51,84 \mathrm{~cm}$ eine signifikant dickere Schotenschicht im Wachstumsstadium 73/74 auf als SY Vesuvio $(47,21 \mathrm{~cm})$.

Tab. 30: Einfluss der Sorte ((So), $\mathrm{P}=\mathrm{NK}$ Petrol bzw. V = SY Vesuvio) auf die Schotenschichtdicke [cm] in BBCH 73/74 (Sah_3) im Versuchsjahr 2012/13 am Standort Göttingen. Dargestellt sind die Mittelwerte und die Standardabweichung (SD). Verschiedene Buchstaben kennzeichnen signifikante Unterschiede zwischen den Sorten nach dem Tukey-Test $(p \leq 0,05, n=4)$, errechnet innerhalb des verwendeten gemischten Modells.

\begin{tabular}{lccccc}
\hline Parameter & Effekt & So & Mittelwert & SD & Buchstaben \\
\hline Schotenschichtdicke [cm] & So & P & 51,84 & 1,75 & a \\
in BBCH 73/74 (Schi_3) & So & V & 47,21 & 2,04 & b \\
\hline
\end{tabular}

\section{Grünfärbung des Pflanzenbestandes in BBCH 65/66 (NDVI_B2); (indirekt ertragsrelevant)}

Die Grünfärbung des Pflanzenbestandes in BBCH 65/66 wurde signifikant durch die Sorte, die Fungizidbehandlung und die Interaktion zwischen Sorte $x$ Fungizidbehandlung beeinflusst. Bei SY Vesuvio konnte zum Wachstumsstadium 65/66 ein signifikant höherer NDVI-Wert ermittelt werden (NDVI =0,448) als NK Petrol (NDVI = 0,376; Tab. 31).

Tab. 31: Einfluss der Sorte ((So), $P=N K$ Petrol bzw. $V=S Y$ Vesuvio) auf die Grünfärbung des Pflanzenbestandes in BBCH 65/66 (NDVI_B2) im Versuchsjahr 2012/13 am Standort Göttingen. Dargestellt sind die Mittelwerte und die Standardabweichung (SD). Verschiedene Buchstaben kennzeichnen signifikante Unterschiede zwischen den Sorten nach dem Tukey-Test $(p \leq 0,05, n=4)$, errechnet innerhalb des verwendeten gemischten Modells.

\begin{tabular}{lccccc}
\hline Parameter & Effekt & So & Mittelwert & SD & Buchstaben \\
\hline Grünfärbung des Pflanzenbestandes & So & P & 0,376 & 0,010 & b \\
in BBCH 65/66 (NDVI_B2) & So & V & 0,448 & 0,015 & a \\
\hline
\end{tabular}


Die Abb. 34 zeigt, dass die Grünfärbung des Pflanzenbestandes in BBCH 65/66 in den Fungizidvarianten 1 (NDVI =0,422), 4 (NDVI =0,428), 6 (NDVI =0,433) und 7 (NDVI = 0,421 ) signifikant höher war als in den Varianten 2 (NDVI =0,385), 3 (NDVI =0,423) und 5 $(\mathrm{NDVI}=0,400)$. Außerdem war der NDVI-Wert in Variante 4 und 6 signifikant höher als in Variante $8(\mathrm{NDVI}=0,405)$. Des Weiteren war der Pflanzenbestand in den Fungizidvarianten 3 und 8 signifikant grüner als in Variante 2.

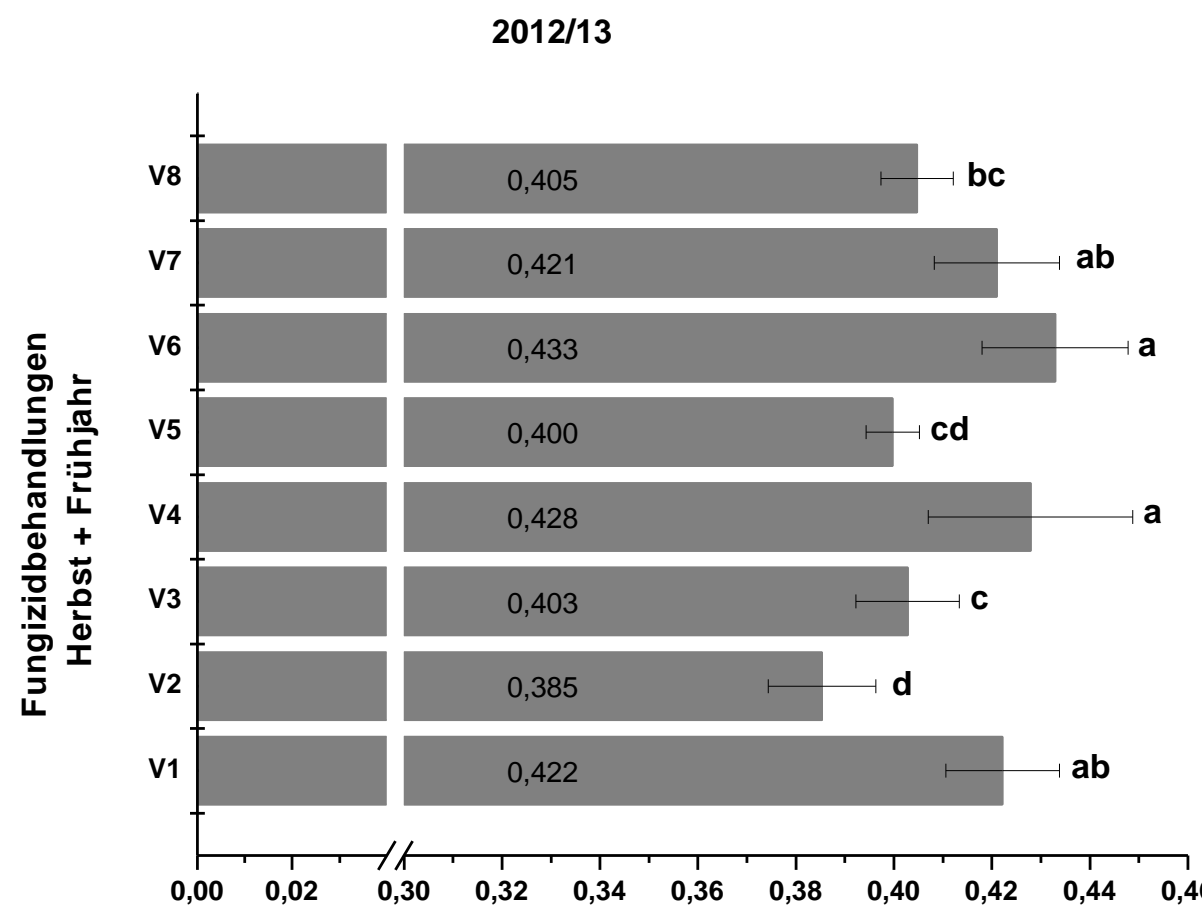

Grünfärbung des Pflanzenbestandes in BBCH 65/66 (NDVI_B2)

Abb. 34: Einfluss der im Herbst und im Frühjahr durchgeführten Fungizidbehandlungen auf die Grünfärbung des Pflanzenbestandes in BBCH 65/66 (NDVI_B2) im Versuchsjahr 2012/13 am Standort Göttingen. Verschiedene Buchstaben kennzeichnen signifikante Unterschiede zwischen den Fungizidbehandlungen nach dem Tukey-Test $(p \leq 0,05, n=4)$, errechnet innerhalb des verwendeten gemischten Modells. Die Fehlerbalken stellen die jeweilige Standardabweichung dar. $V=$ Variante: $V 1$ $=$ unbehandelte Kontrolle, V2 = 0,5 l/ha Toprex ${ }^{\circledR}$ (Difenoconazol + Paclobutrazol) in BBCH 33/35, V3 = 0,5 I/ha Toprex ${ }^{\circledR}$ in BBCH 14 und 33/35, V4 = 0,5 I/ha Toprex ${ }^{\circledR}$ in BBCH 14, 16 und 33/35, V5 = 0,5 I/ha Toprex ${ }^{\circledR}$ in BBCH 14, 33/35 und 53/55, V6 $=0,5$ l/ha Toprex ${ }^{\circledR}$ in BBCH 14, 16, 33/35 und 53/55, V7 $=0,5 \mathrm{l} / \mathrm{ha}$ Toprex $^{\circledR}$ in $\mathrm{BBCH} 14, \mathrm{~V} 8=$ praxisüblich $=0,5 \mathrm{l} /$ ha Carax $^{\circledR}$ (Mepiquatchlorid + Metconazol) in $\mathrm{BBCH} 14$ und 33/35; alle Varianten erhielten in $\mathrm{BBCH} 651 \mathrm{l} /$ ha Ortiva ${ }^{\circledR}$ (Azoxystrobin). 
Für die Interaktion zwischen Sorte und Fungizidbehandlung wurde nachgewiesen, dass unter dem Einfluss von NK Petrol, die Fungizidvarianten 4 (NDVI =0,394) und 6 (NDVI = 0,404), im Vergleich zu den Varianten 2 (NDVI = 0,358), 3 (NDVI = 0,364), 5 (NDVI = 0,364) und 8 (NDVI = 0,363), die Grünfärbung des Pflanzenbestandes in $\mathrm{BBCH}$ 65/66 signifikant erhöhten (vgl. Tab. 27A im Anhang II). Unter dem Einfluss von SY Vesuvio war die Grünfärbung des Pflanzenbestandes in $\mathrm{BBCH}$ 65/66 in den Varianten 1 (NDVI = 0,467), 3 $(\mathrm{NDVI}=0,442), 4(\mathrm{NDVI}=0,462), 6(\mathrm{NDVI}=0,462), 7(\mathrm{NDVI}=0,461)$ und $8(\mathrm{NDVI}=0,446)$ signifikant höher als in Variante 2 (NDVI =0,413). Weiterhin war der NDVI-Wert in der Variante 1 signifikant höher als in der Variante 5 (NDVI =0,436).

\section{Grünfärbung des Pflanzenbestandes in BBCH 89 (NDVI_A5); (direkt ertragsrelevant)}

Die Grünfärbung des Pflanzenbestandes in $\mathrm{BBCH} 89$ wurde durch die Sorte und die Fungizidbehandlung signifikant beeinflusst. Die Pflanzen der Sorte SY Vesuvio waren im Wachstumsstadium 89 signifikant grüner gefärbt $(\mathrm{NDVI}=0,343)$ als die Pflanzen der Sorte NK Petrol (NDVI = 0,275; Tab. 32).

Tab. 32: Einfluss der Sorte ((So), $P=N K$ Petrol bzw. V = SY Vesuvio) auf die Grünfärbung des Pflanzenbestandes in BBCH 89 (NDVI_A5) im Versuchsjahr 2012/13 am Standort Göttingen. Dargestellt sind die Mittelwerte und die Standardabweichung (SD). Verschiedene Buchstaben kennzeichnen signifikante Unterschiede zwischen den Sorten nach dem Tukey-Test $(p \leq 0,05, n=4)$, errechnet innerhalb des verwendeten gemischten Modells.

\begin{tabular}{lccccc}
\hline Parameter & Effekt & So & Mittelwert & SD & Buchstaben \\
\hline Grünfärbung des Pflanzenbestandes & So & P & 0,275 & 0,015 & b \\
in BBCH 89 (NDVI_A5) & So & V & 0,343 & 0,015 & $\mathrm{a}$ \\
\hline
\end{tabular}

Die Fungizidvarianten 2 (NDVI =0,302), $3(\mathrm{NDVI}=0$ 0,324), 4 (NDVI = 0322$), 5$ (NDVI = 0,323), 6 (NDVI = 0,324) 7 (NDVI = 0,306) und 8 (NDVI = 0,297) erhöhten, im Vergleich zur unbehandelten Kontrolle (Variante 1; NDVI =0,274), signifikant die Grünfärbung des Pflanzenbestandes in BBCH 89 (Abb. 35). Weiterhin war der mittlere NDVI-Wert in den Varianten 3, 4, 5 und 6 signifikant höher als in den Varianten 2 und 8. 


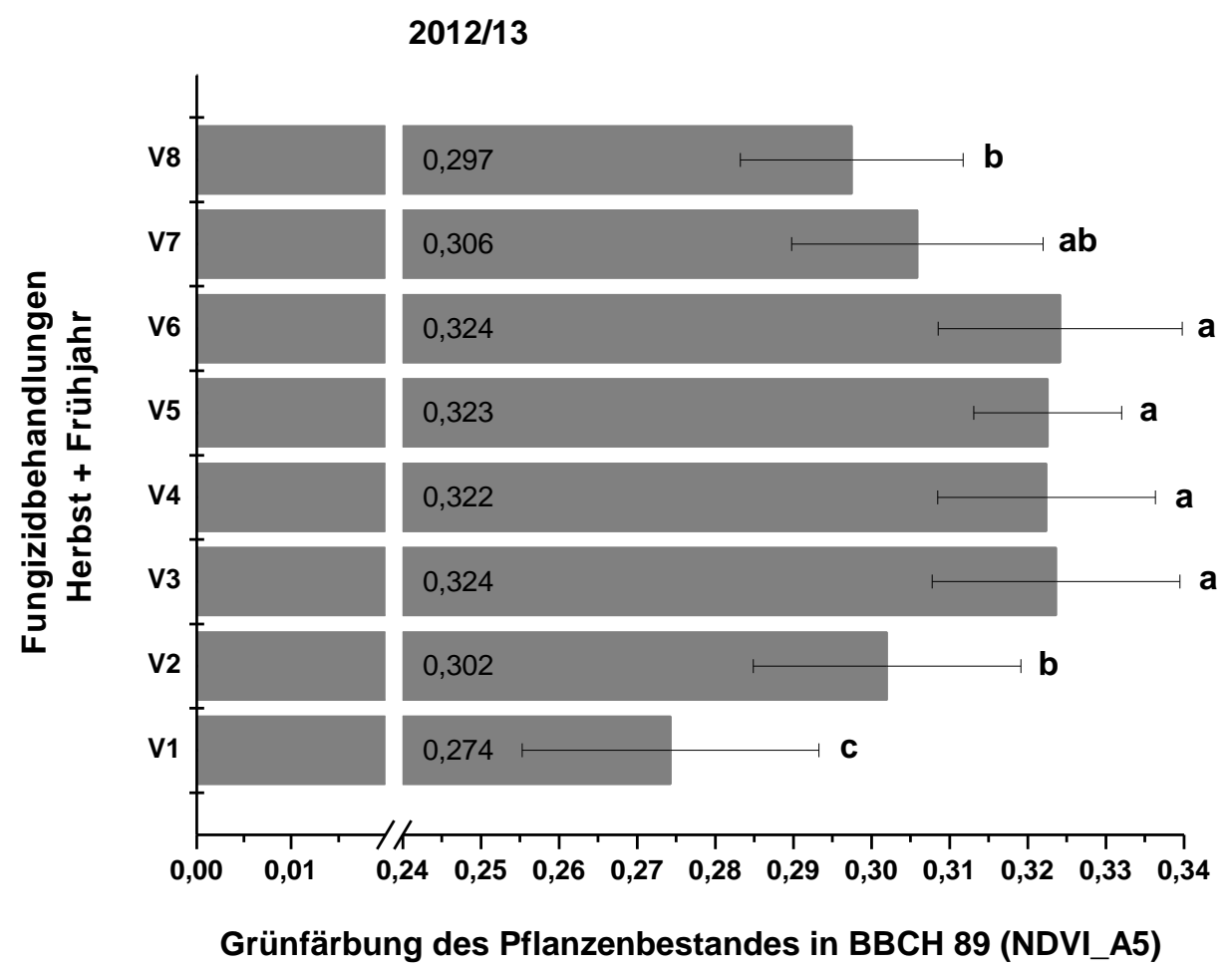

Abb. 35: Einfluss der im Herbst und im Frühjahr durchgeführten Fungizidbehandlungen auf die Grünfärbung des Pflanzenbestandes in BBCH 89 (NDVI_A5) im Versuchsjahr 2012/13 am Standort Göttingen. Verschiedene Buchstaben kennzeichnen signifikante Unterschiede zwischen den Fungizidbehandlungen nach dem Tukey-Test $(p \leq 0,05, n=4)$, errechnet innerhalb des verwendeten gemischten Modells. Die Fehlerbalken stellen die jeweilige Standardabweichung dar. V = Variante: V1 $=$ unbehandelte Kontrolle, V2 $=0,5 \mathrm{l} /$ ha Toprex $^{\circledR}$ (Difenoconazol + Paclobutrazol) in BBCH 33/35, V3 = 0,5 I/ha Toprex ${ }^{\circledR}$ in BBCH 14 und 33/35, V4 = 0,5 I/ha Toprex ${ }^{\circledR}$ in BBCH 14, 16 und 33/35, V5 = 0,5 I/ha Toprex ${ }^{\circledR}$ in BBCH 14, 33/35 und 53/55, V6 $=0,5$ l/ha Toprex ${ }^{\circledR}$ in BBCH 14, 16, 33/35 und 53/55, V7 $=0,5 \mathrm{l} / \mathrm{ha}$ Toprex $^{\circledR}$ in $\mathrm{BBCH} 14, \mathrm{~V} 8=$ praxisüblich $=0,5 \mathrm{l} /$ ha Carax $^{\circledR}$ (Mepiquatchlorid + Metconazol) in $\mathrm{BBCH} 14$ und 33/35; alle Varianten erhielten in $\mathrm{BBCH} 651$ l/ha Ortiva ${ }^{\circledR}$ (Azoxystrobin).

\section{BH mit der Wurzelhals- und Stängelfäule am unteren Stängel im Frühjahr in $\mathrm{BBCH}$ 80/81(BH_St_Fj); (indirekt ertragsrelevant)}

Die Effekte der Versuchsfaktoren Sorte, Saatstärke und Fungizidbehandlung auf die $\mathrm{BH}$ mit der Wurzelhals- und Stängelfäule am unteren Stängel im Frühjahr in BBCH 80/81 wurden in Kapitel 3.5.2 vorgestellt und werden daher an dieser Stelle nicht noch einmal erwähnt. 


\subsection{Einfluss von Bestandes- und Befallsparametern auf den Befall mit der Wurzelhals- und Stängelfäule}

Zu Beginn dieses Kapitels wird erläutert, in welchem Versuchsjahr der Befall mit der Wurzelhals- und Stängelfäule einen stärkeren Einfluss auf den Kornertrag hatte. Danach werden die Bestandes- und Befallsparameter vorgestellt, die im Jahr 2010/11 maßgeblich den BW mit der Wurzelhals- und Stängelfäule am Wurzelhals im Frühjahr in BBCH 83/84 beeinflusst haben. Zur Ermittlung der Bestandes- und Befallsparameter, die den stärksten Zusammenhang mit dem BW mit der Wurzelhals- und Stängelfäule am Wurzelhals im Frühjahr in $\mathrm{BBCH}$ 83/84 aufwiesen, wurden einfache, lineare- und multiple Regressionsanalysen angewendet. Die Ergebnisse dieser Analysen werden im Folgenden nacheinander vorgestellt. Zu den Bestandes- und Befallsparametern zählen alle Parameter, die nicht im Kapitel Material und Methoden als Ertragsparameter bzw. Ertragsfaktoren definiert wurden. Der Parameter Pflanzen $/ \mathrm{m}^{2}$ im Frühjahr stellt sowohl einen Ertragsfaktor als auch einen wichtigen Bestandesparameter dar. Daher wurden dieser und der Parameter Pflanzen $/ \mathrm{m}^{2}$ im Herbst bei den folgenden Betrachtungen mit berücksichtigt.

Beim Vergleich von Tab. 17 und Tab. 18 zeigte sich, dass im Jahr 2010/11 sowohl im Herbst als auch im Frühjahr eine höhere $\mathrm{BH}$ und ein höherer BW mit der Wurzelhals- und Stängelfäule am Wurzelhals bzw. am unteren Stängel auftrat als im Jahr 2012/13. Weiterhin konnte bei den einfachen, linearen Regressionsrechnungen mit den verschiedenen Befallsparametern der Wurzelhals- und Stängelfäule und der Zielvariablen Kornertrag festgestellt werden, dass im Jahr 2010/11 generell der Befall mit der Wurzelhals- und Stängelfäule stärker mit dem Kornertrag korreliert war als im Jahr 2012/13 (Tab. 33). Dabei wies im Jahr 2010/11 der BW mit der Wurzelhals- und Stängelfäule am Wurzelhals im Frühjahr in BBCH 83/84 (BW_Wh_Fj) die höchste negative Korrelation mit dem Kornertrag auf $\left(r_{p}=-0,363\right)$. Dagegen war BW_Wh_Fj im Jahr 2012/13 nicht signifikant mit dem Kornertrag korreliert (Tab. 33). In diesem Jahr waren die BH und der BW mit der Wurzelhalsund Stängelfäule an Laubblättern im Herbst in $\mathrm{BBCH}$ 17/18 (BH_He bzw. BW_He) und die $\mathrm{BH}$ sowie der BW mit der Wurzelhals- und Stängelfäule am unteren Stängel in $\mathrm{BBCH}$ 80/81 (BH_St_Fj bzw. BW_St_Fj) schwach positiv mit dem Kornertrag korreliert (BH_He: $r_{p}=$

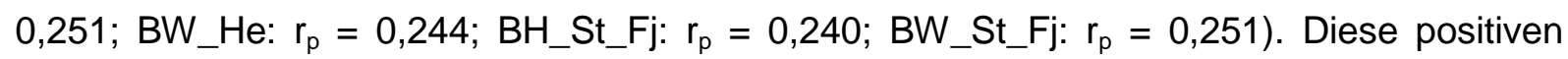
Korrelationen sind auf die Doppelwirkung der eingesetzten Fungizide (fungizide und wachstumsregulatorische Wirkung) zurückzuführen und werden in der Diskussion näher erläutert. Auf Basis dieser Ergebnisse wurden nur für das Jahr 2010/11 eine einfache, 
lineare- und eine multiple Regressionsanalyse mit dem Parameter BW_Wh_Fj als Zielvariable durchgeführt.

Tab. 33: Einfache, lineare Regressionen zwischen den verschiedenen Befallsparametern der Wurzelhals- und Stängelfäule und der Zielvariablen Kornertrag getrennt nach den Versuchsjahren 2010/11 und 2012/13. Dargestellt sind die Anzahl der Werte (n), die in jede Regressionsrechnung eingeflossen sind, der Korrelationskoeffizient nach Pearson $\left(r_{p}\right)$, das Bestimmtheitsmaß nach Pearson $\left(R_{p}{ }^{2}\right)$ und die Überschreitungswahrscheinlichkeit ( $p$-Wert) für die Pearson-Korrelation $\left(p_{p}\right)$. Für jedes Jahr sind die Daten aufsteigend nach den $r_{p}$-Werten sortiert. Signifikante Effekte sind fett hervorgehoben.

\begin{tabular}{cccccc}
\hline Jahr & Parameter & $\mathbf{n}$ & $\mathbf{r}_{\mathbf{p}}$ & $\mathbf{R}_{\mathbf{p}}{ }^{2}$ & $\mathbf{p}_{\mathbf{p}}$ \\
\hline & BW_Wh_Fj & 119 & $-0,363$ & 0,132 & $\mathbf{0 , 0 0 0}$ \\
& BH_St_Fj & 119 & $-0,198$ & 0,039 & $\mathbf{0 , 0 3 1}$ \\
$\mathbf{2 0 1 0 / 1 1}$ & BW_He & 119 & $-0,154$ & 0,024 & 0,094 \\
& BW_St_Fj & 119 & $-0,105$ & 0,011 & 0,254 \\
& BH_He & 119 & $-0,091$ & 0,008 & 0,327 \\
& BH_Wh_Fj & 119 & $-0,054$ & 0,003 & 0,557 \\
& BH_Wh_He & 119 & 0,096 & 0,009 & 0,302 \\
& BW_Wh_He & 119 & 0,134 & 0,018 & 0,147 \\
\hline \multirow{2012/13}{*}{} & BH_Wh_He & 124 & $-0,150$ & 0,022 & 0,097 \\
& BW_Wh_He & 124 & $-0,045$ & 0,002 & 0,618 \\
& BH_Wh_Fj & 124 & 0,161 & 0,026 & 0,073 \\
& BW_Wh_Fj & 124 & 0,170 & 0,029 & 0,058 \\
& BH_St_Fj & 124 & 0,240 & 0,058 & $\mathbf{0 , 0 0 7}$ \\
& BW_He & 124 & 0,244 & 0,059 & $\mathbf{0 , 0 0 6}$ \\
& BH_He & 124 & 0,251 & 0,063 & $\mathbf{0 , 0 0 5}$ \\
& BW_St_Fj & 124 & 0,251 & 0,063 & $\mathbf{0 , 0 0 5}$
\end{tabular}

*Erklärung der Parameterabkürzungen: BH_St_Fj bzw. BH_Wh_Fj = Befallshäufigkeit [\%] mit der Wurzelhals- und Stängelfäule am unteren Stängel bzw. am Wurzelhals im Frühjahr; BW_St_Fj bzw. BW_Wh_Fj $=$ Befallswert mit der Wurzelhals- und Stängelfäule am unteren Stängel bzw. am Wurzelhals im Frühjahr; BH_He bzw. BH_Wh_He = Befallshäufigkeit mit der Wurzelhals- und Stängelfäule an Laubblättern bzw. am Wurzelhals im Herbst; BW_He bzw. BW_Wh_He = Befallswert mit der Wurzelhals- und Stängelfäule an Laubblättern bzw. am Wurzelhals im Herbst. 


\section{Einfache, lineare Regression - BW mit der Wurzelhals- und Stängelfäule am Wurzelhals im Frühjahr in BBCH 83/84}

In Tab. 34 sind die signifikanten (nach Pearson und Spearman) Ergebnisse aus der einfachen, linearen Regressionsrechnung zwischen allen untersuchten Bestandes- und Befallsparametern und der Zielvariablen BW_Wh_Fj für das Versuchsjahr 2010/11 wiedergegeben. Diese signifikanten Ergebnisse wurden aus der Tab. 23A im Anhang II entnommen, die sämtliche signifikante sowie nicht signifikante Ergebnisse der Regressionsrechnung enthält. Den stärksten positiven Zusammenhang mit der Zielvariablen BW_Wh_Fj wies der Parameter BH mit der Wurzelhals- und Stängelfäule am unteren Stängel im Frühjahr in $\mathrm{BBCH}$ 83/84 (BH_St_Fj; $\left.r_{p}=0,571\right)$ auf. Dahinter folgten die Parameter Wurzelhalsdurchmesser im Frühjahr in BBCH 83/84 (WHD_Fj; $r_{p}=0,547$ ), BH mit der Wurzelhals- und Stängelfäule am Wurzelhals im Frühjahr in BBCH 83/84 (BH_Wh_Fj; $r_{p}$ $=0,544)$, BW mit der Wurzelhals- und Stängelfäule am unteren Stängel im Frühjahr in $\mathrm{BBCH}$ 83/84 (BW_St_Fj; $\left.r_{p}=0,495\right)$ und Anteil an PAR am Boden in BBCH 75 (PAR_B4; $r_{p}=$ 0,462). Die stärkste negative Korrelation mit der Zielvariablen BW_Wh_Fj konnte der Parameter Anzahl Pflanzen/m² im Frühjahr in BBCH 16/18 (Di_Fj) mit $r_{p}=-0,572$ vorweisen. Dahinter reihten sich folgende Parameter ein: Anzahl Pflanzen $/ \mathrm{m}^{2}$ im Herbst in $\mathrm{BBCH}$ 14/15 (Di_He; $\left.r_{p}=-0,544\right)$, Kulturdeckungsgrad im Frühjahr in BBCH 32/34 (KDG_Fj; $\left.r_{p}=-0,497\right)$ und Grünfärbung des Pflanzenbestandes in BBCH 73 (NDVI_B4; $\left.r_{p}=-0,464\right)$. Wenngleich die positiven Korrelationen von den Parametern $\mathrm{BH}$ mit der Kleinen Kohlfliege im Frühjahr in BBCH 83/84 (BH_Kf_Fj; $\left.r_{p}=0,305\right)$, BW mit der Wurzelhals- und Stängelfäule an Laubblättern im Herbst in BBCH 16/18 (BW_He; $\left.r_{p}=0,304\right)$ und BH mit der Wurzelhals- und Stängelfäule an Laubblättern im Herbst in $\mathrm{BBCH} 16 / 18\left(\mathrm{BH} \_\mathrm{He} ; r_{p}=0,263\right)$ mit der Zielvariablen nicht besonders hoch waren, sollen sie nicht unerwähnt bleiben. Beim Vergleich der genannten höchsten positiven und negativen Korrelationskoeffizienten fiel auf, dass sie unabhängig von ihrem Vorzeichen ähnlich hoch waren. 
Tab. 34: Signifikante, einfache, lineare Regressionen zwischen verschiedenen Bestandes- bzw. Befallsparametern und der Zielvariablen Befallswert mit der Wurzelhals- und Stängelfäule am Wurzelhals im Frühjahr in BBCH 83/84 (BW_Wh_Fj; Feldversuch Göttingen 2010/11). Dargestellt ist die Anzahl der Werte ( $n$ ), die in jede Regressionsrechnung eingeflossen sind, der Korrelationskoeffizient nach Pearson $\left(r_{p}\right)$, das Bestimmtheitsmaß nach Pearson $\left(R_{p}{ }^{2}\right)$ und die Überschreitungswahrscheinlichkeit ( $p$-Wert) für die Pearson-Korrelation $\left(p_{p}\right)$. Korrelationen bzw. Bestimmtheitsmaße sind signifikant bei einem Wert $p_{p} \leq 0,05$ (hoch signifikant bei $p_{p} \leq 0,01$, höchst signifikant bei $\left.p_{p} \leq 0,001\right)$. Die Tabelle ist aufsteigend nach den $r_{p}$-Werten sortiert.

\begin{tabular}{|c|c|c|c|c|}
\hline Parameter & $\mathbf{n}$ & $r_{p}$ & $\mathbf{R}_{\mathbf{p}}^{2}$ & $\mathbf{p}_{\mathrm{p}}$ \\
\hline Pflanzen/m² in BBCH 16/18 (Fj) & 120 & $-0,572$ & 0,327 & 0,000 \\
\hline Pflanzen/m² in BBCH 14/15 (He) & 120 & $-0,544$ & 0,296 & 0,000 \\
\hline Kulturdeckungsgrad in ВВСН $32 / 34$ & 120 & $-0,497$ & 0,247 & 0,000 \\
\hline Grünfärbung des Pflanzenbestandes in $\mathrm{BBCH} 73$ & 120 & $-0,464$ & 0,215 & 0,000 \\
\hline relativer Anteil an Schoten am 3. Seitentrieb & 120 & $-0,421$ & 0,177 & 0,000 \\
\hline relativer Anteil an Schoten am 4. Seitentrieb & 120 & $-0,296$ & 0,088 & 0,001 \\
\hline relativer Anteil an Schoten am Haupttrieb & 120 & $-0,284$ & 0,081 & 0,002 \\
\hline relativer Anteil an Schoten am 2. Seitentrieb & 120 & $-0,235$ & 0,055 & 0,010 \\
\hline Grünfärbung des Pflanzenbestandes in BBCH 79 & 120 & $-0,232$ & 0,054 & 0,011 \\
\hline Grünfärbung des Pflanzenbestandes in BBCH 84 & 120 & $-0,196$ & 0,038 & 0,032 \\
\hline relativer Anteil an Schoten am 1. Seitentrieb & 120 & $-0,190$ & 0,036 & 0,037 \\
\hline Anteil an PAR am Boden in BBCH 63/65 & 120 & 0,212 & 0,045 & 0,020 \\
\hline absolute Anzahl an Schoten am 4. Seitentrieb & 120 & 0,226 & 0,051 & 0,013 \\
\hline Grünfärbung des Pflanzenbestandes in BBCH 89 & 120 & 0,232 & 0,054 & 0,011 \\
\hline absolute Anzahl an Schoten am Haupttrieb & 120 & 0,255 & 0,065 & 0,005 \\
\hline $\begin{array}{l}\text { BH mit der Wurzelhals- und Stängelfäule } \\
\text { an Laubblättern in } \mathrm{BBCH} 16 / 18(\mathrm{He})^{\star}\end{array}$ & 120 & 0,263 & 0,069 & 0,004 \\
\hline Grünfärbung des Pflanzenbestandes in BBCH 69 & 120 & 0,283 & 0,080 & 0,002 \\
\hline $\begin{array}{l}\text { BW mit der Wurzelhals- und Stängelfäule } \\
\text { an Laubblättern in } \mathrm{BBCH} 16 / 18(\mathrm{He})^{\star}\end{array}$ & 120 & 0,304 & 0,092 & 0,001 \\
\hline BH mit der Kleinen Kohlfliege & 120 & 0,305 & 0,093 & 0,001 \\
\hline Anteil an PAR unter den Schoten in BBCH 67/69 & 120 & 0,318 & 0,101 & 0,000 \\
\hline Anteil an PAR am Boden in BBCH 73/74 & 120 & 0,361 & 0,131 & 0,000 \\
\hline Anteil an PAR unter den Schoten in BBCH 75 & 120 & 0,394 & 0,155 & 0,000 \\
\hline Anteil an PAR am Boden in BBCH 67/69 & 120 & 0,397 & 0,158 & 0,000 \\
\hline Anteil an PAR unter den Schoten in BBCH 73/74 & 120 & 0,408 & 0,166 & 0,000 \\
\hline Grünfärbung des Pflanzenbestandes in BBCH 65/66 & 120 & 0,426 & 0,181 & 0,000 \\
\hline Seitentriebe/Pflanze & 120 & 0,438 & 0,192 & 0,000 \\
\hline
\end{tabular}




\begin{tabular}{lrrrr}
\hline $\begin{array}{l}\text { Anteil an PAR am Boden in BBCH 75 } \\
\text { BW mit der Wurzelhals- und Stängelfäule } \\
\text { am unteren Stängel in BBCH 83/84 }\end{array}$ & 120 & 0,462 & 0,213 & 0,000 \\
$\begin{array}{l}\text { BH mit der Wurzelhals- und Stängelfäule } \\
\text { am Wurzelhals in BBCH 83/84 }\end{array}$ & 120 & 0,495 & 0,245 & 0,000 \\
$\begin{array}{l}\text { Wurzelhalsdurchmesser in BBCH 83/84 } \\
\begin{array}{l}\text { BH mit der Wurzelhals- und Stängelfäule } \\
\text { am unteren Stängel in BBCH 83/84 }\end{array}\end{array}$ & 119 & 0,547 & 0,295 & 0,000 \\
\hline
\end{tabular}

${ }^{*} \mathrm{He}=$ Herbst, $\mathrm{Fj}=$ Frühjahr

\section{Multiple Regression - BW mit der Wurzelhals- und Stängelfäule am Wurzelhals im Frühjahr in BBCH 83/84}

In der Abb. 36 sind die Zusammenhänge zwischen bestimmten Parametern ausgehend von der Zielvariablen BW mit der Wurzelhals- und Stängelfäule am Wurzelhals im Frühjahr in BBCH 83/84 (BW_Wh_Fj) für das Jahr 2010/11 wiedergegeben. Diese hierarchische Darstellung beruht auf mehreren multiplen Regressionsanalysen, deren signifikante Ergebnisse im Anhang II in den Tabellen 43A bis 53A aufgeführt sind. BW_Wh_Fj wurde am stärksten durch den Parameter Anzahl Pflanzen/m² im Frühjahr in BBCH 16/18 (Di_Fj) mit $32,7 \%$ beeinflusst. An zweiter Stelle folgte der Parameter BW mit der Wurzelhals-und Stängelfäule am unteren Stängel im Frühjahr in BBCH 83/84 (BW_St_Fj) mit 20,9\%. Von den beiden Prädiktoren war Di_Fj negativ und BW_St_Fj positiv mit BW_Wh_Fj korreliert. Der Parameter Di_Fj wurde insbesondere durch die Pflanzendichte im Herbst in BBCH 14/15 (Di_He; 71,9\%) und der Bestandeshöhe in $\mathrm{BBCH} 75$ (Hoe_4; 4,3\%) beeinflusst. Beide Prädiktoren besaßen einen positiven Zusammenhang mit der Zielvariablen Di_Fj. Hier ist allerdings zu beachten, dass die Bestandeshöhe nicht die Pflanzendichte im Frühjahr beeinflussen kann. Vielmehr hat die Pflanzendichte im Frühjahr einen Einfluss auf die Bestandeshöhe. Dieser Zusammenhang ist als logisch und das zuvor beschriebene Ergebnis, was durch die multiple Regressionsanalyse ermittelt wurde, ist als unlogisch anzusehen. Hoe_4 wurde primär durch die Schotenansatzhöhe in BBCH 75 (Sah_4; 86,4\%) und der Schotenschichtdicke in BBCH 75 (Schi_4; 13,6\%) erklärt. Das war nicht verwunderlich, da sich die Bestandeshöhe rechnerisch aus der Schotenansatzhöhe und der Schotenschichtdicke ergab. Auf der linken Seite der hierarchischen Darstellung ist zu erkennen, dass der Parameter BW_St_Fj am stärksten durch den Parameter BH mit der Wurzelhals- und Stängelfäule am unteren Stängel im Frühjahr in BBCH 83/84 (BH_St_Fj; $31,7 \%$ ) beeinflusst wurde. Als zweite erklärende Variable für BW_St_Fj wurde die Bestandeshöhe in $\mathrm{BBCH}$ 73/74 (Hoe_3; 22,1\%) ermittelt. Beide Prädiktoren waren positiv mit dem Parameter BW_St_Fj korreliert. BH_St_Fj wurde am stärksten durch den Parameter BH mit der Wurzelhals- und Stängelfäule am Wurzelhals im Frühjahr in $\mathrm{BBCH} 83 / 84$ 
(BH_Wh_Fj; 36,4\%) beeinflusst. Den zweitstärksten Einfluss hatte der Parameter BH mit der Wurzelhals- und Stängelfäule an Laubblättern im Herbst in $\mathrm{BBCH} 16 / 18(\mathrm{BH} H \mathrm{He}$; 6,4\%). Beide Prädiktoren waren positiv mit dem Parameter BH_St_Fj korreliert. Hoe_3 wurde primär durch den Parameter Schotenansatzhöhe in BBCH 73/74 (Sah_3; 82,9\%) und sekundär durch den Parameter Schotenschichtdicke in BBCH 73/74 (Schi_3; 17,1\%) erklärt. Die beiden Prädiktoren waren positiv mit Hoe_3 korreliert. 


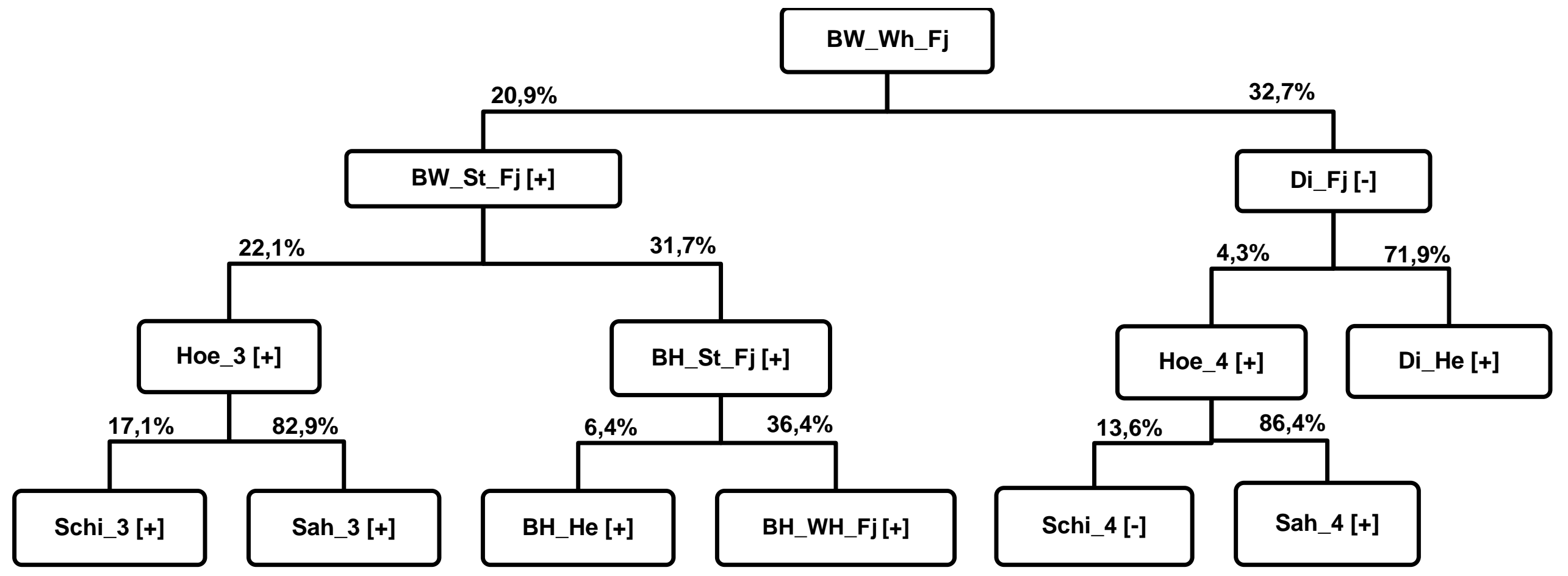

Abb. 36: Hierarchische Darstellung von Parametern, die im Versuchsjahr 2010/11 die Zielvariable Befallswert mit der Wurzelhals- und Stängelfäule am Wurzelhals im Frühjahr in BBCH 83/84 (BW_Wh_Fj) maßgeblich beeinflusst haben bzw. von denen sie selbst beeinflusst wurden. Die Prozentzahlen stellen das partielle $\mathrm{R}^{2}$ dar und drücken das Maß der Güte des Zusammenhangs mit der jeweiligen Zielvariable aus. Auf jeder Hierarchieebene ist der erste und zweite Prädiktor für die entsprechende Zielvariable dargestellt. Alle weiteren Prädiktoren, die eine Zielvariable beschreiben, wurden in dieser Darstellung nicht berücksichtigt. Diese Abbildung beruht auf den Ergebnissen mehrerer multipler Regressionen, wovon die Ergebnisse auszugsweise im Anhang II in den Tabellen 43A - 53A zu finden sind. Ein Parameter wurde als Prädiktor für die jeweilige Zielvariable in das Regressionsmodell aufgenommen, wenn dieser ein Signifikanzniveau von $p \leq 0,05$ einhielt. $[+]=$ positiv bzw. $[-]=$ negativ mit der Zielvariablen korreliert. Erklärungen der Parameterabkürzungen: Di_He $=$ Pflanzen/m² im Herbst in BBCH 14/15; Di_Fj = Pflanzen/m² im Frühjahr in BBCH 16/18; Hoe_3, 4 = Bestandeshöhe [cm] in BBCH 73/74, 75; Sah_3, $4=$ Schotenansatzhöhe $[\mathrm{cm}]$ in BBCH 73/74, 75; Schi_3, $4=$ Schotenschichtdicke [cm] in BBCH 73/74, 75; BW_St_Fj bzw. BH_St_Fj $=$ Befallswert bzw. Befallshäufigkeit [\%] mit der Wurzelhals- und Stängelfäule am unteren Stängel im Frühjahr (BBCH 83/84); BH_Wh_Fj = Befallshäufigkeit [\%] mit der Wurzelhals- und Stängelfäule am Wurzelhals im Frühjahr (BBCH 83/84); $\mathrm{BH} \_\mathrm{He}=$ Befallshäufigkeit [\%] mit der Wurzelhals- und Stängelfäule an Blättern (Blattläsionen) im Herbst (BBCH 16/18). 


\subsection{Effekte der Sorte, Saatstärke und Fungizidbehandlung auf Bestandes- und Befallsparameter, die den Befall mit der Wurzelhals- und Stängelfäule beeinflusst haben}

In Anlehnung an Kapitel 3.7 werden in diesem Kapitel die signifikanten Effekte der drei Versuchsfaktoren Sorte, Saatstärke und Fungizidbehandlung auf die Bestandes- und Befallsparameter vorgestellt (Ergebnisse der Varianzanalysen), die im Jahr 2010/11 direkt oder indirekt den BW mit der Wurzelhals- und Stängelfäule am Wurzelhals im Frühjahr in $\mathrm{BBCH}$ 83/84 beeinflusst haben (vgl. Abb. 36). Bevor die Ergebnisse zu einem Parameter beschrieben werden, wird dieser durch eine Überschrift angekündigt. Der Überschrift kann zusätzlich entnommen werden, ob der Parameter direkt (1. Hierarchieebene bei multipler Regression) oder indirekt (2. oder 3. Hierarchieebene bei multipler Regression) krankheitsbeeinflussend war. Da zu den meisten Parametern, die in Abb. 36 dargestellt sind, die Effekte der drei unabhängigen Versuchsfaktoren schon in anderen Kapiteln beschrieben wurden, werden diese hier nicht noch einmal erwähnt. Stattdessen wird auf das jeweilige Kapitel verwiesen, in dem die Ergebnisse der Varianzanalysen zu den entsprechenden Parametern nachgelesen werden können.

\section{Pflanzen/m² im Herbst in BBCH 14/15 (Di_He); (indirekt krankheitsbeeinflussend)}

Die Effekte der drei unabhängigen Versuchsfaktoren auf die Anzahl Pflanzen $/ \mathrm{m}^{2} \mathrm{im}$ Herbst in BBCH 14/15 wurden in Kapitel 3.7.1 auf Seite 118 beschrieben.

Pflanzen/m² im Frühjahr in BBCH 16/18 (Di_Fj); (direkt krankheitsbeeinflussend)

Die Effekte der drei unabhängigen Versuchsfaktoren auf die Anzahl Pflanzen $/ \mathrm{m}^{2} \mathrm{im}$ Frühjahr in BBCH 16/18 wurden in Kapitel 3.4.1 auf Seite 61 beschrieben.

Schotenansatzhöhe in BBCH 73/74 (Sah_3) und BBCH 75 (Sah_4) sowie Bestandeshöhe in $\mathrm{BBCH} 73 / 74$ (Hoe_3) und $\mathrm{BBCH} 75$ (Hoe_4); (indirekt krankheitsbeeinflussend)

Die Schotenansatzhöhe in $\mathrm{BBCH} 73 / 74$ und in $\mathrm{BBCH} 75$ sowie die Bestandeshöhe in $\mathrm{BBCH} 73 / 74$ und $\mathrm{BBCH} 75$ wurden durch die Sorte und durch die Fungizidbehandlung signifikant beeinflusst. Im Fall von der Bestandeshöhe in BBCH 75 hatte zusätzlich auch die Saatstärke einen signifikanten Effekt auf die Bestandeshöhe. Aus der Tab. 26A im Anhang II geht hervor, dass zum einen die Schotenansatzhöhe und die Bestandeshöhe 
von Messtermin zu Messtermin zunahmen und zum anderen die signifikanten Effekte von den Sorten und den Fungizidbehandlungen sich von Messtermin zu Messtermin nur geringfügig bis gar nicht geändert hatten. Die grundlegende Tendenz der Effekte blieb immer gleich. Aus diesem Grund werden an dieser Stelle nur die signifikanten Effekte der Versuchsfaktoren zu den Bestandesparametern Schotenansatzhöhe in BBCH 75 und Bestandeshöhe in $\mathrm{BBCH} 75$ explizit beschrieben. Für nähere Informationen zu der Schotenansatzhöhe in $\mathrm{BBCH} 73 / 74$ bzw. der Bestandeshöhe in $\mathrm{BBCH} 73 / 74$ wird auf die Tab. 26A im Anhang II verwiesen

\section{Schotenansatzhöhe in BBCH 75 (Sah_4); (indirekt krankheitsbeeinflussend)}

Der Bestandesparameter Schotenansatzhöhe in $\mathrm{BBCH} 75$ wurde signifikant durch die Sorte und die Fungizidbehandlung beeinflusst. Die Pflanzen der Sorte NK Petrol wiesen eine signifikant höhere Schotenansatzhöhe in $\mathrm{BBCH} 75$ auf $(\mathrm{ca} .76,8 \mathrm{~cm})$ als die Pflanzen der Sorte SY Merlot (ca. 64,0 cm, Tab. 35).

Tab. 35: Einfluss der Sorte ((So), $M=S Y$ Merlot bzw. $P=$ NK Petrol) auf die Schotenansatzhöhe in BBCH 75 (Sah_4) im Versuchsjahr 2010/11 am Standort Göttingen. Dargestellt sind die Mittelwerte und die Standardabweichung (SD). Verschiedene Buchstaben kennzeichnen signifikante Unterschiede zwischen den Sorten nach dem Tukey-Test $(p \leq 0,05, n=4)$, errechnet innerhalb des verwendeten gemischten Modells.

\begin{tabular}{lccccc}
\hline Parameter & Effekt & So & Mittelwert & SD & Buchstaben \\
\hline Schotenansatzhöhe & So & M & 64,04 & 2,76 & b \\
in BBCH 75 (Sah_4) & So & P & 76,87 & 3,19 & a \\
\hline
\end{tabular}


Bei den Fungizidbehandlungen zeigte sich, dass die Variante 4 von allen Fungizidvarianten am stärksten die Schotenansatzhöhe in $\mathrm{BBCH} 75$ einkürzte (Abb. 37). Mit etwa 65,4 cm war die Schotenansatzhöhe in $\mathrm{BBCH} 75$ in Variante 4 signifikant kürzer als in den Varianten 1 (ca. 75,7 cm), 2 (ca. 75,4 cm), 5 (ca. 70,6 cm), 6 (ca. 69,7 cm) und 7 (ca. 69,9 cm). Weiterhin reduzierten die Varianten $3(\mathrm{ca} .68,8 \mathrm{~cm}), 5,6,7$ und $8(68,4$ $\mathrm{cm})$ signifikant stärker die Schotenansatzhöhe in $\mathrm{BBCH} 75$ als die Varianten 1 und 2.

2010/11

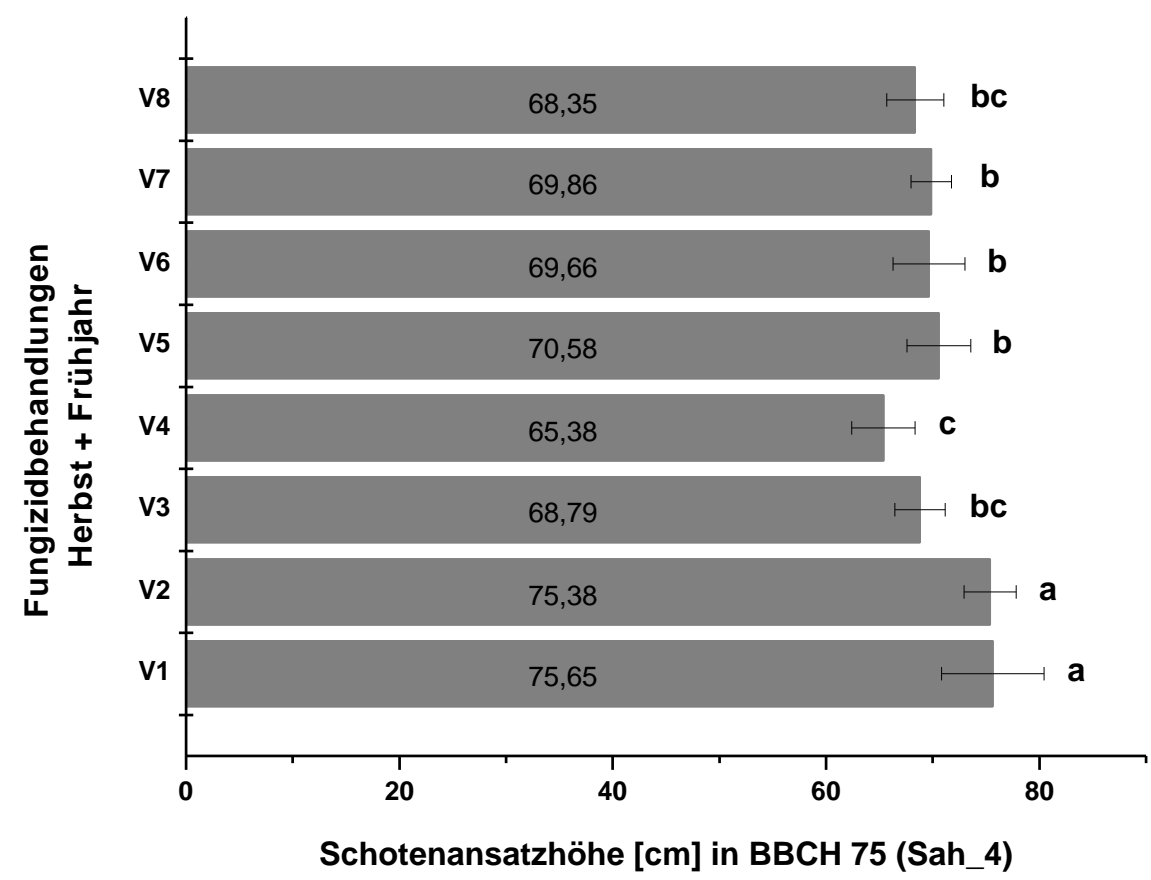

Abb. 37: Einfluss der im Herbst und im Frühjahr durchgeführten Fungizidbehandlungen auf die Bestandeshöhe [cm] in BBCH 75 (Hoe_4) im Versuchsjahr 2010/11 am Standort Göttingen. Verschiedene Buchstaben kennzeichnen signifikante Unterschiede zwischen den Fungizidbehandlungen nach dem Tukey-Test $(p \leq 0,05, n=4)$, errechnet innerhalb des verwendeten gemischten Modells. Die Fehlerbalken stellen die jeweilige Standardabweichung dar. $\mathrm{V}=$ Variante: $\mathrm{V} 1=$ unbehandelte Kontrolle, $\mathrm{V} 2=0,5 \mathrm{l} / \mathrm{ha}$ Toprex $^{\circledR}$ (Difenoconazol + Paclobutrazol) in $\mathrm{BBCH} 33 / 35, \mathrm{~V} 3=0,5 \mathrm{l} / \mathrm{ha}$ Toprex $^{\circledR}$ in $\mathrm{BBCH} 14$ und $33 / 35, \mathrm{~V} 4=0,5 \mathrm{I} /$ ha Toprex $^{\circledR}$ in BBCH 14 , 16 und 33/35, V5 $=0,5 \mathrm{l} / \mathrm{ha}$ Toprex $^{\circledR}$ in $\mathrm{BBCH} 14,33 / 35$ und 53/55, V6 $=0,5 \mathrm{l} /$ ha Toprex $^{\circledR}$ in BBCH $14+1,0$ l/ha Toprex $^{\circledR}$ in $\mathrm{BBCH} 33 / 35, \mathrm{~V} 7=$ wie Nr. 3 aber in $\mathrm{BBCH} 65$ 2,0 l/ha Ortiva ${ }^{\circledR}$ (Azoxystrobin), V8 $=$ praxisüblich $=0,6 \mathrm{l} /$ ha Folicur $^{\circledR}$ (Tebuconazol) in $\mathrm{BBCH} 14+0,7 \mathrm{l} /$ ha Carax $^{\circledR}$ (Mepiquatchlorid + Metconazol) in $\mathrm{BBCH} 33 / 35+0,8 \mathrm{I} /$ ha Harvesan ${ }^{\circledR}$ (Flusilazol + Carbendazim) in BBCH 65; Varianten 1-6 erhielten in BBCH $651 \mathrm{l} /$ ha Ortiva $^{\circledR}$. 


\section{Bestandeshöhe in BBCH 75 (Hoe_4); (indirekt krankheitsbeeinflussend)}

Die Bestandeshöhe in $\mathrm{BBCH} 75$ wurde signifikant durch die Sorte, die Saatstärke und die Fungizidbehandlung beeinflusst. Pflanzen von NK Petrol waren im Wachstumsstadium 75 signifikant höher (ca. 129,9 cm) als Pflanzen von SY Merlot (ca. 117,3 cm; Tab. 36). Unabhängig davon waren die Pflanzen bei einer Saatstärke von $60 \mathrm{Körnern} / \mathrm{m}^{2}$ signifikant höher (ca. 125,0 cm) als bei einer Saatstärke von 30 Körnern/m² $(\mathrm{ca} .122,2 \mathrm{~cm}$ ).

Tab. 36: Einfluss der Sorte ((So), $M=$ SY Merlot bzw. $P=$ NK Petrol) und der Saatstärke ((Di), 30 Körner $/ \mathrm{m}^{2}$ bzw. $60 \mathrm{Körner} / \mathrm{m}^{2}$ ) auf die Bestandeshöhe in BBCH 75 (Hoe_4) im Versuchsjahr 2010/11 am Standort Göttingen. Dargestellt sind die Mittelwerte und die Standardabweichung (SD). Verschiedene Buchstaben kennzeichnen signifikante Unterschiede zwischen den Mittelwerten nach dem Tukey-Test $(p \leq 0,05, n=4)$, errechnet innerhalb des verwendeten gemischten Modells. Großbuchstaben kennzeichnen Unterschiede zwischen den Sorten und kleingeschriebene Buchstaben zwischen den Saatstärken.

\begin{tabular}{|c|c|c|c|c|c|c|}
\hline Parameter & Effekt & So & $\mathrm{Di}$ & Mittelwert & SD & Buchstaben \\
\hline Bestandeshöhe & So & $M$ & & 117,34 & 2,56 & $B$ \\
\hline \multirow[t]{3}{*}{ in BBCH 75 (Hoe_4) } & So & $P$ & & 129,85 & 3,76 & A \\
\hline & $\mathrm{Di}$ & & 30 & 122,18 & 3,72 & $\mathrm{~b}$ \\
\hline & $\mathrm{Di}$ & & 60 & 125,00 & 2,62 & a \\
\hline
\end{tabular}


Die Bestandeshöhe in $\mathrm{BBCH} 75$ wurde wie die Schotenansatzhöhe in $\mathrm{BBCH} 75$ am stärksten durch die Fungizidvariante 4 eingekürzt (Abb. 38). Mit ca. 118,4 cm war die Bestandeshöhe in Variante 4 signifikant niedriger als in den Varianten 1 (ca. 130,2 cm), 2 (ca. 128,5 cm) 5 (ca. 123,5 cm) und 6 (ca. 123,0 cm). Weiterhin verringerten die Varianten 3 (ca. 122,1 cm), 5 (ca. 123,5 cm), 6 (ca. 123,0 cm), 7 (ca. 122,5 cm) und 8 (ca. 120,5 $\mathrm{cm})$ signifikant stärker die Bestandeshöhe in $\mathrm{BBCH} 75$ als die Varianten 1 und 2.

2010/11

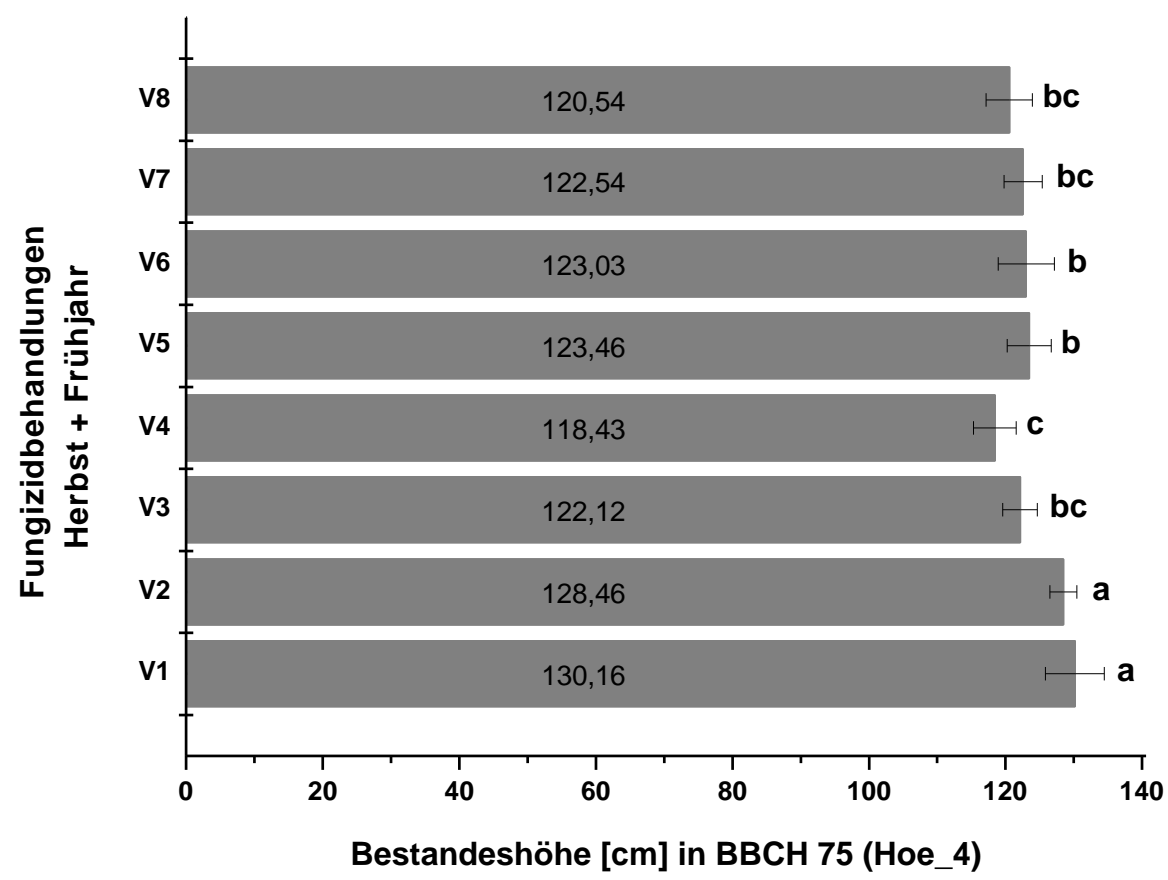

Abb. 38: Einfluss der im Herbst und im Frühjahr durchgeführten Fungizidbehandlungen auf die Bestandeshöhe [cm] in BBCH 75 (Hoe_4) im Versuchsjahr 2010/11 am Standort Göttingen. Verschiedene Buchstaben kennzeichnen signifikante Unterschiede zwischen den Fungizidbehandlungen nach dem Tukey-Test $(p \leq 0,05, n=4)$, errechnet innerhalb des verwendeten gemischten Modells. Die Fehlerbalken stellen die jeweilige Standardabweichung dar. $\mathrm{V}=$ Variante: $\mathrm{V} 1=$ unbehandelte Kontrolle, $\mathrm{V} 2=0,5 \mathrm{l} / \mathrm{ha} \mathrm{Topre}^{\circledR}$ (Difenoconazol + Paclobutrazol) in $\mathrm{BBCH} 33 / 35, \mathrm{~V} 3=0,5 \mathrm{l} /$ ha Toprex $^{\circledR}$ in $\mathrm{BBCH} 14$ und $33 / 35, \mathrm{~V} 4=0,5 \mathrm{I} /$ ha Toprex $^{\circledR}$ in BBCH 14 , 16 und 33/35, V5 $=0,5 \mathrm{l} / \mathrm{ha}$ Toprex $^{\circledR}$ in $\mathrm{BBCH} 14,33 / 35$ und 53/55, V6 $=0,5 \mathrm{l} /$ ha Toprex $^{\circledR}$ in BBCH $14+1,0 \mathrm{l} / \mathrm{ha}$ Toprex $^{\circledR}$ in $\mathrm{BBCH} 33 / 35, \mathrm{~V} 7=$ wie Nr. 3 aber in $\mathrm{BBCH} 65$ 2,0 l/ha Ortiva ${ }^{\circledR}$ (Azoxystrobin), V8 $=$ praxisüblich $=0,6 \mathrm{l} /$ ha Folicur $^{\circledR}$ (Tebuconazol) in $\mathrm{BBCH} 14+0,7 \mathrm{l} /$ ha Carax $^{\circledR}$ (Mepiquatchlorid + Metconazol) in $\mathrm{BBCH} 33 / 35+0,8 \mathrm{I} /$ ha Harvesan ${ }^{\circledR}$ (Flusilazol + Carbendazim) in BBCH 65; Varianten 1-6 erhielten in BBCH $651 \mathrm{l} /$ ha Ortiva $^{\circledR}$. 
Schotenschichtdicke in BBCH 73/74 (Schi_3); (indirekt krankheitsbeeinflussend)

Die Effekte der drei unabhängigen Versuchsfaktoren auf die Schotenschichtdicke in $\mathrm{BBCH}$ 73/74 wurden in Kapitel 3.7.1 auf Seite 125 beschrieben.

\section{Schotenschichtdicke in BBCH 75 (Schi_4); (indirekt krankheitsbeeinflussend)}

Die Schotenschichtdicke in $\mathrm{BBCH} 75$ wurde weder von den drei unabhängigen Haupteffekten Sorte, Saatstärke und Fungizidbehandlung noch von den daraus resultierenden Interaktionen signifikant beeinflusst (vgl. Tab. 25A im Anhang II).

BH mit der Wurzelhals- und Stängelfäule an Laubblättern im Herbst in BBCH 16/18 (BH_He); (indirekt krankheitsbeeinflussend)

Die Effekte der drei unabhängigen Versuchsfaktoren auf die $\mathrm{BH}$ mit der Wurzelhals- und Stängelfäule an Laubblättern im Herbst in $\mathrm{BBCH}$ 16/18 wurden in Kapitel 3.5.1 auf Seite 80 beschrieben.

BH mit der Wurzelhals- und Stängelfäule am Wurzelhals im Frühjahr in BBCH 83/84 (BH_Wh_Fj); (indirekt krankheitsbeeinflussend)

Die Effekte der drei unabhängigen Versuchsfaktoren auf die $\mathrm{BH}$ mit der Wurzelhals- und Stängelfäule am Wurzelhals im Frühjahr in $\mathrm{BBCH}$ 83/84 wurden in Kapitel 3.5.1 auf Seite 81 beschrieben.

BH mit der Wurzelhals- und Stängelfäule am unteren Stängel im Frühjahr in BBCH 83/84 (BH_St_Fj); (indirekt krankheitsbeeinflussend)

Die Effekte der drei unabhängigen Versuchsfaktoren auf die $\mathrm{BH}$ mit der Wurzelhals- und Stängelfäule am unteren Stängel im Frühjahr in $\mathrm{BBCH}$ 83/84 wurden in Kapitel 3.5.1 auf Seite 82 beschrieben.

BW mit der Wurzelhals- und Stängelfäule am unteren Stängel im Frühjahr in BBCH 83/84 (BW_St_Fj); (direkt krankheitsbeeinflussend)

Die Effekte der drei unabhängigen Versuchsfaktoren auf den BW mit der Wurzelhals- und Stängelfäule am unteren Stängel im Frühjahr in $\mathrm{BBCH}$ 83/84 wurden in Kapitel 3.5.1 auf Seite 82 beschrieben. 


\subsection{Einfluss der Ertragsparameter und Ertragsfaktoren auf den Kornertrag}

Nachdem in vorherigen Kapiteln die Einflüsse von verschiedenen Bestandes- und Befallsparametern auf die Ertragshöhe (Kapitel 3.6) und auf den Befall mit der Wurzelhals- und Stängelfäule am Wurzelhals im Frühjahr in $\mathrm{BBCH}$ 83/84 (Kapitel 3.8) dargestellt wurden, werden in diesem Kapitel die Einflüsse der Ertragsparameter (Strohbiomasseertrag, Ölgehalt, Ölertrag und Ernteindex) sowie der Ertragsfaktoren (Pflanzen/m² im Frühjahr, Schoten/Pflanze, Körner/Schote, TKM, Schoten $/ \mathrm{m}^{2}$, Körner/Pflanze und Korndichte) auf den erzielten Kornertrag dargestellt. Zusätzlich werden die Zusammenhänge zwischen der Ertragshöhe und der Anzahl Seitentriebe/Pflanze beschrieben. Um die Einflüsse der einzelnen Ertragsparameter sowie Ertragsfaktoren auf den Kornertrag von Winterraps ermitteln zu können, wurden einfache, lineare Regressionsanalysen durchgeführt. Anhand dieser Methode konnte gezielt die jeweilige erklärende Variable für die Zielvariable ausgewählt werden. Es wurden sowohl der Korrelationskoeffizient nach Pearson $\left(r_{p}\right)$ sowie nach Spearman $\left(r_{s}\right)$ ermittelt. Die gleichzeitige Analyse nach Pearson und Spearman stellte sicher, dass eindeutig signifikante Ergebnisse (signifikant nach beiden Verfahren) in die weiteren Betrachtungen eingingen. Für eine bessere Übersicht wurden in den Tabellen nur die Korrelationskoeffizienten und die Bestimmtheitsmaße nach Pearson wiedergegeben und die Daten nach dem $\mathrm{R}^{2}$-Wert absteigend sortiert.

\subsubsection{Versuchsjahr 2010/11}

Im Versuchsjahr 2010/11 hatten von vier Ertragsparametern drei einen signifikanten Einfluss auf den Kornertrag (Tab. 37). Die stärkste positive Korrelation bestand dabei zwischen dem Ölertrag und dem Kornertrag $\left(r_{p}=0,992\right)$, was allerdings trivial ist, da sich der Ölertrag aus dem Kornertrag und dem Ölgehalt errechnet. Dahinter folgten der Ernteindex mit $r_{p}=0,501$ und der Strohbiomasseertrag mit $r_{p}=0,383$. Mit steigendem Ernteindex bzw. steigendem Strohbiomasseertrag nahm der Kornertrag zu. Von den acht Ertragsfaktoren hatten im Versuchsjahr 2010/11 alle einen signifikanten Einfluss auf den Kornertrag, wobei die Pflanzen $/ \mathrm{m}^{2}$ im Frühjahr in $\mathrm{BBCH} 16 / 18$ den stärksten Zusammenhang mit dem Kornertrag $\left(r_{p}=0,482\right)$ aufwiesen (Tab. 37). Mit steigender Pflanzendichte nahm der Kornertrag zu. Die weiteren drei klassischen Ertragsfaktoren Schoten/Pflanze, Körner/Schote und TKM waren alle negativ mit dem Kornertrag korreliert, wobei die TKM die stärkste negative Korrelation aufwies $\left(r_{p}=-0,405\right)$. Dahinter 
folgte die Anzahl an Schoten/Pflanze $\left(r_{p}=-0,398\right)$ und die Anzahl an Körner/Schote $\left(r_{p}=-0,229\right)$. Die positiven Korrelationen von den berechneten Ertragsfaktoren Anzahl an Schoten $/ m^{2} \quad\left(r_{p}=0,342\right)$ und Korndichte $\left(r_{p}=0,274\right)$ spiegelten den positiven Zusammenhang zwischen der Anzahl an Pflanzen/m² im Frühjahr in BBCH 16/18 und dem Kornertrag wider. Der berechnete Ertragsfaktor Anzahl Körner/Pflanze wies den zweitstärksten Zusammenhang mit dem Kornertrag auf $\left(r_{p}=-0,407\right)$. Dieser Parameter war negativ mit dem Kornertrag korreliert, was sich aus den negativen Korrelationen der Anzahl an Körnern/Schote und der Anzahl an Schoten/Pflanze ergab. Die Anzahl Seitentriebe/Pflanze hatte ebenfalls einen negativen Einfluss auf die Ertragshöhe $\left(r_{p}=-0,375\right)$. Insgesamt zeigen die niedrigen Korrelationskoeffizienten und Bestimmtheitsmaße (ohne Ölertrag), dass die Zusammenhänge zwischen Ertragsparametern bzw. Ertragsfaktoren und Kornertrag im betrachteten Versuchsjahr 2010/11 nicht besonders hoch waren.

Tab. 37: Einfache, lineare Regressionsanalyse zwischen den Ertragsparametern bzw. den Ertragsfaktoren und der Zielvariablen Kornertrag im Versuchsjahr 2010/11. Die Ertragsparameter und Ertragsfaktoren sind absteigend nach dem $R_{p}{ }^{2}$-Wert sortiert. $\left(r_{p}=\right.$ Korrelationskoeffizient nach Pearson; $R_{p}{ }^{2}=$ Bestimmtheitsmaß nach Pearson; $p \leq 0,05 ; n=120 ; n s=$ nicht signifikant)

\begin{tabular}{lccc}
\hline & Parameter & $\mathbf{r}_{\mathbf{p}}$ & $\mathbf{R}_{\mathbf{p}}{ }^{2}$ \\
\hline \multirow{4}{*}{ Ertragsparameter } & Ölertrag & 0,992 & 0,985 \\
& Ernteindex & 0,501 & 0,251 \\
& Strohbiomasseertrag & 0,383 & 0,147 \\
\cline { 2 - 4 } Ertragsfaktoren & Ölgehalt & $\mathrm{ns}$ & $\mathrm{ns}$ \\
& Pflanzen/m² im Frühjahr & 0,482 & 0,232 \\
& Körner/Pflanze & $-0,407$ & 0,165 \\
& TKM & $-0,405$ & 0,164 \\
& Schoten/Pflanze & $-0,398$ & 0,158 \\
& Seitentriebe/Pflanze & $-0,375$ & 0,141 \\
& Schoten/m & 0,342 & 0,117 \\
& Korndichte & 0,274 & 0,075 \\
& Körner/Schote & $-0,229$ & 0,053 \\
\hline
\end{tabular}

In Abb. 39 ist die positive Korrelation zwischen der Anzahl an Pflanzen/m² im Frühjahr in BBCH 16/18 und dem Kornertrag sowie die negative Korrelation zwischen der Anzahl an Seitentriebe/Pflanze und dem Kornertrag dargestellt. Durch diese gemeinsame grafische Darstellung konnte ein Optimum zwischen Bestandesdichte und Anzahl an 
Seitentriebe/Pflanze abgeleitet werden. Im Jahr 2010/11 lag das Optimum bei ca. 40 Pflanzen $/ \mathrm{m}^{2}$ und ca. 8 Seitentriebe/Pflanze. Bei diesem Optimum wäre ein Kornertrag von ungefähr 4,8 tha möglich gewesen. Die Abb. 39 zeigt weiterhin, dass bei einer niedrigen Bestandesdichte (ca. 10-30 Pflanzen $/ \mathrm{m}^{2}$; schwarze Quadrate) mehr Seitentriebe/Pflanze (ca. 8-11; graue Kreise) gebildet wurden und damit Kornerträge bis zu 4,5 t/ha möglich waren. Höhere Kornerträge von 5 t/ha und mehr ließen sich in der Regel nur durch eine höhere Bestandesdichte, nicht aber durch eine höhere Zahl an Seitentriebe/Pflanze realisieren. Diese Ergebnisse zeigen, dass zwischen der Pflanzendichte und der Anzahl an Seitentriebe/Pflanze ein negativer Zusammenhang bestand ( $r_{p}=-0,654 R_{p}^{2}=0,428$; Daten in Abb. 39 nicht angegeben).

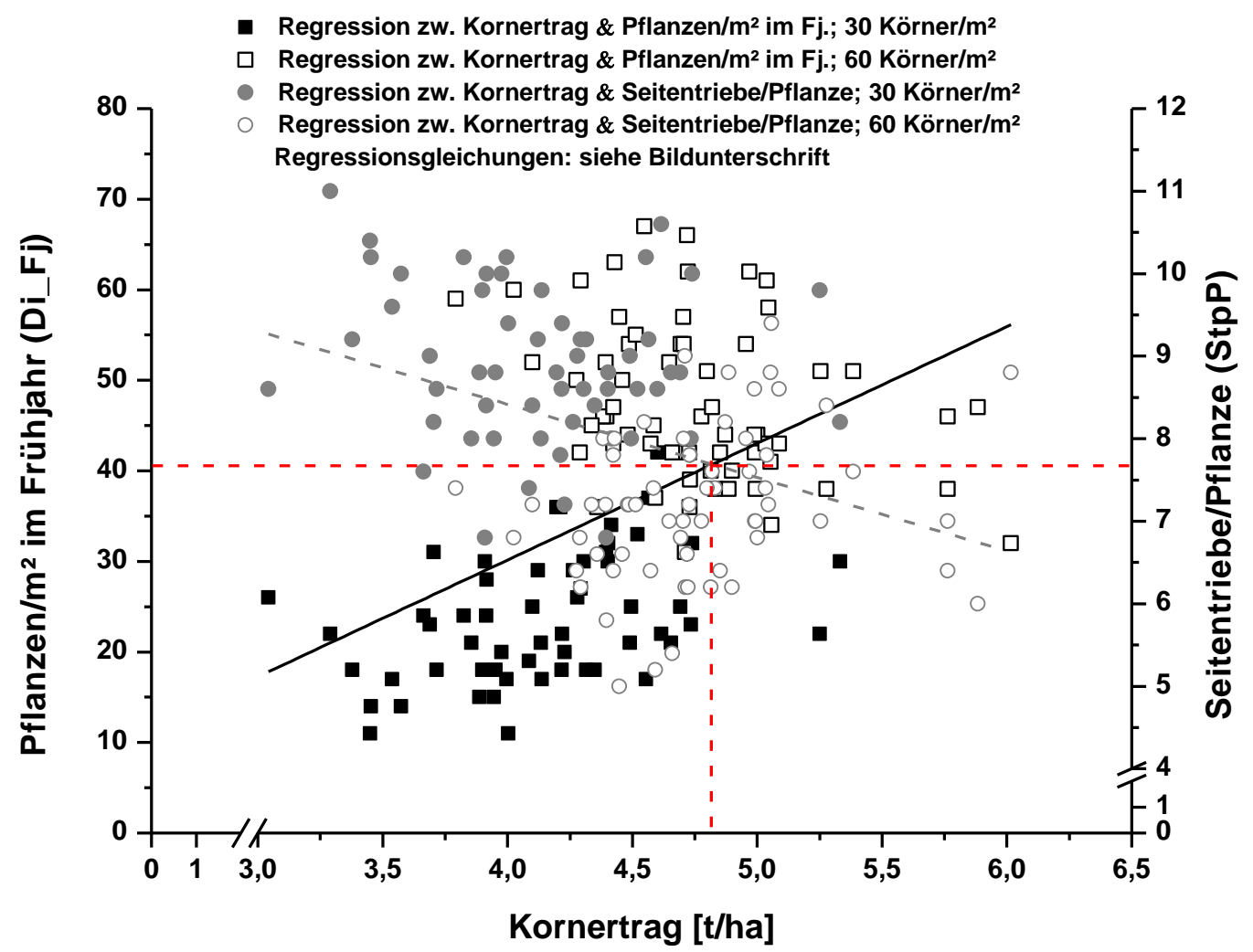

Abb. 39: Einfache lineare Regressionen von Bestandesdichte und Seitentriebbildung mit dem Kornertrag im Versuchsjahr 2010/11. Regressionsgleichung und andere Kennwerte für Kornertrag x Pflanzen $/ \mathrm{m}^{2}$ im Frühjahr: $y=-21,3882+12,8856^{*} x ; r_{p}=0,482 ; R_{p}{ }^{2}=0,232 ; p \leq 0,0001$. Regressionsgleichung und andere Kennwerte für Kornertrag $x$ Seitentriebe/Pflanze: $y=11,9663$ $0,8875^{*} x ; r_{p}=-0,375 ; R_{p}{ }^{2}=0,141 ; p \leq 0,0001\left(r_{p}=\right.$ Korrelationskoeffizient nach Pearson; $R_{p}{ }^{2}=$ Bestimmtheitsmaß nach Pearson; $n=120$ ) 


\subsubsection{Versuchsjahr 2012/13}

Im Versuchsjahr 2012/13 wiesen von vier Ertragsparametern zwei einen signifikanten Zusammenhang mit dem Kornertrag auf (Tab. 38). Dazu zählten die Parameter Ölertrag und Strohbiomasseertrag, wobei der Ölertrag mit $r_{p}=0,964$ stärker mit dem Kornertrag korreliert war als der Strohbiomasseertrag $\left(r_{p}=0,627\right)$. Der Grund für die hohe Korrelation zwischen Ölertrag und Kornertrag wurde zuvor bei den Erläuterungen für das Versuchsjahr 2010/11 genannt. Im Vergleich der beiden Versuchsjahre zeigte sich, dass im Jahr 2012/13 der Strohbiomasseertrag einen fast doppelt so hohen positiven Zusammenhang mit dem Kornertrag aufwies $\left(r_{p}=0,627\right)$ als im Jahr 2010/11 ( $\left.r_{p}=0,383\right)$. Von den acht Ertragsfaktoren hatten im Versuchsjahr 2012/13 drei einen signifikanten Einfluss auf den Kornertrag (Tab. 38). Dazu gehörten die Parameter Seitentriebe/Pflanze, Pflanzen $/ \mathrm{m}^{2}$ im Frühjahr in BBCH 51/52 und TKM $\left(\mathrm{R}_{\mathrm{p}}{ }^{2}=0,051 ; 0,046 ; 0,039\right)$. Die sehr niedrigen Bestimmtheitsmaße zeigen aber, dass die Zusammenhänge nicht besonders stark waren. Sie waren noch niedriger als im ersten Versuchsjahr. Während die Anzahl Seitentriebe/Pflanze wiederum negativ $\left(r_{p}=-0,225\right)$ mit dem Kornertrag korreliert war, waren die Anzahl Pflanzen/m² im Frühjahr in BBCH 51/52 und die TKM ( $r_{p}=0,215$ bzw. 0,198) positiv mit dem Kornertrag korreliert. Im Versuchsjahr 2010/11 war die TKM negativ mit dem Kornertrag korreliert. Die anderen beiden Parameter zeigten in beiden Jahren jeweils die gleiche Art von Korrelation.

Tab. 38: Einfache, lineare Regressionsanalyse zwischen den Ertragsparametern bzw. den Ertragsfaktoren und der Zielvariablen Kornertrag im Versuchsjahr 2012/13. Die Ertragsparameter und Ertragsfaktoren sind absteigend nach dem $R_{p}{ }^{2}$-Wert sortiert. $\left(r_{p}=\right.$ Korrelationskoeffizient nach Pearson; $R_{p}{ }^{2}=$ Bestimmtheitsmaß nach Pearson; $p \leq 0,05 ; n=124 ; n s=$ nicht signifikant)

\begin{tabular}{lccc}
\hline & Parameter & $\mathbf{r}_{\mathbf{p}}$ & $\mathbf{R}_{\mathbf{p}}{ }^{2}$ \\
\hline \multirow{4}{*}{ Ertragsparameter } & Ölertrag & 0,964 & 0,929 \\
& Strohbiomasseertrag & 0,627 & 0,393 \\
& Ernteindex & $\mathrm{ns}$ & $\mathrm{ns}$ \\
\cline { 2 - 3 } & Ölgehalt & $\mathrm{ns}$ & $\mathrm{ns}$ \\
\cline { 2 - 3 } Ertragsfaktoren & Seitentriebe/Pflanze & $-0,225$ & 0,051 \\
& Pflanzen/m² im Frühjahr & 0,215 & 0,046 \\
& TKM & 0,198 & 0,039 \\
& Schoten/Pflanze & $\mathrm{ns}$ & $\mathrm{ns}$ \\
& Schoten/m² & $\mathrm{ns}$ & $\mathrm{ns}$ \\
& Korndichte & $\mathrm{ns}$ & $\mathrm{ns}$ \\
& Körner/Schote & $\mathrm{ns}$ & $\mathrm{ns}$ \\
& Körner/Pflanze & $\mathrm{ns}$ & $\mathrm{ns}$ \\
\hline
\end{tabular}


Obwohl die Zusammenhänge schwächer waren, wurde auch für das Jahr 2012/13 die positive Korrelation zwischen der Anzahl Pflanzen/m² im Frühjahr in BBCH 51/52 und dem Kornertrag sowie die negative Korrelation zwischen der Anzahl an Seitentriebe/Pflanze und dem Kornertrag in einer gemeinsamen Abbildung dargestellt (Abb. 40). In diesem Jahr lag das Optimum bei ca. 45 Pflanzen $/ \mathrm{m}^{2}$ und ca. 7 Seitentriebe/Pflanze. Bei diesem Optimum hätte ein Kornertrag von ca. 6 t/ha erzielt werden können. Es konnte wie im Versuchsjahr 2010/11 ein negativer Zusammenhang zwischen der Anzahl an Pflanzen $/ \mathrm{m}^{2}$ und der Anzahl an Seitentriebe/Pflanze nachgewiesen werden $\left[r_{p}=-0,640 ; R_{p}^{2}=0,409\right.$; Daten in (Abb. 40) nicht angegeben]. Obwohl in beiden Versuchsjahren die Optima für Bestandesdichte und Anzahl an Seitentriebe/Pflanze nur geringfügig voneinander abwichen, lag das potenzielle Ertragsniveau stärker auseinander. Dies deutet auf einen Jahreseffekt hin, bei dem die Witterung einen deutlichen Einfluss auf den Kornertrag hatte.

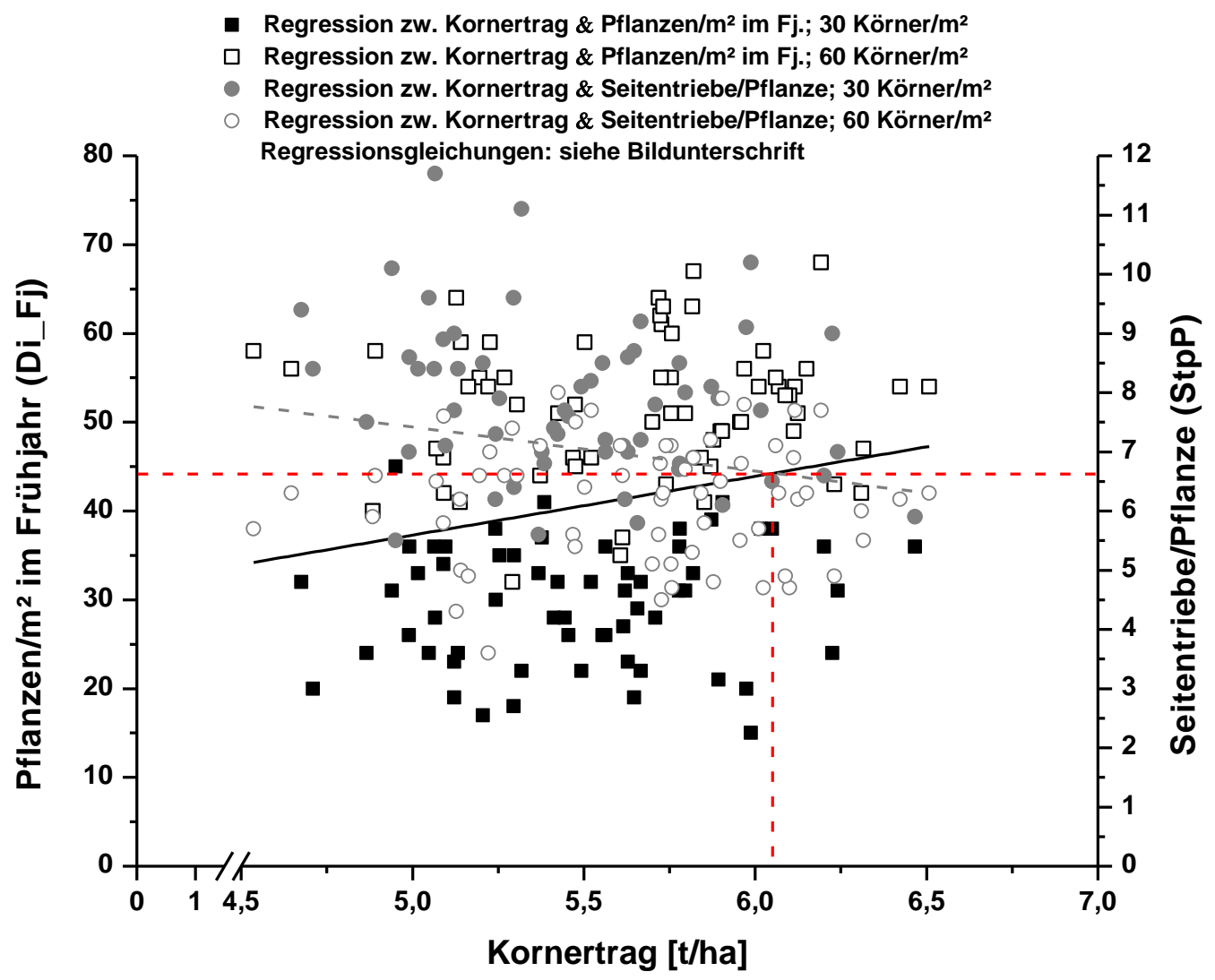

Abb. 40: Einfache, lineare Regressionen von Bestandesdichte und Seitentriebbildung mit dem Kornertrag im Versuchsjahr 2012/13. Regressionsgleichung und andere Kennwerte für Kornertrag x Pflanzen $/ \mathrm{m}^{2}$ im Frühjahr: $y=4,1670+6,6232^{*} x ; r_{p}=0,215 ; R_{p}{ }^{2}=0,046 ; p \leq 0,0165$. Regressionsgleichung und andere Kennwerte für Kornertrag $x$ Seitentriebe/Pflanze: $y=11,1310$ $0,7426^{*} x ; r_{p}=-0,225 ; R_{p}{ }^{2}=0,051 ; p \leq 0,0119\left(r_{p}=\right.$ Korrelationskoeffizient nach Pearson; $R_{p}{ }^{2}=$ Bestimmtheitsmaß nach Pearson; $n=124$ ) 
Zum Abschluss dieses Kapitels sei darauf hingewiesen, dass sich die Ertragsfaktoren auch gegenseitig beeinflusst haben. Wie die einzelnen Ertragsfaktoren miteinander korreliert waren, geht aus der Tab. 69A im Anhang II hervor. Die Kenntnis dieser Zusammenhänge trägt dazu bei die Korrelationen zwischen bestimmten Ertragsfaktoren und dem Kornertrag einfacher zu interpretieren.

\subsection{Summe der Effekte von Sorte, Saatstärke und Fungizidbehandlung auf ertragsrelevante Parameter}

Um eine Aussage darüber treffen zu können, welcher von den drei Versuchsfaktoren Sorte, Saatstärke und Fungizidbehandlung in dem jeweiligen Versuchsjahr die meisten signifikanten Effekte auf die ertragsrelevanten Parameter hatte, wurden diese über alle ertragsrelevanten Parameter hinweg aufsummiert. Dabei wurden nur die signifikanten Effekte zu den ertragsrelevanten Parametern berücksichtigt, die aus der Abb. 24 und Abb. 27 sowie aus der Tab. 37 und Tab. 38 hervorgehen. Wenn ein ertragsrelevanter Parameter mehrmals vorkam, so gingen die dazugehörigen signifikanten Effekte nur einmal in die Berechnung der jeweiligen Effektsummen ein. Die Tab. 39 zeigt, dass im Versuchsjahr 2010/11 die Saatstärke am häufigsten (19-mal) ertragsrelevante Parameter beeinflusst hat. Dahinter folgte die Fungizidbehandlung (10-mal) und die Sorte (8-mal). Im Versuchsjahr 2012/13 trat ein komplett entgegengesetztes Ergebnis auf. In diesem Jahr wurden die jeweiligen ertragsrelevanten Parameter am meisten durch die Fungizidbehandlung (12-mal) beeinflusst. An zweiter Stelle folgte die Sorte (9-mal) und an dritter Stelle die Saatstärke (2-mal).

Tab. 39: Summe der signifikanten Effekte von den drei Versuchsfaktoren Sorte, Saatstärke und Fungizidbehandlung auf die jeweiligen ertragsrelevanten Parameter, getrennt nach den Versuchsjahren 2010/11 und 2012/13. Als Datengrundlage dienten die signifikanten Effekte zu den ertragsrelevanten Parametern, die aus den Abb. 24, und Abb. 27 sowie aus den Tab. 37 und Tab. 38 hervorgehen. Wenn ein ertragsrelevanter Parameter mehrmals vorkam, so gingen die dazugehörigen signifikanten Effekte nur einmal in die Berechnung der jeweiligen Effektsummen ein.

\begin{tabular}{lccc}
\hline & & \multicolumn{2}{c}{ Summe signifikante Effekte von Versuchsfaktoren } \\
\hline Versuchsjahr & Sorte & Saatstärke & Fungizidbehandlung \\
\hline $2010 / 11$ & 8 & 19 & 10 \\
$2012 / 13$ & 9 & 2 & 12 \\
\hline
\end{tabular}




\section{Diskussion}

Im Rahmen der vorliegenden Arbeit wurde in einem Feldversuch der Einfluss der Bestandesarchitektur auf die Ertragsbildung im Winterraps untersucht. Die folgende Diskussion setzt sich zunächst mit dem Einfluss der Witterung auf die Ertragsbildung im Winterraps (4.1) und anschließend mit der Bedeutung der ermittelten ertragsrelevanten Bestandesparameter (4.2) sowie deren Beeinflussung durch die drei Anbaufaktoren Sorte, Saatstärke (4.3) und Fungizidbehandlungen mit wachstumsregulatorischer Nebenwirkung (4.4) auseinander. Kapitel 4.5 erläutert den Befall und die Schadwirkung von $P$. lingam auf die Ertragshöhe und im folgenden Kapitel 4.6 wird der Einfluss von ausgewählten Bestandesparametern sowie von den drei Anbaufaktoren auf den Phomabefall diskutiert. In Kapitel 4.7 wird die Rolle der Ertragsfaktoren in der Ertragsbildung von Winterraps, sowie deren Beeinflussung durch die drei Anbaufaktoren näher erörtert. Eine Bewertung der verschiedenen statistischen Analyseverfahren erfolgt in Kapitel 4.8. Zum Schluss wird in Kapitel 4.9 eine abschließende Bewertung des ganzen Feldversuches vorgenommen.

\subsection{Einfluss der Witterung auf die Ertragsbildung im Winterraps}

Die vier Faktoren Sorte, Anbautechnik, Standort und Wetter beeinflussen im Wesentlichen die Ertragshöhe von Winterraps und damit den Erfolg im Rapsanbau. Aus Sicht des Rapsanbauers stellen die Sorte und die Anbautechnik eine steuerbare, der Standort und das Wetter eine nicht steuerbare Einflussgröße dar. Hierbei sind die Standorteigenschaften grundsätzlich bekannt und können für den Winterrapsanbau günstig oder ungünstig sein. Die Witterung hingegen ist von allen vier Faktoren der unberechenbarste Parameter. Licht, Wasser und Temperatur üben dabei den größten Einfluss auf die Entwicklung und letztendlich auf den Ertrag von Winterraps aus. Auswertungen des Wetterverlaufs in verschiedenen Anbauregionen und verschiedenen Rapsjahren zeigten, dass folgende Kombination für Höchsterträge entscheidend waren: ein trockener Herbst, ein milder Winter, ein kühles, trockenes Frühjahr sowie kühlere Temperaturen und hohe gleichmäßige Niederschläge von Blühbeginn bis Abreife. Dies macht deutlich, dass nicht die Jahresniederschlagsmenge oder die Jahresdurchschnittstemperatur ausschlaggebend ist, sondern bestimmte Entwicklungsphasen besondere Ansprüche an die Witterung stellen. Eine Schlüsselrolle beim Winterraps, nimmt dabei die Temperatur und die verfügbare Wassermenge von April bis Juli ein (AlPMANN, 2006a, 2007). Für Spitzenerträge von 5-6 t/ha muss ein Rapsbestand ca. 20-22 t/ha Gesamttrockenmasse produzieren (ALPMANN, 2006b, 2007). Davon werden ca. 6-8 t/ha Trockenmasse (TM) im Herbst und Frühjahr bis zum 
Blühbeginn und ca. 12-14 t/ha TM in der Zeit von Blühbeginn bis Abreife gebildet (ALPMANN, 2006b, 2007). Dieser letzte Entwicklungsabschnitt umfasst die generative Entwicklung eines Rapsbestandes und dauert ca. 70-80 Tage. Um in dieser Phase den starken Zuwachs an TM in Form von Seitentrieben, Schotenwänden und Samen zu sichern, ist der Raps neben kontinuierlicher Lichteinstrahlung und ausreichenden Nährstoffmengen v.a. auf Temperaturen zwischen 20 und $25^{\circ} \mathrm{C}$ und Wassermengen von 250-350 l/ $\mathrm{m}^{2}$ angewiesen (ALPMANN, 2007). Bei $20-25^{\circ} \mathrm{C}$ verläuft die Netto-Assimilation von Blättern und Schoten optimal (INANAGA et al., 1979). Erst bei $30^{\circ} \mathrm{C}$ stellt die Pflanze die effiziente Stoffproduktion ein (ALPMANN, 2007). Generell sind kühlere Temperaturen für die Entwicklung der Pflanzen besser, da durch die kühleren Temperaturen die Wachstumsdauer verlängert wird und so die einzelnen Phasen der Anlage der Ertragsorgane langsamer durchlaufen werden (ALPMANN, 2006a; MENDHAM et al., 1981a). Der hohe Wasserbedarf von 250-350 l/m² wird idealerweise durch natürliche Quellen wie die in diesem Zeitraum auftretenden Niederschläge, im Boden vorhandenes Wasser (nutzbare Feldkapazität), hohe Luftfeuchtigkeiten und Wasserreserven in der Pflanze gedeckt (ALPMANN, 2007). Die zuvor erläuterten optimalen, klimatischen Bedingungen traten in den Anbaujahren 2003/04 und 2008/09 auf und führten dazu, dass die Erträge im bundesweiten Durchschnitt auf über 4 t/ha stiegen. Je nach Region und Betrieb wurden im Durchschnitt sogar mehr als 5 t/ha geerntet. ALPMANN (2006a) führte für das Jahr 2003/04 die hohen Erträge auf fünf wesentliche Eckpunkte zurück: 1. Aufgrund der langen Dürre- und Hitzeperiode im Frühjahr und Sommer 2003 herrschte im Herbst 2003 eine sehr gute Bodenstruktur, bei der sich der Raps, insbesondere die Wurzeln, sehr gut entwickeln konnten. 2. Der trockene Herbst verhinderte fast vollkommen die Entwicklung und Ausbreitung von Schädlingen und Krankheiten, v.a. der besonders ertragsrelevanten Wurzelhals- und Stängelfäule. 3. Der milde Winter führte dazu, dass so gut wie keine Pflanzenverluste auftraten. 4. Die wegen anhaltender Trockenheit in 2003 nicht stattgefundene Stickstoff-Mineralisierung fand in vollem Umfang im Frühjahr 2004 statt. Nachdem im April/Mai der Boden wieder krumentief durchfeuchtet war, setzte eine hohe Mineralisierung ein und die Bestände waren sehr gut aus natürlichen Stickstoff-Quellen mit Stickstoff versorgt. 5. Die kühle Witterung im Frühjahr 2004 begrenzte die unproduktive Wasserverdunstung, so dass die Niederschläge von April bis Juli höchst effizient zur Trockenmassebildung genutzt werden konnten. Von den beiden Versuchsjahren, die dieser Doktorarbeit zugrunde liegen, war der Witterungsverlauf im Jahr 2012/13 vergleichbar mit dem Wetter im Anbaujahr 2003/04. Die Ernte der Vorfrucht (Winterweizen) und die anschließende Bodenbearbeitung erfolgten unter optimalen Bedingungen, sodass die Aussaat des Winterrapses termingerecht am 29.08.2012 durchgeführt werden konnte. Geringer Niederschlag am 30.08.2012 führte dazu, dass die 
Rapspflanzen innerhalb von einer Woche aufliefen. Die trockenen Bedingungen im Herbst verhinderten Infektionen mit $P$. lingam und Schäden durch Schnecken bzw. Rapserdflöhe. Anders als im Jahr 2003/04 war der Winter im Jahr 2012/13 kalt und dauerte bis Anfang April. Dennoch traten kaum Pflanzenverluste auf, da die Bestände die meiste Zeit unter einer Schneedecke vor den kalten Temperaturen geschützt waren. Bedingt durch den späten Vegetationsbeginn, begann das Hauptwachstum des Rapses erst im Mai 2013. Die ausgiebigen Niederschläge und kühlen Temperaturen in diesem Monat (vgl. Abb. 22) waren sehr förderlich für die generative Entwicklung des Rapses. Die hohe Wasserspeicherkapazität des Bodens (92 Bodenpunkte) sorgte dafür, dass die geringen Niederschläge im Juni und Juli den Winterraps in seiner Entwicklung nicht besonders beeinträchtigten. $P$. lingam und $S$. sclerotiorum stellten im Frühjahr kein Problem dar, da das Wetter keine optimalen Infektionsbedingungen zuließ. Unter diesen sehr günstigen Wetterbedingungen, v.a. durch die ausreichende Wasserversorgung zum Hauptwachstum des Rapses, war das Ertragsniveau überdurchschnittlich und lag im Mittel über alle Parzellen bei 5,58 t/ha. Dagegen ist das Versuchsjahr 2010/11 nicht mit dem Hochertragsjahr 2003/04 oder dem Versuchsjahr 2012/13 vergleichbar. In diesem Jahr erfolgte die Aussaat des Rapses zu einem relativ späten Zeitpunkt (07.09.2010), da sich die Ernte der Vorfrucht (Winterweizen) durch regelmäßige Niederschläge im August verzögerte. Der nasse und kühle Herbst führte dazu, dass die Rapspflanzen früh durch $P$. lingam infiziert wurden und der Pilz bis in den Wurzelhals vordringen konnte. Zusätzlich bedingte die Übernässung einen Sauerstoffmangel im Boden, der eine vitale Pflanzenund Wurzelentwicklung verhinderte. Obwohl die Pflanzen für eine lange Zeit von einer Schneeschicht bedeckt waren, verursachte der früh einsetzende und kalte Winter, v.a. bei der Sorte SY Merlot einige Pflanzenverluste. Im Frühjahr setzte sich das ungünstige Wetter fort, da die Rapspflanzen bis Ende Mai nur sehr unzureichend mit Wasser versorgt waren (vgl. Abb. 20). Die überdurchschnittlichen Niederschläge im Juni verhinderten einen stärkeren Ertragsabfall, indem sie sich förderlich auf die Kornfüllung auswirkten. Das Krankheitsauftreten im Frühjahr, insbesondere mit S. sclerotiorum war aufgrund der langanhaltenden Trockenheit gering. Allerdings breitete sich im Juni, mit Beginn der Niederschläge, der Befall mit der Wurzelhals- und Stängelfäule am Wurzelhals weiter aus und griff auch auf den unteren Stängelbereich über. Bei diesen ungünstigen Wetterbedingungen war das Ertragsniveau durchschnittlich und lag im Mittel über alle Parzellen bei 4,47 t/ha. Der unterschiedliche Witterungsverlauf in den beiden Versuchsjahren und die damit verbundenen Konsequenzen für die Bestandesentwicklung sind der Hauptgrund dafür, dass im Jahr 2010/11 der Kornertrag von Winterraps um mehr als 1 t/ha signifikant niedriger war als im Jahr 2012/13 (statistische Daten nicht angegeben). LUNN et al. (2001) zeigten in ihren vierjährigen Untersuchungen, dass das 
Versuchsjahr den stärksten Einfluss auf die Ertragshöhe hatte. Zwischen dem besten (1997) und dem schlechtesten Jahr (1999) lag ein Unterschied von 1,92 t/ha. Nach Auffassung der Autoren, waren diese Jahreseffekte v.a. auf Schwankungen von ca. \pm $25 \%$ bei der einfallenden Strahlung (PAR) zurückzuführen.

Die Witterung hat nicht nur einen Einfluss auf das Pflanzenwachstum und das Auftreten von Schädlingen und Krankheiten, sondern auch auf die Wirkung von Pflanzenschutzmitteln. So hatten die Fungizidapplikationen unter den trockenen Bedingungen im Frühjahr 2010/11 einen deutlich geringeren wuchsreduzierenden Effekt (ca. $-12 \mathrm{~cm}$ ) als die Fungizidapplikationen unter den feuchten Bedingungen im Frühjahr 2012/13 (ca. -33 cm; vgl. die Daten zu den Bestandeshöhen in $\mathrm{BBCH} 75$ in Tab. 26A und 27A im Anhang II). Bedingt durch die Trockenheit wurden die Wirkstoffe nicht optimal aufgenommen und in der Pflanze verteilt. Des Weiteren stagnierte das Wachstum, sodass die WR ihre Wirkung gar nicht richtig entfalten konnten. Für Triazole wurde nachgewiesen, dass sie primär über das Xylem akropetal verlagert werden und sowohl über die Laubblätter und Stängel als auch über die Wurzeln im Boden aufgenommen werden können. Dabei zeigte sich, dass die Wirkstoffaufnahme über die Wurzeln einen wesentlich stärkeren wachstumsregulatorischen Effekt auslöste, als eine Aufnahme über die Blätter (FROGGATT et al., 1982; RICHARDSON and QUINLAN, 1986; JUNG et al., 1987; HEDDEN et al., 1989). Die Triazole werden allerdings nur gut durch die Wurzeln aufgenommen, wenn der Boden feucht genug ist und die Pflanzen viel Wasser verdunsten (SCARISBRICK et al., 1985; BOUMA, 2009). Aus diesen Gründen sind Niederschläge ein paar Tage nach der Behandlung von Vorteil, da die Niederschläge die Wirkstoffe, die auf die Bodenoberfläche gelangt sind, in den Wurzelhorizont einwaschen und so für die Wurzeln besser verfügbar sind. Je nach Persistenz der Triazolwirkstoffe im Boden, besitzen diese über einen langen Zeitraum eine Wirkung. Hierzu zählt z.B. Paclobutrazol, dass nur sehr langsam, über mehrere Monate, im Boden abgebaut wird (RADEMACHER, 2000). Zusammenfassend sind wüchsige Witterungsverhältnisse ausschlaggebend für den Erfolg von WR-Maßnahmen im Winterraps. Diese Erkenntnis gilt allerdings nicht nur für Winterraps, sondern für alle Kulturen die durch synthetische WR im Wachstum gehemmt werden sollen. 


\subsection{Einfluss ausgewählter Bestandesparameter auf die Ertragsbildung im Winterraps}

Im Anbaujahr 2010/11 stellte der vom Pflanzenbestand absorbierte Anteil an photosynthetisch aktiver Strahlung (PAR) zum Zeitpunkt der mittleren Schotenentwicklung (BBCH 75) die wichtigste Determinante für den Kornertrag dar. Je mehr einfallende Strahlung unter den Schoten und damit auch am Boden gemessen werden konnte, desto weniger PAR wurde von der grünen Pflanzenbiomasse absorbiert und desto niedriger war der Kornertrag. Die folgende Gleichung verdeutlicht wie der Anteil an PAR am Boden und der aufgenommene Anteil an PAR zusammenhängen (LUNN et al., 2003):

$$
\text { Lichtinterzeption [\%] }=\left(1-\left(\frac{\text { PAR am Boden }}{\text { PAR über dem Bestand }}\right)\right) * 100
$$

Das Intensitätsverhältnis der Strahlung am Boden gegenüber der Intensität über dem Bestand wird als Transmission bezeichnet. Da die Laubblätter und die restliche grüne Pflanzenoberfläche einen gewissen Anteil an PAR wieder reflektieren, sollte der Anteil an absorbierter PAR um den Anteil an reflektierter PAR korrigiert werden. Nach LARCHER (1984) liegt der Anteil an reflektierter PAR zwischen 6 und 12\%.

Wie viel PAR letztlich zur Zeit der Schotenentwicklung am Boden gemessen werden konnte, war von der grünen Pflanzenbiomasse, die den Boden bedeckte, abhängig. Dies zeigte sich durch die negativen Beziehungen zwischen Kulturdeckungsgrad in $\mathrm{BBCH}$ 32/34 und dem Anteil an PAR unter den Schoten in BBCH 75 (vgl. Abb. 24) sowie zwischen der Grünfärbung des Bestandes in $\mathrm{BBCH} 73$ und dem Anteil an gemessener PAR am Boden in BBCH 75 (vgl. Abb. 25). Diese Zusammenhänge lassen den Schluss $\mathrm{zu}$, dass sich bei einem hohen Kulturdeckungsgrad in $\mathrm{BBCH} 32 / 34$ im weiteren Verlauf der Bestandesentwicklung ein geschlossener grüner Bestand entwickelte, der eine dichte Schotenschicht ausbildete und damit viel PAR absorbieren konnte. Der Kulturdeckungsgrad war maßgeblich von der Pflanzendichte im Frühjahr in BBCH 16/18 abhängig (vgl. Tab. 40A/41A im Anhang II).

STAFFORD (1996) wies in dreijährigen Feldversuchen am Standort Nottingham (England) ebenfalls nach, dass die vom Pflanzenbestand absorbierte Sonneneinstrahlung den stärksten Einfluss auf den Kornertrag hatte. Sie stellte fest, dass der Kornertrag durch das Ausmaß der Photosynthese während der Kornentwicklung bestimmt wurde, wobei die Photosynthese primär von der kumulierten Strahlungsaufnahme des Bestandes abhängig war. Die hier gefundene Ertragsrelevanz der Absorption von PAR während der Schotenentwicklung und die von STAFFORD (1996) identifizierte ertragsrelevante Strahlungsaufnahme zur Zeit der Kornentwicklung stimmen im Ergebnis somit überein, da 
die Ausbildung der Schoten und der darin befindlichen Kornanlagen annähernd zeitgleich erfolgt (DIEPENBROCK \& GROSSE, 1995; DiePENBROCK, 2000). Diese Ergebnisse belegen den Zusammenhang zwischen dem Wachstumsfaktor Licht und dem Ertrag, der u.a. von BAEUMER (1992) beschrieben wurde. Der Autor schlussfolgert, dass in einem Pflanzenbestand mit guter Wasser- und Nährstoffversorgung und einem geschlossenen, gesunden Blätterdach die Trockenmasse nur noch von der Lichtenergie, der $\mathrm{CO}_{2}$-Konzentration in der Atmosphäre und der Temperatur abhängt. Nach DE WIT (1965) verhält sich unter solchen Wachstumsbedingungen die Brutto-Assimilationsrate eines Pflanzenbestandes proportional zur Sonnenenergie.

Während der Ontogenese der Winterrapspflanzen entwickeln diese drei Arten von „Bestandesdächern“, um PAR zu absorbieren und zu nutzen. Zuerst entsteht das Blätterdach, darauf folgt während der Anthese das Blütendach und nach der Blüte bildet sich das Schotendach aus. Damit sich ein entsprechend dichtes Schotendach entwickeln kann, um viel PAR absorbieren zu können und so letztlich einen hohen Kornertrag produzieren zu können, muss eine hohe Anzahl an Blüten gebildet werden. Die dafür benötigten Assimilate werden durch die Photosynthese des Blätterdachs zur Verfügung gestellt. BRAR \& THIES (1977) und MAJOR et al. (1978) konnten zeigen, dass von den Laubblättern und Stängeln produzierte Assimilate in die Knospen, Blüten und jungen Schoten verlagert wurden und so zu deren Entwicklung beitrugen. HABEKOTTÉ (1993) fand heraus, dass eine lineare Beziehung zwischen der bis zum Beginn der Blüte produzierten Trockenmasse und der Schotendichte $\left(\right.$ Schoten $\left./ \mathrm{m}^{2}\right)$ bestand. Weitere Autoren stellten fest, dass eine Mindestmenge an Trockenmasse bis zur Blüte ausgebildet sein muss, um einen hohen Kornertrag zu erzielen (MENDHAM et al., 1981a; HABEKOTTE', 1997c). LUNN et al. (2001) bestätigten dies und folgerten aus ihren Ergebnissen, dass der Blattflächenindex (BFI) mindestens einen Wert von 1,75 oder der Grünflächenindex (Green Area Index, GAI) mindestens einen Wert von 3 zu Beginn der Anthese aufweisen sollte. Lag der BFI oder GAI unter den genannten kritischen Werten, so war die Ertragshöhe begrenzt. Bei der hiesigen Arbeit wurde anstatt des Blattflächenindex zu Beginn der Blüte der Kulturdeckungsgrad zu Beginn des Längenwachstums (BBCH 32/34) bestimmt. Es zeigte sich, dass für hohe Kornerträge mindestens ein Kulturdeckungsgrad von etwa 40\% vorliegen musste (vgl. Abb. 19A im Anhang II). Außerdem wird aus dieser Abbildung ersichtlich, dass v.a. SY Merlot bei einer Saatstärke von $30 \mathrm{Körnern} / \mathrm{m}^{2}$ unter der 40\%-Grenze blieb. Das erklärt, unter Beachtung der weiter oben dargelegten Zusammenhänge zwischen Kulturdeckungsgrad, Strahlungsaufnahme durch den grünen Bestand und dem Kornertrag, wieso diese Sorten x SaatstärkenKombination einen signifikant niedrigeren Ertrag erzielte, als die anderen drei Sorten $\mathrm{x}$ 
Saatstärken-Kombinationen. Zusammenfassend stellt die Zeit nach Vegetationsbeginn bis zur Blüte eine wichtige Phase in der Ertragsbildung von Raps dar, in der die Ausbildung einer großen Blattfläche eng mit der Verzweigungsstärke, der Schotenzahl pro Pflanze und auch mit der Kornzahl pro Schote korreliert (DIEPENBROCK, 2007).

Die kritischste Phase in der Ertragsbildung des Winterrapses stellt die Blühperiode dar, da in einem Zeitraum von ca. vier Wochen die endgültige Anzahl an Schoten und Körnern festgelegt wird (HABEKOTTÉ, 1993; DIEPENBROCK, 2000). Damit sich die Schoten und die darin befindlichen Kornanlagen gut ausbilden können, sind diese Organe auf eine kontinuierliche Versorgung mit Assimilaten angewiesen. Dabei wird die Verfügbarkeit von Assimilaten durch das Verhältnis von Source (Quelle für Assimilate) und Sink (Senke für Assimilate) gesteuert (EVANS, 1984; KeILlER \& MORGAN, 1988; LETERME, 1988). Dieses Verhältnis gerät mit Beginn der Blüte ins Ungleichgewicht, da durch die zunehmende Blütenfläche die Blattfläche immer mehr beschattet wird und deutlich weniger PAR absorbieren kann. Die Laubblätter fangen an zu altern und fallen nach einer gewissen Zeit ab. Die gelbe Blütenschicht wird bis zur Hauptblüte immer dichter und reflektiert bzw. absorbiert 60-65\% der einfallenden Strahlung (BILSBORROW \& NORTON, 1984; YATES \& SteVEN, 1987; LEACH et al., 1989). Zeitgleich nimmt die Photosyntheseleistung der Laubblätter um 40\% ab (ROBELIN \& TRIBOI, 1983). Im Verlauf der Blüte beginnt die Schotenentwicklung an der Rapspflanze, sodass in einem Rapsbestand Blüte und Schotenbildung über einen längeren Zeitraum parallel verlaufen (DIEPENBROCK, 2007). Die wachsende Schotenoberfläche, die zum Ende ihrer Entwicklung in etwa der maximalen Blattfläche entspricht (ALLEN \& MORGAN, 1972), ist in der Lage PAR zu absorbieren und übernimmt Schritt für Schritt die Assimilatproduktion der bedeckten bzw. abgängigen Blattoberfläche. Allerdings übertreffen die Schoten erst ca. zwei Wochen nach der Hauptblüte die Photosyntheseleistung der Laubblätter (GAMMELVIND et al., 1996). Somit ist von Beginn der Blüte bis zu dem zuvor genannten Zeitpunkt die Assimilatproduktion eingeschränkt und eine kontinuierliche Versorgung mit Assimilaten nicht sichergestellt. Es kommt zu einem Konkurrenzkampf zwischen den einzelnen generativen Organen um die verbliebenen Assimilate, was letztlich dazu führt, dass Knospen, Blüten, Schoten und Kornanlagen reduziert werden (KEILLER \& MORGAN, 1988; DiEPENBROCK \& GROSSE, 1995). Dabei nehmen die Verluste an generativen Organen vertikal von den oberen zu den unteren Blüten zu (WILLIAMS, 1978; WILLIAMS \& FreE, 1979). Dies ist durch den insertionsabhängigen Blühverlauf und die damit verbundenen intraspezifischen Konkurrenzbedingungen sowie Beschattungsverhältnisse erklärbar. Die Blüte setzt zuerst am Haupttrieb ein und schreitet dann über die obersten Seitentriebe zu den untersten Seitentrieben 1. Ordnung fort (DIEPENBROCK, 2006). Dies führt zu einer gestaffelten Ausbildung der Schoten, bei der die obersten, zuerst gebildeten Schoten zum 
einen eine höhere Anziehungskraft auf die Assimilate ausüben (stärkeres Sink) und zum anderen die später gebildeten Schoten beschatten. In dieser Phase der beschränkten Verfügbarkeit von Assimilaten ist die Assimilatverlagerung aus Wurzeln, Stängeln und Blättern für die Ertragsbildung ganz entscheidend. Der Anteil an Reservekohlenhydraten, die aus den angesprochenen Organen mobilisiert werden und so indirekt zum Endertrag beitragen, liegt bei 12 bis 17,5\% (QUILLERE \& TRIBOI, 1987; HABEKOTTÉ, 1993). Das ist deutlich weniger als bei Getreide, wo bis zu 30\% an Reservekohlenhydrate aus dem Stängel in die wachsende Ähre verlagert werden und damit knapp ein Drittel des Kornertrages ausmachen (FOULKES et al., 1997).

Die Zeit nach der Anthese wird durch die Schoten- und Kornentwicklung repräsentiert und stellt die letzte wichtige Phase in der Ertragsbildung von Winterraps dar. Wie diese vorliegende Arbeit zeigt und andere Literaturquellen belegen (STAFFORD, 1996; DIEPENBROCK, 2000), korreliert der in dieser Phase vom Pflanzenbestand aufgenommene Anteil an Strahlung eng mit dem endgültigen Kornertrag. Demnach sollte möglichst ein dichtes, zusammenhängendes Schotendach zur Lichtinterzeption vorliegen. Andererseits lässt sich in der Literatur die Aussage finden, dass offenere, lichtere Schotenschichten, bei gleichen Einstrahlungsverhältnissen einen höheren Ertrag lieferten als dichte Schotenschichten (MENDHAM et al., 1981a; JENKINS \& LEITCH, 1986; MCWILLIAM et al., 1995; StAFFORD et al., 1995; STAFFORD, 1996; ScOTT et al., 1999; LUNN et al., 2001). Die verschiedenen Autoren führen dies darauf zurück, dass mehr PAR bis in die untere Schotenschicht und v.a. in die darunter liegende Blattetage vordringen kann. Durch die stärkere Belichtung wird die Photosyntheseleistung in den basalen Schoten und Laubblättern erhöht, was dazu führt, dass diese pflanzlichen Gewebeschichten länger erhalten bleiben, mehr Assimilate produzieren und so die unteren Schoten sowie die darin befindlichen Körner besser mit Assimilaten versorgt werden. Auf diese Weise überleben in der unteren Schotenschicht mehr Schoten und Körner, wodurch der Endertrag erhöht wird. Insbesondere die Belichtung der Laubblätter erhöht die Assimilatproduktion und damit die Überlebensrate von Schoten und Körnern, da die Photosynthese in Laubblättern aufgrund ihrer größeren Oberfläche deutlich effizienter ist als in Schoten oder Stängeln (BILSBORROW \& NORTON, 1987). STAFFORD (1996) stellte fest, dass bei einer erhöhten Belichtung der Blattetage deren Anteil an der Gesamtproduktion von Assimilaten ca. 30\% betrug. Das machte ca. $20 \%$ des Endertrags aus. Starben dagegen die Laubblätter frühzeitig während der Blüte aufgrund zu dichter Bestände $a b$, verringerte sich deren Beitrag zur Kornfüllung auf etwa 10\%.

Damit die verbesserte Assimilatversorgung in offeneren Beständen tatsächlich in mehr Kornertrag umgesetzt wird, muss eine entsprechende Nachfrage durch ein ausreichend 
großes Sink-Gewebe vorliegen (Lichtnutzungseffizienz). Ist dies nicht der Fall, z.B. durch eine längere Trockenperiode während der Anthese, wodurch weniger Schoten ausgebildet werden, so wird der Überschuss an Assimilaten vermehrt ins Stängelgewebe eingelagert (ANDERSEN et al., 1996). In diesem Zusammenhang konnte HABEKOTTE' (1997b) durch Simulationsberechnungen mit dem eigens weiterentwickelten Model LINTUL-BRASNAP (HABEKOTTE', 1997c) aufzeigen, dass der Kornertrag nur dann gesteigert werden kann, wenn die Source- und Sinkkapazitäten simultan erhöht werden. Er bezog dies auf die Kornfüllungsphase, in der bei einer erhöhten Korndichte und einem knapperen Angebot an Assimilaten das Korngewicht reduziert wird. Dieser kompensatorische Effekt zwischen Korndichte und TKM kann gebrochen werden, wenn bis zur Abreife einer hohen Nachfrage nach Assimilaten auch ein hohes Angebot gegenübersteht. Somit ist das Gleichgewicht zwischen Source und Sink elementar für die Ertragsbildung und die Ertragshöhe.

Die Grünfärbung des Pflanzenbestandes in $\mathrm{BBCH} 73$ stellte die zweitwichtigste Determinante für den Kornertrag im Jahr 2010/11 dar. Allerdings war der Einfluss mit ca. 6,6\% sehr gering. Die Grünfärbung des Pflanzenbestandes, ausgedrückt über den Vegetationsindex Normalized Difference Vegetation Index [(NDVI); (RouSE, 1973; ROUSE et al., 1974)], wurde mit dem GreenSeeker ${ }^{\circledR}$ ermittelt. Der NDVI-Wert repräsentiert einen Mischwert zwischen der Bestandesentwicklung (Vorhandensein von grüner, pflanzlicher Biomasse) und der Photosyntheseleistung der Einzelpflanze (Grad der Chlorophyllaktivität) (PEÑUELAS et al., 1994; BOSCH, 2012). Weitere Einzelheiten zum Messverfahren des GreenSeekers ${ }^{\circledR}$ und den theoretischen Hintergründen zum NDVI können Kapitel 2.7.8 entnommen werden. Zu Beginn der Entwicklung eines Pflanzenbestandes wird der NDVI vornehmlich durch die Bestandesdichte sowie durch die Zunahme des Kulturdeckungsgrades beeinflusst. Mit Erreichen der artspezifischen, höchstmöglichen Bodenbedeckung wird der NDVI vor allem durch den Chlorophyllgehalt und die Photosyntheseleistung beeinflusst (Bosch, 2012). Ab diesem Zeitpunkt sind Rückschlüsse auf den physiologischen Zustand eines Pflanzenbestandes möglich. Ursprünglich wurde der GreenSeeker ${ }^{\circledR}$ für die Präzisionslandwirtschaft entwickelt, um die Versorgung eines Pflanzenbestandes mit Nährstoffen (v.a. mit Stickstoff) abschätzen zu können und dementsprechend die N-Düngung teilflächenspezifisch anpassen zu können (SOLIE et al., 2002; INMAN et al., 2005). In der vorliegenden Arbeit wurde dieser Sensor dazu eingesetzt, um den Verlauf der Entwicklung der grünen Assimilationsfläche ab Beginn der Anthese zu beschreiben. Dabei stellte sich heraus, dass durch die wöchentlichen NDVI-Messungen sehr gut der Verlauf der Blüte sowie der Abreifeprozess quantifiziert werden konnte. So nahmen die NDVI-Werte mit zunehmender Blütenfläche 
bis zur Hauptblüte $a b$ und stiegen danach wieder an. Gegen Ende der Schotenentwicklung erreichten die NDVI-Werte ähnlich hohe Werte oder sogar höhere Werte wie vor der Blüte. Das ist ein Beleg dafür, dass die maximale Schotenoberfläche annähernd der maximalen Blattoberfläche entspricht (Daten nicht angegeben). Mit Beginn der Abreife und der Degradation von Chlorophyll nahmen die NDVI-Werte bis kurz vor der Ernte kontinuierlich ab. Hieraus könnte eine weitere Nutzungsmöglichkeit für den GreenSeeker $^{\circledR}$ abgeleitet werden: Die Ermittlung der optimalen Druschreife von Winterraps. Allerdings macht dies nur dann Sinn, wenn der NDVI-Wert nicht durch Zwiewuchs und/oder starken Unkrautbesatz verfälscht wird. Ferner können solche Messungen nur am Rand durchgeführt werden, um vorzeitige Körnerverluste durch ein Aufplatzen der Schoten zu verhindern. Inwieweit durch wiederholte Messungen an mehreren Stellen am Rand eines Rapsbestandes auf die optimale Druschreife des kompletten Bestandes geschlossen werden kann und ob sich diese Messmethode überhaupt als geeignet herausstellt, müsste in weiteren Praxisversuchen näher untersucht werden.

Die Grünfärbung des Pflanzenbestandes in $\mathrm{BBCH} 73$ war primär schwach negativ mit dem Wurzelhalsdurchmesser in BBCH 83/84 korreliert (vgl. Abb. 24). Zur Deutung dieses negativen Zusammenhangs darf man sich nicht davon irritieren lassen, dass der Wurzelhalsdurchmesser deutlich später als die Grünfärbung des Pflanzenbestandes erfasst wurde. Der Wurzelhalsdurchmesser nimmt im Laufe der Ontogenese einer Rapspflanze zu. Dies zeigte sich beim Vergleich der Messwerte vom Wurzelhalsdurchmesser aus dem Herbst mit denen aus dem Frühjahr (gilt für beide Versuchsjahre, Daten nicht explizit angegeben). Damit der Wurzelhals weiter wachsen kann, ist dieser auf Assimilate aus dem Spross angewiesen. Diese werden nach den Untersuchungen von MAJOR et al. (1978) v.a. aus den untersten, inserierten Laubblättern zur Verfügung gestellt. Nach DiEPENBROCK et al. (2005) zählt Brassica napus zu den semi-terminierten Arten. Bei diesen unterliegt die Verteilung von neu gebildeter Trockenmasse nach der Sink-Differenzierung der innerpflanzlichen Konkurrenz zwischen vegetativen und reproduktiven Sinks, mit einer leichten Dominanz der reproduktiven Organe. Gräser oder Getreide gehören dagegen zu den terminierten Arten, bei denen mit Beginn der generativen Phase der überwiegende Teil an neu produzierten Assimilaten in die Ertragsorgane verlagert wird. Kann aufgrund von ungünstigen Wetterbedingungen oder Schädlings- bzw. Krankheitsbefall weniger Trockenmasse neu gebildet werden, so verstärkt sich die intraspezifische Konkurrenz zwischen vegetativen und generativen Verbrauchsorten für Assimilate. Diese verschiedenen Argumente erklären, warum der Wurzelhalsdurchmesser und die Grünfärbung des Pflanzenbestandes in $\mathrm{BBCH} 73$ im Jahr 
2010/11 (ungünstige Wetterverhältnisse von März bis Mai) negativ miteinander korreliert waren und 2012/13 (günstige Wetterverhältnisse von März bis Mai) kein signifikanter Zusammenhang zwischen diesen beiden Parametern nachgewiesen werden konnte (Daten für 2012/13 nicht angegeben).

Die Pflanzendichte im Herbst in $\mathrm{BBCH}$ 14/15, wirkte sich primär auf den Wurzelhalsdurchmesser in $\mathrm{BBCH} 83 / 84$ aus. Dieser verringerte sich mit steigender Anzahl an Pflanzen $/ \mathrm{m}^{2}$ im Herbst. Dieser Zusammenhang ist trivial, da mit steigender Pflanzenzahl $/ \mathrm{m}^{2}$ im Herbst der Standraum jeder Einzelpflanze weniger wird, damit weniger Licht, Wasser und Nährstoffe verfügbar sind und somit die individuelle Entwicklung jeder Einzelpflanze begrenzt ist. Unter solchen Bedingungen bilden die Rapspflanzen einen dünneren Wurzelhals als auch weniger Blätter je Pflanze aus und neigen stärker zu einer unerwünschten frühen Sprossstreckung (SCHÖNBERGER, 2012; STEMANN, 2014). Demnach stellte einerseits die intraspezifische Konkurrenz um Wachstumsfaktoren zwischen Pflanzen einer Art und andererseits, die unter den ungünstigen Wetterbedingungen 2010/11 stärker ausgeprägte intraspezifische Konkurrenz um Assimilate zwischen verschiedenen Pflanzengeweben einer Rapspflanze, eine wesentliche Einflussgröße auf die Entwicklung des Rapsbestandes dar.

Im Versuchsjahr 2012/13 war die Schotenansatzhöhe in BBCH 75, die entscheidendste Determinante für den Kornertrag. Die Auswertungen zeigten, dass hohe Ausgangsbestände in $\mathrm{BBCH}$ 65/67 zu einer hohen Schotenansatzhöhe in $\mathrm{BBCH} 75$ und damit zu einem hohen Kornertrag führten (vgl. Abb. 27). Somit hatte im Jahr 2012/13 das Längenwachstum der Bestände einen primären Einfluss auf den Kornertrag. Weiterhin beeinflusste die Schotenansatzhöhe bzw. Bestandeshöhe den Strohbiomasseertrag positiv (vgl. Tab. 70A im Anhang II). Dieser positive Zusammenhang ist wie zuvor bei der negativen Beziehung zwischen Pflanzendichte im Herbst und Wurzelhalsdurchmesser im Frühjahr als trivial anzusehen, da mit zunehmender Schotenansatzhöhe der Anteil an der Stängelbiomasse steigt und dies wiederum den gesamten Anteil an der Strohbiomasse (alles außer Samen) erhöht. Da im Jahr 2012/13 ein wesentlich stärkerer Zusammenhang zwischen dem Strohbiomasseertrag und dem Kornertrag bestand $(r p=0,627)$ als im Jahr 2010/11 ( $r p=0,383$ ), kann geschlussfolgert werden, dass das Längenwachstum der Bestände über die gebildete Strohbiomasse einen wesentlichen Einfluss auf den Kornertrag hatte. Wie schon an anderer Stelle erklärt wurde (vgl. Seite 159-162), ist ein ausgeglichenes Verhältnis zwischen vegetativen (Source) und generativen (Sink) Pflanzenorganen entscheidend für die Ertragsbildung und die Ertragshöhe. Für die Bildung und Stofffüllung von Ertragsorganen muss zuvor immer ein ausreichender Assimilat-Pool durch die vegetativen Organe gebildet werden (DIEPENBROCK et al., 2005). 
Hier nehmen, aufgrund ihrer Nähe zum Verbrauchsort, die oberen Laubblätter und die oberen Stängelabschnitte als Assimilat-produzierendes sowie -speicherndes Pflanzengewebe eine besondere Stellung ein (BRAR \& THIES, 1977; MAJOR et al., 1978). Vor allem die Möglichkeit Assimilate zwischenspeichern zu können, um sie dann in Phasen abzurufen, in denen die Produktion und Bereitstellung von Assimilaten eingeschränkt ist (z.B. Blühperiode), ist ganz entscheidend für eine kontinuierliche Entwicklung der Ertragsorgane und letztlich für die Ertragshöhe. Solche Reservekohlenhydrate werden aus Wurzeln, Blättern, Stängeln (Haupttrieb+Seitentriebe) und Schotenwänden mobilisiert (ROOD et al., 1984; ADDO-QUAYE et al., 1985). Ist die Zwischenlagerkapazität für Reservekohlenhydrate nicht hinreichend gegeben, kann es zu Ertragseinbußen kommen. Wie in dieser Arbeit gezeigt werden konnte, wirkte sich im Jahr 2012/13 eine Hemmung des Längenwachstums durch synthetische WR negativ auf den Kornertag aus. Durch den Einsatz der wachstumsregulierenden Fungizide wurde das Stängelgewebe so stark reduziert, dass dieses nicht mehr genügend Assimilate bilden bzw. zwischenspeichern konnte. Ähnliche Beobachtungen stellten RAO \& MENDHAM (1991a), RAO et al. (1991b) und FISAHN (1993) fest. Weitere Details zu dem vorstehenden Abschnitt sowie zu den Erkenntnissen der zuvor genannten Autoren werden in Kapitel 4.4 diskutiert.

Die Grünfärbung des Pflanzenbestandes in BBCH 89 (NDVI_A5) stellte die zweitwichtigste Determinante für den Kornertrag im Jahr 2012/13 dar, wobei eine positive Beziehung zwischen diesen beiden Parametern bestand. In der Vergangenheit wurde die ertragsphysiologische Bedeutung einer verzögerten Seneszenz u.a. von EvANS et al. (1975), GAN \& AMASINO (1997) und LIM et al. (2007) beschrieben. Für Winterweizen wies z.B. SIMPSON (1968) nach, dass eine verzögerte Abreife mit höheren Erträgen korreliert. An Winterraps konnte HABEKOTTE' (1997b) diesen Zusammenhang zeigen, wobei in seinen Untersuchungen unter allen getesteten Faktoren, eine deutlich verlängerte Abreifeperiode die höchsten Ertragszuwächse verursachte. LIU (1983) berichtete, dass mit jedem weiteren Tag, den die Abreife bei Winterraps dauert, ein Ertragszuwachs von $2 \%$ erwartet werden kann. In der vorliegenden Arbeit ist die gesteigerte Grünfärbung des Pflanzenbestandes auf den sogenannten „Greening“-Effekt zurückzuführen, der u.a. durch Triazolwirkstoffe, wie sie in den eigenen Feldversuchen verwendet wurden, ausgelöst wird (vgl. Kapitel 1.2). Da diese Wirkstoffgruppe die Produktion von Ethylen unterbindet, die Bildung von Polyaminen fördert und den Abbau von Cytokininen verlangsamt (BUCHENAUER, 1995; SIEFERT and GROSSMANN, 1996) besitzen Triazole eine seneszenzverzögernde Wirkung. Dies führt dazu, dass das Gewebe länger grün bleibt und die Assimilationsphase verlängert wird. Als Resultat des „Greening“-Effekts wird z.B. 
für Winterweizen eine Zunahme der TKM genannt, welche signifikant den Ertrag beeinflusst (ENTZ et al., 1990; GERHARD, 2001; BECK, 2005).

Die Grünfärbung des Pflanzenbestandes in $\mathrm{BBCH} 89$ wurde primär durch die Bestandeshöhe in $\mathrm{BBCH} 73 / 74$ und sekundär durch die Schotenschichtdicke in $\mathrm{BBCH}$ 73/74 beeinflusst. Dabei nahm der NDVI-Wert in BBCH 89 mit sinkender Bestandeshöhe bzw. abnehmender Schotenschichtdicke zu. Dies ist darauf zurückzuführen, dass die stauchende Wirkung und der sekundäre „Greening“-Effekt von Triazolen immer gleichzeitig auftreten.

Die Bestandeshöhe in $\mathrm{BBCH}$ 73/74 ergab sich rechnerisch aus der Schotenansatzhöhe sowie Schotenschichtdicke in $\mathrm{BBCH} 73 / 74$. Somit war es logisch, dass die beiden zuletzt genannten Bestandesparameter als einzige Prädiktoren für die Bestandeshöhe in $\mathrm{BBCH}$ 73/74 ermittelt wurden.

Die Schotenschichtdicke in $\mathrm{BBCH} 73 / 74$ wurde v.a. durch die Grünfärbung des Pflanzenbestandes in $\mathrm{BBCH}$ 65/66 erklärt. Dahinter folgte die Schotenansatzhöhe in BBCH 73/74. Nahm die Grünfärbung des Pflanzenbestandes in BBCH 65/66 bzw. die Schotenansatzhöhe in $\mathrm{BBCH} 73 / 74 \mathrm{zu}$, verringerte sich die Schotenschichtdicke in $\mathrm{BBCH}$ 73/74. Diese negativen Zusammenhänge lassen sich durch den Greening-Effekt und den zeitgleich auftretenden Einkürzungseffekt der verwendeten Triazolfungizide erklären. Es zeigte sich, dass mit zunehmender Anzahl an Applikationen der Pflanzenbestand in $\mathrm{BBCH}$ 65/66 intensiver grün gefärbt war und die Schotenansatzhöhe in $\mathrm{BBCH} 73 / 74$ kleiner wurde. Zeitgleich nahm die Schotenschichtdicke zu (Daten nicht angegeben, da nicht signifikant). Der negative Zusammenhang zwischen Schotenansatzhöhe und Schotenschichtdicke erscheint dabei plausibler als die negative Beziehung zwischen Grünfärbung des Pflanzenbestandes und Schotenschichtdicke, auch wenn die partiellen $\mathrm{R}^{2}$-Werte etwas anderes wiedergeben. Im letzten Fall handelt es sich vielmehr um eine Scheinkorrelation, die sich aus den verschiedenen Wirkungsweisen der Fungizide ergeben hat. 


\subsection{Einfluss der Anbaufaktoren Sorte und Saatstärke auf ertragsrelevante Bestandesparameter und den Ertrag}

Auf Grundlage aller ertragsrelevanten Parameter, die in der hierarchischen Abb. 24 und Abb. 27 sowie in Tab. 37 und Tab. 38 aufgeführt sind, wurde ermittelt, welcher von den drei Anbaufaktoren Sorte, Saatstärke und Fungizidbehandlung am häufigsten die ertragsrelevanten Parameter signifikant beeinflusst hat. Im Jahr 2010/11 hatten viele Parameter einen direkten oder indirekten Einfluss auf den Kornertrag, die direkt oder indirekt von der Pflanzendichte im Frühjahr abhängig sind. Dazu zählen z.B. der Kulturdeckungsgrad im Frühjahr, der Anteil an PAR unter den Schoten bzw. am Boden, die Grünfärbung des Pflanzenbestandes oder der Wurzelhalsdurchmesser. Da die Pflanzendichte im Frühjahr primär von der Pflanzendichte im Herbst und diese wiederum von der Saatstärke abhängig ist, hatte letztlich im Versuchsjahr 2010/11 die Saatstärke am häufigsten einen signifikanten Einfluss auf die ertragsrelevanten Parameter. Dadurch dass im Jahr 2010/11 höhere Pflanzenverluste über Winter auftraten als im Jahr 2012/13, kam es bei den Parametern, die von der Pflanzendichte im Frühjahr abhängig sind, häufiger zu signifikanten Effekten durch die Saatstärke. Oft war der jeweilige Parameter bei der höheren Saatstärke signifikant besser ausgeprägt als bei der niedrigen Saatstärke. Dies ist darauf zurückzuführen, dass ein Bestand mit geringer Pflanzendichte den Ausfall einzelner Pflanzen schlechter kompensieren kann, als ein Bestand mit einer höheren Pflanzendichte (HENNING, 1979). HENNING (1979) untersuchte u.a. wie sich eine Bestandesdichte von 9, 18 und 50 Pflanzen $/ \mathrm{m}^{2}$ auf die Entwicklung und Ertragsbildung zweier Winterrapssorten auswirkte. Er stellte dabei fest, dass mit zunehmender Bestandesdichte der Flächenertrag stieg. Dies deckt sich mit den Ergebnissen für das Versuchsjahr 2010/11 der vorliegenden Arbeit. HENNING (1979) konnte nachweisen, dass durch eine höhere Bestandesdichte die Verzweigungsneigung der Einzelpflanze abgeschwächt und die Anzahl von leistungsfähigeren Schoten im oberen Sprossbereich gesteigert wurde. Dem Autor zufolge war die erhöhte Anzahl von leistungsfähigeren Schoten am Haupttrieb und den oberen Nebentrieben entscheidend für einen hohen Flächenertrag.

Im Jahr 2012/13 beeinflusste die Saatstärke von allen drei Anbaufaktoren die ertragsrelevanten Parameter am wenigsten. In dieser Vegetationsperiode traten kaum Pflanzenverluste über Winter auf, sodass im Frühjahr in beiden Saatstärkenvarianten mehr Pflanzen $/ \mathrm{m}^{2}$ vorhanden waren als im Jahr 2010/11 (Tab. 72A im Anhang II). Die allgemein höhere Pflanzendichte in beiden Saatstärkenvarianten hatte zur Folge, dass sich v.a. bei der niedrigen Saatstärke ein entsprechend höherer Kulturdeckungsgrad in BBCH 32/34 ausbildete als im Jahr 2010/11 (vgl. die Daten zum Kulturdeckungsgrad in 
$\mathrm{BBCH} 32 / 34$ in Tab. 26A und 27A sowie die Abb. 19A und 20A im Anhang II). Dadurch entwickelte sich im weiteren Verlauf der Vegetationsperiode 2012/13 ein geschlossener, grüner Bestand, bei dem bei beiden Saatstärkenvarianten keine signifikanten Unterschiede zwischen dem Anteil an PAR am Boden bzw. unter den Schoten in BBCH 75 auftraten. Insgesamt war der Anteil an gemessener PAR am Boden bzw. unter den Schoten niedriger als im Versuchsjahr 2010/11. Demzufolge konnten die Bestände viel PAR absorbieren und für die Photosynthese nutzen. Ein weiterer Beleg für die ähnliche Entwicklung der Pflanzenbestände war, dass im Jahr 2012/13 keine signifikanten Unterschiede zwischen den verschiedenen Saatstärkenvarianten in Bezug auf die Grünfärbung des Pflanzenbestandes in $\mathrm{BBCH} 73$ auftraten. Letztendlich führte im Jahr 2012/13 die niedrige Saatstärke zu ähnlich hohen Kornerträgen wie die hohe Saatstärke (vgl. Tab. 16). Die Ergebnisse zum Einfluss der Saatstärke auf den Kornertrag der beiden Versuchsjahre verdeutlichen, dass die optimale Saatstärke bzw. die optimale Bestandesdichte von Jahr zu Jahr schwankt. Verschiedene Literaturstellen belegen diese Erkenntnis, wobei die einzelnen Autoren häufig einen weiten Bereich feststellten, in dem die Pflanzen $/ \mathrm{m}^{2}$ den Ertrag nicht beeinflussten. Nach VosKERUSA (1970) sowie SEIFFERT and BOELCKE (1977) waren 35-60 Pflanzen/ $\mathrm{m}^{2}$ optimal für hohe Kornerträge von Winterraps. BOELCKE (1981) nennt in seiner Arbeit 30-150 Pflanzen $/ \mathrm{m}^{2}$. STOY (1983) und VOBHENRICH and HEEGE (1985) berichteten von ähnlichen Erträgen bei 40-80 Pflanzen $/ \mathrm{m}^{2}$, wohingegen SIERTS (1987) dies bei 40-120 Pflanzen $/ \mathrm{m}^{2}$ beobachtete. Für Sommerraps stellte sich eine Pflanzenzahl von 40-80 Pflanzen $/ \mathrm{m}^{2}$ als geeignet heraus (ANGADI et al., 2003). Nach SCHÖNBERGER (2012) können ähnlich hohe Erträge mit 30-60 Pflanzen/m² erzielt werden. Das entspricht dem eigenen Ergebnis aus dem Jahr 2012/13.

Der Anbaufaktor Sorte war im Jahr 2010/11 am dritthäufigsten und im Jahr 2012/13 am zweithäufigsten für einen signifikanten Effekt bei den ertragsrelevanten Parametern verantwortlich. Dabei wurden hauptsächlich solche Parameter durch die Sorten beeinflusst, die typischerweise vom Genotyp abhängig sind. Dazu zählen z.B. die Bestandeshöhe, die Grünfärbung des Bestandes v.a. zur Abreife, die TKM oder auch der Ölgehalt, wobei letzterer in beiden Jahren nicht als ertragsrelevanter Parameter identifiziert wurde. Die stets signifikanten Höhenunterschiede zwischen den beiden Sorten NK Petrol und SY Vesuvio, hatten im Jahr 2012/13 keinen Einfluss auf den Strohbiomasseertrag bzw. Kornertrag. Gleiches galt für die signifikanten Sortenunterschiede in Bezug auf die Grünfärbung des Pflanzenbestandes in BBCH 89. Eine besondere Ertragsrelevanz hatten im Jahr 2010/11 die Feldaufgangsverluste bei der Sorte SY Merlot. Diese wirkten sich zusätzlich zu den Auswinterungsverlusten negativ auf die Pflanzendichte im Frühjahr und auf alle von der Pflanzendichte im Frühjahr 
abhängigen ertragsrelevanten Bestandesparameter aus. Die Feldaufgangsverluste wurden aus dem Parameter Pflanzendichte im Herbst abgeleitet (Daten nicht explizit angegeben). Die zuvor geschilderten sortenbedingten Feldaufgangsverluste und die generellen Überwinterungsverluste führten zu den signifikanten Ertragsunterschieden zwischen der niedrigen und hohen Aussaatstärke bei SY Merlot. Zusammenfassend wurde in beiden Versuchsjahren ein Sorteneinfluss auf gewisse ertragsrelevante Parameter beobachtet, allerdings waren diese in der Summe nicht so entscheidend wie die Saatstärke (2010/11) oder die Fungizidbehandlungen (2012/13, vgl. Kapitel 4.4). Unabhängig davon sollte der Einfluss verschiedener Genotypen auf die Ertragsbildung und die Ausbildung von Ertragskomponenten nicht unterschätzt werden. Dies geht insbesondere aus der Arbeit von GROSSE (1989) hervor, in der dieser ein Sortiment von zehn verschiedenen Winterrapssorten bzw. -stämmen untersucht hat. Der Autor konnte dabei für eine Vielzahl von Merkmalen [u.a. Blühbeginn, Schotenreifung, Verlauf der Trockenmassebildung des Sprosses und seiner Fraktionen (Sprossachsen, Blatt und Schoten) vor Winter und nach Winter, maximaler BFI zu Blühbeginn, Seitentriebbildung, Blütenanlage und insertionsabhängige Ausbildung der Ertragsfaktoren] eine hohe Variabilität innerhalb des Sortimentes nachweisen. Als besonders ertragsrelevante und zugleich züchterisch selektierbare Merkmale stellten sich die Trockenmassebildung vor der Blüte, der maximale BFI zu Blühbeginn und der Ernteindex bzw. die Gesamttrockenmasse zum Reifetermin heraus. Aufgrund der sortenabhängigen Plastizität in der Ertragsbildung schlussfolgerte GROSSE (1989), dass zur Ausschöpfung des Ertragspotenzials bestimmter Sorten eine sortenspezifische Produktionstechnik in Betracht gezogen werden müsste. Dem Autor zufolge sollte v.a. die Bestandesdichte und der Saattermin sortenabhängig gewählt werden. Seitdem die Züchterfirmen zu jeder Sorte individuelle Sortenbeschreibungen erstellen, aus denen auch die optimale Saatstärke und Saatzeit hervorgehen, hat sich diese Empfehlung in der landwirtschaftlichen Praxis durchgesetzt.

GROSSE (1989) identifizierte u.a. den Ernteindex und die Gesamttrockenmasse zum Reifetermin als Merkmale, die für die Züchtung auf Ertrag in Frage kommen. Diese beiden Selektionsmerkmale sind laut BECKER (2011) die einzigen um züchterisch den Ernteertrag zu erhöhen. Dabei lässt sich dem Autor zufolge der Kornertrag entweder durch eine Erhöhung der gesamten, oberirdisch, produzierten Trockenmasse (Biomasseertrag) oder des Ernteindexes, das ist der Anteil des Ernteprodukts an der Gesamttrockenmasse, steigern. Speziell bei Getreide wurden Ertragssteigerungen durch die Erhöhung des Ernteindexes erzielt, indem durch die Einkreuzung von Genen für Zwergwuchs, die Strohlänge reduziert wurde (BECKER, 2011). Solche Gene können allerdings auch zu 
einem reduzierten Wurzeltiefgang und einem stärkeren Krankheitsbefall führen, wenn die Krankheitserreger durch die verkürzte Wuchslänge ein günstiges Mikroklima vorfinden (BECKER, 2011). Aus diesem Grund schlägt BECKER (2011) als Selektionsziel „große Zwerge" vor, bei denen die Wuchshöhe nicht zu kurz ist. Seit einigen Jahren gibt es auch Winterrapssorten, die einen verkürzten Habitus aufweisen und als Halbzwerghybride bezeichnet werden. Aus den Versuchen der letztjährigen Landessortenversuche für Winterraps der Landwirtschaftskammern Nordrhein-Westfalen, Niedersachsen und Schleswig-Holstein geht jedoch hervor, dass dieser neue Sortentyp bisher nicht zu den gewünschten Ertragssteigerungen geführt hat, sondern in den meisten Fällen unterdurchschnittliche Erträge lieferte (LANDWIRTSCHAFTSKAMMER NIEDERSACHSEN, 2009; 2010; 2011; 2012; LANDWIRTSCHAFTSKAMMER NORDRHEIN-WESTFALEN, 2007; 2008; 2009; 2010; LANDWIRTSCHAFTSKAMMER SCHLESWIG-HOLSTEIN, 2010a; 2010b; 2010c).

\subsection{Einfluss der Fungizidbehandlungen auf ertragsrelevante Bestandesparameter und den Ertrag}

Im Jahr 2012/13 hatten vermehrt solche Parameter einen direkten oder indirekten Einfluss auf den Kornertrag, die direkt von den primären und sekundären Wirkungen von wachstumsregulierenden Triazol-Fungiziden abhängig sind. Dazu zählen z.B. die Bestandeshöhe, die Schotenansatzhöhe, die Schotenschichtdicke und die Grünfärbung des Bestandes. Somit hatten im Versuchsjahr 2012/13 die Fungizidbehandlungen am häufigsten einen signifikanten Einfluss auf die ertragsrelevanten Parameter. Die Wirksamkeit der Fungizidbehandlungen war im Jahr 2012/13 deutlich stärker als im Jahr 2010/11, was sich insbesondere in der Reduktion der Wuchshöhe (Schotenansatzhöhe bzw. Bestandeshöhe) bemerkbar machte. Die erhöhte Wirksamkeit lässt sich dadurch erklären, dass in den Monaten März bis Mai im Jahr 2012/13 deutlich mehr Niederschlag gefallen war als im Jahr 2010/11 [vgl. Abb. 20 (2010/11) bzw. Abb. 22 (2012/13)]. Dies begünstigte das Wachstum der Bestände und die Aufnahme der eingesetzten Triazolwirkstoffe in die Pflanzen sowie deren akropetale Verlagerung. Es wurde nachgewiesen, dass sich mit zunehmender Anzahl an Behandlungen mit der Wirkstoffkombination aus Paclobutrazol und Difenoconazol die Wuchshöhe immer stärker verringerte. Hervorzuheben sind hier v.a. die Doppelbehandlung im Herbst (V4), die Doppelbehandlung im Frühjahr (V5) und die Doppelbehandlung im Herbst und Frühjahr (V6). Dabei muss allerdings beachtet werden, dass bei gleicher Anzahl an Applikationen die Doppelbehandlung im Herbst signifikant besser war als die Doppelbehandlung im Frühjahr. Die Doppelbehandlung im Herbst wirkte stärker wuchsregulierend als die 
Doppelbehandlung im Frühjahr, da der Wirkstoff Paclobutrazol eine hohe Persistenz im Boden aufweist (RADEMACHER, 2000). Damit verfügt dieser Wirkstoff über einen langen Wirkungszeitraum, wobei sich die Wirkung nur dann entfalten kann, wenn der Wirkstoff, bei entsprechender Bodenfeuchte, durch die Wurzeln der Pflanzen aufgenommen und akropetal verlagert wird (vgl. letzten Abschnitt von Kapitel 4.1). Die stärksten Kornertragsreduktionen traten ebenfalls in den drei angesprochenen Fungizidvarianten auf, wobei diese in V4 und V6 mit signifikanten Reduktionen in der Strohbiomasse einhergingen. Die praxisübliche Variante, in der die Wirkstoffkombination aus Metconazol und Mepiquatchlorid eingesetzt wurde, nahm eine Mittelstellung im Hinblick auf die Regulation des Längenwachstums und der damit verbunden Ertragsreduktion ein. Ähnliche Beziehungen zwischen Wuchshöhe, Strohbiomasseertrag und Kornertrag konnten auch im Jahr 2010/11 nachgewiesen werden, wobei diese jedoch nicht so deutlich ausgeprägt waren wie im Jahr 2012/13. So führte nur die signifikante Einkürzung der Schotenansatz- bzw. der Bestandeshöhe in $\mathrm{BBCH} 75$ durch die praxisübliche Variante (V8), in der die wuchsregulierenden Wirkstoffe Tebuconazol und Mepiquatchlorid eingesetzt wurden, zu einem signifikant reduzierten Strohgewicht und Kornertrag. (vgl. die Parameter Schotenansatz- bzw. Bestandeshöhe in BBCH 75, Strohbiomasseertrag und Kornertrag in Tab. 26A im Anhang II). Es traten nur schwach positive Beziehungen zwischen dem Strohbiomasseertrag und dem Kornertrag, der Schotenansatzhöhe in $\mathrm{BBCH} 75$ und dem Kornertrag sowie der Bestandeshöhe in $\mathrm{BBCH} 75$ und dem Kornertrag auf (vgl. Tab 22A im Anhang II). Zwischen der Schotenansatz- bzw. Bestandeshöhe und dem Strohbiomasseertrag bestand jedoch kein Zusammenhang (vgl. Tab. 71A im Anhang II). Dies ist auf die trockenen Bedingungen in den Monaten März bis Mai 2011 zurückzuführen, wodurch der wuchsregulierende Effekt der Fungizidmaßnahmen deutlich schwächer ausfiel. Insgesamt war der in den eigenen Versuchen verfolgte Ansatz, den Ernteindex von Winterraps über eine chemische Wuchsregulierung zu steigern, nicht erfolgreich.

Die Grünfärbung des Pflanzenbestandes in BBCH 89 (NDVI_A5) wurde im Vergleich zur unbehandelten Kontrolle von allen Fungizidvarianten signifikant erhöht, wobei die Varianten V3 (Einmalbehandlung im Herbst und Frühjahr), V4, V5, und V6 die Abreife signifikant länger hinauszögerten als die Varianten V2 (Einmalbehandlung im Frühjahr) und V8 (vgl. Abb. 35). Die Unterschiede in der Grünfärbung des Pflanzenbestandes zwischen den verschiedenen Fungizidvarianten sind zum einen auf eine erhöhte Wirkstoffmenge der Wirkstoffe Paclobutrazol und Difenoconazol (V3-V6) und zum anderen auf die anderen Wirkstoffe Metconazol und Mepiquatchlorid, die in der praxisüblichen Variante verwendet wurden, zurückzuführen. Der „Greening“-Effekt ist bei 
der Wirkstoffkombination aus Metconazol und Mepiquatchlorid nicht so stark gewesen, da diese Kombination nur aus einem Triazol und nicht wie bei der Wirkstoffkombination aus Paclobutrazol und Difenoconazol aus zwei Triazolen bestand. Zwischen der Grünfärbung des Pflanzenbestandes in $\mathrm{BBCH} 89$ und dem Kornertrag bestand eine positive Beziehung, die bei näherer Betrachtung jedoch nur für die Einmalbehandlung mit der Wirkstoffkombination aus Paclobutrazol und Difenoconazol im Frühjahr (V2) sowie für die Einmalbehandlung mit derselben Wirkstoffkombination im Herbst (V7) zutraf. Allerdings führte die signifikant erhöhte Grünfärbung der Pflanzenbestände in $\mathrm{BBCH} 89$ in diesen beiden Varianten nicht zu einem signifikant höheren Kornertrag. In den anderen Varianten, insbesondere bei Variante 4, 5 und 6, überlagerte die ertragsreduzierende Einkürzung der Bestände, die positive Wirkung einer erhöhten Grünfärbung. Im Jahr 2010/11 war der Einfluss der Fungizide auf die Grünfärbung des Pflanzenbestandes in $\mathrm{BBCH} 89$ relativ gering. Einzig die Variante 4 führte im Vergleich zur unbehandelten Kontrolle (V1) zu einer signifikant erhöhten Grünfärbung. Dies hatte allerdings keinen Einfluss auf den Kornertrag.

Eine Erklärung für die beschriebenen Zusammenhänge zwischen Längenwachstum, Strohbiomasse und Kornertrag liefern die Befunde aus den Untersuchungen von RAO and MENDHAM (1991a) und RAO et al. (1991b). Die Autoren stellten fest, dass der Wirkstoff Paclobutrazol die Anzahl an Blüten und damit auch die Anzahl an Schoten $/ \mathrm{m}^{2}$ in Sommerraps erhöhte, wobei jedoch der Anteil an unproduktiven Schoten (abgestorbene Schoten, Kornanlagen in Schoten nicht ausdifferenziert) signifikant zunahm. Dies und eine signifikant verringerte Anzahl an Körner/Schote hatten zur Folge, dass der Kornertrag signifikant niedriger war als in der unbehandelten Kontrolle. Weiterhin führte der Einsatz des Wirkstoffes Paclobutrazol zu einer signifikanten Reduktion der Pflanzenhöhe und der oberirdischen Trockenmasse. RAO and MENDHAM (1991a) und RAO et al. (1991b) schlussfolgerten daraus, dass die Pflanzen insgesamt zu klein waren, um die zusätzlichen potenziellen Schoten ausreichend mit Assimilaten zu versorgen. Diese Schlussfolgerung kann auf die eigenen Versuche übertragen werden. Dabei wurde jedoch keine erhöhte Anzahl an Schoten $/ \mathrm{m}^{2}$ festgestellt, die eine stärkere Nachfrage nach Assimilaten erklärt hätte. Vielmehr deuten die niedrigere TKM in den Fungizidvarianten 5 und 6 (vgl. Tab. 16) und die niedrigere Anzahl an Körnern/Schote in Variante 6 (vgl. Tab. 27A im Anhang II) auf eine Unterversorgung mit Assimilaten hin. Auch wenn für Variante 4 keine signifikanten Unterschiede bei den einzelnen Ertragsfaktoren nachgewiesen werden konnte, ist trotzdem davon auszugehen, dass durch die starke Einkürzung des Stängelgewebes, auch in dieser Variante die Ertragsorgane nicht ausreichend mit Assimilaten versorgt wurden. FISAHN (1993) stellte in zwei von drei Versuchsjahren auch 
Mindererträge nach dem Einsatz von WR fest, die mit einem verringerten Strohgewicht einhergingen. Die verminderten Strohgewichte waren auf den verkürzten Stängel zurückzuführen, der innerhalb der Strohfraktion den größten Masseanteil ausmacht. Als mögliche Ursache nennt FISAHN (1993) ebenfalls eine zu starke Einkürzung des Stängels, wodurch die Zwischenlagerkapazität von Assimilaten im Sprossachsensystem vermindert wird und so die Assimilatversorgung von Schoten und Körnern eingeschränkt ist.

LUNN et al. (2003) stellten in ihren Untersuchungen sowohl Ertragssteigerungen als auch Ertragsreduktionen nach dem Einsatz der wachstumsregulierenden Fungizide Folicur $^{\circledR}$ (Tebuconazol) und Caramba $^{\circledR}$ (Metconazol) fest, wobei diese aufgrund hoher Standardfehler nur in sehr wenigen Fällen statistisch abgesichert werden konnten. Dennoch waren sie in der Lage eine lineare Beziehung zwischen der Bestandesentwicklung zum Applikationszeitpunkt und dem Kornertrag zu identifizieren. Unterdurchschnittlich entwickelte Pflanzenbestände, die zum Applikationstermin im März (Mitte März) einen GAl kleiner 0,5 oder im April (Mitte April) einen GAl kleiner 1 aufwiesen, reagierten auf die WR-Maßnahmen mit einem Ertragsrückgang. Demgegenüber wirkten sich in den meisten Fällen WR-Anwendungen bei überdurchschnittlich entwickelten Pflanzenbeständen (GAl im März größer 1 oder im April größer 2) positiv auf den Kornertrag aus. Als Grund für die Ertragsreduktionen nennen die Autoren eine durch die WR-Anwendungen induzierte Verringerung der Schotentrockenmasse sowie der gesamten oberirdischen Trockenmasse. Letzteres deckt sich mit den eigenen Befunden aus dem Versuchsjahr 2012/13. LUNN et al. (2003) schlussfolgerten aus ihren Ergebnissen, dass der Einsatz von wachstumsregulierenden Fungiziden erst ab einem bestimmten GAl (s.o.) sinnvoll ist. Aus diesem Grund suchten die Autoren nach einer einfachen, günstigen und schnellen Methode, um den GAI ermitteln zu können. Als beste Methode stellte sich die Erfassung der oberirdischen Frischmasse (FM) von einem Quadratmeter heraus. Dieser Parameter wies den höchsten Zusammenhang mit dem GAl auf $\left(R^{2}=0,90\right)$ und war zugleich von den Versuchsjahren, den Versuchsstandorten und den verwendeten Sorten unabhängig. Die entsprechende Regressionsgleichung lautete:

$$
\begin{aligned}
& G A I=0,0008 \times F M\left(F M \text { in } g / \mathrm{m}^{2}\right) \text { oder } \\
& G A I=0,8 \times F M\left(F M \text { in } \mathrm{kg} / \mathrm{m}^{2}\right)(\text { LUNN et al., 2003). }
\end{aligned}
$$

Somit entsprachen die von LUNN et al. (2003) ermittelten kritischen GAI-Grenzen, ab denen sich eine WR-Maßnahme positiv auf den Ertrag auswirkte, einer FM im März von $1,25 \mathrm{~kg} / \mathrm{m}^{2}$ oder einer FM im April von $2,5 \mathrm{~kg} / \mathrm{m}^{2}$. 
Die eigenen Ergebnisse sprechen ebenfalls gegen eine pauschale und für eine angepasste Anwendung von wachstumsregulierenden Fungiziden. Auch der wirtschaftliche Nutzen solcher Anwendungen war in den letzten Jahren nur noch selten gegeben (HAHN, 2013; KRULL, 2013; LANDWIRTSCHAFTSKAMMER NORDRHEIN-WESTFALEN, 2014). Daher sollten im Sinne einer Optimierung der WR-Maßnahmen, die von LUNN et al. (2003) identifizierten Beziehungen zwischen dem GAI vor der Blüte und dem Kornertrag sowie zwischen der FM und dem GAI, in Feldversuchen unter hiesigen Bedingungen und für in Deutschland zugelassene Winterrapssorten überprüft werden. Wenn sich diese Zusammenhänge bestätigen lassen, könnte im Frühjahr zu den bisher üblichen Behandlungsterminen, der oberirdische Pflanzenaufwuchs von einem Quadratmeter bestimmt werden und darüber eine Entscheidung für oder gegen eine wuchsregulierende Maßnahme getroffen werden. Als Hilfsmittel zur Ermittlung der FM pro Quadratmeter könnte die Rapool-N-Waage herangezogen werden (ANONYMUS, 2014a). Diese wird normalerweise dazu verwendet, um über die FM pro Quadratmeter, die vor dem Winter vom Pflanzenbestand aufgenommene N-Menge abzuschätzen und dementsprechend die N-Düngung im Frühjahr anzupassen. Die Rapool-N-Waage und der dazugehörige Beutel ermöglichen es, direkt im Feld das Gewicht der FM von einem Quadratmeter zu bestimmen. Um den Aufwuchs an Winterraps auf einem ganzen Ackerschlag beurteilen zu können, sollte die Bestimmung der FM an drei bis fünf repräsentativen Stellen im Feld wiederholt werden. Die vorherigen Erläuterungen machen deutlich, dass wuchsregulierende Fungizide im Winterraps nicht nur Ertragsvorteile, sondern auch Ertragsnachteile verursachen können und es sehr wichtig ist, deren Einsatz entsprechend der Witterung (Wasserhaushalt), dem Standort, der Lageranfälligkeit der Sorte und der Bestandesentwicklung- und dichte anzupassen.

\subsection{Einfluss des Phomabefalls auf den Ertrag}

So unterschiedlich die beiden Versuchsjahre im Witterungsverlauf und im maximalen Kornertrag waren, so unterschiedlich war auch der Befall der Rapspflanzen mit $P$. lingam. Im Jahr 2010/11 lag der durchschnittliche BW mit der Wurzelhals- und Stängelfäule zwischen 3 und 5 (3-4 am unteren Stängel, 4-5 am Wurzelhals) und 2012/13 zwischen 1 und 2, was bei einer Boniturskala von 1 bis 9 ( 1 = kein Befall, $9=$ Pflanze abgestorben), jeweils als ein mittlerer bzw. geringer Krankheitsdruck eingestuft werden konnte (vgl. die Daten zu den Phoma-Parametern vom Frühjahr in Tab. 26A und 27A im Anhang II). Der höhere Befall mit $P$. lingam im Jahr 2010/11 wirkte sich letztlich negativ auf den Kornertrag aus, wobei der BW mit der Wurzelhals- und Stängelfäule am Wurzelhals in 
BBCH 83/84 den stärksten, negativen, linearen Zusammenhang aufwies (vgl. Tab. 33). Durch multiple Regressionsanalysen wurde nachgewiesen, dass dieser Befallsparameter einen sehr schwachen, negativen Einfluss auf die Grünfärbung des Pflanzenbestandes in $\mathrm{BBCH} 73$ hatte (vgl. Abb. 24). Hier erklärt ein später erfasster Parameter einen früher erfassten Parameter, was in diesem Fall nicht als unlogisch anzusehen ist, da die Bonitur im BBCH-Stadium 83/84 nur eine Momentaufnahme des Befalls wiedergab, der sich je nach Witterungsbedingungen und Inokulumpotenzial sukzessive über die Vegetationsperiode entwickelte und somit auch schon in früheren Wachstumsstadien Schäden an den Rapspflanzen hervorgerufen hat. Schlussendlich kann festgehalten werden, dass der Wurzelhalsbefall mit $P$. lingam indirekt über die Grünfärbung des Pflanzenbestandes einen negativen Einfluss auf den Kornertrag hatte.

Im Versuchsjahr 2012/13 hatte der niedrige Befall mit der Wurzelhals- und Stängelfäule keinen negativen Einfluss auf den Kornertrag. Es wurden vielmehr sehr niedrige, positive Korrelationen zwischen dem Auftreten dieser Krankheit und dem Kornertrag nachgewiesen (vgl. Tab. 33). Die Hintergründe für die positiven Korrelationen werden am Ende von Kapitel 4.6 näher erläutert.

Die Wurzelhals- und Stängelfäule ist weltweit die wichtigste Krankheit im Winterraps (VON TiedemANN and STEINBACH, 2007). Nach Schätzung von FITT et al. (2008) beträgt der jährliche monetäre Verlust durch diese Rapskrankheit weltweit mehr als 900 Millionen USDollar. Besonders hohe Ertragsverluste treten v.a. in Europa, Australien und Nordamerika auf (WEST et al., 2001; HOWLETT, 2004), wobei diese bis zu 60\% betragen können (VON TiedemAnN and StEINBACH, 2007). Selbst ein Spätbefall in der Phase Rapsblüte bis Schotenbildung kann noch Ertragsverluste bis zu 15\% verursachen (VON TIEDEMANN and STEINBACH, 2007). Den weiter oben beschriebenen signifikanten, negativen, linearen Zusammenhang zwischen Wurzelhalsbefall und Kornertrag konnten z.B. auch KHANGURA \& BARBETTI (2002) in ihren Untersuchungen mit Sommerraps in Westaustralien nachweisen. Generell wird im weltweiten Rapsanbau dem Wurzelhalsbefall die größte ertragsreduzierende Wirkung zugeschrieben, da er neben massiven Ausfällen im Jungpflanzenstadium (SALISBURY et al., 1995; KHANGURA and BARBETTI, 1999), v.a. in den späteren Entwicklungsstadien nach dem Schossen der Rapspflanzen durch Vermorschung und Verkorkung zu Lager, Stängelbruch und vorzeitiger Abreife (Notreife) führen kann (HALL, 1992; HOWLETT et al., 2001; WEST et al., 2001; FITT et al., 2006). Besonders wenn es im Herbst bei einer anhaltend feucht warmen Witterung, zu einem zeitigen und massiven Blattbefall kommt, kann dies zu erheblichen Ertragsverlusten führen, da $P$. lingam dann optimale Bedingungen antrifft, um systemisch über den Blattstiel bis zum Wurzelhals zu wachsen (FITT et al., 1999; WEST et al., 2001; WHERRETT 
et al., 2004). Allerdings führt ein starker Blattbefall im Herbst nicht zwingend zu einem starken Wurzelhalsbefall im Frühjahr, so dass dieser Parameter nicht für eine exakte Vorhersage des potenziellen Ertragsausfalls geeignet ist. THÜRWÄCHTER (1995) und ZHOU et al. (1999) fanden durch ihre Untersuchungen heraus, dass erst wenige Wochen vor der Rapsernte, wenn das Ausmaß des Wurzelhalsbefalls und die damit verbundenen Notreifeerscheinungen sichtbar geworden sind, konkrete Befalls-Verlust-Relationen ermittelt werden können. Die vorzeitige Abreife der infizierten Rapspflanzen wirkt sich auf die Grünfärbung des Pflanzenbestandes aus, was in den hiesigen Untersuchungen durch die wöchentlichen GreenSeeker ${ }^{\circledR}$-Messungen als negative Beziehung zwischen dem Wurzelhalsbefall und der Grünfärbung des Pflanzenbestandes in $\mathrm{BBCH} 73$ festgestellt werden konnte.

\subsection{Einfluss von ausgewählten Bestandesparametern und Anbaufaktoren auf den Phomabefall}

Im Jahr 2010/11 wurde der ertragsrelevante Befall mit $P$. lingam am Wurzelhals primär durch die Pflanzendichte im Frühjahr in $\mathrm{BBCH}$ 16/18 beeinflusst. Dabei stieg der Wurzelhalsbefall mit abnehmender Pflanzendichte an (vgl. Abb. 36). Die varianzanalytischen Ergebnisse bestätigen die Regressionsanalysen, indem bei der niedrigen Aussaatstärke ein signifikant höherer Befall ( $\mathrm{BH}$ und $\mathrm{BW}$ ) mit $P$. lingam am Wurzelhals im BBCH-Stadium 83/84 vorlag als bei der hohen Aussaatstärke (vgl. Tab. 17).

Eine Erklärung für den negativen Zusammenhang zwischen der Pflanzendichte und der Infektion mit $P$. lingam am Wurzelhals liefert ein Vergleich mit dem Befall mit der Kleinen Kohlfliege (Delia radicum). Die BH mit der Kleinen Kohlfliege im BBCH-Stadium 83/84 war wie der Wurzelhalsbefall mit $P$. lingam bei der niedrigen Saatstärke signifikant höher als bei der hohen Saatstärke. Zudem konnte eine signifikante, schwach positive Korrelation $\left(r_{p}=0,305\right)$ zwischen diesen beiden Befallsparametern nachgewiesen werden. KEUNECKE (2009) konnte darlegen, dass der Larvenfraß der Kleinen Kohlfliege den PhomaWurzelhalsbefall durch Wundeffekte direkt begünstigt. Dabei war mehr die Fraßschädigung am Hypokotyl als an der Wurzel ausschlaggebend für eine signifikante Erhöhung des Phoma-Wurzelhalsbefalls. Dennoch ist $P$. lingam prinzipiell dazu in der Lage, auch verletzte Wurzeln von Raps zu infizieren (SOSNOWSKI et al., 2001; SPRAGUE et al., 2007), wobei das Inokulumpotenzial im Boden durch infektiöses Stoppelmaterial ausreichend hoch sein muss. Nach Ansicht von KEUNECKE (2009) kann nicht ausgeschlossen werden, dass systemisch bedingte Wurzelhalsnekrosen durch den 
Kohlfliegenbefall indirekt gefördert werden. Weiterhin fördern stängelminierende Schadinsekten (Großer Rapsstängelrüssler, Gefleckter Kohltriebrüssler, Rapserdfloh) den Phoma-Befall am Stängel (NDIMANDE, 1976; KRÜGER, 1982; NEWMAN \& PlumRIDGE, 1983; NeWMAN, 1984; SCHULZ \& DAEBELER, 1984; SCHULZ, 1992; UlBER, 1994; HARTLEB et al., 1998). Zudem begünstigt der Larvenfraß des Rapserdflohs den Befall mit $P$. lingam am Wurzelhals (NeWman and PlumRIDGe, 1983; NeWMan, 1984; SchUlz and DaEbeler, 1984). Eine Bekämpfung des Rapserdflohs mit Insektiziden führte zu einer deutlichen Verringerung des Phoma-Wurzelhalsbefalls (NEWMAN, 1984). In dem eigenen Versuch kann davon ausgegangen werden, dass ein Phoma-Wurzelhalsbefall im Herbst 2010 nicht durch den Larvenfraß des Rapserdflohs gefördert wurde, da die nass-kalte Witterung (vgl. Abb. 20), ein stärkeres Auftreten des Rapserdflohs verhinderte (SCHÖNBERGER, 2012). Eine gezielte Bekämpfung mit Insektiziden war nicht nötig.

Die niedrige BH mit der Kleinen Kohlfliege im Herbst 2010 (vgl. Tab. 17) verdeutlicht, dass sich der Befall im Frühjahr 2011 unabhängig vom Ausgangsbefall im Herbst entwickelt hat. Dies deckt sich mit Befunden von HÜNMÖRDER (2003) und KEUNECKE (2009), wonach im Frühjahr häufig mehr Pflanzen geschädigt werden als im Herbst. Die stärkere BH mit der Kleinen Kohlfliege in der niedrigen Aussaatstärke ist darauf zurückzuführen, dass die Einzelpflanzen bei einer niedrigen Saatstärke normalerweise stärker entwickelt sind als bei einer hohen Saatstärke. Aufgrund des größeren Standraumes stehen den Einzelpflanzen mehr Nährstoffe, Wasser und Licht zur Verfügung, wodurch diese u.a. einen größeren Wurzelhals- sowie basalen Stängeldurchmesser ausbilden. Solche gut entwickelten Pflanzen stellen einen optischen Reiz für die Kohlfliege dar, der ihnen vermittelt, dass es sich bei diesen Pflanzen um eine gute Nahrungsquelle handelt. Die Kohlfliegenweibchen wählen vermehrt diese Pflanzen für ihre Eiablage aus, wodurch letztlich auch eine stärkere Schädigung durch den Larvenfraß eintritt (DOSDALL et al., 1996). Es gibt weitere optische Reize, wie die Farbe (hell/dunkelgrün) und die Pflanzengröße, die ebenfalls die Auswahl der Wirtspflanze durch die Kleine Kohlfliege beeinflussen (ABU-YAMAN, 1960; TRAYNIER, 1967; ROESSINGH and STÄDLER, 1990; KoŠŤ́́, 1993). Neben den optischen Reizen stimulieren auch olfaktorische Reize die Kohlfliege bei der Suche nach einer geeigneten Wirtspflanze. Hier spielen v.a. die Senföle, die durch Hydrolyse von Glukosinolaten entstehen, eine wesentliche Rolle (TRAYNIER, 1965; FINCH, 1978; BAUR et al., 1996a; BAUR et al., 1996b). Abschließend sollte auch in Betracht gezogen werden, dass den Kohlfliegen bei einer niedrigen Saatstärke nicht so viele Pflanzen als Nahrungsgrundlage zur Verfügung stehen wie bei einer hohen Saatstärke. Dies kann bei einer hohen Schaderregerpopulation dazu führen, dass fast alle Pflanzen befallen werden und die Befallsstärke an den einzelnen Pflanzen 
stärker ausgeprägt ist. Bei einer hohen Saatstärke muss dies nicht zwingend der Fall sein, da die Kleine Kohlfliege eine größere Auswahl an Wirtspflanzen hat. Zudem kann eine normale Bestandesdichte den Ausfall einzelner Pflanzen besser kompensieren als ein Bestand mit ohnehin sehr geringer Pflanzendichte (DöRING, 2014).

Den zweitstärksten Einfluss auf den Wurzelhalsbefall mit $P$. lingam hatte der Phomabefall am unteren Stängel. Dieser wurde wiederum von anderen Phoma-Befallsparametern (BH am unteren Stängel bzw. am Wurzelhals) primär positiv beeinflusst (vgl. Abb. 36). Diese positiven Beziehungen zwischen einzelnen Befallsparametern von Phoma (BW oder Befallsstärke und $\mathrm{BH}$ ) stellen nichts Außergewöhnliches dar und wurden schon in früheren Arbeiten (XI et al., 1990; XI et al., 1991; REMPEL et al., 1991; ZHOU et al., 1999; Sun et al., 2000) nachgewiesen. Der hier vorgefundene positive Zusammenhang zwischen dem Befall mit $P$. lingam am Wurzelhals und am unteren Stängel deckt sich mit den Ergebnissen von BRAZAUSKIENE \& PETRAITIENE (2006). Diese fanden in zweijährigen Untersuchungen über die epidemiologische Entwicklung von $P$. lingam Infektionen u.a. heraus, dass sich ein Befall an Winterraps hauptsächlich in einer Doppelinfektion am Wurzelhals sowie am darüber liegenden Stängelbereich äußert. Dass sowohl Wurzelhals und darüber liegender Stängelbereich infiziert werden, ist auf den Ausgangsbefall im Herbst und das anschließende systemische Wachstum des Pathogens zurückzuführen: Der Pilz breitet sich ausgehend von den Blattläsionen über die Petiolen ins Hypokotyl und den Wurzelhals aus. HAMMOND et al. (1985) beschrieben erstmals, dass der Pilz unter befallsfördernden Bedingungen zu diesem systemischen Wachstum befähigt ist.

Aus der Abb. 36 wird weiterhin ersichtlich, dass der Phomabefall am unteren Stängel auch durch die Bestandeshöhe in $\mathrm{BBCH} 73 / 74$ positiv beeinflusst wurde. Hierbei handelt es sich um eine Scheinkorrelation, die durch die Doppelfunktion der eingesetzten Fungizide zustande gekommen ist. Diese haben sowohl eine fungizide als auch eine wachstumsregulatorische Wirkung. So konnte mit steigender Wirkstoffmenge von der Wirkstoffkombination aus Paclobutrazol (WR-Wirkung) und Difenoconazol (fungizide Wirkung) nicht nur eine zunehmende stauchende Wirkung, sondern auch eine zunehmend bessere Wirksamkeit gegen $P$. lingam festgestellt werden.

Die Bekämpfung der Wurzelhals- und Stängelfäule durch Fungizide wird im Folgenden nur kurz diskutiert, da dies nicht der Schwerpunkt der vorliegenden Arbeit war. Mit der Wirkstoffkombination aus Paclobutrazol und Difenoconazol konnte im Jahr 2010/11, unabhängig von den Behandlungsvarianten, der BW mit der Wurzelhals- und Stängelfäule am unteren Stängel signifikant reduziert werden. Die Wirkung gegen $P$. lingam geht dabei ausschließlich von dem Wirkstoff Difenoconazol aus. Weiterhin war die Wirkung von Difenoconazol signifikant besser als die der Wirkstoffe Tebuconazol und Metconazol, die 
in der praxisüblichen Variante (V8) eingesetzt wurden (vgl. Tab. 17). Ebenso wurden signifikante Unterschiede bei der Wirkung gegen $P$. lingam am Wurzelhals festgestellt. Hierbei reduzierten aber nur die Varianten wirkungsvoll den Befall am Wurzelhals, bei denen schon im Herbst eine Applikation mit Difenoconazol erfolgte. Diese Varianten waren wiederum der praxisüblichen Variante überlegen und zeigten untereinander keine verschiedene Wirksamkeiten. Obwohl bei der Fungizidvariante 5 auch eine Behandlung im Herbst durchgeführt wurde, reduzierte diese, im Vergleich zur unbehandelten Kontrolle (V1) und praxisüblichen Variante, nicht signifikant den Befall mit $P$. lingam am Wurzelhals (vgl. Tab. 17). Für dieses Ergebnis gibt es keine plausible Erklärung. Denkbar wäre es, dass z.B. bei einer der drei Applikationen in dieser Variante technische Probleme bei der Spritzung aufgetreten sind, wodurch weniger Wirkstoff auf die Pflanzen ausgebracht wurde. Die schlechte Wirksamkeit der Praxisvariante gegenüber der Wurzelhals- und Stängelfäule hängt zum einen mit einer anscheinend zu niedrig gewählten Aufwandmenge bei dem Produkt Folicur ${ }^{\circledR}$ (Herbstanwendung) und zum anderen mit einem zu niedrigen Wirkstoffgehalt von Metconazol im Produkt Carax ${ }^{\circledR}$ (Frühjahrsanwendung) zusammen. Bei einer Aufwandmenge von 0,6 I/ha Folicur ${ }^{\circledR}$ werden $150 \mathrm{~g} / \mathrm{ha}$ von dem Wirkstoff Tebuconazol ausgebracht. Bedingt durch den jahrelangen Einsatz von Tebuconazol hat sich eine quantitative Fungizidresistenz (Shifting) ausgebildet, wodurch die genannte Wirkstoffmenge mittlerweile nicht mehr ausreicht, um P. lingam erfolgreich zu bekämpfen (SCHÖNBERGER, 2012). Dem Autor zu Folge liegt die derzeitige Mindestaufwandmenge bei $175 \mathrm{~g} / \mathrm{ha}$ Tebuconazol. Ende der 90iger Jahre reichten noch $100 \mathrm{~g} / \mathrm{ha}$ Tebuconazol, um im 2- bis 4-Blatt-Stadium den Befall am Wurzelhals zu unterbinden (SCHÖNBERGER, 2012). Das Produkt Carax ${ }^{\circledR}$ enthält die Wirkstoffe Mepiquatchlorid und Metconazol, wobei das Metconazol ausschließlich für die fungizide Wirkung des Produktes verantwortlich ist. Dieser Wirkstoff ist aus dem Produkt Caramba $^{\circledR}$ bekannt, dass seit vielen Jahren im Raps zur Wuchsregulierung und zur Kontrolle von Phoma eingesetzt wird. Im Vergleich zu Caramba ${ }^{\circledR}$ enthält Carax ${ }^{\circledR}$ nur den halben Wirkstoffgehalt von Metconazol (30 g), wodurch dieses eine grundsätzlich geringere Wirkung gegen Phoma aufweist. Ferner hat der langjährige Einsatz dieses Azolwirkstoffs, wie beim Tebuconazol, zu einem Shifting geführt. Dadurch ist derzeit eine Wirkstoffmenge von $50 \mathrm{~g} / \mathrm{ha}$ erforderlich, um $P$. lingam effektiv bekämpfen zu können (SCHÖNBERGER, 2012). Von den Difenoconazolvarianten, die signifikant den Befall mit der Wurzelhals- und Stängelfäule am unteren Stängel sowie am Wurzelhals reduzierten, zeigte die Variante 4, mit der Doppelbehandlung im Herbst, den größten Effekt gegen $P$. lingam. Durch die zweifache Behandlung im 4- und 6-Blatt-Stadium (BBCH $14+16$ ) verlängerte sich der Wirkungszeitraum gegen $P$. lingam, wodurch später auftretende Blattinfektionen gestoppt werden konnten. Das Pathogen war nicht in der Lage früh in den 
Wurzelhals einzuwachsen. Dadurch fiel die Schädigung am Wurzelhals in BBCH 83/84 geringer aus, als in den Varianten, in denen im Herbst nur einmal Difenoconazol eingesetzt wurde. Gleiches konnte KRUSE (2004) bei einer Doppelbehandlung im Herbst mit dem Wirkstoff Tebuconazol feststellen. Dass der Phoma-Blattbefall im Herbst einen hohen Einfluss auf den Wurzelhalsbefall im Frühjahr haben kann, wurde u.a. von GLAdDERS \& MUSA (1980), HAMMOND \& LeWIS (1986), GARBE (1998), SUN et al. (2000) und KRUSE (2004) nachgewiesen. Nach HALL (1992) werden die stärksten Ertragsverluste durch Wurzelhalsbefall hervorgerufen, wenn sich dieser aus einer Blattinfektion im Keimblatt bis 8-Blatt-Stadium entwickelt. Obwohl in den meisten Fungizidvarianten mit der Wirkstoffkombination aus Paclobutrazol und Difenoconazol eine signifikante Reduktion des Befalls mit der Wurzelhals- und Stängelfäule am Wurzelhals bzw. am unteren Stängel erzielt werden konnte, hatte dies nur einen geringen ertragssteigernden Effekt. Dies deckt sich mit Befunden von THÜRWÄCHTER (1995); SCHMIEDEL \& KÖPPL (1996), WOHLLEBEN (2001) und KRUSE (2004), die mit anderen Wirkstoffen gute Bekämpfungserfolge gegen Phoma erzielen konnten, wobei dies aber insgesamt auch nur einen geringen Einfluss auf die Ertragsleistung hatte. GARBE (2000) weist daraufhin, dass bei schwachem bis mittlerem Befallsniveau die Befallsverminderungen durch den Einsatz von Fungiziden relativ betrachtet geringer ausfallen als bei einem höheren Befallsniveau und dadurch niedrigere Ertragssteigerungen die Folge sind als bei einem hohen Befallsniveau. Da in dem eigenen Versuch ein mittleres Befallsniveau vorlag, stellt dies eine potenzielle Erklärung für die niedrigen Ertragseffekte der Fungizidanwendungen dar.

Im Versuchsjahr 2012/13 war der Befall mit der Wurzelhals- und Stängelfäule nicht besonders hoch. Der Kornertrag wurde daher nicht negativ beeinflusst. Vielmehr wurden sehr niedrige, positive Korrelationen zwischen dem Auftreten dieser Krankheit und dem Kornertrag nachgewiesen (vgl. Tab. 33). Dieser auf den ersten Blick unlogische Zusammenhang lässt sich dadurch erklären, dass die eingesetzten Fungizide sowohl eine fungizide als auch wachstumsregulatorische Wirkung besitzen und beide Effekte immer gleichzeitig zum Tragen kommen. Somit konnte mit steigender Wirkstoffmenge von der Wirkstoffkombination aus Paclobutrazol (WR-Wirkung) und Difenoconazol (fungizide Wirkung) nicht nur eine zunehmende stauchende Wirkung, sondern auch eine zunehmend bessere Wirksamkeit gegen $P$. lingam festgestellt werden. Hier sind die Doppelbehandlung im Herbst (V4), die Doppelbehandlung im Frühjahr (V5) und die Doppelbehandlung im Herbst und Frühjahr (V6) mit signifikanten Befallsreduktionen hervorzuheben, wobei diese auf einem sehr niedrigen Befallsniveau auftraten (vgl. Tab. 27A im Anhang II). Bedingt durch die Tatsache, dass im Jahr 2012/13 eine zunehmende Stauchung der Bestände, v.a. in den Fungizidvarianten 4, 5 und 6, eine signifikante 
Ertragsreduktion zur Folge hatte, erklärt sich nun, warum der Befall mit $P$. lingam sehr schwach positiv mit dem Kornertrag korreliert war. Die weniger gestauchten Bestände, die einen etwas höheren aber nicht ertragsrelevanten Befall mit der Wurzelhals- und Stängelfäule aufwiesen, erzielten schlussendlich den höheren Kornertrag.

\subsection{Einfluss der Ertragsfaktoren auf die Ertragsbildung im Winterraps}

Der Kornertrag von Winterraps je Fläche ist das Produkt aus der Pflanzenzahl $/ \mathrm{m}^{2}$ (Pflanzendichte oder Bestandesdichte), der Anzahl Schoten/Pflanze, der Anzahl Körner/Schote und der Tausendkornmasse (TKM). Von diesen vier primären Ertragsfaktoren lassen sich weitere sekundäre Ertragsfaktoren (z.B. Körner/Pflanze, Schotendichte $=$ Schoten $/ \mathrm{m}^{2}$ und Korndichte $=$ Körner $/ \mathrm{m}^{2}$ ) ableiten, womit die Ertragsstruktur von Winterraps näher beschrieben werden kann (vgl. Abb. 2) (DiEPENBROCK, 2000). Die Seitentriebe/Pflanze zählen nicht zu den klassischen Ertragskomponenten. Da allerdings die Schotenzahl pro Pflanze in enger, positiver Beziehung zur Anzahl Seitentriebe/Pflanze steht und die Zahl der Seitentriebe/Pflanze wiederum negativ von der Pflanzendichte abhängig ist (GEISLER \& HENNING, 1981a; MENDHAM et al., 1981b; SCARISBRICK et al., 1982; STOY, 1983), haben diese ebenfalls eine wichtige Rolle in der Ertragsbildung von Winterraps. Im Rahmen dieser Arbeit wurden alle vier primären Ertragsfaktoren sowie die Anzahl Seitentriebe/Pflanze erfasst, um den jeweiligen Beitrag der einzelnen Faktoren zum Kornertrag feststellen zu können. Mit Hilfe der einfachen, linearen Regressionsanalyse wurde überprüft, welcher Ertragsfaktor am stärksten positiv oder negativ den Kornertrag beeinflusst hat und wie die Ertragsfaktoren untereinander korreliert waren. Im Versuchsjahr 2010/11 hatte von allen Ertragsfaktoren die Pflanzendichte im Frühjahr in BBCH 16/18 den stärksten positiven Einfluss auf den Kornertrag. Dies stimmt mit den Ausführungen von DIEPENBROCK and Grosse (1995) und DiePENBROCK (2000) überein, die die Pflanzendichte als den wichtigsten Ertragsfaktor definiert haben. Die anderen drei klassischen Ertragsfaktoren Schoten/Pflanze, Körner/Schote und TKM waren negativ mit dem Kornertrag korreliert (vgl. Tab. 37), was auf die negativen Beziehungen zwischen diesen drei Faktoren und der Pflanzendichte zurückzuführen ist (vgl. Tab. 69A im Anhang II). Die hier identifizierten negativen Zusammenhänge zwischen Pflanzendichte und Schoten/Pflanze, Körner/Schote sowie TKM stimmen mit den Ergebnissen von GEISLER \& HENNING (1981a), SCARISBRICK et al. (1982), JeNKINS \& LEITCH (1986), GEISLER \& STOY (1987), SieRTS et al. (1987), CHAY \& THURLING (1989) und LEACH et al. (1999) überein. Die höheren Kornerträge bei der Saatstärkenvariante mit 60 Körnern $/ \mathrm{m}^{2}$ sind das Resultat von 
einer erhöhten Schotendichte, die mit steigender Pflanzendichte zunahm. Diese Zusammenhänge wiesen MENDHAM et al. (1981b), GEISLER and STOY (1987) und HABEKOTTÉ (1993) in ihren Untersuchungen ebenfalls nach. Neben der Schotendichte nahm auch die Korndichte mit steigender Pflanzendichte zu, wobei die Korndichte einen etwas geringeren, positiven Einfluss auf den Kornertrag $\left(r_{p}=0,274\right)$ hatte als die Schotendichte $\left(r_{p}=0,342\right)$. Für SCHÖNBERGER (2012) liegen bei einem Ertragsniveau von 4,5-6,0 t/ha die größten Ertragsreserven in der Korndichte bzw. in der Schotendichte. Nach Ansicht des Autors muss die Produktionstechnik in diesem Bereich ansetzen. Da beide sekundären Ertragsfaktoren primär von der Pflanzendichte abhängig sind, stellt die Saatstärke die entscheidende produktionstechnische Größe dar.

Bedingt durch die stärkeren Auswinterungsverluste bei SY Merlot, wies diese Sorte eine signifikant niedrigere Pflanzendichte, Schotendichte und Korndichte auf als NK Petrol. Dafür war bei SY Merlot die TKM signifikant höher als bei NK Petrol, da durch die niedrigere Pflanzendichte die intraspezifische Konkurrenz um Assimilate nicht so stark ausgeprägt war. Als weiterer Grund für die sortenbedingten Unterschiede bei der TKM, kommt die hohe genetische Variabilität der TKM in Frage (SCHÖNBERGER, 2012).

Im Jahr 2012/13 hatten von den primären Ertragsfaktoren nur die Pflanzendichte und die TKM einen signifikanten Einfluss auf den Kornertrag. Beide Faktoren beeinflussten den Kornertrag positiv, wobei von der Pflanzendichte eine höhere Wirkung ausging (vgl. Tab. 38). Insgesamt waren in diesem Jahr die Einflüsse der Ertragsfaktoren wesentlich niedriger als im Jahr 2010/11. Vermutlich ist dies darauf zurückzuführen, dass durch die geringeren Pflanzenverluste über Winter genügend Pflanzen $/ \mathrm{m}^{2}$ vorhanden waren und zum anderen die günstigen Witterungsverhältnisse während der Ausbildung der generativen Organe zu keinem starken Abwurf von Schoten oder Körnern geführt haben. $\mathrm{Da}$ in diesem Jahr recht homogene Bestandesdichten vorlagen und kaum Verluste über Winter zu beklagen waren, sind die Sortenunterschiede bei der TKM auf die ausgeprägte genetische Variabilität dieses Ertragsfaktors zurückzuführen. Die signifikant reduzierte TKM in den Fungizidvarianten 5 und 6 ist das Resultat von zu stark eingekürzten Beständen und der damit verbundenen verringerten Zwischenlagerkapazität von Assimilaten (RAO and MENDHAM, 1991a; RAO et al., 1991b; FISAHN, 1993). Einzelheiten zu dieser Begründung finden sich im Kapitel 4.4.

Für die Anzahl Seitentriebe/Pflanze wurde in beiden Versuchsjahren eine stärkere negative Beziehung mit der Pflanzendichte (vgl. Tab. 69A im Anhang II) nachgewiesen. Dieses Ergebnis stimmt mit den Befunden von GeISLER and HENNING (1981a), MENDHAM et al. (1981b), SCARISBRICK et al. (1982), STOY (1983) und RAO and MENDHAM (1991a) überein. In beiden Jahren waren die Seitentriebe/Pflanze negativ mit dem Kornertrag 
korreliert, wobei dies im Jahr 2010/11 ausgeprägter war als im Jahr 2012/13. Daraus ließ sich für jedes Versuchsjahr, entsprechend der individuellen Witterungsbedingungen ein Optimum für die Pflanzendichte und die Anzahl Seitentriebe/Pflanze ableiten [vgl. Abb. 39 (2010/11) und Abb. 40 (2012/13)]. Für das Jahr 2010/11 lag das Optimum bei einer Pflanzendichte von ca. 40 Pflanzen $/ \mathrm{m}^{2}$ und ca. 8 Seitentrieben/Pflanze. Im Jahr 2012/13 lag es bei ca. 45 Pflanzen $/ \mathrm{m}^{2}$ und ca. 7 Seitentrieben/Pflanze. Nach SCHÖNBERGER (2012) können nur dann überdurchschnittliche Erträge erzielt werden, wenn die Einzelpflanze mindestens 7-8 Verzweigungen bilden kann. Speziell das Jahr 2010/11 zeigte, dass Erträge über 4,5 tha nur mit einer erhöhten Bestandesdichte, nicht aber mit einer erhöhten Verzweigung erzielt werden konnten (vgl. Abb. 39). Hieraus kann abgeleitet werden, dass bei Unterschreitung einer bestimmten Pflanzendichte die verbliebenen Pflanzen nicht in der Lage sind, durch eine erhöhte Seitentriebbildung einen Ertragsausgleich zu schaffen. Da diese Aussage für das Jahr 2012/13 nicht gilt, bedarf es weiterer Untersuchungen, um diese These wissenschaftlich untermauern zu können. Generell konnte festgestellt werden, dass bei einer Erhöhung der Aussaatstärke um den Faktor 2, im Durchschnitt ca. 2 Seitentriebe/Pflanze weniger ausgebildet wurden [vgl. Tab. 15 (2010/11) bzw. Tab. 16 (2012/13)]. Die von BAYLIS \& HUTLEY-BULL (1991) und ZHOU and XI (1993) beschriebene Erhöhung der Seitentriebzahl nach dem Einsatz des Wirkstoffs Paclobutrazol wurde in der vorliegenden Arbeit beim überwiegenden Teil der verschiedenen Fungizidbehandlungen nicht beobachtet. Einzig im Jahr 2010/11 konnte durch die Variante 4, bei der zweimal im Herbst und einmal im Frühjahr die Wirkstoffkombination aus Paclobutrazol und Difenoconazol eingesetzt wurde, die Seitentriebzahl im Vergleich zur unbehandelten Kontrolle signifikant um ca. 2 Seitentriebe erhöht werden. Diese Erhöhung wirkte sich jedoch nicht positiv auf den Kornertrag aus und widersprach damit den Ergebnissen von ZHOU and XI (1993). Insgesamt kann aus den vorliegenden Ergebnissen der Schluss gezogen werden, dass die Reduktion der Bestandeshöhe durch wuchsregulierende Fungizide nicht die Seitentriebbildung der Einzelpflanzen verbessert hat. Die verwendeten Hybridsorten hatten keinen signifikanten Einfluss auf die Seitentriebbildung der Rapspflanzen. Beim Vergleich der Jahresmittelwerte der primären Ertragsfaktoren, der Schotendichte und der Anzahl an Seitentrieben/Pflanze (vgl. Tab. 73A im Anhang II) zeigte sich wiederum, welch hohe Plastizität die Ertragsstruktur von Raps aufweist (DIEPENBROCK and GROSSE, 1995; DIEPENBROCK, 2000). 


\subsection{Bewertung der statistischen Analyseverfahren}

In der vorliegenden Arbeit wurden zur Analyse der Zusammenhänge zwischen den einzelnen Parametern die Verfahren der einfachen, linearen Regressionsanalyse, der schrittweisen multiplen Regressionsanalyse und die Hauptkomponentenanalyse (principal component analysis $=\mathrm{PCA}$ ) verwendet. Primäres Ziel dabei war es, das für die Auswertung des Datensatzes beste statistische Analyseverfahren zu wählen. Es stellte sich heraus, dass die multiple Regressionsanalyse, mit der schrittweisen Aufnahme der Parameter die geeignetste Methode war. Hiermit konnte am einfachsten ermittelt werden, von welchen Parametern der Kornertrag am stärksten abhing. Dass dieses Verfahren sich als das beste herausgestellt hat ist nicht verwunderlich, denn schließlich basiert es darauf, die Zusammenhänge zwischen einer (abhängigen) Variablen (Zielvariable) auf der einen Seite und mehreren (erklärenden) Variablen (erklärende Parameter) auf der anderen Seite aufzuzeigen (BRosIUS, 2007). Man erhält ein Regressionsmodell, in das schrittweise und in Abhängigkeit vom gewählten Signifikanzniveau all die Parameter aufgenommen werden, die am besten die Varianz im Datensatz der Zielvariablen erklären. Dabei kann direkt an den partiellen $\mathrm{R}^{2}$-Werten abgelesen werden, wie gut sich die Werte der Zielvariablen tatsächlich anhand der Werte aus den erklärenden Parametern herleiten lassen (BRosius, 2007). Ferner kann anhand der Kennzahl des standardisierten Schätzers festgestellt werden, ob der entsprechende Parameter negativ oder positiv mit der Zielvariablen korreliert ist. Es werden bei diesem Verfahren auf eine schnelle Art und Weise alle nötigen Kennzahlen ausgegeben, um die Zusammenhänge zwischen der Zielvariablen und den erklärenden Parametern interpretieren zu können. Die einfache, lineare Regressionsanalyse dient dazu, die Beziehungen zwischen einer Zielvariablen und nur einem Parameter festzustellen. Sie war in der vorliegenden Arbeit geeignet, um einen ersten Überblick über die Korrelationen zwischen den einzelnen Parametern und der jeweiligen Zielvariablen zu bekommen. Um aber unter dem Einfluss aller Parameter den einen Parameter zu selektieren, der die Zielvariable am stärksten beeinflusst, eignet sich dieses Verfahren nicht. Weiterhin kann hiermit auch keine Rangfolge zwischen den Parametern festgestellt werden, da eben nur ein erklärender Parameter zur Verfügung steht. Grundsätzlich werden bei dieser Analysemethode Kennzahlen (Korrelationskoeffizient, Bestimmtheitsmaß) ausgegeben, die sofort eine Interpretation des Zusammenhangs ermöglichen. Beim Vergleich der Ergebnisse der einfachen, linearen Regressionen mit den jeweiligen multiplen Regressionen wurde festgestellt, dass bei beiden Verfahren unabhängig voneinander immer die gleichen Parameter mit dem stärksten und zweitstärksten Einfluss auf die Zielvariable ermittelt wurden. Dadurch konnte die einfache, lineare Regression auch dazu genutzt werden, um die Ergebnisse 
der multiplen Regression zu überprüfen. Bedingt durch die unterschiedliche Anzahl an Parametern, die in beide Verfahren einfließen, waren nur die Werte der Bestimmtheitsmaße für den Parameter mit dem stärksten Einfluss bei beiden Methoden annähernd identisch. Die PCA und die damit verbundene visuelle Ausgabe der Ergebnisse in Form eines Biplots stellte im Hinblick auf die Fragestellungen dieser Arbeit keine geeignete Methode für die Datenauswertung dar. Das ist darauf zurückzuführen, dass bei diesem Verfahren keine Zielvariable vorgegeben wird. Somit ist auch keine gezielte Analyse der Zusammenhänge zwischen einer oder mehreren erklärenden Variablen und einer Zielvariablen möglich. Weiterhin werden bei diesem Verfahren keine konkreten Kennzahlen, wie Korrelationskoeffizienten oder Bestimmtheitsmaße ausgegeben, die die Beziehungen zwischen den Parametern beschreiben. Die PCA ist in erster Linie ein Instrument zur Datenreduktion, bei der aus ursprünglichen Daten (Variablen, hier Parameter) neue latente Variablen, sogenannte Hauptkomponenten (HK), berechnet werden (SCHNELL, 1994). Dabei stellen die HK Linearkombinationen aus den ursprünglichen Variablen dar und die erste HK nimmt den größten Anteil der Varianz im gesamten Datensatz auf, die zweite HK das Maximum der verbleibenden Varianz usw. (SCHNELL, 1994). Ziel ist es, mit möglichst wenigen HK die komplette Varianz im Datensatz erklären zu können. Anhand der Faktorladungen, die eine Maßgröße für den Zusammenhang zwischen ursprünglichen Variablen und der jeweiligen HK darstellen (BACKHAUS et al., 1996), kann nachvollzogen werden, welche Ausgangsvariablen am stärksten die jeweilige HK beeinflussen und somit am stärksten für die Varianz im Datensatz verantwortlich sind. Diese Originaldaten können dann für weitere Analysen verwendet werden. Demnach dient eine PCA dazu, umfangreiche Datensätze zu strukturieren bzw. zu vereinfachen und möglichst wenige, bedeutsame Variablen zu selektieren. Indem die Ergebnisse einer PCA durch einen Biplot visualisiert werden, kann man schnell erkennen, welche Variablen besonders gut mit den HK korrelieren und wie stark sie diese beeinflussen. Werden allerdings, wie in dieser Arbeit, viele Variablen (Parameter) untersucht und kommen viele Kombinationen von Versuchsfaktoren zum Einsatz, so wird ein Biplot schnell unübersichtlich. Dann ist zur endgültigen Interpretation des Biplots die Faktorladung jedes Parameters von besonderer Bedeutung. Weiterhin werden in einem Biplot auch die Zusammenhänge zwischen den einzelnen Parametern wiedergeben. Da aber weitere Kennzahlen für die genaue Beschreibung der Korrelationen fehlen, bietet dieser nur einen grundlegenden Überblick über die Korrelationen zwischen den Parametern. Genaue fundierte Aussagen sind nicht möglich.

Wie zuvor dargelegt, stellte die multiple Regressionsanalyse mit der schrittweisen Parameteraufnahme, das beste Verfahren dar, um Abhängigkeiten zwischen mehreren 
erklärenden Parametern und einer Zielvariable zu identifizieren. Hierbei muss aber berücksichtigt werden, dass auch ein noch so hohes (partielles) $R^{2}$ nicht auf einen kausalen Zusammenhang zwischen den erklärenden Parametern und der Zielvariablen schließen lässt. Ein hohes (partielles) Bestimmtheitsmaß besagt lediglich, dass die erklärenden Parameter und die Zielvariable so stark miteinander korreliert sind, dass die Werte der erklärenden Parameter (zumindest in den zugrunde liegenden Daten) recht zuverlässige Rückschlüsse auf die Werte der Zielvariablen ermöglichen. Warum das so ist, kann allein aus den statistischen Berechnungen nicht abgelesen werden. Deshalb ist es besonders wichtig, jedes Ergebnis einer Regressionsanalyse einer inhaltlichen Plausibilitätsprüfung zu unterziehen. Die vorgefundenen Zusammenhänge, sollten unabhängig von der Stärke des Zusammenhangs logisch erklärbar sein und nicht dem gesunden Menschenverstand widersprechen (BROsIUS, 2007).

\subsection{Abschließende Bewertung der Feldversuche}

In Abb. 41 sind die wesentlichen Zusammenhänge zwischen Bestandesaufbau und Ertrag vergleichend für die beiden Versuchsjahre dargestellt. Diese Zusammenhänge wurden in der vorliegenden Arbeit ermittelt und beschrieben. Die Abb. 41 soll noch einmal hervorheben, welche Bestandesparameter den Ertrag beeinflussten und welchen Stellenwert die unterschiedlichen Parameter im jeweiligen Versuchsjahr hatten. Es wird deutlich, dass die Jahreswitterung die Zusammenhänge zwischen Bestandesarchitektur und Kornertrag besonders stark beeinflusste. Ferner wird klar, welche bedeutende Rolle die Saatstärke und wachstumsregulatorische Fungizide im Bestandesaufbau spielen können. Letztendlich lassen sich die beiden Versuchsjahre in Bezug auf den Standort Göttingen einmal als ungünstiges (2010/11) und einmal als günstiges (2012/13) Rapsjahr typisieren. 

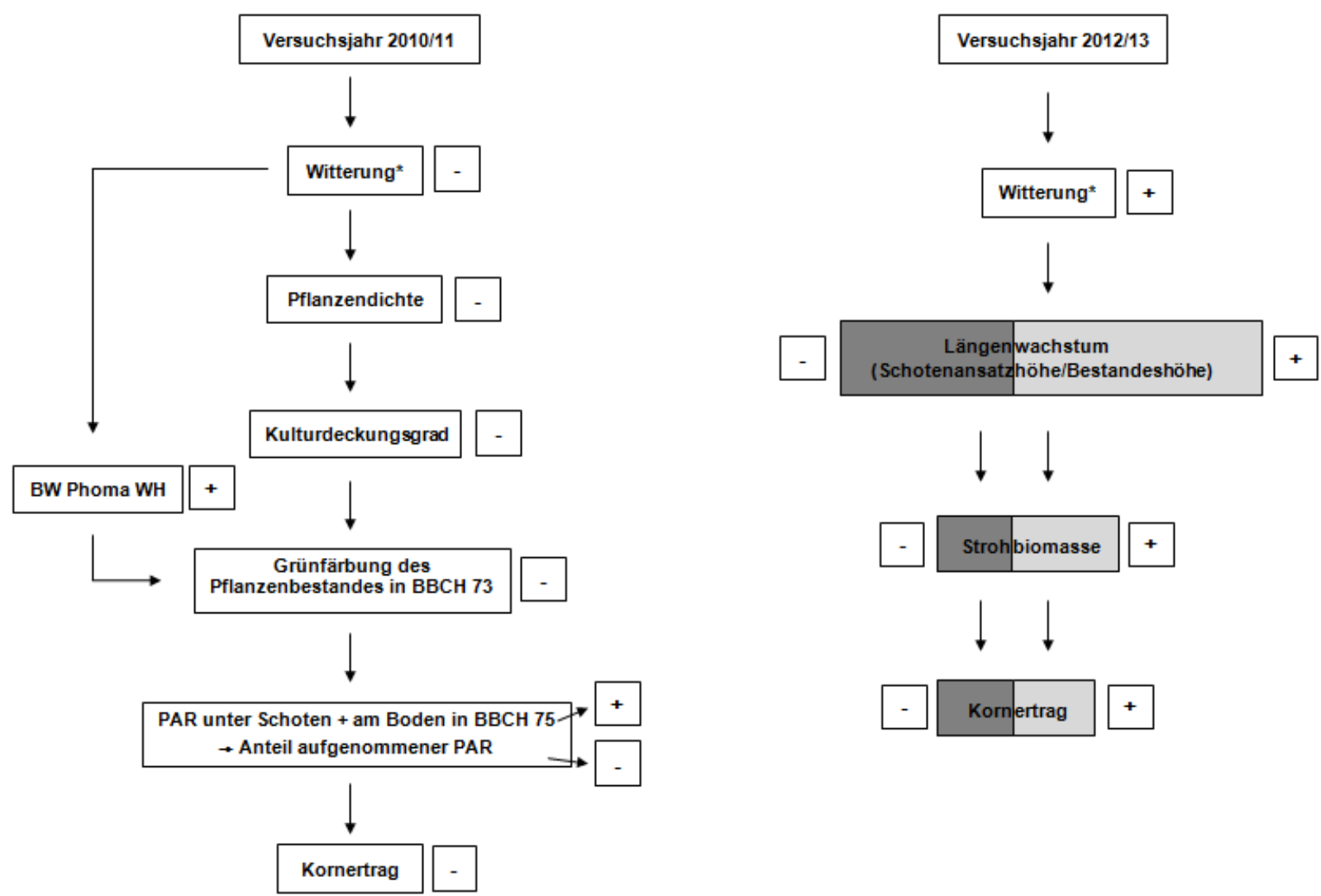

Abb. 41: Wesentliche, im Feldversuch in Göttingen, identifizierte Zusammenhänge zwischen Bestandesaufbau und Kornertrag. *Witterung 2010/11 schlecht: nass, kalter Herbst, kalter schneereicher Winter, kaum Niederschlag und warme Temperaturen im Frühjahr (März-Mai); Witterung 2012/13 gut: milder, trockener Herbst, kalter, trockener, langer Winter, ausreichend Niederschlag und kühle Temperaturen im Frühjahr, warm und trocken zur Abreife. BW Phoma $\mathrm{WH}=$ Befallswert mit der Wurzelhals- und Stängelfäule am Wurzelhals in $\mathrm{BBCH} 83 / 84$. Bedeutung der Symbole: - = negativ beeinflusst oder bei Witterung = schlecht $\quad+\quad$ = positiv beeinflusst oder bei Witterung = gut; $\square=$ mit wuchsregulierenden Fungiziden; $\square=$ ohne wuchsregulierende Fungizide 
Ein anderer Punkt der grundsätzlich bei Versuchen mit wuchsregulierenden Fungiziden im Winterraps berücksichtigt werden sollte, ist die zweifache Wirkungsweise dieser Pflanzenschutzmittel. Dadurch kann in bestimmten Fällen die Interpretation von Ergebnissen erschwert werden, da je nach Situation ein positiver oder negativer Ertragseffekt der Behandlung nicht eindeutig der Wuchsregulierung oder der Krankheitsbekämpfung zugeordnet werden kann. Damit solche Probleme möglichst vermieden werden, wäre es sinnvoll zwei weitere Fungizidvarianten einzuplanen, in denen nur ein reines Fungizid bzw. nur ein reiner WR zum Einsatz kommen. Des Weiteren dürfen die aus den eigenen Fungizidbehandlungen gewonnenen Erkenntnisse nicht verallgemeinernd auf alle im Winterraps zugelassenen wachstumsregulierenden Fungizide übertragen werden, da bei den hiesigen Untersuchungen schwerpunktmäßig nur ein Präparat $\left(\right.$ Toprex $^{\circledR}$ ) bzw. zwei weitere Präparate $\left(\right.$ Carax $^{\circledR}$ und Folicur ${ }^{\circledR}$ ) eingesetzt wurden. Um in diesem Fall allgemeingültige Aussagen treffen zu können, müssten weitere Versuche mit verschiedenen wachstumsregulatorischen Fungiziden durchgeführt werden.

Die häufig bei den Zusammenhangsanalysen mit dem Kornertrag aufgetretenen niedrigen Korrelationskoeffizienten und Bestimmtheitsmaße sind ein Indiz dafür, dass der Kornertrag von Winterraps nicht durch wenige Bestandesparameter erklärt werden kann, sondern von vielen verschiedenen Bestandesparametern abhängig ist. Dabei bleibt ein gewisser Anteil der Varianz im Datensatz vom Kornertrag unaufgeklärt, da es neben den hier untersuchten Parametern noch weitere Parameter gibt, die die Ertragsbildung von Winterraps beeinflussen. 


\section{Schlussfolgerungen}

Der im Rahmen dieser Arbeit durchgeführte dreijährige Feldversuch verdeutlichte, wie stark der Einfluss der Witterung auf die Ertragsbildung von Winterraps ist. Um auf die jahresspezifischen Witterungsverhältnisse entsprechend reagieren zu können, sollten die jeweiligen kulturabhängigen Produktionssysteme jedes Jahr aufs Neue individuell angepasst werden. Starre Anbautechniken führen daher nicht zu den gewünschten Höchsterträgen. In Bezug auf Winterraps kann aus den vorliegenden Ergebnissen geschlussfolgert werden, dass eine Mindestbestandesdichte von etwa 40-45 Pflanzen/ $\mathrm{m}^{2}$ vorliegen muss, um das Ertragspotenzial von Winterraps ausschöpfen zu können. Wird diese insbesondere bei einer niedrig gewählten Saatstärke oder durch erhöhte Auswinterungsverluste unterschritten, können stärkere Ertragsdepressionen die Folge sein. Eine geringere Bestandesdichte kann weniger gut den Verlust von Einzelpflanzen kompensieren als eine normale bis erhöhte Bestandesdichte. Daher sollte im Sinne der Ertragsabsicherung in Regionen, in denen vermehrt mit Pflanzenverlusten über Winter zu rechnen ist, sei es durch Krankheits- und/oder Schädlingsbefall im Herbst oder durch ungünstige Wetterverhältnisse im Herbst und Winter, auf eine starke Saatstärkenreduktion verzichtet werden. Aussaatstärken von $30 \mathrm{Körnern} / \mathrm{m}^{2}$ sind in diesem Fall v.a. bei der herkömmlichen Drillsaat als ungeeignet anzusehen. Anders ist es auf einem Gunststandort, der sich u.a. durch eine gute Wasserversorgung auszeichnet und bei dem meist nur geringe Pflanzenverluste über Winter auftreten. Hier können durchaus mit $30 \mathrm{Körnern} / \mathrm{m}^{2}$ ähnlich hohe Kornerträge erzielt werden wie mit 60 Körner $/ \mathrm{m}^{2}$. Aber auch hier sollte, im Sinne der Ertragsabsicherung, die Aussaatstärke etwas höher als $30 \mathrm{Körner} / \mathrm{m}^{2}$ gewählt werden, da nie ausgeschlossen werden kann, dass auch auf einem besseren Standort vermehrt Pflanzenverluste auftreten. Die vorliegenden Ergebnisse zum Einsatz von wuchsregulierenden Fungiziden in Winterraps haben deutlich gemacht, dass der pauschale Einsatz solcher Pflanzenschutzmittel sowohl unter nicht wüchsigen (knappe Wasserversorgung) als auch unter wüchsigen (gute Wasserversorgung) Witterungsbedingungen in den Monaten März bis Mai keine generellen Ertragsvorteile bietet und daher grundsätzlich überdacht werden sollte. Aus pflanzenbaulicher und ökonomischer Sicht, macht es wesentlich mehr Sinn, die WRBehandlung im Herbst und im Frühjahr noch gezielter von der Bestandesentwicklung abhängig zu machen. Wenn ein Rapsbestand bis Ende September keine sechs Laubblätter entwickelt hat, ist die Gefahr einer vorzeitigen Sprossstreckung sehr gering und die Behandlung sollte sich eher am potenziellen Krankheitsdruck mit Phoma ausrichten. Hat der Raps dagegen sechs oder mehr Laubblätter bis Ende September ausgebildet und liegt zugleich eine hohe Bestandesdichte vor (erhöhte Schossneigung), 
sollte eine Behandlung erfolgen (SCHÖNBERGER, 2012). Im Frühjahr sollte vor einer WRMaßnahme die FM von einem Quadratmeter an mehreren Stellen im Feld mit der Rapool$\mathrm{N}$-Waage bestimmt werden. Liegt diese Mitte März über $1,25 \mathrm{~kg} / \mathrm{m}^{2}$ oder Mitte April über $2,5 \mathrm{~kg} / \mathrm{m}^{2}$ so ist eine Behandlung mit wachstumsregulierenden Fungiziden ratsam. Hierbei handelt es sich allerdings um Grenzwerte die unter englischen Bedingungen und mit englischen Rapssorten ermittelt wurden. Dennoch kann diese Vorgehensweise die Entscheidung für oder gegen eine WR-Spritzung im Frühjahr erleichtern. Neben diesen Empfehlungen sollten immer auch die Standfestigkeit einer Sorte, die N-Versorgung, die Bestandesdichte und der standortspezifische Krankheitsdruck mit $P$. lingam in die Überlegungen mit einbezogen werden. Generell kann aus den vorliegenden Untersuchungen mit wuchsregulierenden Fungiziden folgendes Fazit gezogen werden: „Weniger ist mehr“. Inwieweit das ein allgemeingültiges Fazit ist, müsste in weitergehenden Versuchen näher untersucht werden. 


\section{Zusammenfassung}

Im Rahmen der vorliegenden Arbeit sollte anhand eines dreifaktoriellen Feldversuchs bestehend aus den Faktoren Sorte, Saatstärke und wachstumsregulierende Fungizide der Zusammenhang zwischen der Bestandesarchitektur eines Winterrapsbestandes (Brassica napus L.) und dem Kornertrag analysiert werden. Dabei war das Ziel, den optimalen Bestandesaufbau zu ermitteln, welcher zum maximalen Ertrag führt, und zu untersuchen, wie er durch die drei agronomischen Faktoren beeinflusst wird.

Der Versuch wurde von 2010/11 bis 2012/13 auf Versuchsflächen der Universität Göttingen durchgeführt. Von den drei Versuchsjahren flossen nur die Daten vom ersten und dritten Versuchsjahr in die Endauswertung ein, da der Versuch im zweiten Versuchsjahr nach starken Auswinterungsverlusten und massivem Befall mit $B$. cinerea aufgegeben werden musste. Der Versuch bestand aus 32 Versuchsgliedern, die sich aus zwei Winterrapshybridsorten (2010/11: NK Petrol + SY Merlot; 2012/13: NK Petrol + SY Vesuvio), zwei Saatstärken (30 Körner $/ \mathrm{m}^{2}$ bzw. $\left.60 \mathrm{Körner} / \mathrm{m}^{2}\right)$ und acht wuchsregulierenden Fungizidbehandlungen zusammensetzten. Die Fungizidvarianten variierten in der Anzahl der Behandlungen pro Jahreszeit (Herbst/Frühjahr), im Vergleich zu einer unbehandelten Kontrolle.

Um die Bestandesarchitektur von Winterraps zu beschreiben, sowie deren Einfluss auf die Ertragsbildung von Winterraps zu beurteilen, wurden neben dem Kornertrag, den Ertragsparametern (Strohbiomasse, Ölgehalt, Ölertrag, Ernteindex) und den Ertragsfaktoren (Pflanzen/m², Schoten/Pflanze, Körner/Schote, TKM) folgende Bestandesparameter erfasst: Anzahl der Seitentriebe, Bestandeshöhe, Schotenansatzhöhe, Schotenschichtdicke, photosynthetisch aktive Strahlung (PAR) im Bestand, Kulturdeckungsgrad, Grünfärbung des Pflanzenbestandes zur Blüte und zur Abreife [Normalized Difference Vegetation Index (NDVI)], Wurzelhalsdurchmesser, Blätter/Pflanze, Blattlänge und Blattflächenindex (BFI). Zusätzlich wurde das Auftreten von Krankheiten und Schädlingen bonitiert, wobei der Schwerpunkt bei der Wurzelhalsund Stängelfäule (Leptosphaeria maculans/Leptosphaeria biglobosa, anamorph Phoma lingam) und der Kleinen Kohlfliege (Delia radicum) lag. Die Daten der einzelnen Parameter wurden für jedes Versuchsjahr getrennt voneinander ausgewertet. Mit Hilfe multipler Regressionen wurde der Bestandesparameter bestimmt, der im jeweiligen Jahr den größten Einfluss auf den Kornertrag hatte.

Das erste Versuchsjahr 2010/11 war gekennzeichnet von einem nass kalten Herbst, auf den ein kalter und schneereicher Winter folgte. Die Hauptwachstumsphase des Rapses (März bis Mai) zeichnete sich durch unterdurchschnittliche Niederschlagsmengen 
$(-98,8 \mathrm{~mm})$ und leicht überdurchschnittliche Temperaturen $\left(+0,5^{\circ} \mathrm{C}\right)$ aus. Ausreichende Niederschläge im Juni verhinderten stärkere Ertragsdepressionen. Die Abreife erfolgte unter kühlen und trockenen Bedingungen. Die Witterung des Versuchsjahres 2012/13 unterschied sich von der Witterung des Jahres 2010/11 dahingehend, dass der Herbst milder und trockener, der Winter länger und trockener, die Hauptwachstumsphase des Rapses deutlich feuchter $(+98,0 \mathrm{~mm})$ und kühler $\left(-2,8^{\circ} \mathrm{C}\right)$ und die Abreifephase warm und trocken war. Bedingt durch die Witterung, winterten im Jahr 2010/11 mehr Pflanzen/m² aus als im Jahr 2012/13. Ferner kürzten die wachstumsregulatorischen Fungizide unter den trockenen Bedingungen im Frühjahr 2011 die Rapsbestände nicht so stark ein wie unter den feuchteren Bedingungen im Frühjahr 2013. Insgesamt lagen durch die Witterungsunterschiede die gemittelten Winterrapserträge im Jahr 2012/13 mit 5,58 t/ha um 1,11 t/ha höher als im Jahr 2010/11.

Im Versuchsjahr 2010/11 hatte die Strahlungsaufnahme durch den grünen Pflanzenbestand zur Mitte der Schotenentwicklung (BBCH 75) den stärksten positiven Einfluss auf den Kornertrag. Wie viel PAR vom Pflanzenbestand in $\mathrm{BBCH} 75$ aufgenommen wurde, war primär von der Pflanzendichte im Frühjahr in BBCH 16/18 abhängig. Die Pflanzendichte beeinflusste hauptsächlich den Kulturdeckungsgrad in $\mathrm{BBCH}$ 32/34 (65,5\%), der mit zunehmender Pflanzendichte anstieg. Ein dichter Kulturdeckungsgrad führte im weiteren Entwicklungsverlauf zu einer dichten, grünen Schotenschicht, die wenig PAR bis zum Boden durchließ. Bei der hohen Saatstärke von 60 Körnern $/ \mathrm{m}^{2}$ waren die Pflanzendichte in $\mathrm{BBCH} 16 / 18$, der Kulturdeckungsgrad in $\mathrm{BBCH} 32 / 34$ sowie die Grünfärbung des Pflanzenbestandes in $\mathrm{BBCH} 73$ signifikant höher und der Anteil an PAR unter den Schoten sowie am Boden in $\mathrm{BBCH} 75$ signifikant niedriger als bei der niedrigen Saatstärke von $30 \mathrm{Körnern} / \mathrm{m}^{2}$. Der Kornertrag war bei der Sorte SY Merlot bei der hohen Saatstärke signifikant höher als bei der niedrigen Saatstärke. Bei der Sorte NK Petrol war der Kornertrag zwar auch bei der hohen Saatstärke höher als bei der niedrigen Saatstärke, allerdings waren diese Unterschiede nicht signifikant. Die Fungizidbehandlungen hatten kaum einen Einfluss auf die ertragsrelevanten Bestandesparameter. Aufgrund eines geringeren Feldaufganges und höheren Auswinterungsverlusten bei SY Merlot, kam es u.a. bei der Pflanzendichte im Herbst in $\mathrm{BBCH}$ 14/15 sowie im Frühjahr in $\mathrm{BBCH}$ 16/18 oder beim Kulturdeckungsgrad in BBCH 32/34 zu signifikanten Unterschieden zwischen den beiden Sorten SY Merlot und NK Petrol. Insgesamt hatte die Saatstärke im Jahr 2010/11 den größten Einfluss auf die Bestandesarchitektur und damit auf die Ertragsbildung im Winterraps.

Alle untersuchten Ertragsfaktoren hatten einen signifikanten Einfluss auf den Kornertrag, wobei die Anzahl Pflanzen $/ \mathrm{m}^{2}$ den stärksten Effekt aufwies. Mit steigender Pflanzendichte 
nahm der Kornertrag zu. Die Anzahl Schoten/Pflanze, die Anzahl Körner/Schote, die TKM und die Anzahl Seitentriebe/Pflanze waren dagegen negativ mit dem Kornertrag korreliert, was auf den negativen Zusammenhang zwischen diesen Ertragsfaktoren und der Pflanzendichte zurückzuführen war.

Im Jahr 2010/11 war der Befall mit der Wurzelhals- und Stängelfäule schwach negativ mit dem Kornertrag korreliert. Dabei wies der Befallswert (BW) mit der Wurzelhals- und Stängelfäule am Wurzelhals in $\mathrm{BBCH}$ 83/84 den stärksten, negativen Zusammenhang mit dem Kornertrag auf $\left(r_{p}=-0,363\right)$. Die schwach negative Beziehung zwischen dem Wurzelhalsbefall mit $P$. lingam und der Grünfärbung des Pflanzenbestandes in $\mathrm{BBCH} 73$ $(3,9 \%)$ verdeutlichte, wie sich der Befall auf den Kornertrag auswirkte. Für das Jahr 2012/13 wurden dagegen keine signifikanten, negativen Beziehungen zwischen dem Befall mit der Wurzelhals- und Stängelfäule und dem Kornertrag festgestellt, da der Befall mit $P$. lingam deutlich niedriger war $(B W=1-2)$ als im Jahr 2010/11(BW $=3-5)$.

Der BW mit der Wurzelhals- und Stängelfäule am Wurzelhals in BBCH 83/84 war zum einen von der Pflanzendichte im Frühjahr in BBCH 16/18 und zum anderen von dem BW mit der Wurzelhals- und Stängelfäule am unteren Stängel abhängig. Die Pflanzen in der niedrigen Saatstärkenvariante waren stärker mit $P$. lingam am Wurzelhals befallen als die Pflanzen in der hohen Saatstärkenvariante, da bei der niedrigen Saatstärke mehr Pflanzen durch den Larvenfraß der Kleinen Kohlfliege geschädigt wurden als bei der hohen Saatstärke.

Der BW der Wurzelhals- und Stängelfäule am unteren Stängel sowie am Wurzelhals ließ sich im Jahr 2010/11 signifikant durch die Wirkstoffkombination aus Paclobutrazol und Difenoconazol reduzieren. Beim Wurzelhalsbefall war allerdings entscheidend, dass die besagte Wirkstoffkombination schon im Herbst appliziert wurde (Var. 3, 4, 6 und 7). Die praxisübliche Fungizidvariante, in der die Wirkstoffkombination aus Mepiquatchlorid und Metconazol sowie der Wirkstoff Tebuconazol eingesetzt wurden, reduzierte den Befall mit $P$. lingam nicht signifikant.

Im Versuchsjahr 2012/13 hatte die Schotenansatzhöhe in $\mathrm{BBCH} 75$ den stärksten positiven Einfluss auf den Kornertrag (30,6\%). Die Schotenansatzhöhe in BBCH 75 wurde wiederum am stärksten durch die Bestandeshöhe in $\mathrm{BBCH} 65 / 67$ beeinflusst (96,2\%). Die Bestandeshöhe in $\mathrm{BBCH} 65 / 67$ zeigte die stärkste positive Korrelation mit der Schotenansatzhöhe desselben Stadiums (95,5\%). Somit hatten im Jahr 2012/13 das Längenwachstum der Bestände und die Beeinflussung des Längenwachstums durch wuchsregulierende Fungizide einen wesentlichen Anteil an der Ertragsbildung von Winterraps. Je häufiger die Wirkstoffkombination aus Paclobutrazol und Difenoconazol appliziert wurde, desto stärker wurde die Schotenansatzhöhe in $\mathrm{BBCH} 75$ signifikant 
eingekürzt. Im Fall der Bestandeshöhe in BBCH 65/67 wurde eine ähnliche Wirkungsweise beobachtet. Je stärker das Stängelgewebe am Wachstum gehindert wurde, desto stärker verringerten sich der Strohbiomasseertrag und damit auch der Kornertrag. Zu signifikanten Ertragsreduktionen führten insbesondere die Variante 4, in der zweimal im Herbst und einmal im Frühjahr die Wirkstoffkombination aus Paclobutrazol und Difenoconazol verwendet wurde und die Variante 6, in der zweimal im Herbst und zweimal im Frühjahr die gleiche Wirkstoffkombination eingesetzt wurde. Die signifikanten Höhenunterschiede zwischen NK Petrol und SY Vesuvio hatten keinen Einfluss auf den Strohbiomasseertrag bzw. Kornertrag. Die Saatstärke stellte im Jahr 2012/13 keinen ertragslimitierenden Faktor dar, sodass bei beiden Saatstärken ähnlich hohe Kornerträge erzielt wurden. Zusammenfassend hatten im Jahr 2012/13 die wuchsregulierenden Fungizidbehandlungen den größten Einfluss auf die Bestandesarchitektur und damit auf die Ertragsbildung im Winterraps.

Im Jahr 2012/13 hatten von den Ertragsfaktoren die Anzahl Seitentriebe/Pflanze, die Pflanzendichte im Frühjahr und die TKM einen signifikanten Einfluss auf den Kornertrag. Der stärkste Einfluss ging dabei von der Anzahl an Seitentriebe/Pflanze aus, wobei mit zunehmender Seitentriebzahl der Kornertrag sank. Die Pflanzendichte und die TKM beeinflussten den Kornertrag positiv. Aufgrund sehr niedriger Bestimmtheitsmaße von maximal 5\%, waren diese Zusammenhänge allerdings recht gering. Demnach spielten die Ertragsfaktoren in der Ertragsbildung eine untergeordnete Rolle.

Das Optimum zwischen der Pflanzendichte im Frühjahr und der Anzahl an Seitentrieben/Pflanze lag im Jahr $2010 / 11$ bei ca. $40 \mathrm{Pflanzen} / \mathrm{m}^{2}$ und ca. 8 Seitentrieben/Pflanze und im Jahr $2012 / 13$ bei ca. 45 Pflanzen $/ \mathrm{m}^{2}$ und ca. 7 Seitentrieben/Pflanze. Generell konnte festgestellt werden, dass bei einer Erhöhung der Aussaatstärke um den Faktor 2, im Durchschnitt 2 Seitentriebe/Pflanze weniger ausgebildet wurden. Die Anzahl der Seitentriebe/Pflanze wurde in beiden Versuchsjahren in fast allen Fällen nicht signifikant durch die wuchsregulierenden Fungizidbehandlungen erhöht. Somit konnte die Seitentriebbildung der Einzelpflanzen nicht verbessert werden.

Insgesamt kann festgehalten werden, dass je nach Jahreswitterung die Saatstärke, teils in Kombination mit der Sorte, oder die wuchsregulierenden Fungizidbehandlungen die Bestandesarchitektur von Winterraps beeinflusst haben und dadurch maßgeblich an der Ertragsbildung von Winterraps beteiligt waren. Damit stehen dem Landwirt v.a. durch die Saatstärke und durch die wachstumsregulierenden Fungizide anbautechnische Instrumente zur Verfügung, um gezielt in die Bestandesarchitektur von Winterraps einzugreifen. Nach den vorliegenden Ergebnissen sollte die Saatstärke ca. 40 bis 50 Körner $/ \mathrm{m}^{2}$ betragen, um bei widrigen Wetterverhältnissen einen Pflanzenausfall kompensieren zu können. Um Ertragsdepressionen durch eine Wuchshemmung zu vermeiden, sollten wuchsregulierende Fungizide nicht pauschal und im Übermaß, sondern nach den Regeln des integrierten Pflanzenschutzes eingesetzt werden. 


\section{Summary}

In the present study, a three-factorial field trial, consisting of the factors cultivar, seed rate and growth regulating fungicides was conducted to analyze the relationship between crop architecture of a winter oilseed rape (WOSR) crop and yield. The aim was to identify the optimal crop architecture to achieve the maximum possible yield and to explore how it was affected by the three cropping factors.

The field trial was carried out from $2010 / 11$ to $2012 / 13$ on experimental fields of the University of Göttingen. Only the data from 2010/11 and 2012/13 were used for the final statistical data analysis. Due to strong damage induced by winterkill and a subsequent massive attack by $B$. cinerea the experiment was abandoned in the second year in spring 2012. The field trial consisted of 32 treatments which were composed of two WOSR hybrid cultivars (2010/11: NK Petrol + SY Merlot; 2012/13: NK Petrol + SY Vesuvio), two seeding rates (30 seeds $/ \mathrm{m}^{2}$ or 60 seeds $/ \mathrm{m}^{2}$ ) and eight growth-regulating fungicide treatments. The fungicide applications varied in frequency per season (autumn/spring), and were compared with an untreated control.

In order to be able to describe and explain the crop architecture of WOSR and to assess their influence on the yield formation of WOSR, a lot of different crop parameters were examined including grain yield, straw biomass, oil content, oil yield, harvest index, plants $/ \mathrm{m}^{2}$, number of pods/plant, number of seeds/pod, thousand grain weight (TGW), number of side branches, crop height, pod set height, thickness of pod layer, photosynthetic active radiation (PAR) in the crop, culture coverage, green colour of the canopy during flowering and during ripening [Normalized Difference Vegetation Index (NDVI)] root crown diameter, number of leaves/plant, length of leaves and leaf area index (LAI). In addition, the occurrence of diseases and pests was assessed with special emphasis on blackleg (Leptosphaeria maculans/Leptosphaeria biglobosa, anamorph Phoma lingam) and cabbage root fly (Delia radicum). The data of the individual parameters were evaluated separately for each year of the trial. Using multiple regressions was the best method to determine the crop parameter, which had the greatest impact on grain yield.

The first experimental year 2010/11 was characterized by a cold, wet autumn, which was followed by a cold and snowy winter. The main growth period of oilseed rape (March to May) was characterized by below-average rainfall $(-98.8 \mathrm{~mm})$ and slightly above average temperatures $\left(+0.5^{\circ} \mathrm{C}\right)$. Sufficient rainfall in June prevented stronger yield reductions. The maturation took place under cool and dry conditions. The weather of the year 2012/13 was different from the weather of the year $2010 / 11$ to the effect that the autumn was 
milder and drier, the winter was longer and drier, the main growth period of rape was much more wetter $(+98.0 \mathrm{~mm})$ and cooler $\left(-2,8^{\circ} \mathrm{C}\right)$ and the maturation period was warmer and drier. The year-specific weather conditions had a major impact on the plant density and the growth-regulating effect of the fungicides used. So more plants $/ \mathrm{m}^{2}$ were lost over winter in 2010/11 than in 2012/13. The growth-regulatory fungicides shortened the WOSR plants under the dry conditions in spring 2011 not as much as under the humid conditions in spring 2013. Moreover, the variable weather conditions were responsible for different average yield levels of WOSR. In 2010/11, the average yield level was around $4.47 \mathrm{t} / \mathrm{ha}$ and in 2012/13 it was around $5.58 \mathrm{t} / \mathrm{ha}$.

In 2010/11, the radiation absorption by the green plant canopy during the middle of pod development $(\mathrm{BBCH} 75)$ had the strongest positive influence on grain yield. How much PAR was absorbed by the plant canopy in $\mathrm{BBCH} 75$ was primarily dependent on the plant density in spring in $\mathrm{BBCH} 16 / 18$. The plant density influenced mainly the cultural coverage in $\mathrm{BBCH} 32 / 34$ (65.5\%), which rose with increasing plant density. Dense culture coverage resulted in the further development into a dense, green pod layer, which absorbed more PAR while only a small amount of unused radiation reached the ground. At the high seed rate of 60 seeds $/ \mathrm{m}^{2}$ plant density in $\mathrm{BBCH} 16 / 18$, culture coverage in $\mathrm{BBCH} 32 / 34$ and green colour of the plant canopy in $\mathrm{BBCH} 73$ were significantly higher than at the low rate of 30 seeds $/ \mathrm{m}^{2}$. The proportion of PAR under the pods as well as on the ground in $\mathrm{BBCH}$ 75 at the high seed rate was significantly lower than at the low seed rate. The grain yield of SY Merlot was only significantly higher at the high sowing rate than the low sowing rate. In case of NK Petrol, the grain yield even at the high seed rate was higher than at the low seed rate, but these differences were not significant. The fungicide treatments had little effects on the yield-relevant crop parameters. Due to a poorer crop emergence and higher plant losses over winter in SY Merlot, the two varieties SY Merlot and NK Petrol significantly influenced some crop parameters, such as the plant density in autumn in $\mathrm{BBCH} 14 / 15$ as well as in spring in $\mathrm{BBCH} 16 / 18$ and the culture coverage in BBCH 32/34. Overall, the seed rate in 2010/11 had the greatest impact on crop architecture and thus on yield formation.

All tested yield factors had a significant impact on grain yield, whereas the number of plants $/ \mathrm{m}^{2}$ had the strongest effect. With rising plant density, the grain yield increased. The number of pods/plant, number of seeds/pod, the TGW and the number of side branches/plant were negatively correlated with grain yield, which was due to the negative correlation between these factors and plants $/ \mathrm{m}^{2}$.

In 2010/11, phoma crown canker and phoma stem lesions (first $30 \mathrm{~cm}$ of the stem) were weakly negatively correlated with grain yield. Hereby, disease severity (DS) of phoma 
crown canker in $\mathrm{BBCH} 83 / 84$ had the strongest negative correlation with grain yield $\left(r_{p}=\right.$ -0.363). The weak negative relationship between root collar infestation with $P$. lingam and the green colour of the plant canopy in $\mathrm{BBCH} 73$ (3.9\%) explained how the grain yield was affected by the infestation. In $2012 / 13$, there was no significant negative relationship between phoma crown canker or phoma stem lesions and grain yield, because the infection with $P$. lingam was significantly lower than in 2010/11. In 2010/11 the mean DS of blackleg was between 3 and 5 and in 2012/13 between 1 and 2 .

DS of phoma crown canker in $\mathrm{BBCH} 83 / 84$ was on the one hand dependent on the plant density in spring in $\mathrm{BBCH} 16 / 18$ and on the other hand on DS with phoma stem lesions. The plants at the low seed rate were more infested with $P$. lingam at the root collar than plants at the high seed rate, because at the low seed rate more plants were damaged by larvae of the cabbage root fly than at the high seed rate.

In 2010/11, the infection with phoma stem lesions and phoma crown canker were significantly reduced by the fungicide variants in which the combination of the active ingredients of paclobutrazol and difenoconazole was used. For phoma crown canker, it was crucial that the mentioned substance combination was applied for the first time in autumn (var. 3, 4, 6 and 7). The common practice fungicide treatment, in which the combination of the active ingredients of mepiquat chloride and metconazole and the compound tebuconazole were used, did not significantly reduce the infestation with $P$. lingam.

In the experimental year 2012/13, the pod set height in $\mathrm{BBCH} 75$ had the strongest positive effect on grain yield (30.6\%). In $\mathrm{BBCH} 75$, the pod set height offered the strongest interaction with the canopy height in $\mathrm{BBCH} 65 / 67$ (96.2\%). In $\mathrm{BBCH} 65 / 67$, the canopy height was primarily affected by the pod set height of the same growth stage (95.5\%). Therefore in 2012/13, the growth of the crop and the growth-regulating fungicides had a substantial influence on yield formation. The more frequent the combination of the active ingredients of paclobutrazol and difenoconazole was applied, the stronger the pod set height in $\mathrm{BBCH} 75$ was shortened. In case of the canopy height in $\mathrm{BBCH} 65 / 67$, this effect could be observed in a similar manner. The stronger the pod set height was shortened, the stronger the straw biomass yield was reduced. This reduction was significant in variant 4 , in which the substance combination of paclobutrazol and difenoconazole was used twice in autumn and once in spring, and in variant 6, wherein the same combination of active ingredients was used twice in autumn and twice in spring. This significant reduction of the stem tissue induced by the fungicide treatments also significantly decreased the grain yield. The significant height differences between NK Petrol and SY Vesuvio had no influence on the straw biomass yield or grain yield. In 2012/13, the seed rate did not 
present a yield limiting factor. Thus, in both seed densities similar grain yields were obtained. In summary, in 2012/13 the growth-regulating fungicide treatments had the greatest impact on the crop architecture and thus on the yield formation.

In 2012/13, the side branches/plant, the plant density in spring and the TGW were the only yield factors which had a significant effect on grain yield. Hereby, the side branches/plant had the strongest influence, whereas the grain yield decreased with increasing number of side branches. The plant density and the TGW influenced the grain yield positively. Due to very low coefficients of determination (max. 5\%), these relationships were not very distinct. This meant that the yield factors played a minor role in the yield formation of WOSR.

The optimum ratio between the plant density in spring and the number of side branches/plant in 2010/11 was approximately 40 plants $/ \mathrm{m}^{2}$ and circa 8 side branches/plant and in 2012/13 approximately 45 plants $/ \mathrm{m}^{2}$ and circa 7 side branches/plant. In general it was found that with an increase in the seed rate by a factor of two, on the average, two side branches/plant were less developed. In both years, most of the growth-regulating fungicide treatments did not increase the number of side branches/plant. Therefore, the formation of side branches of individual plants could not be enhanced by growth-regulating fungicides.

Overall, it can be noted that, depending on annual weather conditions, the seed rate, partly in combination with the variety, or the growth-regulating fungicide treatments have affected the crop architecture of WOSR and therefore these production factors were important in yield formation of WOSR. Hence, especially by the seed rate or by the growth-regulating fungicides, cultivation tools are available to the farmers to specifically manipulate the crop architecture of WOSR. According to the results, the seed rate should be about 40 to 50 seeds $/ \mathrm{m}^{2}$ in order to compensate a crop failure in adverse weather conditions. To avoid yield reductions due to inhibition of growth, growth-regulating fungicides should not be used across-the-board and in excess, but according to the rules of integrated pest management. 


\section{Literaturverzeichnis}

ABU-YAMAN, I.K. (1960). Natural control in cabbage root fly populations and influence of chemicals. Veenman, Wageningen.

Adams, R., Kerber, E., Pfister, K. \& Weiler, E.-W. (1992). Studies on the action of the new growth retardant CGA 163'935 (cimectacarb). In: Progress in plant growth regulation (Hrsg. Karssen, C.M., Van Loon, L.C. \& Vreugdenhil, D.). Kluwer Academic Publishers, Dordrecht, The Netherlands, 818-827.

Addo-Quaye, A.A., DaNIELS, R.W. \& SCARISBRICK, D.H. (1985). The influence of paclobutrazol on the distribution and utilization of ${ }^{14} \mathrm{C}$-labelled assimilate fixed at anthesis in oilseed rape (Brassica napus L.). The Journal of Agricultural Science, 105, 365-373.

AKERS, A., KÖHLE, H.H. \& Gold, R.E. (1990). Uptake, transport and mode of action of BAS $480 \mathrm{~F}$, a new triazole fungicide. In: Brighton Crop Proctection Conference. Pests and Diseases Vol. 2 (Hrsg. Anonymus). British Crop Protection Council Publications, Croydon, UK, 837-845.

ALLEN, E.J. \& MORGAN, D.G. (1972). A quantitative analysis of the effects of nitrogen on the growth, development and yield of oilseed rape. The Journal of Agricultural Science, 78, 315-324.

ALPMANN, L. (2006a). Standortansprüche für eine erfolgreiche Rapsproduktion. In: Raps Anbau und Verwertung einer Kultur mit Perspektive (Hrsg. Landwirtschaftsverlag Münster-Hiltrup \& BASF Aktiengesellschaft Limburgerhof). Landwirtschaftsverlag, Münster-Hiltrup, 84-90.

AlpmanN, L. (2006b). Wie viel Wetter braucht der Raps? Kurier, 25-26.

ALPMANN, L. (2007). Hochertrag beim Winterraps - Einfluss von Witterung und Anbauregion. URL http://www.rapool.de/index.cfm/nav/85/article/420.html, online abgerufen am 21.02.2014.

Andersen, M.N., Heidmann, T. \& Plauborg, F. (1996). The effects of drought and nitrogen on light interception, growth and yield of winter oilseed rape. Acta Agriculturae Scandinavica, Section B - Soil \& Plant Science, 46, 55-67.

ANGADI, S.V., CUTFORTH, H.W., McCONKEY, B.G. \& GAN, Y. (2003). Yield adjustment by canola grown at different plant populations under semiarid conditions. Crop Science, 43, 1358-1366.

ANONYMUS (2007). Model 505 GreenSeeker hand held optical sensor unit - Operating Manual. NTech® Industries, Ukiah, CA, USA. 
ANONYMUS (2009). BASF erhält Zulassung für Carax. URL

http://www.agrarheute.com/basf-erhaelt-zulassung-fuer-carax, online abgerufen am 12.04.2014.

ANONYMUS (2010). Sortenprofil Winterrapssorte SY Merlot. E-Mail vom 02.02.2011 von Dr. Astrid Günther an Prof. von Tiedemann.

ANONYMUS (2012a). Feldschätzkarte: Gemarkung Weende, Flur 12, Maßstab 1 : 2000. Finanzamt Göttingen.

ANONYMUS (2012b). Feldschätzkarte: Gemarkung Rosdorf, Flur 26, Maßstab 1 : 2000. Finanzamt Göttingen.

ANONYMUS (2013a). Produktinformationen Toprex®. URL http://www3.syngenta.com/country/de/de/Produkte/Documents/TOPREX_Produktinfor mation.pdf, online abgerufen am 21.09.2013.

ANONYMUS (2013b). Produktinformationen Carax®. URL http://www.agrar.basf.de/agroportal/de/media/migrated/de/produkte_neu_1/carax_2/Ca rax_Produktbroschuere_DE_08022010.pdf, online abgerufen am 21.09.2013.

ANONYMUS (2013c). Produktinformationen Folicur®. URL http://agrar.bayer.de/schnellinformation.cms?Productld=423, online abgerufen am 21.09.2013.

ANONYMUS (2013d). Produktinformationen Harvesan®. URL http://www.dupont.de/content/dam/assets/products-and-services/cropprotection_dede/getreide/products/documents/DuPont_Produktinformation_2013_Harv esan.pdf, online abgerufen am 21.09.2013.

ANONYMUS (2013e). Produktinformationen Ortiva®. URL http://www3.syngenta.com/country/de/de/Produkte/Documents/ORTIVA_Produktinform ation.pdf, online abgerufen am 21.09.2013.

ANONYMUS (2013f). Formulierungstypen von Pflanzenschutzmitteln. URL http://www.bvl.bund.de/DE/04_Pflanzenschutzmittel/01_Aufgaben/08_Produktchemie/0 1_BeistoffeFormulierungschemie/01_Formulierungstypen/psm_BeistoffeFormulierungs chemie_formulierungstypen_node.html, online abgerufen am 21.09.2013.

ANONYMUS (2013g). Brochure for the LAI-2000 Plant Canopy Analyzer. URL http://envsupport.licor.com/docs/LAl2000_brochure.pdf, online abgerufen am 10.12.2013.

ANONYMUS (2013h). Sortenprofil Winterrapssorte NK Petrol. URL http://www3.syngenta.com/country/de/de/Produkte/Documents/NK_Petrol_Sortenprofil. pdf, online abgerufen am 21.09.2013. 
ANONYMUS (2013i). Sortenprofil Winterrapssorte SY Vesuvio. URL

http://www3.syngenta.com/country/de/de/Produkte/Documents/SY_Vesuvio_Sortenprof il.pdf, online abgerufen am 21.09.2013.

ANONYMUS (2014a). Rapool-N-Waage. URL http://www.rapool.de/index.cfm/action/gauge.html, online abgerufen am 24.05.2014.

ANONYMUS (2014b). Hauptkomponentenanalyse. URL http://www.statoek.wiso.unigoettingen.de/veranstaltungen/Multivariate/Daten/mvsec4.pdf, online abgerufen am 06.03.2014.

ANONYMUS (2014c). LI-191SA Line Quantum Sensor. URL

http://www.kohsieh.com.tw/PDF_Files/LICOR/191sa.pdf, online abgerufen am 02.08.2014.

BackHaus, K., ERICHSON, B., PlinKe, W. \& Weiber, R. (1996). Multivariate Analysemethoden. 8. Aufl. Springer, Berlin.

Baeumer, K. (1992). Allgemeiner Pflanzenbau. 3. Aufl. Ulmer, Stuttgart.

BARTMER, C.-A. (2007). Ölpflanzen im Spannungsfeld der Agrarpolitik. In: Winterraps. Das Handbuch für Profis (Hrsg. Christen, O. \& Friedt, W.). DLG-Verlag, Frankfurt am Main, 3-4.

BAUR, R., KOŠTÁL, V. \& STÄDLER, E. (1996a). Root damage by conspecific larvae induces preference for oviposition in cabbage root flies. Entomologia Experimentalis et Applicata, 80, 224-227.

Baur, R., Kosal, V., Patrian, B. \& Stadler, E. (1996b). Preference for plants damaged by conspecific larvae in ovipositing cabbage root flies: influence of stimuli from leaf surface and roots. Entomologia Experimentalis et Applicata, 81, 353-364.

BAYLIS, A.D. \& HUTLEY-BULL, P.D. (1991). The effects of a paclobutrazol-based growth regulator on the yield, quality and ease of management of oilseed rape. Annals of Applied Biology, 118, 445-452.

BECK, L. (2005). Einfluss von Fungiziden auf die Ertragsphysiologie von Weizen. Dissertation, Rheinische Friedrich-Wilhelms-Universität Bonn.

BECKER, H. (2011). Pflanzenzüchtung. 2. Aufl. Verlag Eugen Ulmer, Stuttgart.

BILSBORROW, P.E. \& NORTON, G. (1984). A consideration of factors affecting the yield of oilseed rape. Aspects of Applied Biology, 6, 91-100.

BILsBorRow, P.E. \& NORTON, G. (1987). Physiological factors affecting the yield of oilseed rape. In: Proceedings of the 7th International Rapeseed Congress (Hrsg. Instytut Hodowli i Aklimatyzacji Roślin), Poznań, Poland, 794-797.

BOELCKE, B. (1981). Untersuchung zur optimalen Bestandesdichte bei Winterraps. Arch. Acker- und. Pflanzenbau und Bodenkunde, 25, 637-643. 
Boiffin, J., FAbre, B., Gautronneau, Y. \& Sebillotte, M. (1981). Observations sur l'evolution de la densite de peuplement du colza d'hiver apres la levee. Inf. Techn. CETIOM, 74, 31-36.

Bosch, J. (2012). Bestandesführung mit Sensor. Teil 2: Anwendung. Getreidemagazin, $17,42-45$.

BoumA, E. (2009). Wetter \& Pflanzenschutz. Roodbont Verlag, Zutphen.

BRAR, G. \& THIES, W. (1977). Contribution of leaves, stem, siliques and seeds to dry matter accumulation in ripening seeds of rapeseed, Brassica napus L. Z. Pflanzenphysiolol., 82, 1-13.

Brazauskiene, I. \& Petraitiene, E. (2006). Epidemiological studies into Phoma lingam (teleomorph Leptosphaeria maculans) infections in winter and spring oilseed rape. Agronomy Research, 4, 137-140.

BRosiUS, F. (2007). SPSS für Dummies. [statistische Analyse statt Datenchaos - Daten aufbereiten und analysieren, grafische Darstellung der Ergebnisse, Export in Excel, Word \& Co.]. 1. Aufl. WILEY-VCH, Weinheim.

BÜCHEL, K.H. (1986). The history of azole chemistry. In: Fungicide Chemistry (Hrsg. Green, M.B. \& Spilker, D.A.). American Chemical Society, Washington, DC, 1-23.

BUCHENAUER, H. (1977). Mode of action and selectivity of fungicides which interfere with ergosterol biosynthesis. In: Proceedings of the 1977 British Crop Protection Conference - Pest and Diseases (Hrsg. Anonymus). British Crop Protection Council, London, 699-711.

BUCHENAUER, H. (1995). DMI-fungicides - side effects on the plant and problems of resistance. In: Modern Selective Fungicides - Properties, Applications, Mechanisms of Action (Hrsg. Lyr, H.). Gustav Fischer Verlag, Jena, 259-290.

Buchenauer, H., Kutzner, B. \& Koths, T. (1984). Wirkung verschiedener TriazolFungizide auf das Wachstum von Getreidekeimlingen und Tomatenpflanzen sowie auf die Gibberellingehalte und den Lipidstoffwechsel von Gerstenkeimlingen. Journal of Plant Diseases and Protection, 91, 506-524.

BUCHENAUER, H. \& RÖHNER, E. (1981). Effect of triadimefon and triadimenol on growth of various plant species as well as on gibberellin content and sterol metabolism in shoots of barley seedlings. Pesticide Biochemistry and Physiology, 15, 58-70.

BUNDESAMT FÜR VERBRAUCHERSCHUTZ UND LEBENSMITTELSICHERHEIT (BVL) (2014). Online Datenbank Pflanzenschutzmittel. URL http://www.bvl.bund.de/DE/04_Pflanzenschutzmittel/01_Aufgaben/02_ZulassungPSM/ 01_ZugeIPSM/01_OnlineDatenbank/psm_onlineDB_node.html, online abgerufen am 09.04.2014. 
Burden, R.S., Carter, G.A., Clark, T., Cooke, D.T., Croker, S.J. \& Deas, Adrian H. B. et al. (1987a). Comparative activity of the enantiomers of triadimenol and paclobutrazol as inhibitors of fungal growth and plant sterol and gibberellin biosynthesis. Pesticide Science, 21, 253-267.

Burden, R.S., ClaRK, T. \& Holloway, P.J. (1987b). Effects of sterol biosynthesisinhibiting fungicides and plant growth regulators on the sterol composition of barley plants. Pesticide Biochemistry and Physiology, 27, 289-300.

CAMPBelL, C.L. \& MADDEN, L.V. (1990). Introduction to plant disease epidemiology. John Wiley and Sons, New York.

CAMPBELL, J.B. (2002). Introduction to remote sensing. 3. Aufl. Guilford Press, New York.

CHAY, P. \& THURLING, N. (1989). Variation in pod length in spring rape (Brassica napus) and its effect on seed yield and yield components. The Journal of Agricultural Science, $113,139-147$.

CLARKE, J.M. (1978). The effects of leaf removal on yield and yield components of Brassica napus rape. Canadian Journal of Plant Science, 58, 1103-1105.

CLARKE, J.M. (1979). Intra-plant variation in number of seeds per pod and seed weight in Brassica napus "Tower". Canadian Journal of Plant Science, 59, 959-962.

DANSON, F.M. (1995). Developments in the remote sensing of forest canopy structure. In: Advances in environmental remote sensing (Hrsg. Danson, F.M. \& Plummer, S.E.). Wiley, Chichester, 53-69.

DAVIS, T.D., STEFFENS, G.L. \& SANKHLA, N. (1988). Triazole plant growth regulators. Horticultural Review, 10, 63-105.

de Bouille, P., Sotta, B., Migniac, E. \& Merrien, A. (1989). Hormones and pod development in oilseed rape (Brassica napus). Plant Physiol., 90, 876-880.

DE WIT, C.T. (1965). Photosynthesis of leaf canopies. Pudoc, Wageningen.

DEGENHARDT, D.F. \& KONDRA, Z.P. (1981). The influence of seeding date and seeding rate on seed yield and growth characters of five genotypes of Brassica napus.

Canadian Journal of Plant Science, 61, 185-190.

DEUKER-ISERMEYER, B., KeLLNER, G. \& HOPPE, H.-. (1991). Einsatz von Wachstumsreglern in Winterraps. Gesunde Pflanzen, 43, 294-299.

DEUTSCHER WETTERDIENST (2013). Klimadaten Deutschland. Langjährige Mittelwerte. DIEPENBROCK, W. (2000). Yield analysis of winter oilseed rape (Brassica napus L.): a review. Field Crops Res., 67, 35-49.

DiePENBROCK, W. (2006). Raps. Biologische und ökologische Grundlagen. In: Handbuch des Pflanzenbaues 4. Ölfrüchte, Faserpflanzen, Arzneipflanzen und Sonderkulturen (Hrsg. Heyland, K.-U., Hanus, H. \& Keller, E.R.). Ulmer, Stuttgart (Hohenheim), 41-63. 
DiePENBROCK, W. (2007). Biologische Grundlagen. In: Winterraps. Das Handbuch für Profis (Hrsg. Christen, O. \& Friedt, W.). DLG-Verlag, Frankfurt am Main, 53-62.

Diepenbrock, W., ElLmer, F. \& LÉON, J. (2005). Ackerbau, Pflanzenbau und Pflanzenzüchtung. Ulmer, Stuttgart.

DiePEnBRoCK, W. \& GRosse, F. (1995). Rapeseed (Brassica napus L.). Yield structure. In: Physiological potentials for yield improvement of annual oil and protein crops. Advances in plant breeding. Supplement 17 to the Journal "Plant Breeding" (Hrsg. Diepenbrock, W. \& Becker, H.). Blackwell Wissenschafts-Verlag, Berlin, Wien, 34-44. DÖRING, A. (2014). Was tun ohne Premiumbeizung? Innovation, 20, 10-11.

Dosdall, L.M., Herbut, M.J., Cowle, N.T. \& MiCKLICH, T.M. (1996). The effect of seeding date and plant density on infestations of root maggots, Delia spp. (Diptera: Anthomyiidae), in canola. Canadian Journal of Plant Science, 76, 169-177.

ELVIDGE, C.D. \& CHEN, Z. (1995). Comparison of broad-band and narrow-band red and near-infrared vegetation indices. Remote Sensing of Environment, 54, 38-48.

EnTZ, M.H., van DEN Berg, C.G.J., StobBe, E.H., RossnaGel, B.G., LAFOND, G.P. \& AUSTENSON, H.M. (1990). Effect of late-season fungicide application on grain yield and seed size distribution in wheat and barley. Canadian Journal of Plant Science, 70, 699706.

EVANS, E.J. (1984). Pre-anthesis growth and its influence on seed yield in winter oilseed rape. Aspects of Applied Biology, 6, 81-90.

EVANS, L.T., WARDLAW, I.F. \& FISHER, R.A. (1975). Wheat. In: Crop physiology. Some case histories (Hrsg. Evans, L.T.). Cambridge University Press, London, 101-149.

FABER, M. (2011). Wann sind Fungizide im Raps wirtschaftlich? Top Agrar, 2011, 70-73.

FIELD, A.P. (2006). Discovering statistics using SPSS. (and sex, drugs and rock'n'roll). 2. Aufl. SAGE Publ, London.

FINCH, S. (1978). Volatile plant chemicals and their effect on host plant finding by the cabbage root fly (Delia brassicae). Entomologia Experimentalis et Applicata, 24, 350359.

FISAHN, J. (1993). Beeinflussbarkeit der Ontogenese von Raps (Brassica napus L.) durch exogen applizierte Wachstumsregulatoren (Gibberelline - Dominanzbeziehungen Ertragsstruktur). Wiss. Fachverl, Giessen.

FITT, B.D.L., BRUN, H., BARBETTI, M.J. \& RIMMER, S.R. (2006). World-Wide Importance of Phoma Stem Canker (Leptosphaeria maculans and L. biglobosa) on Oilseed Rape (Brassica napus). European Journal of Plant Pathology, 114, 3-15.

Fitt, B.D.L., Gladders, P., Sutherland, K.G., Turner, A.J. \& Welham, S.J. (1999). Epidemology, forecasting and management of winter oilseed rape diseases in the UK. 
In: Proceedings of the $10^{\text {th }}$ International Rapeseed Congress (Hrsg. Wratten, N. \& Salisbury, P.A.). The regional institute Ltd., Canberra, Australia, 4.

FITT, B.D.L., HU, B.C., LI, Z.Q., LIU, S.Y., LANGE, R.M. \& KHARBANDA, P.D. et al. (2008). Strategies to prevent spread of Leptosphaeria maculans (phoma stem canker) onto oilseed rape crops in China; costs and benefits. Plant Pathology, 57, 652-664.

FLETCHER, R.A., GILLEY, A., DAVIS, T.D. \& SANKHLA, N. (2000). Triazoles as plant growth regulators and stress protrectants. In: Horticultural reviews. Vol. 24 (Hrsg. Janick, J.). John Wiley \& Sons Inc, New York, 55-138.

FletCHER, R.A. \& HofStRA, G. (1988). Triazoles as potential plant protectants. In: Sterol synthesis inhibitors in plant protection (Hrsg. Berg, D. \& Plempel, M.). Ellis Horwood Limited, Cambridge, UK, 321-331.

Fletcher, R.A., Hofstra, G. \& GAO, J.-g. (1986). Comparative fungitoxic and plant growth regulating properties of triazole derivatives. Plant Cell Physiology, 27, 367-371.

FOULKES, M.J., SCOTT, R.K. \& SYLVESTER-BRAdLEY, R. (1997). Optimising winter wheat varietal selection on drought-prone soil types. Optimising cereal inputs, its scientific basis. Aspects of Applied Biology, 50, 61-76.

FRAUEN, M. (2012). Maximales Ertragspotenzial von Hybridraps. In: Hohe Erträge Wurzeln Tief. Das kleine Wurzelwerk von Rapool (Hrsg. Alpmann, L., Baer, A., Döpke, G., Hemmers, A., Kahl, R., Pferdmenges, S., Schäfer, A. \& Wellmann, N.), Isernhagen $\mathrm{HB}, 67$.

FREUDHOFMAIER, O. (1991). Standraum und Ertragsstruktur von Raps. Raps, 9, 148-152.

FRIENDLY, M. (2008). The biplot macro. URL http://www.datavis.ca/sasmac/biplot.html, online abgerufen am 10.04.2014.

FROGGATT, R.J., THOMAS, W.D. \& BATCH, J.J. (1982). The value of lodging control in winter wheat as exemplified by the growth regulator PP333. In: Opportunities for manipulation of cereal productivity. Proceedings of a meeting; held at Wye College, University of London, Ashford, Kent, on 2nd \& 3rd September, 1981 (Hrsg. Hawkins, A.F. \& Jeffcoat, B.). British Plant Growth Regulator Group, Wantage, Oxfordshire.

Gammelvind, L.H., SchJoerRinG, J.K., Mogensen, V.O., Jensen, C.R. \& BOCK, J.G.H. (1996). Photosynthesis in leaves and siliques of winter oilseed rape (Brassica napus L.). Plant Soil, 186, 227-236.

GAN, S. \& AMASINO, R.M. (1997). Making sense of senescence. (Molecular genetic regulation and manipulation of leaf senescence). Plant Physiol., 113, 313-319.

GARBE, V. (1998). Control of canker (Phoma lingam) in winter oilseed rape and possibilities of integrated pest management. International Organization for Biological Control Bulletin, 21, 105-110.

GarBE, V. (2000). Fungizideinsatz im Winterraps. Raps, 18, 60-65. 
GeISLER, G. \& HENNING, K. (1981a). Untersuchungen zur Ertragsstruktur von Raps

(Brassica napus L. var. napus). I. Die vegetative Entwicklung der Rapspflanze in Abhängigkeit von der Bestandesdichte. Bayer. Landw. Jahrb., 58, 203-211.

GEISLER, G. \& HENNING, K. (1981b). Untersuchungen zur Ertragsstruktur von Raps

(Brassica napus L. var. napus). II. Die generative Entwicklung der Rapspflanze in Abhängigkeit von der Bestandesdichte. Bayer. Landw. Jahrb., 58, 322-332.

Geisler, G. \& Stoy, A. (1987). Untersuchungen zum Einfluß der Bestandesdichte auf das Ertragspotential von Rapspflanzen (Brassica napus L. var. napus). Journal of Agronomy and Crop Science, 159, 232-240.

GERHARD, M. (2001). Der Einfluß strobilurinhaltiger Fungizide auf physiologische Abläufe der Ertragsbildung an Weizensorten. Dissertation, Technische Universität München, Wissenschaftszentrum für Ernährung, Landnutzung und Umwelt Weihenstephan.

GISI, U., ChIN, K.M., KNAPOVA, G., KÜNG FÄRBER, R., Mohr, U. \& PARISI, S. et al. (2000). Recent developments in elucidating modes of resistance to phenylamide, DMI and strobilurin fungicides. Crop Protection, 19, 863-872.

GLADDERS, P. \& MuSA, T.M. (1980). Observations on the epidemiology of Leptosphaeria maculans stem canker in winter oilseed rape. Plant Pathology, 29, 28-37.

Gold, R., Köhle, H., Siefert, F. \& Grossmann, K. (1992). Aufnahme, Transport und Wirkungsmechanismus von BAS $480 \mathrm{~F}$ - einem neuen Getreidefungizid. In:

Mitteilungen aus der Biologischen Bundesanstalt für Land- und Forstwirtschaft, BerlinDahlem. 48. Deutsche Pflanzenschutztagung (Hrsg. Laux, W.). Paul Parey Kommissionsverlag, Berlin, Hamburg, 435.

GoWER, J.C. \& HAND, D.J. (1996). Biplots. Chapman \& Hall, London.

Graebe, J.E. (1987). Gibberellin Biosynthesis and Control. Annual Review of Plant Physiology, 38, 419-465.

Griggs, D.L., Hedden, P., Temple-Smith, K.E. \& Rademacher, W. (1991). Inhibition of gibberellin $2 \beta$-hydroxylases by acylcyclohexanedione derivatives. Phytochemistry, 30 , 2513-2517.

GROSSE, F. (1989). Untersuchungen zur Ertragsbildung und Ertragsstruktur in einem Winterrapssortiment. Dissertation, Christian-Albrechts-Universität Kiel.

GrossmanN, K. (1990). Plant growth retardants as tools in physiological research. Physiologia Plantarum, 78, 640-648.

GrossmanN, K., SaUERBREY, E. \& JUNG, J. (1989). Synthetische Wachstumsretardanzien - was sie bewirken. Biologie in unserer Zeit, 19, 112-120.

HABEKOTTÉ, B. (1993). Quantitative analysis of pod formation, seed set and seed filling in winter oilseed rape (Brassica napus L.) under field conditions. Field Crops Res., 35, 21-33. 
HABEKOTTE', B. (1997c). Evaluation of seed yield determining factors of winter oilseed rape (Brassica napus L.) by means of crop growth modelling. Field Crops Research, 54, 137-151.

HABEKOTTE', B. (1997b). Options for increasing seed yield of winter oilseed rape (Brassica napus L.): a simulation study. Field Crops Research, 54, 109-126.

HAHN, M. (2013). Auswertung langjähriger Versuchsreihen zu Fungiziden in Raps, Vortrag beim Treffen der DPG Arbeitsgruppe Raps am 26.02.2013 in Braunschweig.

HALL, R. (1992). Epidemiology of blackleg of oilseed rape. Canadian Journal of Plant Pathology, 14, 46-55.

Hallmann, J., Quadt-Hallmann, A. \& Tiedemann, A. von (2009). Phytomedizin. [Grundwissen Bachelor]. 2. Aufl. Ulmer, Stuttgart.

HAMMOND, K.E. \& LEWIS, B.G. (1986). The timing and sequence of events leading to stem canker disease in populations of Brassica napus var. oleifera in the field. Plant Pathology, 35, 551-564.

HAMmOND, K.E., LEWIS, B.G. \& MUSA, T.M. (1985). A systemic pathway in the infection of oilseed rape plants by Leptosphaeria maculans. Plant Pathology, 34, 557-565.

HANHART, H. (2014). Raps: Witterung entscheidet über Fungizideinsatz. Top Agrar, 2014, 70-74.

HaRtleb, H., WolfF, C., Kufeld, W. \& Briswitz, H. (1998). Phoma-Spätbefall durch Triebrüsslerbekämpfung reduzieren. Raps, 16, 26-31.

HEDDEN, P. (1991). Gibberellin biosynthetic enzymes and the regulation of gibberellin concentrations. In: Gibberellins (Hrsg. Takahashi, N., Phinney, B.O. \& MacMillan, J.). Springer, New York, 94-105.

Hedden, P., Croker, S.J., Rademacher, W. \& Jung, J. (1989). Effects of the triazole plant growth retardant BAS $111 \mathrm{~W}$ on gibberellin levels in oilseed rape, Brassica napus. Physiologia Plantarum, 75, 445-451.

HEDDEN, P. \& GRAEBE, J.E. (1985). Inhibition of gibberellin biosynthesis by paclobutrazol in cell-free homogenates of Cucurbita maxima endosperm and Malus pumila embryos. Journal of Plant Growth Regulation, 4, 111-122.

HELMSCHROT, J. (1999). Integration von Fernerkundung, GIS und empirischer Geländeaufnahme zur Parameterisierung physiographischer Faktoren für die distributive hydrologische Modellierung. Eine Fallstudie im semiariden Flußeinzugsgebiet des Umzimvubu, Ostkap Provinz, Südafrika. Diplomarbeit (unveröffentlicht), Friedrich-Schiller-Universität Jena.

HENNING, K. (1979). Untersuchungen über die Entwicklung und Ertragsbildung zweier Winterrapssorten unter besonderer Berücksichtigung des Einflusses von Bestandesdichte und Saatzeit. Dissertation, Christian-Albrechts-Universität Kiel. 
HILDEBRANDT, G. (1996). Fernerkundung und Luftbildmessung. Für Forstwirtschaft, Vegetationskartierung und Landschaftsökologie. 1. Aufl. Wichmann, Heidelberg. HodGSON, A.S. (1979). Rapeseed adaptation in northern New South Wales. III. Yield, yield components and grain quality of Brassica campestris and Brassica napus in relation to planting date. Australian Journal of Agricultural Research, 30, 19-27.

HOWLETT, B.J. (2004). Current knowledge of the interaction between Brassica napus and Leptosphaeria maculans. Canadian Journal of Plant Pathology, 26, 245-252.

Howlett, B.J., IDNURM, A. \& PedRAS, M.S. (2001). Leptosphaeria maculans, the causal agent of Blackleg Disease of Brassicas. Fungal Genetics and Biology, 33, 1-14. HÜNMÖRDER, S. (2003). Untersuchungen zur Biologie, Ökologie und Bekämpfung der Kleinen Kohlfliege (Delia radicum L.) an Winterraps. Diplomarbeit, Universität Rostock. INANAGA, S., KUmURA, A. \& MuRATA, Y. (1979). Photosynthesis and yield of rapeseed. Japan Agricultural Research Quarterly, 13, 169-172.

INMAN, D., KHOSLA, R. \& MAYFIELD, T. (2005). On-the-go active remote sensing for efficient crop nitrogen management. Sensor Review, 25, 209-214.

JENKINS, P.D. \& LEITCH, D.M.H. (1986). Effects of sowing date on the growth and yield of winter oil-seed rape (Brassica napus). The Journal of Agricultural Science, 107, 405420.

JUnG, J., LUiB, M., SAUter, H., Zeeh, B. \& RademacheR, W. (1987). Growth regulation in crop plants with new types of triazole compounds. Journal of Agronomy and Crop Science, 158, 324-332.

KEILLER, D.R. \& MORGAN, D.G. (1988). Distribution of 14 carbon-labelled assimilates in flowering plants of oilseed rape (Brassica napus L.). The Journal of Agricultural Science, 111, 347-355.

Kende, H. \& ZeEvaART, J.A.D. (1997). The five "classical" plant hormones. The Plant Cell, 9, 1197-1210.

KENWARD, M.G. \& RogeR, J.H. (1997). Small sample inference for fixed effects from restricted maximum likelihood. Biometrics, 53, 983-997.

KEUNECKE, H. (2009). Einfluss von Kohlfliegenbefall auf die Infektion und Schadwirkung von Verticillium longisporum und Phoma lingam an Raps. Dissertation, Georg-AugustUniversität Göttingen.

KHALIL, I.A. \& RAHMAN, H.-u. (1995). Effect of paclobutrazol on growth, chloroplast pigments and sterol biosynthesis of maize (Zea mays L.). Plant Science, 105, 15-21.

KHANGURA, R.K. \& BARBETTI, M.J. (1999). Chemical control of blackleg disease of canola in Western Australia. In: Proceedings of the $10^{\text {th }}$ International Rapeseed Congress (Hrsg. Wratten, N. \& Salisbury, P.A.). The regional institute Ltd., Canberra, Australia, 194. 
KHANGURA, R.K. \& BARBETTI, M.J. (2002). Efficacy of Impact® to manage blackleg (Leptosphaeria maculans) in canola. Australian Journal of Agricultural Research, 53, 311-321.

Kim, Y., Glenn, D.M., PARK, J., NGugl, H.K. \& Lehman, B.L. (2010). Active spectral sensor evaluation under varying conditions. ASABE Meeting Presentation, Paper Number: 1009111.

KošŤÁL, V. (1993). Physical and chemical factors influencing landing and oviposition by the cabbage root fly on host-plant models. Entomologia Experimentalis et Applicata, $66,109-118$.

KRÄMER, D.W. (1986). Chemistry of sterol biosynthesis inhibiting fungicides. In: Chemistry of Plant Protection. Volume 1: Sterol Biosynthesis Inhibitors and Anti-Feeding Compounds (Hrsg. Haug, G. \& Hoffmann, H.). Springer Verlag, Berlin, Heidelberg, 2564.

KRÜGER, W. (1982). Die Wurzelhals- und Stängelfäule des Rapses, verursacht durch Phoma lingam (Leptosphaeria maculans), eine schwer bekämpfbare Krankheit. Zeitschrift für Pflanzenkrankheiten und Pflanzenschutz, 89, 498-507.

KRULL, A. (2013). Ergebnisse zum Wachstumsregler- und Fungizideinsatz in Niedersachsen, Vortrag beim Treffen der DPG Arbeitsgruppe Raps am 26.02.2013 in Braunschweig.

KRUSE, T. (2004). Epidemiologie, Bedeutung und integrierte Bekämpfungsmöglichkeiten von Leptosphaeria maculans (Phoma lingam) sowie weiterer pilzlicher Krankheitserreger im schleswig-holsteinischen Winterrapsanbau (Brassica napus L. var. napus). Dissertation, Christian-Albrechts-Universität Kiel.

KRZANOWSKI, W.J. (1990). Principles of multivariate analysis. A user's perspective. Clarendon Press, Oxford.

KUCK, K.H., ScheinPflug, H. \& PONTZEN, R. (1995). DMI fungicides. In: Modern Selective Fungicides - Properties, Applications, Mechanisms of Action (Hrsg. Lyr, H.). Gustav Fischer Verlag, Jena, 205-258.

LACAZE, B. (1996). Spectral Characterisation of Vegetation Communities and Practical Approaches to Vegetation Cover Changes Monitoring. In: The use of remote sensing for land degradation and desertification monitoring in the Mediterranean basin. State of the art and future research ; proceedings of an experts workshop jointly organized by JRC/IRSA and DG XIII/D.2,D.4 Valencia, Spain, from 13 to 15 June 1994 (Hrsg. Hill, J.). Off. for Off. Publ. of the Europ. Communities, Luxembourg, 149-156.

LANDWIRTSCHAFTSKAMMER NIEDERSACHSEN (2009). Landessortenversuche Winterraps 2009. URL http://www.lwk- 
niedersachsen.de/index.cfm/portal/pflanze/nav/327/article/12638.html, online abgerufen am 08.05.2014.

LANDWIRTSCHAFTSKAMMER NIEDERSACHSEN (2010). Landessortenversuche Winterraps 2010. URL http://www.Iwk-

niedersachsen.de/index.cfm/portal/pflanze/nav/327/article/12638.html, online abgerufen am 08.05.2014.

LANDWIRTSCHAFTSKAMMER NIEDERSACHSEN (2011). Landessortenversuche Winterraps 2011. URL http://www.Iwk-

niedersachsen.de/index.cfm/portal/pflanze/nav/327/article/12638.html, online abgerufen am 08.05.2014.

LANDWIRTSCHAFTSKAMMER NIEDERSACHSEN (2012). Landessortenversuche Winterraps 2012. URL http://www.lwk-

niedersachsen.de/index.cfm/portal/pflanze/nav/327/article/19979.html, online abgerufen am 08.05.2014.

LANDWIRTSCHAFTSKAMMER NORDRHEIN-WESTFALEN (2007). Landessortenversuche Winterraps 2007. URL

https://www.landwirtschaftskammer.de/landwirtschaft/ackerbau/raps/lsvarchiv/winterrap s-sv-2007.htm, online abgerufen am 08.05.2014.

LANDWIRTSCHAFTSKAMMER NORDRHEIN-WESTFALEN (2008). Landessortenversuche Winterraps 2008, erste Ergebnisse. URL https://www.landwirtschaftskammer.de/landwirtschaft/ackerbau/raps/lsvarchiv/winterrap s-sv-1-2008.htm, online abgerufen am 08.05.2014.

LANDWIRTSCHAFTSKAMMER NORDRHEIN-WESTFALEN (2009). Landessortenversuche Winterraps 2009, erste Ergebnisse. URL https://www.landwirtschaftskammer.de/landwirtschaft/ackerbau/pdf/tabellen-winterrapssv-1-2009.pdf, online abgerufen am 08.05.2014.

LANDWIRTSCHAFTSKAMMER NORDRHEIN-WESTFALEN (2010). Landessortenversuche Winterraps 2010, erste Ergebnisse. URL https://www.landwirtschaftskammer.de/landwirtschaft/ackerbau/pdf/tabellen-winterrapssv-1-2010.pdf, online abgerufen am 08.05.2014.

LANDWIRTSCHAFTSKAMMER NORDRHEIN-WESTFALEN (2014). Ratgeber Pflanzenbau und Pflanzenschutz. Ausgabe 2014. 19. Aufl. Kölln-Druck \& Verlag GmbH KG, Bonn. LANDWIRTSCHAFTSKAMMER SCHLESWIG-HOLSTEIN (2010a). Landessortenversuche Winterraps 2010, Marsch. URL http://www.lksh.de/landwirtschaft/pflanze/oelsaatenund-koernerleguminosen/winterraps/, online abgerufen am 08.05.2014. 
LANDWIRTSCHAFTSKAMMER SCHLESWIG-HOLSTEIN (2010b). Landessortenversuche

Winterraps 2010, Geest. URL http://www.Iksh.de/landwirtschaft/pflanze/oelsaaten-undkoernerleguminosen/winterraps/, online abgerufen am 08.05.2014.

LANDWIRTSCHAFTSKAMMER SCHLESWIG-HOLSTEIN (2010c). Landessortenversuche Winterraps 2010, Hügelland. URL http://www.Iksh.de/landwirtschaft/pflanze/oelsaatenund-koernerleguminosen/winterraps/, online abgerufen am 08.05.2014.

LARCHER, W. (1984). Ökologie der Pflanzen auf physiologischer Grundlage. 4. Aufl. Ulmer, Stuttgart.

LeACH, J.E., Milford, G.F., Mullen, L.A., Scott, T. \& SteVenson, H.J. (1989). Accumulation of dry matter in oilseed rape crops in relation to the reflection and absorption of solar radiation by different canopy structures. Aspects of Applied Biology, 23, 117-123.

LeACH, J.E., SteVenson, H.J., RainBow, A.J. \& MulLen, L.A. (1999). Effects of high plant populations on the growth and yield of winter oilseed rape (Brassica napus). The Journal of Agricultural Science, 132, 173-180.

LeON, J. \& BECKER, H. (1995). Rapeseed (Brassica napus L.). Genetics. In: Physiological potentials for yield improvement of annual oil and protein crops. Advances in plant breeding. Supplement 17 to the Journal "Plant Breeding" (Hrsg. Diepenbrock, W. \& Becker, H.). Blackwell Wissenschafts-Verlag, Berlin, Wien, 53-81.

Leroux, P., Bach, J., Debieu, D., Fillinger, S., Fritz, R. \& Walker, A.-S. (2008). Mode of action of sterol biosynthesis inhibitors and resistance phenomena in fungi. In: Modern Fungicides and Antifungal Compounds V (Hrsg. Dehne, H.-W., Deising, H.B., Gisi, U., Kuck, K.H., Russel, P.E. \& Lyr, H.). Deutsche Phytomedizinische Gesellschaft, Selbstverlag, Braunschweig, 85-92.

LeTERME, P. (1988). Croissance et développement du colza d'hiver: Les principales étapes. In: CETIOM (Ed.), Colza - Physiologie et élaboration du rendement du colza d’hiver. Suppl. Inf. Techn. CETIOM, 103, 23-33.

LEVER, B.G., SHEARING, S.J. \& BATCH, J.J. (1982). PP 333 - a new broad spectrum growth retardant. In: Brighton Crop Protection Conference - Weeds, 1 (Hrsg. Anonymus). British Crop Protection Council Publications, Croydon, UK, 3-10.

LIM, P.O., KIM, H.J. \& NAM, H.G. (2007). Leaf senescence. Annual review of plant biology, $58,115-136$.

LIU, D. (1983). The senescence of plant leaves. Plant Physiology Communications, 1419.

LUNN, G.D., SPINK, J.H. \& STOKES, D.T. (2001). Canopy management in winter oilseed rape. Project report no. OS49. 
LUNN, G.D., SpINK, J.H., WADE, A. \& ClARE, R.W. (2003). Spring remedial treatments to improve canopy structure and yield in winter oilseed rape. Project report no. OS 64.

LÜRSSEN, K. (1988). Plant physiological and biochemical activity of the new plant growth regulator triapenthenol (RSW 0411). Pflanzenschutz-Nachrichten Bayer, 41, 306-339.

MA, B.L., DWYER, L.M., CostA, C., COBER, E.R. \& MORRISON, M.J. (2001). Early prediction of soybean yield from canopy reflectance measurements. Agronomy Journal, 93, 1227-1234.

MCGREGOR, D.I. (1987). Effect of plant density on development and yield of rapeseed and its significance to recovery from hail injury. Canadian Journal of Plant Science, 67, 4351.

MCWILLIAM, S.C. (1998). Plant establishment, canopy structure and yield improvement in oilseed rape. Dissertation, University of Nottingham.

McWilliam, S.C., StAFFORD, J.A., Scott, R.K., Norton, G. \& StOKES, D.T. (1995). The relationship between canopy structure and yield in oilseed rape. In: Proceedings of the $9^{\text {th }}$ International Rapeseed Congress. Rapeseed Today and Tomorrow. Organising Committee of the Ninth International Rapeseed Congress, Cambridge, UK, 491-493.

MEIER, U. (2001). Entwicklungsstadien mono- und dikotyler Pflanzen. BBCH Monografie. 2. Aufl., Braunschweig.

MENARD, S.W. (1995). Applied logistic regression analysis. 1. Aufl. Sage, Thousand Oaks, Calif.

MEndham, N.J., ShIPWAY, P.A. \& ScotT, R.K. (1981a). The effects of delayed sowing and weather on growth, development and yield of winter oilseed rape (Brassica napus). The Journal of Agricultural Science, 96, 389-416.

Mendham, N.J., ShIPWAY, P.A. \& ScotT, R.K. (1981b). The effects of seed size, autumn nitrogen and plant population density on the response to delayed sowing in winter oilseed rape (Brassica napus) . The Journal of Agricultural Science, 96, 417-428.

MORGAN, D.G. (1982). Agriculture group symposium recent UK research on oilseed rape. The regulation of yield components in oilseed rape (Brassica napus L.). Journal of the Science of Food and Agriculture, 33, 1266-1268.

MYERS, R.H. (1990). Classical and modern regression with applications. 2. Aufl. Duxbury/Thompson Learning, Pacific Grove, CA.

Nakayama, I., Miyazawa, T., Kobayashi, M., Kamiya, Y., Abe, H. \& SakuRal, A. (1990). Effects of a new plant growth regulator prohexadione calcium (BX-112) on shoot elongation caused by exogenously applied gibberellins in rice (Oryza sativa L.) seedlings. Plant and Cell Physiology, 31, 195-200.

Nakayama, J., Miyazawa, T., Kobayashi, M., Kamiya, Y., Abe, H. \& SakuRal, A. (1991). Studies on the action of the plant growth regulator BX-112, DOCHC, and DOCHC-Et. 
In: Gibberellins (Hrsg. Takahashi, N., Phinney, B.O. \& MacMillan, J.). Springer, New York, 311-319.

Ndimande, B. (1976). Studies on Phoma lingam (Tode ex. Fr.) Desm. and the dry rot in oilseed rape, Brassica napus (L.) var. oleifera Metzger. PhD-Thesis, Agricultural College of Sweden, Uppsala, Sweden.

NEWMAN, P.L. (1984). The effects of insect larval damage upon the incidence of canker in winter oilseed rape. Proceedings of Brighton Crop Protection Conference - Pests and Diseases, 815-822.

Newman, P.L. \& PlumRidge, H. (1983). The effect of insect damage on the incidence of infection of Phoma lingam in winter oilseed rape. Eucarpia: Cruciferae Newsletter No. 8, 30-31.

NöтH, U. (2010). Einsatz von Wachstumsreglern im Herbst. Raps, 28, 214-218.

NULTSCH, W. (2001). Allgemeine Botanik. 11. Aufl. Georg Thieme Verlag, Stuttgart.

PAUL, V.H., DAPPRICH, P., LIU, Y. \& SCHULZE-WieTIS, F. (2001). Einsatz von

Wachstumsregulatoren. Möglichkeiten zur Verbesserung von Rapsanbauverfahren mit Triazolwirkstoffen. Raps, 19, 184-189.

Pechan, P.A. \& Morgan, D.G. (1985). Defoliation and its effects on pod and seed development in oil seed rape (Brassica napus L.). Journal of Experimental Botany, 36, 458-468.

Peñuelas, J., Gamon, J.A., Fredeen, A.L., Merino, J. \& Field, C.B. (1994). Reflectance indices associated with physiological changes in nitrogen- and water-limited sunflower leaves. Remote Sensing of Environment, 48, 135-146.

QUILLERE, I. \& TRIBOI, A.-M. (1987). Dynamique des reserves carbonée chez le colza d'hiver: impacts sur la croissance. In: Proceedings of the 7th International Rapeseed Congress (Hrsg. Instytut Hodowli i Aklimatyzacji Roślin), Poznań, Poland, 219-223.

RADEMACHER, W. (1991). Inhibitors of Gibberellin Biosynthesis: Applications in Agriculture and Horticulture. In: Gibberellins (Hrsg. Takahashi, N., Phinney, B.O. \& MacMillan, J.). Springer, New York, 296-310.

RADEMACHER, W. (2000). Growth retardants: Effects on gibberellin biosynthesis and other metabolic pathways. Annual review of plant physiology and plant molecular biology, 51 , 501-531.

Rademacher, W., Fritsch, H., Graebe, J.E., Sauter, H. \& JunG, J. (1987). Tetcyclacis and triazole-type plant growth retardants: Their influence on the biosynthesis of gibberellins and other metabolic processes. Pesticide Science, 21, 241-252.

RAKOW, G. (1978). Zur Formulierung von Zuchtzielen für Körnerraps. Fette, Seifen, Anstrichmittel, 80, 93-99. 
RAO, M.S.S. \& MendhAM, N.J. (1991a). Comparison of chinoli (Brassica campestris subsp. oleifera $\times$ subsp. chinensis) and $B$. napus oilseed rape using different growth regulators, plant population densities and irrigation treatments. The Journal of Agricultural Science, 117, 177-187.

RAO, M.S.S., MendHAM, N.J. \& BuZZA, G.C. (1991b). Effect of the apetalous flower character on radiation distribution in the crop canopy, yield and its components in oilseed rape (Brassica napus). The Journal of Agricultural Science, 117, 189-196.

Raun, W.R., Solie, J.B., Johnson, G.V., Stone, M.L., LukinA, E.V. \& ThOMAson, W.E. et al. (2001). In-season prediction of potential grain yield in winter wheat using canopy reflectance. Agronomy Journal, 93, 131-138.

REMPEL, C.B., LISIECZKO, Z. \& HALL, R. (1991). Epidemiological aspects of resistance in rapeseed to blackleg. In: GCIRC Eighth International Rapeseed Congress, July 9 to 11, 1991, Saskatoon, Saskatchewan, Canada (Hrsg. McGregor, D.I. \& Groupe consultatif international de recherche sur la colza. Canola Council of Canada.). Organizing Committee of the Eighth International Rapeseed Congress, Saskatoon, Canada, 460 464.

RICHARDSON, P.J. \& QUINLAN, J.D. (1986). Uptake and translocation of paclobutrazol by shoots of M.26 apple rootstock. Plant Growth Regulation, 4, 347-356.

RobeliN, M. \& TRIBOI, A.-M. (1983). Assimilation nette d' une culture de colza d'hiver au cours du cycle de végétation sous I' influence de l' enviroment climatique de la densité du peuplement et de la fertilisation azotée. In: Proceedings of the 6th International Rapeseed Conference, Paris, May 17-19, 1983 (Hrsg. Groupe consultatif international de recherche sur le colza). Organizing committee of the 6th International Rapeseed Conference, 98-103.

ROESSINGH, P. \& STÄDLER, E. (1990). Foliar form, colour and surface characteristics influence oviposition behaviour in the cabbage root fly Delia radicum. Entomologia Experimentalis et Applicata, 57, 93-100.

ROOD, S.B. \& MAJOR, D.J. (1984). Influence of plant density, nitrogen, water supply and pod or leaf removal on growth of oilseed rape. Field Crops Research, 8, 323-331.

ROOD, S.B., MAJOR, D.J. \& CHARNETSKI, W.A. (1984). Seasonal changes in ${ }^{14} \mathrm{CO}_{2}$ assimilation and ${ }^{14} \mathrm{C}$ translocation in oilseed rape. Field Crops Research, 8, 341-348.

ROUSE, J.W. (1973). Monitoring the vernal advancement and retrogradation of natural vegetation. NASA/GSFCT Type II Report, Greenbelt, MD, USA.

Rouse, J.W., HaAs, R.W., Schell, J.A., DeERING, D.W. \& Harlan, J.C. (1974). Monitoring the vernal advancement and retrogradation (Greenwave effect) of natural vegetation. NASA/GSFCT Type III final report, Greenbelt, MD, USA. 
Salisbury, P.A., Ballinger, D.J., Wratten, N., Plummer, K.M. \& Howlett, B.J. (1995). Blackleg disease on oilseed Brassica in Australia: a review. Australian Journal of Experimental Agriculture, 35, 665-672.

ScarisbriCK, D.H., Addo-Quaye, A.A., DANiEls, R.W. \& MAHAMUd, S. (1985). The effect of paclobutrazol on plant height and seed yield of oil-seed rape (Brassica napus L.). The Journal of Agricultural Science, 105, 605-612.

SCARISBRICK, D.H., DANIELS, R.W. \& ALCOCK, M. (1981). The effect of sowing date on the yield and yield components of spring oil-seed rape. The Journal of Agricultural Science, 97, 189-195.

ScARISBRICK, D.H., DANiELS, R.W., ChapMAN, J. \& PARR, M. (1980). The effect of nitrogen on the development of spring oilseed rape. Experimental Husbandry, 37, 63-73.

SCARISBRICK, D.H., DANIELS, R.W. \& NoOR RAWI, A.B. (1982). The effect of varying seed rate on the yield and yield components of oil-seed rape (Brassica napus). The Journal of Agricultural Science, 99, 561-568.

SCHEER, M. (1983). Die Saat als Mittel zur Optimierung inner- und zwischenpflanzlicher Konkurrenzverhältnisse bei Winterweizen und Möglichkeiten der Regulation durch Pflanzenschutz und N-Düngung. Dissertation, Rheinische Friedrich-WilhelmsUniversität Bonn.

SCHMIEDEL, J. \& KÖPPL, H. (1996). Lohnt sich der Fungizideinsatz im Raps. Raps, 14, 1619.

SCHNELL, R. (1994). Graphisch gestützte Datenanalyse. Oldenbourg, München.

SCHÖNBERGER, H. (2012). Rapsanbau. Leitfaden für Bestandesaufbau, Bestandesführung und Ertragssicherung. AgroConcept Verlagsgesellschaft GmbH, Bonn.

SCHULZ, R.R. (1992). Einfluss von tierischen Schaderregern auf Ertragskomponenten und Pilzbefall von Winterraps. Raps, 10, 37-39.

SCHULZ, R.R. \& DAEBELER, F. (1984). Zum Schaden durch den Rapserdfloh (Psylliodes chrysocephala L.), insbesondere seiner Imagines. Nachrichtenblatt für den Pflanzenschutz in der DDR, 38, 113-115.

SCHULZ, S. (1987). Ertragsphysiologische Untersuchungen zur Ontogenese der Rapsfrucht (Brassica napus L.). Dissertation, Christian-Albrechts-Universität Kiel.

ScotT, R.K., OGUnREMI, E.A., IVINS, J.D. \& MENDHAM, N.J. (1973b). The effect of fertilizers and harvest date on growth and yield of oilseed rape sown in autumn and spring. The Journal of Agricultural Science, 81, 287-293.

Scott, R.K., OGunREMI, E.A., IVINS, J.D. \& MENDhAM, N.J. (1973a). The effect of sowing date and season on growth and yield of oilseed rape (Brassica napus). The Journal of Agricultural Science, 81, 277-285. 
Scott, R.K., Stokes, D.T., McWilliam, S.C., SpinK, J.H. \& ClaRE, R.W. (1999). Yield improvement through canopy management. In: Proceedings of the $10^{\text {th }}$ International Rapeseed Congress (Hrsg. Wratten, N. \& Salisbury, P.A.). The regional institute Ltd., Canberra, Australia, 313.

SEIFFERT, M. \& BOELCKE, B. (1977). Untersuchungen zur Ertragsbildung bei Winterraps. Tag.-Ber. d. Akad. Landwirtsch.-Wiss. DDR, Berlin, 149, 185-192.

SELLERS, P.J. (1987). Canopy reflectance, photosynthesis, and transpiration, II. The role of biophysics in the linearity of their interdependence. Remote Sensing of Environment, $21,143-183$.

SHANER, G. \& FINNEY, R.E. (1977). The effect of nitrogen fertilization on the expression of slow-mildewing resistance in knox wheat. Phytopathology, 67, 1051-1056.

SHECHTER, I. \& WEST, C.A. (1969). Biosynthesis of gibberellins. IV. Biosynthesis of cyclic diterpenes from trans-geranylgeranyl pyrophosphate. The Journal of biological chemistry, 244, 3200-3209.

SiEfERT, F. \& GrossmanN, K. (1996). Nichtfungizide Nebenwirkungen von Triazolverbindungen am konkreten Beispiel des Triazolfungizides Epoxiconazol. Gesunde Pflanzen, 48, 224-231.

SIERTS, H.P. (1987). Untersuchung zum Einfluß der intraspezifischen Konkurrenz auf die Ausprägung und Stabilität (Ökovalenz) der leistungsbestimmenden Merkmale bei Winterraps unter Berücksichtigung der Ertragsstruktur. Dissertation, ChristianAlbrechts-Universität Kiel.

SierTS, H.-P., GeISleR, G., LeON, J. \& DiePENBROCK, W. (1987). Stability of yield components from winter oil-seed rape (Brassica napus L.). Journal of Agronomy and Crop Science, 158, 107-113.

SIMPSON, G.M. (1968). Association between grain yield per plant and photosynthetic area above the flag-leaf node in wheat. Canadian Journal of Plant Science, 48, 253-260.

Solie, J.B., Stone, M.L., Raun, W.R., Johnson, G.V., Freeman, K. \& Mullen, R. et al. (2002). Real-time sensing and $N$ fertilization with a field scale GreenSeeker ${ }^{T M}$ applicatior. In: Proceedings of the 6th International Conference on Precision Agriculture and Other Precision Resources Management, July 14-17, 2002, Minneapolis, MN USA (Hrsg. Robert, P.C.), 1466-1476.

Sosnowski, M., Ramsey, M., MurRay, G., Scott, E. \& WILMSHURSt, C. (2001). Symptoms of blackleg (Leptosphaeria maculans) on the roots of canola in Australia. NEW DISEASE REPORT. Plant Pathology, 50, 808.

Sprague, S.J., Watt, M., KirkegaARD, J.A. \& Howlett, B.J. (2007). Pathways of infection of Brassica napus roots by Leptosphaeria maculans. The New phytologist, 176, 211-222. 
STAFFORD, J.A. (1996). The effects of Prochloraz on the growth and yield of oilseed rape.

Dissertation, University of Nottingham.

StAFFORD, J.A., NORTON, G., ScotT, R.K. \& StOKES, D.T. (1995). Effects of prochloraz on the physiology of oilseed rape. In: Proceedings of the $9^{\text {th }}$ International Rapeseed Congress. Rapeseed Today and Tomorrow. Organising Committee of the Ninth International Rapeseed Congress, Cambridge, UK, 512-514.

STATISTISCHES BUNDESAMT (2013). Ernte-u.Betriebsbericht: Feldfrüchte und Grünland; Deutschland; Anbaufläche (ha) und Ertrag je Hektar (dt/ha), Wiesbaden.

StemANN, G. (2014). Erfolgreiche Bestandesetablierung. Raps, 32, 36-41.

STOY, A. (1983). Untersuchungen zur Konkurrenz bei Winterraps (Brassica napus var. napus L.) vor und nach dem Überwintern und deren Bedeutung für das Ertragspotenzial des Bestandes. Dissertation, Christian-Albrechts-Universität Kiel.

SugAVANAM, B. (1984). Diastereoisomers and enantiomers of paclobutrazol: Their preparation and biological activity. Pesticide Science, 15, 296-302.

Sun, P., FitT, B.D.L., Gladders, P. \& Welham, S.J. (2000). Relationships between phoma leaf spot and development of stem canker (Leptosphaeria maculans) on winter oilseed rape (Brassica napus) in southern England. Annals of Applied Biology, 137, 113-125.

taton, M., Ullmann, P., Benveniste, P. \& Rahier, A. (1988). Interaction of triazole fungicides and plant growth regulators with microsomal cytochrome P-450-dependent obtusifoliol 14a-methyl demethylase. Pesticide Biochemistry and Physiology, 30, 178189.

TAYO, T.O. \& MORGAN, D.G. (1979). Factors influencing flower and pod development in oil-seed rape (Brassica napus L.). The Journal of Agricultural Science, 92, 363-373.

ThenkABAIL, P.S., SMith, R.B. \& PAUW, E. de (2000). Hyperspectral Vegetation Indices and Their Relationships with Agricultural Crop Characteristics. Remote Sensing of Environment, 71, 158-182.

THURLING, N. (1974). Morphophysiological determinants of yield in rapeseed (Brassica campestris and Brassica napus ). II. Yield components. Australian Journal of Agricultural Research, 25, 711-721.

THÜRWÄCHTER, F. (1995). Kriterien für die Bekämpfung von Rapskrankheiten unter besonderer Berücksichtigung der Wurzelhals- und Stengelfäule. Dissertation, GeorgAugust-Universität Göttingen.

TOLBERT, N.E. (1960a). (2-Chloroethyl) trimethylammonium chloride and related compounds as plant growth substances. I. Chemical structure and bioassay. The Journal of biological chemistry, 235, 475-479. 
TOLBERT, N.E. (1960b). (2-Chloroethyl) Trimethylammonium Chloride and Related Compounds as Plant Growth Substances. II. Effect on Growth of Wheat. Plant Physiol., 35, 380-385.

TRAYNIER, R.M.M. (1965). Chemostimulation of oviposition by the cabbage root fly Erioischia brassicae (Bouché). Nature, 207, 218-219.

TRAYNIER, R.M.M. (1967). Effect of host plant odour on the behaviour of the adult cabbage root fly, Erioischia brassicae. Entomologia Experimentalis et Applicata, 10, 321-328.

ULBER, B. (1994). Wirkung des kombinierten Befalls von Winterraps mit dem Großen Rapsstängelrüssler (Ceutorhynchus napi Gyll.) und dem Gefleckten Kohltriebrüssler (Ceutorhynchus pallidactylus (Mrsh.) auf den Befall von Phoma lingam. In: Mitteilungen aus der Biologischen Bundesanstalt für Land- und Forstwirtschaft, Berlin-Dahlem. 49. Deutsche Pflanzenschutztagung (Hrsg. Laux, W.). Blackwell Wissenschafts-Verlag, Berling, 96.

von Tiedemann, A. \& SteinBach, P. (2007). Krankheiten durch pilzliche Pathogene. In: Winterraps. Das Handbuch für Profis (Hrsg. Christen, O. \& Friedt, W.). DLG-Verlag, Frankfurt am Main, 136-164.

VOSKERUSA, J. (1970). Wechselwirkung einiger agrotechnischer Faktoren auf Samenproduktion und Fettgehalt des Winterrapses. Zeitschrift für Acker- und Pflanzenbau, 131, 28-43.

VoßHENRICH, H.-H. \& HEEGE, H.J. (1985). Säverfahren und Ertrag bei Raps. Raps, 3, 9698.

WeILeR, E. \& NoVER, L. (2008). Allgemeine und molekulare Botanik. 1. Aufl. Georg Thieme Verlag, Stuttgart.

WeSt, J.S., KharbandA, P.D., BARBetTI, M.J. \& FitT, B.D.L. (2001). Epidemiology and management of Leptosphaeria maculans (phoma stem canker) on oilseed rape in Australia, Canada and Europe. Plant Pathology, 50, 10-27.

WherRetT, A.D., Sivasithamparam, K. \& BARBetti, M.J. (2004). Establishing the relationship of ascospore loads with blackleg (Leptosphaeria maculans) severity on canola (Brassica napus). Australian Journal of Agricultural Research, 55, 849.

WILLIAMS, I.H. (1978). The pollination requirements of swede rape (Brassica napus L.) and of turnip rape (Brassica campestris L.). The Journal of Agricultural Science, 91, 343348.

WILLIAMS, I.H. \& FREE, J.B. (1979). Compensation of oil-seed rape (Brassica napus L.) plants after damage to their buds and pods. The Journal of Agricultural Science, 92, 53-59.

WOHLLEBEN, S. (2001). Epidemie- und Schadensdynamik von pilzlichen Krankheitserregern (Leptosphaeria maculans, Sclerotinia sclerotiorum, Verticillium 
dahliae) an Winterraps (Brassica napus L. var. napus) in Schleswig-Holstein.

Dissertation, Christian-Albrechts-Universität Kiel.

Wohlrab, B., Ernstberger, H., Meuser, A. \& Sokollek, V. (1992).

Landschaftswasserhaushalt: Wasserkreislauf und Gewässer im ländlichen Raum; Veränderungen durch Bodennutzung, Wasserbau und Kulturtechnik. Paul Parey, Hamburg.

Wright, G.C., SMITH, C.J. \& WoOdroOFE, M.R. (1988). The effect of irrigation and nitrogen fertilizer on rapeseed (Brassica napus) production in south eastern Australia. Irrigation Science, 9, 1-13.

XI, K., MorRall, R., BaKeR, R.J. \& Verma, P.R. (1990). Relationship between incidence and severity of blackleg disease of rapeseed. Canadian Journal of Plant Pathology, 12, 164-169.

XI, K., Morrall, R., GugeL, R.K. \& Verma, P.R. (1991). Latent infection in relation to the epidemiology of blackleg of spring rapeseed. Canadian Journal of Plant Pathology, 13, 321-331.

YANG, T., DAVIES, P.J. \& REID, J.B. (1996). Genetic dissection of the relative roles of auxin and gibberellin in the regulation of stem elongation in intact light-grown peas. Plant Physiol., 110, 1029-1034.

YATES, D.J. \& STEVEN, M.D. (1987). Reflexion and absorption of solar-radiation by flower canopies of oilseed rape (Brassica napus L.). The Journal of Agricultural Science, 109, 495-502.

ZANEWICH, K.P. \& ROOD, S.B. (1993). Distribution of endogenous gibberellins in vegetative and reproductive organs of Brassica. Journal of Plant Growth Regulation, 12, 41-46.

ZEEH, B., KÖNIG, K.H. \& JUNG, J. (1974). Development of a new plant growth regulator with biological activity related to CCC. Kemia Kemi (Helsinki), 9, 621-623.

ZHOU, W. \& XI, H. (1993). Effects of mixtalol and paclobutrazol on photosynthesis and yield of rape (Brassica napus). Journal of Plant Growth Regulation, 12, 157-161.

Zhou, Y., FitT, B.D.L., Welham, S.J., Gladders, P., SANSFORD, C.E. \& West, J.S. (1999). Effects of severity and timing of stem canker (Leptosphaeria maculans) symptoms on yield of winter oilseed rape (Brassica napus) in the UK. European Journal of Plant Pathology, 105, 715-728. 


\section{Anhang}

\subsection{Anhang I: Infektionsversuche mit Botrytis cinerea an Winterraps}

\section{Einleitung}

Die Pilzart Botrytis cinerea Persoon: Fries (teleomorph Botryotinia fuckeliana (de Bary) Whetzel) ist der Erreger der Grauschimmelfäule (englisch: grey mould). Dieser hat eine nekrotrophe Lebensweise und befällt weltweit mehr als 235 verschiedene (MACFARLANE, 1968) vor allem dikotyle Pflanzenspezies. Dazu gehören bedeutende agronomische Kulturpflanzen aus dem Obstanbau (z.B. Erdbeere, Himbeere, Apfel, Weintrauben etc.), dem Gemüseanbau (z.B. Tomate, Gurke, Salat, Zwiebel etc.), dem Zierpflanzenanbau (z.B. die Gattung Amaryllis oder Gladiolen) und dem Ackerbau (z.B. Raps, Kartoffel etc.) (JARVIS, 1977; RADTKE et al., 2000; VON TIEDEMANN and STEINBACH, 2007). B. cinerea ist ein Schwächeparasit, der hauptsächlich über Wunden oder andere Schädigungen des Pflanzengewebes die Wirtspflanze infiziert. Je nach Wirtspflanze äußert sich der Befall in Form eines „damping-off“ (Umfallkrankheit) an jungen, gerade auflaufenden Pflanzen (eher selten) oder in Form einer Blüten-, Frucht-, Knollen-, Zwiebel- oder Stängelfäule, die meist durch Blattläsionen initiiert oder begleitet werden (sehr häufig). Die Krankheitssymptome können dabei vor der Ernte oder auch erst nach der Ernte während der Lagerung oder einem längeren Transport auftreten (AGRIOS, 2005).

An Winterraps tritt Befall mit B. cinerea zunächst an Laubblättern auf. Als erstes Symptom weisen die Laubblätter einen weißgrauen Fleck auf, der sich im weiteren Verlauf dunkelgrau bis beigebraun verfärbt. Die Befallsstellen werden größer und breiten sich über die gesamte Blattfläche aus. Schließlich werden die Laubblätter gelb, welken und sterben ab. Über den Blattstiel kann der Erreger in den Stängel wachsen. Hauptsächlich am unteren Teil des Haupttriebes erscheinen wie beim Blattbefall zuerst weißgraue und später beigebraune, ovale Befallsstellen, die sich stängelumfassend ausdehnen können. Befallene Pflanzen bleiben im Wachstum zurück oder werden notreif. Oft brechen die Pflanzen an der Infektionsstelle um. Symptome an Schoten äußern sich durch fahlbraune Flecken. Tritt zum Zeitpunkt des Befalls eine hohe Luftfeuchtigkeit auf, so kann sich an allen befallenen Pflanzenorganen ein graubrauner Konidiosporenrasen bilden (PAUL, 2003; VON TIEDEMANN and StEINBACH, 2007). Die Konidien werden durch Wind, Regen oder Insekten verbreitet. Das Pathogen überlebt saprophytisch auf abgestorbenen Pflanzenresten oder durch die Bildung von Überdauerungsorganen wie z.B. Sklerotien oder Chlamydosporen (HoLz et al., 2007). Der Erreger B. cinerea ist in allen 
Anbaugebieten von Winterraps präsent und tritt vor allem in kühl-feuchten Jahren auf. Der Pilz kann einen frühen Befall an Rapspflanzen auslösen, wenn diese ab Vegetationsstart oder während des Schossens durch Frost geschädigt wurden (PAUL, 2003; VON TIEDEMANN and STEINBACH, 2007).

Eine Koinzidenz von Frostschädigung und anschließendem Befall mit $B$. cinerea an Winterraps ist während dieser Promotionsarbeit im zweiten Versuchsjahr am Standort Göttingen aufgetreten. Nach einer strengen Frostperiode von Ende Januar bis Mitte Februar 2012 konnte ab Mitte März an den Laubblättern und an der Stängelbasis ein starker Befall mit B. cinerea festgestellt werden. Sehr wahrscheinlich hat der Erreger nach der Frostperiode die Pflanzen über die absterbenden Laubblätter infiziert. Der Pilz wuchs durch die Petiolen in Richtung Stängel und hat dort zu einem Fäulnisprozess des Stängels geführt. Die Pflanzenverluste waren durch den Frost und den folgenden Befall so massiv, dass der Feldversuch nicht fortgeführt werden konnte.

Neben der Region Göttingen und weiteren Landkreisen in Südniedersachsen wurden stärkere Schädigungen durch $B$. cinerea an Winterraps auch in Nordrhein-Westfalen, Hessen, Thüringen, Bayern, Baden-Württemberg, Rheinland-Pfalz und Brandenburg nachgewiesen, wodurch ganze Rapsschläge umgebrochen werden mussten (KLAEMT, 2012; TRENCKMANN, 2014). Dabei variierte die Umbruchquote je nach Bundesland zwischen 4-10\% (TRENCKMANN, 2014). Die zuvor genannten Umstände und kaum vorhandene Literatur über die Interaktion von $B$. cinerea und Winterraps führten zu dem Entschluss, Infektionsversuche mit $B$. cinerea unter kontrollierten Bedingungen an Winterraps durchzuführen. Das Ziel war, die Temperaturansprüche von $B$. cinerea bei der Infektion von Winterraps zu untersuchen und zu überprüfen, ob verschiedene Genotypen von Winterraps eine differenzierte Anfälligkeit gegenüber dem Erreger aufweisen. Indem Rapsgenotypen genutzt wurden, die eine unterschiedliche Variabilität in der Sortenanfälligkeit gegenüber Sclerotinia sclerotiorum (Lib.) de Bary zeigten (WULF, 2011), war es möglich einen Vergleich mit einer potenziellen Variabilität in der Sortenanfälligkeit gegenüber $B$. cinerea anzustellen. Weiterhin sollte geklärt werden, welchen Einfluss Verletzungsstellen auf den Befall mit B. cinerea haben und ob verschiedene Pflanzenorgane (Blatt/Stängel) eine unterschiedliche Anfälligkeit gegenüber diesem Erreger aufweisen. 


\section{Material und Methoden}

\section{II.1 Chemikalien und Nährmedien}

Agar-Agar

Carl Roth, Karlsruhe

Ethanol (EtOH, 96\%)

Carl Roth, Karlsruhe

Glukose

AppliChem, Darmstadt

Kaliumchlorid (KCl)

Carl Roth, Karlsruhe

Kaliumdihydrogenphosphat $\left(\mathrm{KH}_{2} \mathrm{PO}_{4}\right)$

Merck, Darmstadt

Kaliumnitrat $\left(\mathrm{KNO}_{3}\right)$

Carl Roth, Karlsruhe

Magnesiumsulfat-Heptahydrat $\left(\mathrm{MgSO}_{4} \times 7 \mathrm{H}_{2} \mathrm{O}\right)$

AppliChem, Darmstadt

Malzextrakt-Agar (MA)

Carl Roth, Karlsruhe

Natriumhypochloritlösung ( $\mathrm{NaOCl}, 12 \% \mathrm{Cl}$ )

Carl Roth, Karlsruhe

Paraffinöl dickflüssig

Carl Roth, Karlsruhe

Saccharose

Carl Roth, Karlsruhe

Siliziumkarbid (Karborund)

Aldrich Chemical, Milwaukee, USA

Streptomycinsulfat

Duchefa Biochemie, Haarlem, Niederlande

Tween $^{\circledR} 20$

Carl Roth, Karlsruhe

Die unten aufgelisteten Medien wurden für $15 \mathrm{~min}$ bei $121^{\circ} \mathrm{C}$ autoklaviert und anschließend im Wasserbad auf eine Temperatur von ca. $55^{\circ} \mathrm{C}$ herunter gekühlt. Bei Bedarf wurde den Medien ab einer Temperatur von etwa $55^{\circ} \mathrm{C}$ ein Antibiotikum zugesetzt. Anschließend wurden die Medien in Polystyrolpetrischalen $(92 \mathrm{~mm}$ Durchmesser, Fa. Sarstetdt, Nümbrecht) ausgegossen. 
Malzextrakt-Agar (MA)

Agar-Agar $2 \mathrm{~g}$

MA-Fertigmedium $34 \mathrm{~g}$

Streptomycinsulfat $200 \mathrm{mg}$

$\mathrm{H}_{2} \mathrm{O}$ ad $1000 \mathrm{ml}$

Bei der Herstellung des Mediums wurde dem Malzextrakt-Fertigmedium 2 g Agar-Agar zugefügt, um eine feste Konsistenz des Mediums zu erreichen.

Hafermehl-Agar (OA)

Gemahlene Haferflocken

$20 \mathrm{~g}$

Agar-Agar

$15 \mathrm{~g}$

$\mathrm{H}_{2} \mathrm{O}$

ad $1000 \mathrm{ml}$

Synthetisch Nährstoffarmer Agar (SNA)

Agar-Agar

$15 \mathrm{~g}$

$\mathrm{KH}_{2} \mathrm{PO}_{4}$

$1 \mathrm{~g}$

$\mathrm{KNO}_{3}$

$1 \mathrm{~g}$

$\mathrm{MgSO}_{4} \times 7 \mathrm{H}_{2} \mathrm{O}$

$0,5 \mathrm{~g}$

$\mathrm{KCl}$

$0,5 \mathrm{~g}$

Glukose

$0,2 \mathrm{~g}$

Saccharose

$0,2 \mathrm{~g}$

Streptomycinsulfat

$200 \mathrm{mg}$

$\mathrm{H}_{2} \mathrm{O}$

ad $1000 \mathrm{ml}$

Wasser-Agar (WA) 2\%

Agar-Agar

$20 \mathrm{~g}$

$\mathrm{H}_{2} \mathrm{O}$

ad $1000 \mathrm{ml}$

\section{II.2 Pflanzenmaterial}

Tabelle 1A zeigt die Rapsgenotypen, die im Sortenversuch verwendet wurden. Neben dem Sortennamen sind auch der Sortentyp, das Züchterunternehmen und die Herkunft bzw. der Vermehrer der Samen angegeben. Bis auf „Ruy 1“ und „Zhongshuang 9“ handelt es sich um Winterrapssorten, die in Deutschland zugelassen sind. „Zhongshuang 9" ist eine in China registrierte Liniensorte, die einen recht geringen Vernalisationsbedarf 
besitzt. Sie wird daher auch als "Semi-Winterraps“ bezeichnet (WANG et al., 2004). „Ruy 1“ ist eine Resynthese, die aus einer Kreuzung von Rübsen (Brassica rapa L. ssp.) und einer wilden Brassica Art hervorgegangen ist. Zur Verfügung gestellt wurde sie von der Abteilung für Pflanzenzüchtung (Prof. Dr. Heiko Becker), Department für Nutzpflanzenwissenschaften (DNPW), Georg-August-Universität Göttingen.

Tab. 1A: Verwendete Rapsgenotypen für den Sortenversuch im Gewächshaus. Neben dem Sortennamen sind auch der Sortentyp $(\mathrm{H}=$ Hybridsorte, $\mathrm{L}=$ Liniensorte, $\mathrm{R}=$ Resynthese), das Züchterhaus und die Herkunft der Samen angegeben.

\begin{tabular}{|c|c|c|c|}
\hline Sorte & Typ & Züchter & Herkunft/Vermehrer \\
\hline NK Petrol & $\mathrm{H}$ & Syngenta Crop Protection AG & Züchter \\
\hline SY Merlot & $\mathrm{H}$ & Syngenta Crop Protection AG & Züchter \\
\hline Sherpa & $\mathrm{H}$ & $\begin{array}{l}\text { Norddeutsche Pflanzenzucht } \\
\text { Hans Georg Lembke KG }\end{array}$ & Züchter \\
\hline Uluru & $\mathrm{H}$ & $\begin{array}{l}\text { Norddeutsche Pflanzenzucht } \\
\text { Hans Georg Lembke KG }\end{array}$ & Züchter \\
\hline Visby & $\mathrm{H}$ & Saatzucht Hans Lembke KG & Züchter \\
\hline Dimension & $\mathrm{H}$ & Deutsche Saatveredelung AG & Züchter \\
\hline Caiman & L & Monsanto Agrar Deutschland GmbH & eigene Vermehrung 2010 \\
\hline Vision & L & Intersaatzucht GmbH \& Co. KG & Züchter \\
\hline Pacific & L & Limagrain GmbH & eigene Vermehrung 2007 \\
\hline Lorenz & L & $\begin{array}{l}\text { Norddeutsche Pflanzenzucht } \\
\text { Hans Georg Lembke KG }\end{array}$ & eigene Vermehrung 2010 \\
\hline Ruy 1 & $\mathrm{R}$ & unbekannt & $\begin{array}{l}\text { Prof. Dr. H. Becker, } \\
\text { Uni Göttingen }\end{array}$ \\
\hline Zhongshuang 9 & L & unbekannt & eigene Vermehrung 2008 \\
\hline
\end{tabular}

In Tabelle 2A sind die Kreuzungspartner, die zur Herstellung von „Ruy 1“ benutzt wurden, angegeben. Zusätzlich enthält diese Tabelle die Angabe der Genbank aus der die Kreuzungspartner stammten, sowie die Akzessionsnummer des Vaters (die Wildart).

Tab. 2A: Charakterisierung der verwendeten Resynthese „Ruy 1“. Aufgeführt sind die zu ihrer Herstellung verwendeten Kreuzungspartner, die Genbank aus der sie stammen, ihre Akzessionsnummer und die Herkunft des Pollenspenders.

\begin{tabular}{llll}
\hline Genotyp & Mutter & Vater & $\begin{array}{l}\text { Genbank / Akzessionsnr. / } \\
\text { Herkunft des Vaters }\end{array}$ \\
\hline \multirow{2}{*}{ RUY 1 } & $\begin{array}{l}\text { Brassica rapa L. ssp. } \\
\text { trilocularis (Roxb.) } \\
\text { Hanelt }\end{array}$ & $\begin{array}{l}\text { Brassica rupestris Raf. var. } \\
\text { hispida (Raimondo \& } \\
\text { Mazzola) }\end{array}$ & $\begin{array}{l}\text { ESPUPMIACB / 6580-84 / } \\
\text { Italien }\end{array}$ \\
\hline
\end{tabular}


Die Tabelle 3A zeigt die Bewertung des Bundessortenamtes (BSA; (ANONYMUS, 2006, 2009b, 2013) für die Anfälligkeit der verwendeten Winterrapssorten gegenüber S. sclerotiorum. Außerdem ist angegeben, welche AUDPC-Werte WULF (2011) in seinem Resistenzscreening im Gewächshaus für die Resynthese „Ruy 1“, die chinesische Liniensorte „Zhongshuang 9“, die Liniensorten „Pacific“ und „Lorenz“ und die Hybridsorte „Visby“ ermittelt hat. Die Sorten „Lorenz" und „Visby“ werden in der Arbeit von WULF (2011) mit NPZ 1 und NPZ 2 bezeichnet. Die zuvor genannten Angaben sind nötig, um die Anfälligkeit der verwendeten Rapsgenotypen gegenüber $S$. sclerotiorum und Botrytis cinerea vergleichen zu können.

Tab. 3A: Im Sortenversuch verwendete Rapsgenotypen, die Einstufung ihrer Anfälligkeit gegenüber Sclerotinia sclerotiorum nach dem Bundessortenamt (BSA; (ANONYMUS, 2006, 2009b, 2013), sowie die von WULF (2011) in einem Resistenzscreening im Gewächshaus ermittelten AUDPC-Werte + Standardabweichung (SD) für „Ruy 1“, „Zhongshuang 9“, „Pacfic“, „Lorenz“ und „Visby".

\begin{tabular}{ccc}
\hline Sorte & $\begin{array}{c}\text { Einstufung nach BSA } \\
\text { (Jahr der Einstufung) }\end{array}$ & $\begin{array}{c}\text { AUDPC-Werte } \pm \text { SD } \\
\text { nach WULF (2011) }\end{array}$ \\
\hline NK Petrol & $5(2013)$ & - \\
SY Merlot & unbekannt & - \\
Sherpa & $5(2013)$ & - \\
Uluru & $5(2013)$ & - \\
Visby & $5(2013)$ & $32,3 \pm 18,3$ \\
Dimension & $5(2013)$ & - \\
Caiman & $5(2006)$ & - \\
Vision & $5(2013)$ & - \\
Pacific & $6(2009)$ & $37,3 \pm 16,7$ \\
Lorenz & $6(2013)$ & $17,3 \pm 19,7$ \\
Ruy 1 & & $26,4 \pm 16,3$ \\
Zhongshuang 9 & & $11,4 \pm 12,2$ \\
\hline
\end{tabular}

*Anfälligkeit für S. sclerotiorum: Note1 = sehr gering, Note 9 = sehr stark (ANONYMUS, 2013)

\section{II.3 Pflanzenanzucht}

Die Aussaat der Pflanzen für den Sortenversuch im Gewächshaus erfolgte in Multitopfschalen (51 Töpfe mit $\varnothing 5 \mathrm{~cm}$ ). Das Substrat in den Multitopfschalen war eine Mischung aus 2 Teilen Torferde (Einheitserde, Typ T25, Archut Fruhstorfer Erde ${ }^{\circledR}$, 
Inverkehrbringer/Hersteller: Hawita Gruppe $\mathrm{GmbH}$, Vechta), 2 Teile gedämpfte Komposterde und 1 Teil Sand. Die gedämpfte Komposterde wurde vor der Verarbeitung gesiebt, um grobe Erdklumpen zu entfernen. Pro Sorte wurden in 15 Töpfe vier Samen ausgesät. Für die Keimung und bis zur Entwicklung des dritten Laubblattes wurden die Pflanzen bei $18-22^{\circ} \mathrm{C}$ und einem Tag/Nacht Rhythmus von 16/8 h im Gewächshaus angezogen. Dies umfasste einen Zeitraum von ca. zwei Wochen. Anschließend wurden sie für mindestens acht Wochen in einem umgebauten Fasskühler bei $4^{\circ} \mathrm{C}, 10 \mathrm{~h}$ Licht und $14 \mathrm{~h}$ Dunkelheit (L 58W/31-830, Warm White, Fa. Osram, München) vernalisiert. Die Beleuchtungsintensität betrug ca. $61,68 \mu \mathrm{mol} / \mathrm{s} / \mathrm{m}^{2}$. Davor wurden die Rapspflanzen mit 2 g Hakaphos ${ }^{\circledR}$ blau je Liter Wasser $\left(15 \% \quad \mathrm{~N}, 10 \% \quad \mathrm{P}_{2} \mathrm{O}_{5}, 15 \% \quad \mathrm{~K}_{2} \mathrm{O}, 2 \% \mathrm{MgO}+\right.$ Mikronährstoffe: B, Cu, Mn, Mo, Zn, Fe; Fa. Compo, Münster) gedüngt. Die Sorte „Zhongshuang 9“ wurde etwas später ausgesät und nur für drei Wochen vernalisiert. Nach der Vernalisation wurden die Pflanzen aus den Multitopfplatten in Göttinger Pflanztöpfe (11 x 11 × $12 \mathrm{~cm}$, Fa. Lamprecht Verpackungen $\mathrm{GmbH}$, Göttingen) umgetopft. Bis zur Inokulation wurden die Pflanzen bei einer Temperatur von ca. $20^{\circ} \mathrm{C}$ und einer relativen Luftfeuchtigkeit von $80-90 \%$ weiter angezogen. Während des gesamten Versuchszeitraums standen sie auf Gewächshaustischen, die mit einem Gießfilz und perforierter Folie ausgelegt waren, sodass die Wasserversorgung von unten sichergestellt war. Die Steuerung der Temperatur erfolgte automatisch durch Zuschalten und Ausschalten der Heizung bzw. der Lüftung. Um Wasserstress zu vermeiden, wurden die Pflanzen täglich gegossen. Die Düngung erfolgte nach Bedarf ca. alle zwei Wochen mit 3 g Hakaphos ${ }^{\circledR}$ blau je Liter Wasser. Um den Befall mit pilzlichen Pathogenen zu vermeiden, wurde regelmäßig Netzschwefel $(80 \%$ S) gegen Echten Mehltau (Erysiphe cruciferarum) appliziert. Den Tabellen 4A und 5A kann entnommen werden, zu welchem Anwendungstermin und mit welcher Aufwandmenge die Winterrapspflanzen gedüngt und gespritzt wurden.

Tab. 4A: Anwendungstermine an denen die Winterrapspflanzen des Sortenversuches im Gewächshaus mit $3 \mathrm{~g}$ Hakaphos ${ }^{\circledR}$ blau je Liter Wasser gedüngt wurden.

\begin{tabular}{lc}
\hline & Termine der Hakaphos $^{\circledR}$ blau-Düngung \\
\hline 1. Versuchsdurchgang & 2. Versuchsdurchgang \\
\hline 28.11 .2012 & 21.03 .2013 \\
19.12 .2012 & 27.03 .2013 \\
02.01 .2013 & 10.04 .2013 \\
\hline
\end{tabular}


Tab. 5A: Anwendungstermine an denen die Winterrapspflanzen des Sortenversuches im Gewächshaus mit $5 \mathrm{~g}$ Netzschwefel (80\% S) je Liter Wasser gespritzt wurden.

Termine der Netzschwefel Applikation

\begin{tabular}{ll}
\hline 1. Versuchsdurchgang & 2. Versuchsdurchgang \\
\hline 25.11 .2012 & 28.02 .2013 \\
12.12 .2012 & 07.03 .2013 \\
27.12 .2012 & 14.03 .2013 \\
10.01 .2013 & 26.03 .2013 \\
- & 09.04 .2013 \\
\hline
\end{tabular}

Unabhängig von der Jahreszeit und der von außen einfallenden Strahlung wurden die Rapspflanzen über zwei Wochen durch eine kontinuierliche Steigerung der Photoperiode an eine künstliche, sechzehnstündige Photoperiode adaptiert. Im Durchschnitt betrug die photosynthetisch aktive Strahlung 92,03 $\mu \mathrm{mol} / \mathrm{s} / \mathrm{m}^{2}$. Zur Beleuchtung wurden Hochdrucknatriumdampflampen mit 400 Watt eingesetzt (Modell HSTM 423, Fa. Hortilux Schreder, Niederlande). Unter den beschriebenen Lichtbedingungen wurden die Pflanzen bis zum Versuchsende gehalten.

\section{II.4 Herkunft und Erhaltung von Pilzisolaten}

Am 11.07.2012 bzw. 16.07.2012 wurden am Standort Göttingen bzw. Deensen Winterrapspflanzen entnommen, die mit $B$. cinerea befallen waren. Verschiedene Pflanzenorgane, die einen eindeutigen Befall aufwiesen, wurden zur Inkubation in Feuchtekammern (Petrischale mit Filterpapier) ausgelegt. Etwa zwei Tage danach konnte von den verschiedenen Pflanzenorganen weißes Myzel auf synthetisch nährstoffarmen Agar (SNA) übertragen werden. Nachdem sich die ersten Konidien von B. cinerea auf dem SNA-Medium gebildet hatten, wurden die Isolate auf Malzextrakt-Agar (MA) überimpft, um Einzelsporisolate herzustellen. Insgesamt konnten durch diese Isolationsschritte vier Einzelsporisolate von B. cinerea gewonnen werden (Tab. 6A). Als Erhaltungskulturen wurden die Isolate in Schrägröhrchen mit Hafermehl-Agar (OA) unter dickflüssigem Paraffinöl bei $4^{\circ} \mathrm{C}$ im Kühlschrank (Fa. Bosch, München, Deutschland) gelagert. 
Tab. 6A: Einzelsporisolate von Botrytis cinerea isoliert von verschiedenen Organen von Winterraps (Brassica napus, L.)

\begin{tabular}{cccc}
\hline Isolat & Herkunft & Ackerschlag & Organ \\
\hline Schote DE & Deensen & --- & Rapsschote \\
Blatt GÖ & Göttingen & Große Lage & Rapsblatt \\
Stängel GÖ & Göttingen & Große Lage & Rapsstängel \\
Schote GÖ & Göttingen & Große Lage & Rapsschote \\
\hline
\end{tabular}

\section{II.5 Inokulumproduktion von B. cinerea}

Für Inokulationen unter kontrollierten Bedingungen wurden je nach Versuch die entsprechenden Isolate von $B$. cinerea aus den Schrägröhrchen auf MA überimpft und bei Raumtemperatur im Labor drei bis fünf Tage inkubiert. Am Tag der Inokulation wurde im Bereich der Wachstumszone der Pilzhyphen mit einem Korkbohrer ( $\varnothing 6$ bzw. 7 mm) Agarscheiben ausgestochen. Auf diese Weise war sichergestellt, dass stets vergleichbares Inokulum verwendet wurde. Alle zuvor genannten Arbeiten wurden unter sterilen Bedingungen durchgeführt.

\section{II.6 Inokulationsmethode in vitro}

Die Inokulation des in vitro Inokulationsversuches wurde mit MA-Scheiben (ø $6 \mathrm{~mm}$ ), welche mit einem drei bis vier Tage alten Isolat von $B$. cinerea bewachsen waren, durchgeführt. Dabei wurde in die Mitte jeder Petrischale eine MA-Scheibe mit der myzelbewachsenen Agarseite auf den WA gelegt (Abb. 1A). Als Kontrolle wurden nicht mit Pilzmyzel bewachsene MA-Scheiben verwendet.

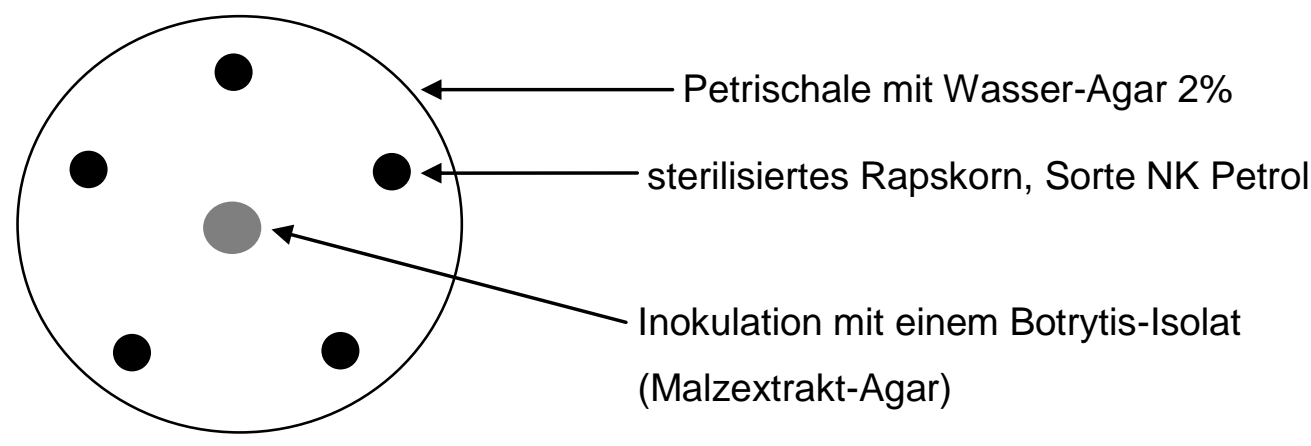

Abb. 1A: Versuchsaufbau des in vitro Inokulationsversuches mit Botrytis cinerea an Winterraps 


\section{II.7 Inokulation im Gewächshaus}

Unter kontrollierten Bedingungen wurden zur Inokulation der Laubblätter bzw. der Stängel von Winterraps Scheiben von MA (ø $7 \mathrm{~mm}$ ) verwendet (vgl. Kapitel 3.5). Diese waren mit dem Botrytis-Isolat "Schote DE“ bewachsen oder wiesen in der Kontrollvariante keinen Pilzbewuchs auf. Mit Hilfe einer $\mathrm{EtOH} \mathrm{(70 \% )} \mathrm{desinfizierten} \mathrm{Impfnadel} \mathrm{wurden} \mathrm{bei} \mathrm{den}$ Laubblättern die Agarscheiben mittig, links und rechts von der Mittelrippe, auf dem Blattgewebe platziert (Abb. 2A, a) und bei den Stängeln bzw. Stängelsegmenten wurden sie in eine Blattachsel gelegt (Abb. 2A, b). Die myzelüberwachsene Agarseite berührte dabei das Laubblatt bzw. den Stängel.
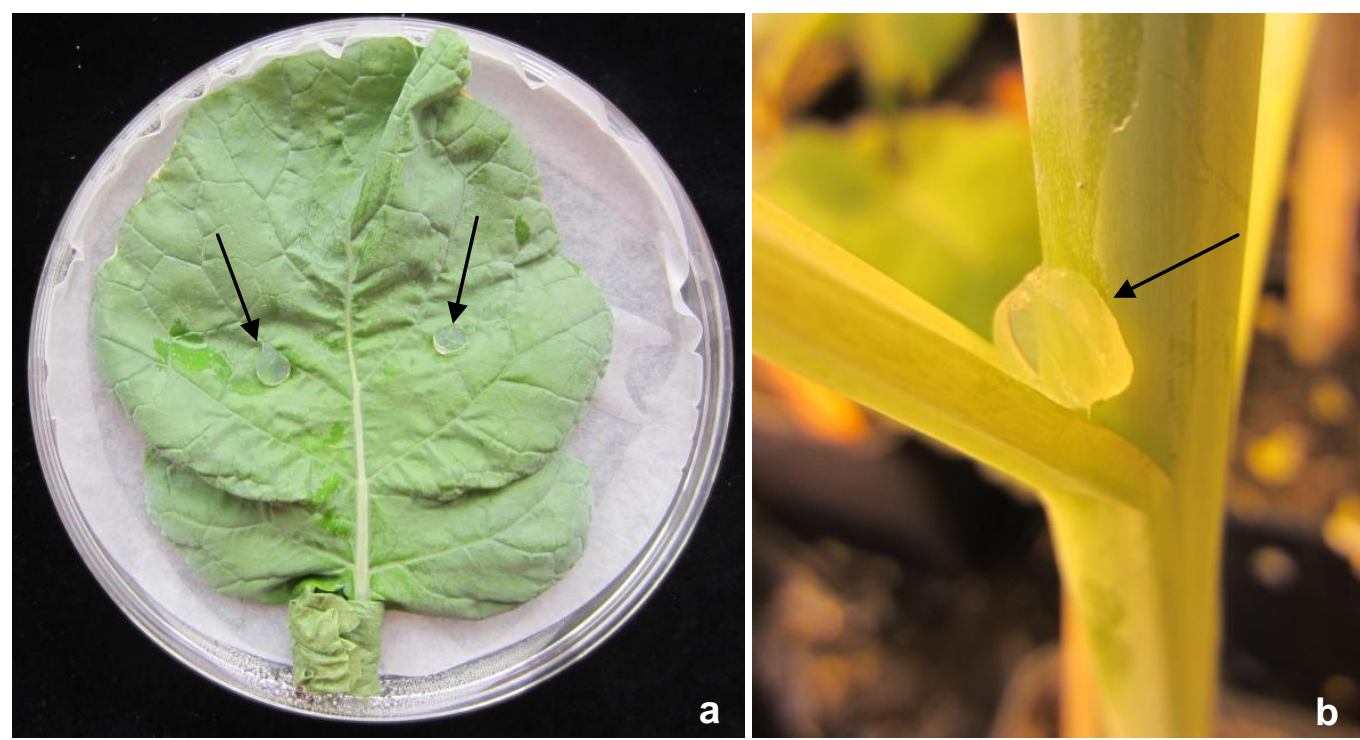

Abb. 2A: Inokulation von einem Laubblatt (a) bzw. einem Stängel (b) von Winterraps mit Botrytis cinerea. Es wurden pilzbewachsene Scheiben von Malzextrakt-Agar (ø $7 \mathrm{~mm})$ verwendet (siehe Pfeile). Als Kontrolle dienten nicht pilzbewachsene Scheiben von MA.

\section{II.8 Erfassung der Befallssymptome von B. cinerea an Winterraps}

\section{II.8.1 In vitro Inokulationsversuch}

In dem in vitro Inokulationsversuch wurden die Krankheitssymptome von Isolaten von B. cinerea an Rapskeimlingen 7 bzw. 11 Tage nach der Inokulation durch eine Sichtbonitur erfasst. Dabei wurden der Grad der Verbräunung des Hypokotyls sowie die Ausprägung einer Chlorose an den Keimblättern in vier Befallsklassen eingeteilt (Tab. $7 A)$. 
Tab. 7A: Boniturschema in Befallsklassen zur Beurteilung der Krankheitssymptome von Botrytis cinerea an Keimlingen von Winterraps (Sorte NK Petrol).

\begin{tabular}{ll}
\hline Befallsklasse & Befallsstärke \\
\hline 1 & kein Befall \\
2 & leichter Befall des Hypokotyls, leichte Chlorose der Keimblätter \\
3 & mittlerer Befall des Hypokotyls, mittlere Chlorose der Keimblätter \\
4 & starker Befall des Hypokotyls, starke Chlorose der Keimblätter oder abgestorben \\
\hline
\end{tabular}

Nach der Klassifizierung der Rapskeimlinge in die einzelnen Befallsklassen wurde der Disease Index nach folgender Formel berechnet:

$$
\text { Disease Index }=\frac{0 * \mathrm{~S}_{1}+1 * \mathrm{~S}_{2}+2 * \mathrm{~S}_{3}+3 * \mathrm{~S}_{4}}{\mathrm{~N} * 4}
$$

- $S_{1}=$ Anzahl Keimlinge in Befallsklasse 1

- $\mathrm{S}_{2}=$ Anzahl Keimlinge in Befallsklasse 2

- $\quad S_{3}=$ Anzahl Keimlinge in Befallsklasse 3

- $\quad \mathrm{S}_{4}=$ Anzahl Keimlinge in Befallsklasse 4

- $\quad \mathrm{N}=$ Anzahl der insgesamt bonitierten Pflanzen

Zum Schluss wurde der Disease Index - Mittelwert von jedem Isolat ermittelt.

\section{II.8.2 Gewächshausversuche}

In den Gewächshausversuchen wurde für die Erfassung der Befallssymptome von B. cinerea an Laubblättern von Winterraps die Läsionslänge [mm] von der Blattbasis in Richtung Blattspitze mit Hilfe einer digitalen Schieblehre (Fa. Max Bahr, Göttingen) gemessen. Die beiden Läsionslängen auf einem Blatt wurden immer in einer bestimmten Reihenfolge gemessen, sodass bei jeder erneuten Bonitur immer mit der gleichen Läsionslänge begonnen wurde. Aus den ermittelten Werten wurde die Area Under Disease Progress Curve (AUDPC) ermittelt. Der AUDPC-Wert wurde nach folgender Formel berechnet (CAMPBELL and MADDEN, 1990; SHANER and FINNEY, 1977):

$$
A U D P C=\frac{y_{i}+y_{i+1}}{2} *\left(t_{i+1}-t_{i}\right)
$$


Wobei $y_{i}$ die Läsionslänge zum Zeitpunkt $i$ und $t_{i}$ die Anzahl der Tage nach der Inokulation ist. Die beiden AUDPC-Werte von einem Blatt wurden für die statische Analyse zu einem Mittelwert zusammengefasst.

Die Bonitur der Krankheitssymptome von B. cinerea an Stängeln bzw. Stängelsegmenten von Winterraps und die Berechnung der AUDPC-Werte erfolgte in derselben Art und Weise, wie die Bonitur der Krankheitssymptome an den Laubblättern. Einziger Unterschied dabei war, dass die Läsionslänge [mm] an dem jeweiligen Stängel bzw. Stängelsegment in vertikaler Richtung gemessen wurde. In dem Temperaturversuch erfolgte die Erhebung der Befallssymptome an den Laubblättern und Stängelsegmenten nach 3, 5, 7 und 11 Tagen. In dem Sortenversuch wurde die Bonitur an den Laubblättern nach 3, 5, 7 und 9 Tagen und an den Stängeln nach 3, 5, 7, 9 und 14 Tagen durchgeführt.

\section{II.9 In vitro Inokulationsversuch}

Die Bestimmung der Aggressivität der vier Isolate von B. cinerea („Schote DE“, „Blatt GÖ“, „Stängel GÖ“ und „Schote GÖ“) erfolgte durch die Inokulation von Winterraps unter in vitro Bedingungen. Dazu wurde ungebeiztes Saatgut der Winterrapshybridsorte NK Petrol verwendet, welches aus der Ernte des Feldversuches 2010/11 stammte. Die Rapssamen wurden für $30 \mathrm{~s}$ in Ethanol (70\%) und anschließend für zweimal 2 min $30 \mathrm{~s}$ in Natriumhypochlorid (2\%), was mit einem Tropfen Tween ${ }^{\circledR} 20$ versetzt war, sterilisiert. Danach wurden die Körner mehrfach mit sterilem Wasser gewaschen und auf sterilem Papier getrocknet. Im Anschluss wurden auf zwölf Wasser-Agar (WA)-Petrischalen jeweils fünf sterile Rapskörner im Kreis ausgelegt. Die Inokulation erfolgte mit Scheiben von MA (ø $6 \mathrm{~mm}$ ), die mit Myzel des jeweiligen Isolates von B. cinerea bewachsen waren (vgl. Kapitel II.6). Je Botrytis-Isolat wurden drei WA-Petrischalen beimpft. Als Kontrolle diente eine Variante mit einer nicht pilzbewachsenen Scheibe von MA. Hierbei wurden ebenfalls drei WA-Petrischalen beimpft. Nach der Inokulation wurden die Petrischalen für vier Tage bei Dunkelheit und ca. $22^{\circ} \mathrm{C}$ inkubiert. Vom fünften bis zum zwölften Tag nach der Beimpfung der WA-Platten, wurden sie bei einem Tag/Nacht-Rhythmus von $12 \mathrm{~h}$ (L 18W/30, Warm White, Fa. Osram, München) bei $22^{\circ} \mathrm{C}$ gelagert. Die Beleuchtungsintensität betrug ca. $34,59 \mu \mathrm{mol} / \mathrm{s} / \mathrm{m}^{2}$. Für die Inkubation bei den zuvor beschriebenen Bedingungen wurde ein Klimaschrank (Modell WB 750 KFL, Fa. Mytron, Heiligenstadt) genutzt. Die Bonitur der Befallssymptome erfolgte in Anlehnung an Kapitel II.8.1 


\section{II.10 Temperaturversuch}

Dieser Versuch diente dazu, die Temperaturansprüche von $B$. cinerea bei der Infektion von Winterraps zu ermitteln. In verschiedenen Versuchsansätzen wurden sowohl Laubblätter als auch Stängelsegmente inokuliert, um zusätzlich einen möglichen Einfluss von unterschiedlichen Pflanzenorganen herauszuarbeiten. Weiterhin sollte untersucht werden, inwieweit Verletzungsstellen den Befall von Winterraps mit $B$. cinerea bei unterschiedlichen Temperaturen begünstigen. Die Laubblattinokulation wurde bei $4^{\circ} \mathrm{C}$, $8^{\circ} \mathrm{C}, 12^{\circ} \mathrm{C}, 16^{\circ} \mathrm{C}, 20^{\circ} \mathrm{C}$ und $24^{\circ} \mathrm{C}$ und die Stängelsegmentinokulation wurde bei den zuvor genannten Temperaturen sowie $18^{\circ} \mathrm{C}$ und $22^{\circ} \mathrm{C}$ durchgeführt. Für beide Versuchsansätze wurden mehrere Klimaschränke (Fa. Rumed, Hannover) und ein Kühlschrank $\left(4^{\circ} \mathrm{C}\right.$; Fa. Bosch, München) genutzt. Als Pflanzenmaterial dienten für beide Versuche Rapspflanzen der Winterrapssorte NK Petrol, die zeitnah zum jeweiligen Versuch aus dem Randbereich des Feldversuches entnommen wurden. Für die Verletzung der Laubblätter wurde die Blattepidermis mittig, links und rechts der Mittelrippe, mit Hilfe eines feuchten Wattestäbchens und Siliziumkarbid, durch dreimaliges Darüberstreichen, aufgeraut. Zusätzlich wurde mit einer EtOH (70\%) desinfizierten Pinnnadel jeweils ein Loch in die aufgerauten Blattstellen gestochen. Bei den Rapsstängeln wurde die Stängelepidermis in den Blattachseln mit Hilfe von einem feuchten Wattestäbchen und Siliziumkarbidpulver durch dreimaliges Darüberstreichen in vertikaler Richtung aufgeraut. Danach wurde mit einer $\mathrm{EtOH}$ (70\%) desinfizierten Pinnnadel an der aufgerauten Stelle ein 2-3 mm tiefes Loch in den Stängel gestochen.

Insgesamt gab es vier verschiedene Inokulationsvarianten:

1. verletzt, inokuliert ( $\mathrm{v}$ i)

2. verletzt, nicht inokuliert ( $v$ ni)

3. nicht verletzt, inokuliert (nv i)

4. nicht verletzt nicht inokuliert (nv ni).

Je Temperaturstufe gab es von jeder Variante vier Wiederholungen. Insgesamt wurde jeder Versuchsansatz (Laubblätter, Stängelsegmente) zweimal durchgeführt.

Für die Inokulation der Laubblätter wurde immer das siebte Laubblatt der Winterrapssorte NK Petrol verwendet. Als Inkubationskammer dienten viereckige Polystyrolpetrischalen mit den Maßen 100 × 100 × 20 mm (Fa. Sarstedt, Nümbrecht), die mit feuchtem Filterpapier (Fa. Glasgeräte Bau Ochs, Bovenden; 2,2 ml Leitungswasser) ausgelegt waren. Bevor die Laubblätter in die Petrischalen gelegt wurden, säuberte man sie gründlich mit Leitungswasser und kürzte die Petiolen entsprechend der Größe der 
Schalen. Zur Frischerhaltung wurden die Blattstängel mit einem Stück feuchten Filterpapier umwickelt (Abb. 3A). Die Inokulation der Laubblätter erfolgte mit Scheiben von MA (ø $7 \mathrm{~mm}$ ), die mit Myzel des Botrytis-Isolates „Schote DE“ bewachsen waren (vgl. Kapitel II.7). Nach der Inokulation wurden die Petrischalen 11 Tage bei den oben genannten sechs verschiedenen Temperaturstufen inkubiert. In den Temperaturschränken und dem Kühlschrank waren die Petrischalen mit den Laubblättern keinem Licht ausgesetzt. Die Bonitur erfolgte nach der Vorgehensweise, die in Kapitel II.8.2 beschrieben ist.

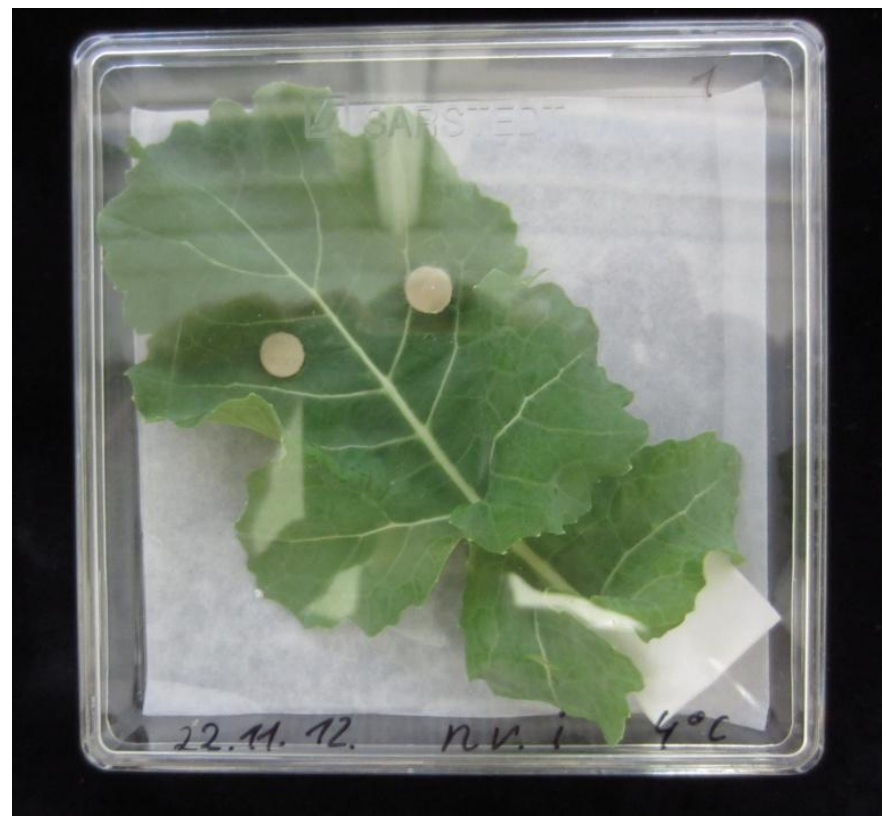

Abb. 3A: Versuchsaufbau des Temperaturversuches mit Botrytis cinerea an Laubblättern von Winterraps. Als Inkubationskammer dienten Polystyrolpetrischalen (Maße: $100 \times 100$ × 20 mm, Fa. Sarstedt, Nümbrecht) mit feuchtem Filterpapier (Fa. Glasgeräte Bau Ochs, Bovenden). Die Petiole wurde mit feuchtem Filterpapier umwickelt, um das Laubblatt lange frisch zu erhalten. Zur Inokulation wurden Scheiben von MA (ø $7 \mathrm{~mm}$ ) verwendet, die je nach Variante mit dem BotrytisIsolat „Schote DE“ bewachsen waren oder kein Pilzbewuchs aufwiesen.

Für die Inokulation der Stängelsegmente wurde von jeder Winterrapspflanze aus dem Stängelabschnitt von $30-60 \mathrm{~cm}$ ein $8 \mathrm{~cm}$ langes Stängelstück mit Seitentrieb herausgeschnitten. Der Seitentrieb wurde auf eine Länge von ca. 2-3 cm gekürzt. Anschließend wurden die Stängelstücke mit Leitungswasser oberflächlich gesäubert und zum Trocknen auf Papiertüchern ausgelegt. Insgesamt wurden 128 Stängelsegmente benötigt. Als Inkubationskammern dienten in diesem Versuch 32 Gerda Schalen mit einer Größe von 200 x 200 × 95 mm (Fa. Gerda, Schwelm). In jede Schale wurde ein $1 \mathrm{~cm}$ 
hohes Gitter hineingestellt, in welches die Stängelstücke aufrecht gesteckt wurden. Pro Schale wurden jeweils vier Stängelsegmente von einer der vier Varianten zwischen den Gitterstäben befestigt (Abb. 4A). Je nach Bedarf wurden die Stängelstücke im unteren Bereich mit Parafilm umwickelt, um eine bessere Standfestigkeit in dem Gitter zu erreichen. Um eine konstant hohe Luftfeuchtigkeit von ca. 99\% zu gewährleisten, wurde in jede Schale $200 \mathrm{ml} \mathrm{H} \mathrm{H}_{2} \mathrm{O}$ hinein gefült. Die Inokulation erfolgte mit Scheiben von MA (ø $7 \mathrm{~mm}$ ), die mit Myzel des Botrytis-Isolates „Schote DE“ bewachsen waren (vgl. Kapitel II.7). Nach der Beimpfung der Stängelstücke wurden alle Schalen mit einem luftdichten Deckel verschlossen und für 11 Tage bei den weiter oben genannten acht verschiedenen Temperaturstufen sowie absoluter Dunkelheit inkubiert. Die Bonitur erfolgte in Anlehnung an Kapitel II.8.2.

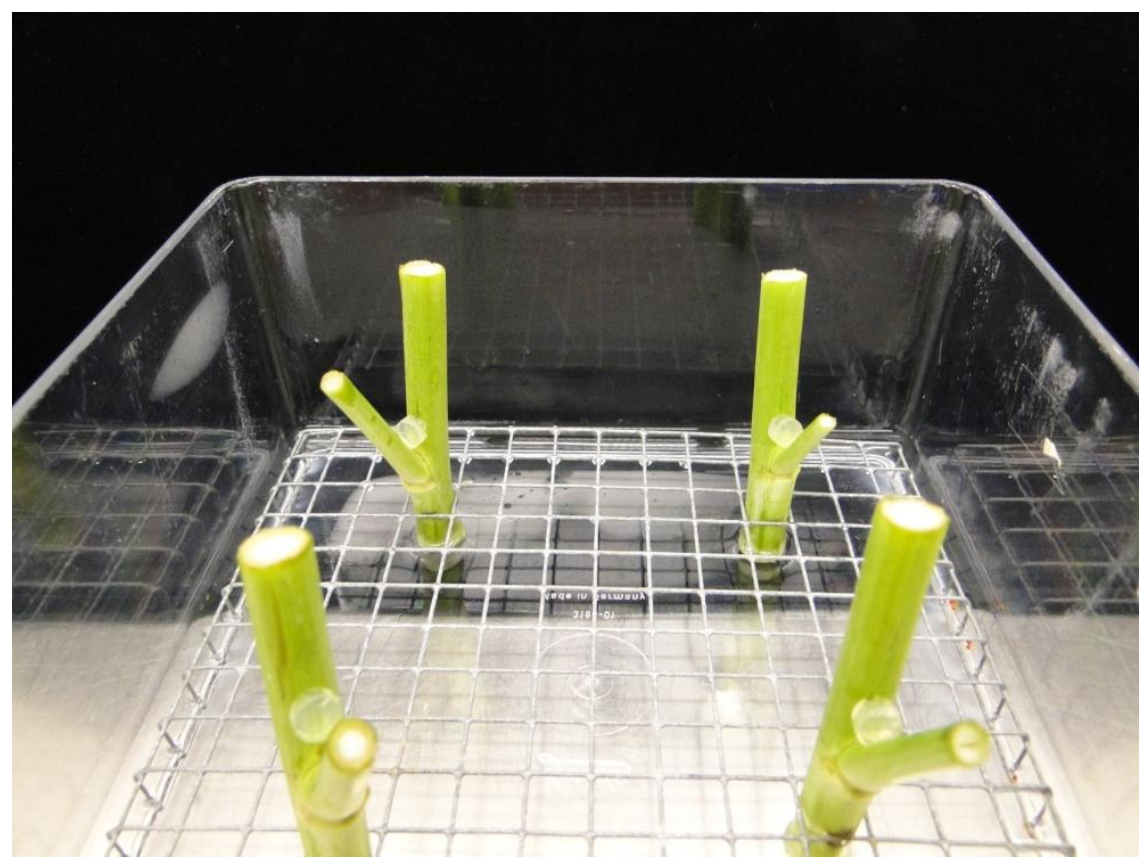

Abb. 4A: Versuchsaufbau des Temperaturversuches mit Botrytis cinerea an Stängelsegmenten von Winterraps. Als Inkubationskammer dienten Gerda Schalen (Maße: 200 × 200 × 95 mm; Fa. Gerda, Schwelm), die mit $200 \mathrm{ml}$ Wasser gefüllt wurden. In jede Schale wurde ein $1 \mathrm{~cm}$ hohes Gitter gelegt, um vier Stängelsegmente darin zu befestigen. Zur Inokulation wurden Scheiben von MA ( $\varnothing$ $7 \mathrm{~mm}$ ) verwendet, die je nach Variante mit dem Botrytis-Isolat „Schote DE“ bewachsen waren oder kein Pilzbewuchs aufwiesen. Diese wurden in der Blattachsel platziert. 


\section{II.11 Sortenversuch}

In diesem Gewächshausversuch wurden zwölf verschiedene Genotypen von Winterraps auf ihre Anfälligkeit gegenüber $B$. cinerea untersucht. Darüber hinaus sollte überprüft werden, ob eine mögliche Variabilität in der Sortenanfälligkeit gegenüber $B$. cinerea mit der Variabilität der Sortenanfälligkeit gegenüber S. sclerotiorum übereinstimmt. Dazu wurden bestimmte Genotypen, die in einer früheren Doktorarbeit (WULF, 2011) auf ihre Anfälligkeit gegenüber $S$. sclerotiorum getestet wurden, mit in das Sortenscreening aufgenommen. Durch die Inokulation von verletzten bzw. unverletzten unterschiedlichen Pflanzenorganen (Laubblätter/Stängel) wurde zusätzlich untersucht, welchen Einfluss Verletzungsstellen auf die Sortenanfälligkeit haben und ob verschiedene Pflanzenorgane eine differenzierte Anfälligkeit gegenüber $B$. cinerea aufweisen. Diese Versuchsfragen führten zu insgesamt vier verschiedenen Inokulationsvarianten:

1. verletzt, inokuliert ( $\mathrm{v}$ i)

2. verletzt, nicht inokuliert ( $\mathrm{v}$ ni)

3. nicht verletzt, inokuliert ( $n v \mathrm{i})$

4. nicht verletzt nicht inokuliert (nv ni).

Die Verletzung der Laubblätter bzw. der Stängel von Winterraps erfolgte nach den Methoden, die in Kapitel 3.10 beschrieben wurden. Der dreifaktorielle Versuch wurde als teilrandomisierte Spaltanlage mit acht Wiederholungen im Gewächshaus angelegt. Jede Wiederholung bestand aus 48 Pflanzen. Der Faktor Inokulation stellte die Spalte dar und innerhalb dieser waren die beiden Faktoren Sorte und Verletzung vollrandomisiert. Eine Spalte (Inokulationsvariante) beinhaltete 24 Pflanzen (zwölf Rapssorten $x$ zwei Verletzungsvarianten). Insgesamt wurde der Sortenversuch mit Laubblatt- und Stängelinokulation zweimal durchgeführt.

Die Inokulation der Laubblätter bzw. der Stängel erfolgte im Entwicklungsstadium der Vollblüte bis Ende der Blüte (BBCH 65-69, (MEIER, 2001) (vgl. Kapitel II.7). Für die Inokulation der Laubblätter wurde pro Pflanze jeweils das achte Laubblatt verwendet. Diese wurden mit einer Schere mittig an der Petiole abgeschnitten, unter fließendem Leitungswasser gesäubert und anschließend zum Trocknen auf Papierhandtüchern ausgelegt. Danach wurden die Laubblätter jeweils in eine Polystyrolpetrischale (ø 150 mm, Fa. Sarstedt, Nümbrecht) mit feuchtem Filterpapier (ø $150 \mathrm{~mm}$, Fa. Sartorius, Göttingen; $5 \mathrm{ml}$ Leitungswasser) gelegt. Je nach Größe des Laubblattes musste der Blattstiel entsprechend der Petrischale gekürzt werden. Damit die Laubblätter nicht so schnell ihre Turgeszenz verloren, wurde von jedem Laubblatt die Petiole mit einem feuchten Papiertuch umwickelt. Das feuchte Filterpapier diente dazu, eine möglichst hohe 
Luftfeuchtigkeit zu generieren. Damit die Inkubation der Laubblätter unter denselben Bedingungen wie die Inkubation der Stängel erfolgen konnte, wurden die Inkubationskammern mit den Laubblättern in Holzkisten unter zwei Folienzelten gelagert (Abb. 5A, a). Damit alle Petrischalen den gleichen Lichtverhältnissen in den Holzkisten ausgesetzt waren, wurden die obersten Schalen jeweils mit einer Petrischale, die ein Filterpapier enthielt, abgedeckt (Abb. 5A, b). Die Bonitur der Befallssymptome erfolgte nach der Vorgehensweise, die in Kapitel II.8.2 beschrieben ist. Zum Zeitpunkt der Inokulation war bei der Sorte „Zhongshuang 9“ nicht mehr jedes achte Laubblatt vorhanden. Dadurch wurde diese Sorte bei der Laubblattinokulation nicht weiter berücksichtigt.

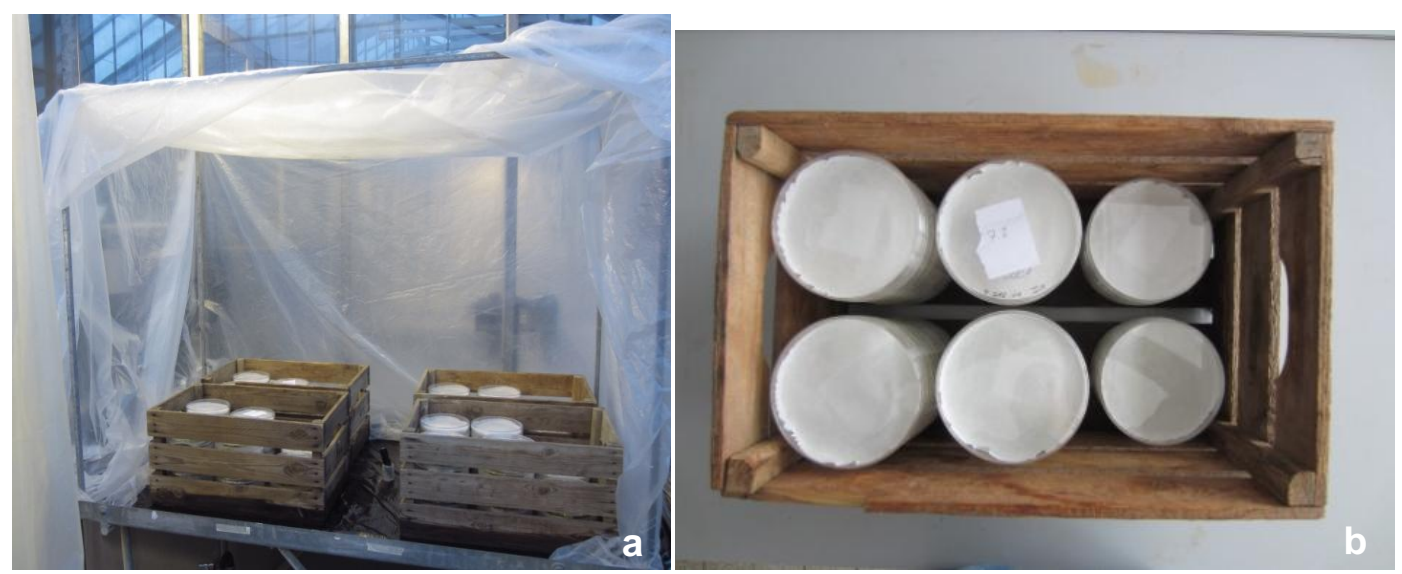

Abb. 5A: Inkubation von Laubblättern von Winterraps nach der Inokulation mit B. cinerea (Isolat: „Schote DE“). Die Inkubation erfolgte für 9 Tage unter Folienzelten bei einer Durchschnittstemperatur von $18-22^{\circ} \mathrm{C}$ und einer mittleren rel. Luftfeuchtigkeit von $81-88 \%$. (a) Während der Inkubation unter den Folienzelten wurden die Petrischalen mit den Laubblättern in Holzkisten gelagert. (b) Damit für alle Laubblätter in den Inkubationskammern die gleichen Lichtverhältnisse in den Holzkisten herrschten, wurden die obersten Kammern jeweils mit einer Petrischale, die ein Filterpapier enthielt, abgedeckt.

Die Rapsstängel der verschiedenen Genotypen wurden jeweils in der sechsten Blattachsel inokuliert. Um eine hohe rel. Luftfeuchtigkeit nach der Inokulation zu gewährleisten und um die inokulierten und nicht inokulierten Pflanzen räumlich voneinander zu trennen, standen diese zwei Gruppen von Rapspflanzen jeweils unter einem eigenen Folienzelt (Abb. 6A, a). Die Folie war transparent und hatte eine Stärke von 0,04 mm (Fa. Max Bahr, Göttingen). Jede Folie wurde mit Wäscheklammern an den Eisenrahmen fixiert (Abb. 6A, b). Um Kontaminationen zu vermeiden, wurden die Varianten nacheinander, beginnend bei der Kontrolle, inokuliert. Die Bonitur erfolgte in Anlehnung an Kapitel II.8.2. 


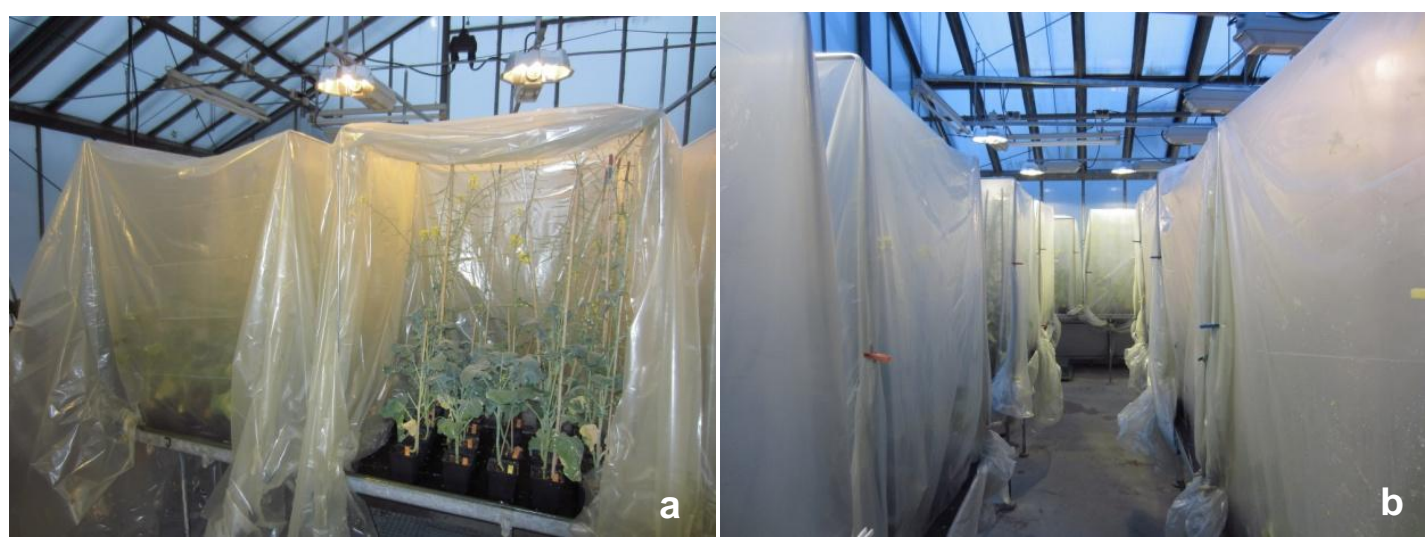

Abb. 6A: Inkubation von Rapspflanzen nach Inokulation mit B. cinerea (Isolat: „Schote DE“) in der sechsten Blattachsel. Die Inkubation erfolgte für 14 Tage unter Folienzelten bei einer Durchschnittstemperatur von $18-22^{\circ} \mathrm{C}$ und einer mittleren rel. Luftfeuchtigkeit von $81-88 \%$. (a) Während der Inokulation: Die Folienzelte der nicht inokulierten Varianten sind verschlossen, damit es zu keiner Kontamination kommt. (b) Nach der Inokulation: Alle Folienzelte sind verschlossen und die Plastikfolien wurden an den Eisenrahmen mit Wäscheklammern fixiert.

Die erste Inkubation der Laubblätter und der Stängel erfolgte im Januar 2013 und die zweite im April 2013. Während der Inkubation herrschte in den Folienzelten im Mittel über alle Inkubationstage und je nach Versuchsdurchgang eine Temperatur von $18^{\circ} \mathrm{C}$ bzw. $22^{\circ} \mathrm{C}$ und eine rel. Luftfeuchtigkeit von $81 \%$ bzw. $88 \%$. Die Entwicklung der Temperatur und der rel. Luftfeuchtigkeit in den Folienzelten wurde mit einem Data Logger (Voltcraft ${ }^{\circledR}$ DL-120 TH, Conrad Electronic $\mathrm{GmbH}$, Hirschau) aufgezeichnet und mit einem analogen Thermometer bei jeder Bonitur überprüft.

\section{II.12 Statistik}

Die statistische Auswertung erfolgte mit Hilfe des Statistikprogramms SAS Version 9.2 (SAS Institute Inc., North Carolina, USA). Für den Temperatur- und Sortenversuch mit $B$. cinerea an Winterraps wurde jeweils eine dreifaktorielle Varianzanalyse mittels der SAS Prozedur „proc mixed“ durchgeführt. Eine gemeinsame Verrechnung der Daten der vier Varianten „verletzt, inokuliert“; „verletzt, nicht inokuliert“; „nicht verletzt, inokuliert“ und „nicht verletzt, nicht inokuliert“ zeigte, dass die Daten weder normalverteilt noch varianzhomogen waren. Dies lag daran, dass in den inokulierten Varianten ein Befall mit $B$. cinerea bonitiert werden konnte und in den nicht inokulierten Varianten nicht. Daraufhin wurden nur die Daten der Varianten „verletzt, inokuliert“ und „nicht verletzt, inokuliert“ statistisch ausgewertet. Um bei diesen Datensätzen eine Normalverteilung und eine Varianzhomogenität zu erreichen, wurden bei allen Daten, bis auf jene aus dem 
Temperaturversuch an Stängelsegmenten von Winterraps nur AUDPC-Werte $>0$ berücksichtigt. Zudem wurden vereinzelt auftretende Extremwerte von der statistischen Berechnung ausgeschlossen. Für den multiplen Mittelwertvergleich wurde der Tukey-Test verwendet. Die Temperaturversuche wurden in vierfacher $(n=4)$ und der Sortenversuch in achtfacher ( $\mathrm{n}=8)$ Wiederholung durchgeführt. Verschiedene Buchstaben kennzeichnen signifikante Unterschiede bei einer Irrtumswahrscheinlichkeit von 5\% $(\alpha=0,05)$.

Für den Vergleich der Sortenanfälligkeit gegenüber S. sclerotiorum und B. cinerea wurden die Daten vom Sortenversuch mit $B$. cinerea, im speziellen von der Stängelinokulation, wie zuvor beschrieben ausgewertet. Einziger Unterschied hierbei war, dass die Daten der Bonitur von 9 Tagen nach der Inokulation verwendet wurden. Bei den anderen Auswertungen zur Stängelinokulation wurden die Daten der Bonitur von 14 Tagen nach der Inokulation verwendet. Die Daten zur Sortenanfälligkeit gegenüber $S$. sclerotiorum wurden der Dissertation von WULF (2011) entnommen.

\section{Ergebnisse}

\section{III.1 In vitro Inokulationsversuch}

Mit Hilfe dieses Versuches sollte von vier Isolaten von B. cinerea (Schote GÖ, Blatt GÖ, Stängel GÖ und Schote DE) das Isolat identifiziert werden, welches die stärksten Befallssymptome an Keimlingen von Winterraps hervorruft und somit am aggressivsten ist. Sowohl 7 Tage als auch 11 Tage nach der Inokulation wurden bei dem Isolat „Schote DE“ die höchsten mittleren Disease Indices ermittelt (Tab. 8A). Von den Isolaten aus Göttingen löste das Isolat „Stängel GÖ“ die stärksten Befallssymptome aus, gefolgt von den Isolaten „Schote GÖ“ und „Blatt GÖ“. Diese Reihenfolge in der Ausprägung der Symptome konnte an beiden Boniturterminen beobachtet werden. Aufgrund dieser Ergebnisse wurde zur Inokulation mit $B$. cinerea in dem Temperatur- und dem Sortenversuch das "Isolat Schote DE“ eingesetzt. In Abbildung 7A ist der Befall der vier Isolate von $B$. cinerea an den Keimlingen von Winterraps, sowie von der nicht inokulierten Kontrolle für die zwei verschiedenen Boniturtermine gegenübergestellt. 7 Tage nach der Inokulation waren die Unterschiede zwischen den Isolaten leichter zu erkennen als 11 Tage nach der Inokulation. Obwohl die Abbildungen von der Abschlussbonitur nach 11 Tagen den Eindruck vermitteln, dass alle Isolate die Keimlinge von Winterraps gleich stark infiziert haben, konnte durch die Beurteilung von drei Wiederholungen je Isolat, die in Tabelle 8A aufgeführten Disease Indices ermittelt werden. Eine statistische Auswertung erfolgte mit diesen Daten nicht. 
Tab. 8A: Mittlerer Disease Index (0-1) von verschiedenen Isolaten von B. cinerea an Keimlingen von Winterraps (Sorte NK Petrol) 7 bzw. 11 Tage nach der Inokulation (dpi = days post inoculation). Die Berechnung des mittleren Disease Index ist in Kapitel II.8.1 beschrieben. Signifikanzbuchstaben sind nicht angegeben, da keine statistische Verrechnung mit diesen Daten durchgeführt wurde.

\begin{tabular}{ccc}
\hline Isolat & \multicolumn{2}{c}{ Durchschnittlicher Disease Index } \\
\hline & $7 \mathrm{dpi}$ & $11 \mathrm{dpi}$ \\
\hline Kontrolle & 0 & 0 \\
Blatt GÖ & 0,17 & 0,62 \\
Schote GÖ & 0,23 & 0,72 \\
Stängel GÖ & 0,42 & 0,73 \\
Schote DE & 0,53 & 0,75 \\
\hline
\end{tabular}




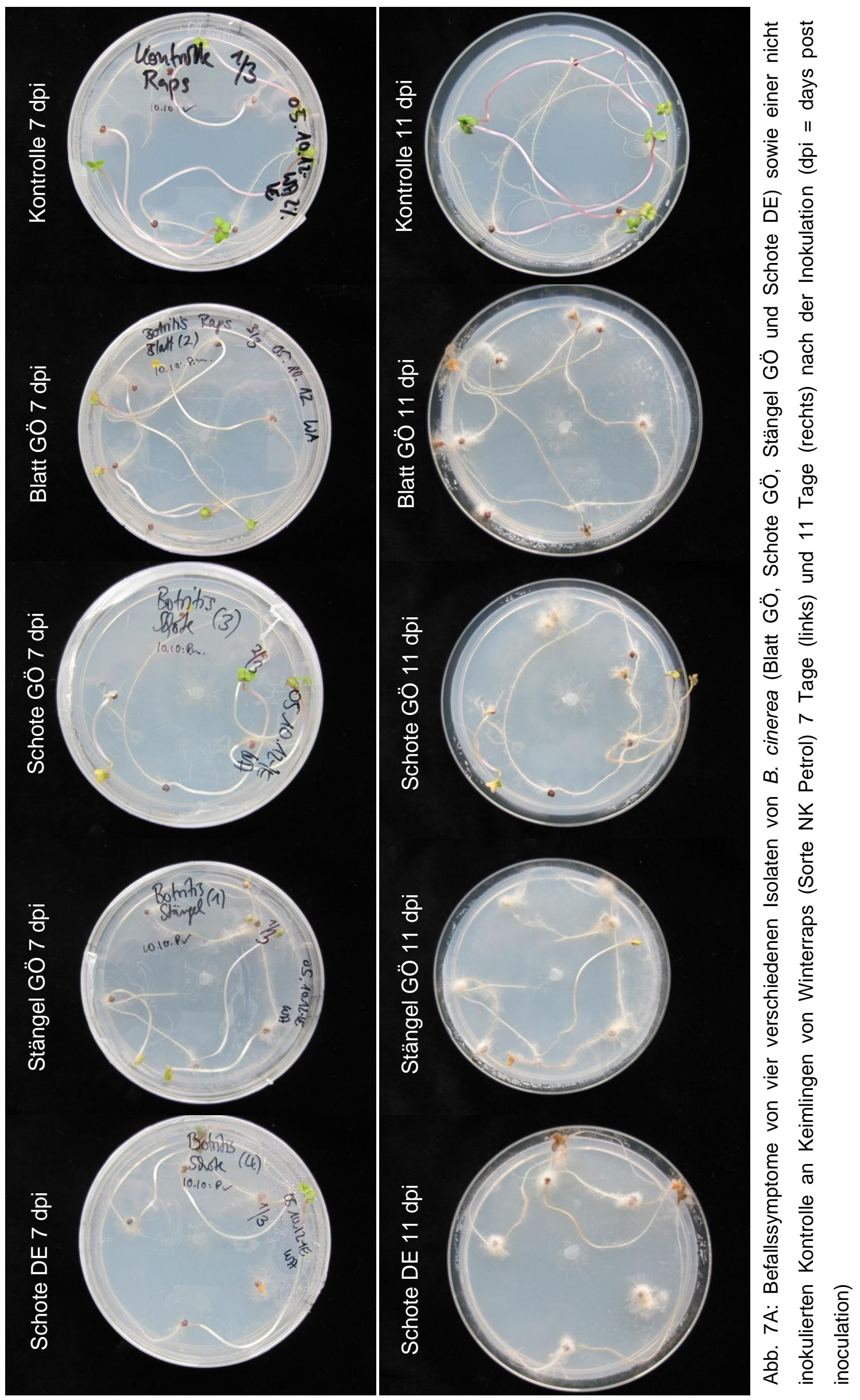




\section{III.2 Temperaturversuch}

Bei diesem Versuchsansatz wurde das Temperaturoptimum für eine Infektion durch B. cinerea an Winterraps ermittelt. Durch die Inokulation von verletzten bzw. unverletzten Laubblättern sowie Stängelsegmenten sollte außerdem untersucht werden, ob Verletzungsstellen den Befall mit $B$. cinerea an Winterraps bei unterschiedlichen Temperaturen begünstigen und ob verschiedene Pflanzenorgane eine differenzierte Anfälligkeit gegenüber $B$. cinerea aufweisen. Im Folgenden werden die Ergebnisse getrennt nach dem Laubblatttest und dem Stängelsegmenttest vorgestellt. Dabei werden für jede Temperaturstufe der mittlere AUDPC-Wert und die jeweilige Standardabweichung dargestellt. Die mittleren AUDPC-Werte wurden aus der ermittelten Läsionslänge errechnet. Zu beachten ist, dass die Inokulation der Laubblätter bei $4^{\circ} \mathrm{C}, 8^{\circ} \mathrm{C}, 12^{\circ} \mathrm{C}, 16^{\circ} \mathrm{C}$, $20^{\circ} \mathrm{C}$ und $24^{\circ} \mathrm{C}$ und die Inokulation der Stängelsegmente bei den zuvor genannten Temperaturen sowie $18^{\circ} \mathrm{C}$ und $22^{\circ} \mathrm{C}$ durchgeführt wurden. Weiterhin muss berücksichtigt werden, dass von den vier verschiedenen Varianten („verletzt, inokuliert“; „nicht verletzt, inokuliert“; „verletzt, nicht inokuliert“ und „nicht verletzt, nicht inokuliert“), unabhängig vom Versuchsdurchgang, nur Befallssymptome in den inokulierten Varianten auftraten.

\section{III.2.1 Laubblatttest}

In der Abbildung 8A sind die mittleren AUDPC-Werte für die Variante „verletzt, inokuliert“ nach 11 dpi für den ersten und den zweiten Versuchsdurchgang sowie dem Mittel aus beiden Versuchsdurchgängen dargestellt. Beim ersten Versuchsansatz wurden im Vergleich zu allen anderen Temperaturen die signifikant höchsten AUDPC-Werte bei einer Temperatur von $16^{\circ} \mathrm{C}(482,2)$ und $20^{\circ} \mathrm{C}(438,4)$ ermittelt. Außerdem waren die AUDPC-Werte bei einer Temperatur von $12^{\circ} \mathrm{C}(310,5)$ und $24^{\circ} \mathrm{C}(322,1)$ signifikant höher als bei $4^{\circ} \mathrm{C}(121,8)$. Der AUDPC-Wert der $4^{\circ} \mathrm{C}$-Variante unterschied sich nicht signifikant vom AUDPC-Wert der $8^{\circ} \mathrm{C}$-Variante. Im zweiten Durchgang wurden die höchsten AUDPC-Werte bei einer Temperatur von $16^{\circ} \mathrm{C}(619,2), 24^{\circ} \mathrm{C}(614,4)$ und $20^{\circ} \mathrm{C}(562,7)$ festgestellt. Die beiden höchsten AUDPC-Werte unterschieden sich dabei signifikant von dem AUDPC-Wert bei $4^{\circ} \mathrm{C}(230,1)$, $8^{\circ} \mathrm{C}(305,0)$ und $12^{\circ} \mathrm{C}(391,8)$. Der AUDPC-Wert bei $20^{\circ} \mathrm{C}$ unterschied sich dagegen nur von den AUDPC-Werten bei $4^{\circ} \mathrm{C}$ und $8^{\circ} \mathrm{C}$. Beim Vergleich der beiden Versuchsdurchgänge fällt auf, dass im zweiten Durchgang bei allen Temperaturen höhere AUDPC-Werte auftraten als im ersten Durchgang. Im Mittel über beide Versuche nahm der AUDPC-Wert von $4^{\circ} \mathrm{C}$ bis $16^{\circ} \mathrm{C}$ kontinuierlich zu und danach sank er bis $24^{\circ} \mathrm{C}$ wieder ab. Dabei war der AUDPC-Wert bei $12^{\circ} \mathrm{C}(385,7)$ signifikant höher als bei $4^{\circ} \mathrm{C}(210,5)$. Weiterhin waren die AUDPC-Werte bei $16^{\circ} \mathrm{C}(585,2), 20^{\circ} \mathrm{C}$ 
$(535,1)$ und $24^{\circ} \mathrm{C}(494,4)$ signifikant höher als bei $4^{\circ} \mathrm{C}, 8^{\circ} \mathrm{C}(299,6)$ und $12^{\circ} \mathrm{C}$. Untereinander waren die ermittelten AUDPC-Werte von $16^{\circ} \mathrm{C}, 20^{\circ} \mathrm{C}$ und $24^{\circ} \mathrm{C}$ nicht signifikant verschieden.

Um einen Eindruck zu vermitteln, wie sich die Symptome von $B$. cinerea nach einer Verletzung des Blattgewebes bei den einzelnen Temperaturstufen entwickelt haben, sind diese in Abbildung 10A auf der linken Seite dargestellt.

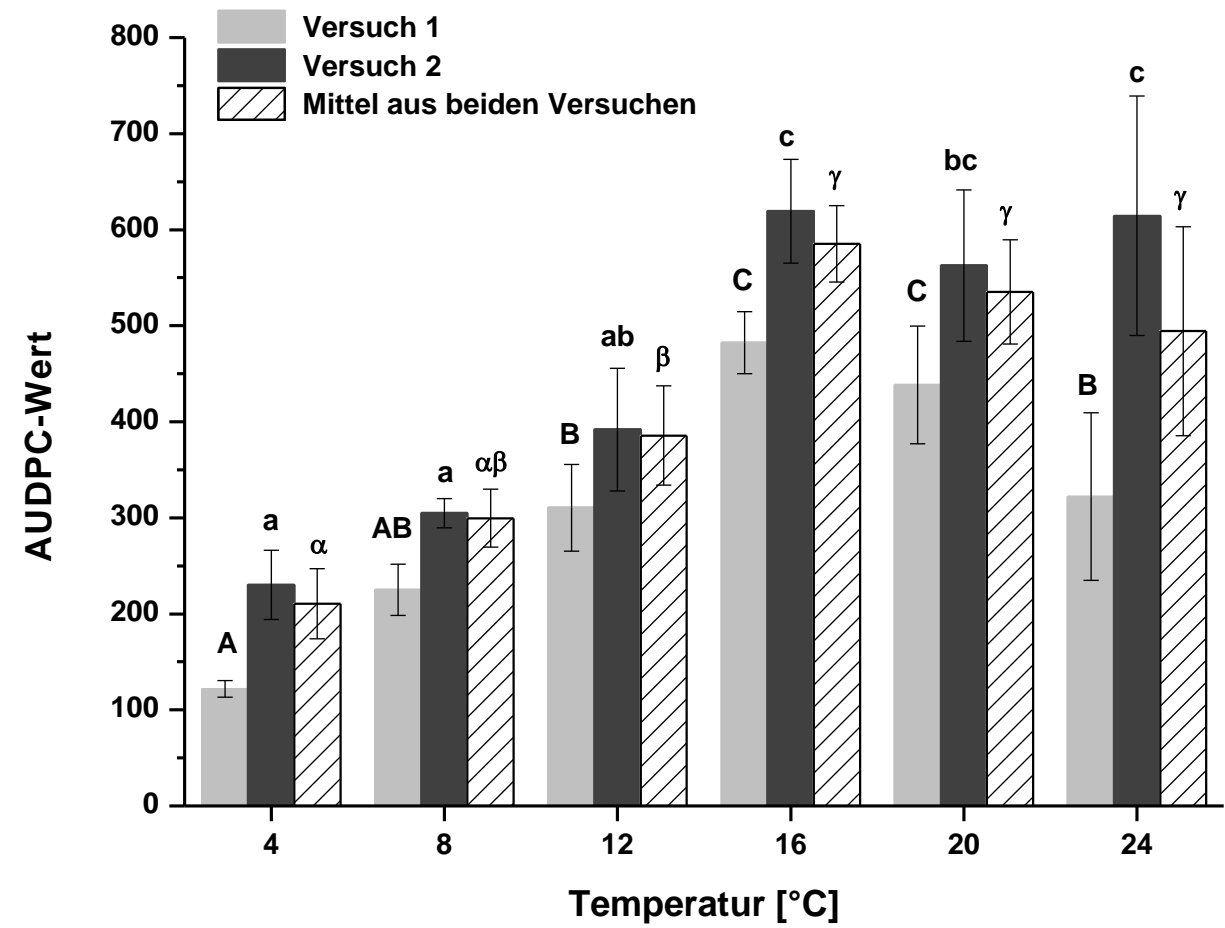

Abb. 8A: Mittlere AUDPC- (Area Under Disease Progress Curve) Werte von B. cinerea an Laubblättern (7. Laubblatt) von Winterraps (Sorte „NK Petrol“) nach 11 Tagen in Abhängigkeit von der Temperatur $\left(4,8,12,16,20\right.$ und $\left.24^{\circ} \mathrm{C}\right)$, ermittelt unter kontrollierten Bedingungen. Dargestellt sind die AUDPC-Werte der Variante „verletzt, inokuliert“ für den ersten und zweiten Versuchsdurchgang sowie dem Mittel aus beiden Versuchen. Verschiedene Buchstaben kennzeichnen signifikante Unterschiede nach dem Tukey-Test $(\alpha \leq 0,05, n=4)$, errechnet innerhalb des verwendeten gemischten Modells. Großbuchstaben kennzeichnen Unterschiede zwischen den Temperaturstufen vom 1. Versuch, kleingeschriebene Buchstaben kennzeichnen Unterschiede zwischen den Temperaturstufen vom 2. Versuch und griechische Buchstaben heben Differenzen zwischen den Temperaturstufen aus dem Mittel von beiden Versuchen hervor. Die Fehlerbalken stellen die jeweilige Standardabweichung dar. 
In der Variante „nicht verletzt, inokuliert“ wurde im ersten Durchgang bei einer Temperatur von $8^{\circ} \mathrm{C}$ und $12^{\circ} \mathrm{C}$ kein Befall mit $B$. cinerea an den Laubblättern bonitiert (Abb. 9A). Aus diesem Grund sind in der Abb. 9A bei den beiden Temperaturvarianten keine Säulen dargestellt. In diesem Durchgang wurde bei einer Temperatur von $20^{\circ} \mathrm{C}$ der signifikant höchste AUDPC-Wert erfasst $(182,6)$. Beim zweiten Versuchsansatz lagen die AUPDCWerte bei jeder Temperaturstufe deutlich über den AUDPC-Werten vom ersten Durchgang. Hier wurde der höchste AUDPC-Wert bei einer Temperatur von $20^{\circ} \mathrm{C}(513,4)$ festgestellt. Die nächst höheren AUDPC-Werte wiesen die Temperaturvarianten von $16^{\circ} \mathrm{C}$ $(475,1)$ und $24^{\circ} \mathrm{C}(468,9)$ auf. Dabei waren alle drei AUDPC-Werte nicht signifikant verschieden. Dies lag an der recht hohen Streuung der Daten, besonders bei der Temperaturstufe von $24^{\circ} \mathrm{C}$. Die AUDPC-Werte der drei genannten Temperaturen waren signifikant höher als die AUDPC-Werte der Temperaturstufen von $4^{\circ} \mathrm{C}(127,4) 8^{\circ} \mathrm{C}(262,6)$ und $12^{\circ} \mathrm{C}(320,3)$. Des Weiteren konnte für die Temperaturstufe von $12^{\circ} \mathrm{C}$ ein signifikant höherer AUDPC-Wert nachgewiesen werden als bei der Temperaturstufe von $4^{\circ} \mathrm{C}$. Im Mittel über beide Versuchsdurchgänge zeigte sich mit zunehmender Temperatur eine ähnliche Entwicklung der AUDPC-Werte wie bei der Variante „verletzt, inokuliert“. Bei der hiesigen Variante stieg der AUDPC-Wert von $4^{\circ} \mathrm{C}$ bis $20^{\circ} \mathrm{C}$ an und sank danach wieder ab. Dabei unterschieden sich die AUDPC-Werte bei $16^{\circ} \mathrm{C}(368,7), 20^{\circ} \mathrm{C}(444,4)$ und $24^{\circ} \mathrm{C}$ $(389,0)$ signifikant von dem AUDPC-Wert bei $4^{\circ} \mathrm{C}(135,2)$. Zwischen den AUDPC-Werten der Temperaturstufen von $16-24^{\circ} \mathrm{C}$ bestanden keine signifikanten Unterschiede. Da im ersten Durchgang bei einer Temperatur von $8^{\circ} \mathrm{C}$ und $12^{\circ} \mathrm{C}$ kein Befall mit $B$. cinerea aufgetreten ist, konnte kein Mittelwert für diese beiden Varianten ermittelt werden.

Die Symptome von B. cinerea an unverletzten Laubblättern in Abhängigkeit der einzelnen Temperaturstufen, können der Abbildung 10A auf der rechten Seite entnommen werden. Gleichzeitig ermöglicht diese Abbildung auch ein Vergleich mit den Symptomen an Laubblättern aus der verletzt, inokulierten Variante. 


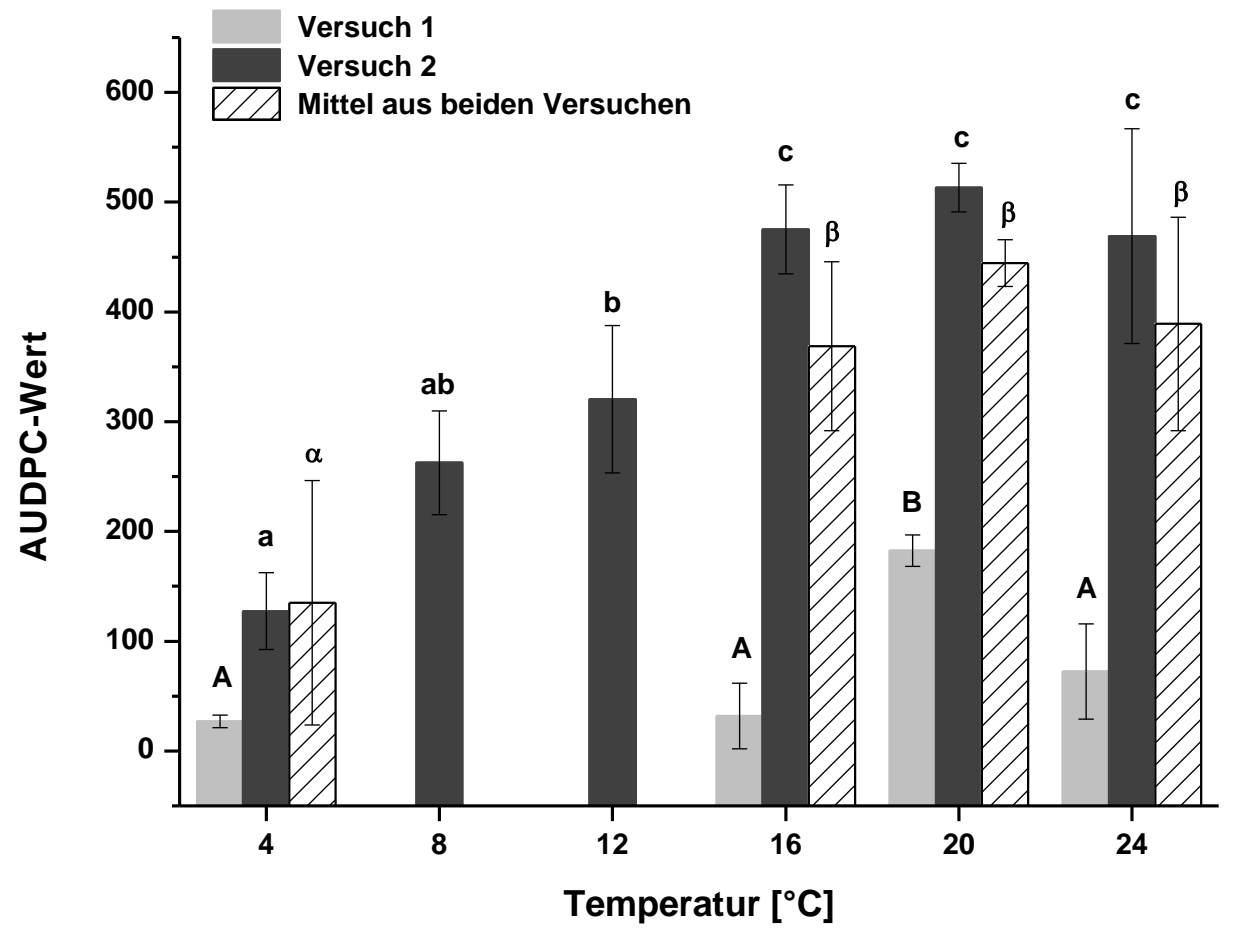

Abb. 9A: Mittlere AUDPC- (Area Under Disease Progress Curve) Werte von B. cinerea an Laubblättern (7. Laubblatt) von Winterraps (Sorte „NK Petrol“) nach 11 Tagen in Abhängigkeit von der Temperatur $\left(4,8,12,16,20\right.$ und $\left.24^{\circ} \mathrm{C}\right)$, ermittelt unter kontrollierten Bedingungen. Dargestellt sind die AUDPC-Werte der Variante „nicht verletzt, inokuliert“ für den ersten und zweiten Versuchsdurchgang sowie dem Mittel aus beiden Versuchen. Verschiedene Buchstaben kennzeichnen signifikante Unterschiede nach dem Tukey-Test $(\alpha \leq 0,05, n=4)$, errechnet innerhalb des verwendeten gemischten Modells. Großbuchstaben kennzeichnen Unterschiede zwischen den Temperaturstufen vom 1. Versuch, kleingeschriebene Buchstaben kennzeichnen Unterschiede zwischen den Temperaturstufen vom 2. Versuch und griechische Buchstaben heben Differenzen zwischen den Temperaturstufen aus dem Mittel von beiden Versuchen hervor. Die Fehlerbalken stellen die jeweilige Standardabweichung dar.

Beim Vergleich der Mittelwerte von der verletzt, inokulierten und der nicht verletzt, inokulierten Variante fällt auf, dass in der Variante mit den verletzten Laubblättern, unabhängig von der Temperaturstufe, höhere AUDPC-Werte ermittelt wurden als in der Variante mit den unverletzten Laubblättern. Im Schnitt über alle Temperaturstufen lag der AUDPC-Wert in der verletzten Variante bei 418,4 und in der unverletzten Variante bei 334,3 . 
An hang 245
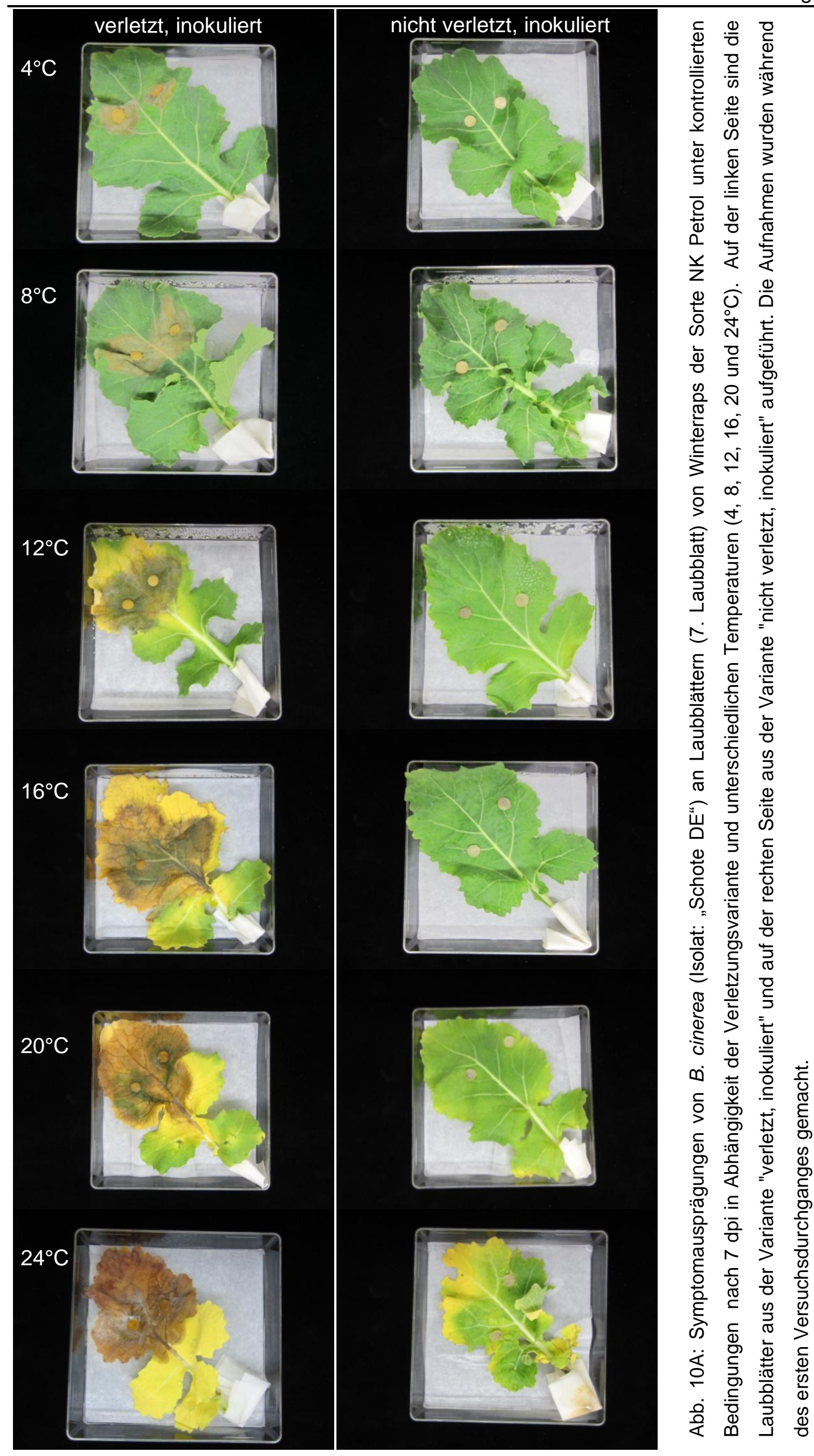


\section{III.2.2 Stängelsegmenttest}

Die Abbildung 11A zeigt die AUDPC-Werte für eine Infektion mit $B$. cinerea an verletzten Stängelsegmenten von Winterraps in Abhängigkeit von verschiedenen Temperaturen. Im ersten Versuchsdurchgang wurde für die Temperaturstufen von $12^{\circ} \mathrm{C}$ bis $22^{\circ} \mathrm{C}$ jeweils ein signifikant höherer AUDPC-Wert festgestellt $(445,7 ; 440,7 ; 426,5 ; 437,6 ; 438,4)$ als bei $4^{\circ} \mathrm{C}(255,5), 8^{\circ} \mathrm{C}(290,1)$ und $24^{\circ} \mathrm{C}(298,3)$. Beim zweiten Durchgang wurden bei den Temperaturstufen von $8^{\circ} \mathrm{C}$ bis $24^{\circ} \mathrm{C}$ signifikant höhere AUDPC-Werte $(265,8 ; 396,5$; $392,5 ; 538,3 ; 534,2 ; 503,1$ und 522,4$)$ ermittelt als bei $4^{\circ} \mathrm{C}(113,1)$. Außerdem unterschieden sich die AUDPC-Werte bei den Temperaturen $18^{\circ} \mathrm{C}, 20^{\circ} \mathrm{C}, 22^{\circ} \mathrm{C}$ und $24^{\circ} \mathrm{C}$ signifikant von dem AUDPC-Wert bei $8^{\circ} \mathrm{C}$. Die AUDPC-Werte von den Temperaturstufen von $12^{\circ} \mathrm{C}$ bis $24^{\circ} \mathrm{C}$ unterschieden sich nicht signifikant, wobei die höchsten AUDPC-Werte in absteigender Reihenfolge bei den Temperaturstufen $18^{\circ} \mathrm{C}(538,3), 20^{\circ} \mathrm{C}(534,2), 24^{\circ} \mathrm{C}$ $(522,4)$ und $22^{\circ} \mathrm{C}(503,1)$ ermittelt wurden. Im Vergleich der beiden Versuchsdurchgänge waren die AUDPC-Werte beim zweiten Durchgang bei den Temperaturstufen von $4^{\circ} \mathrm{C}$ bis $16^{\circ} \mathrm{C}$ niedriger als beim ersten Durchgang. Für die Temperaturstufen von $18^{\circ} \mathrm{C}$ bis $24^{\circ} \mathrm{C}$ trat das Gegenteil auf. Hier waren die mittleren AUDPC-Werte beim zweiten Durchgang höher als beim ersten Durchgang. Im Mittel über beide Versuchsdurchgänge waren die AUDPC-Werte bei den Temperaturen von $12^{\circ} \mathrm{C}$ bis $24^{\circ} \mathrm{C}$ signifikant höher $(421,1 ; 416,6$; $482,4 ; 485,9 ; 470,8 ; 410,3)$ als bei $4^{\circ} \mathrm{C}(184,3)$ und $8^{\circ} \mathrm{C}(278,0)$.

Um zu zeigen, wie sich die Symptome von $B$. cinerea an verletzten Stängelsegmenten unter dem Einfluss der einzelnen Temperaturstufen entwickelt haben, sind diese in Abbildung 13A auf der linken Seite zusammengefasst. 


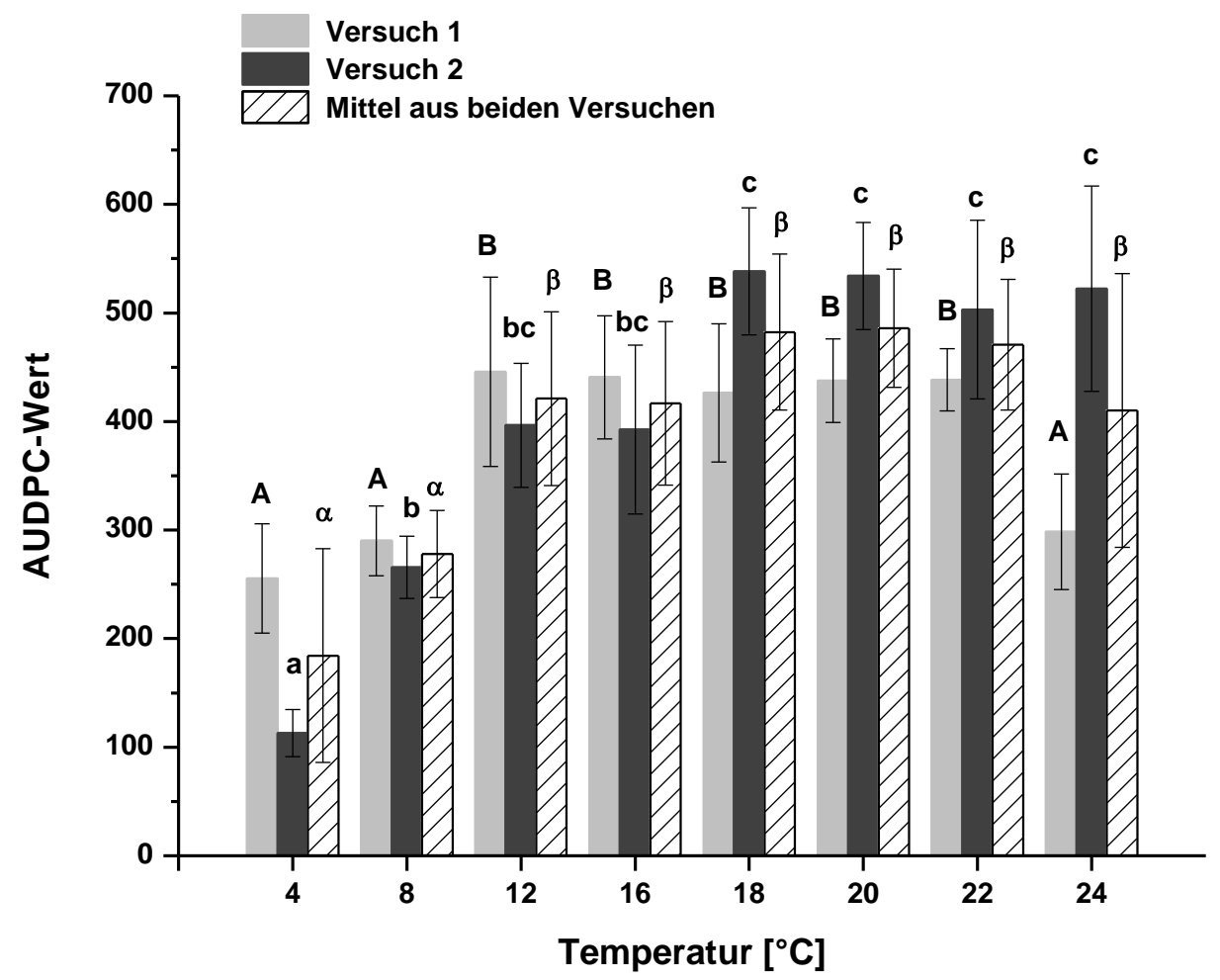

Abb. 11A: Mittlere AUDPC- (Area Under Disease Progress Curve) Werte von B. cinerea an Stängelsegmenten von Winterraps (Sorte „NK Petrol“) nach 11 Tagen in Abhängigkeit von der Temperatur $\left(4,8,12,16,18,20,22\right.$ und $\left.24^{\circ} \mathrm{C}\right)$, ermittelt unter kontrollierten Bedingungen. Dargestellt sind die AUDPC-Werte der Variante „verletzt, inokuliert" für den ersten und zweiten Versuchsdurchgang sowie dem Mittel aus beiden Versuchen. Verschiedene Buchstaben kennzeichnen signifikante Unterschiede nach dem Tukey-Test $(\alpha \leq 0,05, n=4)$, errechnet innerhalb des verwendeten gemischten Modells. Großbuchstaben kennzeichnen Unterschiede zwischen den Temperaturstufen vom 1. Versuch, kleingeschriebene Buchstaben kennzeichnen Unterschiede zwischen den Temperaturstufen vom 2. Versuch und griechische Buchstaben heben Differenzen zwischen den Temperaturstufen aus dem Mittel von beiden Versuchen hervor. Die Fehlerbalken stellen die jeweilige Standardabweichung dar.

In Abbildung 12A sind die mittleren AUDPC-Werte für die Variante "nicht verletzt, inokuliert" nach $11 \mathrm{dpi}$ für die beiden Versuchsdurchgänge sowie dem Mittel aus beiden Durchgängen dargestellt. Bei der Temperaturstufe von $4^{\circ} \mathrm{C}$ im ersten und zweiten Durchgang sowie bei $22^{\circ} \mathrm{C}$ im ersten Versuchsansatz wurde kein Befall mit $B$. cinerea an den Stängelsegmenten beobachtet. Dadurch sind für diese Varianten keine Säulen in der Abbildung $12 \mathrm{~A}$ aufgeführt. Beim ersten Durchgang zeigten sich keine signifikanten Unterschiede für die AUDPC-Werte zwischen den verschiedenen Temperaturstufen. Die höchsten AUDPC-Werte wurden bei einer Temperatur von $24^{\circ} \mathrm{C}(167,8)$ und $16^{\circ} \mathrm{C}(158,2)$ ermittelt. Beim zweiten Versuchsansatz war der AUDPC-Wert bei einer Temperatur von 
$20^{\circ} \mathrm{C}$ signifikant höher $(307,4)$ als bei $8^{\circ} \mathrm{C}(8,7), 12^{\circ} \mathrm{C}(64,9)$ und $16^{\circ} \mathrm{C}(58,6)$. Aufgrund der verhältnismäßig hohen Streuung der Daten innerhalb jeder Temperaturstufe, traten keine weiteren signifikanten Unterschiede auf. Im Mittel über beide Versuchsansätze waren die AUDPC-Werte zwischen den verschiedenen Temperaturstufen nicht signifikant verschieden. Dies lag wiederum an den recht hohen Standardabweichungen.

Nach den einzelnen Temperaturstufen geordnet, sind die Symptome von B. cinerea an unverletzten Stängelsegmenten in der Abbildung $13 \mathrm{~A}$ auf der rechten Seite wiedergegeben. Diese zweigeteilte Abbildung ermöglicht einen Vergleich mit den Symptomen an Stängelsegmenten aus der verletzt, inokulierten Variante.

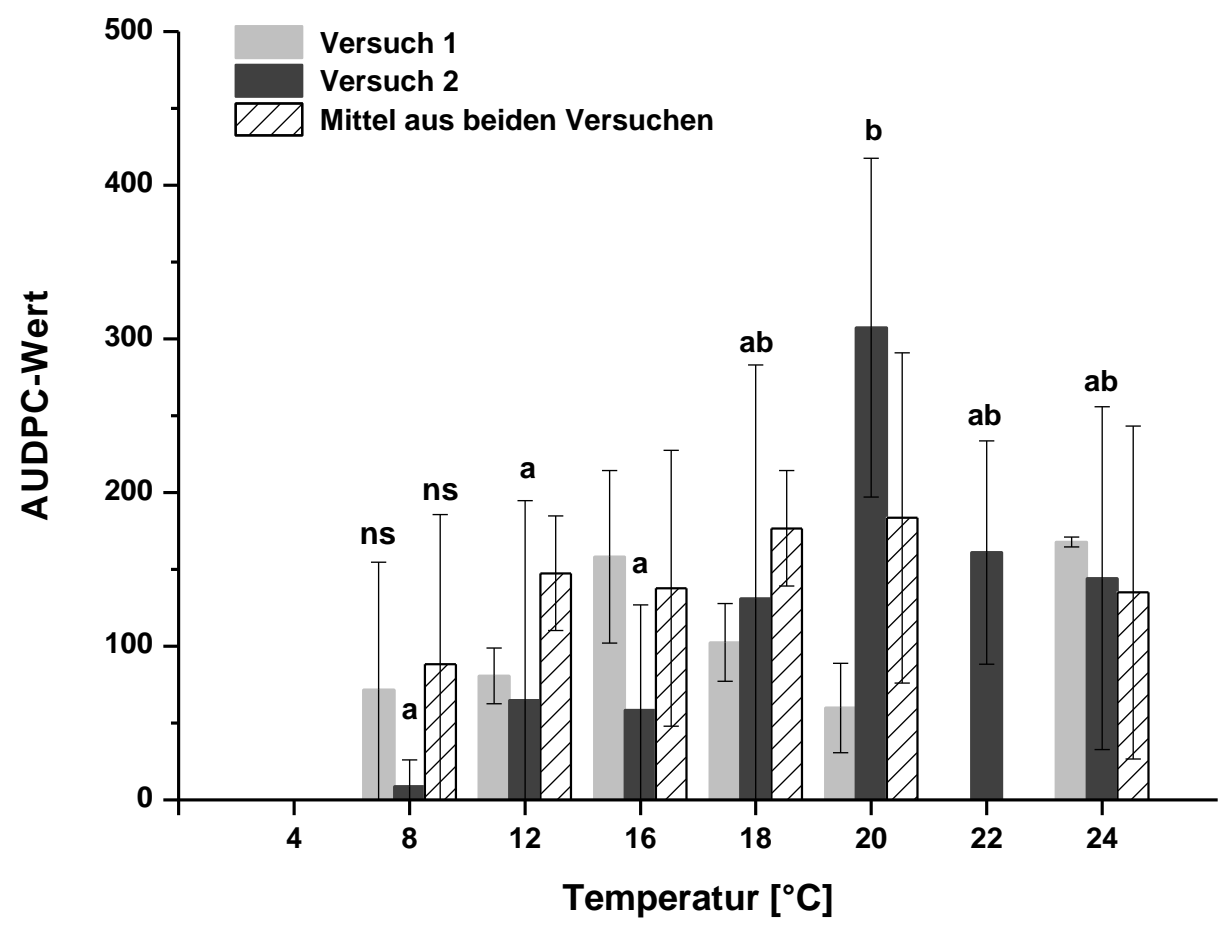

Abb. 12A: Mittlere AUDPC- (Area Under Disease Progress Curve) Werte von B. cinerea an Stängelsegmenten von Winterraps (Sorte "NK Petrol“) nach 11 Tagen in Abhängigkeit von der Temperatur $\left(4,8,12,16,18,20,22\right.$ und $\left.24^{\circ} \mathrm{C}\right)$, ermittelt unter kontrollierten Bedingungen. Dargestellt sind die AUDPC-Werte der Variante "nicht verletzt, inokuliert“ für den ersten und zweiten Versuchsdurchgang sowie dem Mittel aus beiden Versuchen. Verschiedene Buchstaben kennzeichnen signifikante Unterschiede zwischen den Temperaturstufen vom 2. Versuch nach dem Tukey-Test ( $\alpha \leq 0,05, n=4$ ), errechnet innerhalb des verwendeten gemischten Modells. Im ersten Versuch und bei dem Mittel aus beiden Versuchen traten keine statistisch signifikanten Unterschiede auf ( $\mathrm{ns}=$ nicht signifikant). Die Fehlerbalken stellen die jeweilige Standardabweichung dar. 
Wie bei der Inokulation der Laubblätter wurden bei der Inokulation der Stängelsegmente in der Variante mit den verletzten Stängelsegmenten, unabhängig von der Temperaturstufe, höhere AUDPC-Werte ermittelt als in der Variante mit den unverletzten Stängelsegmenten. Der mittlere AUDPC-Wert aus zwei Versuchsdurchgängen und über alle Temperaturstufen lag bei der verletzten Variante bei 393,7 und bei der unverletzten Variante bei 139,7 . 


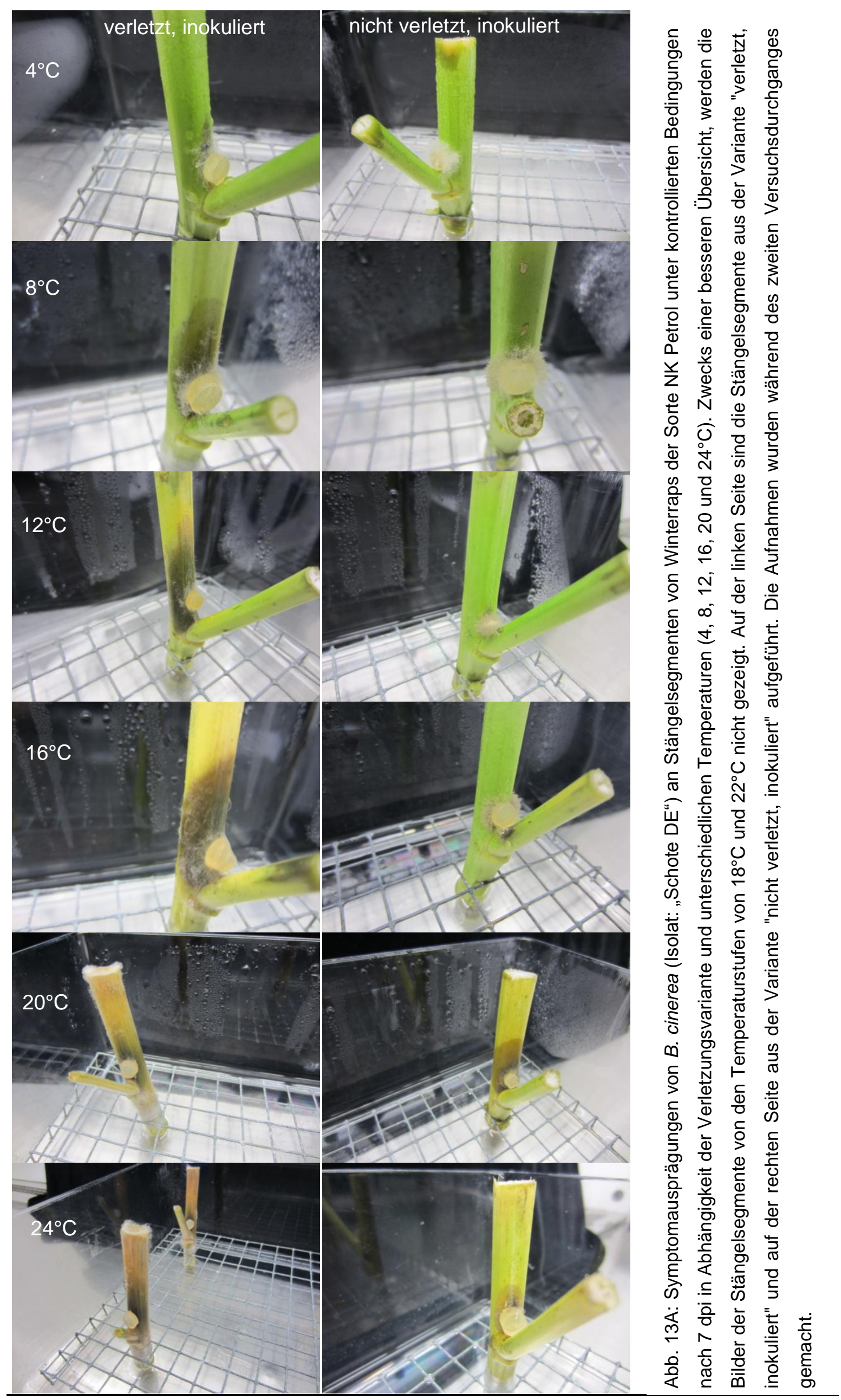




\section{III.3 Sortenversuch}

Durch die Inokulation von zwölf verschiedenen Genotypen von Winterraps mit B. cinerea (Isolat: „Schote DE“) sollte die Anfälligkeit der Genotypen gegenüber diesem Pathogen überprüft werden. Dabei wurden wie bei dem Temperaturversuch Laubblätter und Stängel unabhängig voneinander inokuliert, um einen potenziell unterschiedlichen Befall mit $B$. cinerea an den verschiedenen Pflanzenorganen herauszuarbeiten. Zudem wurden verletzte sowie unverletzte Laubblätter und Stängel eingesetzt, um den Einfluss einer Verletzung auf die Sortenanfälligkeit gegenüber $B$. cinerea zu ermitteln. Weiterhin konnte durch diesen Gewächshausversuch ein Vergleich zwischen einer möglichen Variabilität in der Sortenanfälligkeit gegenüber $B$. cinerea und der Variabilität der Sortenanfälligkeit gegenüber $S$. sclerotiorum angestellt werden, da fünf von den zwölf Genotypen in einer früheren Arbeit auf ihre Resistenz gegenüber einem Befall mit $S$. sclerotiorum getestet wurden (WULF, 2011). Die Ergebnisse werden im Folgenden getrennt nach dem Laubblatttest und dem Stängeltest wiedergegeben. Wie beim Temperaturversuch wurde der Befall mit $B$. cinerea durch die Messung der Läsionslänge quantifiziert und anschließend über die Anzahl der Boniturtage in AUDPC-Werte umgerechnet.

\section{III.3.1 Laubblatttest}

An den Laubblättern zeigten sich in allen vier Varianten („verletzt, inokuliert“; „nicht verletzt, inokuliert“; „verletzt, nicht inokuliert“ und „nicht verletzt, nicht inokuliert“) Befallssymptome. In den nicht mit $B$. cinerea inokulierten Varianten wurden diese Befallssymptome von anderen Pathogenen (z.B. Mucor spp. oder verschiedene Bakterien) ausgelöst. Da die Laubblätter unter nicht sterilen Bedingungen inokuliert und bonitiert wurden, war eine Kontamination der Agarscheiben durch andere Pilze oder Bakterien möglich. In den mit $B$. cinerea (Isolat: „Schote DE“) inokulierten Varianten konnte spätestens nach 5 dpi festgestellt werden, dass an den Agarscheiben Konidien von $B$. cinerea gebildet wurden. Dies war der Beweis dafür, dass sich das Pathogen auf der jeweiligen Agarscheibe etabliert hatte und es kann davon ausgegangen werden, dass die beobachteten Symptome von $B$. cinerea ausgelöst wurden. Wegen den vorherigen Erläuterungen werden an dieser Stelle ausschließlich die Ergebnisse von den mittleren AUDPC-Werten von den inokulierten Varianten näher beschrieben.

Bei der verletzt, inokulierten Variante traten nach 9 dpi in beiden Versuchsdurchgängen und bei dem Mittel aus beiden Durchgängen keine signifikanten Unterschiede zwischen den AUDPC-Werten der einzelnen Sorten auf (Abb. 14A). Im ersten Versuchsdurchgang schwankte der AUDPC-Wert zwischen 391,7 (Sorte: „Vision“) und 465,3 (Sorte: „Sherpa“). 
Im zweiten Durchgang erzielte die Sorte „Dimension“ mit 410,6 den niedrigsten AUDPCWert und die Sorte „NK Petrol“ mit 513,9 den höchsten AUDPC-Wert. Im Mittel über beide Versuchsansätze lag der AUDPC-Wert zwischen 420,1 (Sorte: „Dimension“) und 471,4 (Sorte: „SY Merlot“). Im Vergleich der beiden Versuchsdurchgänge konnte festgestellt werden, dass das Befallsniveau im zweiten Durchgang bei fast allen Sorten höher war als im ersten Durchgang. Nur für die Sorte „Dimension“ traf dies nicht zu.

Um einen Eindruck zu erlangen, wie sich der Befall mit $B$. cinerea an verletzen Laubblättern der verschiedenen Genotypen äußerte, werden beispielhalft die Symptome von den Sorten Uluru, Vision und Sherpa in Abbildung 16A auf der linken Seite dargestellt.

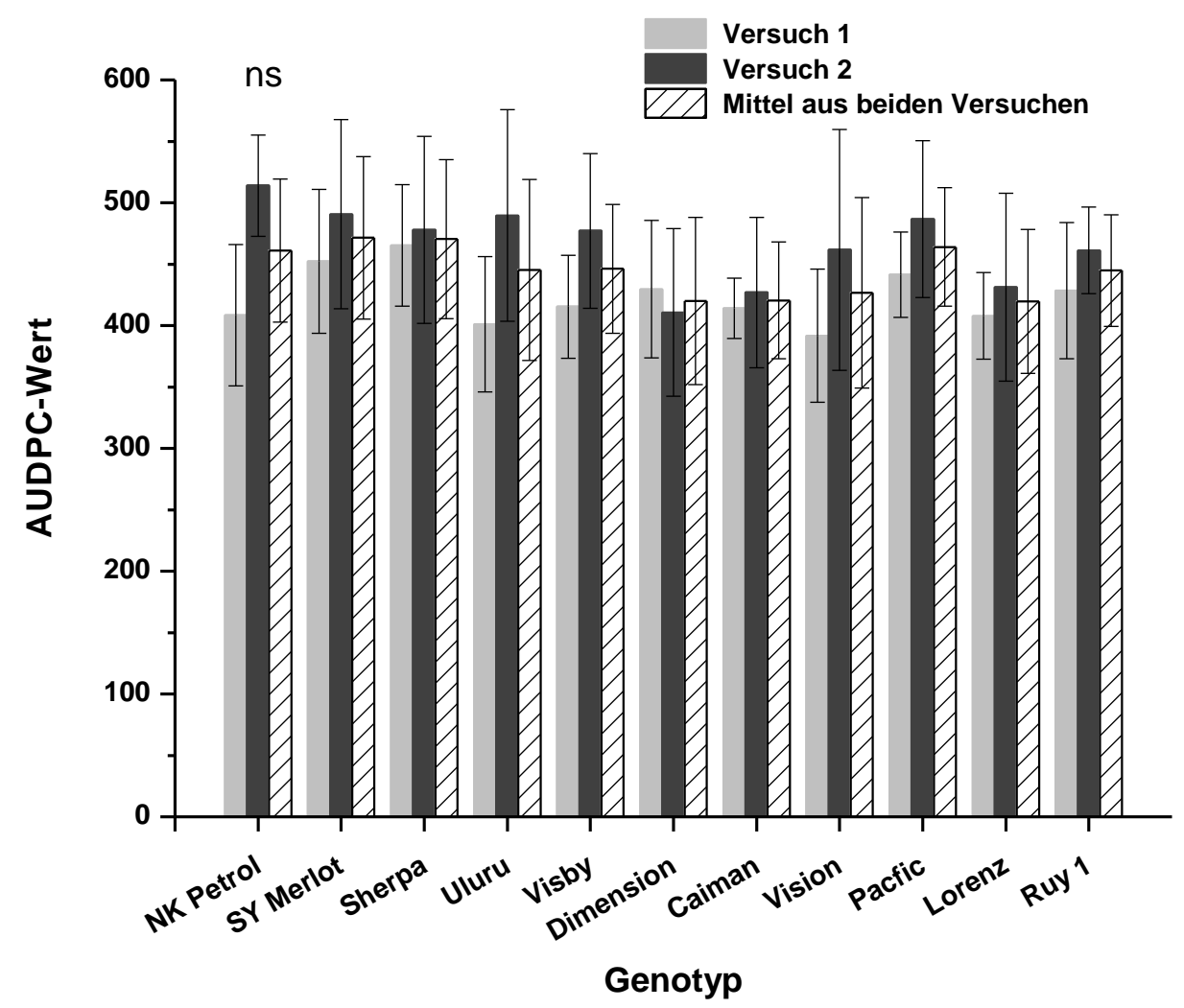

Abb. 14A: Mittlere AUDPC- (Area Under Disease Progress Curve) Werte von B. cinerea an Laubblättern (8. Laubblatt) von zehn Winterrapssorten und einer Resynthese (Ruy 1) nach 9 Tagen, ermittelt unter kontrollierten Bedingungen. Dargestellt sind die AUDPC-Werte der Variante „verletzt, inokuliert“ für den ersten und zweiten Versuchsdurchgang sowie dem Mittel aus beiden Versuchen. Nach dem Tukey-Test ( $\alpha \leq 0,05, n=8)$ konnten unabhängig vom Versuchsdurchgang keine signifikanten Unterschiede zwischen den verschiedenen Sorten nachgewiesen werden (ns = nicht signifikant). Die Fehlerbalken stellen die jeweilige Standardabweichung dar. 
Bei der Variante „nicht verletzt, inokuliert“ konnten für beide Versuchsdurchgänge sowie für das Mittel aus beiden Durchgängen keine signifikanten Unterschiede zwischen den AUDPC-Werten der einzelnen Genotypen von Raps nachgewiesen werden (Abb. 15A). Im ersten Versuchsansatz schwankte der AUDPC-Wert zwischen 253,5 (Sorte: „Vision“) und 355,8 (Sorte: „Caiman“) und im zweiten Versuchsansatz zwischen 334,4 (Sorte: „Caiman“) und 391,2 (Sorte: „SY Merlot“). Beim Durchschnitt aus beiden Versuchen lag der AUDPC-Wert zwischen 309,5 (Sorte: „Vision“) und 360,9 (Sorte: „SY Merlot“). Bei dieser Variante wurde im zweiten Durchgang ebenfalls ein stärkerer Befall mit $B$. cinerea beobachtet als im ersten Versuchsansatz. Einzig die Sorte „Caiman“ war im zweiten Versuchsdurchgang geringer befallen als im ersten Durchgang.

Zum Vergleich mit den Symptomen aus der Variante „verletzt, inokuliert“ werden die Symptome von B. cinerea an unverletzten Laubblättern der Sorte „Uluru“, „Vision“ und „Sherpa“ in Abbildung 16A auf der rechten Seite gezeigt.

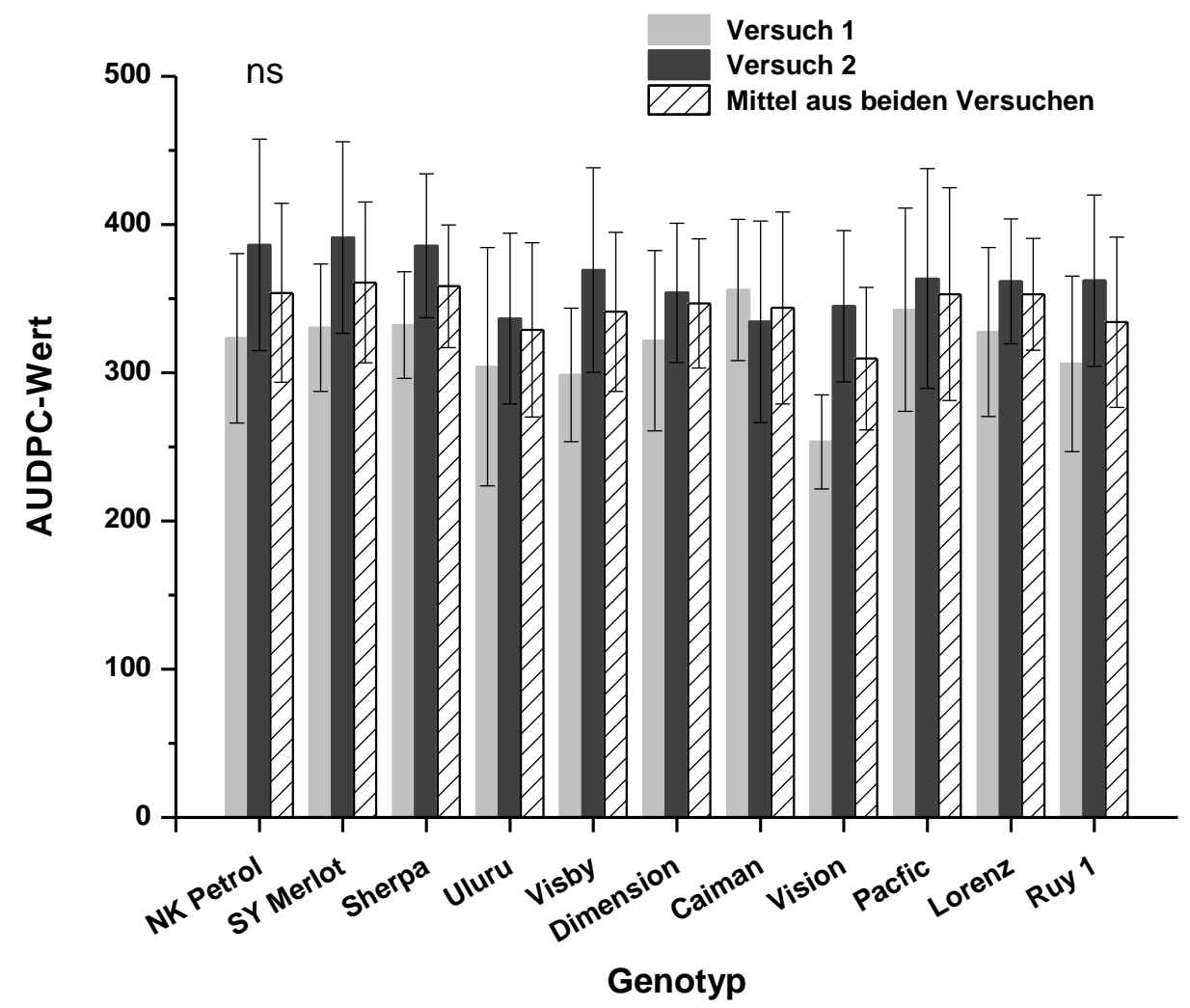

Abb. 15A: Mittlere AUDPC- (Area Under Disease Progress Curve) Werte von B. cinerea an Laubblättern (8. Laubblatt) von zehn Winterrapssorten und einer Resynthese (Ruy 1) nach 9 Tagen, ermittelt unter kontrollierten Bedingungen. Dargestellt sind die AUDPC-Werte der Variante „nicht verletzt, inokuliert" für den ersten und zweiten Versuchsdurchgang sowie dem Mittel aus beiden Versuchen. Nach dem Tukey-Test $(\alpha \leq 0,05, \mathrm{n}=8)$ konnten unabhängig vom Versuchsdurchgang keine signifikanten Unterschiede zwischen den verschiedenen Sorten nachgewiesen werden ( $\mathrm{ns}=$ nicht signifikant). Die Fehlerbalken stellen die jeweilige Standardabweichung dar 
Beim Vergleich der Mittelwerte von der verletzt, inokulierten und der nicht verletzt, inokulierten Variante aus beiden Versuchsdurchgängen, wurde unabhängig von der Sorte nachgewiesen, dass in der verletzten Variante die Laubblätter von Winterraps bzw. der Resynthese einen stärken Befall mit der Grauschimmelfäule aufwiesen als in der unverletzten Variante. Im Schnitt über alle Sorten lag der AUDPC-Wert in der verletzten Variante bei 444,6 und in der unverletzten Variante bei 311,9. Da die Daten, unabhängig vom Versuchsansatz und von der Variante, eine verhältnismäßig hohe Streuung aufwiesen, konnten Unterschiede in den AUDPC-Werten zwischen den einzelnen Sorten nicht statistisch abgesichert werden.

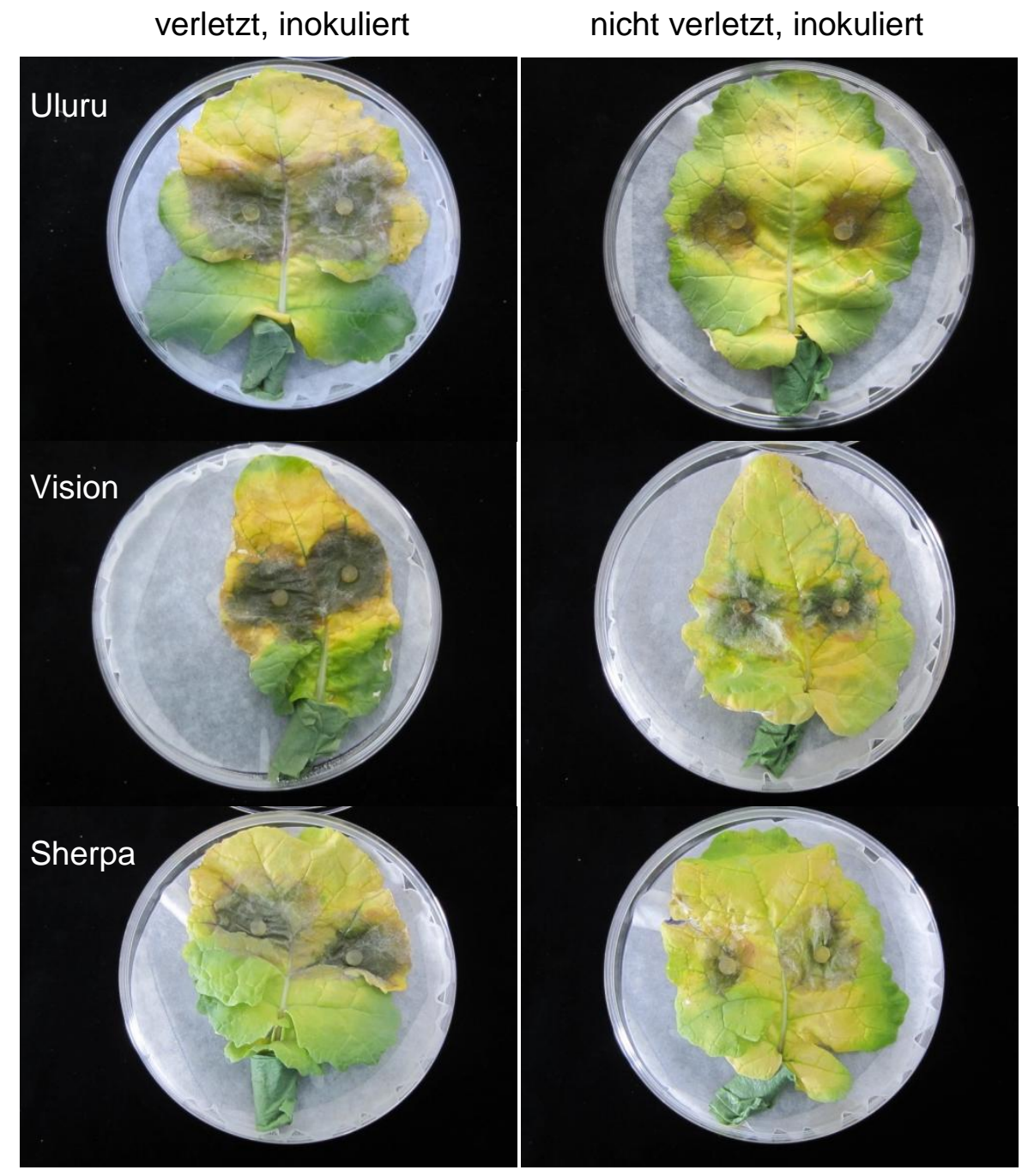

Abb. 16A: Symptomausprägungen von B. cinerea (Isolat: „Schote DE“) an Laubblättern (8. Laubblatt) von Winterraps unter Gewächshausbedingungen nach $5 \mathrm{dpi}$ in Abhängigkeit der Verletzungsvariante und der Sorte. Die dargestellten Sorten wurden zufällig aus den elf geprüften Sorten ausgewählt. Auf der linken Seite sind die Laubblätter aus der Variante "verletzt, inokuliert" und auf der rechten Seite aus der Variante "nicht verletzt, inokuliert" aufgeführt. Die Aufnahmen wurden während des ersten Versuchsdurchganges gemacht. 


\section{III.3.2 Stängeltest}

Bei der Inokulation des Haupttriebes der verschiedenen Rapsgenotypen in der sechsten Blattachsel wurden Symptome von B. cinerea nur in der Variante „verletzt, inokuliert“ registriert. In der Abbildung 17A sind die mittleren AUDPC-Werte der einzelnen Sorten nach 14 dpi für beide Versuchsdurchgänge und dem Mittel aus beiden Versuchen aufgeführt. Beim ersten Durchgang lag der AUDPC-Wert zwischen 191,3 (Sorte: „Uluru“) und 555,3 (Sorte: „Caiman“). Der AUDPC-Wert von der Sorte „Uluru“ war signifikant geringer als die AUDPC-Werte der Sorten „SY Merlot“ $(429,0)$, „Sherpa“ (529,0), „Visby“ (442,2), „Caiman“ (555,3), „Pacific“ (491,6), „Lorenz“ (442,8) und „Zhongshuang 9“ $(479,5)$. Des Weiteren war der AUDPC-Wert von der Sorte „NK Petrol“ $(241,7)$ signifikant geringer als die AUDPC-Werte der Sorten „Sherpa“, „Caiman“ und „Pacific“. Die Sorte „Ruy 1“ $(305,9)$ wies einen signifikant geringeren AUDPC-Wert auf als die Sorte „Caiman“. Die AUDPC-Werte von der Sorte „NK Petrol“, „Uluru“ und „Ruy 1“ unterschieden sich nicht signifikant. Im zweiten Versuchsansatz schwankte der AUDPC-Wert zwischen 151,5 (Sorte: „Lorenz“) und 294,4 (Sorte: „Zhongshuang 9“). Bei diesem Durchgang war der Befall mit $B$. cinerea am Stängel nicht so stark ausgeprägt wie beim ersten Durchgang. Signifikante Unterschiede konnten nur zwischen den Sorten "Dimension“, „Lorenz" und „Zhongshuang 9“ festgestellt werden. Dabei waren die AUDPC-Werte von den Sorten „Dimension“ $(162,7)$ und „Lorenz“ $(151,5)$ signifikant geringer als der AUDPC-Wert von der Sorte „Zhongshuang 9“ $(294,4)$. Im Mittel aus beiden Durchgängen lag der AUDPCWert zwischen 172,3 (Sorte: „Uluru“) und 400,9 (Sorte: „Zhongshuang 9“). Die Sorte „Uluru“ $(172,3)$ wies einen signifikant geringeren AUDPC-Wert auf als die Sorten „Sherpa“ $(351,4)$, „Caiman“ $(400,9)$, „Pacific“ $(353,5)$ und „Zhongshuang 9“ $(384,7)$. Weiterhin konnte für die Sorte „NK Petrol“ (201,6) ein signifikant geringerer AUDPC-Wert nachgewiesen werden als für die Sorten „Caiman“ und „Zhongshuang 9“. Zudem war der AUDPC-Wert von der Sorte „Ruy 1“ $(252,7)$ signifikant geringer als der AUDPC-Wert von der Sorte "Caiman“. Die folgenden Sorten wiesen die geringsten AUDPC-Werte auf: "Uluru“ < "NK Petrol“ < "Ruy 1" < „Dimension“, wobei die Sorte "Uluru“ die meisten signifikanten Unterschiede mit anderen Sorten vorweisen konnte und die Sorte „Dimension“ von keiner anderen Sorte signifikant verschieden war.

Die Abbildung 18A zeigt beispielhaft die Ausprägung der Symptome von B. cinerea an Stängeln der Sorten „Uluru“, „Ruy 1“ und „Zhongshuang 9“. 


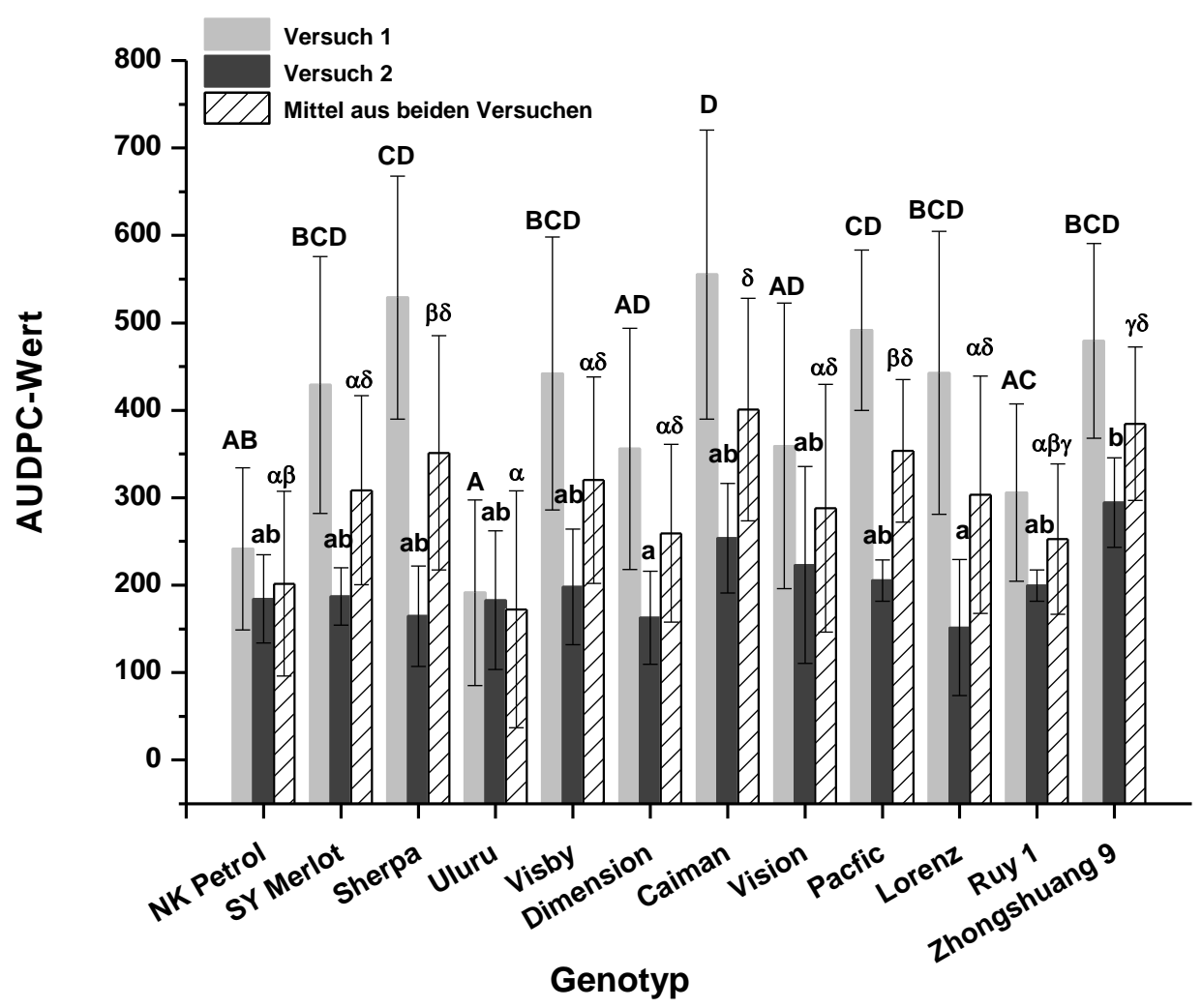

Abb. 17A: Mittlere AUDPC- (Area Under Disease Progress Curve) Werte von B. cinerea an Stängeln von zehn Winterrapssorten, einer Resynthese (Ruy 1) und einer Semi-Winterrapssorte (Zhongshuang 9) nach 14 Tagen, ermittelt unter kontrollierten Bedingungen. Dargestellt sind die AUDPC-Werte der Variante „verletzt, inokuliert" für den ersten und zweiten Versuchsdurchgang sowie dem Mittel aus beiden Versuchen. Verschiedene Buchstaben kennzeichnen signifikante Unterschiede nach dem Tukey-Test $(\alpha \leq 0,05, n=8)$, errechnet innerhalb des verwendeten gemischten Modells. Großbuchstaben kennzeichnen Unterschiede zwischen den Sorten vom 1. Versuch, kleingeschriebene Buchstaben kennzeichnen Unterschiede zwischen den Sorten vom 2. Versuch und griechische Buchstaben heben Differenzen zwischen den Sorten aus dem Mittel von beiden Versuchen hervor. Die Fehlerbalken stellen die jeweilige Standardabweichung dar. 


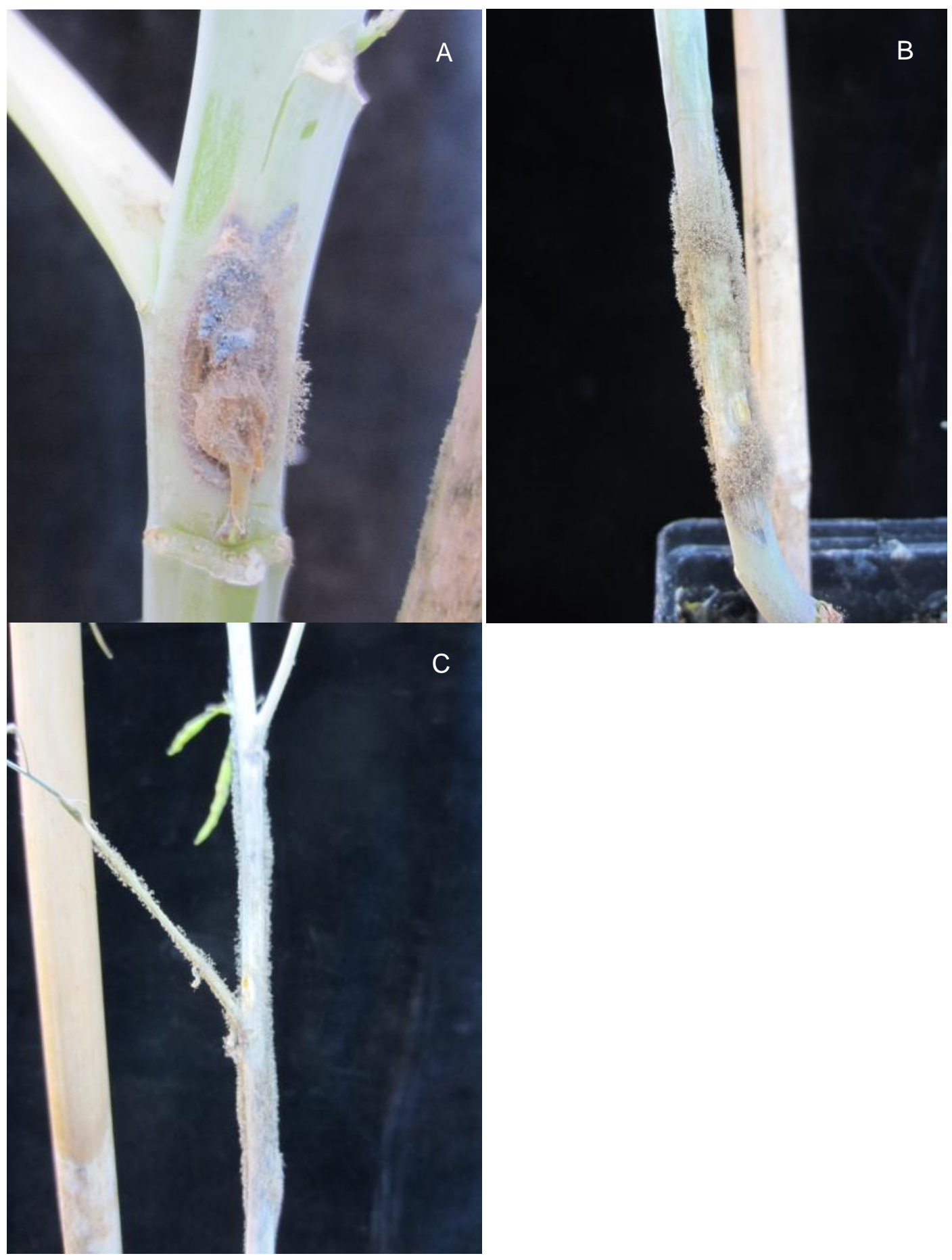

Abb. 18A: Symptomausprägungen von B. cinerea (Isolat: „Schote DE“) an einem verletzten Stängel von A: Winterraps (Sorte „Uluru), B: einer Raps Resynthese (Sorte „Ruy 1“) und C: einer chinesischen Raps Linie (Sorte Zhongshuang 9) unter Gewächshausbedingungen nach 14 dpi. Alle Bilder zeigen den für $B$. cinerea typischen gräulichen Konidiosporenrasen. Die dargestellten Sorten wurden zufällig aus den zwölf geprüften Sorten ausgewählt. Die Aufnahmen wurden während des ersten Versuchsdurchganges gemacht. 
Für den Vergleich der AUDPC-Werte vom Befall mit $S$. sclerotiorum und $B$. cinerea werden vom Versuch mit $B$. cinerea die AUDPC-Werte vom Stängelbefall aus der verletzt inokulierten Variante herangezogen, da nur in dieser Variante ein Befall bonitiert werden konnte. Dabei gehen AUDPC-Werte in den Vergleich ein, die für einen Befallsverlauf über neun Tage ermittelt wurden. Ursprünglich fand die Abschlussbonitur nach 14 Tagen statt. Da die von WULF (2011) ermittelten AUDPC-Werte für den Befall mit S. sclerotiorum an Stängeln von verschiedenen Rapssorten nach derselben Methode erfasst und die AUDPC-Werte aus einem Befallsverlauf über neun Tage berechnet wurden, können diese Werte für einen Vergleich der Variabilität der Sortenanfälligkeit gegenüber $B$. cinerea und S. sclerotiorum genutzt werden.

In Tabelle 9A sind die AUDPC-Werte zusammen mit der Standardabweichung für den Befall mit S. sclerotiorum und B. cinerea für die Rapssorten „Visby“, „Pacific“, „Lorenz“, „Ruy 1“ und „Zhongshuang 9“ gegenübergestellt. Die Untersuchungen von WULF (2011) führten zu dem Ergebnis, dass die Sorten „Lorenz“ und „Zhongshuang 9“ jeweils einen signifikant niedrigeren AUDPC-Wert aufwiesen als die Sorten „Visby“ und „Pacific“. Bei den erst genannten Sorten konnte sich der Pilz S. sclerotiorum in der Pflanze nicht so stark ausbreiten wie bei den zuletzt genannten Sorten. Der AUDPC-Wert für die Sorte „Ruy 1“ nimmt eine intermediäre Stellung zwischen den Werten der vier anderen Sorten ein. Bei der Stängelinokulation mit $B$. cinerea konnten im ersten Versuchsansatz keine signifikanten Unterschiede zwischen den AUDPC-Werten der fünf verschieden Sorten nachgewiesen werden. Die Werte schwankten zwischen 157,5 (Sorte: „Ruy 1“) und 234,4 (Sorte: „Zhongshuang 9“). Im zweiten Versuchsansatz waren die AUDPC-Werte von den Sorten „Visby“ $(108,1)$, „Lorenz" $(84,2)$ und „Ruy 1“ $(108,8)$ signifikant geringer als der AUDPC-Wert von der Sorte „Zhongshuang 9“ $(179,5)$. Zwischen den AUDPC-Werten der drei erst genannten Sorten und der Sorte „Pacific" bestanden keine signifikanten Unterschiede. Bei dem Mittel aus beiden Versuchen wurden für die Sorten "Lorenz" $(142,3)$ und „Ruy 1“ $(133,1)$ signifikant niedrigere AUDPC-Werte ermittelt als bei der Sorte „Zhongshuang 9“ (205,1). Beim Vergleich der AUDPC-Werte vom Befall mit S. sclerotiorum und $B$. cinerea fällt auf, dass die AUDPC-Werte von der Infektion mit $B$. cinerea wesentlich höher waren, als bei der Infektion mit $S$. sclerotiorum. Dies ist durch die artifizielle Verletzung der Stängel bei dem Versuch mit $B$. cinerea zu erklären. Weiterhin lässt sich keine Übereinstimmung in der Variabilität der Anfälligkeit der Sorten gegenüber den beiden Pathogenen feststellen. Die Sorte „Zhongshuang 9“ wies bei einer Infektion mit $S$. sclerotiorum den niedrigsten AUDPC-Wert auf. Stattdessen wurden für diese Sorte bei einer Infektion mit $B$. cinerea in beiden Versuchsdurchgängen die höchsten AUDPC-Werte bestimmt. Für die anderen vier Sorten sind keine genauen 
Vergleiche zwischen den AUDPC-Werten vom Versuch mit B. cinerea und S. sclerotiorum möglich, da zwischen den beiden Versuchsdurchgängen mit $B$. cinerea starke Unterschiede in den AUDPC-Werten auftraten, wodurch die AUDPC-Werte einmal in der Tendenz mit den AUDPC-Werten vom Versuch mit $S$. sclerotiorum übereinstimmten (Sorte „Visby“ und Pacific“, Versuch 1; bzw. Sorte „Lorenz“ und „Ruy 1“, Versuch 2) und ein anderes Mal nicht (Sorte „Visby“ und Pacific“, Versuch 2; bzw. Sorte "Lorenz" und „Ruy 1“, Versuch 1). Generell war die Variabilität in der Anfälligkeit der Sorten gegenüber $B$. cinerea geringer als bei $S$. sclerotiorum. 
Tab. 9A: Gegenüberstellung der mittleren AUDPC (Area Under Disease Progress Curve) Werte von S. sclerotiorum bzw. B. cinerea an Stängeln von drei Winterrapssorten, einer Resynthese (Ruy 1) und einer Semi-Winterrapssorte (Zhongshuang 9) nach 9 Tagen, ermittelt unter kontrollierten Bedingungen. Für S. sclerotiorum stammen die Daten aus der Doktorarbeit von WULF (2011). Sie wurden von WULF (2011) nach dem Fisher-LSD-Test $(\alpha \leq 0,05 ; n=8)$ ausgewertet. Für B. cinerea sind die AUDPC-Werte der Variante „verletzt, inokuliert“ für den ersten und zweiten Versuchsdurchgang sowie dem Mittel aus beiden Versuchen dargestellt. Für die Variante „nicht verletzt, inokuliert“ sind keine Daten angegeben, da in dieser Variante kein Befall aufgetreten ist. Verschiedene Buchstaben kennzeichnen signifikante Unterschiede nach dem Tukey-Test $(\alpha \leq 0,05, n=8)$, errechnet innerhalb des verwendeten gemischten Modells. Großbuchstaben kennzeichnen Unterschiede zwischen den Sorten vom 1. Versuch, kleingeschriebene Buchstaben kennzeichnen Unterschiede zwischen den Sorten vom 2. Versuch und griechische Buchstaben heben Differenzen zwischen den Sorten aus dem Mittel von beiden Versuchen hervor. SD = Standardabweichung.

\begin{tabular}{ccccc}
\hline & & \multicolumn{2}{c}{ AUDPC-Werte \pm SD - Inokulation mit B. cinerea } \\
\hline Genotyp & $\begin{array}{c}\text { AUDPC-Werte } \pm \text { SD - Inokulation mit } \\
\text { S. sclerotiorum (n. WuLF, (2011) }\end{array}$ & 1. Versuch & 2. Versuch & Mittel aus beiden Versuchen \\
\hline Visby & $32,3 \pm 18,3$ klmnopqrs & $202,1 \pm 63,1 \mathrm{BC}$ & $108,1 \pm 36,6 \mathrm{a}$ & $155,1 \pm 51,2 \beta \gamma \delta$ \\
Pacific & $37,3 \pm 16,7$ nopqrstu & $206,2 \pm 29,5 \mathrm{BC}$ & $115,8 \pm 13,9 \mathrm{ab}$ & $161,8 \pm 25,2 \beta \gamma \delta$ \\
Lorenz & $17,3 \pm 19,7$ bcdefghi & $195,1 \pm 58,2 \mathrm{BC}$ & $84,2 \pm 45,2 \mathrm{a}$ & $142,3 \pm 54,4 \alpha \gamma$ \\
Ruy 1 & $26,4 \pm 16,3^{*}$ & $157,5 \pm 40,3 \mathrm{AC}$ & $108,8 \pm 11,6 \mathrm{a}$ & $133,1 \pm 31,3 \alpha \gamma$ \\
Zhongshuang 9 & $11,4 \pm 12,2$ abcde & $234,4 \pm 50,4 \mathrm{C}$ & $179,5 \pm 38,8 \mathrm{~b}$ & $205,1 \pm 44,9 \delta$ \\
\hline
\end{tabular}

${ }^{*}$ Für die Resynthese „Ruy 1“ sind keine Signifikanzbuchstaben angegeben, da dieser Genotyp in einem anderen Gewächshausversuch untersucht wurde als die anderen vier Genotypen. 


\section{Diskussion}

Nachdem in der vorliegenden Doktorarbeit ein komplettes Versuchsjahr wegen einer starken Frostschädigung des Winterrapses und einem anschließenden starken Befall mit $B$. cinerea aufgegeben werden musste, wurden Infektionsversuche mit $B$. cinerea an Winterraps im Gewächshaus durchgeführt. Dabei wurden zum einen verschiedene Umweltansprüche (Temperatur, Verletzung des Pflanzengewebes, Art des Pflanzengewebes) von $B$. cinerea für die Infektion von Winterraps untersucht und zum anderen verschiedene Sorten von Winterraps auf ihre Anfälligkeit gegenüber diesem Pathogen getestet. Zunächst werden die Ergebnisse zu den Umweltansprüchen diskutiert und näher erläutert. Im zweiten Unterkapitel der Diskussion werden die Ergebnisse zur Sortenanfälligkeit interpretiert, sowie der Vergleich zwischen der Sortenanfälligkeit gegenüber $B$. cinerea und $S$. sclerotiorum näher betrachtet.

\section{IV.1 Umweltansprüche von Botrytis cinerea für die Infektion von Winterraps}

In vielen Arbeiten wurden an verschiedenen Kulturpflanzen sowie an unterschiedlichen Pflanzenorganen die Temperaturansprüche von $B$. cinerea für eine Infektion untersucht. Beispielhaft sollen hier die Ergebnisse von 1. NAIR and ALLEN (1993), 2. SosA-ALVAREZ et al. (1995) und 3. O'NEILL et al. (1997) genannt werden, die 1. mit B. cinerea an Weintrauben und Blüten von Wein, 2. mit $B$. cinerea an abgestorbenen Laubblättern von Erdbeeren, sowie 3. mit B. cinerea an Stängeln von Tomaten gearbeitet haben. Alle drei Untersuchungen zeigten, dass der Erreger der Grauschimmelfäule in einem weiten Temperaturbereich $\left[10-30^{\circ} \mathrm{C}\right.$ (NAIR and ALLEN, 1993), $5-25^{\circ} \mathrm{C}$ (SOSA-ALVAREZ et al., 1995); und $5-26^{\circ} \mathrm{C}$ (O'NEILL et al., 1997)] Krankheitssymptome an der jeweils untersuchten Kulturpflanze ausgelöst hat. Weitere Studien bestätigten, dass $B$. cinerea die Fähigkeit besitzt, verschiedene Pflanzenspezies bei Temperaturen von $2^{\circ} \mathrm{C}$ bis mehr als $25^{\circ} \mathrm{C}$ zu infizieren (JARVIS, 1980; MAROIS et al., 1988; ELAD, 1989; ELAD et al., 1989). In dieser Arbeit konnte diese Fähigkeit an der Kulturpflanze Winterraps nachgewiesen werden. Es zeigte sich, dass das Pathogen Laubblätter von Winterraps unabhängig von einer Verletzung in einem Temperaturbereich von $4-24^{\circ} \mathrm{C}$ befällt. Für verletzte Stängelsegmente wurde derselbe Bereich festgestellt. Wurden die Stängelsegmente nicht artifiziell verletzt, so traten Symptome der Grauschimmelfäule nur in einem Bereich von 8$24^{\circ} \mathrm{C}$ auf. Dass der Pilz sowohl bei niedrigen als auch bei hohen Temperaturen Pflanzen befallen kann, beruht auf den Tatsachen, dass Konidien von diesem Pathogen sowohl bei $0^{\circ} \mathrm{C}$ (SCHNEIDER-ORELLI, 1912; BROOKS \& COOLEY, 1917) als auch bei $26^{\circ} \mathrm{C}$ (DORAN, 
1922) keimen können und, dass das Myzel bei $0-25^{\circ} \mathrm{C}$ (optimal bei $20-22^{\circ} \mathrm{C}$ ) merklich wachsen kann (SCHNEIDER-ORELLI, 1912). Die Autoren JARVIS (1980), MAROIS et al. (1988), ELAD (1989) und ELAD et al. (1989) identifizierten in ihren Untersuchungen als optimale Temperatur für eine Infektion mit $B$. cinerea den Temperaturbereich von 10 $20^{\circ} \mathrm{C}$. SOSA-AlvareZ et al. (1995) fanden heraus, dass $B$. cinerea an abgestorbenen Laubblättern von Erdbeeren die meisten Konidien bei einer Temperatur von $15-22^{\circ} \mathrm{C}$ produzierte. Im Fall von Weinreben wiesen NAIR and ALLEN (1993) sowie THOMAS et al. (1988) nach, dass der Erreger für eine massenhafte Vermehrung an Weintrauben $21^{\circ} \mathrm{C}$ favorisiert. An Stängeln von Tomaten konnte die schnellste Krankheitsentwicklung sowie die stärkste Sporulation von $B$. cinerea bei einer Temperatur von $15^{\circ} \mathrm{C}$ beobachtet werden (O'NEILL et al., 1997). PAUL (2003) gibt für optimale Befallsbedingungen an Winterraps einen Temperaturbereich von $10-15^{\circ} \mathrm{C}$ an und VON TIEDEMANN and STEINBACH (2007) nennen einen Bereich von $10-20^{\circ} \mathrm{C}$. Für die Gattung Botrytis gibt AGRIOS (2005) als optimale Temperatur für eine Infektion von Pflanzen einen Temperaturbereich von 18$23^{\circ} \mathrm{C}$ an. In dieser Arbeit wurde nachgewiesen, dass B. cinerea Laubblätter von Winterraps am stärksten bei Temperaturen von $16-24^{\circ} \mathrm{C}$ befällt, wobei dieser Bereich nicht bei jedem Versuchsdurchgang signifikant abgesichert werden konnte. Um die optimale Temperatur für einen Befall von Stängelsegmenten zu definieren, muss in verletztes und unverletztes Pflanzengewebe unterschieden werden. Bei einer Verletzung lag das Temperaturoptimum je nach Versuchsansatz bei $12-22^{\circ} \mathrm{C}$ bzw. $12-24^{\circ} \mathrm{C}$. Unverletztes Stängelgewebe wurde am stärksten bei einer Temperatur von $20^{\circ} \mathrm{C}$ infiziert, was sich allerdings nicht von $18^{\circ} \mathrm{C}, 22^{\circ} \mathrm{C}$ und $24^{\circ} \mathrm{C}$ unterschied. Die ermittelten optimalen Temperaturbedingungen für eine Infektion von $B$. cinerea an Winterraps finden sich in den zuvor vorgestellten Bereichen von $10-20^{\circ} \mathrm{C}$ bzw. $18-23^{\circ} \mathrm{C}$ wieder, wobei sie eher mit dem engeren Bereich von AGRIOS (2005) übereinstimmen.

Welchen Einfluss die Temperatur auf den Befall von B. cinerea an Winterraps haben kann, zeigte sich auch bei der Stängelinokulation von verschiedenen Sorten von Winterraps im Gewächshaus. Im ersten Versuchsdurchgang wurde eine wesentlich höhere Befallsstärke mit $B$. cinerea bonitiert als im zweiten Versuchsdurchgang. Dies ist auf unterschiedlich hohe Temperaturen während des jeweiligen Versuches zurückzuführen. Kontrollmessungen in einem Folienzelt ergaben, dass im ersten Versuchsansatz im Durchschnitt über alle Versuchstage die Temperatur $18,1^{\circ} \mathrm{C}$ und die relative Luftfeuchtigkeit $80,7 \%$ betrug. Im zweiten Versuchsansatz lagen die Werte im Durchschnitt über alle Versuchstage bei $21,9^{\circ} \mathrm{C}$ und $88,4 \%$, wobei Maximaltemperaturen von $36,1^{\circ} \mathrm{C}$ auftraten. Insgesamt wurde an 7 Tagen des ganzen zweiten Versuchzeitraumes eine Temperatur größer $30^{\circ} \mathrm{C}$ gemessen. Diese sehr hohen 
Temperaturen führten dazu, dass sich der Pilz in der Pflanze nicht weiter ausbreitete. Die unterschiedlichen Temperaturen während der zwei Versuchsdurchgänge kamen dadurch zustande, dass die Versuche einmal im Januar und einmal im April 2013 durchgeführt wurden und zu diesen Zeitpunkten unterschiedliche Außentemperaturen herrschten. Im April 2013 traten teils sehr hohe Temperaturen auf, wodurch das Gewächshaus sich aufheizte und die vorhandene Kühltechnik (Außenluftwäsche) die gewünschte Temperatur von $18^{\circ} \mathrm{C}$ nur schwer herstellen konnte. Weitere Gründe für die unterschiedlich hohen Befallsstärken von $B$. cinerea an Stängeln von Winterraps in den beiden Versuchsansätzen können ausgeschlossen werden, da beide Versuchsdurchgänge nach dem ceteris paribus Prinzip angelegt wurden.

Zusätzlich zu der Temperatur sind feuchte Bedingungen in Form von hoher relativer Luftfeuchtigkeit oder freiem Wasser auf der Pflanzenoberfläche (Tau, Regen) ganz entscheidend für eine erfolgreiche Infektion durch den Pilz B. cinerea (WINSPEAR et al., 1970; BlaKeman, 1980; Morgan, 1984). Damit Konidien von B. cinerea keimen können, benötigen sie eine besonders hohe relative Luftfeuchtigkeit von 93-100\% (SNOW, 1949). Die Voraussetzung für eine feuchte Pflanzenoberfläche nimmt umso mehr zu, je mehr die optimale Temperatur unter- bzw. überschritten wird (NAIR and ALLEN, 1993). Der Einfluss der relativen Luftfeuchtigkeit wurde in dieser Arbeit nicht untersucht. Durch feuchtes Filterpapier (Temperatur-/Sortenversuch mit Laubblättern), einer definierten Menge an Wasser in Boxen (Temperaturversuch mit Stängelsegmenten) und durch die Aufbewahrung von ganzen Rapspflanzen (Sortenversuch - Stängelinokulation) in Folienzelten wurde allerdings eine möglichst hohe relative Luftfeuchte generiert.

Bei dem Erreger der Grauschimmelfäule handelt es sich um einen Schwächeparasit, der vornehmlich verletztes Pflanzengewebe (JARVIS, 1977) oder physiologisch geschwächtes Pflanzengewebe (PAUL, 2003) befällt. Der letztgenannte Punkt umfasst z.B. seneszentes oder schlecht mit Nährstoffen versorgtes oder frostgeschädigtes Gewebe (JARVIS, 1977). Ein besonders prädisponierender Faktor stellt eine Frostschädigung dar, selbst dann, wenn das Gewebe nicht stark beschädigt wurde (CICCARONE, 1959). Welchen fördernden Einfluss Frost auf den Befall mit $B$. cinerea haben kann, konnte im Rahmen dieser Doktorarbeit im Jahr 2012 in einem Feldversuch mit Winterraps beobachtet werden. In den hiesigen Gewächshausversuchen zeigte sich, dass die verletzten Laubblätter oder Stängel immer stärker befallen waren als die unverletzten Pflanzenorgane. Speziell bei der Inokulation der Rapsstängel von verschiedenen Sorten, waren Symptome der Grauschimmelfäule nur in der Variante „verletzt, inokuliert“ sichtbar. Gleiches konnten O'NEILL et al. (1997) in ihren Versuchen mit B. cinerea an Tomatenstängeln feststellen, bei denen verletzte Stängel einen Befall aufwiesen und unverletzte nicht. Die beiden 
zuletzt erwähnten Ergebnisse bestätigen die eingangs dieses Absatzes genannte Erkenntnis von JARVIS (1977) und zeigen welch bedeutenden Einfluss die Kutikula, als äußere Schutzbarriere gegen Pathogene, hat.

Die Inokulation von Laubblättern und Stängeln von Winterraps sollte Aufschluss darüber geben, ob es eine differenzierte Anfälligkeit von verschiedenen Pflanzenorganen gegenüber $B$. cinerea gibt. Es wurde nachgewiesen, dass beide Pflanzenorgane von diesem Pathogen befallen werden, wobei Laubblätter unabhängig von einer Verletzung befallen wurden und Stängel nur infiziert wurden, wenn diese eine Verletzung aufwiesen. Dem widerspricht allerdings das Ergebnis von dem Temperaturversuch mit Stängelsegmenten von Winterraps, in dem sowohl an verletzten als auch an unverletzten Stängelsegmenten Krankheitssymptome und neu gebildete Konidiosporen nachgewiesen wurden. Vor der Inokulation der Stängelsegmente wurden diese unter fließendem Wasser gewaschen und dabei die komplette Pflanzenoberfläche der Stängelsegmente mit den Händen sauber gerieben. Bei diesem Säuberungsvorgang wurde eine graue „reifartige“ Schicht, die sogenannte epikutikulare Wachsschicht ganz abgerieben und wohlmöglich weitere Bestandteile der Kutikula beschädigt. Die Kutikula besteht hauptsächlich aus einem unlöslichen Polymer und löslichen Lipiden. Das Polymer heißt Cutin und ist eine Matrix, die vor allem aus $C_{16}$ und $C_{18}$ Hydroxy- und Epoxyfettsäuren (HOLLOWAY, 1982; KOLATTUKUDY, 2001) besteht. Je nach Spezies wird das Cutin durch ein anderes Polymer namens Cutan ersetzt oder es tritt zusätzlich zum Cutin auf (NIP et al., 1986). Die löslichen Lipide stellen eine komplexe Mischung aus verschiedenen aliphatischen und zyklischen Komponenten dar und werden für gewöhnlich als Wachse bezeichnet. Die einzelnen Bestandteile dieser Wachse wurden in verschiedenen Arbeiten genau analysiert (BAKER, 1982; BARTHLOTT, 1990). Diese Lipide werden zum einen in die Cutinmatrix eingebaut (intrakutikulare Wachse) und zum anderen bewegen sie sich an die Oberfläche (epikutikulare Wachse), wo sie häufig komplexe dreidimensionale Strukturen bilden (BARTHLOTT and WOLleNWEBER, 1981; BIANCHI, 1995). Die zwei Hauptaufgaben der Kutikula mit ihren intrakutikularen Wachsen sind zum einen das pflanzliche Gewebe vor einem unkontrollierten Wasserverlust zu schützen (SCHÖNHERR, 1976, 1982) und zum anderen das Auswaschen von organischen und anorganischen Substanzen aus dem Zellinneren zu reduzieren (SCHREIBER and SCHÖNHERR, 1993; SCHÖNHERR, 2000). Die epikutikulare Wachsschicht schützt vor starker Sonneneinstrahlung, indem ein gewisser Teil der Strahlung reflektiert wird (BARNES \& CADOSO-VILHENA, 1996) und sie ist stark hydrophob, wodurch auch ein Transpirationsschutz gegeben ist (HOLLOWAY, 1969, 1971). Die geringe Benetzbarkeit dieser Schicht führt dazu, dass Wassertropfen abperlen und dabei Staub und Mikroorganismen (Virenpartikel, Bakterienzellen, Pilzsporen) mitnehmen. 
Dieser selbstreinigende Mechanismus heißt "Lotus-Effekt“, da er erstmals an der Lotusblume beschrieben wurde (BARTHLOTT \& NEINHUIS, 1997). So stellen die epikutikularen Wachse im speziellen und die Kutikula im Allgemeinen eine wichtige Schutzbarriere gegen Pathogene dar (JENKS et al., 1994; MARIANI \& WOLTERS-ARTS, 2000). Sind diese Schichten allerdings nicht vorhanden oder beschädigt, kann ein Pathogen leichter die unter der Kutikula liegenden Epidermiszellen infizieren. In dem Sortenversuch wurden die Stängel der verschiedenen Winterrapssorten nicht gewaschen und nicht mit den Händen gereinigt. Hier ist davon auszugehen, dass die epikutikulare Wachsschicht und die Kutikula in Takt waren. Die Laubblätter wurden unabhängig von den Versuchen unter fließendem Wasser gewaschen. Dabei wurde die Blattoberfläche nicht mit den Händen säuber gerieben, da die Laubblätter sonst eingerissen wären.

Ein weiterer Grund, der für die Erklärung der Symptome an den unverletzten, inokulierten Stängelsegmenten in Frage kommt, ist die Tatsache, dass die Stängelsegmente aus einem Feldversuch mit Winterraps stammten und somit unterschiedlichen abiotischen Bedingungen ausgesetzt waren. Das Mikroklima auf dem Feld beeinflusst neben vielen anderen Dingen auch den Auf- bzw. Abbau einer epikutikularen Wachsschicht. Verschiedene Untersuchungen zeigten, dass mit abnehmender Strahlung (WHITECROSS \& ARMSTRONG, 1972), steigender relativer Luftfeuchtigkeit (ADAM, 1958; KOCH et al., 2006) und starken Niederschlagsereignissen (AMSDEN \& LEWINS, 1966) die Menge an epikutikularen Wachsen auf Laubblättern abnahm und die Benetzbarkeit eben dieser zunahm. Die Autoren der genannten Untersuchungen konnten auch jeweils den gegenteiligen Effekt nachweisen. Einer oder mehrere der zuvor genannten Gründe könnte dazu geführt haben, dass die Stängelsegmente von Beginn an nur eine dünne Wachsschicht besessen haben. In Bezug auf den Einfluss der Strahlung stellte JUNIPER (1960) an Laubblättern von Pisum sativum fest, dass gar keine Wachskristalle gebildet wurden, wenn die Sämlinge bei dunklen Verhältnissen angezogen wurden. Ähnliche Verhältnisse herrschten zum Zeitpunkt der Probenahme der Stängel. Die stetige Entwicklung der Schoten führte dazu, dass immer weniger Licht die Stängel erreichte und somit sehr wahrscheinlich die epikutikulare Wachsschicht dünner wurde. Prädispositionen der Kutikula durch biotische Faktoren, wie z.B. Insektenfraß, sind auszuschließen, da alle Stängelsegmente beim Säubern daraufhin kontrolliert wurden.

Die differenzierte Anfälligkeit von unverletzten Laubblättern und unverletzten Stängeln kann zum einen auf eine unterschiedliche Anzahl an Stomata und zum anderen auf eine unterschiedliche Menge, sowie eine differenzierte Zusammensetzung der kutikularen Wachse zurückgeführt werden. MAJOR (1975) konnte signifikante Unterschiede in dem Vorkommen von Stomata auf unterschiedlichen Pflanzenoberflächen (adaxiale bzw. 
abaxiale Seite von Laubblättern, Stängel, Schote, Griffel und Blütenstiel) von zwei verschieden Brassica-Arten (Brasscia napus und Brassica campestris) nachweisen. Die meisten Spaltöffnungen fand er in beiden Arten an der abaxialen Seite eines Laubblattes. Die adaxiale Seite eines Laubblattes von Raps wies die zweithöchste und von Rübsen die zweitniedrigste Anzahl an Spaltöffnungen auf. Die niedrigste (Brasscia napus) bzw. zweitniedrigste (Brassica campestris) Dichte an Stomata wies das Stängelgewebe auf. Weitere Studien von HAN-BING et al. (2002) und PAUL \& MONDAL (2007) belegen die Ergebnisse von MAJOR (1975) darin, dass es zwischen verschiedenen Pflanzenarten bzw. zwischen verschiedenen Pflanzengeweben einer Art Unterschiede in der Häufigkeit von Spaltöffnungen gibt und, dass das Blattgewebe mehr Stomata enthält als das Stängelgewebe. Beim Stängelgewebe von Brassica juncea konnten PAUL and MONDAL (2007) zeigen, dass die Dichte der Stomata in basipetale Richtung abnimmt. Um in einen Wirt einzudringen und inn zu infizieren nutzt $B$. cinerea je nach äußerlichen Bedingungen verschiedenste Strategien bzw. Wege, wobei die Penetration via Stomata einen Weg darstellt. Die zuvor genannten Fakten zeigen, dass das Laubblattgewebe von Winterraps grundsätzlich eher durch den Pilz infiziert werden kann als das Stängelgewebe.

Weiterhin wurde nachgewiesen, dass die Kutikula mit ihren intra- und epikutikularen Wachsen in Bezug auf ihre Zusammensetzung, ihre Struktur, ihre Dicke und ihre Quantität eine große Variabilität zwischen verschiedenen Pflanzenspezies, verschiedenen Organen einer Pflanzenart und während der Ontogenese individueller Pflanzenorgane aufweist (GÜLZ, 1994; JETTER et al., 2000; WALTON, 1990; JEFFREE, 2006; ZAMANI-NOOR, 2011). Diese Tatsachen führen zu der Hypothese, dass das Stängelgewebe eine dickere epikutikulare Wachsschicht mit anders strukturierten Wachskristallen ausgebildet haben könnte als das Laubblattgewebe, wodurch dem Erreger die direkte Infektion durch die Kutikula erschwert wurde. Die direkte Penetration durch die Kutikula stellt, zu den schon vorher erwähnten Strategien, einen weiteren Infektionsweg von B. cinerea dar und wurde z.B. von NELSON (1951) an der Kutikula von Weintrauben nachgewiesen. Bis heute ist nicht genau geklärt, ob der Pilz die Kutikula allein durch mechanische Kräfte (Druck), vermittelt durch ein Appressorium, oder durch enzymatische Auflösung der Wachsstrukturen (Kutinasen) durchbricht (TENEBERGE, 2007). Neuere Untersuchungen sprechen dafür, dass ein Zusammenspiel aus beiden genannten Faktoren sowie weiteren Faktoren [u.a. andere zellwandabbauende Enzyme, Bildung von reaktiven Sauerstoffspezies (reactive oxygen spezies, ROS)] dem Erreger die Penetration durch die Kutikula ermöglichen (ELAD et al., 2007; WILLIAMSON et al., 2007). Des Weiteren ist nicht auszuschließen, dass sich durch die kontinuierlichen, künstlichen Lichtverhältnisse im Gewächshaus und durch eine gleichmäßige Verteilung der Pflanzen auf den Gewächshaustischen, vor allem die Stängel, als auch die Laubblätter, anders belichtet 
wurden. Auf diese Weise konnte sich eine andere Kutikula ausbilden, als unter natürlichen Bedingungen. Um die vorgestellten möglichen Erklärungen für die unterschiedliche Anfälligkeit von unverletzten Laubblättern und Stängeln von Winterraps zu verifizieren, sind weitere Untersuchungen notwendig. Dabei gilt es zu überprüfen, ob die hier ermittelten Ergebnisse auch mit verschieden, aggressiven Isolaten von $B$. cinerea reproduziert werden können. Wenn das der Fall ist, kann der Einfluss des Isolates ausgeschlossen werden. Schließlich sollte die Dichte der Stomata auf den zwei Pflanzenoberflächen, insbesondere im Bereich der Blattachsel am Stängel, überprüft, sowie die Interaktion zwischen Pathogen und unterschiedlichen Wachsgehalten der einzelnen Kutikulas näher untersucht werden.

Weiterhin lieferte der Sortenversuch die Erkenntnis, dass der Pilz sich schneller im Laubblattgewebe ausbreitet als im Stängelgewebe. Nach 3 dpi waren die Läsionslängen an den Laubblättern um das anderthalb- bis zweifache größer als an den Stängeln (Daten nicht gezeigt). Dies ist auf die Dicke des Pflanzengewebes zurückzuführen. Ein Laubblatt ist vom morphologischen Aufbau her wesentlich dünner als ein Stängel. Ein Stängel von dikotylen Pflanzen weist durch das mehrzellige Markparenchym, die ringförmig angeordneten Leitbündel und das mehrzellige primäre Rindenparenchym von Natur aus eine bestimmte Dicke (Durchmesser) auf. Ein Blatt enthält die zuvor genannten mehrschichtigen Grundgewebetypen nicht. Es besitzt stattdessen das ein- bis zweizellige Palisadenparenchym und das Schwammparenchym, was große Interzellulare beinhaltet. Des Weiteren haben dikotyle Pflanzen die Möglichkeit, durch sekundäres Dickenwachstum ihren Stängeldurchmesser deutlich zu erweitern. Dies ermöglicht ein Bildungsgewebe, das Kambium, was sich bei offen kollateralen Leitbündeln zwischen dem Xylem und dem Phloem befindet. Um bei zunehmender Höhe genug Standfestigkeit zu erlangen und eine ausreichende Versorgung der Pflanze durch Leitungsbahnen zu gewährleisten, werden beim sekundären Dickenwachstum weitere Leitelemente und Stützgewebe angelegt. Dabei werden in jungen, noch wachsenden Sprossteilen Kollenchymzellen und in älteren, nicht mehr wachsenden Sprossteilen Sklerenchymzellen zur Festigung des Gewebes ausgebildet. Letztere besitzen im Vergleich zum Kollenchym dicke sekundäre Zellwände, die meist mit Lignin verstärkt sind. Mit Erreichen ihrer funktionellen Reife sterben diese Zellen ab (CAMPBELL et al., 2003).

Aufgrund dieser morphologischen Unterschiede fällt es dem Pathogen leichter das komplette Pflanzengewebe eines Laubblattes von der adaxialen bis zur abaxialen Seite zu durchdringen und sich im Pflanzengewebe auszubreiten. Die Besiedlung sämtlicher Stängelgewebearten dauert zum einen wegen der mehrschichtigen Gewebe länger und 
zum anderen erschwert das Lignin in der sekundären Zellwand der Sklerenchymzellen eine schnelle Infektion dieser Zellen.

\section{IV.2 Variabilität der Sortenanfälligkeit}

Eine Einstufung von Winterrapssorten nach ihrer Anfälligkeit gegenüber einem Schaderreger, wie es für das Pathogen S. sclerotiorum beim Bundessortenamt erhältlich ist, gibt es für das Pathogen $B$. cinerea nicht. Um einen ersten Eindruck über das Resistenzverhalten von verschiedenen Rapsgenotypen gegenüber $B$. cinerea zu erhalten, wurde zweimal unter kontrollierten Bedingungen ein Sortenscreening mit zwölf verschiedenen Genotypen von Winterraps durchgeführt. Dazu wurde die Ausbreitungsgeschwindigkeit des Pathogens innerhalb von Laubblättern bzw. von Stängeln in einer bestimmten Zeit, ausgedrückt über den AUDPC-Wert, bestimmt. Ein Vergleich der hiesigen Ergebnisse zur Sortenanfälligkeit, kann mit anderen Ergebnissen nicht angestellt werden, da solche Sorteneinstufungen nicht existieren bzw. bei der Recherche nicht gefunden wurden. Da allerdings fünf von den zwölf eingesetzten Genotypen bei einem Sortenscreening mit $S$. sclerotiorum verwendet wurden (WULF, 2011), kann verglichen werden, inwieweit sich eine mögliche Variabilität der Sortenanfälligkeit gegenüber $B$. cinerea von der Variabilität der Sortenanfälligkeit gegenüber $S$. sclerotiorum unterscheidet. In beiden Versuchen war die Inokulationsmethode identisch.

Bei der Laubblattinokulation wurden die einzelnen Genotypen ähnlich stark durch das Pathogen befallen, sodass keine signifikanten Unterschiede auftraten. Dies galt sowohl für die verletzt, inokulierte als auch die nicht verletzt, inokulierte Variante (Abb. 14A \& 15A). Im Allgemeinen waren die Laubblätter in der verletzten Variante stärker befallen als in der unverletzten Variante. Die möglichen Gründe für diese Unterschiede wurden schon im vorherigen Kapitel diskutiert. Bei der Stängelinokulation zeigte sich eine Infektion nur in der verletzt, inokulierten Variante. Demnach war die Verletzung des Gewebes eine Voraussetzung für die Infektion mit der Grauschimmelfäule. Vor allem im ersten Versuchsdurchgang war eine differenzierte Anfälligkeit zwischen den Sorten zu erkennen (Abb. 17A). Hierbei können die Sorten „Uluru“ und „NK Petrol“ als eher gering anfällig und die Sorten „SY Merlot“, „Sherpa“, „Visby“, „Caiman“, „Pacific“, „Lorenz“ und „Zhongshuang 9“ als eher hoch anfällig eingestuft werden. Im zweiten Versuchsdurchgang war eine variable Anfälligkeit nur schwach ausgeprägt. Hier unterschieden sich lediglich die am wenigsten befallen Sorten "Lorenz" und „Dimension“ von der am stärksten befallenen Sorte „Zhongshuang 9“. Dieser Umstand war auf 
ungünstige Inokulationsbedingungen während des zweiten Versuchszeitraumes zurückzuführen. Durch sehr hohe Außentemperaturen hatte sich, trotz Kühlung, die Temperatur im Gewächshaus und damit in den Folienzelten (Inkubationszelten) deutlich erhöht. Dies hat sich negativ auf die Ausbreitung des Pilzes im Pflanzengewebe ausgewirkt. Nähere Einzelheiten zum Einfluss der Temperatur wurden schon im vorherigen Kapitel diskutiert und werden daher hier nicht noch einmal erwähnt. Innerhalb eines Durchganges kann der Effekt von verschiedenen relativen Luftfeuchtigkeiten ausgeschlossen werden, da durch die Folienzelte die relative Luftfeuchtigkeit konstant hochgehalten wurde. Die Lichtverhältnisse konnten dagegen nicht absolut konstant gehalten werden. Während eines Versuchsansatzes aber auch zwischen den beiden Ansätzen ließ sich aufgrund wechselnder Wetterbedingungen und von außen einfallender Strahlung die Lichtintensität im Gewächshaus, trotz Zusatzbeleuchtung, nicht vollkommen konstant halten. Dies stellt einen ersten Faktor dar, der die Sortenanfälligkeit beeinflusst haben kann. Für die Infektion von Sojabohnen durch S. sclerotiorum konnten PELTIER and GRAU (2008) zeigen, dass es eine optimale Lichtintensität für die Ausbreitung der Läsionen und die Differenzierung der Genotypen gibt.

Durch die unterschiedlichen Temperaturbedingungen, die während des jeweiligen Versuchsansatzes geherrscht haben, kam es bei den Sorten eher zu einem gegensätzlichen und nur in wenigen Fällen zu einem übereinstimmenden Resistenzverhalten. Während z.B. die Sorten „Sherpa“ und „Lorenz“ im ersten Durchgang hoch anfällig waren, zählten sie im zweiten Durchgang zu den Sorten mit dem geringsten Befall. Andererseits wiesen in beiden Versuchen die Sorten „Uluru“ und „NK Petrol“ eine niedrige und die Sorten „Caiman“ und „Zhongshuang 9“ eine hohe Anfälligkeit auf. Diese vergleichbaren Ergebnisse lassen eine klare Aussage über das Resistenz- bzw. Anfälligkeitsverhalten der einzelnen Sorten zu. In dem anderen Fall ist eine klare Aussage über die Anfälligkeit der Sorten gegenüber $B$. cinerea nicht möglich und erfordert weitere Untersuchungen.

WULF (2011) konnte in seiner Arbeit zeigen, dass ein Teil der von ihm verwendeten wilden Brassica-Arten, Winterrapssorten und Resynthesen durch zwei verschiedene Resistenzmechanismen auf einen Befall von S. sclerotiorum reagierten. Er identifizierte bei einigen der wilden Brassica-Arten eine quantitative physiologische Resistenz (Ausbreitungsresistenz), die die Ausbreitung des Pathogens innerhalb der Pflanze reduzierte und bei zwei Rapssorten und einigen Resynthesen traten nicht näher beschriebene Mechanismen auf, die die Infektion selbst beeinflussen oder verhindern konnten. Also zum einen reagierten die Pflanzen postinfektionell und zum anderen 
präinfektionell. Solch unterschiedliche Reaktionen von Pflanzen wurden bei den hiesigen Ergebnissen von der Stängelinokulation mit $B$. cinerea auch beobachtet. Der nicht aufgetretene Befall in der unverletzt, inokulierten Variante deutet auf präinfektionelle Abwehrreaktionen der Winterrapspflanzen hin und bei der verletzt, inokulierten Variante sprechen die teils signifikant unterschiedlich hohen AUDPC-Werte der einzelnen Sorten für postinfektionelle Abwehrreaktionen.

Eine wesentliche präinfektionelle Abwehrreaktion wird durch die Kutikula und ihrer epikutikularen Wachsschicht vermittelt. Sie fungiert als äußerste Schutzbarriere gegen Pathogene (MARIANI and WOLTERS-ARTS, 2000). In Bezug auf B. cinerea konnte LOUIS (1963) an Bohnen, Tomaten und anderen Wirtspflanzen zeigen, dass die erfolgreiche Penetration des Pathogens durch die Kutikula von deren Dicke abhängig war. Weiterhin wurde nachgewiesen, dass ein starker Zusammenhang zwischen der Menge an Wachsen oder ihrer feinen Strukturen und der Intensität einer B. cinerea Infektion bestand (SCHWAB et al., 1993).Wie weiter oben erwähnt wurde, ist die Art der Zusammensetzung, die Struktur und die Dicke der Wachsschicht von Pflanzenspezies zu Pflanzenspezies, von Pflanzenorgan zu Pflanzenorgan und während der Ontogenese der Pflanzenorgane verschieden. Genauso vorstellbar ist eine Variabilität zwischen Sorten einer Art. Dafür sprechen die Ergebnisse von HAMMER \& EVENSEN (1994), die bei einer B. cinerea resistenten Rosensorte eine dickere Kutikula nachwiesen als bei einer anfälligen Sorte. Inwieweit dieser Resistenzfaktor bei den hier verwendeten Rapssorten unterschiedlich ausgeprägt war, kann nicht beantwortet werden, da bei den unverletzt, inokulierten Stängeln kein Befall und somit kein Unterschied zwischen den Sorten auftrat und bei den verletzt, inokulierten Stängeln dieser Faktor von vornherein durch eine Wunde ausgeschaltet wurde. Zudem wurden der Wachsgehalt und die Wachskomposition der Kutikula der Stängel und der Laubblätter nicht näher untersucht.

Die in den Rapspflanzen vorkommenden Glukosinolate besitzen auch eine gewisse Abwehrfunktion, da sie eine hemmende Wirkung auf das Wachstum von Pathogene haben können (MITHEN et al., 1986; MITHEN, 1992). In einer als resistent eingestuften chinesischen Rapssorte stieg nach der Infektion mit S. sclerotiorum, der Gehalt an IndolylGlukosinolaten und 2-Phenylethylglukosinolaten lokal und systemisch deutlich an. Die erhöhten Gehalte der beiden Glukosinolate führten bei einer erneuten Inokulation zu einer gesteigerten Resistenz (LI et al., 1999). Da S. sclerotiorum und B. cinerea aus einer gemeinsamen Familie (Sclerotiniaceae) stammen, wäre es vorstellbar, dass gesteigerte Gehalte an Glukosinolaten ähnliche Resistenzreaktionen bei B. cinerea hervorrufen. Allerdings muss für die hier verwendeten Rapssorten (ohne Resynthese) berücksichtigt werden, dass es sich um 00 Rapssorten handelt, die alle, züchterisch bedingt, einen 
geringen Glukosinolatgehalt aufweisen. Dennoch ist nicht auszuschließen, dass die Restgehalte und die Zusammensetzung der Glukosinolate zwischen den Sorten variieren und dadurch die unterschiedliche Ausbreitungsgeschwindigkeit von $B$. cinerea erklärt werden könnte.

Um die Ausbreitung von $B$. cinerea nach erfolgter Infektion einzudämmen oder möglichst ganz zu verhindern stehen einer Pflanze sowohl strukturelle als auch biochemische Mechanismen zur Verfügung. Dazu zählen u.a. die Papillenbildung, die Okklusion von interzellularen Räumen (EL GHAOUTH et al., 1994), die Lignin- bzw. Pektineinlagerung in Zellwände (El GhaOUTH et al., 1994; MAULE and RIDE, 1976; HeALE and SHARMAN, 1977), die Akkumulation von „pathogenesis related“ (PR)-Proteinen (BENITO et al., 1998; LOON, 1985), die Biosynthese von Phytoalexinen (BENNETT et al., 1994) und der „oxidative Burst“ (DEIGHTON et al., 1999). Zellwandveränderungen in Form von einer Lignin- und/oder Pektineinlagerung treten vor allem an der Infektionsstelle auf, um die Ausbreitung des Pathogens oder um den Abbau von Zellwandbestandteilen, die zur Ernährung des Pathogens dienen, zu verhindern. Bei den PR-Proteinen sind insbesondere Glukanasen ( $\beta$ 1,3-Glukanase) und Chitinasen zu nennen, die das in den Zellwänden des Pilzes enthaltene Glukan und Chitin abbauen (BROEKAERT et al., 1989; TABEl et al., 1998; SALZMAN et al., 1998). Polygalakturonase-hemmende Proteine (,polygalacturonase inhibiting proteins“, PGIP) gehören zu den Proanthocyanidine und hemmen die pektolytischen Enzyme von B. cinerea (STOTz et al., 1994). Inhibitorische Wirkungen durch Phytoalexine gegen $B$. cinerea wurden z.B. an Wein für das Resveratrol (LANGCAKE, 1981; BAVARESCO et al., 1997), an Tomaten für das $\alpha$-Tomatin (VERHOEFF \& LIEM, 1975) und an Kürbisgewächse für das Curcubitacin I (BAR-NUN \& MAYER, 1990) nachgewiesen. Bei dem „oxidative burst“, der meist durch Elicitoren ausgelöst wird, kommt es zu einer Anhäufung von ROS [Superoxidanion $\left(\mathrm{O}_{2}^{-}\right)$, Wasserstoffperoxid $\left(\mathrm{H}_{2} \mathrm{O}_{2}\right)$, Hydroxylradikal $\left.\left(\mathrm{OH}^{-}\right)\right]$in der befallenen Zelle, wodurch das Pathogen direkt geschädigt werden kann oder die Zelle kollabiert und es kommt zu einer hypersensitiven Reaktion bei der die Zelle abstirbt.

Ob einer oder mehrere der zuvor genannten Abwehrreaktionen in den Winterrapspflanzen aufgetreten sind, kann nicht beantwortet werden, da diese Mechanismen nicht näher untersucht wurden. Demnach können auch keine Aussagen darüber getroffen werden, ob einzelne Mechanismen in den verschiedenen Sorten (falls sie auftraten) unterschiedlich ausgeprägt waren. Zudem muss berücksichtigt werden, dass $B$. cinerea verschiedene Strategien entwickelt hat, um mit diesen Abwehrmechanismen zurechtzukommen. Dazu zählen z.B. die enzymatische Spaltung von Phytoalexinen (QUIDDE et al., 1999), die aktive Ausscheidung von sekundären Pflanzeninhaltstoffen durch ABC- (ATP-binding cassette) 
oder MFS- (major facilitator superfamiliy) Transporterproteine (DE WAARD et al., 2006) oder die Unterdrückung des „oxidative burst“ durch die Produktion eines spezifischen Inhibitors (UNGER et al., 2005). Außerdem zeigten neuere Untersuchungen (URBANEK et al., 1996; VON TIEDEMANN, 1997; GOVRIN \& LEVINE, 2000), dass die Bildung von ROS, förderlich für den Befall von Pflanzengewebe durch nekrotrophe Pilze wie $B$. cinerea ist. Diese Strategien des Pilzes könnten dazu führen, dass potenzielle Abwehrreaktionen der Pflanze (z.B. Synthese von Phyotalexinen) gar nicht nachgewiesen werden können. Um diesen Fall vorzubeugen, sollte in entsprechenden Versuchen, der Gehalt an PRProteinen oder an Phytoalexinen zu mehreren Zeitpunkten nachgewiesen werden. Bevor solche Versuche unternommen werden, müsste erst einmal kontrolliert werden, ob Winterrapspflanzen z.B. PR-Proteine oder bestimmte Phyotalexine überhaupt produzieren.

Der Stängeldurchmesser kann einen weiteren Grund für die unterschiedliche Anfälligkeit der verschiedenen Sorten darstellen. PORTER et al. (2009) und WULF (2011) fanden in Untersuchungen mit $S$. sclerotiorum heraus, dass der Stängeldurchmesser und der AUDPC-Wert negativ miteinander korreliert waren. WULF (2011) erklärt diesen negativen Zusammenhang damit, dass bei einem höheren Stängeldurchmesser dem Pathogen bei gleicher Läsionslänge mehr Gewebe zur Kolonisation zur Verfügung steht. Der Erreger hat in diesem Fall mehr Gewebe als Nahrungsgrundlage vorliegen und ist auf eine vertikale Ausbreitung erst einmal nicht angewiesen.

Des Weiteren sollte der Einfluss von Phytohormonen auf die variable Anfälligkeit von Winterrapssorten gegenüber $B$. cinerea nicht ausgeschlossen werden. So haben Auxine und Gibberelline eher eine unterdrückende und Ethylen und Abscisinsäure eine fördernde Wirkung auf die Entwicklung der Grauschimmelfäule (ELAD, 1997).

$\mathrm{Da}$ es sich bei den verwendeten Genotypen um unterschiedliche Sortentypen (Hybridsorten, Liniensorten und Resynthesen) handelt, muss dieser Faktor als mögliche Erklärung für die Unterschiede in der Anfälligkeit bzw. in der Wirkung verschiedener Abwehrreaktionen auch in Betracht gezogen werden.

Ein Einfluss des Inokulums oder von verschiedenen Isolaten kann ausgeschlossen werden, da für einen Versuchsansatz immer Myzel gleichen Alters verwendet und nur ein Isolat von $B$. cinerea eingesetzt wurde.

Welcher bzw. welche von den vielen genannten Einflussfaktoren letztlich für die Variabilität in der Sortenanfälligkeit nach einer Stängelinokulation verantwortlich war bzw. waren, kann nicht genau beantwortet werden. Weiterführende Arbeiten, bei denen gezielt einzelne bzw. mehrere Abwehrreaktionen oder andere Einflussfaktoren (z.B. 
Stängeldurchmesser, Hormongehalte) bei verschiedenen Sorten von Winterraps untersucht werden, können dazu beitragen diese Frage zu beantworten.

Nach den hiesigen Ergebnissen ist $B$. cinerea für den Befall von Stängeln auf eine Verletzung angewiesen. S. sclerotiorum bedarf keiner Verletzungen, um Stängel von Winterraps zu infizieren. Das geht aus der Arbeit von WULF (2011) hervor, der ohne eine artifizielle Verletzung, einen Befall mit $S$. sclerotiorum an den Stängeln generieren konnte. Diese Ergebnisse stellen einen bedeutenden Unterschied zwischen den beiden Pathogenen dar, welcher sich auch auf den Vergleich zwischen der Sortenanfälligkeit gegenüber beiden Pathogenen auswirkt. Die Versuche mit $B$. cinerea zeigten in Bezug auf eine potenzielle Variabilität in der Sortenanfälligkeit keine Übereinstimmung zu der Variabilität der Sortenanfälligkeit gegenüber $S$. sclerotiorum. Entweder trat kein Befall und damit keine Abstufung zwischen den fünf Sorten auf (Variante: „nicht verletzt, inokuliert“) oder die Sorten, vor allem „Zhongshuang 9“, zeigten ein komplett konträres Resistenzverhalten (Variante: „verletzt, inokuliert“) (Tab. 9A). Dies ist primär auf das verletzte Stängelgewebe zurückzuführen. Durch die artifizielle Verletzung wurden Abwehrmechanismen bzw. -reaktionen der Pflanze wie z.B. strukturelle Barrieren (Kutikula) außer Kraft gesetzt, wodurch eine Infektion erst ermöglicht wurde. Diese Ergebnisse deuten, trotz der nahen Verwandtschaft von S. sclerotiorum und B. cinerea, auf unterschiedliche Pathogenitätsfaktoren oder eine differenzierte Wirkung von einem Pathogenitätsfaktor hin, die es vor allem $S$. sclerotiorum ermöglichen unverletztes Stängelgewebe zu befallen. In diesem Zusammenhang wäre die Oxalsäure zu nennen, die grundsätzlich von beiden Pathogenen gebildet werden kann (GENTILE, 1954; VERHOEFF et al., 1988; MARCIANO et al., 1989) Für S. sclerotiorum wird die Oxalsäure als der wichtigste Pathogenitätsfaktor beschrieben, ohne den kein Befall ausgelöst wird (Godoy et al., 1990). Im Fall von B. cinerea stellt sie „nur“ einen wichtigen Co-Faktor für die Pathogenität aber nicht das primäre phytotoxische Mittel dar (PRINS et al., 2000; KARS \& VAN KAN, 2007). Da die Inokulationsversuche aus dieser Arbeit und die Versuche von WULF (2011) jeweils mit einem Isolat der beiden Pathogene durchgeführt wurden, sollte zur Verifizierung der genannten Ergebnisse und Schlussfolgerungen ähnliche Versuche mit anderen und mehreren Isolaten von $B$. cinerea und $S$. sclerotiorum durchgeführt werden. Dabei sollte auch die Rolle der Oxalsäure und möglichen anderen Faktoren näher betrachtet werden. 


\section{Zusammenfassung}

Nachdem ausgangs des Winters im Jahr 2012 in vielen Teilen Deutschlands starker Befall von $B$. cinerea an Winterraps aufgetreten war und dies zur Aufgabe eines eigenen Feldversuches mit Winterraps geführt hat, wurde im Rahmen dieses Teilprojektes der Doktorarbeit, das Infektionsverhalten von $B$. cinerea an Winterraps unter kontrollierten Bedingungen näher untersucht. Im Mittelpunkt der Untersuchungen standen die Fragen, welche Temperaturansprüche $B$. cinerea für eine Infektion von Winterraps hat und ob verschiedene Genotypen von Winterraps eine differenzierte Anfälligkeit gegenüber dem Pathogen zeigten. Weiterhin sollte geklärt werden, welchen Einfluss Verletzungsstellen auf den Befall mit $B$. cinerea haben und ob verschiedene Pflanzenorgane (Blatt/Stängel) eine unterschiedliche Anfälligkeit gegenüber diesem Erreger aufweisen. Indem ein Teil der hier verwendeten Sorten auch im Rahmen einer anderen Arbeit (WULF, 2011) für Inokulationsversuche mit $S$. sclerotiorum an Winterraps verwendet wurden, war ein Vergleich zwischen der Variabilität der Sortenanfälligkeit gegenüber $B$. cinerea und gegenüber $S$. sclerotiorum möglich.

In allen Versuchen wurde die Ausbreitung des Pilzes innerhalb der verschiedenen Pflanzenorgane über einen bestimmten Zeitraum erfasst. Dazu wurde die Läsionslänge an verschiedenen Tagen nach der Inokulation ermittelt und in AUDPC-Werte umgerechnet. In den Temperaturversuchen wurden Laubblätter bzw. Stängelsegmente von Pflanzen der Sorte NK Petrol aus dem Randbereich eines Feldversuches verwendet und bei dem Sortenversuch wurden die verschiedenen Genotypen unter Gewächshausbedingungen angezogen.

Unabhängig von der Temperatur, der Sorte oder des Pflanzenorgans konnte festgestellt werden, dass eine Verletzung des Pflanzengewebes zu einem stärkeren Befall mit $B$. cinerea führt als wenn keine Verletzung vorlag. Dies bestätigt den Status des Pathogens als Schwächeparasit.

In den Temperaturversuchen wurde nachgewiesen, dass das Pathogen Laubblätter von Winterraps, unabhängig von einer Verletzung, sowie verletzte Stängelsegmente in einem Temperaturbereich von $4-24^{\circ} \mathrm{C}$ befallen kann. Bei unverletzten Stängelsegmenten traten Symptome der Grauschimmelfäule in einem Bereich von $8-24^{\circ} \mathrm{C}$ auf. Ideal für einen Befall von Laubblättern waren Temperaturen von $16-24^{\circ} \mathrm{C}$, wobei dieser Bereich nicht bei jedem Versuchsdurchgang signifikant abgesichert werden konnte. Verletzte Stängelsegmente wurden am stärksten in einem Temperaturbereich von $12-24^{\circ} \mathrm{C}$ befallen, wobei dieser Bereich je nach Versuchsdurchgang schwankte. Bei Stängelsegmenten die nicht artifiziell 
verletzt wurden, lag das Temperaturoptimum für eine Infektion bei $20^{\circ} \mathrm{C}$. Dies unterschied sich allerdings nicht signifikant von $18^{\circ} \mathrm{C}, 22^{\circ} \mathrm{C}$ und $24^{\circ} \mathrm{C}$.

Eine differenzierte Anfälligkeit der verschiedenen Rapssorten konnte im Falle einer Laubblattinokulation nicht nachgewiesen werden. Sowohl in der verletzten als auch in der unverletzten Variante traten keine signifikanten Unterschiede zwischen den Sorten auf. Je nach Versuchsdurchgang schwankten die AUDPC-Werte in der verletzten Variante zwischen 391,7 und 465,3 bzw. 410,6 und 513,9. Bei der unverletzten Variante lagen die AUDPC-Werte je nach Versuchsansatz zwischen 253,5 und 355,8 bzw. 334,4 und 391,2. Da die Daten unabhängig vom Versuchsansatz und von der Variante eine verhältnismäßig hohe Streuung aufwiesen, konnten keine Unterschiede in dem Anfälligkeitsverhalten der einzelnen Sorten statistisch abgesichert werden.

Bei der Stängelinokulation der zwölf verschiedenen Rapsgenotypen zeigte sich eine signifikante Abstufung in der Anfälligkeit der Sorten gegenüber $B$. cinerea nur in der verletzten Variante und hier vor allem im ersten Versuchsansatz. Obwohl alle Sorten einen deutlichen Befall aufwiesen, breitete sich das Pathogen unterschiedlich stark in den Stängeln der einzelnen Sorten aus. Dabei waren die Sorten „Uluru“ und „NK Petrol“ geringer anfällig und die Sorten „Caiman“ und „Zhongshuang 9“ hoch anfällig. Die Resynthese „Ruy 1“ und die Sorten „Vision“ und „Dimension“ nahmen eine mittlere Position im Resistenzverhalten gegenüber $B$. cinerea ein. Für die anderen Sorten ist eine genaue Einordnung nicht möglich, da sie im Vergleich der beiden Versuchsdurchgänge unterschiedlich auf den Befall reagiert haben. In der unverletzten Variante wurden keine Infektionen an den Stängeln der verschiedenen Rapssorten beobachtet.

Der angestellte Vergleich zwischen der Variabilität der Sortenanfälligkeit gegenüber $B$. cinerea und $S$. sclerotiorum lieferte keine Übereinstimmung in der Sortenanfälligkeit. Entweder trat gar kein Befall mit $B$. cinerea und damit keine Abstufung zwischen den fünf Sorten auf (Variante: „nicht verletzt, inokuliert") oder die Sorten, insbesondere „Zhongshuang 9“, zeigten ein komplett gegensätzliches Resistenzverhalten. Dies war auf die artifizielle Verletzung zurückzuführen, weshalb diese Variante für einen Vergleich der Sortenanfälligkeiten gegenüber den beiden Pathogenen eigentlich nicht herangezogen werden darf.

Abschließend kann festgehalten werden, dass die Temperaturansprüche von $B$. cinerea für eine Infektion von Winterraps kaum von den Temperaturansprüchen für eine Infektion an anderen Kulturpflanzen abweichen. Des Weiteren zeigen die Ergebnisse der Stängelinokulation der zwölf verschiedenen Rapsgenotypen, dass die verschiedenen Sorten von Winterraps, verschiedene Resistenzmechanismen besitzen, die entweder eine 
Infektion gar nicht erst zulassen (unverletzte Variante) oder nach einer erfolgten Infektion (verletzte Variante), diese an einer Ausbreitung hindern (quantitative physiologische Resistenz). Letzteres lässt sich primär aus den signifikant verschiedenen AUDPC-Werten einzelner Sorten ableiten. Weiterhin scheinen sich die Pathogene S. sclerotiorum und $B$. cinerea, obgleich ihrer nahen Verwandtschaft, in Bezug auf ihre Pathogenitätsfaktoren bzw. in der Ausprägung eines Pathogenitätsfaktors essentiell zu unterscheiden.

\section{Summary}

In a subproject of this thesis, the infection behavior of $B$. cinerea on winter oilseed rape (WOSR) was investigated under controlled conditions. This was done, because an own field trail were lost after the winter in 2012 due to heavy infestations with $B$. cinerea on WOSR. By this subproject it should be answered, which temperature requirements $B$. cinerea has for the infection of WOSR and whether different genotypes of WOSR showed a differential susceptibility to the pathogen. Furthermore, it should be clarified if injury sites promote the infection with $B$. cinerea and whether different plant organs (leaf/stem) have a different susceptibility to this pathogen. Some of the varieties which were used were previously used in another work (WULF, 2011) for inoculation with $S$. sclerotiorum on WOSR. Therefore it was possible to compare the variability of the cultivar susceptibility against $B$. cinerea and $S$. sclerotiorum.

In all tests, the propagation of the fungus within the different plant organs was detected over a certain period of time. Therefore the lesion length was determined at various days after inoculation and converted into AUDPC values. In the temperature experiments leaves and stem segments of plants of the cultivar NK Petrol were used, which were harvested from the border of a field trial. In case of the variety experiment the different genotypes were grown under greenhouse conditions.

Regardless of the temperature, the variety or the plant organ it was found that an injury of the plant tissue results in a stronger infestation with $B$. cinerea as if no injury existed. This confirms the status of the pathogen as a weak parasite.

In the temperature experiments, it was demonstrated that the pathogen can infest leaves of WOSR regardless of an injury and injured stem segments in a temperature range of $4-24^{\circ} \mathrm{C}$. In uninjured stem segments symptoms of gray mould occurred in a range of $8-24^{\circ} \mathrm{C}$. Ideal for an infestation of the leaves were temperatures of $16-24^{\circ} \mathrm{C}$. But this temperature range could not be significantly assured in each test run (repetition). Wounded stem segments were most affected in a temperature range of $12-24^{\circ} \mathrm{C}$. But this range varied depending on the repetition. At stem segments which were not artificially 
injured, the temperature optimum for an infection was at $20^{\circ} \mathrm{C}$. However, this was not significantly different from $18^{\circ} \mathrm{C}, 22^{\circ} \mathrm{C}$ and $24^{\circ} \mathrm{C}$.

A differentiated vulnerability of different rape cultivars could not be detected in the case of a leaf inoculation. The injured and uninjured variant did not reveal any significant differences between the varieties. Depending on the repetition the AUDPC values alternated in the injured variant between 391.7 and 465.3 or 410.6 and 513.9. In the uninjured variant, the AUDPC values alternated, depending on the repetition, between 253.5 and 355.8 or 334.4 and 391.2. No differences in the susceptibility behaviour of each variety could be statistically assured, because the data had, regardless of the repetition and the variant, a relatively high variance.

At the stem inoculation of twelve different rapeseed genotypes, a significant graduation in susceptibility of the varieties to $B$. cinerea was seen only in the injured variant and here especially in the first run. Although all varieties showed a distinct infestation, the pathogen spread to different degrees in the stems of each variety. Thereby the varieties "Uluru" and "NK Petrol" were less susceptible and "Caiman" and "Zhongshuang 9" were highly vulnerable. The resynthesis "Ruy 1" and the varieties "Vision" and "Dimension" had an intermediate position in the resistance response against $B$. cinerea. For the other varieties a specific classification was not possible because in the comparison of the two repetitions they responded differently to the infestation. In the uninjured variant no infections were observed on the stems of the different rapeseed varieties.

The comparison between the variability of the species susceptibility to $B$. cinerea and $S$. sclerotiorum showed no analogy in the cultivar susceptibility. Either no infestation with $B$. cinerea occurred, which led to no graduation between the five varieties (variant: "not injured, inoculated") or the varieties, especially "Zhongshuang 9", showed a completely contrasting resistance behaviour. This was due to the artificial injury. Therefore this variant actually may not be used for a comparison of the cultivar susceptibility towards both pathogens.

In conclusion it can be stated that the temperature requirements of $B$. cinerea for an infection of WOSR hardly differ from the temperature requirements for an infection on other crops. Furthermore, the results of the stem inoculation of the twelve different rapeseed genotypes show that the different varieties of WOSR have various resistance mechanisms. Either no infection occurs (uninjured variant) or subsequent to an infection (injured variant), the propagation is prevented (quantitative physiological resistance). The latter can be derived primarily from the significant different AUDPC values of individual varieties. In addition, although their close relationship, the pathogens $S$. sclerotiorum and $B$. cinerea appear to differ essential in terms of their pathogenicity or in the expression of a pathogenicity factor. 


\section{Literaturverzeichnis}

ADAM, N.K. (1958). Water repellency. Endeavour, 17, 37-41.

AgRIOS, G.N. (2005). Plant Pathology. 5. Aufl. Elsevier Academic Press.

AMSDEN, R.C. \& LEWINS, C.P. (1966). Assessment of wettability of leaves by dipping in crystal violet. World Review of Pest Control, 5, 187-194.

ANONYMUS (2006). Beschreibende Sortenliste 2006. Getreide, Mais, Ölfrüchte, Leguminosen (großkörnig), Hackfrüchte (außer Kartoffeln), Hannover.

ANONYMUS (2009). Beschreibende Sortenliste 2009. Getreide, Mais, Ölfrüchte, Leguminosen (großkörnig), Hackfrüchte (außer Kartoffeln)., Hannover.

ANONYMUS (2013). Beschreibende Sortenliste 2013. Getreide, Mais, Öl- und Faserpflanzen, Leguminosen, Rüben, Zwischenfrüchte. URL http://www.bundessortenamt.de/internet30/fileadmin/Files/PDF/bsl_getreide_2013.pdf, online abgerufen 21.09.2013.

BAKER, E.A. (1982). Chemistry and morphology of plant epicuticular waxes. In: The plant cuticle (Hrsg. Cutler, D.F., Alvin, K.L. \& Price, C.E.). Academic Press, London, 139166.

BARNES, J.D. \& CADOSO-VILHENA, J. (1996). Interactions between electromagnetic radiation and the plant cuticle. In: Plant cuticles. an integrated functional approach (Hrsg. Kerstiens, G.). BIOS Scientif. Publ, Oxford, 157-174.

BAR-NUN, N. \& MAYER, A.M. (1990). Cucurbitacins protect cucumber tissue against infection by Botrytis cinerea. Phytochemistry, 29, 787-791.

BARTHLOTT, W. (1990). Scanning electron microscopy of the epidermal surface in plants. In: Scanning electron microscopy in taxonomy and functional morphology (Hrsg. Claugher, D.). Clarendon Press, Oxford, UK.

BARThlott, W. \& NeinHUIS, C. (1997). Purity of the sacred lotus, or escape from contamination in biological surfaces. Planta, 202, 1-8.

BARTHLOTT, W. \& WollenWEBER, E. (1981). Zur Feinstruktur, Chemie und taxonomischen Signifikanz epicuticularer Wachse und ähnlicher Sekrete. Steiner in Komm, Wiesbaden.

Bavaresco, L., Petegolli, D., Cantu, E., Fregoni, M., Chiusa, G. \& Trevisan, M. (1997). Elicitation and accumulation of stilbene phytoalexins in grapevine berries infected by Botrytis cinerea. 36:77-83. Vitis, 36, 77-83.

Benito, E.P., ten Have, A., van't Klooster, J.W. \& van Kan, J.A.L. (1998). Fungal and plant gene expression during synchronized infection of tomato leaves by Botrytis cinerea. European Journal of Plant Pathology, 104, 207-220. 
Bennett, M.H., Gallagher, M.D.S., Bestwick, C.S., Rossiter, J.T. \& MANSFIELD, J.W. (1994). The phytoalexin response of lettuce to challenge by Botrytis cinerea, Bremia lactucae and Pseudomonas syringae pv. phaseolicola. Physiological and Molecular Plant Pathology, 44, 321-333.

BIANCHI, G. (1995). Plant waxes. In: Waxes:. Chemistry, molecular biology and functions (Hrsg. Hamilton, R.J.). The Oily Press, Dundee, 177-222.

BLAKEMAN, J.P. (1980). Behavior of conidia on aerial plant surfaces. In: The Biology of Botrytis (Hrsg. Coley-Smith, J.R., Verhoeff, K. \& Jarvis, W.R.). Academic Press, London, 115-151.

Broekaert, W.F., Van PariJs, J., Leyns, F., Joos, H. \& Peumans, W.J. (1989). A chitinbinding lectin from stinging nettle rhizomes with antifungal properties. Science, 245 , 1100-1102.

BROOKS, C. \& COOLEY, J. (1917). Temperature relations of apple-rot fungi. Journal of Agricultural Research, 8, 139-164.

CAMPBELL, C.L. \& MAdDEN, L.V. (1990). Introduction to plant disease epidemiology. John Wiley and Sons, New York.

CAmpBelL, N.A., ReECE, J.B. \& MARKL, J. (2003). Biologie. 6. Aufl. Spektrum Akademischer Verlag, Heidelberg.

Ciccarone, A. (1959). Reproduction is affected. In: Plant Pathology (Hrsg. Horsfall, J.G. \& Diamond, A.E.). Academic Press, London, 249-276.

de WaARd, M.A., ANdRAde, A.C., HayAshi, K., SchoOnBeEK, H.-j., Stergiopoulos, I. \& ZWIERS, L.-H. (2006). Impact of fungal drug transporters on fungicide sensitivity, multidrug resistance and virulence. Pest Management Science, 62, 195-207.

Deighton, N., Muckenschnabel, I., Goodman, B.A. \& Williamson, B. (1999). Lipid peroxidation and the oxidative burst associated with infection of Capsicum annuum by Botrytis cinerea. The Plant Journal, 20, 485-492.

DORAN, W.L. (1922). Effect of external and internal factors in the germination of fungous spores. 44: 313-336. Bulletin of the Torrey Botanical Club, 49, 313-336.

El Ghaouth, A., Arul, J., Wilson, C. \& Benhamou, N. (1994). Ultrastructural and cytochemical aspects of the effect of chitosan on decay of bell pepper fruit. Physiological and Molecular Plant Pathology, 44, 417-432.

ELAD, Y. (1989). Effect of abiotic conditions on development of grey mould of rose and scanning electron microscopy. Phytopathologia Mediterranea, 28, 122-130.

ELAD, Y. (1997). Responses of plants to infection by Botrytis cinerea and novel means involved in reducing their susceptibility to infection. Biological Reviews, 72, 381-422.

Elad, Y., Williamson, B., Tudzynski, P. \& Delen, N. (Hrsg.) (2007). Botrytis: Biology Pathology and Control. Springer, Niederlande. 
ELAD, Y., YUNIS, H. \& MAHRER, Y. (1989). Effect of climatic conditions in polyethylene covered structures on grey mould disease of winter cucumber. Applied Agricultural Research, 3, 243-247.

GENTILE, A.C. (1954). Carbohydrate metabolism and oxalic acid synthesis by Botrytis cinerea. Plant Physiol., 29, 257-261.

Godoy, G., SteAdMAN, J.R., DickMAN, M.B. \& DAM, R. (1990). Use of mutants to demonstrate the role of oxalic acid in pathogenicity of Sclerotinia sclerotiorum on Phaseolus vulgaris. Physiological and Molecular Plant Pathology, 37, 179-191.

GovRIN, E.M. \& LEVINE, A. (2000). The hypersensitive response facilitates plant infection by the necrotrophic pathogen Botrytis cinerea. Current Biology, 10, 751-757.

GüLZ, P.G. (1994). Epicuticular waxes in the evolution of the plant kingdom. Journal of Plant Physiology, 143, 453-464.

HAMMER, P.E. \& EVENSEN, K.B. (1994). Differences between rose cultivars in susceptibility to infection by Botrytis cinerea. Phytopathology, 84, 1305-1312.

HAN-BING, L., KE-ZHI, B., YU-XI, H., TING-YUN, K. \& JIN-XING, L. (2002). Stomatal frequency on some non-leaf organs of four crop species and their significance in photosynthesis. Chinese Journal of Plant Ecology, 26, 351-354.

HEALE, J.B. \& SHARMAN, S. (1977). Induced resistance to Botrytis cinerea in root slices and tissue cultures of carrot (Daucus carota L.). Physiological Plant Pathology, 10, 5161.

HOLLOWAY, P.J. (1969). The effects of superficial wax on leaf wettability. Annals of Applied Biology, 63, 145-153.

HOLLOWAY, P.J. (1971). The chemical and physical characteristics of leaf surfaces. In: Ecology of leaf surface micro-organisms (Hrsg. Preece, T.F. \& Dickinson, C.H.). Academic Press, London, 39-53.

HOLLOWAY, P.J. (1982). Structure and histochemistry of plant epicuticular membranes: an overview. In: The plant cuticle (Hrsg. Cutler, D.F., Alvin, K.L. \& Price, C.E.). Academic Press, London, 1-32.

Holz, G., Coertze, S. \& Williamson, B. (2007). The ecology of Botrytis on plant surfaces. In: Botrytis: Biology Pathology and Control (Hrsg. Elad, Y., Williamson, B., Tudzynski, P. \& Delen, N.). Springer, Niederlande, 9-27.

JARVIS, W.R. (1977). Botryotinia and Botrytis species : taxonomy, physiology and pathogenicity: a guide to the literature. Hignell Printing Limited, Ottawa. JARVIS, W.R. (1980). Epidemiology. In: The Biology of Botrytis (Hrsg. Coley-Smith, J.R., Verhoeff, K. \& Jarvis, W.R.). Academic Press, London, 219-250.

JeffreE, C.E. (2006). The fine structure of the plant cuticle. In: Biology of the plant cuticle (Hrsg. Riederer, M. \& Muller, C.). Blackwell, Oxford, 11-125. 
Jenks, M.A., Joly, R.J., Peters, P.J., Rich, P.J., Axtell, J.D. \& AshwORTh, E.N. (1994). Chemically induced cuticle mutation affecting epidermal conductance to water vapor and disease susceptibility in Sorghum bicolor (L.) Moench. Plant Physiol., 105, 12391245.

JetTER, R., SchAFFER, S. \& RiEdERER, M. (2000). Leaf cuticular waxes are arranged in chemically and mechanically distinct layers: evidence from Prunus laurocerasus $\mathrm{L}$. Plant, Cell and Environment, 23, 619-628.

JUNIPER, B.E. (1960). Growth, development, and effect of the environment on the ultrastructure of plant surfaces*. Journal of the Linnean Society of London, Botany, 56, 413-419.

KARS, I. \& VAN KAN, J.A.L. (2007). Extracellular enzymes and metabolites involved in pathogenesis of Botrytis. In: Botrytis: Biology Pathology and Control (Hrsg. Elad, Y., Williamson, B., Tudzynski, P. \& Delen, N.). Springer, Niederlande, 99-118.

KLAEMT, G. (2012). Nach Frost nun Verluste durch Botrytis/Grauschimmel in Winterraps. URL http://suite101.de/article/nach-frost-nun-verluste-durch-botrytisgrauschimmel-inwinterraps-a133104\#.U7GW07FQ2Nc, online abgerufen am 04.01.2014.

Koch, K., Hartmann, K.D., Schreiber, L., Barthlott, W. \& NeinHUis, C. (2006). Influences of air humidity during the cultivation of plants on wax chemical composition, morphology and leaf surface wettability. Environmental and Experimental Botany, 56, $1-9$.

KOLATTUKUDY, P.E. (2001). Polyesters in higher plants. In: Biopolyesters (Hrsg. Babel, W. \& Steinbüchel, A.). Springer, Berlin, Heidelberg, 1-49.

LANGCAKE, P. (1981). Disease resistance of Vitis spp. and the production of the stress metabolites resveratrol, epsilon -viniferin, alpha - viniferin and pterostilbene. Physiology and Plant Pathology, 18, 213-226.

LI, Y., Kiddle, G., Bennett, R.N. \& WAllsgrove, R.M. (1999). Local and systemic changes in glucosinolates in Chinese and European cultivars of oilseed rape (Brassica napus L.) after inoculation with Sclerotinia sclerotiorum (stem rot). Annals of Applied Biology, 134, 45-58.

LOON, L.C. van (1985). Pathogenesis-related proteins. Plant Molcular Biology, 4, 111116.

LOUIS, D. (1963). Les modalites de la penetration du Botrytis cinerea Pers. dans les plantes. Annales des Epiphytes, 14, 57-72.

MACFARLANE, H.H. (1968). Plant host - pathogen index to volumes 1-40 (1922-1961). Review of Applied Mycology. Co.

MAJOR, D.J. (1975). Stomatal frequency and distribution in rape. Canadian Journal of Plant Science, 55, 1077-1078. 
MARCIANO, P., MAgRo, P. \& FAVARON, F. (1989). Sclerotinia sclerotiorum growth and oxalic acid production on selected culture media. FEMS microbiology letters, 61, 5759.

Mariani, M. \& Wolters-Arts, M. (2000). Complex Waxes. The Plant Cell, 12, 17951798.

MAROIS, J.J., REDMOND, J.C. \& MACDONALD, J.D. (1988). Quantification of the impact of environment on the susceptibility of Rosa hybrida flowers to Botrytis cinerea. Journal of the American Society for Horticultural Science, 113, 842-845.

MAULE, A.J. \& RIDE, J.P. (1976). Ammonia-lyase and O-methyl transferase activities related to lignification in wheat leaves infected with Botrytis 15: 1661-1664.

Phytochemistry, 15, 1661-1664.

MEIER, U. (2001). Entwicklungsstadien mono- und dikotyler Pflanzen. BBCH Monografie. 2. Aufl., Braunschweig.

Mithen, R. (1992). Leaf glucosinolate profiles and their relationship to pest and disease resistance in oilseed rape. Euphytica, 63, 71-83.

MITHEN, R.F., LEWIS, B.G. \& FENWICK, G.R. (1986). In vitro activity of glucosinolates and their products against Leptosphaeria maculans. Transactions of the British Mycological Society, 87, 433-440.

MORGAN, W.M. (1984). The effect of night temperature and glasshouse ventilation on the incidence of Botrytis cinerea in a late-planted tomato crop. Crop Protection, 3, 243251.

NAIR, N.G. \& ALLEN, R.N. (1993). Infection of grape flowers and berries by Botrytis cinerea as a function of time and temperature. Mycological Research, 97, 1012-1014.

NELSON, K.E. (1951). Effect of humidity on infection of table grapes by Botrytis cinerea. Phytopathology, 41, 859-864.

NiP, M., TegelaAR, E.W., LeeuW, J.W. de, Schenck, P.A. \& Holloway, P.J. (1986). A new non-saponifiable highly aliphatic and resistant biopolymer in plant cuticles.

Evidence from pyrolysis and ${ }^{13} \mathrm{C}-\mathrm{NMR}$ analysis of present-day and fossil plants. Naturwissenschaften, 73, 579-585.

O'Neill, T.M., ShtienBerg, D. \& Elad, Y. (1997). Effect of Some Host and Microclimate Factors on Infection of Tomato Stems by Botrytis cinerea. Plant Disease, 81, 36-40.

PAUL, N.K. \& MONDAL, R.K. (2007). Stomatal frequency and distribution in mustard (Brassica juncea L.) in relation to soil moisture. Bangladesh Journal of Scientific and Industrial Research, 42, 353-356.

PAUL, V.H. (2003). Raps. Krankheiten Schädlinge Unkräuter. 3. Aufl. Verlag Th. Mann, Gelsenkirchen-Buer. 
Peltier, A.J. \& GraU, C.R. (2008). The Influence of light on relationships between

Sclerotinia stem rot of soybean in field and controlled environments. Plant Disease, 92, 1510-1514.

PORTER, L.D., HOHEISEL, G. \& COFFMAN, V.A. (2009). Resistance of peas to Sclerotinia sclerotiorum in the Pisum core collection. Plant Pathology, 58, 52-60.

Prins, T.W., Tudzynski, P., von Tiedemann, A., Tudzynski, B., ten Have, A. \& Hansen, M.E. et al. (2000). Infection strategies of Botrytis cinerea and related necrotrophic pathogens. In: Fungal pathology (Hrsg. Kronstad, J.W.). Kluwer Academic Publishers, Dordrecht, The Netherlands, 32-64.

QUIDDE, T., BÜTTNER, P. \& TUDZYNSKI, P. (1999). Evidence for three different specific saponin-detoxifying activities in Botrytis cinerea and cloning and functional analysis of a gene coding for a putative avenacinase. European Journal of Plant Pathology, 105, 273-283.

RAdTKE, W., RiECKMANN, W. \& BRendLER, F. (2000). Kartoffel. Krankheiten, Schädlinge, Unkräuter. Verlag Th. Mann, Gelsenkirchen-Buer.

Salzman, R.A., Tikhonova, I., Bordelon, B.P., Hasegawa, P.M. \& Bressan, R.A. (1998). Coordinate accumulation of antifungal proteins and hexoses constitutes a developmentally controlled defence response during fruit ripening in grape. Plant Physiol., 117, 465-472.

SCHNEIDER-ORELLI, O. (1912). Versuche über die Wachstumsbedingungen und Verbreitung der Faulnispilze des Lagerobstes. Zentralbl. Bakteriol. Parasitenkd. 32: 161-169. Zentralbl. Bakteriol. Parasitenkd., 32, 161-169.

SCHÖNHERR, J. (1976). Water permeability of isolated cuticular membranes: The effect of cuticular waxes on diffusion of water. Planta, 131, 159-164.

SCHÖNHERR, J. (1982). Reistance of plant surfaces to water loss:. transport properties of cutin, suberin and associated lipids. In: Physiological Plant Ecology II. Water Relations and Carbon Assimilation (Hrsg. Lange, O.L., Nobel, P.S., Osmond, C.B. \& Ziegler, H.). Springer, Berlin, Heidelberg, 153-179.

SCHÖNHERR, J. (2000). Calcium chloride penetrates plant cuticles via aqueous pores. Planta, 212, 112-118.

SCHREIBER, L. \& SCHÖNHERR, J. (1993). Determination of foliar uptake of chemicals: influence of leaf surface microflora. Plant, Cell and Environment, 16, 743-748.

Schwab, M., NogA, G. \& BARThlott, W. (1993). The infuence of Mg and Ca deficiency on susceptibility of kohlrabi towards Botrytis cinerea infection. Angewandte Botanik, 67, 180-185.

SHANER, G. \& FINNEY, R.E. (1977). The effect of nitrogen fertilization on the expression of slow-mildewing resistance in knox wheat. Phytopathology, 67, 1051-1056. 
SNOW, D. (1949). The germination of mould spores at controlled humidities. Annals of Applied Biology, 36, 1-13.

Sosa-Alvarez, M., Madden, L.V. \& Ellis, M.A. (1995). Effects of temperature and wetness duration on sporulation of Botrytis cinerea on strawberry leaf residues. Plant Disease, 79, 609-615.

Stotz, H.U., Contos, J.J.A., Powell, A.L.T., Bennett, A.B. \& LABAVItCh, J.M. (1994).

Structure and expression of an inhibitor of fungal polygalacturonases from tomato. Plant Molecular Biology, 25, 607-617.

Tabel, Y., Kitade, S., Nishizawa, Y., KiKuchi, N., Kayano, T. \& HiBi, T. et al. (1998).

Transgenic cucumber plants harboring a rice chitinase gene exhibit enhanced resistance to gray mold (Botrytis cinerea). Plant Cell Reports, 17, 159-164.

TENEBERGE, K.B. (2007). Morphology and cellular organisation in Botrytis interactions with plants. In: Botrytis: Biology Pathology and Control (Hrsg. Elad, Y., Williamson, B., Tudzynski, P. \& Delen, N.). Springer, Niederlande, 67-84.

THOMAS, C.S., MAROIS, J.J. \& ENGLISH, J.T. (1988). The effects of wind speed, temperature and relative humidity on development of aerial mycelium and conidia of Botrytis cinerea on grape. Phytopathology, 78, 260-265.

TRENCKMANN, G.S. (2014). Grauschimmel am Raps. Untersuchungen zur Wirkung von Fungiziden gegen Infektionen mit Botrytis cinerea. Raps, 32, 24-26.

Unger, C., KLetA, S., JandL, G. \& von TiedemanN, A. (2005). Suppression of the defence-related oxidative burst in bean leaf tissue and bean suspension cells by the necrotrophic pathogen Botrytis cinerea. Journal of Phytopathology, 153, 15-26.

URBANEK, H., GAJEWSKA, E., KARWOWSKA, R. \& WIELANEK, M. (1996). Generation of superoxide anion and induction of superoxide dismutase and peroxidase in bean leaves infected with pathogenic fungi. Acta Biochimica Polonica 43: 679-685, 43, 679685.

Verhoeff, K., Leeman, M., Peer, R., Posthuma, L., Schot, N. \& ElJK, G.W. (1988). Changes in $\mathrm{pH}$ and the production of organic acids during colonization of tomato petioles by Botrytis cinerea. Journal of Phytopathology, 122, 327-336.

VERHOEFF, K. \& LIEM, J.I. (1975). Toxicity of tomatine to Botrytis cinerea, in relation to latency. Phytopathologische Zeitschrift, 82, 333-338.

VON TIEDEMANN, A. (1997). Evidence for a primary role of active oxygen species in induction of host cell death during infection of bean leaves with Botrytis cinerea. Physiological and Molecular Plant Pathology, 50, 151-166.

von Tiedemann, A. \& Steinbach, P. (2007). Krankheiten durch pilzliche Pathogene. In: Winterraps. Das Handbuch für Profis (Hrsg. Christen, O. \& Friedt, W.). DLG-Verlag, Frankfurt am Main, 136-164. 
WALTON, T.J. (1990). Waxes, cutin and suberin. Methods in Plant Biochemistry, 4, 105158.

WANG, H.-z., LIU, G.-h., ZHENG, Y.-b., WANG, X.-f. \& YANG, Q. (2004). Breeding of the Brassica napus cultivar Zhongshuang 9 with high-resistance to Sclerotinia sclerotiorum and dynamics of its important enzyme activity. Scientia Agricultura Sinica, 37, 23-28.

WHITECROSS, M.I. \& ARMSTRONG, D.J. (1972). Environmental Effects on Epicuticular Waxes of Brassica napus L. Australian Journal of Botany, 20, 87-95.

WILliamson, B., TUDZYNSKI, B., TUDZYNSKI, P. \& VAN KAN, J.A.L. (2007). Botrytis cinerea: the cause of grey mould disease. Molecular Plant Pathology, 8, 561-580.

Winspear, K.W., PostlethWAite, J.D. \& CotTon, R.F. (1970). The restriction of Cladosporium fulvum and Botrytis cinerea, attacking greenhouse tomatoes, by automatic humidity control. Annals of Applied Biology, 65, 75-83.

WULF, T. (2011). Phänotypisierung von Raps-und anderen Brassica-Genotypen zur Identifzierung von Resistenzquellen gegenüber Sclerotinia sclerotiorum. Dissertation, Gerog-August-Universität Göttingen.

ZAMANI-NOOR, N. (2011). Studies on Ramularia leaf spots on barley - Resistance Phenotyping, Epidemiology and Pathogenicity. Dissertation, Georg-August-Universität Göttingen. 


\subsection{Anhang II: Tabellen zum Feldversuch}

Tab. 10A: Versuchsplan WR/Fungizid-Versuch 2010/11 (Schlag "Große Lage“, Weende). Sorte und Saatstärke sind als Blockanlage randomisiert. Innerhalb der Sorten + Saatstärken Kombination sind die Fungizidbehandlungen vollrandomisiert. FG = Fahrgasse; In den Fahrgassen und am Rand wurde die Sorte NK Petrol mit $60 \mathrm{Körner} / \mathrm{m}^{2}$ ausgesät. Jede Parzelle war $9 \mathrm{~m}$ lang und $2,50 \mathrm{~m}$ breit.

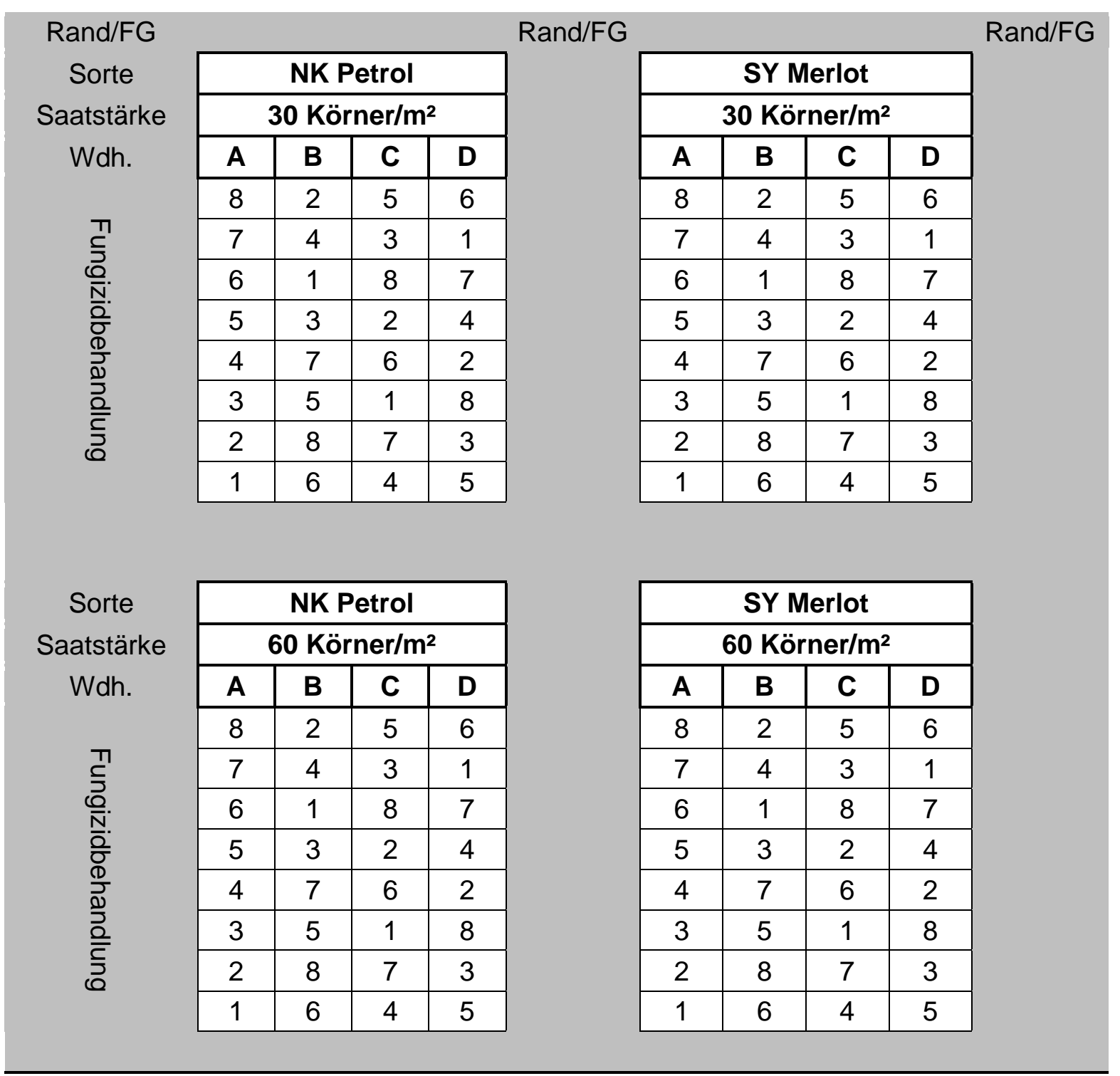

Feldweg zur Leine $\rightarrow$ 
Tab. 11A: Versuchsplan WR/Fungizid-Versuch 2011/12 (Schlag "Große Lage“, Weende). Teilrandomisierte Spalt-Spaltanlage, FG = Fahrgasse; In den Fahrgassen und am Rand wurde die Sorte NK Petrol mit $60 \mathrm{Körner} / \mathrm{m}^{2}$ ausgesät. In diesem Versuchsjahr war jede Parzelle $12 \mathrm{~m}$ lang und $2,50 \mathrm{~m}$ breit.

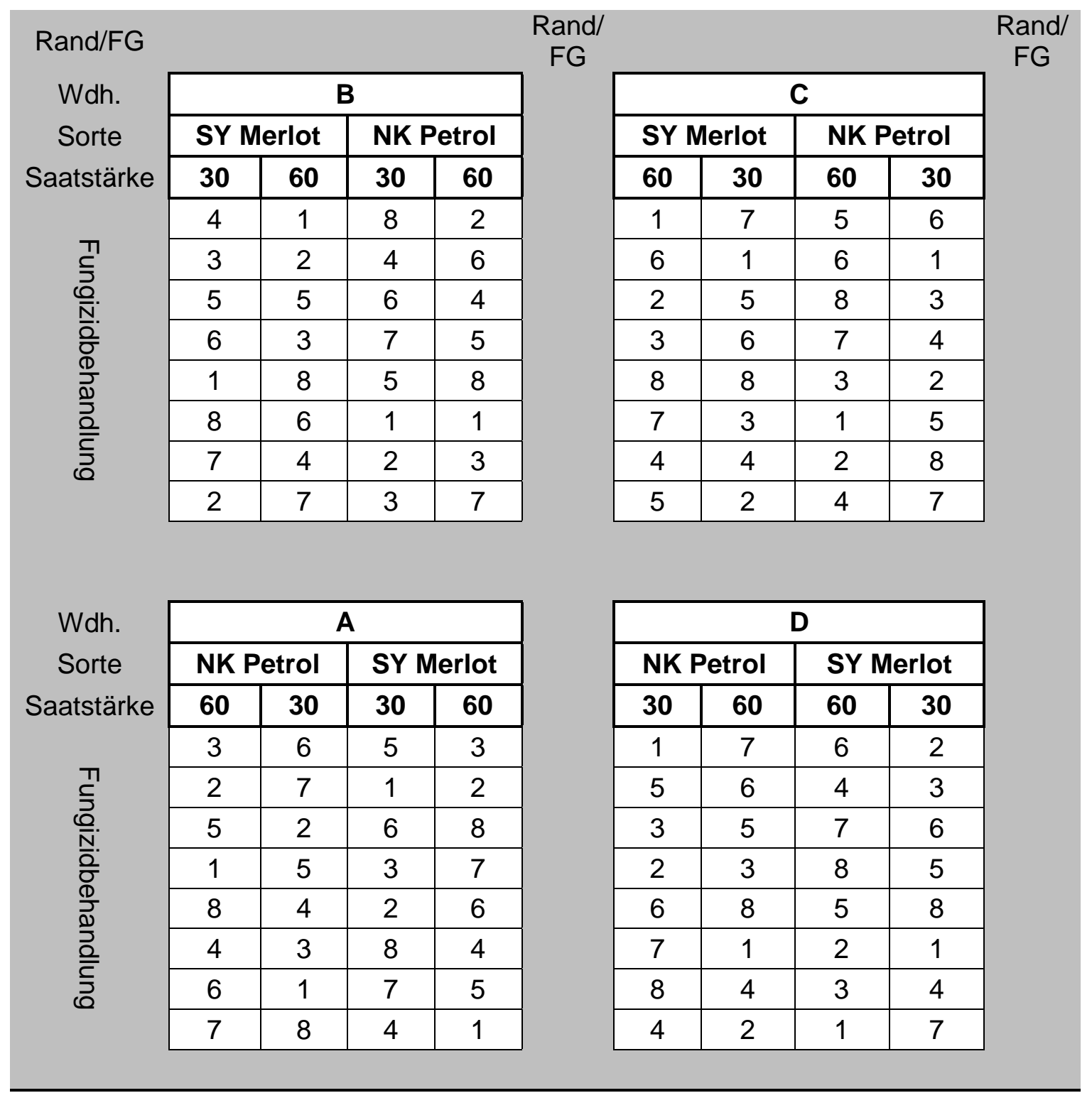


Tab. 12A: Versuchsplan WR/Fungizid-Versuch 2012/13 (Schlag „Dehne“, Rosdorf) Teilrandomisierte Spalt-Spaltanlage, FG = Fahrgasse; In den Fahrgassen und am Rand wurde die Sorte NK Petrol mit 60 Körner $/ \mathrm{m}^{2}$ ausgesät. Jede Parzelle war $10 \mathrm{~m}$ lang und 2,50 m breit.

\begin{tabular}{|c|c|c|c|c|c|c|c|c|}
\hline \multirow{4}{*}{$\begin{array}{l}\text { Rand/FG } \\
\text { Wdh. } \\
\text { Sorte } \\
\text { Saatstärke }\end{array}$} & \multicolumn{8}{|c|}{$\begin{array}{c}\text { Rand/ } \\
\text { FG }\end{array}$} \\
\hline & \multicolumn{4}{|c|}{ B } & \multicolumn{4}{|c|}{ C } \\
\hline & \multicolumn{2}{|c|}{ NK Petrol } & \multicolumn{2}{|c|}{ SY Vesuvio } & \multicolumn{2}{|c|}{ NK Petrol } & \multicolumn{2}{|c|}{ SY Vesuvio } \\
\hline & 30 & 60 & 60 & 30 & 60 & 30 & 60 & 30 \\
\hline \multirow{8}{*}{ 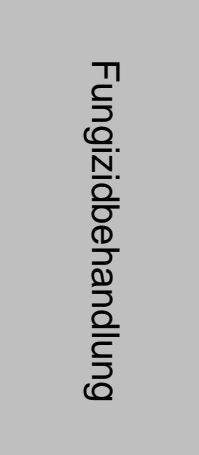 } & 6 & 7 & 3 & 2 & 7 & 4 & 1 & 2 \\
\hline & 1 & 4 & 8 & 5 & 8 & 5 & 6 & 3 \\
\hline & 3 & 5 & 6 & 1 & 2 & 3 & 8 & 7 \\
\hline & 2 & 8 & 7 & 4 & 6 & 1 & 4 & 5 \\
\hline & 5 & 6 & 1 & 3 & 4 & 2 & 5 & 6 \\
\hline & 8 & 2 & 4 & 7 & 3 & 8 & 7 & 1 \\
\hline & 4 & 3 & 5 & 6 & 5 & 7 & 3 & 4 \\
\hline & 7 & 1 & 2 & 8 & 1 & 6 & 2 & 8 \\
\hline
\end{tabular}

Rand/ FG

\begin{tabular}{|c|c|c|c|c|}
\hline \multirow{3}{*}{$\begin{array}{l}\text { Wdh. } \\
\text { Sorte } \\
\text { Saatstärke }\end{array}$} & \multicolumn{4}{|c|}{ A } \\
\hline & \multicolumn{2}{|c|}{ SY Vesuvio } & \multicolumn{2}{|c|}{ NK Petrol } \\
\hline & 60 & 30 & 30 & 60 \\
\hline \multirow{8}{*}{ 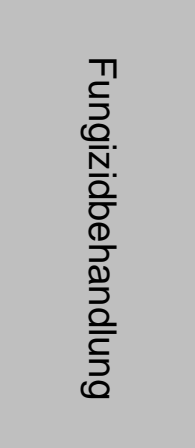 } & 3 & 7 & 2 & 1 \\
\hline & 8 & 5 & 6 & 4 \\
\hline & 2 & 4 & 3 & 8 \\
\hline & 1 & 6 & 5 & 7 \\
\hline & 5 & 2 & 4 & 6 \\
\hline & 4 & 3 & 7 & 3 \\
\hline & 7 & 1 & 1 & 2 \\
\hline & 6 & 8 & 8 & 5 \\
\hline
\end{tabular}

\begin{tabular}{|c|c|c|c|}
\hline \multicolumn{4}{|c|}{ D } \\
\hline \multicolumn{2}{|c|}{ NK Petrol } & \multicolumn{2}{c|}{ SY Vesuvio } \\
\hline 30 & 60 & 30 & 60 \\
\hline 2 & 5 & 6 & 7 \\
\hline 4 & 8 & 1 & 3 \\
\hline 3 & 6 & 2 & 4 \\
\hline 1 & 7 & 8 & 5 \\
\hline 8 & 1 & 3 & 6 \\
\hline 5 & 4 & 7 & 2 \\
\hline 7 & 2 & 5 & 8 \\
\hline 6 & 3 & 4 & 1 \\
\hline
\end{tabular}


Tab. 13A: Sortenprofil für die Winterrapssorte NK Petrol von der Firma Syngenta Agro GmbH (ANONYMUS, 2013h). Die Angaben beruhen auf der Beschreibenden Sortenliste 2013 vom Bundessortenamt in Hannover oder auf eigene Züchtereinstufungen (mit * gekennzeichnet, Stand Juli 2013).

\begin{tabular}{ll}
\hline Sortentyp & Hybride \\
\hline Entwicklung vor Winter & mittel (5) \\
Blühbeginn & früh (3) \\
Reife & früh bis mittel (4) \\
Pflanzenlänge & mittel bis lang (6) \\
Neigung zu & \\
Auswinterung & \\
Lager & gering bis mittel (4) \\
Anfälligkeit für & gering (3) \\
Phoma & \\
Sklerotinia & mittel (5) \\
Kornertrag & mittel (5) \\
Ölertrag & hoch (7) \\
Ölgehalt & mittel bis hoch (6) \\
Glukosinolatgehalt* & mittel (5) \\
\hline
\end{tabular}

Tab 14A: Sortenprofil für die Winterrapssorte SY Merlot von der Firma Syngenta Agro GmbH (ANONYMUS, 2010). Bei den Angaben handelt es sich um reine Züchtereinstufungen (Stand August 2010).

\begin{tabular}{ll}
\hline Sortentyp & Hybride \\
\hline Herbstentwicklung & zügig \\
Blühbeginn & früh bis mittel \\
Reife & früh bis mittel \\
Pflanzenlänge & mittel \\
Neigung zu & \\
Auswinterung & gering bis mittel \\
Lager & gering \\
Anfälligkeit für & \\
Phoma & mittel \\
Sklerotinia & mittel \\
Kornertrag & hoch bis sehr hoch \\
Ölertrag & hoch bis sehr hoch \\
Ölgehalt & mittel bis hoch \\
Glukosinolatgehalt & niedrig \\
\hline
\end{tabular}


Tab. 15A: Sortenprofil für die Winterrapssorte SY Vesuvio von der Firma Syngenta Agro GmbH (ANONYMUS, 2013i). Bei den Angaben handelt es sich um reine Züchtereinstufungen (Stand Juli 2013).

\begin{tabular}{ll}
\hline Sortentyp & Hybride \\
\hline Entwicklung vor Winter & mittel (5) \\
Blühbeginn & früh (3) \\
Reife & früh bis mittel (4) \\
Pflanzenlänge & kurz bis mittel (4) \\
Neigung zu & \\
Auswinterung & gering bis mittel (4) \\
Lager & gering (3) \\
Anfälligkeit für & \\
Phoma & gering bis mittel (4) \\
Sklerotinia & mittel (5) \\
Kornertrag & sehr hoch (9) \\
Ölertrag & sehr hoch (9) \\
Ölgehalt & hoch (7) \\
Glukosinolatgehalt & niedrig (3) \\
\hline
\end{tabular}

Tab. 16A: Auflistung der in der Fungizidvariante acht (praxisüblich) verwendeten Fungizide, sortiert nach Versuchsjahr. Angegeben sind die Aufwandmengen der einzelnen Fungizide und die Entwicklungsstadien der Pflanzen, in denen die Mittel appliziert wurden.

\begin{tabular}{cccccc}
\hline \multicolumn{5}{c}{ Versuchsjahr } \\
\hline 2010/11 & \multicolumn{2}{c}{$\mathbf{2 0 1 1 / 1 2}$} \\
\hline $\begin{array}{c}\text { Produkt }+ \\
\text { Aufwandmenge }\end{array}$ & $\mathrm{BBCH}$ & $\begin{array}{c}\text { Produkt }+ \\
\text { Aufwandmenge }\end{array}$ & $\mathrm{BBCH}$ & $\begin{array}{c}\text { Produkt }+ \\
\text { Aufwandmenge }\end{array}$ & $\mathrm{BBCH}$ \\
\hline Folicur $^{\circledR} 0,6 \mathrm{l} / \mathrm{ha}$ & 14 & Carax $^{\circledR} 0,5 \mathrm{l} / \mathrm{ha}$ & $15 / 16$ & Carax $^{\circledR} 0,5 \mathrm{l} / \mathrm{ha}$ & 14 \\
Carax $^{\circledR} 0,7 \mathrm{l} / \mathrm{ha}$ & $33 / 35$ & Carax $^{\circledR} 0,5 \mathrm{l} / \mathrm{ha}$ & $17 / 18$ & Carax $^{\circledR} 0,5 \mathrm{l} / \mathrm{ha}$ & $33 / 35$ \\
Harvesan $^{\circledR} 0,8 \mathrm{l} / \mathrm{ha}$ & 65 & Folicur $^{\circledR} 0,8 \mathrm{l} / \mathrm{ha}$ & 33 & Ortiva $^{\circledR} 1,0 \mathrm{l} / \mathrm{ha}$ & 65 \\
& & Harvesan $^{\circledR} 0,8 \mathrm{l} / \mathrm{ha}$ & 65 & & \\
\hline
\end{tabular}


Tab. 17A: Acker- und pflanzenbauliche Maßnahmen 2010/11 (Schlag „Große Lage“, Weende)

Vorfrucht

Bodenbearbeitung

1. Saatbettbereitung

2. Saatbettbereitung

Aussaat am

Saatgut (Sorten)

Saatgutbehandlung

$\mathrm{N}_{\min }$ Probenahme

1. N-Düngung

2. N-Düngung

3. N-Düngung

$\mathrm{N}_{\text {gesamt }}$ (incl. $\mathrm{N}_{\text {min }}$ )

S-Düngung

1. Blattdüngung

2. Blattdüngung

1. Herbizid

2. Herbizid

1. WR/Fungizid

2. WR/Fungizid

3. WR/Fungizid

4. WR/Fungizid

Blütenspritzung

1. Insektizid

2. Insektizid

3. Insektizid

4. Insektizid

Schneckenkorn

Scheiteln

Ernte
20.08.10

01.09 .10

03.09.10

06.09.10

07.09.10

NK Petrol

SY Merlot

01.03.11

03.03.11 (ES 16)

04.03.11 (ES 16)

06.04.11 (ES 33/35)

03.03.11 (ES 16)

08.04.11 ( ES 35/37)

18.04.11 (ES 55/57)

08.09.10 (ES VA)

07.10 .10 (ES 13)

11.10.10 (ES 14)

29.10.10 (ES 15/16)

06.04.11 (ES 33/35)

15.04.11 (ES 53/55)

05.05.11 (ES 65)

25.03.11 (ES 15/16)

08.04.11 (ES 35/37)

18.04.11 (ES 55/57)

05.05.11 (ES 65)

15.09.10 (ES 10)

23.09.10 (ES 10)

24.06.11

22.07.11
Ernte Winterweizen

Pflug

Spatenrollegge

Kreiselegge+Walze (2x)

Scheibenschardrillmaschine

TKM: 5,5 g; Kmf.: 98\%

TKM: 6,2 g; Kmf.: 95\%

Elado+TMTD 98\% Satec

$19,9 \mathrm{~kg} \mathrm{~N} / \mathrm{ha}$

$35,7 \mathrm{~kg} \mathrm{~N} / \mathrm{ha}$ (SSA, $170 \mathrm{~kg} / \mathrm{ha}$ )

$70 \mathrm{~kg} \mathrm{~N} / \mathrm{ha}(\mathrm{AHL})$

$85 \mathrm{~kg} \mathrm{~N} / \mathrm{ha}(\mathrm{AHL})$

$210,6 \mathrm{~kg} \mathrm{~N} / \mathrm{ha}$

40,8 kg S/ha (SSA 170 kg/ha)

$2 \mathrm{~kg} / \mathrm{ha}$ Nutribor

$2 \mathrm{~kg} / \mathrm{ha}$ Nutribor

3,5 I/ha Colzor Trio

0,7 I/ha Agil S

T1 nach Plan gespritzt

T2 nach Plan gespritzt

T3 nach Plan gespritzt

T4 nach Plan gespritzt

nach Plan

0,075 I/ha Karate Zeon

0,2 I/ha Trebon

0,2 I/ha Mospilan

0,3 I/ha Biscaya

ca. $6 \mathrm{~kg} / \mathrm{ha}$ Metarex

ca. $6 \mathrm{~kg} / \mathrm{ha}$ Metarex 
Tab. 18A: Acker- und pflanzenbauliche Maßnahmen 2011/12 (Schlag „Große Lage“, Weende)

Vorfrucht

1. Stoppelbearbeitung

2. Stoppelbearbeitung

Bodenbearbeitung

Saatbettbereitung

Aussaat am

Saatgut (Sorten)

Saatgutbehandlung

Grunddüngung

$\mathrm{N}_{\min }$ Probenahme

1. N-Düngung

2. N-Düngung

3. N-Düngung

$\mathrm{N}_{\text {gesamt }}$ (incl. $\mathrm{N}_{\min }$ )

S-Düngung

1. Blattdüngung

2. Blattdüngung

1. Herbizid

2. Herbizid

1. WR/Fungizid

2. WR/Fungizid

3. WR/Fungizid

4. WR/Fungizid

Blütenspritzung

1. Insektizid

2. Insektizid

Schneckenkorn

Mäusegift

Ernte
08.07.11

12.07.11

26.07.11

22.08.11

23.08.11

24.08.11

NK Petrol

SY Merlot

26.07.11

07.03.12

07.03.12 (ES 18)

12.03.12 (ES 18)

28.03.12 (ES 50)

07.03.12 (ES 18)

05.04.12 (ES 52)

18.04.12 (ES 57)

25.08.11 (ES VA)

27.09.11 (ES 15)

29.09.11 (ES 16)

13.10.11 (ES 17)

28.03.12 (ES 33)

17.04.12 (ES 57)

09.05.12 (ES 65)

27.09.11 (ES 15)

22.03.12 (ES 31)

26.08.11 (ES VA)

Nov.11 - Feb. 2012

01.08 .12
Ernte Wintergerste

Scheibenegge Carrier

Grubber $4 \mathrm{~m}$

Pflug

Kreiselegge+Walze

Scheibenschardrillmaschine

TKM: 4,8 g; Kmf.: 93\%

TKM: 6,4 g; Kmf.: 90\%

Elado+TMTD 98\% Satec+DMM

Gärsubstrat 25 t/ha

$20,1 \mathrm{~kg} \mathrm{~N} / \mathrm{ha}$

$42 \mathrm{~kg} \mathrm{~N} / \mathrm{ha}$ (SSA, $200 \mathrm{~kg} / \mathrm{ha}$ )

$70 \mathrm{~kg} \mathrm{~N} / \mathrm{ha}$ (KAS)

$70 \mathrm{~kg} \mathrm{~N} / \mathrm{ha}(\mathrm{AHL})$

$202,1 \mathrm{~kg} \mathrm{~N} / \mathrm{ha}$

$48 \mathrm{~kg} \mathrm{~S} / \mathrm{ha}$ (SSA $200 \mathrm{~kg} / \mathrm{ha}$ )

$3 \mathrm{~kg} / \mathrm{ha}$ Nutribor

$3 \mathrm{~kg} / \mathrm{ha}$ Nutribor

3,0 I/ha Colzor Trio

0,6 I/ha Agil S

T1 nach Plan gespritzt

T2 nach Plan gespritzt

T3 nach Plan gespritzt

T4 nach Plan gespritzt

nach Plan

0,1 I/ha Fastac SC Super Contact

0,2 I/ha Trebon

ca. $5 \mathrm{~kg} / \mathrm{ha}$ Spiess Urania

ca. alle 14 Tage vers. Mittel

keine Ertragsermittlung 
Tab. 19A: Acker- und pflanzenbauliche Maßnahmen 2012/13 (Schlag „Dehne“, Rosdorf)

Vorfrucht

1. Stoppelbearbeitung

2. Stoppelbearbeitung

Bodenbearbeitung

Saatbettbereitung

Aussaat am

Saatgut (Sorten)

Saatgutbehandlung

Grunddüngung

$\mathrm{N}_{\text {min }}$ Probenahme

1. N-Düngung

2. N-Düngung

3. N-Düngung

$\mathrm{N}_{\text {gesamt }}$ (incl. $\mathrm{N}_{\text {min }}$ )

S-Düngung

1. Blattdüngung

2. Blattdüngung

1. Herbizid

2. Herbizid

1. WR/Fungizid

2. WR/Fungizid

3. WR/Fungizid

4. WR/Fungizid

Fungizid

Blütenspritzung

1. Insektizid

2. Insektizid

3. Insektizid

4. Insektizid

Schneckenkorn

Mäusegift

Scheiteln

Ernte
13.08.12

15.08.12

28.08.12

28.08.12

28.08.12

29.08.12

NK Petrol

SY Vesuvio

27.08.12

04.03 .13

06.03.13 (ES 18)

27.03.13 (ES 18)

08.04.13 (ES 30)

04.03.13 (ES 18)

16.04.13 (ES 32/34)

25.04.13 (ES 53/55)

30.08.12 (ES VA)

09.10 .12 (ES 14)

11.10.12 (ES 14)

31.10.12 (ES 17)

18.04.13 (ES 33/35)

25.04.13 (ES 53/55)

16.04.13 (ES 32/34)

15.05.12 (ES 65)

09.10.12 (ES 15)

16.04.13 (ES 32/34)

25.04.13 (ES 53/55)

06.05.13 (ES 61)

$30.08 .12+12.09 .13$

12.09 .12

08.07.13

06.08 .13
Ernte Winterweizen

Scheibenegge Carrier

Grubber

Pflug mit Packer

Kreiselegge+Walze

Scheibenschardrillmaschine

TKM: 4,8 g; Kmf.: 96\%

TKM: 4,7 g; Kmf.: 95\%

Elado+TMTD 98\% Satec+DMM

$138 \mathrm{~kg} \mathrm{P} / \mathrm{ha}$ (TSP $3 \mathrm{dt} / \mathrm{ha}$ )

$200 \mathrm{~kg} \mathrm{~K} / \mathrm{ha}$ (Kornkali $5 \mathrm{dt} / \mathrm{ha}$ )

$24,9 \mathrm{~kg} \mathrm{~N} / \mathrm{ha}$

$39,9 \mathrm{~kg} \mathrm{~N} / \mathrm{ha}$ (SSA, 1,9 dt/ha)

$80 \mathrm{~kg} \mathrm{~N} / \mathrm{ha}$ (KAS)

$70 \mathrm{~kg} \mathrm{~N} / \mathrm{ha}(\mathrm{AHL})$

$214,8 \mathrm{~kg} \mathrm{~N} / \mathrm{ha}$

45,6 kg S/ha (SSA 1,9 dt/ha)

$3 \mathrm{~kg} / \mathrm{ha}$ Nutribor

$3 \mathrm{~kg} / \mathrm{ha}$ Nutribor

3,0 I/ha Colzor Trio

0,6 I/ha Agil S

T1 nach Plan gespritzt

T2 nach Plan gespritzt

T3 nach Plan gespritzt

T4 nach Plan gespritzt

$0,5 \mathrm{~kg} / \mathrm{ha}$ Cantus $\rightarrow$ B. cinerea nach Plan

0,1 I/ha Fastac SC Super Contact

0,2 I/ha Trebon

0,2 I/ha Mospilan

0,3 I/ha Biscaya

ca. $4 \mathrm{~kg} / \mathrm{ha}$ Patrol Pads (Rand)

Ratron Gift-Linsen (Rand) 
Tab. 20A: Nährstoffgehalte im Gärsubstrat vom 26.07.11 in Anlehnung an die Nährstoffanalyse vom 15.07.11. Pro Hektar wurden 25 Tonnen Gärsubstrat ausgebracht.

\begin{tabular}{cccc}
\hline Hauptnährstoffe & & & \\
\hline & $\mathrm{N}$ & FM [kg/t] & kg Nährstoff/ha \\
\hline Gesamtstickstoff & $\mathrm{NH}_{4}-\mathrm{N}$ & 4,50 & 112,5 \\
Ammonium N & $\mathrm{P}_{2} \mathrm{O}_{5}$ & 1,94 & 48,5 \\
Phosphor & $\mathrm{K}_{2} \mathrm{O}$ & 3,31 & 82,75 \\
Kalium & $\mathrm{MgO}$ & 4,16 & 104 \\
Magnesium & $\mathrm{CaO}$ & $\mathrm{n} \cdot \mathrm{b}$. & $\mathrm{n} . \mathrm{b}$. \\
Calcium & $\mathrm{S}$ & 1,39 & 34,75 \\
Schwefel & & 0,32 & 8 \\
\hline Spurennährstoffe & & & $\mathrm{g} \mathrm{Nährstoff/ha}$ \\
\hline & $\mathrm{Cu}$ & $\mathrm{FM}[\mathrm{g} / \mathrm{t}]$ & 94,5 \\
\hline Kupfer & $\mathrm{Zn}$ & 3,78 & 275,25 \\
Zink & 11,01 &
\end{tabular}

$\mathrm{FM}=$ Frischmasse; n.b. $=$ nicht bestimmbar

Tab. 21A: Ergebnisse der Analyse der Bodenproben von den Versuchsflächen aus dem jeweiligen Versuchsjahr.

\begin{tabular}{ccccccc}
\hline Schlag: & \multicolumn{2}{c}{ "Große Lage“ } & \multicolumn{2}{c}{ "Große Lage“ } & \multicolumn{2}{c}{ "Dehne“ } \\
\hline Probenahme: & \multicolumn{2}{c}{01.03 .2011} & \multicolumn{2}{c}{07.03 .2012} & \multicolumn{2}{c}{04.03 .2013} \\
\hline Parameter & Gehalt & Klasse & Gehalt & Klasse & Gehalt & Klasse \\
\hline pH-Wert & 6,9 & & 7,4 & & 7,7 & \\
Humus [\%] & 2,48 & & 2,21 & & 3,41 & \\
C org [\%] & 1,44 & & 1,28 & & 1,98 & \\
C/N & 9,4 & & 8,7 & & 9,8 & \\
Mg [mg/100g] & 10 & D & 6 & C & 5 & B \\
P [mg/100g] & 11 & D & 9 & C & 9 & C \\
K [mg/100g] & 12 & C & 11 & C & 23 & D \\
B [mg/kg TS] & 0,88 & C & 0,46 & B & 0,91 & C \\
\hline
\end{tabular}


Tab. 22A: Kennzahlen der einfachen, linearen Regressionsrechnungen, die zwischen allen Parametern und der Zielvariablen Kornertrag durchgeführt wurden. Die Parameter wurden im Jahr 2010/11, im Feldversuch am Standort Göttingen, untersucht. Dargestellt sind die Anzahl der Werte (n), die in jede Berechnung eingeflossen sind; der Korrelationskoeffizient nach Spearman $\left(r_{s}\right)$ und Pearson $\left(r_{p}\right)$; das Bestimmtheitsmaß nach Spearman $\left(R_{s}{ }^{2}\right)$ und Pearson $\left(R_{p}{ }^{2}\right)$; die Überschreitungswahrscheinlichkeit $(p-W e r t)$ für die Spearman-Korrelationen $\left(p_{s}\right)$ und Pearson-Korrelationen $\left(p_{p}\right)$; die Steigung der Regressionsgeraden $(\mathrm{m})$ mit dem dazugehörigen Standardfehler (SE_m) und der Schnittpunkt der Regressionsgeraden mit der y-Achse (b) mit dem dazugehörigen Standardfehler (SE_b). Die Kennzahlen zur Steigung der Regressionsgeraden, sowie zum Schnittpunkt mit y-Achse ergeben sich aus den Regressionsrechnungen nach Pearson. Korrelationskoeffizienten und Bestimmtheitsmaße sind signifikant bei einem Wert $p \leq 0,05$ (hoch signifikant bei $p \leq$ 0,01 , höchst signifikant bei $p \leq 0,001$ ).

\begin{tabular}{lccccccccccc}
\hline Parameter $^{*}$ & $\mathbf{n}$ & $\mathbf{r}_{\mathbf{s}}$ & $\mathbf{R}_{\mathbf{s}}{ }^{2}$ & $\mathbf{p}_{\mathbf{s}}$ & $\mathbf{r}_{\mathbf{p}}$ & $\mathbf{R}_{\mathbf{p}}{ }^{2}$ & $\mathbf{p}_{\mathbf{p}}$ & $\mathbf{m}$ & $\mathbf{S E} \mathbf{m}$ & $\mathbf{b}$ & $\mathbf{S E} \mathbf{b}$ \\
\hline SBME & 119 & 0,463 & 0,214 & 0,000 & 0,383 & 0,147 & 0,000 & 0,2661 & 0,0593 & 2,9277 & 0,3473 \\
OG & 119 & 0,129 & 0,017 & 0,162 & 0,068 & 0,005 & 0,464 & 0,0568 & 0,0772 & 1,9947 & 3,3706 \\
OE & 119 & 0,990 & 0,981 & 0,000 & 0,992 & 0,985 & 0,000 & 2,2416 & 0,0259 & 0,0978 & 0,0509 \\
EI & 119 & 0,420 & 0,177 & 0,000 & 0,501 & 0,251 & 0,000 & 0,0816 & 0,0130 & 1,1029 & 0,5401 \\
DI_Fj & 119 & 0,531 & 0,282 & 0,000 & 0,482 & 0,232 & 0,000 & 0,0180 & 0,0030 & 3,8191 & 0,1178 \\
SpP & 119 & $-0,409$ & 0,167 & 0,000 & $-0,398$ & 0,158 & 0,000 & $-0,0027$ & 0,0006 & 5,1577 & 0,1530 \\
TKM & 119 & $-0,378$ & 0,143 & 0,000 & $-0,405$ & 0,164 & 0,000 & $-0,6540$ & 0,1363 & 8,0424 & 0,7457 \\
KpS & 119 & $-0,298$ & 0,089 & 0,001 & $-0,229$ & 0,053 & 0,012 & $-0,0565$ & 0,0222 & 5,7572 & 0,5073 \\
Spm2 & 119 & 0,389 & 0,152 & 0,000 & 0,342 & 0,117 & 0,000 & 0,0001 & 0,0000 & 3,8875 & 0,1553 \\
KpP & 119 & $-0,446$ & 0,199 & 0,000 & $-0,407$ & 0,165 & 0,000 & $-0,0001$ & 0,0000 & 5,0852 & 0,1352 \\
Korn_Di & 119 & 0,300 & 0,090 & 0,001 & 0,274 & 0,075 & 0,003 & 0,0000 & 0,0000 & 4,0181 & 0,1547 \\
KDG_Fj & 119 & 0,468 & 0,219 & 0,000 & 0,470 & 0,221 & 0,000 & 0,0191 & 0,0033 & 3,6411 & 0,1503 \\
WHD_Fj & 118 & $-0,504$ & 0,254 & 0,000 & $-0,476$ & 0,226 & 0,000 & $-0,1384$ & 0,0238 & 6,4261 & 0,3377 \\
& & & & & & & & & & & \\
\hline
\end{tabular}




\begin{tabular}{|c|c|c|c|c|c|c|c|c|c|c|c|}
\hline & $n$ & $r_{s}$ & $\mathbf{R}_{\mathrm{s}}^{2}$ & $p_{s}$ & $r_{p}$ & $\mathbf{R}_{\mathrm{p}}^{2}$ & $p_{p}$ & m & SE_m & b & SE_b \\
\hline StpP & 119 & $-0,353$ & 0,124 & 0,000 & $-0,375$ & 0,141 & 0,000 & $-0,1586$ & 0,0362 & 5,7399 & 0,2933 \\
\hline Hoe_1 & 119 & 0,223 & 0,050 & 0,015 & 0,280 & 0,078 & 0,002 & 0,0170 & 0,0054 & 2,4496 & 0,6432 \\
\hline Hoe_2 & 119 & 0,148 & 0,022 & 0,108 & 0,191 & 0,036 & 0,038 & 0,0120 & 0,0057 & 2,9950 & 0,7036 \\
\hline Hoe_3 & 119 & 0,164 & 0,027 & 0,074 & 0,221 & 0,049 & 0,016 & 0,0134 & 0,0055 & 2,8096 & 0,6795 \\
\hline Hoe_4 & 119 & 0,246 & 0,061 & 0,007 & 0,273 & 0,075 & 0,003 & 0,0172 & 0,0056 & 2,3508 & 0,6917 \\
\hline Sah_1 & 119 & 0,090 & 0,008 & 0,330 & 0,147 & 0,022 & 0,112 & 0,0107 & 0,0067 & 3,7385 & 0,4596 \\
\hline Sah_2 & 119 & 0,090 & 0,008 & 0,330 & 0,127 & 0,016 & 0,168 & 0,0080 & 0,0058 & 3,9140 & 0,4045 \\
\hline Sah_3 & 119 & 0,025 & 0,001 & 0,787 & 0,088 & 0,008 & 0,343 & 0,0056 & 0,0059 & 4,0898 & 0,4037 \\
\hline Sah_4 & 119 & 0,198 & 0,039 & 0,031 & 0,237 & 0,056 & 0,009 & 0,0155 & 0,0059 & 3,3852 & 0,4136 \\
\hline Schi_1 & 119 & 0,233 & 0,054 & 0,011 & 0,313 & 0,098 & 0,001 & 0,0378 & 0,0106 & 2,5630 & 0,5372 \\
\hline Schi_2 & 119 & 0,084 & 0,007 & 0,366 & 0,135 & 0,018 & 0,142 & 0,0181 & 0,0122 & 3,5028 & 0,6565 \\
\hline Schi_3 & 119 & 0,335 & 0,112 & 0,000 & 0,333 & 0,111 & 0,000 & 0,0486 & 0,0127 & 1,7461 & 0,7151 \\
\hline Schi_4 & 119 & 0,135 & 0,018 & 0,143 & 0,120 & 0,014 & 0,194 & 0,0204 & 0,0156 & 3,3866 & 0,8319 \\
\hline abs_00 & 119 & $-0,246$ & 0,060 & 0,007 & $-0,279$ & 0,078 & 0,002 & $-0,0247$ & 0,0079 & 5,3460 & 0,2825 \\
\hline abs_01 & 119 & $-0,359$ & 0,129 & 0,000 & $-0,300$ & 0,090 & 0,001 & $-0,0185$ & 0,0054 & 4,8569 & 0,1228 \\
\hline abs_02 & 119 & $-0,341$ & 0,116 & 0,000 & $-0,323$ & 0,104 & 0,000 & $-0,0187$ & 0,0051 & 4,9510 & 0,1379 \\
\hline abs_03 & 119 & $-0,304$ & 0,092 & 0,001 & $-0,278$ & 0,077 & 0,002 & $-0,0183$ & 0,0058 & 4,9908 & 0,1728 \\
\hline abs_04 & 119 & $-0,235$ & 0,055 & 0,010 & $-0,194$ & 0,038 & 0,035 & $-0,0126$ & 0,0059 & 4,8657 & 0,1908 \\
\hline rel_00 & 119 & 0,276 & 0,076 & 0,002 & 0,226 & 0,051 & 0,014 & 0,0295 & 0,0117 & 4,0366 & 0,1799 \\
\hline rel_01 & 119 & $-0,059$ & 0,003 & 0,524 & 0,008 & 0,000 & 0,931 & 0,0016 & 0,0182 & 4,4582 & 0,1579 \\
\hline rel_02 & 119 & $-0,001$ & 0,000 & 0,993 & 0,053 & 0,003 & 0,565 & 0,0109 & 0,0189 & 4,3612 & 0,1967 \\
\hline
\end{tabular}




\begin{tabular}{|c|c|c|c|c|c|c|c|c|c|c|c|}
\hline & $n$ & $r_{s}$ & $\mathbf{R}_{\mathrm{s}}^{2}$ & $p_{s}$ & $r_{p}$ & $\mathbf{R}_{\mathrm{p}}^{2}$ & $p_{p}$ & m & SE_m & b & SE_b \\
\hline rel_03 & 119 & 0,137 & 0,019 & 0,136 & 0,215 & 0,046 & 0,019 & 0,0489 & 0,0206 & 3,9162 & 0,2382 \\
\hline rel_04 & 119 & 0,282 & 0,080 & 0,002 & 0,307 & 0,094 & 0,001 & 0,0645 & 0,0185 & 3,6676 & 0,2348 \\
\hline PAR_M1 & 119 & $-0,173$ & 0,030 & 0,059 & $-0,203$ & 0,041 & 0,027 & $-0,0105$ & 0,0047 & 4,9752 & 0,2299 \\
\hline PAR_M2 & 119 & $-0,402$ & 0,161 & 0,000 & $-0,354$ & 0,125 & 0,000 & $-0,0209$ & 0,0051 & 5,1021 & 0,1607 \\
\hline PAR_M3 & 119 & $-0,312$ & 0,098 & 0,001 & $-0,284$ & 0,080 & 0,002 & $-0,0190$ & 0,0059 & 4,8662 & 0,1321 \\
\hline PAR_M4 & 119 & $-0,489$ & 0,239 & 0,000 & $-0,524$ & 0,275 & 0,000 & $-0,0517$ & 0,0078 & 5,3441 & 0,1376 \\
\hline PAR_B1 & 119 & $-0,401$ & 0,161 & 0,000 & $-0,356$ & 0,126 & 0,000 & $-0,0565$ & 0,0137 & 4,8468 & 0,1022 \\
\hline PAR_B2 & 119 & $-0,463$ & 0,214 & 0,000 & $-0,463$ & 0,215 & 0,000 & $-0,0825$ & 0,0146 & 4,9832 & 0,1005 \\
\hline PAR_B3 & 119 & $-0,471$ & 0,222 & 0,000 & $-0,405$ & 0,164 & 0,000 & $-0,1239$ & 0,0259 & 4,9665 & 0,1128 \\
\hline PAR_B4 & 119 & $-0,649$ & 0,421 & 0,000 & $-0,663$ & 0,439 & 0,000 & $-0,0913$ & 0,0095 & 5,1507 & 0,0799 \\
\hline NDVI_Dauer & 119 & 0,198 & 0,039 & 0,031 & 0,171 & 0,029 & 0,064 & 0,0905 & 0,0484 & 0,5751 & 2,0819 \\
\hline NDVI_B1 & 119 & 0,090 & 0,008 & 0,328 & 0,066 & 0,004 & 0,474 & 0,8778 & 1,2214 & 4,1460 & 0,4553 \\
\hline NDVI_B2 & 119 & $-0,338$ & 0,114 & 0,000 & $-0,315$ & 0,099 & 0,000 & $-4,4383$ & 1,2354 & 5,7359 & 0,3551 \\
\hline NDVI_B3 & 119 & $-0,091$ & 0,008 & 0,324 & $-0,188$ & 0,035 & 0,041 & $-2,3662$ & 1,1444 & 6,0416 & 0,7611 \\
\hline NDVI_B4 & 119 & 0,570 & 0,324 & 0,000 & 0,539 & 0,290 & 0,000 & 20,7545 & 3,0008 & $-10,5362$ & 2,1702 \\
\hline NDVI_A1 & 119 & 0,367 & 0,135 & 0,000 & 0,367 & 0,135 & 0,000 & 12,0096 & 2,8125 & $-3,6897$ & 1,9118 \\
\hline NDVI_A2 & 119 & 0,156 & 0,024 & 0,089 & 0,163 & 0,027 & 0,077 & 3,8741 & 2,1700 & 2,0201 & 1,3739 \\
\hline NDVI_A3 & 119 & 0,349 & 0,122 & 0,000 & 0,304 & 0,093 & 0,001 & 5,3062 & 1,5362 & 1,7650 & 0,7849 \\
\hline NDVI_A4 & 119 & 0,108 & 0,012 & 0,243 & 0,102 & 0,010 & 0,270 & 1,3535 & 1,2205 & 3,9278 & 0,4924 \\
\hline
\end{tabular}




\begin{tabular}{|c|c|c|c|c|c|c|c|c|c|c|c|}
\hline & n & $r_{s}$ & $\mathbf{R}_{\mathrm{s}}^{2}$ & $p_{s}$ & $r_{p}$ & $\mathbf{R}_{\mathrm{p}}^{2}$ & $p_{p}$ & $\mathbf{m}$ & SE_m & b & SE_b \\
\hline NDVI_A5 & 119 & $-0,218$ & 0,048 & 0,017 & $-0,271$ & 0,074 & 0,003 & $-5,4004$ & 1,7718 & 5,8681 & 0,4607 \\
\hline BFI & \multicolumn{11}{|c|}{ nicht ermittelt 2010/11 } \\
\hline KDG_He & \multicolumn{11}{|c|}{ nicht ermittelt 2010/11 } \\
\hline DI_He & 119 & 0,509 & 0,259 & 0,000 & 0,480 & 0,230 & 0,000 & 0,0181 & 0,0031 & 3,6686 & 0,1423 \\
\hline WHD_He & 119 & $-0,237$ & 0,056 & 0,009 & $-0,206$ & 0,043 & 0,024 & $-0,1470$ & 0,0644 & 5,2865 & 0,3606 \\
\hline Blattlae & 119 & 0,003 & 0,000 & 0,971 & $-0,007$ & 0,000 & 0,943 & $-0,0018$ & 0,0256 & 4,4983 & 0,3801 \\
\hline $\mathrm{BpP}$ & 119 & 0,055 & 0,003 & 0,551 & 0,073 & 0,005 & 0,432 & 0,0984 & 0,1248 & 3,9270 & 0,6921 \\
\hline BW_St_Fj & 119 & $-0,117$ & 0,014 & 0,206 & $-0,105$ & 0,011 & 0,254 & $-0,0773$ & 0,0673 & 4,7273 & 0,2284 \\
\hline BH_St_Fj & 119 & $-0,223$ & 0,050 & 0,015 & $-0,198$ & 0,039 & 0,031 & $-0,0072$ & 0,0033 & 5,0979 & 0,2912 \\
\hline BW_Wh_Fj & 119 & $-0,390$ & 0,152 & 0,000 & $-0,363$ & 0,132 & 0,000 & $-0,2240$ & 0,0531 & 5,5595 & 0,2621 \\
\hline BH_Wh_Fj & 119 & $-0,104$ & 0,011 & 0,260 & $-0,054$ & 0,003 & 0,557 & $-0,0049$ & 0,0083 & 4,9484 & 0,8108 \\
\hline BW_He & 119 & $-0,130$ & 0,017 & 0,159 & $-0,154$ & 0,024 & 0,094 & $-0,0582$ & 0,0344 & 4,6124 & 0,0966 \\
\hline BH_He & 119 & $-0,078$ & 0,006 & 0,398 & $-0,091$ & 0,008 & 0,326 & $-0,0028$ & 0,0029 & 4,6794 & 0,2165 \\
\hline BW_Wh_He & 119 & 0,051 & 0,003 & 0,585 & 0,134 & 0,018 & 0,147 & 0,4424 & 0,3032 & 3,9853 & 0,3366 \\
\hline BH_Wh_He & 119 & 0,044 & 0,002 & 0,633 & 0,096 & 0,009 & 0,301 & 0,0154 & 0,0149 & 4,4369 & 0,0590 \\
\hline BH_Kf_Fj & 119 & $-0,199$ & 0,040 & 0,030 & $-0,174$ & 0,030 & 0,059 & $-0,0082$ & 0,0043 & 5,1235 & 0,3455 \\
\hline BH_Kf_He & 119 & 0,060 & 0,004 & 0,517 & $-0,121$ & 0,015 & 0,190 & $-0,0090$ & 0,0068 & 4,4972 & 0,0526 \\
\hline
\end{tabular}

*Erklärung der Parameterabkürzungen: Ertrag = Kornertrag [t/ha]; SBME = Strohbiomasseertrag [t/ha]; OG = Ölgehalt [\%]; OE = Ölertrag [t/ha]; El = Ernteindex [\%]; Di_Fj = Pflanzen/m² im Frühjahr; SpP = Schoten pro Pflanze; TKM = Tausendkornmasse [g]; KpS = Körner pro Schote; Spm2 = Schoten pro $\mathrm{m}^{2} ; \mathrm{KpP}=$ Körner pro Pflanze; Korn_Di = Korndichte; KDG_Fj = Kulturdeckungsgrad [\%] im Frühjahr; WHD_Fj = Wurzelhalsdurchmesser [mm] im Frühjahr; StpP = Seitentriebe pro Pflanze; Hoe_1-4 = Bestandeshöhe [cm] in BBCH 65/67 (1), 67/69 (2), 73/74 (3) und 75 (4); Sah_1-4 = Schotenansatzhöhe [cm] in BBCH 65/67 (1), $67 / 69$ (2), 73/74 (3) und 75 (4); Schi_1-4 = Schotenschichtdicke [cm] in BBCH 65/67 (1), $67 / 69$ (2), 73/74 (3) 
und 75 (4); abs_00-04 = absolute Anzahl der Schoten am Haupttrieb (00), am 1. Seitentrieb (01), am 2. Seitentrieb (02) usw.; rel_00-04 = relativer Anteil der Schoten am Haupttrieb (00), am 1. Seitentrieb (01), am 2. Seitentrieb (02) usw.; PAR_M1-4 = Anteil an photosynthetisch aktiver Strahlung [\%] unter den Schoten in BBCH 63/65 (1), 67/69 (2), 73/74 (3) und 75 (4); PAR_B1-4 = Anteil an photosynthetisch aktiver Strahlung [\%] am Boden in BBCH 63/65 (1), $67 / 69$ (2), 73/74 (3) und 75 (4); NDVI_Dauer = Integration der NDVI-Kurve über den entsprechenden Erhebungszeitraum; NDVI_B1-4 = Grünfärbung des Pflanzenbestandes in BBCH 64/65 (1), 65/66 (2), 69 (3) und 73 (4); NDVI_A1-5 = Grünfärbung des Pflanzenbestandes in BBCH 79 (1), 81 (2), 84 (3), 85/87 (4) und 89 (5); BFI = Blattflächenindex; KDG_He = Kulturdeckungsgrad im Herbst [\%]; DI_He = Pflanzen/m² im Herbst; WHD_He = Wurzelhalsdurchmesser im Herbst $[\mathrm{mm}]$; Blattlae = Blattlänge $[\mathrm{cm}]$; BpP = Blätter pro Pflanze; BW_St_Fj = Befallswert mit der Wurzelhals- und Stängelfäule am unteren Stängel im Frühjahr; BH_St_Fj = Befallshäufigkeit [\%] mit der Wurzelhals- und Stängelfäule am unteren Stängel im Frühjahr; BW_Wh_Fj = Befallswert mit der Wurzelhals- und Stängelfäule am Wurzelhals im Frühjahr; BH_Wh_Fj = Befallshäufigkeit [\%] mit der Wurzelhals- und Stängelfäule am Wurzelhals im Frühjahr; BW_He = Befallswert mit der Wurzelhals- und Stängelfäule an Laubblättern (Blattläsionen) im Herbst; $\mathrm{BH} \_H e=$ Befallshäufigkeit [\%] mit der Wurzelhals- und Stängelfäule an Laubblättern (Blattläsionen) im Herbst; BW_Wh_He = Befallswert mit der Wurzelhals- und Stängelfäule am Wurzelhals im Herbst; $\mathrm{BH} \_W h \_H e=$ Befallshäufigkeit [\%] mit der Wurzelhals- und Stängelfäule am Wurzelhals im Herbst; $\mathrm{BH} \_\mathrm{Kf} \_\mathrm{Fj}=$ Befallshäufigkeit [\%] mit der Kleinen Kohlfliege im Frühjahr; BH_Kf_He = Befallshäufigkeit [\%] mit der Kleinen Kohlfliege im Herbst. 
Tab. 23A: Kennzahlen der einfachen, linearen Regressionsrechnungen, die zwischen allen Parametern und der Zielvariablen Befallswert mit der Wurzelhals- und Stängelfäule am Wurzelhals im Frühjahr (BBCH 83/84) durchgeführt wurden. Die Parameter wurden im Jahr 2010/11, im Feldversuch am Standort Göttingen, untersucht. Dargestellt sind die Anzahl der Werte (n), die in jede Berechnung eingeflossen sind; der Korrelationskoeffizient nach Spearman $\left(r_{s}\right)$ und Pearson $\left(r_{p}\right)$; das Bestimmtheitsmaß nach Spearman $\left(R_{s}{ }^{2}\right)$ und Pearson $\left(R_{p}{ }^{2}\right)$; die Überschreitungswahrscheinlichkeit ( $p$-Wert) für die Spearman-Korrelationen $\left(p_{s}\right)$ und Pearson-Korrelationen $\left(p_{p}\right)$; die Steigung der Regressionsgeraden $(m)$ mit dem dazugehörigen Standardfehler $\left(S E \_m\right)$ und der Schnittpunkt der Regressionsgeraden mit der y-Achse (b) mit dem dazugehörigen Standardfehler (SE_b). Die Kennzahlen zur Steigung der Regressionsgeraden, sowie zum Schnittpunkt mit $y$-Achse ergeben sich aus den Regressionsrechnungen nach Pearson. Korrelationskoeffizienten und Bestimmtheitsmaße sind signifikant bei einem Wert $p \leq 0,05$ (hoch signifikant bei $p \leq 0,01$, höchst signifikant bei $p \leq 0,001$ ). *Erklärung der Parameterabkürzungen: siehe Tabelle 22A

\begin{tabular}{lccccccccccc}
\hline Parameter & $\mathbf{n}$ & $\mathbf{r}_{\mathbf{s}}$ & $\mathbf{R}_{\mathbf{s}}{ }^{*}$ & $\mathbf{p}_{\mathbf{s}}$ & $\mathbf{r}_{\mathbf{p}}$ & $\mathbf{R}_{\mathbf{p}}{ }^{2}$ & $\mathbf{p}_{\mathbf{p}}$ & $\mathbf{m}$ & $\mathbf{S E} \mathbf{m}$ & $\mathbf{b}$ & $\mathbf{S E} \mathbf{b}$ \\
\hline Ertrag & 119 & $-0,390$ & 0,152 & 0,000 & $-0,363$ & 0,132 & 0,000 & $-0,5888$ & 0,1396 & 7,4907 & 0,6288 \\
SBME & 120 & $-0,281$ & 0,079 & 0,002 & $-0,230$ & 0,053 & 0,011 & $-0,2592$ & 0,1009 & 6,3603 & 0,5908 \\
OG & 120 & $-0,109$ & 0,012 & 0,237 & $-0,101$ & 0,010 & 0,272 & $-0,1373$ & 0,1244 & 10,8458 & 5,4274 \\
OE & 119 & $-0,407$ & 0,165 & 0,000 & $-0,369$ & 0,136 & 0,000 & $-1,3519$ & 0,3147 & 7,4957 & 0,6184 \\
EI & 119 & $-0,073$ & 0,005 & 0,433 & $-0,093$ & 0,009 & 0,314 & $-0,0246$ & 0,0243 & 5,8726 & 1,0072 \\
DI_Fj & 120 & $-0,589$ & 0,347 & 0,000 & $-0,572$ & 0,327 & 0,000 & $-0,0345$ & 0,0046 & 6,1114 & 0,1779 \\
SpP & 120 & 0,489 & 0,239 & 0,000 & 0,404 & 0,163 & 0,000 & 0,0044 & 0,0009 & 3,7351 & 0,2449 \\
TKM & 120 & 0,334 & 0,111 & 0,000 & 0,313 & 0,098 & 0,001 & 0,8167 & 0,2284 & 0,3952 & 1,2497 \\
KpS & 120 & 0,221 & 0,049 & 0,015 & 0,197 & 0,039 & 0,031 & 0,0785 & 0,0360 & 3,0716 & 0,8231 \\
Spm2 & 120 & $-0,339$ & 0,115 & 0,000 & $-0,352$ & 0,124 & 0,000 & $-0,0001$ & 0,0000 & 5,8305 & 0,2498 \\
KpP & 120 & 0,478 & 0,228 & 0,000 & 0,400 & 0,160 & 0,000 & 0,0002 & 0,0000 & 3,8835 & 0,2174 \\
Korn_Di & 120 & $-0,259$ & 0,067 & 0,004 & $-0,299$ & 0,090 & 0,001 & 0,0000 & 0,0000 & 5,6605 & 0,2476
\end{tabular}




\begin{tabular}{|c|c|c|c|c|c|c|c|c|c|c|c|}
\hline & $n$ & $r_{s}$ & $\mathbf{R}_{\mathrm{s}}^{2}$ & $p_{s}$ & $r_{p}$ & $\mathbf{R}_{\mathrm{p}}^{2}$ & $p_{p}$ & m & SE_m & b & SE_b \\
\hline KDG_Fj & 120 & $-0,490$ & 0,240 & 0,000 & $-0,497$ & 0,247 & 0,000 & $-0,0328$ & 0,0053 & 6,2798 & 0,2387 \\
\hline WHD_Fj & 119 & 0,576 & 0,332 & 0,000 & 0,547 & 0,299 & 0,000 & 0,2577 & 0,0365 & 1,2209 & 0,5185 \\
\hline StpP & 120 & 0,491 & 0,241 & 0,000 & 0,438 & 0,192 & 0,000 & 0,3002 & 0,0567 & 2,4558 & 0,4589 \\
\hline Hoe_1 & 120 & $-0,018$ & 0,000 & 0,844 & $-0,014$ & 0,000 & 0,882 & $-0,0013$ & 0,0091 & 5,0167 & 1,0817 \\
\hline Hoe_2 & 120 & 0,073 & 0,005 & 0,429 & 0,083 & 0,007 & 0,369 & 0,0084 & 0,0093 & 3,8176 & 1,1535 \\
\hline Hoe_3 & 120 & 0,014 & 0,000 & 0,880 & 0,013 & 0,000 & 0,886 & 0,0013 & 0,0090 & 4,6954 & 1,1245 \\
\hline Hoe_4 & 120 & $-0,104$ & 0,011 & 0,260 & $-0,094$ & 0,009 & 0,307 & $-0,0096$ & 0,0094 & 6,0384 & 1,1559 \\
\hline Sah_1 & 120 & $-0,041$ & 0,002 & 0,660 & $-0,056$ & 0,003 & 0,542 & $-0,0067$ & 0,0109 & 5,3113 & 0,7489 \\
\hline Sah_2 & 120 & 0,046 & 0,002 & 0,619 & 0,031 & 0,001 & 0,739 & 0,0031 & 0,0094 & 4,6381 & 0,6582 \\
\hline Sah_3 & 120 & 0,079 & 0,006 & 0,390 & 0,093 & 0,009 & 0,314 & 0,0096 & 0,0095 & 4,2021 & 0,6515 \\
\hline Sah_4 & 120 & $-0,030$ & 0,001 & 0,741 & $-0,031$ & 0,001 & 0,740 & $-0,0032$ & 0,0097 & 5,0833 & 0,6873 \\
\hline Schi_1 & 120 & 0,059 & 0,003 & 0,523 & 0,065 & 0,004 & 0,477 & 0,0128 & 0,0180 & 4,2090 & 0,9114 \\
\hline Schi_2 & 120 & 0,163 & 0,026 & 0,076 & 0,111 & 0,012 & 0,228 & 0,0240 & 0,0198 & 3,5718 & 1,0633 \\
\hline Schi_3 & 120 & $-0,162$ & 0,026 & 0,078 & $-0,180$ & 0,032 & 0,049 & $-0,0427$ & 0,0214 & 7,2466 & 1,2034 \\
\hline Schi_4 & 120 & $-0,188$ & 0,035 & 0,039 & $-0,174$ & 0,030 & 0,057 & $-0,0480$ & 0,0250 & 7,4067 & 1,3309 \\
\hline abs_00 & 120 & 0,254 & 0,064 & 0,005 & 0,255 & 0,065 & 0,005 & 0,0358 & 0,0125 & 3,5914 & 0,4477 \\
\hline abs_01 & 120 & 0,202 & 0,041 & 0,027 & 0,146 & 0,021 & 0,113 & 0,0145 & 0,0091 & 4,5524 & 0,2055 \\
\hline abs_02 & 120 & 0,204 & 0,042 & 0,025 & 0,172 & 0,030 & 0,060 & 0,0162 & 0,0085 & 4,4420 & 0,2316 \\
\hline abs_03 & 120 & 0,158 & 0,025 & 0,086 & 0,140 & 0,020 & 0,128 & 0,0149 & 0,0097 & 4,4324 & 0,2871 \\
\hline abs_04 & 120 & 0,256 & 0,066 & 0,005 & 0,226 & 0,051 & 0,013 & 0,0233 & 0,0092 & 4,1328 & 0,2969 \\
\hline rel_00 & 120 & $-0,357$ & 0,127 & 0,000 & $-0,284$ & 0,081 & 0,002 & $-0,0599$ & 0,0186 & 5,7394 & 0,2848 \\
\hline
\end{tabular}




\begin{tabular}{|c|c|c|c|c|c|c|c|c|c|c|c|}
\hline & $n$ & $r_{s}$ & $\mathbf{R}_{\mathrm{s}}^{2}$ & $p_{s}$ & $r_{p}$ & $\mathbf{R}_{\mathrm{p}}^{2}$ & $p_{p}$ & m & SE_m & b & SE_b \\
\hline rel_01 & 120 & $-0,198$ & 0,039 & 0,030 & $-0,190$ & 0,036 & 0,037 & $-0,0595$ & 0,0283 & 5,3498 & 0,2469 \\
\hline rel_02 & 120 & $-0,227$ & 0,052 & 0,013 & $-0,235$ & 0,055 & 0,010 & $-0,0773$ & 0,0294 & 5,6398 & 0,3079 \\
\hline rel_03 & 120 & $-0,409$ & 0,168 & 0,000 & $-0,421$ & 0,177 & 0,000 & $-0,1545$ & 0,0306 & 6,6142 & 0,3558 \\
\hline rel_04 & 120 & $-0,327$ & 0,107 & 0,000 & $-0,296$ & 0,088 & 0,001 & $-0,0982$ & 0,0291 & 6,0751 & 0,3692 \\
\hline PAR_M1 & 120 & 0,046 & 0,002 & 0,616 & 0,074 & 0,005 & 0,425 & 0,0062 & 0,0077 & 4,5623 & 0,3754 \\
\hline PAR_M2 & 120 & 0,333 & 0,111 & 0,000 & 0,318 & 0,101 & 0,000 & 0,0303 & 0,0083 & 3,9423 & 0,2615 \\
\hline PAR_M3 & 120 & 0,398 & 0,158 & 0,000 & 0,408 & 0,166 & 0,000 & 0,0440 & 0,0091 & 3,9466 & 0,2009 \\
\hline PAR_M4 & 120 & 0,446 & 0,199 & 0,000 & 0,394 & 0,155 & 0,000 & 0,0630 & 0,0135 & 3,7937 & 0,2396 \\
\hline PAR_B1 & 120 & 0,276 & 0,076 & 0,002 & 0,212 & 0,045 & 0,020 & 0,0546 & 0,0231 & 4,4944 & 0,1716 \\
\hline PAR_B2 & 120 & 0,469 & 0,220 & 0,000 & 0,397 & 0,158 & 0,000 & 0,1144 & 0,0243 & 4,1486 & 0,1671 \\
\hline PAR_B3 & 120 & 0,404 & 0,164 & 0,000 & 0,361 & 0,131 & 0,000 & 0,1787 & 0,0424 & 4,1446 & 0,1844 \\
\hline PAR_B4 & 120 & 0,575 & 0,330 & 0,000 & 0,462 & 0,213 & 0,000 & 0,1030 & 0,0182 & 4,0917 & 0,1522 \\
\hline NDVI_Dauer & 120 & $-0,052$ & 0,003 & 0,573 & $-0,060$ & 0,004 & 0,512 & $-0,0520$ & 0,0791 & 7,0945 & 3,4055 \\
\hline NDVI_B1 & 120 & $-0,184$ & 0,034 & 0,045 & $-0,161$ & 0,026 & 0,079 & $-3,4524$ & 1,9510 & 6,1356 & 0,7271 \\
\hline NDVI_B2 & 120 & 0,450 & 0,203 & 0,000 & 0,426 & 0,181 & 0,000 & 9,5945 & 1,8767 & 2,1171 & 0,5405 \\
\hline NDVI_B3 & 120 & 0,217 & 0,047 & 0,017 & 0,283 & 0,080 & 0,002 & 5,7040 & 1,7825 & 1,0672 & 1,1865 \\
\hline NDVI_B4 & 120 & $-0,477$ & 0,228 & 0,000 & $-0,464$ & 0,215 & 0,000 & $-28,9861$ & 5,0950 & 25,8158 & 3,6848 \\
\hline NDVI_A1 & 120 & $-0,192$ & 0,037 & 0,035 & $-0,232$ & 0,054 & 0,011 & $-12,1461$ & 4,6830 & 13,1070 & 3,1820 \\
\hline NDVI_A2 & 120 & $-0,077$ & 0,006 & 0,403 & $-0,093$ & 0,009 & 0,313 & $-3,5550$ & 3,5107 & 7,1047 & 2,2218 \\
\hline NDVI_A3 & 120 & $-0,219$ & 0,048 & 0,016 & $-0,196$ & 0,038 & 0,032 & $-5,5342$ & 2,5474 & 7,6778 & 1,3010 \\
\hline NDVI_A4 & 120 & $-0,092$ & 0,008 & 0,317 & $-0,096$ & 0,009 & 0,298 & $-2,0617$ & 1,9718 & 5,6839 & 0,7954 \\
\hline
\end{tabular}




\begin{tabular}{|c|c|c|c|c|c|c|c|c|c|c|c|}
\hline & $\mathbf{n}$ & $\mathbf{r}_{\mathrm{s}}$ & $\mathbf{R}_{\mathrm{s}}^{2}$ & $p_{s}$ & $\mathbf{r}_{\mathrm{p}}$ & $\mathbf{R}_{\mathrm{p}}^{2}$ & $p_{p}$ & m & SE_m & b & SE_b \\
\hline NDVI_A5 & 120 & 0,270 & 0,073 & 0,003 & 0,232 & 0,054 & 0,011 & 7,4971 & 2,8901 & 2,9167 & 0,7517 \\
\hline BFI & \multicolumn{11}{|c|}{ nicht ermittelt 2010/11 } \\
\hline KDG_He & \multicolumn{11}{|c|}{ nicht ermittelt 2010/11 } \\
\hline DI_He & 120 & $-0,582$ & 0,339 & 0,000 & $-0,544$ & 0,296 & 0,000 & $-0,0332$ & 0,0047 & 6,3325 & 0,2197 \\
\hline WHD_He & 120 & 0,055 & 0,003 & 0,551 & 0,080 & 0,006 & 0,385 & 0,0923 & 0,1059 & 4,3439 & 0,5929 \\
\hline Blattlae & 120 & $-0,010$ & 0,000 & 0,914 & 0,028 & 0,001 & 0,764 & 0,0123 & 0,0408 & 4,6745 & 0,6081 \\
\hline $\mathrm{BpP}$ & 120 & $-0,153$ & 0,023 & 0,096 & $-0,143$ & 0,021 & 0,118 & $-0,3076$ & 0,1956 & 6,5598 & 1,0860 \\
\hline BW_St_Fj & 120 & 0,464 & 0,215 & 0,000 & 0,495 & 0,245 & 0,000 & 0,5871 & 0,0949 & 2,9092 & 0,3222 \\
\hline BH_St_Fj & 120 & 0,485 & 0,235 & 0,000 & 0,571 & 0,326 & 0,000 & 0,0337 & 0,0045 & 1,9264 & 0,3935 \\
\hline BH_Wh_Fj & 120 & 0,523 & 0,273 & 0,000 & 0,544 & 0,295 & 0,000 & 0,0789 & 0,0112 & $-2,8684$ & 1,1002 \\
\hline BW_He & 120 & 0,291 & 0,085 & 0,001 & 0,304 & 0,092 & 0,001 & 0,1779 & 0,0514 & 4,4183 & 0,1472 \\
\hline BH_He & 120 & 0,239 & 0,057 & 0,009 & 0,263 & 0,069 & 0,004 & 0,0132 & 0,0044 & 3,8874 & 0,3365 \\
\hline BW_Wh_He & 120 & $-0,057$ & 0,003 & 0,535 & $-0,129$ & 0,017 & 0,160 & $-0,6919$ & 0,4891 & 5,6157 & 0,5425 \\
\hline BH_Wh_He & 120 & $-0,025$ & 0,001 & 0,789 & $-0,074$ & 0,006 & 0,419 & $-0,0195$ & 0,0240 & 4,8994 & 0,0949 \\
\hline BH_Kf_Fj & 120 & 0,316 & 0,100 & 0,000 & 0,305 & 0,093 & 0,001 & 0,0233 & 0,0067 & 3,0001 & 0,5386 \\
\hline BH_Kf_He & 120 & 0,049 & 0,002 & 0,595 & 0,065 & 0,004 & 0,477 & 0,0079 & 0,0110 & 4,8338 & 0,0849 \\
\hline
\end{tabular}


Tab. 24A: Kennzahlen der einfachen, linearen Regressionsrechnungen, die zwischen allen Parametern und der Zielvariablen Kornertrag durchgeführt wurden. Die Parameter wurden im Jahr 2012/13, im Feldversuch am Standort Göttingen, untersucht. Dargestellt sind die Anzahl der Werte (n), die in jede Berechnung eingeflossen sind; der Korrelationskoeffizient nach Spearman $\left(r_{s}\right)$ und Pearson $\left(r_{p}\right)$; das Bestimmtheitsmaß nach Spearman $\left(R_{s}{ }^{2}\right)$ und Pearson $\left(R_{p}{ }^{2}\right)$; die Überschreitungswahrscheinlichkeit ( $p$-Wert) für die Spearman-Korrelationen $\left(p_{s}\right)$ und Pearson-Korrelationen $\left(p_{p}\right)$; die Steigung der Regressionsgeraden $(\mathrm{m})$ mit dem dazugehörigen Standardfehler (SE_m) und der Schnittpunkt der Regressionsgeraden mit der y-Achse (b) mit dem dazugehörigen Standardfehler (SE_b). Die Kennzahlen zur Steigung der Regressionsgeraden, sowie zum Schnittpunkt mit y-Achse ergeben sich aus den Regressionsrechnungen nach Pearson. Korrelationskoeffizienten und Bestimmtheitsmaße sind signifikant bei einem Wert $p \leq 0,05$ (hoch signifikant bei $p \leq$ $0,01$, höchst signifikant bei $p \leq 0,001)$. *Erklärung der Parameterabkürzungen: siehe Tabelle $22 \mathrm{~A}$

\begin{tabular}{lccccccccccc}
\hline Parameter $^{*}$ & $\mathbf{n}$ & $\mathbf{r}_{\mathbf{s}}$ & $\mathbf{R}_{\mathbf{s}}{ }^{2}$ & $\mathbf{p}_{\mathbf{s}}$ & $\mathbf{r}_{\mathbf{p}}$ & $\mathbf{R}_{\mathbf{p}}{ }^{2}$ & $\mathbf{p}_{\mathbf{p}}$ & $\mathbf{m}$ & $\mathbf{S E} \mathbf{m}$ & $\mathbf{b}$ & $\mathbf{S E} \mathbf{b}$ \\
\hline SBME & 124 & 0,632 & 0,400 & 0,000 & 0,627 & 0,393 & 0,000 & 0,3683 & 0,0415 & 3,3855 & 0,2484 \\
OG & 124 & 0,089 & 0,008 & 0,325 & 0,085 & 0,007 & 0,346 & 0,0396 & 0,0418 & 3,8835 & 1,7898 \\
OE & 124 & 0,963 & 0,927 & 0,000 & 0,964 & 0,929 & 0,000 & 2,1108 & 0,0528 & 0,5393 & 0,1263 \\
EI & 124 & $-0,012$ & 0,000 & 0,892 & 0,010 & 0,000 & 0,912 & 0,0018 & 0,0167 & 5,4905 & 0,7735 \\
DI_Fj & 124 & 0,236 & 0,056 & 0,008 & 0,215 & 0,046 & 0,017 & 0,0070 & 0,0029 & 5,2892 & 0,1238 \\
SpP & 123 & $-0,156$ & 0,024 & 0,085 & $-0,211$ & 0,044 & 0,019 & $-0,0014$ & 0,0006 & 5,8175 & 0,1101 \\
TKM & 124 & 0,217 & 0,047 & 0,016 & 0,198 & 0,039 & 0,028 & 0,3060 & 0,1374 & 4,2243 & 0,6079 \\
KpS & 124 & 0,048 & 0,002 & 0,598 & 0,084 & 0,007 & 0,353 & 0,0187 & 0,0200 & 5,1234 & 0,4868 \\
Spm2 & 123 & 0,111 & 0,012 & 0,220 & 0,081 & 0,007 & 0,370 & 0,0000 & 0,0000 & 5,4393 & 0,1531 \\
KpP & 124 & $-0,117$ & 0,014 & 0,197 & $-0,145$ & 0,021 & 0,108 & 0,0000 & 0,0000 & 5,7304 & 0,1028 \\
Korn_Di & 124 & 0,132 & 0,017 & 0,144 & 0,100 & 0,010 & 0,269 & 0,0000 & 0,0000 & 5,4185 & 0,1467 \\
KDG_Fj & 124 & 0,323 & 0,104 & 0,000 & 0,345 & 0,119 & 0,000 & 0,0178 & 0,0044 & 4,5769 & 0,2484 \\
WHD_Fj & 124 & $-0,057$ & 0,003 & 0,531 & $-0,068$ & 0,005 & 0,450 & $-0,0173$ & 0,0229 & 5,7986 & 0,2964 \\
& & & & & & & & & & & \\
\hline
\end{tabular}




\begin{tabular}{|c|c|c|c|c|c|c|c|c|c|c|c|}
\hline & $\mathbf{n}$ & $r_{s}$ & $\mathbf{R}_{\mathrm{s}}{ }^{2}$ & $p_{s}$ & $r_{p}$ & $\mathbf{R}_{\mathbf{p}}^{2}$ & $p_{p}$ & m & SE_m & b & SE_b \\
\hline StpP & 124 & $-0,229$ & 0,052 & 0,011 & $-0,225$ & 0,051 & 0,012 & $-0,0684$ & 0,0268 & 6,0536 & 0,1908 \\
\hline Hoe_1 & 124 & 0,434 & 0,188 & 0,000 & 0,494 & 0,244 & 0,000 & 0,0135 & 0,0022 & 3,8062 & 0,2841 \\
\hline Hoe_2 & 124 & 0,430 & 0,185 & 0,000 & 0,492 & 0,242 & 0,000 & 0,0136 & 0,0022 & 3,7552 & 0,2933 \\
\hline Hoe_3 & 124 & 0,407 & 0,165 & 0,000 & 0,475 & 0,225 & 0,000 & 0,0128 & 0,0022 & 3,8481 & 0,2921 \\
\hline Hoe_4 & 124 & 0,381 & 0,145 & 0,000 & 0,448 & 0,201 & 0,000 & 0,0119 & 0,0022 & 3,9907 & 0,2883 \\
\hline Sah_1 & 124 & 0,474 & 0,225 & 0,000 & 0,527 & 0,277 & 0,000 & 0,0150 & 0,0022 & 4,3510 & 0,1820 \\
\hline Sah_2 & 124 & 0,484 & 0,234 & 0,000 & 0,536 & 0,287 & 0,000 & 0,0151 & 0,0022 & 4,3122 & 0,1830 \\
\hline Sah_3 & 124 & 0,485 & 0,235 & 0,000 & 0,546 & 0,298 & 0,000 & 0,0155 & 0,0022 & 4,2511 & 0,1867 \\
\hline Sah_4 & 124 & 0,485 & 0,235 & 0,000 & 0,547 & 0,299 & 0,000 & 0,0155 & 0,0022 & 4,2491 & 0,1865 \\
\hline Schi_1 & 124 & $-0,057$ & 0,003 & 0,527 & $-0,066$ & 0,004 & 0,468 & $-0,0084$ & 0,0116 & 5,9887 & 0,5688 \\
\hline Schi_2 & 124 & $-0,139$ & 0,019 & 0,124 & $-0,158$ & 0,025 & 0,079 & $-0,0211$ & 0,0119 & 6,6409 & 0,6022 \\
\hline Schi_3 & 124 & $-0,186$ & 0,034 & 0,039 & $-0,194$ & 0,037 & 0,031 & $-0,0229$ & 0,0105 & 6,7091 & 0,5214 \\
\hline Schi_4 & 124 & $-0,244$ & 0,060 & 0,006 & $-0,244$ & 0,059 & 0,006 & $-0,0247$ & 0,0089 & 6,7526 & 0,4256 \\
\hline abs_00 & 124 & $-0,181$ & 0,033 & 0,044 & $-0,167$ & 0,028 & 0,063 & $-0,0149$ & 0,0080 & 6,1916 & 0,3309 \\
\hline abs_01 & 124 & 0,079 & 0,006 & 0,383 & 0,080 & 0,006 & 0,376 & 0,0100 & 0,0112 & 5,4022 & 0,1990 \\
\hline abs_02 & 124 & 0,021 & 0,000 & 0,820 & 0,060 & 0,004 & 0,508 & 0,0052 & 0,0078 & 5,4706 & 0,1631 \\
\hline abs_03 & 124 & $-0,044$ & 0,002 & 0,630 & $-0,021$ & 0,000 & 0,821 & $-0,0013$ & 0,0057 & 5,6040 & 0,1301 \\
\hline abs_04 & 124 & $-0,053$ & 0,003 & 0,557 & $-0,013$ & 0,000 & 0,888 & $-0,0007$ & 0,0048 & 5,5897 & 0,1052 \\
\hline rel_00 & 124 & 0,090 & 0,008 & 0,319 & 0,065 & 0,004 & 0,477 & 0,0037 & 0,0052 & 5,4802 & 0,1393 \\
\hline rel_01 & 124 & 0,299 & 0,090 & 0,001 & 0,295 & 0,087 & 0,001 & 0,0544 & 0,0160 & 5,0043 & 0,1716 \\
\hline rel_02 & 124 & 0,333 & 0,111 & 0,000 & 0,349 & 0,121 & 0,000 & 0,0680 & 0,0165 & 4,7524 & 0,2037 \\
\hline
\end{tabular}




\begin{tabular}{|c|c|c|c|c|c|c|c|c|c|c|c|}
\hline & $\mathbf{n}$ & $r_{s}$ & $\mathbf{R}_{\mathrm{s}}{ }^{2}$ & $p_{s}$ & $r_{p}$ & $\mathbf{R}_{\mathbf{p}}^{2}$ & $p_{p}$ & m & SE_m & b & SE_b \\
\hline rel_03 & 124 & 0,337 & 0,113 & 0,000 & 0,341 & 0,116 & 0,000 & 0,0774 & 0,0193 & 4,5939 & 0,2477 \\
\hline rel_04 & 124 & 0,269 & 0,072 & 0,003 & 0,281 & 0,079 & 0,002 & 0,0616 & 0,0191 & 4,8744 & 0,2203 \\
\hline PAR_M1 & 124 & $-0,196$ & 0,038 & 0,029 & $-0,213$ & 0,045 & 0,018 & $-0,0192$ & 0,0080 & 5,8781 & 0,1312 \\
\hline PAR_M2 & 124 & $-0,181$ & 0,033 & 0,044 & $-0,220$ & 0,048 & 0,014 & $-0,0113$ & 0,0045 & 5,7557 & 0,0815 \\
\hline PAR_M3 & 124 & $-0,185$ & 0,034 & 0,039 & $-0,187$ & 0,035 & 0,037 & $-0,0274$ & 0,0130 & 5,8224 & 0,1231 \\
\hline PAR_M4 & 124 & $-0,142$ & 0,020 & 0,115 & $-0,141$ & 0,020 & 0,119 & $-0,0193$ & 0,0123 & 5,7291 & 0,1048 \\
\hline PAR_B1 & 124 & $-0,207$ & 0,043 & 0,021 & $-0,272$ & 0,074 & 0,002 & $-0,2082$ & 0,0667 & 5,8437 & 0,0936 \\
\hline PAR_B2 & 124 & $-0,117$ & 0,014 & 0,194 & $-0,145$ & 0,021 & 0,109 & $-0,0406$ & 0,0251 & 5,6701 & 0,0698 \\
\hline PAR_B3 & 124 & $-0,298$ & 0,089 & 0,001 & $-0,255$ & 0,065 & 0,004 & $-0,1708$ & 0,0586 & 5,8542 & 0,1026 \\
\hline PAR_B4 & 124 & $-0,151$ & 0,023 & 0,094 & $-0,133$ & 0,018 & 0,140 & $-0,0514$ & 0,0346 & 5,6878 & 0,0847 \\
\hline NDVI_Dauer & 124 & $-0,218$ & 0,048 & 0,015 & $-0,209$ & 0,043 & 0,020 & $-0,0544$ & 0,0231 & 8,5851 & 1,2783 \\
\hline NDVI_B1 & 124 & $-0,329$ & 0,108 & 0,000 & $-0,367$ & 0,135 & 0,000 & $-3,5283$ & 0,8084 & 6,8941 & 0,3042 \\
\hline NDVI_B2 & 124 & $-0,050$ & 0,003 & 0,580 & $-0,043$ & 0,002 & 0,638 & $-0,4113$ & 0,8714 & 5,7455 & 0,3616 \\
\hline NDVI_B3 & 124 & 0,175 & 0,031 & 0,052 & 0,183 & 0,034 & 0,042 & 2,8052 & 1,3634 & 3,4876 & 1,0156 \\
\hline NDVI_B4 & 124 & 0,049 & 0,002 & 0,591 & 0,117 & 0,014 & 0,196 & 4,6453 & 3,5696 & 1,8921 & 2,8310 \\
\hline NDVI_A1 & 124 & $-0,369$ & 0,136 & 0,000 & $-0,337$ & 0,114 & 0,000 & $-6,4410$ & 1,6281 & 10,5081 & 1,2473 \\
\hline NDVI_A2 & 124 & $-0,280$ & 0,079 & 0,002 & $-0,279$ & 0,078 & 0,002 & $-3,7994$ & 1,1859 & 8,0573 & 0,7754 \\
\hline NDVI_A3 & 124 & $-0,223$ & 0,050 & 0,013 & $-0,221$ & 0,049 & 0,014 & $-2,4877$ & 0,9951 & 6,7665 & 0,4778 \\
\hline NDVI_A4 & 124 & $-0,121$ & 0,015 & 0,179 & $-0,083$ & 0,007 & 0,359 & $-0,8466$ & 0,9198 & 5,8757 & 0,3280 \\
\hline NDVI_A5 & 124 & $-0,042$ & 0,002 & 0,645 & $-0,001$ & 0,000 & 0,989 & $-0,0112$ & 0,8356 & 5,5793 & 0,2616 \\
\hline BFI & 60 & 0,373 & 0,139 & 0,003 & 0,438 & 0,192 & 0,000 & 0,4591 & 0,1237 & 5,1192 & 0,1323 \\
\hline
\end{tabular}




\begin{tabular}{lccccccccccc}
\hline & $\mathbf{n}$ & $\mathbf{r}_{\mathbf{s}}$ & $\mathbf{R}_{\mathbf{s}}{ }^{2}$ & $\mathbf{p}_{\mathbf{s}}$ & $\mathbf{r}_{\mathbf{p}}$ & $\mathbf{R}_{\mathbf{p}}{ }^{2}$ & $\mathbf{p}_{\mathbf{p}}$ & $\mathbf{m}$ & $\mathbf{S E} \mathbf{m}$ & $\mathbf{b}$ & $\mathbf{S E} \mathbf{b}$ \\
KDG_He & 124 & 0,268 & 0,072 & 0,003 & 0,293 & 0,086 & 0,001 & 0,0159 & 0,0047 & 4,9288 & 0,1945 \\
DI_He & 124 & 0,165 & 0,027 & 0,067 & 0,132 & 0,017 & 0,145 & 0,0035 & 0,0024 & 5,4101 & 0,1193 \\
WHD_He & 124 & $-0,141$ & 0,020 & 0,119 & $-0,109$ & 0,012 & 0,227 & $-0,0508$ & 0,0419 & 5,8979 & 0,2683 \\
SprLae & 124 & 0,114 & 0,013 & 0,207 & 0,127 & 0,016 & 0,159 & 0,0236 & 0,0167 & 5,1646 & 0,2929 \\
BpP & 124 & $-0,028$ & 0,001 & 0,753 & $-0,020$ & 0,000 & 0,829 & $-0,0108$ & 0,0499 & 5,6543 & 0,3655 \\
BW_St_Fj & 124 & 0,233 & 0,055 & 0,009 & 0,251 & 0,063 & 0,005 & 0,5058 & 0,1766 & 4,9348 & 0,2269 \\
BH_St_Fj & 124 & 0,231 & 0,053 & 0,010 & 0,240 & 0,058 & 0,007 & 0,0097 & 0,0035 & 5,4345 & 0,0638 \\
BW_Wh_Fj & 124 & 0,206 & 0,042 & 0,022 & 0,170 & 0,029 & 0,058 & 0,2109 & 0,1103 & 5,2247 & 0,1876 \\
BH_Wh_Fj & 124 & 0,187 & 0,035 & 0,038 & 0,161 & 0,026 & 0,073 & 0,0055 & 0,0031 & 5,3953 & 0,1070 \\
BW_He & 124 & 0,226 & 0,051 & 0,012 & 0,244 & 0,059 & 0,006 & 0,6949 & 0,2504 & 5,5081 & 0,0447 \\
BH_He & 124 & 0,225 & 0,051 & 0,012 & 0,251 & 0,063 & 0,005 & 0,0108 & 0,0038 & 5,4984 & 0,0462 \\
BW_Wh_He & 124 & $-0,069$ & 0,005 & 0,446 & $-0,045$ & 0,002 & 0,617 & $-0,6696$ & 1,3366 & 6,2504 & 1,3471 \\
BH_Wh_He & 124 & $-0,077$ & 0,006 & 0,397 & $-0,150$ & 0,022 & 0,097 & $-0,0380$ & 0,0227 & 5,5954 & 0,0400 \\
BH_Kf_Fj & 124 & $-0,087$ & 0,008 & 0,339 & $-0,094$ & 0,009 & 0,297 & $-0,0036$ & 0,0035 & 5,8195 & 0,2360 \\
BH_Kf_He & n.e. & & & & & & & & &
\end{tabular}


Tab. 25A: Varianzanalyse zu allen Parametern, die in den Jahren 2010/11 und 2012/13 im Feldversuch am Standort Göttingen untersucht wurden (Typ 3 Tests der festen Effekte, SAS „proc mixed“, ausgewertet als Spalt-Spalt-Anlage, Details siehe Material und Methoden). Dargestellt sind die Effekte der drei Versuchsfaktoren Sorte (So), Saatstärke (Di) und Fungizid (Fu) und die daraus resultierenden Interaktionen getrennt nach Jahren. Effekte sind signifikant bei einem Wert $p \leq 0,05$ (hoch signifikant bei $p \leq 0,01$, höchst signifikant bei $p \leq 0,001$ ). Signifikante Effekte sind fett hervorgehoben. $\mathrm{FG}=$ Freiheitsgrade; $\mathrm{BI}=$ Block

\begin{tabular}{|c|c|c|c|c|c|c|c|c|c|}
\hline \multirow[b]{2}{*}{ Parameter } & \multicolumn{5}{|c|}{ 2010/11 } & \multicolumn{4}{|c|}{ 2012/13 } \\
\hline & Effekt & $\begin{array}{c}\text { FG- } \\
\text { Zähler }\end{array}$ & $\begin{array}{c}\text { FG- } \\
\text { Nenner }\end{array}$ & F-Wert & $\begin{array}{c}\text { p- } \\
\text { Wert }\end{array}$ & $\begin{array}{c}\text { FG- } \\
\text { Zähler }\end{array}$ & $\begin{array}{c}\text { FG- } \\
\text { Nenner }\end{array}$ & $\begin{array}{c}\text { F- } \\
\text { Wert }\end{array}$ & $\begin{array}{c}p- \\
\text { Wert }\end{array}$ \\
\hline \multirow[t]{8}{*}{ Kornertrag [t/ha] } & So & 1 & 3 & 1,43 & 0,318 & 1 & 3 & 0,09 & 0,783 \\
\hline & $\mathrm{Di}$ & 1 & 6 & 23,69 & 0,003 & 1 & 6 & 2,40 & 0,172 \\
\hline & So*Di & 1 & 6 & 6,83 & 0,040 & 1 & 6 & 1,46 & 0,272 \\
\hline & $\mathrm{Fu}$ & 7 & 75 & 2,67 & 0,016 & 7 & 80 & 16,05 & 0,000 \\
\hline & So*Fu & 7 & 75 & 0,95 & 0,472 & 7 & 80 & 2,06 & 0,057 \\
\hline & $\mathrm{Di}{ }^{\star} \mathrm{Fu}$ & 7 & 75 & 0,77 & 0,617 & 7 & 80 & 1,91 & 0,079 \\
\hline & $\begin{array}{c}\text { So }^{*} \mathrm{Di}^{*} \mathrm{~F} \\
\mathrm{u}\end{array}$ & 7 & 75 & 0,47 & 0,856 & 7 & 80 & 1,24 & 0,292 \\
\hline & $\mathrm{BI}$ & 3 & 3 & 0,25 & 0,858 & 3 & 3 & 0,56 & 0,678 \\
\hline \multirow[t]{8}{*}{$\begin{array}{l}\text { Strohbiomasse- } \\
\text { ertrag [t/ha] }\end{array}$} & So & 1 & 3 & 0,89 & 0,415 & 1 & 3 & 0,01 & 0,917 \\
\hline & $\mathrm{Di}$ & 1 & 6 & 9,16 & 0,023 & 1 & 6 & 1,93 & 0,215 \\
\hline & So*Di & 1 & 6 & 1,64 & 0,247 & 1 & 6 & 0,04 & 0,850 \\
\hline & $\mathrm{Fu}$ & 7 & 76 & 3,07 & 0,007 & 7 & 80 & 6,77 & 0,000 \\
\hline & So*Fu & 7 & 76 & 0,37 & 0,919 & 7 & 80 & 1,31 & 0,257 \\
\hline & $\mathrm{Di}^{*} \mathrm{Fu}$ & 7 & 76 & 1,35 & 0,240 & 7 & 80 & 1,09 & 0,380 \\
\hline & $\begin{array}{c}\text { So }^{*} \mathrm{Di}^{*} \mathrm{~F} \\
\mathrm{u}\end{array}$ & 7 & 76 & 1,05 & 0,404 & 7 & 80 & 0,45 & 0,867 \\
\hline & $\mathrm{BI}$ & 3 & 3 & 2,33 & 0,253 & 3 & 3 & 1,75 & 0,328 \\
\hline \multirow[t]{8}{*}{ Ölgehalt [\%] } & So & 1 & 3 & 19,07 & 0,022 & 1 & 3 & 14,11 & 0,033 \\
\hline & $\mathrm{Di}$ & 1 & 6 & 18,67 & 0,005 & 1 & 6 & 13,55 & 0,010 \\
\hline & So* ${ }^{*} \mathrm{i}$ & 1 & 6 & 0,14 & 0,719 & 1 & 6 & 1,19 & 0,318 \\
\hline & $\mathrm{Fu}$ & 7 & 76 & 0,78 & 0,603 & 7 & 80 & 2,65 & 0,016 \\
\hline & So*Fu & 7 & 76 & 0,36 & 0,920 & 7 & 80 & 0,12 & 0,997 \\
\hline & $\mathrm{Di}^{*} \mathrm{Fu}$ & 7 & 76 & 1,10 & 0,373 & 7 & 80 & 0,82 & 0,577 \\
\hline & $\begin{array}{c}\text { So }^{*} \mathrm{Di}^{*} \mathrm{~F} \\
\mathrm{u}\end{array}$ & 7 & 76 & 0,60 & 0,753 & 7 & 80 & 0,40 & 0,899 \\
\hline & $\mathrm{BI}$ & 3 & 3 & 0,18 & 0,906 & 3 & 3 & 1,46 & 0,382 \\
\hline \multirow[t]{8}{*}{ Ölertrag [t/ha] } & So & 1 & 3 & 0,15 & 0,726 & 1 & 3 & 1,64 & 0,290 \\
\hline & $\mathrm{Di}$ & 1 & 6 & 29,33 & 0,002 & 1 & 6 & 0,91 & 0,376 \\
\hline & So*Di & 1 & 6 & 7,34 & 0,035 & 1 & 6 & 1,58 & 0,256 \\
\hline & $\mathrm{Fu}$ & 7 & 75 & 2,55 & 0,021 & 7 & 80 & 20,01 & 0,000 \\
\hline & So*Fu & 7 & 75 & 0,97 & 0,460 & 7 & 80 & 2,25 & 0,038 \\
\hline & $\mathrm{Di}{ }^{\star} \mathrm{Fu}$ & 7 & 75 & 0,72 & 0,654 & 7 & 80 & 2,26 & 0,038 \\
\hline & $\begin{array}{c}\text { So }^{*} \mathrm{Di}^{*} \mathrm{~F} \\
\mathrm{u}\end{array}$ & 7 & 75 & 0,48 & 0,844 & 7 & 80 & 1,23 & 0,296 \\
\hline & $\mathrm{Bl}$ & 3 & 3 & 0,22 & 0,874 & 3 & 3 & 0,15 & 0,925 \\
\hline
\end{tabular}




\begin{tabular}{|c|c|c|c|c|c|c|c|c|c|}
\hline \multirow[t]{8}{*}{ Ernteindex [\%] } & So & 1 & 3 & 3,23 & 0,170 & 1 & 3 & 0,04 & 0,854 \\
\hline & $\mathrm{Di}$ & 1 & 6 & 2,43 & 0,170 & 1 & 6 & 0,01 & 0,935 \\
\hline & So*Di & 1 & 6 & 1,71 & 0,239 & 1 & 6 & 1,25 & 0,305 \\
\hline & $\mathrm{Fu}$ & 7 & 75 & 2,41 & 0,028 & 7 & 80 & 1,67 & 0,128 \\
\hline & So*Fu & 7 & 75 & 0,61 & 0,743 & 7 & 80 & 1,19 & 0,316 \\
\hline & $\mathrm{Di}^{\star} \mathrm{Fu}$ & 7 & 75 & 1,16 & 0,337 & 7 & 80 & 1,42 & 0,209 \\
\hline & $\begin{array}{c}\text { So }^{*} \mathrm{Di}^{*} \mathrm{~F} \\
\mathrm{u}\end{array}$ & 7 & 75 & 0,68 & 0,690 & 7 & 80 & 1,27 & 0,277 \\
\hline & $\mathrm{BI}$ & 3 & 3 & 1,76 & 0,327 & 3 & 3 & 2,28 & 0,258 \\
\hline Pflanzen $/ \mathrm{m}^{2}$ & So & 1 & 3 & 89,17 & 0,003 & 1 & 3 & 0,06 & 0,825 \\
\hline \multirow[t]{7}{*}{ im Frühjahr } & $\mathrm{Di}$ & 1 & 6 & 493,42 & 0,000 & 1 & 6 & $\begin{array}{c}173,1 \\
0\end{array}$ & 0,000 \\
\hline & So* $\mathrm{Di}$ & 1 & 6 & 0,11 & 0,753 & 1 & 6 & 6,17 & 0,048 \\
\hline & $\mathrm{Fu}$ & 7 & 84 & 2,12 & 0,051 & 7 & 80 & 1,18 & 0,324 \\
\hline & So*Fu & 7 & 84 & 0,65 & 0,713 & 7 & 80 & 1,43 & 0,204 \\
\hline & $\mathrm{Di}^{\star} \mathrm{Fu}$ & 7 & 84 & 1,12 & 0,361 & 7 & 80 & 0,58 & 0,770 \\
\hline & $\begin{array}{c}\text { So }^{*} \mathrm{Di}^{*} \mathrm{~F} \\
\mathrm{u}\end{array}$ & 7 & 84 & 0,12 & 0,997 & 7 & 80 & 1,70 & 0,120 \\
\hline & $\mathrm{BI}$ & 3 & 3 & 4,12 & 0,138 & 3 & 3 & 0,77 & 0,582 \\
\hline \multirow[t]{8}{*}{ Schoten/Pflanze } & So & 1 & 3 & 9,96 & 0,051 & 1 & 3 & 0,00 & 0,964 \\
\hline & $\mathrm{Di}$ & 1 & 6 & 114,75 & 0,000 & 1 & 6 & 31,05 & 0,001 \\
\hline & So* Di & 1 & 6 & 17,04 & 0,006 & 1 & 6 & 0,13 & 0,727 \\
\hline & $\mathrm{Fu}$ & 7 & 76 & 1,93 & 0,077 & 7 & 79 & 1,08 & 0,387 \\
\hline & So*Fu & 7 & 76 & 0,69 & 0,682 & 7 & 79 & 1,40 & 0,218 \\
\hline & $\mathrm{Di}^{\star} \mathrm{Fu}$ & 7 & 76 & 1,44 & 0,200 & 7 & 79 & 1,18 & 0,322 \\
\hline & $\begin{array}{c}\text { So }^{*} \mathrm{Di}^{*} \mathrm{~F} \\
\mathrm{u}\end{array}$ & 7 & 76 & 0,97 & 0,458 & 7 & 79 & 1,94 & 0,074 \\
\hline & $\mathrm{BI}$ & 3 & 3 & 1,01 & 0,496 & 3 & 3 & 1,92 & 0,303 \\
\hline \multirow[t]{8}{*}{ Körner/Schote } & So & 1 & 3 & 6,98 & 0,078 & 1 & 3 & 0,01 & 0,918 \\
\hline & $\mathrm{Di}$ & 1 & 6 & 11,65 & 0,014 & 1 & 6 & 0,89 & 0,382 \\
\hline & So*Di & 1 & 6 & 0,72 & 0,429 & 1 & 6 & 0,22 & 0,655 \\
\hline & $\mathrm{Fu}$ & 7 & 76 & 1,82 & 0,095 & 7 & 80 & 2,23 & 0,040 \\
\hline & So*Fu & 7 & 76 & 0,90 & 0,515 & 7 & 80 & 0,90 & 0,514 \\
\hline & $\mathrm{Di}{ }^{*} \mathrm{Fu}$ & 7 & 76 & 2,85 & 0,011 & 7 & 80 & 0,94 & 0,477 \\
\hline & $\begin{array}{c}\text { So }^{*} \mathrm{Di}^{*} \mathrm{~F} \\
\mathrm{u}\end{array}$ & 7 & 76 & 0,83 & 0,564 & 7 & 80 & 1,41 & 0,213 \\
\hline & $\mathrm{BI}$ & 3 & 3 & 1,09 & 0,471 & 3 & 3 & 0,15 & 0,925 \\
\hline \multirow[t]{8}{*}{ TKM [g] } & So & 1 & 3 & 272,21 & 0,000 & 1 & 3 & $\begin{array}{c}104,0 \\
6\end{array}$ & 0,002 \\
\hline & $\mathrm{Di}$ & 1 & 6 & 86,36 & 0,000 & 1 & 6 & 0,63 & 0,457 \\
\hline & So*Di & 1 & 6 & 17,02 & 0,006 & 1 & 6 & 0,09 & 0,776 \\
\hline & $\mathrm{Fu}$ & 7 & 76 & 3,70 & 0,002 & 7 & 80 & 5,05 & 0,000 \\
\hline & So*Fu & 7 & 76 & 0,38 & 0,910 & 7 & 80 & 0,29 & 0,958 \\
\hline & $\mathrm{Di}^{\star} \mathrm{Fu}$ & 7 & 76 & 0,20 & 0,984 & 7 & 80 & 0,43 & 0,881 \\
\hline & $\begin{array}{c}\text { So }^{*} \mathrm{Di}^{*} \mathrm{~F} \\
\mathrm{u}\end{array}$ & 7 & 76 & 1,08 & 0,382 & 7 & 80 & 0,39 & 0,908 \\
\hline & $\mathrm{BI}$ & 3 & 3 & 2,59 & 0,228 & 3 & 3 & 2,86 & 0,206 \\
\hline
\end{tabular}




\begin{tabular}{|c|c|c|c|c|c|c|c|c|c|}
\hline \multirow[t]{8}{*}{ Schoten $/ \mathrm{m}^{2}$} & So & 1 & 3 & 22,85 & 0,017 & 1 & 3 & 0,09 & 0,788 \\
\hline & Di & 1 & 6 & 39,74 & 0,001 & 1 & 6 & 1,49 & 0,268 \\
\hline & So*Di & 1 & 6 & 2,74 & 0,149 & 1 & 6 & 1,19 & 0,317 \\
\hline & $\mathrm{Fu}$ & 7 & 76 & 0,98 & 0,455 & 7 & 79 & 0,45 & 0,864 \\
\hline & So*Fu & 7 & 76 & 1,31 & 0,258 & 7 & 79 & 1,43 & 0,206 \\
\hline & $\mathrm{Di}^{\star} \mathrm{Fu}$ & 7 & 76 & 1,29 & 0,265 & 7 & 79 & 0,88 & 0,530 \\
\hline & $\begin{array}{c}\text { So* } \mathrm{Di}^{*} \mathrm{~F} \\
\mathrm{u}\end{array}$ & 7 & 76 & 0,47 & 0,850 & 7 & 79 & 1,05 & 0,406 \\
\hline & $\mathrm{BI}$ & 3 & 3 & 2,53 & 0,233 & 3 & 3 & 0,51 & 0,701 \\
\hline \multirow[t]{8}{*}{ Körner/Pflanze } & So & 1 & 3 & 1,39 & 0,324 & 1 & 3 & 0,07 & 0,812 \\
\hline & $\mathrm{Di}$ & 1 & 6 & 104,77 & 0,000 & 1 & 6 & 29,78 & 0,002 \\
\hline & So*Di & 1 & 6 & 12,76 & 0,012 & 1 & 6 & 0,00 & 0,955 \\
\hline & $\mathrm{Fu}$ & 7 & 76 & 1,96 & 0,071 & 7 & 80 & 0,57 & 0,781 \\
\hline & So*Fu & 7 & 76 & 0,61 & 0,744 & 7 & 80 & 1,21 & 0,309 \\
\hline & $\mathrm{Di}{ }^{\star} \mathrm{Fu}$ & 7 & 76 & 1,12 & 0,357 & 7 & 80 & 0,74 & 0,635 \\
\hline & $\begin{array}{c}\text { So* } \mathrm{Di}^{\star} \mathrm{F} \\
\mathrm{u}\end{array}$ & 7 & 76 & 0,95 & 0,472 & 7 & 80 & 1,41 & 0,212 \\
\hline & $\mathrm{BI}$ & 3 & 3 & 1,24 & 0,431 & 3 & 3 & 2,06 & 0,284 \\
\hline \multirow[t]{8}{*}{ Korndichte } & So & 1 & 3 & 27,71 & 0,013 & 1 & 3 & 0,05 & 0,840 \\
\hline & $\mathrm{Di}$ & 1 & 6 & 19,14 & 0,005 & 1 & 6 & 0,62 & 0,460 \\
\hline & So*Di & 1 & 6 & 4,33 & 0,083 & 1 & 6 & 1,75 & 0,234 \\
\hline & $\mathrm{Fu}$ & 7 & 76 & 0,97 & 0,461 & 7 & 80 & 0,46 & 0,863 \\
\hline & So*Fu & 7 & 76 & 1,01 & 0,432 & 7 & 80 & 1,32 & 0,251 \\
\hline & $\mathrm{Di}{ }^{\star} \mathrm{Fu}$ & 7 & 76 & 0,80 & 0,590 & 7 & 80 & 0,83 & 0,568 \\
\hline & $\begin{array}{c}\text { So* } \mathrm{Di}^{\star} \mathrm{F} \\
\mathrm{u}\end{array}$ & 7 & 76 & 0,36 & 0,923 & 7 & 80 & 0,82 & 0,577 \\
\hline & $\mathrm{BI}$ & 3 & 3 & 2,20 & 0,267 & 3 & 3 & 0,71 & 0,607 \\
\hline \multirow{8}{*}{$\begin{array}{l}\text { Kulturdeckungs- } \\
\text { grad [\%] } \\
\text { im Frühjahr }\end{array}$} & So & 1 & 3 & 105,19 & 0,002 & 1 & 3 & 0,02 & 0,894 \\
\hline & $\mathrm{Di}$ & 1 & 6 & 200,61 & 0,000 & 1 & 6 & 11,38 & 0,015 \\
\hline & So*Di & 1 & 6 & 1,22 & 0,312 & 1 & 6 & 0,40 & 0,551 \\
\hline & $\mathrm{Fu}$ & 7 & 76 & 2,01 & 0,065 & 7 & 80 & 2,22 & 0,041 \\
\hline & So*Fu & 7 & 76 & 0,54 & 0,800 & 7 & 80 & 0,75 & 0,630 \\
\hline & $\mathrm{Di}^{\star} \mathrm{Fu}$ & 7 & 76 & 0,66 & 0,705 & 7 & 80 & 1,04 & 0,410 \\
\hline & $\begin{array}{c}\text { So* } \mathrm{Di}^{\star} \mathrm{F} \\
\mathrm{u}\end{array}$ & 7 & 76 & 1,16 & 0,333 & 7 & 80 & 0,74 & 0,640 \\
\hline & $\mathrm{BI}$ & 3 & 3 & 11,14 & 0,039 & 3 & 3 & 0,41 & 0,758 \\
\hline \multirow{8}{*}{$\begin{array}{l}\text { Wurzelhalsdurch- } \\
\text { messer [mm] } \\
\text { im Frühjahr }\end{array}$} & So & 1 & 3 & 0,19 & 0,696 & 1 & 3 & 0,10 & 0,777 \\
\hline & $\mathrm{Di}$ & 1 & 6 & 87,73 & 0,000 & 1 & 6 & 11,71 & 0,014 \\
\hline & So*Di & 1 & 6 & 1,21 & 0,313 & 1 & 6 & 1,09 & 0,336 \\
\hline & $\mathrm{Fu}$ & 7 & 75 & 1,05 & 0,404 & 7 & 80 & 0,47 & 0,853 \\
\hline & So*Fu & 7 & 75 & 1,84 & 0,091 & 7 & 80 & 0,69 & 0,681 \\
\hline & $\mathrm{Di}^{\star} \mathrm{Fu}$ & 7 & 75 & 0,92 & 0,497 & 7 & 80 & 3,22 & 0,005 \\
\hline & $\begin{array}{c}\text { So* }^{\star} \mathrm{Di}^{\star} \mathrm{F} \\
\mathrm{u}\end{array}$ & 7 & 75 & 2,04 & 0,061 & 7 & 80 & 2,24 & 0,039 \\
\hline & $\mathrm{BI}$ & 3 & 3 & 1,43 & 0,387 & 3 & 3 & 0,11 & 0,947 \\
\hline
\end{tabular}




\begin{tabular}{|c|c|c|c|c|c|c|c|c|c|}
\hline Seitentriebe/ & So & 1 & 3 & 0,95 & 0,402 & 1 & 3 & 0,71 & 0,462 \\
\hline \multirow{7}{*}{ Pflanze } & $\mathrm{Di}$ & 1 & 6 & 102,18 & 0,000 & 1 & 6 & 32,33 & 0,001 \\
\hline & So*Di & 1 & 6 & 2,46 & 0,168 & 1 & 6 & 0,01 & 0,924 \\
\hline & $\mathrm{Fu}$ & 7 & 76 & 2,23 & 0,041 & 7 & 80 & 1,98 & 0,068 \\
\hline & So*Fu & 7 & 76 & 0,65 & 0,717 & 7 & 80 & 0,75 & 0,628 \\
\hline & $\mathrm{Di}^{\star} \mathrm{Fu}$ & 7 & 76 & 1,42 & 0,208 & 7 & 80 & 0,81 & 0,579 \\
\hline & $\begin{array}{c}\text { So }^{*} \mathrm{Di}^{*} \mathrm{~F} \\
\mathrm{u}\end{array}$ & 7 & 76 & 0,54 & 0,800 & 7 & 80 & 1,19 & 0,319 \\
\hline & $\mathrm{BI}$ & 3 & 3 & 1,13 & 0,462 & 3 & 3 & 1,48 & 0,378 \\
\hline \multirow{8}{*}{$\begin{array}{l}\text { Bestandeshöhe } \\
\text { [cm] } \\
\text { in } \mathrm{BBCH} 65 / 67\end{array}$} & So & 1 & 3 & 114,01 & 0,002 & 1 & 3 & $\begin{array}{c}116,3 \\
4\end{array}$ & 0,002 \\
\hline & $\mathrm{Di}$ & 1 & 6 & 2,20 & 0,189 & 1 & 6 & 4,32 & 0,083 \\
\hline & So*Di & 1 & 6 & 0,36 & 0,571 & 1 & 6 & 0,01 & 0,918 \\
\hline & $\mathrm{Fu}$ & 7 & 76 & 16,14 & 0,000 & 7 & 80 & $\begin{array}{c}147,0 \\
4\end{array}$ & 0,000 \\
\hline & So*Fu & 7 & 76 & 0,45 & 0,869 & 7 & 80 & 2,12 & 0,051 \\
\hline & $\mathrm{Di}^{\star} \mathrm{Fu}$ & 7 & 76 & 0,56 & 0,782 & 7 & 80 & 0,32 & 0,944 \\
\hline & $\begin{array}{c}\text { So }^{*} \mathrm{Di}^{*} \mathrm{~F} \\
\mathrm{u}\end{array}$ & 7 & 76 & 0,56 & 0,789 & 7 & 80 & 0,92 & 0,496 \\
\hline & $\mathrm{BI}$ & 3 & 3 & 4,38 & 0,128 & 3 & 3 & 0,35 & 0,794 \\
\hline \multirow{8}{*}{$\begin{array}{l}\text { Bestandeshöhe } \\
\text { [cm] } \\
\text { in } \mathrm{BBCH} 67 / 69\end{array}$} & So & 1 & 3 & 185,81 & 0,001 & 1 & 3 & $\begin{array}{c}159,7 \\
5\end{array}$ & 0,001 \\
\hline & $\mathrm{Di}$ & 1 & 6 & 0,74 & 0,423 & 1 & 6 & 5,43 & 0,059 \\
\hline & So*Di & 1 & 6 & 0,63 & 0,459 & 1 & 6 & 0,02 & 0,902 \\
\hline & $\mathrm{Fu}$ & 7 & 76 & 11,83 & 0,000 & 7 & 80 & $\begin{array}{c}169,4 \\
7\end{array}$ & 0,000 \\
\hline & So*Fu & 7 & 76 & 0,34 & 0,935 & 7 & 80 & 2,08 & 0,055 \\
\hline & $\mathrm{Di}^{*} \mathrm{Fu}$ & 7 & 76 & 0,23 & 0,976 & 7 & 80 & 0,39 & 0,904 \\
\hline & $\begin{array}{c}\text { So }^{*} \mathrm{Di}^{*} \mathrm{~F} \\
\mathrm{~F}\end{array}$ & 7 & 76 & 0,36 & 0,925 & 7 & 80 & 0,82 & 0,576 \\
\hline & $\mathrm{BI}$ & 3 & 3 & 6,52 & 0,079 & 3 & 3 & 0,67 & 0,625 \\
\hline \multirow{8}{*}{$\begin{array}{l}\text { Bestandeshöhe } \\
\text { [cm] } \\
\text { in } \mathrm{BBCH} 73 / 74\end{array}$} & So & 1 & 3 & 184,01 & 0,001 & 1 & 3 & $\begin{array}{c}163,1 \\
8\end{array}$ & 0,001 \\
\hline & $\mathrm{Di}$ & 1 & 6 & 0,18 & 0,684 & 1 & 6 & 4,81 & 0,071 \\
\hline & So*Di & 1 & 6 & 0,07 & 0,796 & 1 & 6 & 0,02 & 0,906 \\
\hline & $\mathrm{Fu}$ & 7 & 76 & 13,89 & 0,000 & 7 & 80 & $\begin{array}{c}154,5 \\
0\end{array}$ & 0,000 \\
\hline & So*Fu & 7 & 76 & 0,58 & 0,771 & 7 & 80 & 1,92 & 0,077 \\
\hline & $\mathrm{Di}^{\star} \mathrm{Fu}$ & 7 & 76 & 0,38 & 0,914 & 7 & 80 & 0,29 & 0,955 \\
\hline & $\begin{array}{c}\text { So }^{*} \mathrm{Di}^{*} \mathrm{~F} \\
\end{array}$ & 7 & 76 & 0,29 & 0,955 & 7 & 80 & 0,48 & 0,847 \\
\hline & $\mathrm{Bl}$ & 3 & 3 & 4,59 & 0,121 & 3 & 3 & 0,66 & 0,631 \\
\hline \multirow{8}{*}{$\begin{array}{l}\text { Bestandeshöhe } \\
\text { [cm] } \\
\text { in } \mathrm{BBCH} 75\end{array}$} & So & 1 & 3 & 167,75 & 0,001 & 1 & 3 & $\begin{array}{c}227,9 \\
6\end{array}$ & 0,001 \\
\hline & $\mathrm{Di}$ & 1 & 6 & 8,55 & 0,027 & 1 & 6 & 11,86 & 0,014 \\
\hline & So*Di & 1 & 6 & 0,13 & 0,732 & 1 & 6 & 0,01 & 0,907 \\
\hline & $\mathrm{Fu}$ & 7 & 76 & 15,15 & 0,000 & 7 & 80 & $\begin{array}{c}166,7 \\
4\end{array}$ & 0,000 \\
\hline & So*Fu & 7 & 76 & 0,44 & 0,873 & 7 & 80 & 2,21 & 0,042 \\
\hline & $\mathrm{Di}^{*} \mathrm{Fu}$ & 7 & 76 & 0,40 & 0,901 & 7 & 80 & 0,45 & 0,868 \\
\hline & $\begin{array}{c}\text { So }^{*} \mathrm{Di}^{*} \mathrm{~F} \\
\mathrm{u}\end{array}$ & 7 & 76 & 0,31 & 0,946 & 7 & 80 & 0,46 & 0,861 \\
\hline & $\mathrm{BI}$ & 3 & 3 & 3,36 & 0,173 & 3 & 3 & 0,69 & 0,616 \\
\hline
\end{tabular}




\begin{tabular}{|c|c|c|c|c|c|c|c|c|c|}
\hline Schotenansatz- & So & 1 & 3 & 499,76 & 0,000 & 1 & 3 & 68,46 & 0,004 \\
\hline höhe [cm] & $\mathrm{Di}$ & 1 & 6 & 0,41 & 0,545 & 1 & 6 & 1,19 & 0,318 \\
\hline \multirow[t]{6}{*}{ in BBCH 65/67 } & So*Di & 1 & 6 & 9,32 & 0,022 & 1 & 6 & 0,00 & 0,946 \\
\hline & $\mathrm{Fu}$ & 7 & 76 & 12,10 & 0,000 & 7 & 80 & $\begin{array}{c}175,4 \\
9\end{array}$ & 0,000 \\
\hline & So*Fu & 7 & 76 & 0,77 & 0,616 & 7 & 80 & 2,52 & 0,021 \\
\hline & $\mathrm{Di}^{\star} \mathrm{Fu}$ & 7 & 76 & 0,16 & 0,992 & 7 & 80 & 0,43 & 0,881 \\
\hline & $\begin{array}{c}\text { So* } \mathrm{Di}^{\star} \mathrm{F} \\
\mathrm{u}\end{array}$ & 7 & 76 & 0,86 & 0,540 & 7 & 80 & 1,11 & 0,363 \\
\hline & $\mathrm{BI}$ & 3 & 3 & 12,43 & 0,034 & 3 & 3 & 0,86 & 0,550 \\
\hline \multirow{8}{*}{$\begin{array}{l}\text { Schotenansatz- } \\
\text { höhe [cm] } \\
\text { in BBCH } 67 / 69\end{array}$} & So & 1 & 3 & 442,61 & 0,000 & 1 & 3 & 66,69 & 0,004 \\
\hline & Di & 1 & 6 & 0,80 & 0,406 & 1 & 6 & 1,49 & 0,268 \\
\hline & So*Di & 1 & 6 & 6,37 & 0,045 & 1 & 6 & 0,05 & 0,825 \\
\hline & $\mathrm{Fu}$ & 7 & 76 & 12,03 & 0,000 & 7 & 80 & $\begin{array}{c}179,5 \\
3\end{array}$ & 0,000 \\
\hline & So*Fu & 7 & 76 & 1,34 & 0,243 & 7 & 80 & 1,96 & 0,071 \\
\hline & $\mathrm{Di}^{\star} \mathrm{Fu}$ & 7 & 76 & 0,47 & 0,856 & 7 & 80 & 1,11 & 0,366 \\
\hline & $\begin{array}{c}\text { So* } \mathrm{Di}^{\star} \mathrm{F} \\
\mathrm{u}\end{array}$ & 7 & 76 & 0,53 & 0,807 & 7 & 80 & 1,15 & 0,341 \\
\hline & $\mathrm{Bl}$ & 3 & 3 & 3,95 & 0,144 & 3 & 3 & 0,61 & 0,654 \\
\hline \multirow{8}{*}{$\begin{array}{l}\text { Schotenansatz- } \\
\text { höhe [cm] } \\
\text { in } \mathrm{BBCH} 73 / 74\end{array}$} & So & 1 & 3 & 295,05 & 0,000 & 1 & 3 & 47,62 & 0,006 \\
\hline & $\mathrm{Di}$ & 1 & 6 & 4,27 & 0,084 & 1 & 6 & 1,31 & 0,297 \\
\hline & So*Di & 1 & 6 & 2,60 & 0,158 & 1 & 6 & 0,23 & 0,650 \\
\hline & $\mathrm{Fu}$ & 7 & 76 & 19,84 & 0,000 & 7 & 80 & $\begin{array}{c}192,4 \\
6\end{array}$ & 0,000 \\
\hline & So*Fu & 7 & 76 & 0,50 & 0,828 & 7 & 80 & 2,73 & 0,014 \\
\hline & $\mathrm{Di}{ }^{\star} \mathrm{Fu}$ & 7 & 76 & 0,78 & 0,606 & 7 & 80 & 0,88 & 0,529 \\
\hline & $\begin{array}{c}\text { So* } \mathrm{Di}^{*} \mathrm{~F} \\
\mathrm{u}\end{array}$ & 7 & 76 & 0,57 & 0,781 & 7 & 80 & 1,42 & 0,211 \\
\hline & $\mathrm{Bl}$ & 3 & 3 & 2,46 & 0,240 & 3 & 3 & 0,42 & 0,752 \\
\hline \multirow{8}{*}{$\begin{array}{l}\text { Schotenansatz- } \\
\text { höhe [cm] } \\
\text { in } \mathrm{BBCH} 75\end{array}$} & So & 1 & 3 & 258,89 & 0,001 & 1 & 3 & 47,91 & 0,006 \\
\hline & $\mathrm{Di}$ & 1 & 6 & 2,90 & 0,139 & 1 & 6 & 1,32 & 0,295 \\
\hline & So*Di & 1 & 6 & 1,36 & 0,288 & 1 & 6 & 0,23 & 0,648 \\
\hline & $\mathrm{Fu}$ & 7 & 76 & 14,13 & 0,000 & 7 & 80 & $\begin{array}{c}191,3 \\
8\end{array}$ & 0,000 \\
\hline & So*Fu & 7 & 76 & 0,77 & 0,611 & 7 & 80 & 2,84 & 0,011 \\
\hline & $\mathrm{Di}{ }^{*} \mathrm{Fu}$ & 7 & 76 & 0,37 & 0,916 & 7 & 80 & 0,85 & 0,550 \\
\hline & $\begin{array}{c}\text { So }^{\star} \mathrm{Di}^{\star} \mathrm{F} \\
\mathrm{u}\end{array}$ & 7 & 76 & 0,97 & 0,460 & 7 & 80 & 1,41 & 0,213 \\
\hline & $\mathrm{BI}$ & 3 & 3 & 2,63 & 0,224 & 3 & 3 & 0,41 & 0,759 \\
\hline \multirow{2}{*}{$\begin{array}{l}\text { Schotenschicht- } \\
\text { dicke }[\mathrm{cm}]\end{array}$} & So & 1 & 3 & 0,02 & 0,885 & 1 & 3 & 9,68 & 0,053 \\
\hline & $\mathrm{Di}$ & 1 & 6 & 1,97 & 0,210 & 1 & 6 & 3,05 & 0,131 \\
\hline \multirow[t]{6}{*}{ in BBCH 65/67 } & So*Di & 1 & 6 & 5,90 & 0,051 & 1 & 6 & 0,12 & 0,738 \\
\hline & $\mathrm{Fu}$ & 7 & 76 & 3,87 & 0,001 & 7 & 80 & 0,73 & 0,651 \\
\hline & So*Fu & 7 & 76 & 0,61 & 0,743 & 7 & 80 & 2,09 & 0,054 \\
\hline & $\mathrm{Di}{ }^{\star} \mathrm{Fu}$ & 7 & 76 & 0,54 & 0,799 & 7 & 80 & 0,51 & 0,827 \\
\hline & $\begin{array}{c}\text { So* } \mathrm{Di}^{\star} \mathrm{F} \\
\mathrm{u}\end{array}$ & 7 & 76 & 0,53 & 0,807 & 7 & 80 & 0,62 & 0,734 \\
\hline & $\mathrm{BI}$ & 3 & 3 & 1,76 & 0,328 & 3 & 3 & 1,34 & 0,407 \\
\hline
\end{tabular}




\begin{tabular}{|c|c|c|c|c|c|c|c|c|c|}
\hline Schotenschicht- & So & 1 & 3 & 1,79 & 0,274 & 1 & 3 & 8,21 & 0,064 \\
\hline dicke $[\mathrm{cm}]$ & $\mathrm{Di}$ & 1 & 6 & 0,03 & 0,859 & 1 & 6 & 1,41 & 0,280 \\
\hline \multirow[t]{6}{*}{ in $\mathrm{BBCH} 67 / 69$} & So*Di & 1 & 6 & 5,08 & 0,065 & 1 & 6 & 0,13 & 0,727 \\
\hline & $\mathrm{Fu}$ & 7 & 76 & 2,10 & 0,054 & 7 & 80 & 0,71 & 0,662 \\
\hline & So*Fu & 7 & 76 & 1,05 & 0,407 & 7 & 80 & 1,35 & 0,240 \\
\hline & $\mathrm{Di}^{\star} \mathrm{Fu}$ & 7 & 76 & 0,79 & 0,596 & 7 & 80 & 0,98 & 0,453 \\
\hline & $\begin{array}{c}\text { So }^{*} \mathrm{Di}^{*} \mathrm{~F} \\
\mathrm{u}\end{array}$ & 7 & 76 & 0,72 & 0,657 & 7 & 80 & 0,22 & 0,980 \\
\hline & $\mathrm{BI}$ & 3 & 3 & 1,35 & 0,405 & 3 & 3 & 0,34 & 0,802 \\
\hline \multirow{8}{*}{$\begin{array}{l}\text { Schotenschicht- } \\
\text { dicke [cm] } \\
\text { in } \mathrm{BBCH} 73 / 74\end{array}$} & So & 1 & 3 & 0,15 & 0,727 & 1 & 3 & 25,60 & 0,015 \\
\hline & $\mathrm{Di}$ & 1 & 6 & 4,66 & 0,074 & 1 & 6 & 1,37 & 0,286 \\
\hline & So*Di & 1 & 6 & 2,62 & 0,156 & 1 & 6 & 0,86 & 0,389 \\
\hline & $\mathrm{Fu}$ & 7 & 76 & 0,97 & 0,463 & 7 & 80 & 1,39 & 0,222 \\
\hline & So*Fu & 7 & 76 & 0,40 & 0,901 & 7 & 80 & 1,67 & 0,128 \\
\hline & $\mathrm{Di}^{*} \mathrm{Fu}$ & 7 & 76 & 1,34 & 0,243 & 7 & 80 & 1,32 & 0,250 \\
\hline & $\begin{array}{c}\text { So }^{*} \mathrm{Di}^{*} \mathrm{~F} \\
\mathrm{u}\end{array}$ & 7 & 76 & 0,61 & 0,745 & 7 & 80 & 0,91 & 0,503 \\
\hline & $\mathrm{BI}$ & 3 & 3 & 1,26 & 0,427 & 3 & 3 & 0,13 & 0,937 \\
\hline \multirow{8}{*}{$\begin{array}{l}\text { Schotenschicht- } \\
\text { dicke [cm] } \\
\text { in } \mathrm{BBCH} 75\end{array}$} & So & 1 & 3 & 0,23 & 0,664 & 1 & 3 & 26,23 & 0,014 \\
\hline & $\mathrm{Di}$ & 1 & 6 & 4,72 & 0,073 & 1 & 6 & 3,35 & 0,117 \\
\hline & So*Di & 1 & 6 & 0,74 & 0,421 & 1 & 6 & 0,74 & 0,422 \\
\hline & $\mathrm{Fu}$ & 7 & 76 & 0,67 & 0,694 & 7 & 80 & 1,31 & 0,255 \\
\hline & So*Fu & 7 & 76 & 0,88 & 0,530 & 7 & 80 & 1,78 & 0,102 \\
\hline & $\mathrm{Di}^{*} \mathrm{Fu}$ & 7 & 76 & 0,44 & 0,871 & 7 & 80 & 1,98 & 0,068 \\
\hline & $\begin{array}{c}\text { So }^{*} \mathrm{Di}^{*} \mathrm{~F} \\
\mathrm{u}\end{array}$ & 7 & 76 & 0,79 & 0,601 & 7 & 80 & 1,39 & 0,223 \\
\hline & $\mathrm{BI}$ & 3 & 3 & 1,10 & 0,468 & 3 & 3 & 0,12 & 0,942 \\
\hline \multirow{8}{*}{$\begin{array}{l}\text { absolute Anzahl } \\
\text { an Schoten am } \\
\text { Haupttrieb }\end{array}$} & So & 1 & 3 & 7,63 & 0,070 & 1 & 3 & 2,59 & 0,206 \\
\hline & $\mathrm{Di}$ & 1 & 6 & 8,37 & 0,028 & 1 & 6 & 25,93 & 0,002 \\
\hline & So*Di & 1 & 6 & 0,78 & 0,410 & 1 & 6 & 1,00 & 0,357 \\
\hline & $\mathrm{Fu}$ & 7 & 76 & 2,47 & 0,024 & 7 & 80 & 2,03 & 0,061 \\
\hline & So*Fu & 7 & 76 & 0,59 & 0,765 & 7 & 80 & 2,15 & 0,048 \\
\hline & $\mathrm{Di}^{\star} \mathrm{Fu}$ & 7 & 76 & 2,11 & 0,052 & 7 & 80 & 1,01 & 0,431 \\
\hline & $\begin{array}{c}\text { So }^{*} \mathrm{Di}^{*} \mathrm{~F} \\
\end{array}$ & 7 & 76 & 0,87 & 0,533 & 7 & 80 & 1,69 & 0,122 \\
\hline & $\mathrm{BI}$ & 3 & 3 & 0,11 & 0,948 & 3 & 3 & 1,17 & 0,451 \\
\hline \multirow{8}{*}{$\begin{array}{l}\text { absolute Anzahl } \\
\text { an Schoten am } \\
\text { 1. Seitentrieb }\end{array}$} & So & 1 & 3 & 3,38 & 0,163 & 1 & 3 & 0,04 & 0,855 \\
\hline & $\mathrm{Di}$ & 1 & 6 & 20,41 & 0,004 & 1 & 6 & 27,01 & 0,002 \\
\hline & So*Di & 1 & 6 & 9,00 & 0,024 & 1 & 6 & 1,23 & 0,310 \\
\hline & $\mathrm{Fu}$ & 7 & 76 & 1,61 & 0,145 & 7 & 80 & 0,79 & 0,601 \\
\hline & So*Fu & 7 & 76 & 0,28 & 0,959 & 7 & 80 & 0,38 & 0,909 \\
\hline & $\mathrm{Di}^{\star} \mathrm{Fu}$ & 7 & 76 & 1,36 & 0,236 & 7 & 80 & 0,97 & 0,461 \\
\hline & $\begin{array}{c}\text { So }^{*} \mathrm{Di}^{*} \mathrm{~F} \\
\end{array}$ & 7 & 76 & 0,50 & 0,833 & 7 & 80 & 0,67 & 0,697 \\
\hline & $\mathrm{BI}$ & 3 & 3 & 0,14 & 0,928 & 3 & 3 & 2,88 & 0,204 \\
\hline
\end{tabular}




\begin{tabular}{|c|c|c|c|c|c|c|c|c|c|}
\hline absolute Anzahl & So & 1 & 3 & 6,70 & 0,081 & 1 & 3 & 0,05 & 0,832 \\
\hline an Schoten am & $\mathrm{Di}$ & 1 & 6 & 34,67 & 0,001 & 1 & 6 & 29,67 & 0,002 \\
\hline \multirow[t]{6}{*}{ 2. Seitentrieb } & So*Di & 1 & 6 & 37,26 & 0,001 & 1 & 6 & 0,02 & 0,906 \\
\hline & $\mathrm{Fu}$ & 7 & 76 & 0,97 & 0,460 & 7 & 80 & 0,80 & 0,591 \\
\hline & So*Fu & 7 & 76 & 1,24 & 0,294 & 7 & 80 & 0,66 & 0,706 \\
\hline & $\mathrm{Di}^{*} \mathrm{Fu}$ & 7 & 76 & 2,01 & 0,064 & 7 & 80 & 1,16 & 0,335 \\
\hline & $\begin{array}{c}\text { So }^{*} \mathrm{Di}^{*} \mathrm{~F} \\
\mathrm{u}\end{array}$ & 7 & 76 & 1,61 & 0,146 & 7 & 80 & 0,79 & 0,600 \\
\hline & $\mathrm{BI}$ & 3 & 3 & 0,36 & 0,786 & 3 & 3 & 1,14 & 0,460 \\
\hline absolute Anzahl & So & 1 & 3 & 1,04 & 0,383 & 1 & 3 & 0,01 & 0,935 \\
\hline an Schoten am & $\mathrm{Di}$ & 1 & 6 & 23,12 & 0,003 & 1 & 6 & 33,12 & 0,001 \\
\hline \multirow[t]{6}{*}{ 3. Seitentrieb } & So* $\mathrm{Di}$ & 1 & 6 & 19,75 & 0,004 & 1 & 6 & 0,03 & 0,872 \\
\hline & $\mathrm{Fu}$ & 7 & 76 & 0,64 & 0,720 & 7 & 80 & 0,87 & 0,534 \\
\hline & So*Fu & 7 & 76 & 0,99 & 0,444 & 7 & 80 & 1,00 & 0,439 \\
\hline & $\mathrm{Di}^{*} \mathrm{Fu}$ & 7 & 76 & 1,38 & 0,225 & 7 & 80 & 1,22 & 0,304 \\
\hline & $\begin{array}{c}\text { So }^{*} \mathrm{Di}^{\star} \mathrm{F} \\
\mathrm{u}\end{array}$ & 7 & 76 & 0,57 & 0,776 & 7 & 80 & 0,98 & 0,453 \\
\hline & $\mathrm{BI}$ & 3 & 3 & 1,07 & 0,477 & 3 & 3 & 2,03 & 0,288 \\
\hline absolute Anzahl & So & 1 & 3 & 0,07 & 0,809 & 1 & 3 & 0,12 & 0,756 \\
\hline an Schoten am & $\mathrm{Di}$ & 1 & 6 & 33,85 & 0,001 & 1 & 6 & 30,72 & 0,001 \\
\hline \multirow[t]{6}{*}{ 4. Seitentrieb } & So*Di & 1 & 6 & 8,12 & 0,029 & 1 & 6 & 0,25 & 0,635 \\
\hline & $\mathrm{Fu}$ & 7 & 76 & 1,73 & 0,115 & 7 & 80 & 0,34 & 0,934 \\
\hline & So*Fu & 7 & 76 & 1,08 & 0,383 & 7 & 80 & 0,56 & 0,784 \\
\hline & $\mathrm{Di}^{*} \mathrm{Fu}$ & 7 & 76 & 1,32 & 0,250 & 7 & 80 & 0,39 & 0,905 \\
\hline & $\begin{array}{c}\text { So }^{*} \mathrm{Di}^{\star} \mathrm{F} \\
\mathrm{u}\end{array}$ & 7 & 76 & 0,76 & 0,621 & 7 & 80 & 1,18 & 0,326 \\
\hline & $\mathrm{BI}$ & 3 & 3 & 0,45 & 0,736 & 3 & 3 & 1,41 & 0,393 \\
\hline relativer Anteil [\%] & So & 1 & 3 & 0,05 & 0,835 & 1 & 3 & 0,36 & 0,593 \\
\hline an Schoten am & $\mathrm{Di}$ & 1 & 6 & 63,34 & 0,000 & 1 & 6 & 38,63 & 0,001 \\
\hline \multirow[t]{6}{*}{ Haupttrieb } & So* $\mathrm{Di}$ & 1 & 6 & 8,24 & 0,028 & 1 & 6 & 0,00 & 0,961 \\
\hline & $\mathrm{Fu}$ & 7 & 76 & 4,63 & 0,000 & 7 & 80 & 1,15 & 0,340 \\
\hline & So*Fu & 7 & 76 & 0,50 & 0,830 & 7 & 80 & 1,08 & 0,385 \\
\hline & $\mathrm{Di}{ }^{*} \mathrm{Fu}$ & 7 & 76 & 1,40 & 0,217 & 7 & 80 & 0,79 & 0,598 \\
\hline & $\begin{array}{c}\text { So }^{*} \mathrm{Di}^{\star} \mathrm{F} \\
\mathrm{u}\end{array}$ & 7 & 76 & 0,34 & 0,933 & 7 & 80 & 1,18 & 0,326 \\
\hline & $\mathrm{BI}$ & 3 & 3 & 0,52 & 0,699 & 3 & 3 & 1,56 & 0,362 \\
\hline relative Anteil [\%] & So & 1 & 3 & 0,32 & 0,610 & 1 & 3 & 0,04 & 0,863 \\
\hline an Schoten am & $\mathrm{Di}$ & 1 & 6 & 1,96 & 0,211 & 1 & 6 & 40,40 & 0,001 \\
\hline \multirow[t]{6}{*}{ 1. Seitentrieb } & So* $\mathrm{Di}$ & 1 & 6 & 0,31 & 0,600 & 1 & 6 & 0,06 & 0,815 \\
\hline & $\mathrm{Fu}$ & 7 & 76 & 0,67 & 0,695 & 7 & 80 & 1,43 & 0,204 \\
\hline & So*Fu & 7 & 76 & 0,28 & 0,961 & 7 & 80 & 1,84 & 0,092 \\
\hline & $\mathrm{Di}{ }^{\star} \mathrm{Fu}$ & 7 & 76 & 1,29 & 0,267 & 7 & 80 & 0,28 & 0,962 \\
\hline & $\begin{array}{c}\text { So }^{*} \mathrm{Di}^{\star} \mathrm{F} \\
\mathrm{u}\end{array}$ & 7 & 76 & 0,18 & 0,989 & 7 & 80 & 1,53 & 0,169 \\
\hline & $\mathrm{Bl}$ & 3 & 3 & 0,24 & 0,867 & 3 & 3 & 0,55 & 0,680 \\
\hline
\end{tabular}




\begin{tabular}{|c|c|c|c|c|c|c|c|c|c|}
\hline relativer Anteil [\%] & So & 1 & 3 & 0,56 & 0,507 & 1 & 3 & 0,04 & 0,856 \\
\hline an Schoten am & $\mathrm{Di}$ & 1 & 6 & 7,19 & 0,036 & 1 & 6 & 24,99 & 0,002 \\
\hline \multirow[t]{6}{*}{ 2. Seitentrieb } & So*Di & 1 & 6 & 13,13 & 0,011 & 1 & 6 & 0,18 & 0,682 \\
\hline & $\mathrm{Fu}$ & 7 & 76 & 2,99 & 0,008 & 7 & 80 & 1,33 & 0,247 \\
\hline & So*Fu & 7 & 76 & 1,71 & 0,120 & 7 & 80 & 0,78 & 0,603 \\
\hline & $\mathrm{Di}^{\star} \mathrm{Fu}$ & 7 & 76 & 1,22 & 0,302 & 7 & 80 & 0,19 & 0,987 \\
\hline & $\begin{array}{c}\text { So }^{*} \mathrm{Di}^{*} \mathrm{~F} \\
\mathrm{u}\end{array}$ & 7 & 76 & 2,09 & 0,054 & 7 & 80 & 1,05 & 0,404 \\
\hline & $\mathrm{BI}$ & 3 & 3 & 0,92 & 0,526 & 3 & 3 & 1,93 & 0,301 \\
\hline relativer Anteil [\%] & So & 1 & 3 & 5,69 & 0,097 & 1 & 3 & 0,23 & 0,665 \\
\hline an Schoten am & $\mathrm{Di}$ & 1 & 6 & 30,98 & 0,001 & 1 & 6 & 10,31 & 0,018 \\
\hline \multirow[t]{6}{*}{ 3. Seitentrieb } & So*Di & 1 & 6 & 3,17 & 0,125 & 1 & 6 & 0,21 & 0,663 \\
\hline & $\mathrm{Fu}$ & 7 & 76 & 0,74 & 0,640 & 7 & 80 & 3,25 & 0,004 \\
\hline & So*Fu & 7 & 76 & 0,77 & 0,616 & 7 & 80 & 0,28 & 0,959 \\
\hline & $\mathrm{Di}^{*} \mathrm{Fu}$ & 7 & 76 & 0,34 & 0,935 & 7 & 80 & 0,71 & 0,661 \\
\hline & $\begin{array}{c}\text { So }^{*} \mathrm{Di}^{*} \mathrm{~F} \\
\mathrm{u}\end{array}$ & 7 & 76 & 0,67 & 0,694 & 7 & 80 & 0,86 & 0,539 \\
\hline & $\mathrm{BI}$ & 3 & 3 & 1,69 & 0,339 & 3 & 3 & 0,14 & 0,927 \\
\hline relativer Anteil [\%] & So & 1 & 3 & 8,32 & 0,063 & 1 & 3 & 0,95 & 0,401 \\
\hline an Schoten am & Di & 1 & 6 & 20,81 & 0,004 & 1 & 6 & 0,11 & 0,753 \\
\hline \multirow[t]{6}{*}{ 4. Seitentrieb } & So*Di & 1 & 6 & 0,01 & 0,928 & 1 & 6 & 0,37 & 0,563 \\
\hline & $\mathrm{Fu}$ & 7 & 76 & 1,14 & 0,347 & 7 & 80 & 2,08 & 0,055 \\
\hline & So*Fu & 7 & 76 & 1,15 & 0,342 & 7 & 80 & 1,85 & 0,089 \\
\hline & $\mathrm{Di}^{*} \mathrm{Fu}$ & 7 & 76 & 0,38 & 0,913 & 7 & 80 & 1,04 & 0,407 \\
\hline & $\begin{array}{c}\text { So }^{*} \mathrm{Di}^{*} \mathrm{~F} \\
\mathrm{u}\end{array}$ & 7 & 76 & 1,56 & 0,160 & 7 & 80 & 0,90 & 0,509 \\
\hline & $\mathrm{BI}$ & 3 & 3 & 0,09 & 0,959 & 3 & 3 & 0,26 & 0,852 \\
\hline Anteil an PAR [\%] & So & 1 & 3 & 10,75 & 0,046 & 1 & 3 & 1,18 & 0,357 \\
\hline unter den Schoten & $\mathrm{Di}$ & 1 & 6 & 2,07 & 0,200 & 1 & 6 & 2,16 & 0,192 \\
\hline in $\mathrm{BBCH} 65$ & So*Di & 1 & 6 & 5,79 & 0,053 & 1 & 6 & 0,19 & 0,675 \\
\hline \multirow[t]{5}{*}{ (PAR_M1) } & $\mathrm{Fu}$ & 7 & 76 & 1,48 & 0,186 & 7 & 80 & 1,55 & 0,163 \\
\hline & So*Fu & 7 & 76 & 0,52 & 0,814 & 7 & 80 & 0,65 & 0,710 \\
\hline & $\mathrm{Di}^{\star} \mathrm{Fu}$ & 7 & 76 & 1,69 & 0,125 & 7 & 80 & 0,77 & 0,616 \\
\hline & $\begin{array}{c}\text { So }^{*} \mathrm{Di}^{*} \mathrm{~F} \\
\end{array}$ & 7 & 76 & 0,12 & 0,997 & 7 & 80 & 1,18 & 0,321 \\
\hline & $\mathrm{BI}$ & 3 & 3 & 2,72 & 0,216 & 3 & 3 & 1,87 & 0,310 \\
\hline Anteil an PAR [\%] & So & 1 & 3 & 15,27 & 0,030 & 1 & 3 & 3,49 & 0,159 \\
\hline unter den Schoten & Di & 1 & 6 & 100,33 & 0,000 & 1 & 6 & 0,75 & 0,420 \\
\hline in $\mathrm{BBCH} 67 / 69$ & So*Di & 1 & 6 & 1,90 & 0,218 & 1 & 6 & 0,67 & 0,444 \\
\hline \multirow[t]{5}{*}{ (PAR_M2) } & $\mathrm{Fu}$ & 7 & 76 & 4,61 & 0,000 & 7 & 80 & 0,92 & 0,493 \\
\hline & So*Fu & 7 & 76 & 1,54 & 0,165 & 7 & 80 & 1,82 & 0,096 \\
\hline & $\mathrm{Di}^{\star} \mathrm{Fu}$ & 7 & 76 & 0,62 & 0,736 & 7 & 80 & 1,13 & 0,355 \\
\hline & $\begin{array}{c}\text { So }^{*} \mathrm{Di}^{*} \mathrm{~F} \\
\mathrm{u}\end{array}$ & 7 & 76 & 1,68 & 0,126 & 7 & 80 & 0,59 & 0,762 \\
\hline & $\mathrm{BI}$ & 3 & 3 & 2,65 & 0,222 & 3 & 3 & 0,40 & 0,763 \\
\hline
\end{tabular}




\begin{tabular}{|c|c|c|c|c|c|c|c|c|c|}
\hline Anteil an PAR [\%] & So & 1 & 3 & 3,27 & 0,168 & 1 & 3 & 2,66 & 0,202 \\
\hline unter den Schoten & Di & 1 & 6 & 36,54 & 0,001 & 1 & 6 & 0,17 & 0,696 \\
\hline in $\mathrm{BBCH} 73 / 74$ & So*Di & 1 & 6 & 0,87 & 0,388 & 1 & 6 & 0,01 & 0,928 \\
\hline \multirow[t]{5}{*}{ (PAR_M3) } & $\mathrm{Fu}$ & 7 & 76 & 2,18 & 0,045 & 7 & 80 & 1,33 & 0,245 \\
\hline & So*Fu & 7 & 76 & 0,90 & 0,514 & 7 & 80 & 1,82 & 0,094 \\
\hline & $\mathrm{Di}^{*} \mathrm{Fu}$ & 7 & 76 & 1,48 & 0,187 & 7 & 80 & 1,54 & 0,166 \\
\hline & $\begin{array}{c}\mathrm{So}^{*} \mathrm{Di}^{\star} \mathrm{F} \\
\mathrm{u}\end{array}$ & 7 & 76 & 0,54 & 0,800 & 7 & 80 & 0,71 & 0,666 \\
\hline & $\mathrm{Bl}$ & 3 & 3 & 0,69 & 0,614 & 3 & 3 & 2,86 & 0,205 \\
\hline Anteil an PAR [\%] & So & 1 & 3 & 19,47 & 0,022 & 1 & 3 & 4,28 & 0,130 \\
\hline unter den Schoten & $\mathrm{Di}$ & 1 & 6 & 83,67 & 0,000 & 1 & 6 & 0,73 & 0,426 \\
\hline in $\mathrm{BBCH} 75$ & So* $\mathrm{Di}$ & 1 & 6 & 0,06 & 0,809 & 1 & 6 & 0,00 & 0,998 \\
\hline \multirow[t]{5}{*}{ (PAR_M4) } & $\mathrm{Fu}$ & 7 & 76 & 2,55 & 0,021 & 7 & 80 & 0,94 & 0,482 \\
\hline & So*Fu & 7 & 76 & 1,15 & 0,343 & 7 & 80 & 0,37 & 0,919 \\
\hline & $\mathrm{Di}^{*} \mathrm{Fu}$ & 7 & 76 & 0,84 & 0,558 & 7 & 80 & 1,27 & 0,276 \\
\hline & $\begin{array}{c}\mathrm{So}^{*} \mathrm{Di}^{*} \mathrm{~F} \\
\mathrm{u}\end{array}$ & 7 & 76 & 0,67 & 0,699 & 7 & 80 & 0,53 & 0,806 \\
\hline & $\mathrm{BI}$ & 3 & 3 & 3,43 & 0,169 & 3 & 3 & 9,24 & 0,051 \\
\hline Anteil an PAR [\%] & So & 1 & 3 & 52,11 & 0,005 & 1 & 3 & 0,00 & 0,980 \\
\hline am Boden & $\mathrm{Di}$ & 1 & 6 & 25,64 & 0,002 & 1 & 6 & 6,74 & 0,041 \\
\hline in $\mathrm{BBCH} 65$ & So* $\mathrm{Di}$ & 1 & 6 & 0,68 & 0,442 & 1 & 6 & 0,11 & 0,756 \\
\hline \multirow[t]{5}{*}{ (PAR_B1) } & $\mathrm{Fu}$ & 7 & 76 & 1,36 & 0,233 & 7 & 80 & 1,96 & 0,070 \\
\hline & So*Fu & 7 & 76 & 0,79 & 0,601 & 7 & 80 & 1,20 & 0,311 \\
\hline & $\mathrm{Di}^{*} \mathrm{Fu}$ & 7 & 76 & 0,56 & 0,785 & 7 & 80 & 0,86 & 0,538 \\
\hline & $\begin{array}{c}\mathrm{So}^{*} \mathrm{Di}^{*} \mathrm{~F} \\
\mathrm{u}\end{array}$ & 7 & 76 & 1,36 & 0,235 & 7 & 80 & 1,25 & 0,286 \\
\hline & $\mathrm{BI}$ & 3 & 3 & 3,81 & 0,151 & 3 & 3 & 0,42 & 0,753 \\
\hline Anteil an PAR [\%] & So & 1 & 3 & 13,91 & 0,034 & 1 & 3 & 0,06 & 0,829 \\
\hline am Boden & $\mathrm{Di}$ & 1 & 6 & 52,03 & 0,000 & 1 & 6 & 0,27 & 0,622 \\
\hline in BBCH 67/69 & So* $\mathrm{Di}$ & 1 & 6 & 0,09 & 0,779 & 1 & 6 & 0,01 & 0,918 \\
\hline \multirow[t]{5}{*}{ (PAR_B2) } & $\mathrm{Fu}$ & 7 & 76 & 2,52 & 0,022 & 7 & 80 & 0,93 & 0,490 \\
\hline & So*Fu & 7 & 76 & 2,03 & 0,062 & 7 & 80 & 1,94 & 0,074 \\
\hline & $\mathrm{Di}^{\star} \mathrm{Fu}$ & 7 & 76 & 0,75 & 0,630 & 7 & 80 & 1,01 & 0,433 \\
\hline & $\begin{array}{c}\text { So* } \mathrm{Di}^{*} \mathrm{~F} \\
\mathrm{u}\end{array}$ & 7 & 76 & 0,52 & 0,813 & 7 & 80 & 0,80 & 0,590 \\
\hline & $\mathrm{BI}$ & 3 & 3 & 1,80 & 0,320 & 3 & 3 & 0,99 & 0,505 \\
\hline Anteil an PAR [\%] & So & 1 & 3 & 1,89 & 0,263 & 1 & 3 & 0,24 & 0,660 \\
\hline am Boden & Di & 1 & 6 & 20,62 & 0,004 & 1 & 6 & 0,00 & 0,952 \\
\hline in $\mathrm{BBCH} 73 / 74$ & So* $\mathrm{Di}$ & 1 & 6 & 0,89 & 0,381 & 1 & 6 & 0,75 & 0,421 \\
\hline \multirow[t]{5}{*}{ (PAR_B3) } & $\mathrm{Fu}$ & 7 & 76 & 1,36 & 0,234 & 7 & 80 & 2,62 & 0,017 \\
\hline & So*Fu & 7 & 76 & 0,57 & 0,780 & 7 & 80 & 0,69 & 0,678 \\
\hline & $\mathrm{Di}^{*} \mathrm{Fu}$ & 7 & 76 & 0,35 & 0,929 & 7 & 80 & 0,91 & 0,502 \\
\hline & $\begin{array}{c}\text { So* } \mathrm{Di}^{*} \mathrm{~F} \\
\mathrm{u}\end{array}$ & 7 & 76 & 0,84 & 0,556 & 7 & 80 & 1,04 & 0,407 \\
\hline & $\mathrm{Bl}$ & 3 & 3 & 0,85 & 0,550 & 3 & 3 & 4,05 & 0,140 \\
\hline
\end{tabular}




\begin{tabular}{|c|c|c|c|c|c|c|c|c|c|}
\hline Anteil an PAR [\%] & So & 1 & 3 & 16,19 & 0,028 & 1 & 3 & 1,05 & 0,381 \\
\hline am Boden & $\mathrm{Di}$ & 1 & 6 & 81,62 & 0,000 & 1 & 6 & 0,05 & 0,836 \\
\hline in BBCH 75 & So*Di & 1 & 6 & 4,07 & 0,090 & 1 & 6 & 0,26 & 0,627 \\
\hline \multirow[t]{5}{*}{ (PAR_B4) } & $\mathrm{Fu}$ & 7 & 76 & 1,01 & 0,434 & 7 & 80 & 1,58 & 0,155 \\
\hline & So*Fu & 7 & 76 & 0,96 & 0,470 & 7 & 80 & 2,44 & 0,026 \\
\hline & $\mathrm{Di}^{\star} \mathrm{Fu}$ & 7 & 76 & 0,55 & 0,797 & 7 & 80 & 1,03 & 0,416 \\
\hline & $\begin{array}{c}\text { So }^{*} \mathrm{Di}^{*} \mathrm{~F} \\
\mathrm{u}\end{array}$ & 7 & 76 & 0,76 & 0,621 & 7 & 80 & 1,06 & 0,394 \\
\hline & $\mathrm{BI}$ & 3 & 3 & 3,90 & 0,147 & 3 & 3 & 19,31 & 0,018 \\
\hline \multirow[t]{8}{*}{ NDVI_Dauer } & So & 1 & 3 & 14,79 & 0,031 & 1 & 3 & 30,87 & 0,012 \\
\hline & $\mathrm{Di}$ & 1 & 6 & 0,03 & 0,875 & 1 & 6 & 10,52 & 0,018 \\
\hline & So* $\mathrm{Di}$ & 1 & 6 & 28,04 & 0,002 & 1 & 6 & 1,97 & 0,210 \\
\hline & $\mathrm{Fu}$ & 7 & 76 & 3,53 & 0,002 & 7 & 80 & 49,48 & 0,000 \\
\hline & So*Fu & 7 & 76 & 0,52 & 0,815 & 7 & 80 & 3,56 & 0,002 \\
\hline & $\mathrm{Di}^{\star} \mathrm{Fu}$ & 7 & 76 & 0,33 & 0,938 & 7 & 80 & 0,98 & 0,454 \\
\hline & $\begin{array}{l}\text { So }^{*} \mathrm{Di}^{*} \mathrm{~F} \\
\mathrm{u}\end{array}$ & 7 & 76 & 0,11 & 0,998 & 7 & 80 & 0,80 & 0,586 \\
\hline & $\mathrm{BI}$ & 3 & 3 & 0,45 & 0,738 & 3 & 3 & 3,04 & 0,193 \\
\hline Grünfärbung des & So & 1 & 3 & 1,02 & 0,387 & 1 & 3 & 0,60 & 0,494 \\
\hline Pflanzenbestandes & $\mathrm{Di}$ & 1 & 6 & 0,12 & 0,745 & 1 & 6 & 2,28 & 0,182 \\
\hline in $\mathrm{BBCH}$ 64/65 & So*Di & 1 & 6 & 3,19 & 0,124 & 1 & 6 & 0,70 & 0,436 \\
\hline \multirow[t]{5}{*}{ (NDVI_B1) } & $\mathrm{Fu}$ & 7 & 76 & 7,74 & 0,000 & 7 & 80 & 33,35 & 0,000 \\
\hline & So*Fu & 7 & 76 & 1,07 & 0,392 & 7 & 80 & 2,49 & 0,023 \\
\hline & $\mathrm{Di}{ }^{*} \mathrm{Fu}$ & 7 & 76 & 0,38 & 0,914 & 7 & 80 & 0,61 & 0,749 \\
\hline & $\begin{array}{c}\text { So }^{*} \mathrm{Di}^{*} \mathrm{~F} \\
\mathrm{u}\end{array}$ & 7 & 76 & 0,44 & 0,871 & 7 & 80 & 0,48 & 0,846 \\
\hline & $\mathrm{BI}$ & 3 & 3 & 0,77 & 0,582 & 3 & 3 & 0,25 & 0,858 \\
\hline Grünfärbung des & So & 1 & 3 & 26,64 & 0,014 & 1 & 3 & $\begin{array}{c}206,1 \\
8\end{array}$ & 0,001 \\
\hline Pflanzenbestandes & $\mathrm{Di}$ & 1 & 6 & 25,91 & 0,002 & 1 & 6 & 2,70 & 0,152 \\
\hline in $\mathrm{BBCH}$ 65/66 & So*Di & 1 & 6 & 12,40 & 0,013 & 1 & 6 & 0,20 & 0,672 \\
\hline \multirow[t]{5}{*}{ (NDVI_B2) } & $\mathrm{Fu}$ & 7 & 76 & 12,37 & 0,000 & 7 & 80 & 18,32 & 0,000 \\
\hline & So*Fu & 7 & 76 & 1,26 & 0,282 & 7 & 80 & 2,36 & 0,030 \\
\hline & $\mathrm{Di}{ }^{\star} \mathrm{Fu}$ & 7 & 76 & 2,56 & 0,020 & 7 & 80 & 1,26 & 0,283 \\
\hline & $\begin{array}{c}\text { So }^{*} \mathrm{Di}^{*} \mathrm{~F} \\
\mathrm{u}\end{array}$ & 7 & 76 & 0,66 & 0,701 & 7 & 80 & 0,98 & 0,448 \\
\hline & $\mathrm{BI}$ & 3 & 3 & 0,91 & 0,531 & 3 & 3 & 7,17 & 0,070 \\
\hline Grünfärbung des & So & 1 & 3 & 31,91 & 0,011 & 1 & 3 & 3,13 & 0,175 \\
\hline Pflanzenbestandes & $\mathrm{Di}$ & 1 & 6 & 2,78 & 0,147 & 1 & 6 & 1,23 & 0,310 \\
\hline in BBCH 69 & So*Di & 1 & 6 & 19,38 & 0,005 & 1 & 6 & 0,00 & 0,983 \\
\hline \multirow[t]{5}{*}{ (NDVI_B3) } & $\mathrm{Fu}$ & 7 & 76 & 15,44 & 0,000 & 7 & 80 & 2,59 & 0,018 \\
\hline & So*Fu & 7 & 76 & 1,23 & 0,296 & 7 & 80 & 1,02 & 0,425 \\
\hline & $\mathrm{Di}{ }^{*} \mathrm{Fu}$ & 7 & 76 & 0,88 & 0,525 & 7 & 80 & 2,86 & 0,010 \\
\hline & $\begin{array}{c}\text { So }^{*} \mathrm{Di}^{*} \mathrm{~F} \\
\mathrm{u}\end{array}$ & 7 & 76 & 0,68 & 0,690 & 7 & 80 & 1,31 & 0,258 \\
\hline & $\mathrm{Bl}$ & 3 & 3 & 0,20 & 0,891 & 3 & 3 & 0,22 & 0,877 \\
\hline
\end{tabular}




\begin{tabular}{|c|c|c|c|c|c|c|c|c|c|}
\hline Grünfärbung des & So & 1 & 3 & 0,04 & 0,852 & 1 & 3 & 0,94 & 0,403 \\
\hline Pflanzenbestandes & $\mathrm{Di}$ & 1 & 6 & 37,80 & 0,001 & 1 & 6 & 3,65 & 0,105 \\
\hline in BBCH 73 & So*Di & 1 & 6 & 0,64 & 0,454 & 1 & 6 & 0,24 & 0,642 \\
\hline \multirow[t]{5}{*}{ (NDVI_B4) } & $\mathrm{Fu}$ & 7 & 76 & 2,98 & 0,008 & 7 & 80 & 4,87 & 0,000 \\
\hline & So*Fu & 7 & 76 & 1,55 & 0,164 & 7 & 80 & 2,50 & 0,022 \\
\hline & $\mathrm{Di}^{*} \mathrm{Fu}$ & 7 & 76 & 1,63 & 0,139 & 7 & 80 & 2,23 & 0,040 \\
\hline & $\begin{array}{c}\text { So }^{*} \mathrm{Di}^{*} \mathrm{~F} \\
\mathrm{u}\end{array}$ & 7 & 76 & 0,41 & 0,894 & 7 & 80 & 0,36 & 0,922 \\
\hline & $\mathrm{BI}$ & 3 & 3 & 1,41 & 0,392 & 3 & 3 & 10,05 & 0,045 \\
\hline Grünfärbung des & So & 1 & 3 & 0,00 & 0,969 & 1 & 3 & 24,35 & 0,016 \\
\hline Pflanzenbestandes & $\mathrm{Di}$ & 1 & 6 & 0,86 & 0,390 & 1 & 6 & 34,36 & 0,001 \\
\hline in BBCH 79 & So*Di & 1 & 6 & 5,10 & 0,065 & 1 & 6 & 3,56 & 0,108 \\
\hline \multirow[t]{5}{*}{ (NDVI_A1) } & $\mathrm{Fu}$ & 7 & 76 & 4,78 & 0,000 & 7 & 80 & 76,31 & 0,000 \\
\hline & So*Fu & 7 & 76 & 0,20 & 0,985 & 7 & 80 & 4,53 & 0,000 \\
\hline & $\mathrm{Di}^{*} \mathrm{Fu}$ & 7 & 76 & 0,68 & 0,686 & 7 & 80 & 2,81 & 0,011 \\
\hline & $\begin{array}{c}\text { So }^{*} \mathrm{Di}^{*} \mathrm{~F} \\
\mathrm{u}\end{array}$ & 7 & 76 & 0,19 & 0,986 & 7 & 80 & 1,29 & 0,265 \\
\hline & $\mathrm{Bl}$ & 3 & 3 & 0,82 & 0,562 & 3 & 3 & 2,04 & 0,286 \\
\hline Grünfärbung des & So & 1 & 3 & 0,19 & 0,692 & 1 & 3 & 2,32 & 0,225 \\
\hline Pflanzenbestandes & $\mathrm{Di}$ & 1 & 6 & 0,49 & 0,509 & 1 & 6 & 16,63 & 0,007 \\
\hline in BBCH 81 & So*Di & 1 & 6 & 1,52 & 0,264 & 1 & 6 & 0,83 & 0,398 \\
\hline \multirow[t]{5}{*}{ (NDVI_A2) } & $\mathrm{Fu}$ & 7 & 76 & 3,69 & 0,002 & 7 & 80 & 32,27 & 0,000 \\
\hline & So*Fu & 7 & 76 & 0,36 & 0,921 & 7 & 80 & 0,50 & 0,833 \\
\hline & $\mathrm{Di}^{\star} \mathrm{Fu}$ & 7 & 76 & 0,38 & 0,910 & 7 & 80 & 0,84 & 0,556 \\
\hline & $\begin{array}{c}\text { So }^{*} \mathrm{Di}^{*} \mathrm{~F} \\
\mathrm{u}\end{array}$ & 7 & 76 & 0,38 & 0,913 & 7 & 80 & 0,55 & 0,791 \\
\hline & $\mathrm{BI}$ & 3 & 3 & 0,21 & 0,885 & 3 & 3 & 2,33 & 0,253 \\
\hline Grünfärbung des & So & 1 & 3 & 20,25 & 0,020 & 1 & 3 & 6,23 & 0,088 \\
\hline Pflanzenbestandes & $\mathrm{Di}$ & 1 & 6 & 3,12 & 0,128 & 1 & 6 & 8,13 & 0,029 \\
\hline in BBCH 84 & So* Di & 1 & 6 & 6,23 & 0,047 & 1 & 6 & 3,38 & 0,116 \\
\hline \multirow[t]{5}{*}{ (NDVI_A3) } & $\mathrm{Fu}$ & 7 & 76 & 4,86 & 0,000 & 7 & 80 & 29,22 & 0,000 \\
\hline & So*Fu & 7 & 76 & 0,45 & 0,865 & 7 & 80 & 1,73 & 0,113 \\
\hline & $\mathrm{Di}^{\star} \mathrm{Fu}$ & 7 & 76 & 0,50 & 0,831 & 7 & 80 & 1,49 & 0,182 \\
\hline & $\begin{array}{c}\text { So }^{*} \mathrm{Di}^{*} \mathrm{~F} \\
\end{array}$ & 7 & 76 & 0,32 & 0,943 & 7 & 80 & 0,74 & 0,639 \\
\hline & $\mathrm{Bl}$ & 3 & 3 & 0,37 & 0,780 & 3 & 3 & 3,24 & 0,180 \\
\hline Grünfärbung des & So & 1 & 3 & 31,77 & 0,011 & 1 & 3 & 47,34 & 0,006 \\
\hline Pflanzenbestandes & $\mathrm{Di}$ & 1 & 6 & 0,04 & 0,857 & 1 & 6 & 0,02 & 0,881 \\
\hline in $\mathrm{BBCH} 85 / 87$ & So* $\mathrm{Di}$ & 1 & 6 & 1,77 & 0,232 & 1 & 6 & 0,06 & 0,821 \\
\hline \multirow[t]{5}{*}{ (NDVI_A4) } & $\mathrm{Fu}$ & 7 & 76 & 7,02 & 0,000 & 7 & 80 & 12,68 & 0,000 \\
\hline & So*Fu & 7 & 76 & 0,48 & 0,848 & 7 & 80 & 1,56 & 0,161 \\
\hline & $\mathrm{Di}^{\star} \mathrm{Fu}$ & 7 & 76 & 0,38 & 0,912 & 7 & 80 & 1,09 & 0,378 \\
\hline & $\begin{array}{c}\text { So }^{*} \mathrm{Di}^{*} \mathrm{~F} \\
\mathrm{u}\end{array}$ & 7 & 76 & 0,16 & 0,991 & 7 & 80 & 0,85 & 0,547 \\
\hline & $\mathrm{BI}$ & 3 & 3 & 0,13 & 0,934 & 3 & 3 & 2,35 & 0,251 \\
\hline
\end{tabular}




\begin{tabular}{|c|c|c|c|c|c|c|c|c|c|}
\hline Grünfärbung des & So & 1 & 3 & 69,20 & 0,004 & 1 & 3 & 59,41 & 0,005 \\
\hline Pflanzenbestandes & $\mathrm{Di}$ & 1 & 6 & 12,74 & 0,012 & 1 & 6 & 0,24 & 0,641 \\
\hline in BBCH 89 & So*Di & 1 & 6 & 0,16 & 0,706 & 1 & 6 & 1,18 & 0,319 \\
\hline \multirow[t]{5}{*}{ (NDVI_A5) } & $\mathrm{Fu}$ & 7 & 76 & 2,81 & 0,012 & 7 & 80 & 13,34 & 0,000 \\
\hline & So*Fu & 7 & 76 & 0,91 & 0,507 & 7 & 80 & 1,54 & 0,164 \\
\hline & $\mathrm{Di}^{*} \mathrm{Fu}$ & 7 & 76 & 1,48 & 0,189 & 7 & 80 & 1,51 & 0,175 \\
\hline & $\begin{array}{c}\text { So }^{*} \mathrm{Di}^{*} \mathrm{~F} \\
\mathrm{u}\end{array}$ & 7 & 76 & 0,78 & 0,605 & 7 & 80 & 0,82 & 0,570 \\
\hline & $\mathrm{BI}$ & 3 & 3 & 0,17 & 0,909 & 3 & 3 & 2,76 & 0,214 \\
\hline \multirow[t]{8}{*}{$\mathrm{BFI}\left[\mathrm{m}^{2} / \mathbf{m}^{2}\right]$} & So & & & & & 1 & 3 & 0,10 & 0,774 \\
\hline & $\mathrm{Di}$ & & & & & 1 & 6 & 0,73 & 0,427 \\
\hline & So*Di & & & & & 1 & 6 & 0,38 & 0,558 \\
\hline & $\mathrm{Fu}$ & \multicolumn{4}{|c|}{ nicht ermittelt 2010/11 } & 3 & 32 & 18,29 & 0,000 \\
\hline & So*Fu & & & & & 3 & 32 & 1,11 & 0,361 \\
\hline & $\mathrm{Di}{ }^{\star} \mathrm{Fu}$ & & & & & 3 & 32 & 0,03 & 0,994 \\
\hline & $\begin{array}{c}\text { So }^{*} \mathrm{Di}^{*} \mathrm{~F} \\
\mathrm{u}\end{array}$ & & & & & 3 & 32 & 1,26 & 0,305 \\
\hline & $\mathrm{BI}$ & & & & & 3 & 3 & 4,59 & 0,121 \\
\hline Kulturdeckungs- & So & & & & & 1 & 3 & 0,24 & 0,659 \\
\hline grad [\%] & $\mathrm{Di}$ & & & & & 1 & 6 & 0,04 & 0,857 \\
\hline \multirow[t]{6}{*}{ im Herbst } & So*Di & & & & & 1 & 6 & 0,02 & 0,880 \\
\hline & $\mathrm{Fu}$ & \multicolumn{4}{|c|}{ nicht ermittelt 2010/11 } & 7 & 80 & 2,22 & 0,041 \\
\hline & So*Fu & & & & & 7 & 80 & 1,47 & 0,191 \\
\hline & Di*Fu & & & & & 7 & 80 & 2,42 & 0,027 \\
\hline & $\begin{array}{c}\text { So }^{*} \mathrm{Di}^{*} \mathrm{~F} \\
\mathrm{u}\end{array}$ & & & & & 7 & 80 & 1,20 & 0,310 \\
\hline & $\mathrm{BI}$ & & & & & 3 & 3 & 0,35 & 0,791 \\
\hline Pflanzen $/ \mathrm{m}^{2}$ & So & 1 & 3 & 36,85 & 0,009 & 1 & 3 & 0,28 & 0,631 \\
\hline \multirow[t]{7}{*}{ im Herbst } & $\mathrm{Di}$ & 1 & 6 & 328,01 & 0,000 & 1 & 6 & 98,87 & 0,000 \\
\hline & So*Di & 1 & 6 & 0,02 & 0,905 & 1 & 6 & 1,99 & 0,208 \\
\hline & $\mathrm{Fu}$ & 7 & 84 & 0,64 & 0,723 & 7 & 80 & 0,92 & 0,498 \\
\hline & So*Fu & 7 & 84 & 0,45 & 0,864 & 7 & 80 & 2,06 & 0,057 \\
\hline & $\mathrm{Di}^{\star} \mathrm{Fu}$ & 7 & 84 & 1,09 & 0,380 & 7 & 80 & 0,15 & 0,994 \\
\hline & $\begin{array}{c}\text { So }^{*} \mathrm{Di}^{*} \mathrm{~F} \\
\end{array}$ & 7 & 84 & 0,31 & 0,947 & 7 & 80 & 0,72 & 0,653 \\
\hline & $\mathrm{Bl}$ & 3 & 3 & 0,92 & 0,528 & 3 & 3 & 0,82 & 0,562 \\
\hline Wurzelhals- & So & 1 & 3 & 4,36 & 0,128 & 1 & 3 & 2,03 & 0,249 \\
\hline durchmesser [mm] & $\mathrm{Di}$ & 1 & 6 & 2,62 & 0,157 & 1 & 6 & 59,43 & 0,000 \\
\hline \multirow[t]{6}{*}{ im Herbst } & So* $\mathrm{Di}$ & 1 & 6 & 0,50 & 0,508 & 1 & 6 & 0,42 & 0,543 \\
\hline & $\mathrm{Fu}$ & 7 & 84 & 0,63 & 0,733 & 7 & 80 & 1,00 & 0,440 \\
\hline & So*Fu & 7 & 84 & 0,35 & 0,930 & 7 & 80 & 0,73 & 0,648 \\
\hline & $\mathrm{Di}^{*} \mathrm{Fu}$ & 7 & 84 & 0,52 & 0,821 & 7 & 80 & 0,84 & 0,560 \\
\hline & $\begin{array}{c}\text { So }^{*} \mathrm{Di}^{*} \mathrm{~F} \\
\mathrm{u}\end{array}$ & 7 & 84 & 0,60 & 0,753 & 7 & 80 & 0,64 & 0,719 \\
\hline & $\mathrm{BI}$ & 3 & 3 & 0,89 & 0,536 & 3 & 3 & 0,98 & 0,508 \\
\hline
\end{tabular}




\begin{tabular}{|c|c|c|c|c|c|c|c|c|c|}
\hline \multirow[t]{8}{*}{ Blattlänge [cm] } & So & 1 & 3 & 8,67 & 0,060 & 1 & 3 & 0,00 & 0,953 \\
\hline & $\mathrm{Di}$ & 1 & 6 & 0,02 & 0,883 & 1 & 6 & 53,06 & 0,000 \\
\hline & So*Di & 1 & 6 & 0,87 & 0,388 & 1 & 6 & 0,00 & 0,979 \\
\hline & $\mathrm{Fu}$ & 7 & 84 & 18,82 & 0,000 & 7 & 80 & 2,44 & 0,025 \\
\hline & So*Fu & 7 & 84 & 0,78 & 0,603 & 7 & 80 & 1,64 & 0,138 \\
\hline & $\mathrm{Di}^{*} \mathrm{Fu}$ & 7 & 84 & 0,81 & 0,579 & 7 & 80 & 0,93 & 0,490 \\
\hline & $\begin{array}{c}\text { So }^{*} \mathrm{Di}^{*} \mathrm{~F} \\
\mathrm{u}\end{array}$ & 7 & 84 & 1,21 & 0,305 & 7 & 80 & 0,85 & 0,551 \\
\hline & $\mathrm{Bl}$ & 3 & 3 & 0,97 & 0,510 & 3 & 3 & 2,51 & 0,235 \\
\hline \multirow[t]{8}{*}{ Blätter/Pflanze } & So & 1 & 3 & 3,91 & 0,142 & 1 & 3 & 13,47 & 0,035 \\
\hline & $\mathrm{Di}$ & 1 & 6 & 4,48 & 0,079 & 1 & 6 & 15,11 & 0,008 \\
\hline & So* $\mathrm{Di}$ & 1 & 6 & 0,10 & 0,765 & 1 & 6 & 0,27 & 0,620 \\
\hline & $\mathrm{Fu}$ & 7 & 84 & 1,25 & 0,286 & 7 & 80 & 3,55 & 0,002 \\
\hline & So*Fu & 7 & 84 & 1,26 & 0,278 & 7 & 80 & 0,67 & 0,701 \\
\hline & $\mathrm{Di}^{*} \mathrm{Fu}$ & 7 & 84 & 0,44 & 0,875 & 7 & 80 & 0,69 & 0,682 \\
\hline & $\begin{array}{c}\text { So }^{*} \mathrm{Di}^{*} \mathrm{~F} \\
\mathrm{u}\end{array}$ & 7 & 84 & 0,72 & 0,657 & 7 & 80 & 0,68 & 0,690 \\
\hline & BI & 3 & 3 & 1,64 & 0,347 & 3 & 3 & 1,14 & 0,458 \\
\hline BH [\%] mit der & So & 1 & 3 & 0,70 & 0,464 & 1 & 3 & 7,59 & 0,070 \\
\hline Wurzelhals- und & $\mathrm{Di}$ & 1 & 6 & 1,82 & 0,225 & 1 & 6 & 4,35 & 0,082 \\
\hline Stängelfäule & So* $\mathrm{Di}$ & 1 & 6 & 6,29 & 0,046 & 1 & 6 & 0,40 & 0,550 \\
\hline an Laubblättern & $\mathrm{Fu}$ & 7 & 84 & 14,03 & 0,000 & 7 & 80 & 24,19 & 0,000 \\
\hline \multirow[t]{4}{*}{ im Herbst } & So*Fu & 7 & 84 & 2,49 & 0,023 & 7 & 80 & 2,38 & 0,029 \\
\hline & $\mathrm{Di}{ }^{\star} \mathrm{Fu}$ & 7 & 84 & 1,63 & 0,138 & 7 & 80 & 1,90 & 0,081 \\
\hline & $\begin{array}{c}\text { So }^{*} \mathrm{Di}^{*} \mathrm{~F} \\
\mathrm{u}\end{array}$ & 7 & 84 & 1,57 & 0,155 & 7 & 80 & 0,40 & 0,900 \\
\hline & $\mathrm{BI}$ & 3 & 3 & 2,03 & 0,288 & 3 & 3 & 1,15 & 0,454 \\
\hline BW mit der & So & 1 & 3 & 0,51 & 0,528 & 1 & 3 & 4,92 & 0,113 \\
\hline Wurzelhals- und & $\mathrm{Di}$ & 1 & 6 & 1,83 & 0,225 & 1 & 6 & 3,70 & 0,103 \\
\hline Stängelfäule & So* $\mathrm{Di}$ & 1 & 6 & 3,53 & 0,109 & 1 & 6 & 0,41 & 0,547 \\
\hline an Laubblättern & $\mathrm{Fu}$ & 7 & 84 & 22,37 & 0,000 & 7 & 80 & 23,95 & 0,000 \\
\hline \multirow[t]{4}{*}{ im Herbst } & So*Fu & 7 & 84 & 2,59 & 0,018 & 7 & 80 & 1,98 & 0,067 \\
\hline & $\mathrm{Di}^{\star} \mathrm{Fu}$ & 7 & 84 & 2,34 & 0,031 & 7 & 80 & 1,99 & 0,066 \\
\hline & $\begin{array}{c}\text { So }^{*} \mathrm{Di}^{*} \mathrm{~F} \\
\mathrm{u}\end{array}$ & 7 & 84 & 1,32 & 0,252 & 7 & 80 & 0,44 & 0,873 \\
\hline & $\mathrm{BI}$ & 3 & 3 & 1,11 & 0,468 & 3 & 3 & 1,50 & 0,373 \\
\hline $\mathrm{BH}[\%]$ mit der & So & 1 & 3 & 2,49 & 0,212 & 1 & 3 & 1,42 & 0,319 \\
\hline Wurzelhals- und & $\mathrm{Di}$ & 1 & 6 & 0,28 & 0,618 & 1 & 6 & 3,24 & 0,122 \\
\hline Stängelfäule & So* $\mathrm{Di}$ & 1 & 6 & 0,00 & 1,000 & 1 & 6 & 1,42 & 0,278 \\
\hline am Wurzelhals & $\mathrm{Fu}$ & 7 & 84 & 0,60 & 0,754 & 7 & 80 & 1,69 & 0,122 \\
\hline \multirow[t]{4}{*}{ im Herbst } & So*Fu & 7 & 84 & 0,64 & 0,719 & 7 & 80 & 0,74 & 0,637 \\
\hline & $\mathrm{Di}^{*} \mathrm{Fu}$ & 7 & 84 & 0,90 & 0,511 & 7 & 80 & 0,52 & 0,820 \\
\hline & $\begin{array}{c}\text { So }^{*} \mathrm{Di}^{*} \mathrm{~F} \\
\mathrm{u}\end{array}$ & 7 & 84 & 1,37 & 0,228 & 7 & 80 & 1,59 & 0,152 \\
\hline & $\mathrm{Bl}$ & 3 & 3 & 2,17 & 0,270 & 3 & 3 & 0,68 & 0,621 \\
\hline
\end{tabular}




\begin{tabular}{|c|c|c|c|c|c|c|c|c|c|}
\hline BW mit der & So & 1 & 3 & 0,40 & 0,570 & 1 & 3 & 1,45 & 0,315 \\
\hline Wurzelhals- und & $\mathrm{Di}$ & 1 & 6 & 0,69 & 0,437 & 1 & 6 & 2,75 & 0,148 \\
\hline Stängelfäule & So*Di & 1 & 6 & 0,00 & 0,963 & 1 & 6 & 2,37 & 0,175 \\
\hline am Wurzelhals & $\mathrm{Fu}$ & 7 & 84 & 0,64 & 0,723 & 7 & 80 & 1,79 & 0,101 \\
\hline \multirow[t]{4}{*}{ im Herbst } & So*Fu & 7 & 84 & 0,54 & 0,800 & 7 & 80 & 0,86 & 0,543 \\
\hline & $\mathrm{Di}{ }^{\star} \mathrm{Fu}$ & 7 & 84 & 1,06 & 0,394 & 7 & 80 & 0,72 & 0,655 \\
\hline & $\begin{array}{c}\mathrm{So}^{*} \mathrm{Di}^{*} \mathrm{~F} \\
\mathrm{u}\end{array}$ & 7 & 84 & 1,16 & 0,335 & 7 & 80 & 0,68 & 0,690 \\
\hline & $\mathrm{BI}$ & 3 & 3 & 2,24 & 0,263 & 3 & 3 & 0,93 & 0,524 \\
\hline $\mathrm{BH}$ [\%] mit der & So & 1 & 3 & 24,22 & 0,016 & 1 & 3 & 2,52 & 0,210 \\
\hline Wurzelhals- und & $\mathrm{Di}$ & 1 & 6 & 13,09 & 0,011 & 1 & 6 & 5,85 & 0,052 \\
\hline Stängelfäule & So* Di & 1 & 6 & 9,20 & 0,023 & 1 & 6 & 2,00 & 0,207 \\
\hline am unteren & $\mathrm{Fu}$ & 7 & 76 & 9,86 & 0,000 & 7 & 80 & 5,01 & 0,000 \\
\hline Stängel & So*Fu & 7 & 76 & 3,65 & 0,002 & 7 & 80 & 0,89 & 0,521 \\
\hline \multirow[t]{3}{*}{ im Frühjahr } & $\mathrm{Di}{ }^{\star} \mathrm{Fu}$ & 7 & 76 & 1,52 & 0,174 & 7 & 80 & 0,74 & 0,635 \\
\hline & $\begin{array}{c}\text { So* }{ }^{*}{ }^{*} \mathrm{~F} \\
\mathrm{u}\end{array}$ & 7 & 76 & 2,04 & 0,061 & 7 & 80 & 1,47 & 0,191 \\
\hline & BI & 3 & 3 & 1,24 & 0,431 & 3 & 3 & 0,43 & 0,748 \\
\hline BW mit der & So & 1 & 3 & 0,90 & 0,412 & 1 & 3 & 0,38 & 0,580 \\
\hline Wurzelhals- und & $\mathrm{Di}$ & 1 & 6 & 3,47 & 0,112 & 1 & 6 & 10,03 & 0,019 \\
\hline Stängelfäule & So*Di & 1 & 6 & 1,05 & 0,345 & 1 & 6 & 0,57 & 0,480 \\
\hline am unteren & $\mathrm{Fu}$ & 7 & 76 & 20,22 & 0,000 & 7 & 80 & 4,04 & 0,001 \\
\hline Stängel & So*Fu & 7 & 76 & 1,83 & 0,094 & 7 & 80 & 0,93 & 0,486 \\
\hline \multirow[t]{3}{*}{ im Frühjahr } & $\mathrm{Di}^{\star} \mathrm{Fu}$ & 7 & 76 & 2,27 & 0,038 & 7 & 80 & 1,03 & 0,415 \\
\hline & $\begin{array}{c}\text { So* }{ }^{*}{ }^{*} F \\
u\end{array}$ & 7 & 76 & 1,33 & 0,250 & 7 & 80 & 0,66 & 0,705 \\
\hline & $\mathrm{BI}$ & 3 & 3 & 0,06 & 0,979 & 3 & 3 & 0,40 & 0,763 \\
\hline $\mathrm{BH}$ [\%] mit der & So & 1 & 3 & 4,22 & 0,132 & 1 & 3 & 1,08 & 0,375 \\
\hline Wurzelhals- und & $\mathrm{Di}$ & 1 & 6 & 5,58 & 0,056 & 1 & 6 & 0,17 & 0,692 \\
\hline Stängelfäule & So* $\mathrm{Di}$ & 1 & 6 & 5,22 & 0,062 & 1 & 6 & 0,13 & 0,726 \\
\hline am Wurzelhals & $\mathrm{Fu}$ & 7 & 76 & 0,80 & 0,589 & 7 & 80 & 4,17 & 0,001 \\
\hline \multirow[t]{4}{*}{ im Frühjahr } & So*Fu & 7 & 76 & 0,77 & 0,612 & 7 & 80 & 1,05 & 0,406 \\
\hline & $\mathrm{Di}^{\star} \mathrm{Fu}$ & 7 & 76 & 0,83 & 0,569 & 7 & 80 & 1,18 & 0,323 \\
\hline & $\begin{array}{c}\text { So* } \mathrm{Di}^{*} \mathrm{~F} \\
\mathrm{u}\end{array}$ & 7 & 76 & 0,77 & 0,613 & 7 & 80 & 0,86 & 0,539 \\
\hline & $\mathrm{BI}$ & 3 & 3 & 0,92 & 0,526 & 3 & 3 & 2,36 & 0,249 \\
\hline BW mit der & So & 1 & 3 & 0,01 & 0,935 & 1 & 3 & 12,97 & 0,037 \\
\hline Wurzelhals- und & $\mathrm{Di}$ & 1 & 6 & 219,04 & 0,000 & 1 & 6 & 1,25 & 0,305 \\
\hline Stängelfäule & So* $\mathrm{Di}$ & 1 & 6 & 41,35 & 0,001 & 1 & 6 & 1,26 & 0,304 \\
\hline am Wurzelhals & $\mathrm{Fu}$ & 7 & 76 & 8,12 & 0,000 & 7 & 80 & 9,44 & 0,000 \\
\hline \multirow[t]{4}{*}{ im Frühjahr } & So*Fu & 7 & 76 & 1,17 & 0,328 & 7 & 80 & 1,94 & 0,073 \\
\hline & $\mathrm{Di}{ }^{\star} \mathrm{Fu}$ & 7 & 76 & 0,51 & 0,828 & 7 & 80 & 2,68 & 0,015 \\
\hline & $\begin{array}{c}\text { So* } \mathrm{Di}^{*} \mathrm{~F} \\
\mathrm{u}\end{array}$ & 7 & 76 & 0,17 & 0,990 & 7 & 80 & 1,85 & 0,088 \\
\hline & $\mathrm{Bl}$ & 3 & 3 & 0,61 & 0,654 & 3 & 3 & 2,16 & 0,271 \\
\hline
\end{tabular}




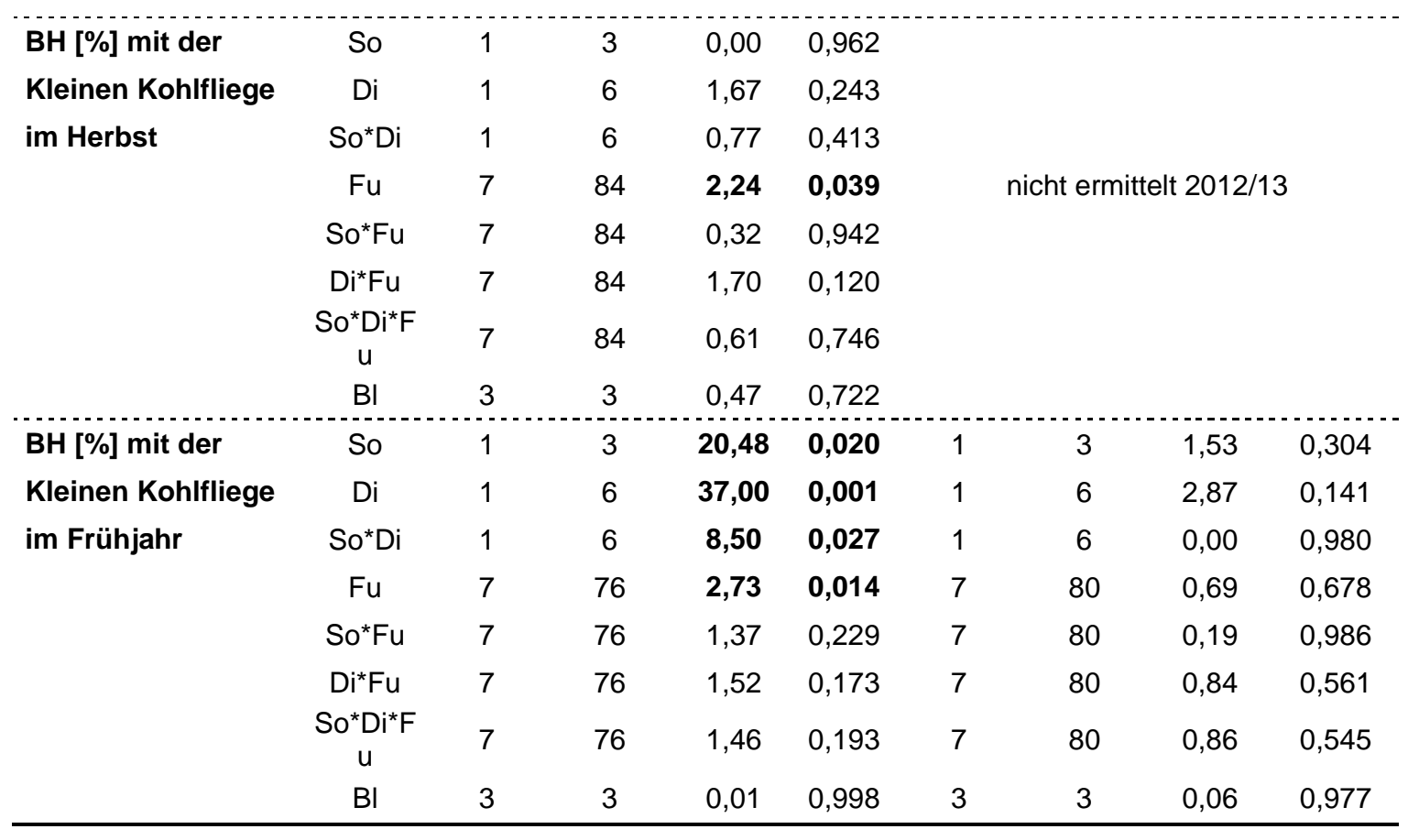


Tab. 26A: Kleinste-Quadrate-Mittelwerte für Parameter mit signifikanten Effekten (Tab. 25A) der drei Versuchsfaktoren Sorte (So), Saatstärke (Di) und Fungizid (Fu) bzw. deren Interaktionen, die in dem Jahr 2010/11 im Feldversuch am Standort Göttingen untersucht wurden. Mittelwerte, die mit unterschiedlichen Buchstaben kennzeichnet sind, unterscheiden sich signifikant (Tukey-Test, $p \leq 0,05)$. Hierbei muss folgendes beachtet werden: Bei den Haupteffekten und der Interaktion zwischen Sorte $x$ Saatstärke (So*Di) können jeweils alle Ausprägungen eines Effektes durch die Buchstaben miteinander verglichen werden. Bei den Interaktionen zwischen Sorte x Fungizid (So* $\mathrm{Fu}$ ) und Saatstärke x Fungizid ( $\mathrm{Di}{ }^{\star} \mathrm{Fu}$ ) beziehen sich die Buchstaben auf die einfachen Effekte, sodass durch die Buchstaben nur Vergleiche zwischen den Fungizidvarianten innerhalb einer Sorte oder einer Saatstärke möglich sind. Entsprechendes gilt für die Interaktion zwischen Sorte $\mathrm{x}$ Saatstärke $x$ Fungizid $\left(\mathrm{So}^{*} \mathrm{Di}^{*} \mathrm{Fu}\right.$ ). Hier ermöglichen die Buchstaben nur einen Vergleich zwischen den Fungiziden innerhalb einer Sorte $\times$ Saatstärken-Kombination. Dargestellt sind die Mittelwerte, die Standardabweichung (SD), errechnet aus den Residuen des gegebenen Modells, und die Anzahl der Werte (n), die in die jeweilige Berechnung eingegangen sind. Kursive Buchstaben stellen Unterschiede zwischen den Mittelwerten auf Basis des Globaltests (F-Test, $p \leq 0,05)$ und nicht des Tukey-Tests dar. So = Sorte $(M=S Y$ Merlot, $P=N K$ Petrol); $\mathrm{Di}=$ Saatstärke $(30 \mathrm{bzw} .60$ Körner $\left./ \mathrm{m}^{2}\right) ; \mathrm{Fu}=$ Fungizid $\left(1=\right.$ unbehandelte Kontrolle, $2=0,5 \mathrm{l} / \mathrm{ha}$ Toprex $^{\circledR}$ in BBCH 33/35, $3=$ 0,5 I/ha Toprex ${ }^{\circledR}$ in BBCH 14 und 33/35, $4=0,5 \mathrm{l} /$ ha Toprex $^{\circledR}$ in BBCH 14, 16 und 33/35, $5=0,5$ I/ha Toprex ${ }^{\circledR}$ in BBCH 14, 33/35 und 53/55, $6=0,5$ l/ha Toprex ${ }^{\circledR}$ in BBCH $14+1,0$ l/ha Toprex ${ }^{\circledR}$ in

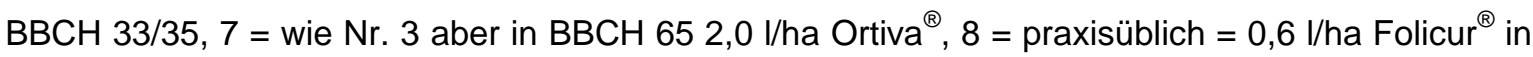
$\mathrm{BBCH} 14+0,7 \mathrm{l} / \mathrm{ha}$ Carax $^{\circledR}$ in $\mathrm{BBCH} 33 / 35+0,8 \mathrm{I} /$ ha Harvesan ${ }^{\circledR}$ in $\mathrm{BBCH}$ 65; Varianten 1-6 erhielten in $\mathrm{BBCH} 651 \mathrm{l} /$ ha Ortiva $^{\circledR}$ ).

\begin{tabular}{|c|c|c|c|c|c|c|c|c|}
\hline Parameter & Effekt & So & $\mathrm{Di}$ & $\mathrm{Fu}$ & Mittelwert & SD & $\mathbf{n}$ & Buchstaben \\
\hline \multirow[t]{14}{*}{ Kornertrag [t/ha] } & $\mathrm{Di}$ & & 30 & & 4,17 & 0,31 & 64 & $b$ \\
\hline & $\mathrm{Di}$ & & 60 & & 4,76 & 0,28 & 64 & a \\
\hline & $\mathrm{So}^{*} \mathrm{Di}$ & $M$ & 30 & & 3,94 & 0,32 & 32 & b \\
\hline & So* $\mathrm{Di}$ & M & 60 & & 4,85 & 0,29 & 32 & a \\
\hline & So* Di & $P$ & 30 & & 4,40 & 0,30 & 32 & $a b$ \\
\hline & So* $\mathrm{Di}$ & $P$ & 60 & & 4,68 & 0,28 & 32 & a \\
\hline & $\mathrm{Fu}$ & & & 1 & 4,35 & 0,21 & 16 & $a b$ \\
\hline & $\mathrm{Fu}$ & & & 2 & 4,42 & 0,26 & 16 & $a b$ \\
\hline & $\mathrm{Fu}$ & & & 3 & 4,42 & 0,20 & 16 & $a b$ \\
\hline & $\mathrm{Fu}$ & & & 4 & 4,52 & 0,34 & 16 & $a b$ \\
\hline & $\mathrm{Fu}$ & & & 5 & 4,62 & 0,43 & 16 & $a b$ \\
\hline & $\mathrm{Fu}$ & & & 6 & 4,74 & 0,34 & 16 & $\mathrm{a}$ \\
\hline & $\mathrm{Fu}$ & & & 7 & 4,43 & 0,20 & 16 & $a b$ \\
\hline & $\mathrm{Fu}$ & & & 8 & 4,25 & 0,36 & 16 & $b$ \\
\hline Strohbiomasseertrag & $\mathrm{Di}$ & & 30 & & 5,53 & 0,57 & 64 & $\mathrm{~b}$ \\
\hline [t/ha] & $\mathrm{Di}$ & & 60 & & 6,04 & 0,47 & 64 & a \\
\hline
\end{tabular}




\begin{tabular}{|c|c|c|c|c|c|c|c|c|}
\hline & $\mathrm{Fu}$ & & & 1 & 5,66 & 0,41 & 16 & $a b$ \\
\hline & $\mathrm{Fu}$ & & & 2 & 6,27 & 0,65 & 16 & $a$ \\
\hline & $\mathrm{Fu}$ & & & 3 & 5,58 & 0,53 & 16 & $a b$ \\
\hline & $\mathrm{Fu}$ & & & 4 & 5,54 & 0,41 & 16 & $b$ \\
\hline & $\mathrm{Fu}$ & & & 5 & 5,70 & 0,45 & 16 & $a b$ \\
\hline & $\mathrm{Fu}$ & & & 6 & 6,07 & 0,76 & 16 & $a b$ \\
\hline & $\mathrm{Fu}$ & & & 7 & 5,99 & 0,46 & 16 & $a b$ \\
\hline & $\mathrm{Fu}$ & & & 8 & 5,48 & 0,49 & 16 & $b$ \\
\hline \multirow[t]{4}{*}{ Ölgehalt [\%] } & So & $M$ & & & 44,01 & 0,37 & 64 & $a$ \\
\hline & So & $\mathrm{P}$ & & & 43,16 & 0,32 & 64 & $b$ \\
\hline & $\mathrm{Di}$ & & 30 & & 43,37 & 0,30 & 64 & $\mathrm{~b}$ \\
\hline & $\mathrm{Di}$ & & 60 & & 43,80 & 0,39 & 64 & a \\
\hline \multirow{14}{*}{ Ölertrag [t/ha] } & $\mathrm{Di}$ & & 30 & & 1,81 & 0,13 & 64 & $b$ \\
\hline & $\mathrm{Di}$ & & 60 & & 2,09 & 0,12 & 64 & a \\
\hline & So* $\mathrm{Di}$ & $M$ & 30 & & 1,73 & 0,14 & 32 & b \\
\hline & So*Di & $\mathrm{M}$ & 60 & & 2,15 & 0,13 & 32 & $a$ \\
\hline & So*Di & $P$ & 30 & & 1,89 & 0,13 & 32 & $a b$ \\
\hline & So* $\mathrm{Di}$ & $P$ & 60 & & 2,03 & 0,11 & 32 & $\mathrm{a}$ \\
\hline & $\mathrm{Fu}$ & & & 1 & 1,91 & 0,09 & 16 & $a b$ \\
\hline & $\mathrm{Fu}$ & & & 2 & 1,93 & 0,11 & 16 & $a b$ \\
\hline & $\mathrm{Fu}$ & & & 3 & 1,93 & 0,09 & 16 & $a b$ \\
\hline & $\mathrm{Fu}$ & & & 4 & 1,97 & 0,15 & 16 & $a b$ \\
\hline & $\mathrm{Fu}$ & & & 5 & 2,01 & 0,18 & 16 & $a b$ \\
\hline & $\mathrm{Fu}$ & & & 6 & 2,06 & 0,14 & 16 & $a$ \\
\hline & $\mathrm{Fu}$ & & & 7 & 1,93 & 0,09 & 16 & $a b$ \\
\hline & $\mathrm{Fu}$ & & & 8 & 1,85 & 0,16 & 16 & $b$ \\
\hline \multirow[t]{8}{*}{ Ernteindex [\%] } & $\mathrm{Fu}$ & & & 1 & 41,08 & 2,57 & 16 & $a b$ \\
\hline & $\mathrm{Fu}$ & & & 2 & 39,18 & 2,45 & 16 & $b$ \\
\hline & $\mathrm{Fu}$ & & & 3 & 41,97 & 2,23 & 16 & $a b$ \\
\hline & $\mathrm{Fu}$ & & & 4 & 42,65 & 2,39 & 16 & $\mathrm{a}$ \\
\hline & $\mathrm{Fu}$ & & & 5 & 42,47 & 2,51 & 16 & $a b$ \\
\hline & $\mathrm{Fu}$ & & & 6 & 41,71 & 2,82 & 16 & $a b$ \\
\hline & $\mathrm{Fu}$ & & & 7 & 40,21 & 2,24 & 16 & $a b$ \\
\hline & $\mathrm{Fu}$ & & & 8 & 41,33 & 2,37 & 16 & $a b$ \\
\hline Pflanzen $/ \mathrm{m}^{2}$ & So & $M$ & & & 30,91 & 4,70 & 64 & $b$ \\
\hline \multirow[t]{3}{*}{ im Frühjahr } & So & $P$ & & & 40,75 & 5,41 & 64 & a \\
\hline & $\mathrm{Di}$ & & 30 & & 24,25 & 4,52 & 64 & b \\
\hline & $\mathrm{Di}$ & & 60 & & 47,41 & 5,56 & 64 & a \\
\hline \multirow[t]{6}{*}{ Schoten/Pflanze } & $\mathrm{Di}$ & & 30 & & 309,25 & 50,40 & 64 & a \\
\hline & $\mathrm{Di}$ & & 60 & & 206,79 & 37,51 & 64 & $b$ \\
\hline & So*Di & $\mathrm{M}$ & 30 & & 345,57 & 61,76 & 32 & a \\
\hline & So*Di & $\mathrm{M}$ & 60 & & 203,63 & 42,26 & 32 & c \\
\hline & So*Di & $\mathrm{P}$ & 30 & & 272,93 & 30,53 & 32 & $b$ \\
\hline & So*Di & $\mathrm{P}$ & 60 & & 209,96 & 32,76 & 32 & c \\
\hline
\end{tabular}




\begin{tabular}{|c|c|c|c|c|c|c|c|c|}
\hline \multirow[t]{18}{*}{ Körner/Schote } & \multirow{2}{*}{\multicolumn{2}{|c|}{$\begin{array}{l}\mathrm{Di} \\
\mathrm{Di}\end{array}$}} & \multirow{2}{*}{\multicolumn{2}{|c|}{$\begin{array}{l}30 \\
60\end{array}$}} & \multirow{2}{*}{$\begin{array}{l}23,80 \\
21,89\end{array}$} & \multirow{2}{*}{$\begin{array}{l}1,33 \\
1,02\end{array}$} & \multirow{2}{*}{$\begin{array}{l}64 \\
64\end{array}$} & \multirow{2}{*}{$\begin{array}{l}a \\
b\end{array}$} \\
\hline & & & & & & & & \\
\hline & \multicolumn{2}{|l|}{$\mathrm{Di}{ }^{*} \mathrm{Fu}$} & 30 & 1 & 24,00 & 0,93 & 8 & $a b$ \\
\hline & \multicolumn{2}{|l|}{$\mathrm{Di}{ }^{\star} \mathrm{Fu}$} & 30 & 2 & 22,15 & 2,07 & 8 & $\mathrm{~b}$ \\
\hline & \multicolumn{2}{|l|}{$\mathrm{Di}{ }^{*} \mathrm{Fu}$} & 30 & 3 & 24,21 & 0,98 & 8 & $a b$ \\
\hline & \multicolumn{2}{|l|}{$\mathrm{Di}{ }^{\star} \mathrm{Fu}$} & 30 & 4 & 24,02 & 1,15 & 8 & $a b$ \\
\hline & \multicolumn{2}{|l|}{$\mathrm{Di}{ }^{\star} \mathrm{Fu}$} & 30 & 5 & 25,29 & 1,58 & 8 & $a$ \\
\hline & \multicolumn{2}{|l|}{$\mathrm{Di}{ }^{\star} \mathrm{Fu}$} & 30 & 6 & 24,04 & 1,41 & 8 & $a b$ \\
\hline & \multicolumn{2}{|l|}{$\mathrm{Di}{ }^{\star} \mathrm{Fu}$} & 30 & 7 & 24,61 & 1,44 & 8 & $a b$ \\
\hline & \multicolumn{2}{|l|}{$\mathrm{Di}{ }^{\star} \mathrm{Fu}$} & 30 & 8 & 22,11 & 1,52 & 8 & $\mathrm{~b}$ \\
\hline & \multicolumn{2}{|l|}{$\mathrm{Di}{ }^{\star} \mathrm{Fu}$} & 60 & 1 & 21,95 & 0,76 & 8 & $a$ \\
\hline & \multicolumn{2}{|l|}{$\mathrm{Di}^{\star} \mathrm{Fu}$} & 60 & 2 & 22,02 & 0,96 & 8 & $\mathrm{a}$ \\
\hline & \multicolumn{2}{|l|}{$\mathrm{Di}^{\star} \mathrm{Fu}$} & 60 & 3 & 21,90 & 0,81 & 8 & $\mathrm{a}$ \\
\hline & \multicolumn{2}{|l|}{$\mathrm{Di}{ }^{\star} \mathrm{Fu}$} & 60 & 4 & 21,37 & 1,49 & 8 & $\mathrm{a}$ \\
\hline & $\mathrm{Di}^{\star} \mathrm{Fu}$ & & 60 & 5 & 21,56 & 0,94 & 8 & $\mathrm{a}$ \\
\hline & $\mathrm{Di}^{\star} \mathrm{Fu}$ & & 60 & 6 & 21,89 & 1,08 & 8 & $\mathrm{a}$ \\
\hline & $\mathrm{Di}^{\star} \mathrm{Fu}$ & & 60 & 7 & 22,24 & 1,03 & 8 & $\mathrm{a}$ \\
\hline & $\mathrm{Di}^{\star} \mathrm{Fu}$ & & 60 & 8 & 22,19 & 1,36 & 8 & $\mathrm{a}$ \\
\hline \multirow[t]{16}{*}{ TKM [g] } & So & $M$ & & & 5,71 & 0,13 & 64 & $a$ \\
\hline & So & $\mathrm{P}$ & & & 5,19 & 0,10 & 64 & $b$ \\
\hline & $\mathrm{Di}$ & & 30 & & 5,57 & 0,11 & 64 & $a$ \\
\hline & $\mathrm{Di}$ & & 60 & & 5,33 & 0,13 & 64 & $b$ \\
\hline & So* $\mathrm{Di}$ & $\mathrm{M}$ & 30 & & 5,88 & 0,11 & 32 & $a$ \\
\hline & So* Di & $M$ & 60 & & 5,53 & 0,15 & 32 & $\mathrm{~b}$ \\
\hline & So* $\mathrm{Di}$ & $P$ & 30 & & 5,26 & 0,11 & 32 & $c$ \\
\hline & $\mathrm{So}^{*} \mathrm{Di}$ & $\mathrm{P}$ & 60 & & 5,13 & 0,10 & 32 & $d$ \\
\hline & $\mathrm{Fu}$ & & & 1 & 5,57 & 0,19 & 16 & $a$ \\
\hline & $\mathrm{Fu}$ & & & 2 & 5,49 & 0,11 & 16 & $a b$ \\
\hline & $\mathrm{Fu}$ & & & 3 & 5,46 & 0,09 & 16 & $a b$ \\
\hline & $\mathrm{Fu}$ & & & 4 & 5,37 & 0,11 & 16 & $b$ \\
\hline & $\mathrm{Fu}$ & & & 5 & 5,42 & 0,10 & 16 & $a b$ \\
\hline & $\mathrm{Fu}$ & & & 6 & 5,35 & 0,14 & 16 & $\mathrm{~b}$ \\
\hline & $\mathrm{Fu}$ & & & 7 & 5,43 & 0,09 & 16 & $a b$ \\
\hline & $\mathrm{Fu}$ & & & 8 & 5,50 & 0,09 & 16 & $a b$ \\
\hline \multirow[t]{4}{*}{ Schoten $/ \mathrm{m}^{2}$} & So & $M$ & & & 7610,72 & 1702,72 & 64 & $b$ \\
\hline & So & $P$ & & & 9465,21 & 1884,22 & 64 & $a$ \\
\hline & $\mathrm{Di}$ & & 30 & & 7315,04 & 1590,92 & 64 & $b$ \\
\hline & $\mathrm{Di}$ & & 60 & & 9760,88 & 1946,55 & 64 & $\mathrm{a}$ \\
\hline \multirow[t]{6}{*}{ Körner/Pflanze } & $\mathrm{Di}$ & & 30 & & 7361,10 & 1307,34 & 64 & $a$ \\
\hline & $\mathrm{Di}$ & & 60 & & 4540,45 & 922,35 & 64 & $b$ \\
\hline & So*Di & $\mathrm{M}$ & 30 & & 8066,15 & 1562,94 & 32 & $a$ \\
\hline & So* $\mathrm{Di}$ & $M$ & 60 & & 4261,11 & 996,05 & 32 & $b$ \\
\hline & So*Di & $P$ & 30 & & 6656,05 & 891,42 & 32 & $\mathrm{a}$ \\
\hline & So* $\mathrm{Di}$ & $\mathrm{P}$ & 60 & & 4819,79 & 858,37 & 32 & $\mathrm{~b}$ \\
\hline
\end{tabular}




\begin{tabular}{|c|c|c|c|c|c|c|c|}
\hline \multirow[t]{4}{*}{ Korndichte } & So & $M$ & & 167336,08 & 41067,95 & 64 & $\mathrm{~b}$ \\
\hline & So & $\mathrm{P}$ & & 222107,36 & 45734,11 & 64 & $\mathrm{a}$ \\
\hline & $\mathrm{Di}$ & & 30 & 174122,37 & 39951,51 & 64 & $\mathrm{~b}$ \\
\hline & $\mathrm{Di}$ & & 60 & 215321,08 & 46034,16 & 64 & a \\
\hline Kulturdeckungsgrad & So & $M$ & & 37,20 & 4,74 & 64 & $\mathrm{~b}$ \\
\hline \multirow[t]{3}{*}{ [\%] in BBCH $32 / 34$} & So & $P$ & & 49,47 & 6,29 & 64 & a \\
\hline & $\mathrm{Di}$ & & 30 & 34,87 & 6,11 & 64 & $\mathrm{~b}$ \\
\hline & $\mathrm{Di}$ & & 60 & 51,80 & 4,93 & 64 & a \\
\hline Wurzelhalsdurch- & $\mathrm{Di}$ & & 30 & 15,66 & 0,81 & 64 & $a$ \\
\hline messer [mm] & $\mathrm{Di}$ & & 60 & 12,72 & 0,65 & 64 & $b$ \\
\hline \multicolumn{8}{|l|}{ in $\mathrm{BBCH} 83 / 84$} \\
\hline \multirow[t]{10}{*}{ Seitentriebe/Pflanze } & $\mathrm{Di}$ & & 30 & 8,86 & 0,67 & 64 & $a$ \\
\hline & $\mathrm{Di}$ & & 60 & 7,21 & 0,81 & 64 & $b$ \\
\hline & $\mathrm{Fu}$ & & & 7,43 & 0,72 & 16 & $\mathrm{~b}$ \\
\hline & $\mathrm{Fu}$ & & & 8,11 & 0,69 & 16 & $a b$ \\
\hline & $\mathrm{Fu}$ & & & 8,12 & 1,00 & 16 & $a b$ \\
\hline & $\mathrm{Fu}$ & & & 8,65 & 0,71 & 16 & $\mathrm{a}$ \\
\hline & $\mathrm{Fu}$ & & & 7,97 & 0,89 & 16 & $a b$ \\
\hline & $\mathrm{Fu}$ & & & 7,94 & 0,55 & 16 & $a b$ \\
\hline & $\mathrm{Fu}$ & & & 8,21 & 0,76 & 16 & $a b$ \\
\hline & $\mathrm{Fu}$ & & $\varepsilon$ & 7,85 & 0,73 & 16 & $a b$ \\
\hline Bestandeshöhe $[\mathrm{cm}]$ & So & $M$ & & 113,21 & 3,07 & 64 & $b$ \\
\hline \multirow[t]{9}{*}{ in $\mathrm{BBCH} 65 / 67$} & So & $P$ & & 125,24 & 3,98 & 64 & a \\
\hline & $\mathrm{Fu}$ & & & 125,89 & 4,72 & 16 & $a$ \\
\hline & $\mathrm{Fu}$ & & & 125,52 & 2,08 & 16 & $\mathrm{a}$ \\
\hline & $\mathrm{Fu}$ & & & 117,84 & 3,03 & 16 & $\mathrm{~b}$ \\
\hline & $\mathrm{Fu}$ & & & 112,79 & 3,31 & 16 & c \\
\hline & $\mathrm{Fu}$ & & & 118,92 & 3,51 & 16 & $\mathrm{~b}$ \\
\hline & $\mathrm{Fu}$ & & & 118,36 & 4,29 & 16 & $b$ \\
\hline & $\mathrm{Fu}$ & & & 118,60 & 3,09 & 16 & $b$ \\
\hline & $\mathrm{Fu}$ & & 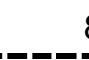 & 115,87 & 4,19 & 16 & $b c$ \\
\hline Bestandeshöhe [cm] & So & $M$ & & 117,52 & 2,82 & 64 & $\mathrm{~b}$ \\
\hline \multirow[t]{9}{*}{ in BBCH 67/69 } & So & $P$ & & 130,04 & 4,35 & 64 & a \\
\hline & $\mathrm{Fu}$ & & & 129,61 & 4,37 & 16 & a \\
\hline & $\mathrm{Fu}$ & & & 129,12 & 1,77 & 16 & $a$ \\
\hline & $\mathrm{Fu}$ & & & 122,04 & 4,64 & 16 & $\mathrm{bc}$ \\
\hline & $\mathrm{Fu}$ & & & 118,12 & 3,23 & 16 & c \\
\hline & $\mathrm{Fu}$ & & & 123,29 & 2,69 & 16 & $\mathrm{~b}$ \\
\hline & $\mathrm{Fu}$ & & & 122,87 & 4,64 & 16 & $\mathrm{bc}$ \\
\hline & $\mathrm{Fu}$ & & & 123,84 & 2,76 & 16 & $\mathrm{~b}$ \\
\hline & Fu & & 8 & 121,34 & 4,43 & 16 & $b c$ \\
\hline Bestandeshöhe [cm] & So & M & & 117,75 & 2,50 & 64 & $\mathrm{~b}$ \\
\hline in $\mathrm{BBCH} 73 / 74$ & So & $\mathrm{P}$ & & 131,53 & 3,81 & 64 & $a$ \\
\hline
\end{tabular}




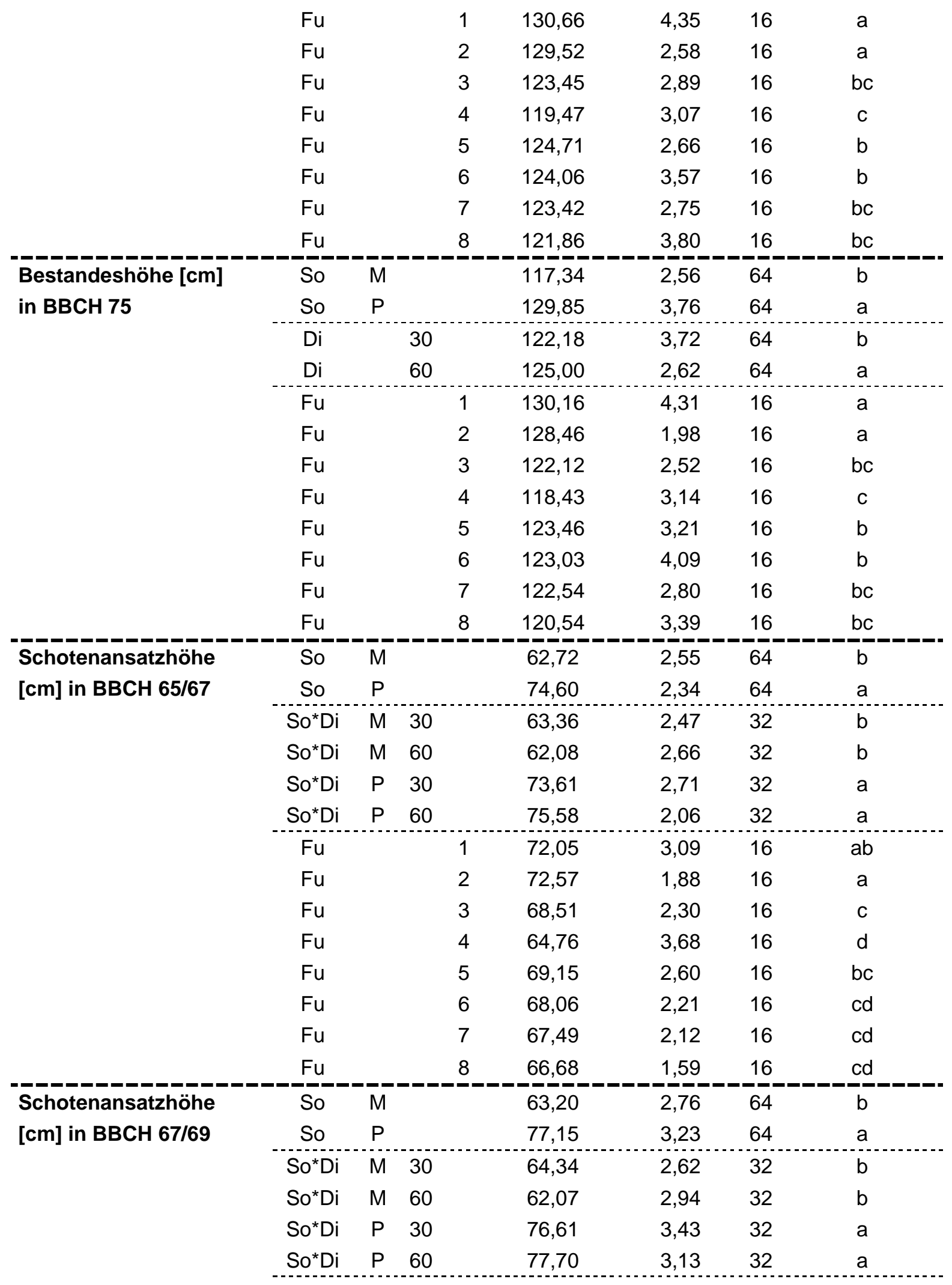




\begin{tabular}{|c|c|c|c|c|c|c|c|}
\hline & $\mathrm{Fu}$ & & 1 & 75,05 & 3,26 & 16 & $a$ \\
\hline & $\mathrm{Fu}$ & & 2 & 74,21 & 2,70 & 16 & $a b$ \\
\hline & $\mathrm{Fu}$ & & 3 & 70,75 & 2,57 & 16 & $b c$ \\
\hline & $\mathrm{Fu}$ & & 4 & 65,28 & 3,03 & 16 & $d$ \\
\hline & $\mathrm{Fu}$ & & 5 & 69,99 & 3,25 & 16 & $c$ \\
\hline & $\mathrm{Fu}$ & & 6 & 68,99 & 3,51 & 16 & $\mathrm{~cd}$ \\
\hline & $\mathrm{Fu}$ & & 7 & 68,92 & 2,36 & 16 & $\mathrm{~cd}$ \\
\hline & $\mathrm{Fu}$ & & 8 & 68,25 & 3,61 & 16 & $\mathrm{~cd}$ \\
\hline \multirow{10}{*}{$\begin{array}{l}\text { Schotenansatzhöhe } \\
{[\mathrm{cm}] \text { in } \mathrm{BBCH} 73 / 74}\end{array}$} & So & $M$ & & 61,97 & 2,41 & 64 & b \\
\hline & So & $P$ & & 75,29 & 3,08 & 64 & a \\
\hline & $\mathrm{Fu}$ & & 1 & 74,12 & 3,50 & 16 & $a$ \\
\hline & $\mathrm{Fu}$ & & 2 & 74,39 & 2,21 & 16 & a \\
\hline & $\mathrm{Fu}$ & & 3 & 67,80 & 2,00 & 16 & $b$ \\
\hline & $\mathrm{Fu}$ & & 4 & 62,93 & 2,51 & 16 & c \\
\hline & $\mathrm{Fu}$ & & 5 & 67,93 & 2,45 & 16 & $b$ \\
\hline & $\mathrm{Fu}$ & & 6 & 67,38 & 3,77 & 16 & $b$ \\
\hline & $\mathrm{Fu}$ & & 7 & 67,52 & 2,24 & 16 & $b$ \\
\hline & $\mathrm{Fu}$ & & 8 & 67,00 & 3,26 & 16 & b \\
\hline \multirow{10}{*}{$\begin{array}{l}\text { Schotenansatzhöhe } \\
{[\mathrm{cm}] \text { in BBCH } 75}\end{array}$} & So & $M$ & & 64,04 & 2,76 & 64 & b \\
\hline & So & $P$ & & 76,87 & 3,19 & 64 & a \\
\hline & $\mathrm{Fu}$ & & 1 & 75,65 & 4,80 & 16 & $a$ \\
\hline & $\mathrm{Fu}$ & & 2 & 75,38 & 2,43 & 16 & $a$ \\
\hline & $\mathrm{Fu}$ & & 3 & 68,79 & 2,35 & 16 & $b c$ \\
\hline & $\mathrm{Fu}$ & & 4 & 65,38 & 2,98 & 16 & $c$ \\
\hline & $\mathrm{Fu}$ & & 5 & 70,58 & 2,98 & 16 & $b$ \\
\hline & $\mathrm{Fu}$ & & 6 & 69,66 & 3,37 & 16 & $b$ \\
\hline & $\mathrm{Fu}$ & & 7 & 69,86 & 1,91 & 16 & $b$ \\
\hline & $\mathrm{Fu}$ & & 8 & 68,35 & 2,68 & 16 & bc \\
\hline \multirow{8}{*}{$\begin{array}{l}\text { Schotenschichtdicke } \\
{[\mathrm{cm}] \text { in } \mathrm{BBCH} 65 / 67}\end{array}$} & $\mathrm{Fu}$ & & 1 & 53,82 & 2,65 & 16 & a \\
\hline & $\mathrm{Fu}$ & & 2 & 52,93 & 1,46 & 16 & $a b$ \\
\hline & $\mathrm{Fu}$ & & 3 & 49,30 & 3,11 & 16 & $b c$ \\
\hline & $\mathrm{Fu}$ & & 4 & 48,01 & 4,16 & 16 & $c$ \\
\hline & $\mathrm{Fu}$ & & 5 & 49,75 & 2,69 & 16 & ac \\
\hline & $\mathrm{Fu}$ & & 6 & 50,28 & 3,90 & 16 & ac \\
\hline & $\mathrm{Fu}$ & & 7 & 51,19 & 3,44 & 16 & ac \\
\hline & $\mathrm{Fu}$ & & 8 & 49,26 & 3,86 & 16 & bc \\
\hline absolute Anzahl & $\mathrm{Di}$ & 30 & & 36,76 & 4,80 & 64 & a \\
\hline an Schoten am & $\mathrm{Di}$ & 60 & & 33,80 & 4,64 & 64 & $b$ \\
\hline
\end{tabular}




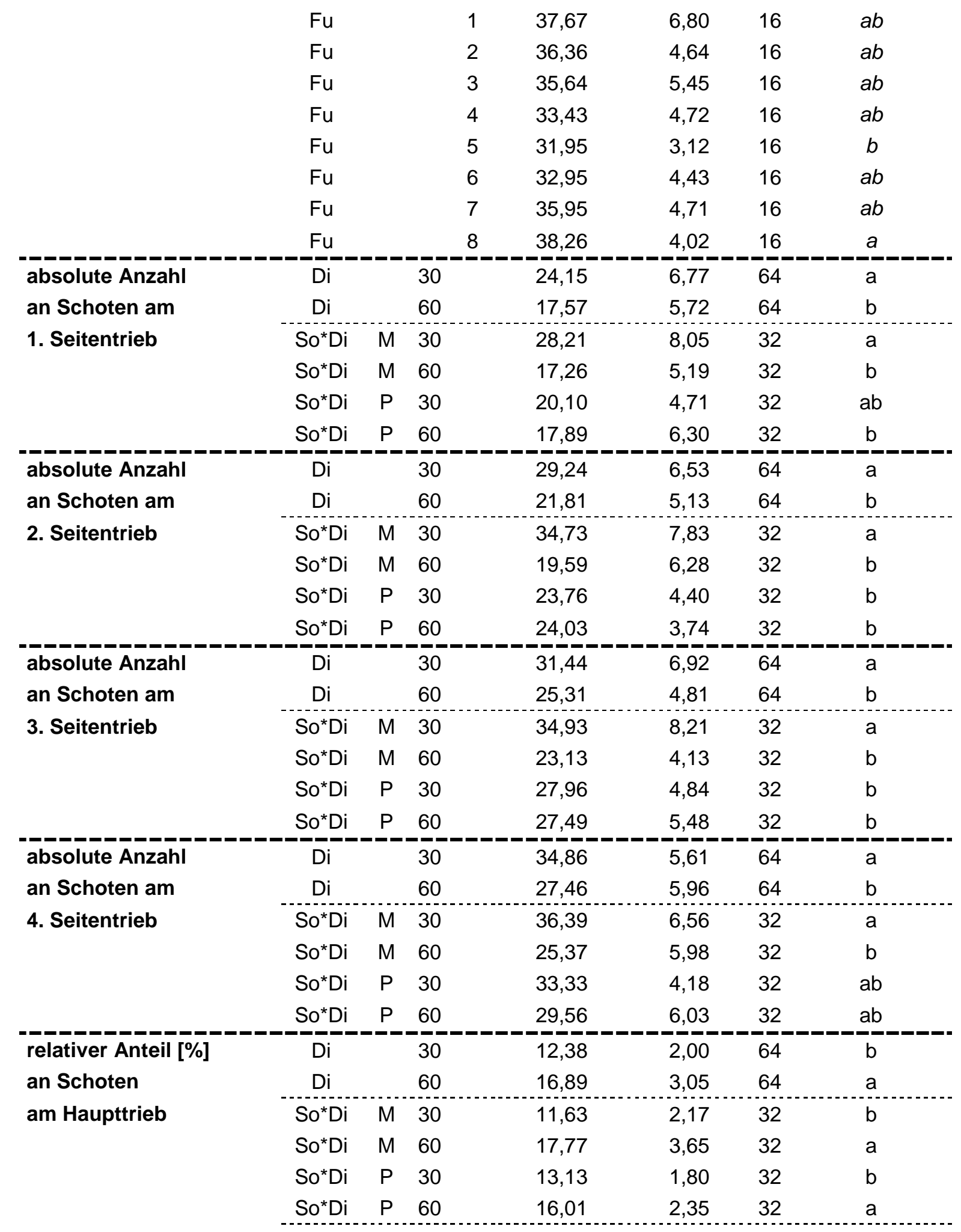




\begin{tabular}{|c|c|c|c|c|c|c|c|}
\hline & $\mathrm{Fu}$ & & 1 & 17,68 & 3,38 & 16 & $a$ \\
\hline & $\mathrm{Fu}$ & & 2 & 15,13 & 2,14 & 16 & $a b$ \\
\hline & $\mathrm{Fu}$ & & 3 & 14,80 & 2,43 & 16 & $a b$ \\
\hline & $\mathrm{Fu}$ & & 4 & 12,46 & 2,48 & 16 & $b$ \\
\hline & $\mathrm{Fu}$ & & 5 & 12,67 & 3,33 & 16 & $b$ \\
\hline & $\mathrm{Fu}$ & & 6 & 13,62 & 2,31 & 16 & $b$ \\
\hline & $\mathrm{Fu}$ & & 7 & 14,81 & 2,81 & 16 & $a b$ \\
\hline & $\mathrm{Fu}$ & & 8 & 15,92 & 2,27 & 16 & $a b$ \\
\hline \multirow{14}{*}{$\begin{array}{l}\text { relativer Anteil [\%] } \\
\text { an Schoten } \\
\text { am 2. Seitentrieb }\end{array}$} & $\mathrm{Di}$ & & 30 & 9,48 & 1,62 & 64 & $b$ \\
\hline & $\mathrm{Di}$ & & 60 & 10,62 & 2,02 & 64 & $a$ \\
\hline & So* $\mathrm{Di}$ & $M$ & 30 & 10,09 & 1,57 & 32 & $a b$ \\
\hline & So*Di & $M$ & 60 & 9,69 & 2,15 & 32 & $a b$ \\
\hline & So*Di & $\mathrm{P}$ & 30 & 8,87 & 1,71 & 32 & $b$ \\
\hline & So* $\mathrm{Di}$ & $\mathrm{P}$ & 60 & 11,55 & 1,93 & 32 & $a$ \\
\hline & $\mathrm{Fu}$ & & 1 & 11,92 & 1,49 & 16 & $a$ \\
\hline & $\mathrm{Fu}$ & & 2 & 9,89 & 1,90 & 16 & $a b$ \\
\hline & $\mathrm{Fu}$ & & 3 & 8,88 & 1,95 & 16 & $b$ \\
\hline & $\mathrm{Fu}$ & & 4 & 9,14 & 1,34 & 16 & $b$ \\
\hline & $\mathrm{Fu}$ & & 5 & 10,62 & 2,77 & 16 & $a b$ \\
\hline & $\mathrm{Fu}$ & & 6 & 10,63 & 1,59 & 16 & $a b$ \\
\hline & $\mathrm{Fu}$ & & 7 & 9,95 & 2,14 & 16 & $a b$ \\
\hline & $\mathrm{Fu}$ & & 8 & 9,40 & 1,57 & 16 & $a b$ \\
\hline \multirow{2}{*}{$\begin{array}{l}\text { relativer Anteil [\%] } \\
\text { an Schoten } \\
\text { am 3. Seitentrieb }\end{array}$} & $\mathrm{Di}$ & & 30 & 10,23 & 1,54 & 64 & $b$ \\
\hline & $\mathrm{Di}$ & & 60 & 12,39 & 1,99 & 64 & $a$ \\
\hline \multirow{2}{*}{$\begin{array}{l}\text { relativer Anteil [\%] } \\
\text { an Schoten } \\
\text { am } 4 \text {. Seitentrieb }\end{array}$} & $\mathrm{Di}$ & & 30 & 11,46 & 1,35 & 64 & 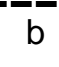 \\
\hline & $\mathrm{Di}$ & & 60 & 13,35 & 2,27 & 64 & $a$ \\
\hline \multirow{4}{*}{$\begin{array}{l}\text { Anteil an PAR [\%] } \\
\text { unter den Schoten } \\
\text { in BBCH 63/65 } \\
\text { (PAR_M1) }\end{array}$} & So & $M$ & & 50,44 & 7,94 & 64 & $a$ \\
\hline & So & $P$ & & 44,41 & 7,63 & 64 & $b$ \\
\hline & & & & & & & \\
\hline & & & & & & & \\
\hline \multirow{12}{*}{$\begin{array}{l}\text { Anteil an PAR [\%] } \\
\text { unter den Schoten } \\
\text { in BBCH } 67 / 69 \\
\text { PAR_M2) }\end{array}$} & So & $M$ & & 33,25 & 4,63 & 64 & a \\
\hline & So & $P$ & & 27,50 & 4,86 & 64 & $b$ \\
\hline & $\mathrm{Di}$ & & 30 & 35,57 & 4,87 & 64 & $a$ \\
\hline & $\mathrm{Di}$ & & 60 & 25,18 & 4,62 & 64 & $b$ \\
\hline & $\mathrm{Fu}$ & & 1 & 25,59 & 3,63 & 16 & C \\
\hline & $\mathrm{Fu}$ & & 2 & 28,60 & 4,00 & 16 & $b c$ \\
\hline & $\mathrm{Fu}$ & & 3 & 29,80 & 5,43 & 16 & ac \\
\hline & $\mathrm{Fu}$ & & 4 & 36,21 & 6,29 & 16 & $a$ \\
\hline & $\mathrm{Fu}$ & & 5 & 31,18 & 3,95 & 16 & ac \\
\hline & $\mathrm{Fu}$ & & 6 & 31,24 & 6,25 & 16 & $\mathrm{ac}$ \\
\hline & $\mathrm{Fu}$ & & 7 & 32,15 & 3,95 & 16 & $a b$ \\
\hline & $\mathrm{Fu}$ & & 8 & 28,22 & 4,56 & 16 & $\mathrm{bc}$ \\
\hline
\end{tabular}




\begin{tabular}{|c|c|c|c|c|c|c|c|}
\hline Anteil an PAR [\%] & $\mathrm{Di}$ & 30 & & 24,93 & 5,99 & 64 & $a$ \\
\hline unter den Schoten & $\mathrm{Di}$ & 60 & & 16,75 & 4,66 & 64 & $b$ \\
\hline in $\mathrm{BBCH} 73 / 74$ & $\mathrm{Fu}$ & & 1 & 18,48 & 5,98 & 16 & $a b$ \\
\hline \multirow[t]{7}{*}{ (PAR_M3) } & $\mathrm{Fu}$ & & 2 & 18,34 & 3,66 & 16 & $a b$ \\
\hline & $\mathrm{Fu}$ & & 3 & 19,71 & 5,00 & 16 & $a b$ \\
\hline & $\mathrm{Fu}$ & & 4 & 18,23 & 4,82 & 16 & $b$ \\
\hline & $\mathrm{Fu}$ & & 5 & 21,62 & 5,13 & 16 & $a b$ \\
\hline & $\mathrm{Fu}$ & & 6 & 22,80 & 5,28 & 16 & $a b$ \\
\hline & $\mathrm{Fu}$ & & 7 & 23,11 & 5,82 & 16 & $a b$ \\
\hline & $\mathrm{Fu}$ & & 8 & 24,42 & 7,30 & 16 & $a$ \\
\hline Anteil an PAR [\%] & So & $M$ & & 18,97 & 3,24 & 64 & $a$ \\
\hline unter den Schoten & So & $P$ & & 14,89 & 2,57 & 64 & $\mathrm{~b}$ \\
\hline in $\mathrm{BBCH} 75$ & $\mathrm{Di}$ & 30 & & 19,88 & 3,53 & 64 & $a$ \\
\hline \multirow[t]{9}{*}{ (PAR_M4) } & $\mathrm{Di}$ & 60 & & 13,98 & 2,33 & 64 & $b$ \\
\hline & $\mathrm{Fu}$ & & 1 & 14,67 & 2,86 & 16 & $\mathrm{~b}$ \\
\hline & $\mathrm{Fu}$ & & 2 & 17,19 & 3,15 & 16 & $a b$ \\
\hline & $\mathrm{Fu}$ & & 3 & 15,19 & 2,54 & 16 & $a b$ \\
\hline & $\mathrm{Fu}$ & & 4 & 19,12 & 2,85 & 16 & $a$ \\
\hline & $\mathrm{Fu}$ & & 5 & 16,96 & 3,34 & 16 & $a b$ \\
\hline & $\mathrm{Fu}$ & & 6 & 17,27 & 3,52 & 16 & $a b$ \\
\hline & $\mathrm{Fu}$ & & 7 & 16,80 & 2,83 & 16 & $a b$ \\
\hline & $\mathrm{Fu}$ & & 8 & 18,26 & 3,00 & 16 & $a b$ \\
\hline Anteil an PAR [\%] & So & $M$ & & 8,27 & 2,43 & 64 & $a$ \\
\hline am Boden & So & $P$ & & 4,89 & 1,65 & 64 & $b$ \\
\hline in $\mathrm{BBCH} 63 / 65$ & $\mathrm{Di}$ & 30 & & 7,77 & 2,00 & 64 & $\mathrm{a}$ \\
\hline (PAR_B1) & $\mathrm{Di}$ & 60 & & 5,40 & 2,19 & 64 & $b$ \\
\hline Anteil an PAR [\%] & So & $M$ & & 7,31 & 1,44 & 64 & a \\
\hline am Boden & So & $P$ & & 5,15 & 1,61 & 64 & $b$ \\
\hline in $\mathrm{BBCH}$ 67/69 & $\mathrm{Di}$ & 30 & & 7,98 & 1,65 & 64 & a \\
\hline \multirow[t]{9}{*}{ (PAR_B2) } & $\mathrm{Di}$ & 60 & & 4,48 & 1,40 & 64 & $b$ \\
\hline & $\mathrm{Fu}$ & & 1 & 5,02 & 1,32 & 16 & $\mathrm{~b}$ \\
\hline & $\mathrm{Fu}$ & & 2 & 5,92 & 1,21 & 16 & $a b$ \\
\hline & $\mathrm{Fu}$ & & 3 & 6,14 & 0,91 & 16 & $a b$ \\
\hline & $\mathrm{Fu}$ & & 4 & 7,03 & 1,76 & 16 & $a b$ \\
\hline & $\mathrm{Fu}$ & & 5 & 6,65 & 1,82 & 16 & $a b$ \\
\hline & Fu & & 6 & 6,49 & 1,95 & 16 & $a b$ \\
\hline & $\mathrm{Fu}$ & & 7 & 5,39 & 1,40 & 16 & $a b$ \\
\hline & $\mathrm{Fu}$ & & 8 & 7,20 & 1,83 & 16 & a \\
\hline Anteil an PAR [\%] & $\mathrm{Di}$ & 30 & & 4,76 & 1,47 & 64 & a \\
\hline am Boden & $\mathrm{Di}$ & 60 & & 3,26 & 1,18 & 64 & $b$ \\
\hline \multicolumn{8}{|c|}{ in $\mathrm{BBCH} 73 / 74$ (PAR_B3) } \\
\hline Anteil an PAR [\%] & So & $M$ & & 8,92 & 2,18 & 64 & $a$ \\
\hline am Boden & So & $P$ & & 5,96 & 1,45 & 64 & $b$ \\
\hline in $\mathrm{BBCH} 75$ & $\mathrm{Di}$ & 30 & & 9,71 & 2,44 & 64 & a \\
\hline (PAR_B4) & $\mathrm{Di}$ & 60 & & 5,17 & 1,19 & 64 & $b$ \\
\hline
\end{tabular}




\begin{tabular}{|c|c|c|c|c|c|c|c|c|}
\hline \multirow[t]{14}{*}{ NDVI_Dauer } & So & $M$ & & & 43,56 & 0,57 & 64 & a \\
\hline & So & $\mathrm{P}$ & & & 42,47 & 0,60 & 64 & $b$ \\
\hline & So* $\mathrm{Di}$ & $\mathrm{M}$ & 30 & & 43,23 & 0,71 & 32 & $b$ \\
\hline & So* $\mathrm{Di}$ & $M$ & 60 & & 43,89 & 0,40 & 32 & $\mathrm{a}$ \\
\hline & So* $\mathrm{Di}$ & $\mathrm{P}$ & 30 & & 42,82 & 0,57 & 32 & $a b$ \\
\hline & So*Di & $\mathrm{P}$ & 60 & & 42,12 & 0,64 & 32 & $c$ \\
\hline & $\mathrm{Fu}$ & & & 1 & 42,54 & 0,66 & 16 & b \\
\hline & $\mathrm{Fu}$ & & & 2 & 42,88 & 0,72 & 16 & $a b$ \\
\hline & $\mathrm{Fu}$ & & & 3 & 43,13 & 0,56 & 16 & $a b$ \\
\hline & $\mathrm{Fu}$ & & & 4 & 43,68 & 0,66 & 16 & $\mathrm{a}$ \\
\hline & $\mathrm{Fu}$ & & & 5 & 43,10 & 0,36 & 16 & $a b$ \\
\hline & $\mathrm{Fu}$ & & & 6 & 43,06 & 0,59 & 16 & $a b$ \\
\hline & $\mathrm{Fu}$ & & & 7 & 43,04 & 0,36 & 16 & $a b$ \\
\hline & $\mathrm{Fu}$ & & & 8 & 42,68 & 0,75 & 16 & $b$ \\
\hline \multirow{8}{*}{$\begin{array}{l}\text { Grünfärbung des } \\
\text { Pflanzenbestandes } \\
\text { in BBCH 64/65 } \\
\text { (NDVI_B1) }\end{array}$} & $\mathrm{Fu}$ & & & 1 & 0,349 & 0,018 & 16 & $\mathrm{~cd}$ \\
\hline & $\mathrm{Fu}$ & & & 2 & 0,354 & 0,026 & 16 & $\mathrm{~cd}$ \\
\hline & $\mathrm{Fu}$ & & & 3 & 0,357 & 0,028 & 16 & $\mathrm{~cd}$ \\
\hline & $\mathrm{Fu}$ & & & 4 & 0,395 & 0,027 & 16 & $a b$ \\
\hline & $\mathrm{Fu}$ & & & 5 & 0,409 & 0,038 & 16 & a \\
\hline & $\mathrm{Fu}$ & & & 6 & 0,385 & 0,031 & 16 & $\mathrm{ac}$ \\
\hline & $\mathrm{Fu}$ & & & 7 & 0,368 & 0,030 & 16 & bcd \\
\hline & $\mathrm{Fu}$ & & & 8 & 0,345 & 0,023 & 16 & $d$ \\
\hline \multirow{24}{*}{$\begin{array}{l}\text { Grünfärbung des } \\
\text { Pflanzenbestandes } \\
\text { in BBCH } 65 / 66 \\
\text { (NDVI_B2) }\end{array}$} & So & $M$ & & & 0,303 & 0,017 & 64 & $a$ \\
\hline & So & $P$ & & & 0,268 & 0,020 & 64 & $b$ \\
\hline & $\mathrm{Di}$ & & 30 & & 0,296 & 0,021 & 64 & $a$ \\
\hline & $\mathrm{Di}$ & & 60 & & 0,275 & 0,017 & 64 & $b$ \\
\hline & So*Di & $M$ & 30 & & 0,306 & 0,015 & 32 & $a$ \\
\hline & So* $\mathrm{Di}$ & $M$ & 60 & & 0,300 & 0,020 & 32 & $\mathrm{a}$ \\
\hline & So* Di & $P$ & 30 & & 0,286 & 0,028 & 32 & $a$ \\
\hline & So*Di & $P$ & 60 & & 0,250 & 0,013 & 32 & $b$ \\
\hline & $\mathrm{Fu}$ & & & 1 & 0,327 & 0,021 & 16 & $a$ \\
\hline & $\mathrm{Fu}$ & & & 2 & 0,299 & 0,015 & 16 & $b$ \\
\hline & $\mathrm{Fu}$ & & & 3 & 0,283 & 0,021 & 16 & $\mathrm{bd}$ \\
\hline & $\mathrm{Fu}$ & & & 4 & 0,265 & 0,015 & 16 & $\mathrm{~cd}$ \\
\hline & $\mathrm{Fu}$ & & & 5 & 0,280 & 0,020 & 16 & $\mathrm{bd}$ \\
\hline & $\mathrm{Fu}$ & & & 6 & 0,263 & 0,021 & 16 & $d$ \\
\hline & $\mathrm{Fu}$ & & & 7 & 0,277 & 0,019 & 16 & $\mathrm{bd}$ \\
\hline & $\mathrm{Fu}$ & & & 8 & 0,289 & 0,020 & 16 & $\mathrm{bc}$ \\
\hline & $\mathrm{Di}^{\star} \mathrm{Fu}$ & & 30 & 1 & 0,323 & 0,025 & 8 & $a$ \\
\hline & $\mathrm{Di}{ }^{\star} \mathrm{Fu}$ & & 30 & 2 & 0,308 & 0,016 & 8 & $a b$ \\
\hline & $\mathrm{Di}{ }^{\star} \mathrm{Fu}$ & & 30 & 3 & 0,306 & 0,028 & 8 & $a b$ \\
\hline & $\mathrm{Di}^{\star} \mathrm{Fu}$ & & 30 & 4 & 0,279 & 0,019 & 8 & $b$ \\
\hline & $\mathrm{Di}{ }^{\star} \mathrm{Fu}$ & & 30 & 5 & 0,284 & 0,026 & 8 & $a b$ \\
\hline & $\mathrm{Di}{ }^{\star} \mathrm{Fu}$ & & 30 & 6 & 0,277 & 0,027 & 8 & $b$ \\
\hline & $\mathrm{Di}{ }^{\star} \mathrm{Fu}$ & & 30 & 7 & 0,299 & 0,022 & 8 & $a b$ \\
\hline & $\mathrm{Di}{ }^{*} \mathrm{Fu}$ & & 30 & 8 & 0,293 & 0,012 & 8 & $a b$ \\
\hline
\end{tabular}




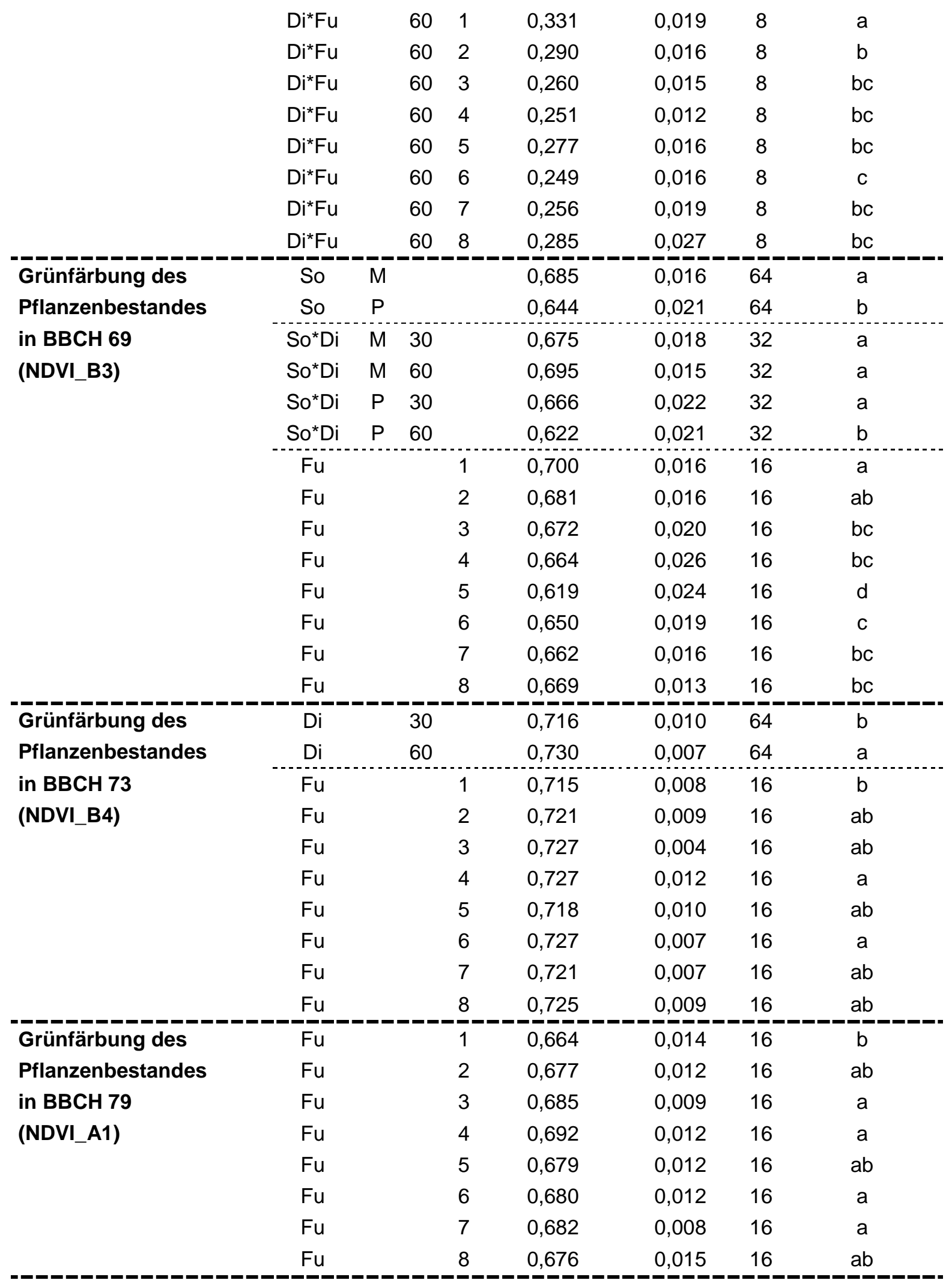




\begin{tabular}{|c|c|c|c|c|c|c|c|}
\hline Grünfärbung des & $\mathrm{Fu}$ & & 1 & 0,613 & 0,016 & 16 & $b$ \\
\hline Pflanzenbestandes & $\mathrm{Fu}$ & & 2 & 0,624 & 0,019 & 16 & $a b$ \\
\hline in $\mathrm{BBCH} 81$ & $\mathrm{Fu}$ & & 3 & 0,639 & 0,015 & 16 & a \\
\hline \multirow[t]{5}{*}{ (NDVI_A2) } & $\mathrm{Fu}$ & & 4 & 0,646 & 0,019 & 16 & $\mathrm{a}$ \\
\hline & $\mathrm{Fu}$ & & 5 & 0,635 & 0,015 & 16 & $a b$ \\
\hline & $\mathrm{Fu}$ & & 6 & 0,634 & 0,016 & 16 & $a b$ \\
\hline & $\mathrm{Fu}$ & & 7 & 0,639 & 0,014 & 16 & $\mathrm{a}$ \\
\hline & $\mathrm{Fu}$ & & 8 & 0,631 & 0,020 & 16 & $a b$ \\
\hline Grünfärbung des & So & $M$ & & 0,524 & 0,019 & 64 & $\mathrm{a}$ \\
\hline Pflanzenbestandes & So & $P$ & & 0,494 & 0,021 & 64 & $b$ \\
\hline in BBCH 84 & So* Di & $M$ & 30 & 0,514 & 0,023 & 32 & $a b$ \\
\hline \multirow[t]{11}{*}{ (NDVI_A3) } & So* $\mathrm{Di}$ & $M$ & 60 & 0,534 & 0,015 & 32 & a \\
\hline & So* $\mathrm{Di}$ & $P$ & 30 & 0,496 & 0,017 & 32 & $b$ \\
\hline & So* $\mathrm{Di}$ & $P$ & 60 & 0,493 & 0,024 & 32 & $b$ \\
\hline & $\mathrm{Fu}$ & & 1 & 0,484 & 0,024 & 16 & c \\
\hline & $\mathrm{Fu}$ & & 2 & 0,499 & 0,026 & 16 & bc \\
\hline & $\mathrm{Fu}$ & & 3 & 0,517 & 0,014 & 16 & $a b$ \\
\hline & $\mathrm{Fu}$ & & 4 & 0,528 & 0,022 & 16 & $\mathrm{a}$ \\
\hline & $\mathrm{Fu}$ & & 5 & 0,511 & 0,015 & 16 & $a b$ \\
\hline & $\mathrm{Fu}$ & & 6 & 0,518 & 0,019 & 16 & $a b$ \\
\hline & $\mathrm{Fu}$ & & 7 & 0,512 & 0,020 & 16 & $a b$ \\
\hline & $\mathrm{Fu}$ & & 8 & 0,503 & 0,023 & 16 & $\mathrm{ac}$ \\
\hline Grünfärbung des & So & $M$ & & 0,427 & 0,021 & 64 & a \\
\hline Pflanzenbestandes & So & $\mathrm{P}$ & & 0,373 & 0,020 & 64 & $b$ \\
\hline in $\mathrm{BBCH} 85 / 87$ & $\mathrm{Fu}$ & & 1 & 0,368 & 0,021 & 16 & $\mathrm{c}$ \\
\hline \multirow[t]{7}{*}{ (NDVI_A4) } & $\mathrm{Fu}$ & & 2 & 0,390 & 0,027 & 16 & $\mathrm{bc}$ \\
\hline & $\mathrm{Fu}$ & & 3 & 0,403 & 0,018 & 16 & $a b$ \\
\hline & $\mathrm{Fu}$ & & 4 & 0,424 & 0,017 & 16 & $\mathrm{a}$ \\
\hline & $\mathrm{Fu}$ & & 5 & 0,410 & 0,020 & 16 & $a b$ \\
\hline & $\mathrm{Fu}$ & & 6 & 0,413 & 0,024 & 16 & $a b$ \\
\hline & $\mathrm{Fu}$ & & 7 & 0,402 & 0,021 & 16 & $a b$ \\
\hline & $\mathrm{Fu}$ & & 8 & 0,390 & 0,020 & 16 & $\mathrm{bc}$ \\
\hline Grünfärbung des & So & $M$ & & 0,277 & 0,014 & 64 & $a$ \\
\hline Pflanzenbestandes & So & $P$ & & 0,239 & 0,009 & 64 & $b$ \\
\hline in BBCH 89 & $\mathrm{Di}$ & & 30 & 0,266 & 0,012 & 64 & a \\
\hline \multirow[t]{9}{*}{ (NDVI_A5) } & $\mathrm{Di}$ & & 60 & 0,250 & 0,011 & 64 & $b$ \\
\hline & $\mathrm{Fu}$ & & 1 & 0,251 & 0,007 & 16 & $\mathrm{~b}$ \\
\hline & $\mathrm{Fu}$ & & 2 & 0,251 & 0,013 & 16 & $b$ \\
\hline & $\mathrm{Fu}$ & & 3 & 0,253 & 0,007 & 16 & $b$ \\
\hline & $\mathrm{Fu}$ & & 4 & 0,270 & 0,013 & 16 & a \\
\hline & $\mathrm{Fu}$ & & 5 & 0,261 & 0,016 & 16 & $a b$ \\
\hline & $\mathrm{Fu}$ & & 6 & 0,260 & 0,014 & 16 & $a b$ \\
\hline & $\mathrm{Fu}$ & & 7 & 0,259 & 0,012 & 16 & $a b$ \\
\hline & $\mathrm{Fu}$ & & 8 & 0,260 & 0,010 & 16 & $a b$ \\
\hline
\end{tabular}




\begin{tabular}{|c|c|c|c|c|c|c|c|c|}
\hline Pflanzen $/ \mathrm{m}^{2}$ & So & $M$ & & & 40,28 & 5,74 & 64 & $\mathrm{~b}$ \\
\hline im Herbst & So & $\mathrm{P}$ & & & 47,94 & 6,35 & 64 & $a$ \\
\hline \multirow[t]{2}{*}{ in $B B C H ~ 14 / 15$} & $\mathrm{Di}$ & \multicolumn{3}{|c|}{30} & 32,69 & 5,08 & 64 & $\mathrm{~b}$ \\
\hline & Di & \multicolumn{3}{|c|}{60} & 55,53 & 6,88 & 64 & a \\
\hline Blattlänge [cm] & $\mathrm{Fu}$ & & & 1 & 16,55 & 0,94 & 16 & a \\
\hline im Herbst & $\mathrm{Fu}$ & & & 2 & 16,35 & 0,97 & 16 & a \\
\hline \multirow[t]{6}{*}{ in $\mathrm{BBCH} 16 / 18$} & $\mathrm{Fu}$ & & & 3 & 14,47 & 0,84 & 16 & $b$ \\
\hline & $\mathrm{Fu}$ & & & 4 & 13,20 & 0,98 & 16 & $c$ \\
\hline & $\mathrm{Fu}$ & & & 5 & 14,71 & 0,68 & 16 & $b$ \\
\hline & $\mathrm{Fu}$ & & & 6 & 14,54 & 1,00 & 16 & $b$ \\
\hline & $\mathrm{Fu}$ & & & 7 & 14,62 & 0,56 & 16 & $b$ \\
\hline & $\mathrm{Fu}$ & & & 8 & 14,45 & 0,72 & 16 & $b$ \\
\hline $\mathrm{BH}$ mit der & So* $\mathrm{Di}$ & $M$ & \multicolumn{2}{|l|}{30} & 72,19 & 10,94 & 32 & $a b$ \\
\hline Wurzelhals- & So* Di & M & \multicolumn{2}{|l|}{60} & 75,00 & 12,74 & 32 & $a b$ \\
\hline und Stängelfäule & So*Di & $\mathrm{P}$ & \multicolumn{2}{|l|}{30} & 80,31 & 9,67 & 32 & $a$ \\
\hline an Laubblättern & So* $\mathrm{Di}$ & $P$ & \multicolumn{2}{|l|}{60} & 70,94 & 8,28 & 32 & $b$ \\
\hline im Herbst & $\mathrm{Fu}$ & & & 1 & 82,81 & 12,01 & 16 & $a b c$ \\
\hline \multirow[t]{23}{*}{ in $\mathrm{BBCH} 16 / 18$} & $\mathrm{Fu}$ & & & 2 & 86,88 & 11,86 & 16 & $a b$ \\
\hline & $\mathrm{Fu}$ & & & 3 & 69,69 & 10,27 & 16 & $\mathrm{~cd}$ \\
\hline & $\mathrm{Fu}$ & & & 4 & 52,81 & 10,41 & 16 & e \\
\hline & $\mathrm{Fu}$ & & & 5 & 75,31 & 8,94 & 16 & $\mathrm{ad}$ \\
\hline & $\mathrm{Fu}$ & & & 6 & 73,75 & 7,52 & 16 & bd \\
\hline & $\mathrm{Fu}$ & & & 7 & 68,13 & 14,88 & 16 & $d$ \\
\hline & $\mathrm{Fu}$ & & & 8 & 87,50 & 7,80 & 16 & $\mathrm{a}$ \\
\hline & So*Fu & $M$ & & 1 & 78,75 & 16,75 & 8 & $a b$ \\
\hline & So*Fu & M & & 2 & 80,00 & 16,08 & 8 & $a b$ \\
\hline & So*Fu & $M$ & & 3 & 67,50 & 7,27 & 8 & $a b$ \\
\hline & So*Fu & $M$ & & 4 & 60,00 & 11,09 & 8 & $b$ \\
\hline & So*Fu & M & & 5 & 80,63 & 8,69 & 8 & $a b$ \\
\hline & So*Fu & $M$ & & 6 & 69,38 & 6,49 & 8 & $a b$ \\
\hline & So*Fu & $M$ & & 7 & 66,25 & 17,55 & 8 & $a b$ \\
\hline & So ${ }^{*} \mathrm{Fu}$ & $M$ & & 8 & 86,25 & 10,40 & 8 & $a$ \\
\hline & So*Fu & $P$ & & 1 & 86,88 & 5,33 & 8 & $a b$ \\
\hline & So*Fu & $P$ & & 2 & 93,75 & 6,56 & 8 & $\mathrm{a}$ \\
\hline & So*Fu & $\mathrm{P}$ & & 3 & 71,88 & 13,17 & 8 & $b$ \\
\hline & So*Fu & $P$ & & 4 & 45,63 & 10,46 & 8 & $c$ \\
\hline & So*Fu & $P$ & & 5 & 70,00 & 9,78 & 8 & $b$ \\
\hline & So*Fu & $P$ & & 6 & 78,13 & 8,89 & 8 & $a b$ \\
\hline & So*Fu & $P$ & & 7 & 70,00 & 12,91 & 8 & $b$ \\
\hline & So*Fu & $P$ & & 8 & 88,75 & 4,70 & 8 & $a b$ \\
\hline
\end{tabular}




\begin{tabular}{|c|c|c|c|c|c|c|c|c|}
\hline BW mit der & $\mathrm{Fu}$ & & & 1 & 3,60 & 1,11 & 16 & $\mathrm{a}$ \\
\hline Wurzelhals- & $\mathrm{Fu}$ & & & 2 & 4,11 & 1,21 & 16 & $\mathrm{a}$ \\
\hline und Stängelfäule & $\mathrm{Fu}$ & & & 3 & 2,04 & 0,70 & 16 & $b$ \\
\hline an Laubblättern & $\mathrm{Fu}$ & & & 4 & 0,78 & 0,34 & 16 & $c$ \\
\hline im Herbst & $\mathrm{Fu}$ & & & 5 & 2,29 & 0,89 & 16 & $b$ \\
\hline \multirow[t]{35}{*}{ in $\mathrm{BBCH} 16 / 18$} & $\mathrm{Fu}$ & & & 6 & 1,93 & 0,35 & 16 & $b$ \\
\hline & $\mathrm{Fu}$ & & & 7 & 1,91 & 0,81 & 16 & $b$ \\
\hline & $\mathrm{Fu}$ & & & 8 & 3,58 & 0,74 & 16 & a \\
\hline & So*Fu & $\mathrm{M}$ & & 1 & 3,17 & 1,47 & 8 & $a b$ \\
\hline & So*Fu & $M$ & & 2 & 3,40 & 1,38 & 8 & $a$ \\
\hline & So*Fu & $M$ & & 3 & 2,01 & 0,62 & 8 & $\mathrm{ac}$ \\
\hline & So*Fu & $M$ & & 4 & 0,84 & 0,42 & 8 & $\mathrm{c}$ \\
\hline & So*Fu & $M$ & & 5 & 2,78 & 1,20 & 8 & $a b$ \\
\hline & So*Fu & $M$ & & 6 & 1,55 & 0,24 & 8 & $\mathrm{bc}$ \\
\hline & So*Fu & $M$ & & 7 & 2,05 & 1,08 & 8 & ac \\
\hline & So*Fu & $M$ & & 8 & 3,64 & 1,00 & 8 & $\mathrm{a}$ \\
\hline & So* $\mathrm{Fu}$ & $P$ & & 1 & 4,04 & 0,70 & 8 & $\mathrm{a}$ \\
\hline & So* $\mathrm{Fu}$ & $P$ & & 2 & 4,82 & 1,12 & 8 & $\mathrm{a}$ \\
\hline & $\mathrm{So}^{\star} \mathrm{Fu}$ & $P$ & & 3 & 2,07 & 0,82 & 8 & $\mathrm{bc}$ \\
\hline & So* $\mathrm{Fu}$ & $P$ & & 4 & 0,73 & 0,28 & 8 & $c$ \\
\hline & So* $\mathrm{Fu}$ & $P$ & & 5 & 1,81 & 0,51 & 8 & $c$ \\
\hline & So ${ }^{*} \mathrm{Fu}$ & $\mathrm{P}$ & & 6 & 2,32 & 0,45 & 8 & $b c$ \\
\hline & So*Fu & $\mathrm{P}$ & & 7 & 1,78 & 0,49 & 8 & $c$ \\
\hline & $\mathrm{So}^{*} \mathrm{Fu}$ & $P$ & & 8 & 3,51 & 0,43 & 8 & $a b$ \\
\hline & $\mathrm{Di}^{*} \mathrm{Fu}$ & & 30 & 1 & 3,09 & 0,85 & 8 & $\mathrm{bc}$ \\
\hline & $\mathrm{Di}^{\star} \mathrm{Fu}$ & & 30 & 2 & 4,81 & 1,08 & 8 & $\mathrm{a}$ \\
\hline & $\mathrm{Di}^{\star} \mathrm{Fu}$ & & 30 & 3 & 2,44 & 0,94 & 8 & $\mathrm{bd}$ \\
\hline & $\mathrm{Di}^{\star} \mathrm{Fu}$ & & 30 & 4 & 0,80 & 0,27 & 8 & $d$ \\
\hline & $\mathrm{Di}^{\star} \mathrm{Fu}$ & & 30 & 5 & 2,22 & 1,05 & 8 & $\mathrm{~cd}$ \\
\hline & $\mathrm{Di}^{\star} \mathrm{Fu}$ & & 30 & 6 & 2,04 & 0,19 & 8 & $\mathrm{~cd}$ \\
\hline & $\mathrm{Di}^{\star} \mathrm{Fu}$ & & 30 & 7 & 1,91 & 0,59 & 8 & $\mathrm{~cd}$ \\
\hline & $\mathrm{Di}^{\star} \mathrm{Fu}$ & & 30 & 8 & 3,91 & 0,77 & 8 & $a b$ \\
\hline & $\mathrm{Di}^{\star} \mathrm{Fu}$ & & 60 & 1 & 4,12 & 1,39 & 8 & $\mathrm{a}$ \\
\hline & $\mathrm{Di}^{\star} \mathrm{Fu}$ & & 60 & 2 & 3,41 & 1,41 & 8 & $a b$ \\
\hline & $\mathrm{Di}^{\star} \mathrm{Fu}$ & & 60 & 3 & 1,64 & 0,42 & 8 & $\mathrm{~cd}$ \\
\hline & $\mathrm{Di}^{\star} \mathrm{Fu}$ & & 60 & 4 & 0,76 & 0,42 & 8 & $d$ \\
\hline & $\mathrm{Di}^{\star} \mathrm{Fu}$ & & 60 & 5 & 2,37 & 0,78 & 8 & $\mathrm{bd}$ \\
\hline & $\mathrm{Di}^{\star} \mathrm{Fu}$ & & 60 & 6 & 1,83 & 0,47 & 8 & $\mathrm{bd}$ \\
\hline & $\mathrm{Di}^{\star} \mathrm{Fu}$ & & 60 & 7 & 1,91 & 1,03 & 8 & $\mathrm{bd}$ \\
\hline & $\mathrm{Di}^{\star} \mathrm{Fu}$ & & 60 & 8 & 3,24 & 0,76 & 8 & $a b c$ \\
\hline $\mathrm{BH}$ mit der & So & $M$ & & & 93,94 & 3,83 & 64 & a \\
\hline Wurzelhals- & So & $P$ & & & 80,25 & 7,80 & 64 & $b$ \\
\hline und Stängelfäule & $\mathrm{Di}$ & & 30 & & 92,13 & 4,28 & 64 & $a$ \\
\hline am unteren Stängel & $\mathrm{Di}$ & & 60 & & 82,06 & 7,20 & 64 & $b$ \\
\hline im Frühjahr & So* $\mathrm{Di}$ & $\mathrm{M}$ & 30 & & 94,75 & 3,20 & 32 & a \\
\hline in $\mathrm{BBCH} 83 / 84$ & So* $\mathrm{Di}$ & $M$ & 60 & & 93,13 & 4,43 & 32 & $\mathrm{a}$ \\
\hline
\end{tabular}




\begin{tabular}{|c|c|c|c|c|c|c|c|c|}
\hline & So*Di & $P$ & \multicolumn{2}{|l|}{30} & 89,50 & 5,47 & 32 & $a$ \\
\hline & So*Di & $\mathrm{P}$ & \multicolumn{2}{|l|}{60} & 71,00 & 9,26 & 32 & $b$ \\
\hline & $\mathrm{Fu}$ & & & 1 & 94,05 & 4,43 & 16 & $a b$ \\
\hline & $\mathrm{Fu}$ & & & 2 & 87,09 & 3,75 & 16 & bc \\
\hline & $\mathrm{Fu}$ & & & 3 & 86,39 & 7,34 & 16 & bd \\
\hline & $\mathrm{Fu}$ & & & 4 & 78,43 & 5,28 & 16 & $d$ \\
\hline & $\mathrm{Fu}$ & & & 5 & 86,39 & 8,03 & 16 & bd \\
\hline & $\mathrm{Fu}$ & & & 6 & 82,14 & 8,21 & 16 & $\mathrm{~cd}$ \\
\hline & $\mathrm{Fu}$ & & & 7 & 84,96 & 5,89 & 16 & $\mathrm{~cd}$ \\
\hline & Fu & & & 8 & 97,29 & 4,83 & 16 & $\mathrm{a}$ \\
\hline & So*Fu & M & & 1 & 97,00 & 3,17 & 8 & $a$ \\
\hline & $\mathrm{So}{ }^{\star} \mathrm{Fu}$ & $M$ & & 2 & 96,00 & 4,05 & 8 & a \\
\hline & So*Fu & M & & 3 & 92,50 & 3,20 & 8 & a \\
\hline & So*Fu & M & & 4 & 92,00 & 2,17 & 8 & a \\
\hline & $\mathrm{So} F u$ & M & & 5 & 94,00 & 4,81 & 8 & a \\
\hline & So*Fu & M & & 6 & 90,50 & 6,01 & 8 & a \\
\hline & So*Fu & M & & 7 & 90,50 & 5,09 & 8 & a \\
\hline & So*Fu & M & & 8 & 99,00 & 2,40 & 8 & a \\
\hline & So*Fu & $\mathrm{P}$ & & 1 & 91,11 & 5,84 & 8 & $a b$ \\
\hline & $\mathrm{So}{ }^{\star} \mathrm{Fu}$ & $\mathrm{P}$ & & 2 & 78,19 & 3,71 & 8 & bd \\
\hline & So*Fu & $\mathrm{P}$ & & 3 & 80,29 & 10,66 & 8 & bc \\
\hline & So*Fu & $\mathrm{P}$ & & 4 & 64,85 & 7,71 & 8 & $d$ \\
\hline & So*Fu & $\mathrm{P}$ & & 5 & 78,79 & 11,11 & 8 & bd \\
\hline & $\mathrm{So}^{*} \mathrm{Fu}$ & $\mathrm{P}$ & & 6 & 73,77 & 10,74 & 8 & $\mathrm{~cd}$ \\
\hline & So*Fu & $\mathrm{P}$ & & 7 & 79,42 & 7,12 & 8 & bc \\
\hline & So*Fu & $P$ & & 8 & 95,59 & 6,91 & 8 & a \\
\hline BW mit der & $\mathrm{Fu}$ & & & 1 & 4,10 & 0,39 & 16 & a \\
\hline Wurzelhals- & $\mathrm{Fu}$ & & & 2 & 3,16 & 0,32 & 16 & $b$ \\
\hline und Stängelfäule & $\mathrm{Fu}$ & & & 3 & 3,14 & 0,31 & 16 & $\mathrm{~b}$ \\
\hline am unteren Stängel & $\mathrm{Fu}$ & & & 4 & 2,82 & 0,27 & 16 & $b$ \\
\hline im Frühjahr & $\mathrm{Fu}$ & & & 5 & 3,10 & 0,32 & 16 & $b$ \\
\hline in BBCH 83/84 & $\mathrm{Fu}$ & & & 6 & 3,00 & 0,40 & 16 & $b$ \\
\hline & $\mathrm{Fu}$ & & & 7 & 3,26 & 0,30 & 16 & $b$ \\
\hline & $\mathrm{Fu}$ & & & 8 & 4,16 & 0,48 & 16 & a \\
\hline & $\mathrm{Di}{ }^{\star} \mathrm{Fu}$ & & 30 & 1 & 4,37 & 0,26 & 8 & a \\
\hline & $\mathrm{Di}{ }^{\star} \mathrm{Fu}$ & & 30 & 2 & 3,49 & 0,29 & 8 & b \\
\hline & $\mathrm{Di} F u$ & & 30 & 3 & 3,44 & 0,39 & 8 & $b$ \\
\hline & $\mathrm{Di}{ }^{\star} \mathrm{Fu}$ & & 30 & 4 & 3,12 & 0,32 & 8 & $b$ \\
\hline & $\mathrm{Di}{ }^{\star} \mathrm{Fu}$ & & 30 & 5 & 2,96 & 0,30 & 8 & $b$ \\
\hline & $\mathrm{Di}{ }^{\star} \mathrm{Fu}$ & & 30 & 6 & 3,00 & 0,33 & 8 & $\mathrm{~b}$ \\
\hline & $\mathrm{Di} F u$ & & 30 & 7 & 3,49 & 0,31 & 8 & $b$ \\
\hline & $\mathrm{Di}{ }^{\star} \mathrm{Fu}$ & & 30 & 8 & 4,39 & 0,43 & 8 & a \\
\hline & $\mathrm{Di}^{\star} \mathrm{Fu}$ & & 60 & 1 & 3,82 & 0,49 & 8 & a \\
\hline & $\mathrm{Di}^{\star} \mathrm{Fu}$ & & 60 & 2 & 2,83 & 0,37 & 8 & $b$ \\
\hline & $\mathrm{Di}{ }^{\star} \mathrm{Fu}$ & & 60 & 3 & 2,84 & 0,25 & 8 & b \\
\hline & $\mathrm{Di}^{\star} \mathrm{Fu}$ & & 60 & 4 & 2,52 & 0,25 & 8 & $b$ \\
\hline
\end{tabular}




\begin{tabular}{|c|c|c|c|c|c|c|c|c|}
\hline & $\mathrm{Di}^{\star} \mathrm{Fu}$ & & 60 & 5 & 3,23 & 0,36 & 8 & $a b$ \\
\hline & $\mathrm{Di}^{\star} \mathrm{Fu}$ & & 60 & 6 & 3,00 & 0,48 & 8 & $\mathrm{~b}$ \\
\hline & $\mathrm{Di}{ }^{\star} \mathrm{Fu}$ & & 60 & 7 & 3,03 & 0,32 & 8 & $b$ \\
\hline & $\mathrm{Di} \mathrm{i}^{*} \mathrm{Fu}$ & & 60 & 8 & 3,93 & 0,55 & 8 & $a$ \\
\hline BW mit der & $\mathrm{Di}$ & & 30 & & 5,53 & 0,37 & 64 & $a$ \\
\hline Wurzelhals- & $\mathrm{Di}$ & & 60 & & 4,30 & 0,39 & 64 & $b$ \\
\hline und Stängelfäule & So*Di & $\mathrm{M}$ & 30 & & 5,27 & 0,38 & 32 & $\mathrm{a}$ \\
\hline am Wurzelhals & So*Di & $M$ & 60 & & 4,58 & 0,32 & 32 & $b$ \\
\hline im Frühjahr & So*Di & $\mathrm{P}$ & 30 & & 5,79 & 0,35 & 32 & $a$ \\
\hline \multirow[t]{9}{*}{ in $\mathrm{BBCH} 83 / 84$} & So*Di & $P$ & 60 & & 4,02 & 0,45 & 32 & $b$ \\
\hline & $\mathrm{Fu}$ & & & 1 & 5,32 & 0,50 & 16 & a \\
\hline & $\mathrm{Fu}$ & & & 2 & 5,15 & 0,44 & 16 & $a b$ \\
\hline & $\mathrm{Fu}$ & & & 3 & 4,70 & 0,35 & 16 & $b c$ \\
\hline & $\mathrm{Fu}$ & & & 4 & 4,49 & 0,40 & 16 & c \\
\hline & $\mathrm{Fu}$ & & & 5 & 4,94 & 0,39 & 16 & ac \\
\hline & $\mathrm{Fu}$ & & & 6 & 4,62 & 0,25 & 16 & $\mathrm{C}$ \\
\hline & $\mathrm{Fu}$ & & & 7 & 4,73 & 0,38 & 16 & $\mathrm{bc}$ \\
\hline & $\mathrm{Fu}$ & & & 8 & 5,38 & 0,34 & 16 & $a$ \\
\hline $\mathrm{BH}$ mit der & $\mathrm{Fu}$ & & & 1 & 3,13 & 3,39 & 16 & $a b$ \\
\hline Kleinen Kohlfliege & $\mathrm{Fu}$ & & & 2 & 3,13 & 3,75 & 16 & $a b$ \\
\hline im Herbst & $\mathrm{Fu}$ & & & 3 & 1,56 & 2,62 & 16 & $b$ \\
\hline \multirow[t]{5}{*}{ in $\mathrm{BBCH} 16 / 18$} & $\mathrm{Fu}$ & & & 4 & 9,06 & 14,61 & 16 & $a$ \\
\hline & $\mathrm{Fu}$ & & & 5 & 1,56 & 2,97 & 16 & $b$ \\
\hline & $\mathrm{Fu}$ & & & 6 & 1,88 & 2,16 & 16 & $a b$ \\
\hline & $\mathrm{Fu}$ & & & 7 & 2,50 & 2,57 & 16 & $a b$ \\
\hline & $\mathrm{Fu}$ & & & 8 & 1,25 & 3,40 & 16 & $b$ \\
\hline $\mathrm{BH}$ mit der & So & $M$ & & & 83,38 & 7,56 & 64 & a \\
\hline Kleinen Kohlfliege & So & $\mathrm{P}$ & & & 76,23 & 6,95 & 64 & $b$ \\
\hline im Frühjahr & $\mathrm{Di}$ & & 30 & & 84,60 & 6,73 & 64 & a \\
\hline \multirow[t]{13}{*}{ in $\mathrm{BBCH} 83 / 84$} & $\mathrm{Di}$ & & 60 & & 75,00 & 7,73 & 64 & $b$ \\
\hline & So* Di & $\mathrm{M}$ & 30 & & 85,88 & 7,00 & 32 & a \\
\hline & So*Di & $M$ & 60 & & 80,88 & 8,20 & 32 & a \\
\hline & So* Di & $\mathrm{P}$ & 30 & & 83,33 & 6,51 & 32 & a \\
\hline & So* Di & $P$ & 60 & & 69,13 & 7,37 & 32 & $\mathrm{~b}$ \\
\hline & $\mathrm{Fu}$ & & & 1 & 76,82 & 7,78 & 16 & $a b$ \\
\hline & $\mathrm{Fu}$ & & & 2 & 80,43 & 7,25 & 16 & $a b$ \\
\hline & $\mathrm{Fu}$ & & & 3 & 79,07 & 9,17 & 16 & $a b$ \\
\hline & $\mathrm{Fu}$ & & & 4 & 83,76 & 6,28 & 16 & a \\
\hline & $\mathrm{Fu}$ & & & 5 & 84,99 & 6,33 & 16 & a \\
\hline & $\mathrm{Fu}$ & & & 6 & 81,74 & 8,14 & 16 & $a b$ \\
\hline & $\mathrm{Fu}$ & & & 7 & 77,76 & 8,32 & 16 & $a b$ \\
\hline & $\mathrm{Fu}$ & & & 8 & 73,84 & 5,90 & 16 & $b$ \\
\hline
\end{tabular}


Tab. 27A: Kleinste-Quadrate-Mittelwerte für Parameter mit signifikanten Effekten (Tab. 25A) der drei Versuchsfaktoren Sorte (So), Saatstärke (Di) und Fungizid (Fu) bzw. deren Interaktionen, die in dem Jahr 2012/13 im Feldversuch am Standort Göttingen untersucht wurden. Mittelwerte, die mit unterschiedlichen Buchstaben gekennzeichnet sind, unterscheiden sich signifikant (Tukey-Test, $p \leq 0,05)$. Hierbei muss folgendes beachtet werden: Bei den Haupteffekten und der Interaktion zwischen Sorte $x$ Saatstärke (So*Di) können jeweils alle Ausprägungen eines Effektes durch die Buchstaben miteinander verglichen werden. Bei den Interaktionen zwischen Sorte $x$ Fungizid (So* $\mathrm{Fu}$ ) und Saatstärke x Fungizid ( $\mathrm{Di}{ }^{\star} \mathrm{Fu}$ ) beziehen sich die Buchstaben auf die einfachen Effekte, sodass durch die Buchstaben nur Vergleiche zwischen den Fungizidvarianten innerhalb einer Sorte oder einer Saatstärke möglich sind. Entsprechendes gilt für die Interaktion zwischen Sorte $x$ Saatstärke $x$ Fungizid $\left(\mathrm{So}^{*} \mathrm{Di}^{*} \mathrm{Fu}\right.$ ). Hier ermöglichen die Buchstaben nur einen Vergleich zwischen den Fungiziden innerhalb einer Sorte $x$ Saatstärken-Kombination. Dargestellt sind die Mittelwerte, die Standardabweichung (SD), errechnet aus den Residuen des gegebenen Modells, und die Anzahl der Werte $(n)$, die in die jeweilige Berechnung eingegangen sind. Kursive Buchstaben stellen Unterschiede zwischen den Mittelwerten auf Basis des Globaltests (F-Test, $p \leq 0,05)$ und nicht des Tukey-Tests dar. So = Sorte $(\mathrm{V}=\mathrm{SY}$ Vesuvio, $\mathrm{P}=\mathrm{NK}$ Petrol); $\mathrm{Di}=$ Saatstärke (30 bzw. $\left.60 \mathrm{Körner} / \mathrm{m}^{2}\right) ; \mathrm{Fu}=$ Fungizid $\left(1=\right.$ unbehandelte Kontrolle, $2=0,5 \mathrm{l} / \mathrm{ha}$ Toprex ${ }^{\circledR}$ in BBCH 33/35, $3=$ 0,5 I/ha Toprex ${ }^{\circledR}$ in BBCH 14 und 33/35, $4=0,5 \mathrm{l} /$ ha Toprex $^{\circledR}$ in BBCH 14, 16 und 33/35, $5=0,5$ I/ha Toprex ${ }^{\circledR}$ in BBCH 14, 33/35 und 53/55, $6=0,5$ I/ha Toprex ${ }^{\circledR}$ in BBCH 14, 16, $33 / 35$ und 53/55, $7=0,5 \mathrm{l} /$ ha Toprex $^{\circledR}$ in $\mathrm{BBCH} 14,8=$ praxisüblich $=0,5 \mathrm{l} /$ ha Carax $^{\circledR}$ in $\mathrm{BBCH} 14$ und 33/35; alle Varianten erhielten in $\mathrm{BBCH} 651 \mathrm{l} /$ ha Ortiva $^{\circledR}$ ).

\begin{tabular}{|c|c|c|c|c|c|c|c|c|}
\hline Parameter & Effekt & So & Di & Fu & Mittelwert & SD & $\mathbf{n}$ & Buchstaben \\
\hline \multirow[t]{8}{*}{ Kornertrag [t/ha] } & $\mathrm{Fu}$ & & & 1 & 5,79 & 0,26 & 16 & a \\
\hline & $\mathrm{Fu}$ & & & 2 & 5,87 & 0,19 & 16 & a \\
\hline & $\mathrm{Fu}$ & & & 3 & 5,63 & 0,21 & 16 & $a b$ \\
\hline & $\mathrm{Fu}$ & & & 4 & 5,24 & 0,23 & 16 & $\mathrm{~cd}$ \\
\hline & $\mathrm{Fu}$ & & & 5 & 5,47 & 0,15 & 16 & $\mathrm{bc}$ \\
\hline & $\mathrm{Fu}$ & & & 6 & 5,15 & 0,27 & 16 & $d$ \\
\hline & $\mathrm{Fu}$ & & & 7 & 5,81 & 0,25 & 16 & a \\
\hline & Fu & & & -8 & 5,63 & -0,19. & 16 & $a b$ \\
\hline \multirow[t]{8}{*}{ Strohbiomasseertrag [t/ha] } & $\mathrm{Fu}$ & & & 1 & 6,29 & 0,48 & 16 & $a b$ \\
\hline & $\mathrm{Fu}$ & & & 2 & 6,23 & 0,41 & 16 & $a b$ \\
\hline & $\mathrm{Fu}$ & & & 3 & 6,04 & 0,47 & 16 & ac \\
\hline & $\mathrm{Fu}$ & & & 4 & 5,41 & 0,44 & 16 & c \\
\hline & $\mathrm{Fu}$ & & & 5 & 5,94 & 0,36 & 16 & ac \\
\hline & $\mathrm{Fu}$ & & & 6 & 5,49 & 0,69 & 16 & $c$ \\
\hline & $\mathrm{Fu}$ & & & 7 & 6,48 & 0,55 & 16 & a \\
\hline & Fu‥ & & & -8 & 5,74 & $-\underline{0,50}$ & -16 & $b c$ \\
\hline \multirow[t]{4}{*}{ Ölgehalt [\%] } & So & $P$ & & & 42,32 & 0,59 & 64 & $b$ \\
\hline & So & $\mathrm{V}$ & & & 43,28 & 0,57 & 64 & a \\
\hline & $\mathrm{Di}$ & & 30 & & 43,02 & 0,59 & 64 & a \\
\hline & Di & & 60 & & 42,57 & 0,57 & 64 & b. \\
\hline
\end{tabular}




\begin{tabular}{|c|c|c|c|c|c|c|c|}
\hline & $\mathrm{Fu}$ & & 1 & 43,11 & 0,43 & 16 & $a$ \\
\hline & $\mathrm{Fu}$ & & 2 & 43,06 & 0,59 & 16 & $a b$ \\
\hline & $\mathrm{Fu}$ & & 3 & 42,79 & 0,75 & 16 & $a b$ \\
\hline & $\mathrm{Fu}$ & & 4 & 42,62 & 0,75 & 16 & $a b$ \\
\hline & $\mathrm{Fu}$ & & 5 & 42,43 & 0,35 & 16 & $a b$ \\
\hline & $\mathrm{Fu}$ & & 6 & 42,41 & 0,49 & 16 & $b$ \\
\hline & $\mathrm{Fu}$ & & 7 & 43,06 & 0,64 & 16 & $a b$ \\
\hline & Fu‥ & & -8 & $-42,89$ & $-0,62$ & -16 & $-a b$ \\
\hline Ölertrag [t/ha] & $\mathrm{Fu}$ & & 1 & 2,50 & 0,11 & 16 & a \\
\hline & $\mathrm{Fu}$ & & 2 & 2,53 & 0,10 & 16 & $\mathrm{a}$ \\
\hline & $\mathrm{Fu}$ & & 3 & 2,41 & 0,10 & 16 & $a b$ \\
\hline & $\mathrm{Fu}$ & & 4 & 2,23 & 0,08 & 16 & $\mathrm{~cd}$ \\
\hline & $\mathrm{Fu}$ & & 5 & 2,32 & 0,07 & 16 & bc \\
\hline & $\mathrm{Fu}$ & & 6 & 2,18 & 0,11 & 16 & $d$ \\
\hline & $\mathrm{Fu}$ & & 7 & 2,50 & 0,10 & 16 & $\mathrm{a}$ \\
\hline & Fu & & 8 & 2,41 & 0,10 & 16 & $a b$ \\
\hline & So*Fu & $P$ & 1 & 2,39 & 0,10 & 8 & $\mathrm{ac}$ \\
\hline & So*Fu & $P$ & 2 & 2,47 & 0,10 & 8 & $\mathrm{a}$ \\
\hline & $\mathrm{So}^{\star} \mathrm{Fu}$ & $P$ & 3 & 2,40 & 0,07 & 8 & $a b$ \\
\hline & So*Fu & $P$ & 4 & 2,23 & 0,06 & 8 & $\mathrm{bc}$ \\
\hline & So*Fu & $P$ & 5 & 2,34 & 0,08 & 8 & ac \\
\hline & So*Fu & $P$ & 6 & 2,19 & 0,13 & 8 & $c$ \\
\hline & So*Fu & $P$ & 7 & 2,43 & 0,09 & 8 & $a b$ \\
\hline & So*Fu & $P$ & 8 & 2,36 & 0,08 & 8 & $\mathrm{ac}$ \\
\hline & So*Fu & V & 1 & 2,60 & 0,12 & 8 & $\mathrm{a}$ \\
\hline & So*Fu & V & 2 & 2,59 & 0,11 & 8 & $a$ \\
\hline & So*Fu & V & 3 & 2,42 & 0,13 & 8 & $a b c$ \\
\hline & So*Fu & V & 4 & 2,23 & 0,10 & 8 & $\mathrm{~cd}$ \\
\hline & So*Fu & V & 5 & 2,30 & 0,06 & 8 & bd \\
\hline & So*Fu & V & 6 & 2,17 & 0,09 & 8 & $d$ \\
\hline & So*Fu & V & 7 & 2,57 & 0,12 & 8 & $\mathrm{a}$ \\
\hline & So*Fu & $\mathrm{V}$ & 8 & 2,47 & 0,12 & 8 & $a b$ \\
\hline & $\mathrm{Di}^{\star} \mathrm{Fu}$ & 30 & 1 & 2,45 & 0,13 & 8 & $a b$ \\
\hline & $\mathrm{Di}{ }^{\star} \mathrm{Fu}$ & 30 & 2 & 2,58 & 0,10 & 8 & $a$ \\
\hline & $\mathrm{Di}{ }^{\star} \mathrm{Fu}$ & 30 & 3 & 2,42 & 0,12 & 8 & $a b$ \\
\hline & $\mathrm{Di}{ }^{\star} \mathrm{Fu}$ & 30 & 4 & 2,21 & 0,09 & 8 & $c$ \\
\hline & $\mathrm{Di}{ }^{*} \mathrm{Fu}$ & 30 & 5 & 2,28 & 0,08 & 8 & $\mathrm{bc}$ \\
\hline & $\mathrm{Di}^{\star} \mathrm{Fu}$ & 30 & 6 & 2,16 & 0,08 & 8 & $c$ \\
\hline & $\mathrm{Di}^{\star} \mathrm{Fu}$ & 30 & 7 & 2,46 & 0,11 & 8 & $a b$ \\
\hline & $\mathrm{Di}^{\star} \mathrm{Fu}$ & 30 & 8 & 2,31 & 0,10 & 8 & $\mathrm{bc}$ \\
\hline
\end{tabular}




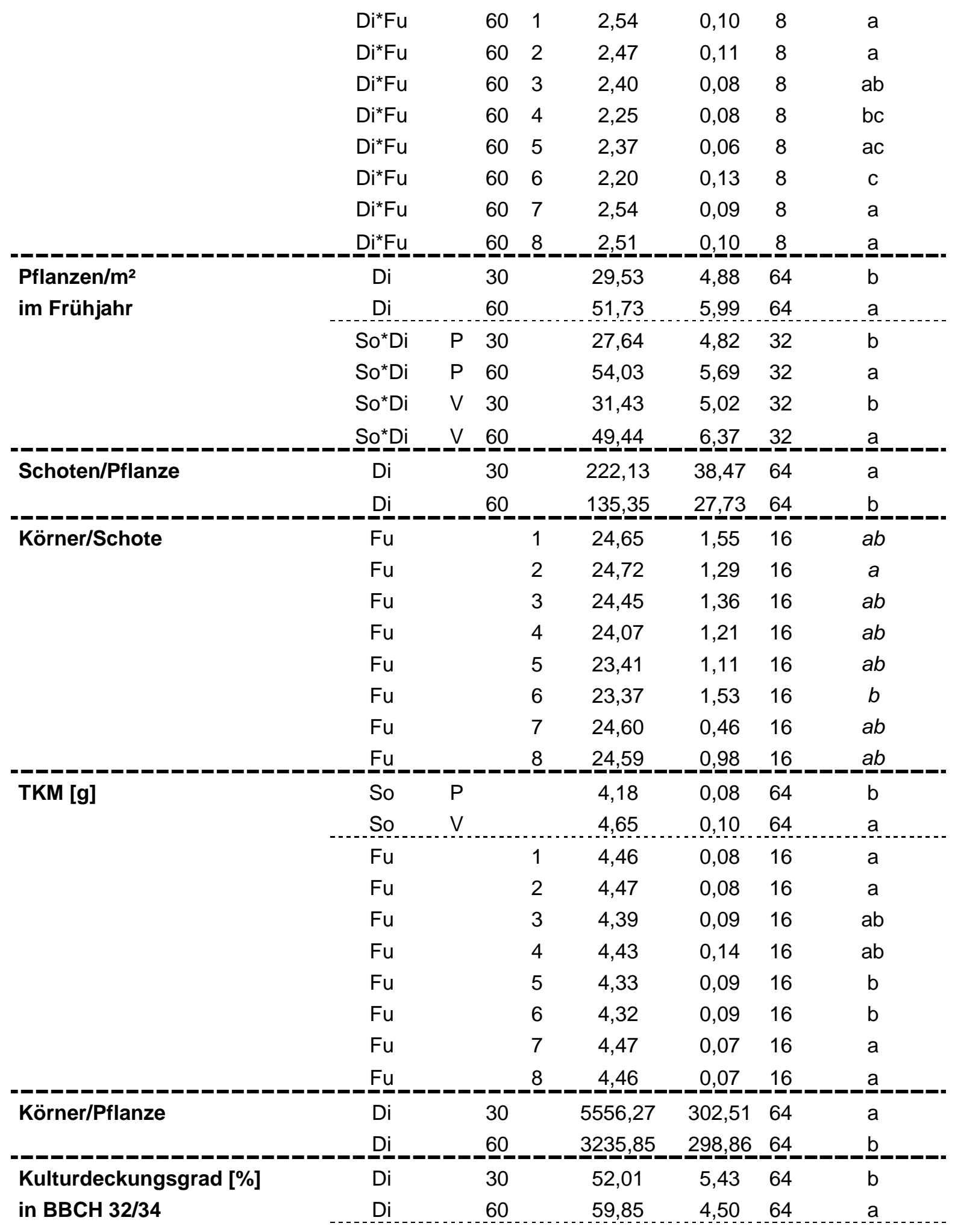




\begin{tabular}{|c|c|c|c|c|c|c|c|c|}
\hline & \multicolumn{3}{|l|}{$\mathrm{Fu}$} & 1 & 56,35 & 6,05 & 16 & $a b$ \\
\hline & \multicolumn{3}{|l|}{$\mathrm{Fu}$} & 2 & 55,80 & 5,15 & 16 & $a b$ \\
\hline & \multicolumn{3}{|l|}{$\mathrm{Fu}$} & 3 & 55,32 & 4,04 & 16 & $a b$ \\
\hline & \multicolumn{3}{|l|}{$\mathrm{Fu}$} & 4 & 53,72 & 5,89 & 16 & $a b$ \\
\hline & \multicolumn{3}{|l|}{$\mathrm{Fu}$} & 5 & 58,35 & 4,38 & 16 & $a b$ \\
\hline & \multicolumn{3}{|l|}{$\mathrm{Fu}$} & 6 & 53,43 & 4,07 & 16 & $b$ \\
\hline & \multicolumn{3}{|l|}{$\mathrm{Fu}$} & 7 & 60,01 & 5,26 & 16 & $a$ \\
\hline & \multicolumn{2}{|l|}{ Fu․ } & & 8 & 54,48 & 5,73 & 16 & $a b$ \\
\hline \multirow{34}{*}{$\begin{array}{l}\text { Wurzelhalsdurchmesser } \\
{[\mathrm{mm}] \text { in } \mathrm{BBCH} 80 / 81}\end{array}$} & \multirow{2}{*}{\multicolumn{2}{|c|}{$\begin{array}{l}\mathrm{Di} \\
\mathrm{Di}\end{array}$}} & 30 & & 13,96 & 0,72 & 64 & $a$ \\
\hline & & & 60 & & 11,82 & 0,65 & 64 & $b$ \\
\hline & \multicolumn{2}{|l|}{$\mathrm{Di}^{*} \mathrm{Fu}$} & 30 & 1 & 13,67 & 0,69 & 8 & $a b$ \\
\hline & \multicolumn{2}{|l|}{$\mathrm{Di}^{*} \mathrm{Fu}$} & 30 & 2 & 13,67 & 1,05 & 8 & $a b$ \\
\hline & \multicolumn{2}{|l|}{$\mathrm{Di}^{*} \mathrm{Fu}$} & 30 & 3 & 13,97 & 0,49 & 8 & $a b$ \\
\hline & \multicolumn{2}{|l|}{$\mathrm{Di}^{\star} \mathrm{Fu}$} & 30 & 4 & 14,35 & 0,64 & 8 & $a b$ \\
\hline & \multicolumn{2}{|l|}{$\mathrm{Di}^{*} \mathrm{Fu}$} & 30 & 5 & 14,06 & 1,00 & 8 & $a b$ \\
\hline & \multicolumn{2}{|l|}{$\mathrm{Di}^{*} \mathrm{Fu}$} & 30 & 6 & 13,16 & 0,47 & 8 & $b$ \\
\hline & \multicolumn{2}{|l|}{$\mathrm{Di}^{*} \mathrm{Fu}$} & 30 & 7 & 14,60 & 0,85 & 8 & $a$ \\
\hline & \multicolumn{2}{|l|}{$\mathrm{Di}^{\star} \mathrm{Fu}$} & 30 & 8 & 14,23 & 0,66 & 8 & $a b$ \\
\hline & \multicolumn{2}{|l|}{$\mathrm{Di}^{*} \mathrm{Fu}$} & 60 & 1 & 11,51 & 0,76 & 8 & $a b$ \\
\hline & \multicolumn{2}{|l|}{$\mathrm{Di}^{*} \mathrm{Fu}$} & 60 & 2 & 12,28 & 0,22 & 8 & $a b$ \\
\hline & \multicolumn{2}{|l|}{$\mathrm{Di}^{*} \mathrm{Fu}$} & 60 & 3 & 11,96 & 0,45 & 8 & $a b$ \\
\hline & \multicolumn{2}{|l|}{$\mathrm{Di}^{\star} \mathrm{Fu}$} & 60 & 4 & 11,46 & 0,54 & 8 & $a b$ \\
\hline & \multicolumn{2}{|l|}{$\mathrm{Di}^{*} \mathrm{Fu}$} & 60 & 5 & 11,94 & 0,89 & 8 & $a b$ \\
\hline & $\mathrm{Di}^{*} \mathrm{Fu}$ & & 60 & 6 & 12,29 & 0,84 & 8 & $a$ \\
\hline & $\mathrm{Di}^{\star} \mathrm{Fu}$ & & 60 & 7 & 11,38 & 0,92 & 8 & $b$ \\
\hline & $\mathrm{Di}^{*} \mathrm{Fu}$ & & 60 & 8 & 11,72 & 0,63 & 8 & $a b$ \\
\hline & So* $\mathrm{Di}^{\star} \mathrm{Fu}$ & $P$ & 30 & 1 & 13,04 & 0,95 & 4 & $a b$ \\
\hline & So* $\mathrm{Di}^{\star} \mathrm{Fu}$ & $P$ & 30 & 2 & 13,75 & 0,91 & 4 & $a b$ \\
\hline & $\mathrm{So}^{\star} \mathrm{Di}{ }^{\star} \mathrm{Fu}$ & $P$ & 30 & 3 & 13,94 & 0,71 & 4 & $a b$ \\
\hline & So* $\mathrm{Di}^{\star} \mathrm{Fu}$ & $P$ & 30 & 4 & 13,63 & 0,40 & 4 & $a b$ \\
\hline & So* $\mathrm{Di}^{\star} \mathrm{Fu}$ & $P$ & 30 & 5 & 13,41 & 1,13 & 4 & $a b$ \\
\hline & $\mathrm{So}^{*} \mathrm{Di}^{\star} \mathrm{Fu}$ & $\mathrm{P}$ & 30 & 6 & 12,40 & 0,16 & 4 & $b$ \\
\hline & So* $\mathrm{Di}^{\star} \mathrm{Fu}$ & $P$ & 30 & 7 & 14,56 & 1,11 & 4 & $a$ \\
\hline & $\mathrm{So}^{\star} \mathrm{Di}^{\star} \mathrm{Fu}$ & $P$ & 30 & 8 & 13,57 & 0,87 & 4 & $a b$ \\
\hline & So* $\mathrm{Di}^{\star} \mathrm{Fu}$ & $P$ & 60 & 1 & 11,90 & 0,59 & 4 & $a b$ \\
\hline & So* $\mathrm{Di}^{\star} \mathrm{Fu}$ & $P$ & 60 & 2 & 11,82 & 0,22 & 4 & $a b$ \\
\hline & $\mathrm{So}^{\star} \mathrm{Di}^{\star} \mathrm{Fu}$ & $P$ & 60 & 3 & 12,26 & 0,66 & 4 & $a b$ \\
\hline & $\mathrm{So}^{\star} \mathrm{Di}^{\star} \mathrm{Fu}$ & $P$ & 60 & 4 & 11,54 & 0,53 & 4 & $b$ \\
\hline & So* $\mathrm{Di}^{\star} \mathrm{Fu}$ & $P$ & 60 & 5 & 12,76 & 0,76 & 4 & $a$ \\
\hline & So* $\mathrm{Di}^{\star} \mathrm{Fu}$ & $P$ & 60 & 6 & 12,72 & 0,97 & 4 & $a b$ \\
\hline & $\mathrm{So}^{\star} \mathrm{Di}^{\star} \mathrm{Fu}$ & $P$ & 60 & 7 & 11,60 & 0,87 & 4 & $a b$ \\
\hline & So* $\mathrm{Di}^{\star} \mathrm{Fu}$ & $P$ & 60 & 8 & 11,77 & 0,37 & 4 & $a b$ \\
\hline
\end{tabular}




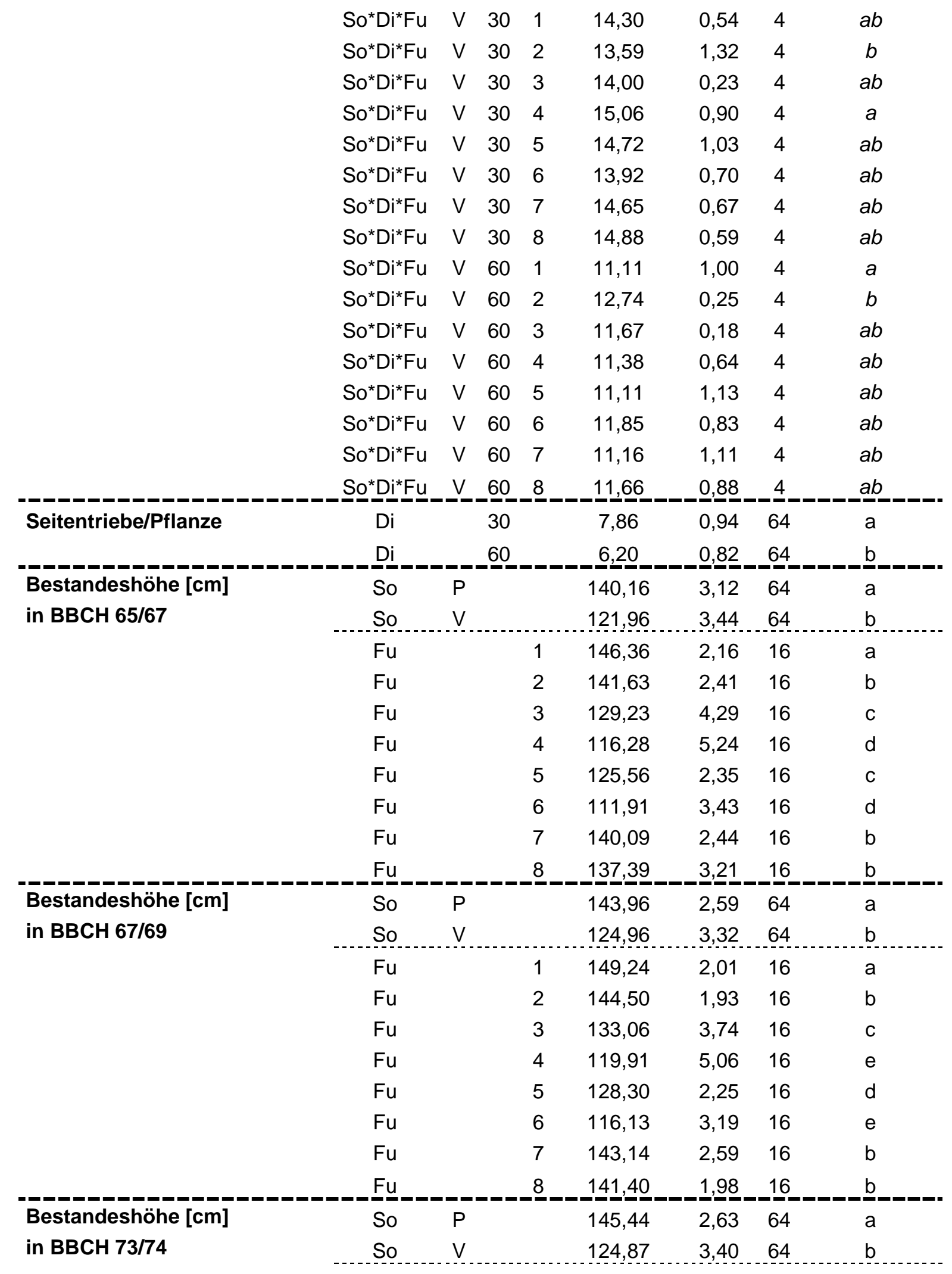




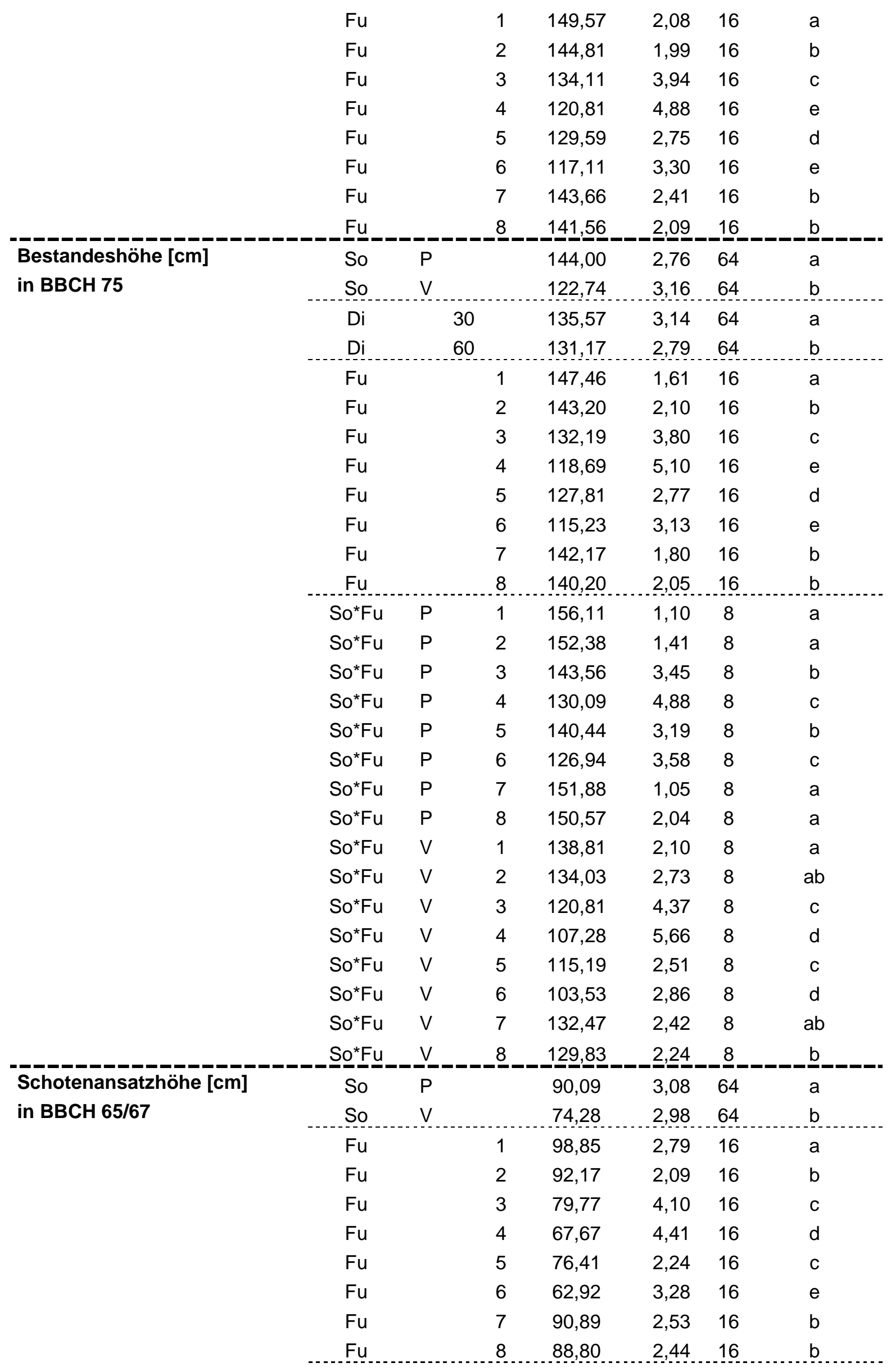




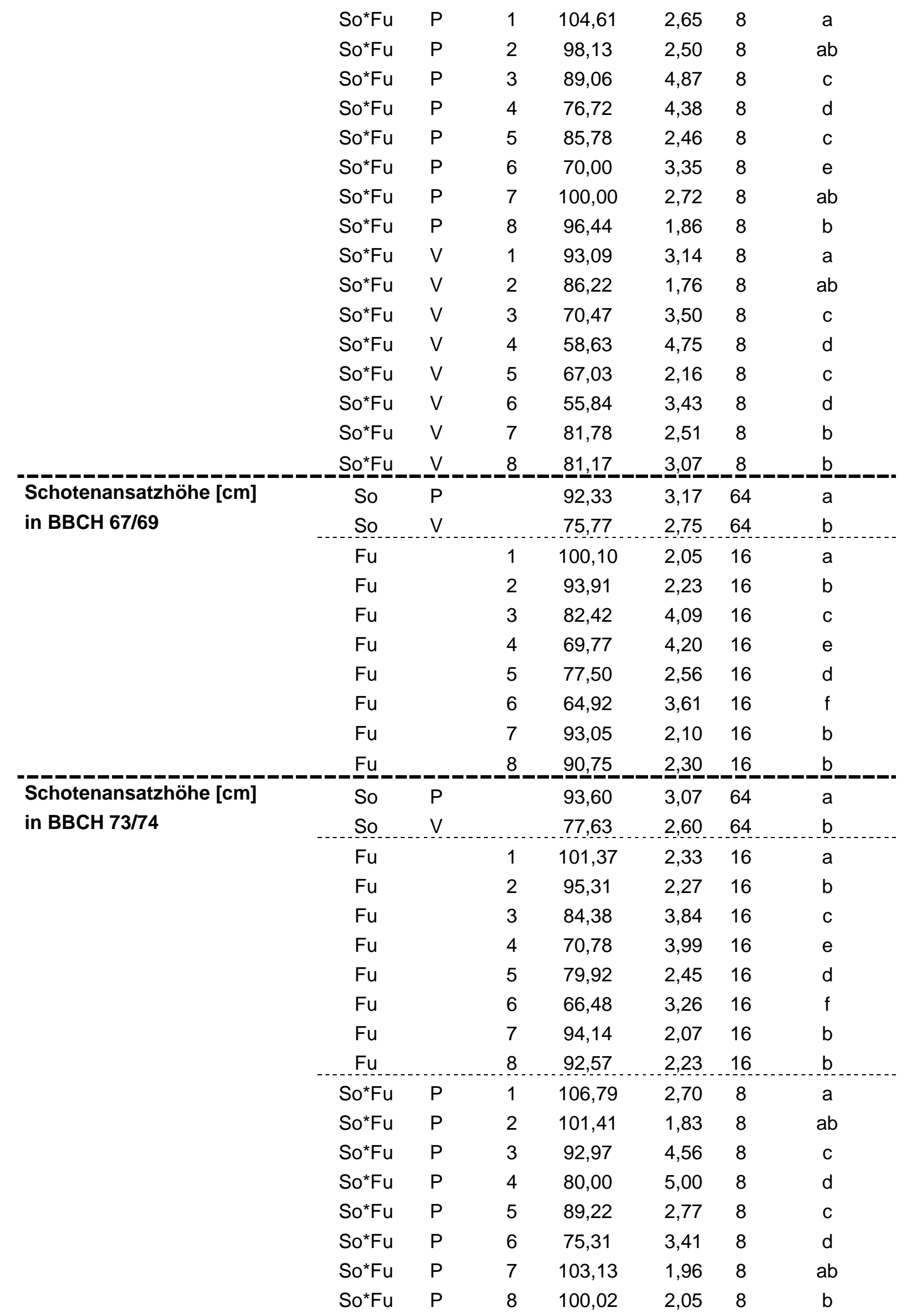




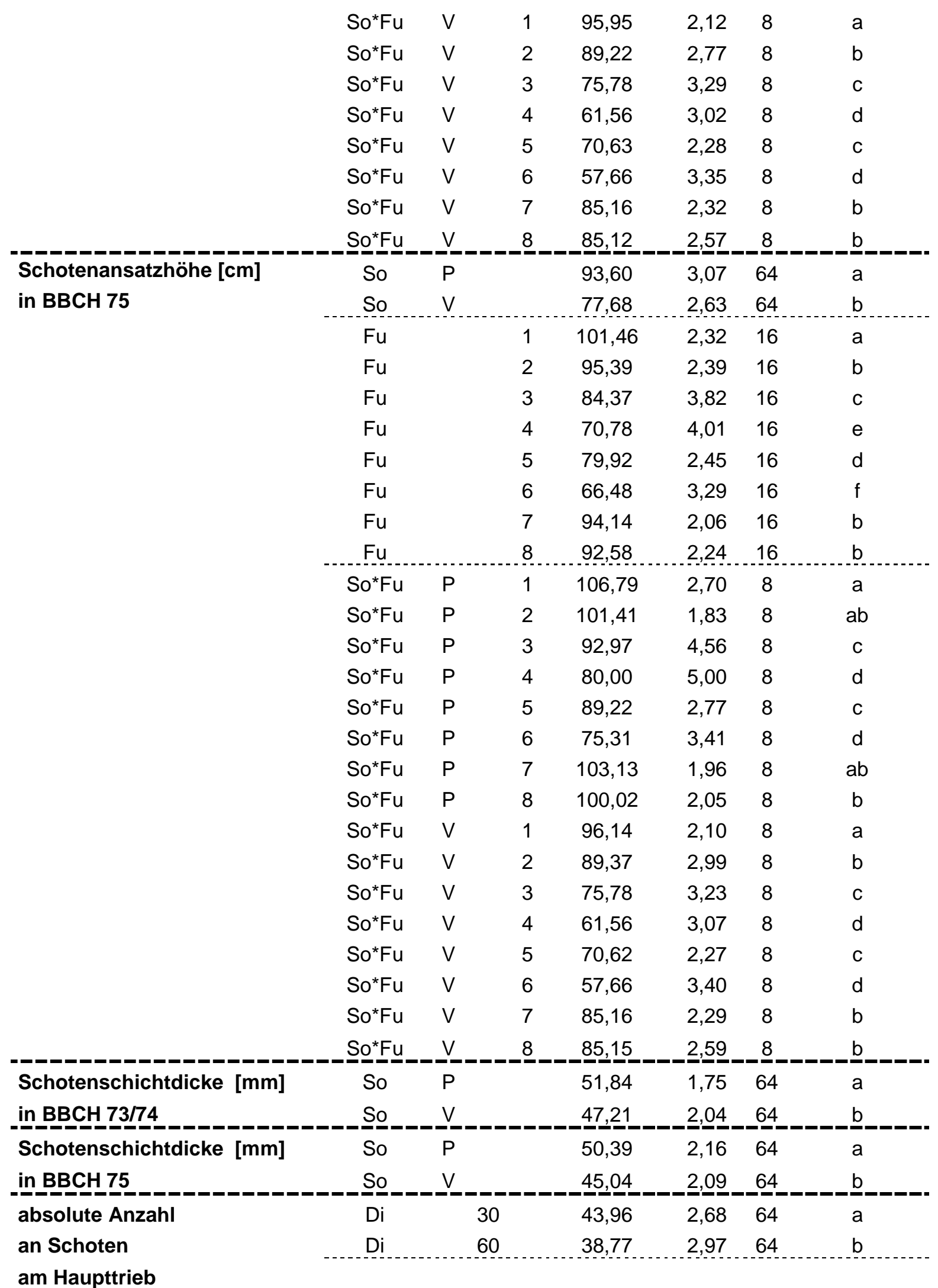




\begin{tabular}{|c|c|c|c|c|c|c|c|}
\hline & So*Fu & $P$ & 1 & 37,76 & 3,44 & 8 & $a b$ \\
\hline & So*Fu & $P$ & 2 & 41,43 & 2,05 & 8 & $a b$ \\
\hline & So*Fu & $P$ & 3 & 43,66 & 3,37 & 8 & $a$ \\
\hline & So*Fu & $P$ & 4 & 41,44 & 1,80 & 8 & $a b$ \\
\hline & So*Fu & $P$ & 5 & 39,81 & 2,83 & 8 & $a b$ \\
\hline & $\mathrm{So}^{*} \mathrm{Fu}$ & $P$ & 6 & 42,86 & 3,25 & 8 & $a b$ \\
\hline & So*Fu & $P$ & 7 & 40,48 & 1,89 & 8 & $a b$ \\
\hline & So*Fu & $P$ & 8 & 36,95 & 2,59 & 8 & $b$ \\
\hline & So*Fu & $\mathrm{V}$ & 1 & 42,81 & 2,32 & 8 & $a$ \\
\hline & $\mathrm{So}^{\star} \mathrm{Fu}$ & $\mathrm{V}$ & 2 & 39,95 & 3,15 & 8 & a \\
\hline & So*Fu & $\mathrm{V}$ & 3 & 43,03 & 3,93 & 8 & $a$ \\
\hline & So*Fu & V & 4 & 43,01 & 3,07 & 8 & $\mathrm{a}$ \\
\hline & $\mathrm{So}^{\star} \mathrm{Fu}$ & $\mathrm{V}$ & 5 & 41,23 & 3,60 & 8 & $a$ \\
\hline & So*Fu & $\mathrm{V}$ & 6 & 42,73 & 3,48 & 8 & $a$ \\
\hline & $\mathrm{So}^{\star} \mathrm{Fu}$ & $\mathrm{V}$ & 7 & 41,73 & 3,94 & 8 & $a$ \\
\hline & So으므. & V & -8 & 43,03 & $-1,90$ & -8 & -a \\
\hline absolute Anzahl an & $\mathrm{Di}$ & 30 & & 19,36 & 2,43 & 64 & a \\
\hline Schoten am 1. Seitentrieb & Di & 60. & & 15,63 & $-2,21$ & 64 & - \\
\hline absolute Anzahl an & $\mathrm{Di}$ & 30 & & 23,48 & 3,67 & 64 & a \\
\hline Schoten am 2. Seitentrieb & Di & 60 & & 17,67 & $2, \underline{2}, \underline{9}$ & 64 & b. \\
\hline absolute Anzahl an & $\mathrm{Di}$ & 30 & & 26,50 & 4,49 & 64 & a \\
\hline Schoten am 3. Seitentrieb & Di & 60. & & 17,94 & $-3,83$ & 64 & b. \\
\hline absolute Anzahl an & $\mathrm{Di}$ & 30 & & 25,53 & 5,94 & 64 & a \\
\hline Schoten am 4. Seitentrieb & Di & 60 & & 15,66 & $-4,45$ & 64 & - \\
\hline relativer Anteil [\%] an & $\mathrm{Di}$ & 30 & & 21,02 & 3,92 & 64 & $\mathrm{~b}$ \\
\hline Schoten am Haupttrieb & Di & 60 & & 29,95 & $-5,46$ & 64 & $-a$ \\
\hline relativer Anteil [\%] an & $\mathrm{Di}$ & 30 & & 9,08 & 1,48 & 64 & $\mathrm{~b}$ \\
\hline Schoten am 1. Seitentrieb & Di & 60 & & 11,82 & $-1,53$ & 64 & -a \\
\hline relativer Anteil [\%] an & $\mathrm{Di}$ & 30 & & 10,86 & 1,48 & 64 & $\mathrm{~b}$ \\
\hline Schoten am 2. Seitentrieb & Di & 60 & & $-13,23$ & $-1,46$ & 64 & $-\underline{a}$ \\
\hline relativer Anteil [\%] an & $\mathrm{Di}$ & 30 & & 12,06 & 1,46 & 64 & $\mathrm{~b}$ \\
\hline \multirow[t]{9}{*}{ Schoten am 3. Seitentrieb } & $\mathrm{Di}$ & 60 & & 13,29 & 1,34 & 64 & $a$ \\
\hline & $\mathrm{Fu}$ & & 1 & 13,54 & 1,18 & 16 & a \\
\hline & $\mathrm{Fu}$ & & 2 & 13,07 & 1,52 & 16 & $a b$ \\
\hline & $\mathrm{Fu}$ & & 3 & 13,13 & 1,52 & 16 & $a b$ \\
\hline & $\mathrm{Fu}$ & & 4 & 11,60 & 1,33 & 16 & $\mathrm{~b}$ \\
\hline & $\mathrm{Fu}$ & & 5 & 12,98 & 1,65 & 16 & $a b$ \\
\hline & $\mathrm{Fu}$ & & 6 & 11,37 & 1,74 & 16 & $\mathrm{~b}$ \\
\hline & $\mathrm{Fu}$ & & 7 & 12,88 & 1,35 & 16 & $a b$ \\
\hline & Fu & & -8 & 12,84 & $-0,94$ & 16 & ab \\
\hline Anteil an PAR [\%] am Boden & $\mathrm{Di}$ & 30 & & 1,47 & 0,43 & 64 & a \\
\hline in BBCH 65 (PAR_B1) & Di & 60 & & 1,12 & - & 64 & - $\underline{\mathrm{b}}$. \\
\hline
\end{tabular}




\begin{tabular}{|c|c|c|c|c|c|c|c|}
\hline Anteil an PAR [\%] am Boden & $\mathrm{Fu}$ & & 1 & 1,57 & 0,55 & 16 & $a b$ \\
\hline \multirow[t]{7}{*}{ in BBCH 73/74 (PAR_B3) } & $\mathrm{Fu}$ & & 2 & 1,49 & 0,29 & 16 & $a b$ \\
\hline & $\mathrm{Fu}$ & & 3 & 1,60 & 0,35 & 16 & $a b$ \\
\hline & $\mathrm{Fu}$ & & 4 & 1,96 & 0,63 & 16 & $a$ \\
\hline & $\mathrm{Fu}$ & & 5 & 1,34 & 0,30 & 16 & $\mathrm{~b}$ \\
\hline & $\mathrm{Fu}$ & & 6 & 1,89 & 0,46 & 16 & $a b$ \\
\hline & $\mathrm{Fu}$ & & 7 & 1,54 & 0,48 & 16 & $a b$ \\
\hline & Fu‥ & & -8. & 1,54 & 0,33 & 16 & $a b$ \\
\hline Anteil an PAR [\%] am Boden & So*Fu & $\mathrm{P}$ & 1 & 2,01 & 0,50 & 8 & $a b$ \\
\hline \multirow[t]{15}{*}{ in BBCH 75 (PAR_B4) } & So*Fu & $P$ & 2 & 2,37 & 0,69 & 8 & $a b$ \\
\hline & So*Fu & $\mathrm{P}$ & 3 & 1,98 & 0,51 & 8 & $a b$ \\
\hline & So*Fu & $P$ & 4 & 2,23 & 0,67 & 8 & $a b$ \\
\hline & So*Fu & $\mathrm{P}$ & 5 & 1,53 & 0,52 & 8 & $b$ \\
\hline & So*Fu & $P$ & 6 & 2,65 & 0,77 & 8 & $a b$ \\
\hline & So*Fu & $P$ & 7 & 2,95 & 0,88 & 8 & $a$ \\
\hline & So*Fu & $P$ & 8 & 2,18 & 0,64 & 8 & $a b$ \\
\hline & So*Fu & V & 1 & 1,74 & 0,78 & 8 & a \\
\hline & So*Fu & V & 2 & 1,87 & 0,72 & 8 & $a$ \\
\hline & So*Fu & V & 3 & 1,90 & 0,54 & 8 & $a$ \\
\hline & So*Fu & V & 4 & 2,24 & 0,78 & 8 & $a$ \\
\hline & So*Fu & V & 5 & 2,12 & 0,40 & 8 & $a$ \\
\hline & So*Fu & V & 6 & 2,42 & 0,40 & 8 & $a$ \\
\hline & So*Fu & V & 7 & 1,54 & 0,59 & 8 & $a$ \\
\hline & Só $\underline{S}^{*} \underline{\mathrm{u}}$ & V & -8 & $\underline{2}, \underline{39}$ & 1,02 & -8 & $-\underline{a}$ \\
\hline \multirow[t]{20}{*}{ NDVI_Dauer } & So & $\mathrm{P}$ & & 54,35 & 0,50 & 64 & $b$ \\
\hline & So & $\mathrm{V}$ & & 56,22 & 0,47 & 64 & a \\
\hline & $\mathrm{Di}$ & \multicolumn{2}{|c|}{30} & 54,98 & 0,54 & 64 & $\mathrm{~b}$ \\
\hline & $\mathrm{Di}$ & \multicolumn{2}{|c|}{60} & 55,59 & 0,43 & 64 & $a$ \\
\hline & $\mathrm{Fu}$ & & 1 & 53,66 & 0,51 & 16 & e \\
\hline & $\mathrm{Fu}$ & & 2 & 54,40 & 0,62 & 16 & $d$ \\
\hline & $\mathrm{Fu}$ & & 3 & 55,61 & 0,48 & 16 & $b c$ \\
\hline & $\mathrm{Fu}$ & & 4 & 56,00 & 0,48 & 16 & $b$ \\
\hline & $\mathrm{Fu}$ & & 5 & 56,24 & 0,48 & 16 & $a b$ \\
\hline & $\mathrm{Fu}$ & & 6 & 56,87 & 0,44 & 16 & $a$ \\
\hline & $\mathrm{Fu}$ & & 7 & 55,00 & 0,54 & 16 & $\mathrm{~cd}$ \\
\hline & $\mathrm{Fu}$ & & 8 & 54,51 & 0,40 & 16 & d \\
\hline & So*Fu & $P$ & 1 & 52,84 & 0,60 & 8 & e \\
\hline & So*Fu & $P$ & 2 & 53,38 & 0,44 & 8 & de \\
\hline & So*Fu & $P$ & 3 & 54,26 & 0,61 & 8 & $\mathrm{~cd}$ \\
\hline & So*Fu & $P$ & 4 & 55,41 & 0,63 & 8 & $a b$ \\
\hline & So*Fu & $P$ & 5 & 55,19 & 0,34 & 8 & $b c$ \\
\hline & So*Fu & $P$ & 6 & 56,28 & 0,40 & 8 & $a$ \\
\hline & So*Fu & $P$ & 7 & 53,76 & 0,67 & 8 & de \\
\hline & So*Fu & $P$ & 8 & 53,64 & 0,49 & 8 & de \\
\hline
\end{tabular}




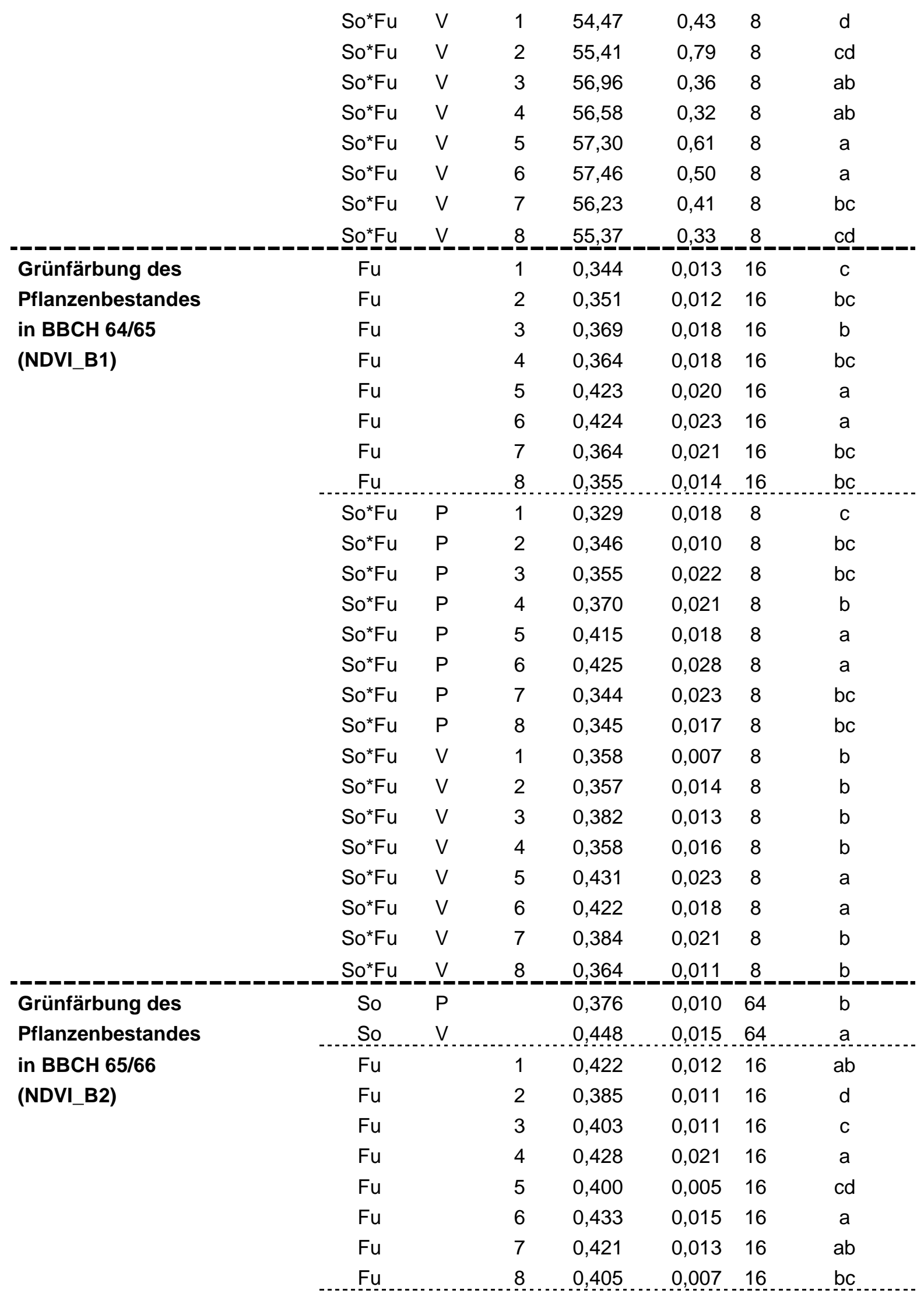




\begin{tabular}{|c|c|c|c|c|c|c|c|}
\hline & So* $\mathrm{Fu}$ & $P$ & 1 & 0,377 & 0,006 & 8 & $a b$ \\
\hline & So* $\mathrm{Fu}$ & $P$ & 2 & 0,358 & 0,008 & 8 & $\mathrm{~b}$ \\
\hline & So ${ }^{\star} \mathrm{Fu}$ & $P$ & 3 & 0,364 & 0,008 & 8 & $\mathrm{~b}$ \\
\hline & So*Fu & $P$ & 4 & 0,394 & 0,013 & 8 & $a$ \\
\hline & So* $\mathrm{Fu}$ & $P$ & 5 & 0,364 & 0,006 & 8 & $b$ \\
\hline & So* $\mathrm{Fu}$ & $P$ & 6 & 0,404 & 0,018 & 8 & $a$ \\
\hline & So* $\mathrm{Fu}$ & $P$ & 7 & 0,381 & 0,012 & 8 & $a b$ \\
\hline & So*Fu & $P$ & 8 & 0,363 & 0,010 & 8 & $b$ \\
\hline & So* $\mathrm{Fu}$ & V & 1 & 0,467 & 0,017 & 8 & $a$ \\
\hline & So*Fu & V & 2 & 0,413 & 0,015 & 8 & $\mathrm{c}$ \\
\hline & So* $\mathrm{Fu}$ & V & 3 & 0,442 & 0,015 & 8 & $a b$ \\
\hline & So* $\mathrm{Fu}$ & V & 4 & 0,462 & 0,028 & 8 & $a b$ \\
\hline & So*Fu & V & 5 & 0,436 & 0,005 & 8 & $b c$ \\
\hline & So* $\mathrm{Fu}$ & V & 6 & 0,462 & 0,013 & 8 & $a b$ \\
\hline & So* $\mathrm{Fu}$ & V & 7 & 0,461 & 0,014 & 8 & $a b$ \\
\hline & So*Fu & V & 8 & 0,446 & 0,004 & - & $a b$ \\
\hline Grünfärbung des & $\mathrm{Fu}$ & & 1 & 0,755 & 0,012 & 16 & $a$ \\
\hline Pflanzenbestandes & $\mathrm{Fu}$ & & 2 & 0,745 & 0,018 & 16 & $a b$ \\
\hline in $\mathrm{BBCH} 69$ & $\mathrm{Fu}$ & & 3 & 0,744 & 0,015 & 16 & $a b$ \\
\hline \multirow[t]{21}{*}{ (NDVI_B3) } & $\mathrm{Fu}$ & & 4 & 0,745 & 0,013 & 16 & $a b$ \\
\hline & $\mathrm{Fu}$ & & 5 & 0,731 & 0,010 & 16 & $\mathrm{~b}$ \\
\hline & $\mathrm{Fu}$ & & 6 & 0,734 & 0,023 & 16 & $a b$ \\
\hline & $\mathrm{Fu}$ & & 7 & 0,752 & 0,018 & 16 & $a b$ \\
\hline & Fu & & 8 & 0,745 & 0,016 & 16 & $a b$ \\
\hline & $\mathrm{Di}^{\star} \mathrm{Fu}$ & 30 & 1 & 0,751 & 0,013 & 8 & $\mathrm{a}$ \\
\hline & $\mathrm{Di}^{\star} \mathrm{Fu}$ & 30 & 2 & 0,745 & 0,014 & 8 & $\mathrm{a}$ \\
\hline & $\mathrm{Di}^{\star} \mathrm{Fu}$ & 30 & 3 & 0,743 & 0,011 & 8 & $\mathrm{a}$ \\
\hline & $\mathrm{Di}^{\star} \mathrm{Fu}$ & 30 & 4 & 0,742 & 0,013 & 8 & $\mathrm{a}$ \\
\hline & $\mathrm{Di}^{\star} \mathrm{Fu}$ & 30 & 5 & 0,730 & 0,011 & 8 & $\mathrm{a}$ \\
\hline & $\mathrm{Di}^{\star} \mathrm{Fu}$ & 30 & 6 & 0,738 & 0,021 & 8 & $\mathrm{a}$ \\
\hline & $\mathrm{Di}^{\star} \mathrm{Fu}$ & 30 & 7 & 0,737 & 0,023 & 8 & $a$ \\
\hline & $\mathrm{Di}^{\star} \mathrm{Fu}$ & 30 & 8 & 0,723 & 0,021 & 8 & $a$ \\
\hline & $\mathrm{Di}^{\star} \mathrm{Fu}$ & 60 & 1 & 0,758 & 0,012 & 8 & ac \\
\hline & $\mathrm{Di}^{\star} \mathrm{Fu}$ & 60 & 2 & 0,745 & 0,022 & 8 & ac \\
\hline & $\mathrm{Di}^{\star} \mathrm{Fu}$ & 60 & 3 & 0,745 & 0,019 & 8 & ac \\
\hline & $\mathrm{Di}^{\star} \mathrm{Fu}$ & 60 & 4 & 0,749 & 0,014 & 8 & ac \\
\hline & $\mathrm{Di}{ }^{\star} \mathrm{Fu}$ & 60 & 5 & 0,732 & 0,011 & 8 & bc \\
\hline & $\mathrm{Di}^{\star} \mathrm{Fu}$ & 60 & 6 & 0,730 & 0,027 & 8 & $c$ \\
\hline & $\mathrm{Di}^{\star} \mathrm{Fu}$ & 60 & 7 & 0,767 & 0,014 & 8 & $a$ \\
\hline & Di ${ }^{\star} F u$ & 60 & 8 & 0,767. & 0,013 & 8 & $a b$ \\
\hline
\end{tabular}




\begin{tabular}{|c|c|c|c|c|c|c|c|}
\hline Grünfärbung des & $\mathrm{Fu}$ & & 1 & 0,785 & 0,008 & 16 & $\mathrm{c}$ \\
\hline Pflanzenbestandes & $\mathrm{Fu}$ & & 2 & 0,789 & 0,007 & 16 & $b c$ \\
\hline in $\mathrm{BBCH} 73$ & $\mathrm{Fu}$ & & 3 & 0,796 & 0,002 & 16 & $a b$ \\
\hline \multirow[t]{37}{*}{ (NDVI_B4) } & $\mathrm{Fu}$ & & 4 & 0,798 & 0,006 & 16 & $\mathrm{a}$ \\
\hline & $\mathrm{Fu}$ & & 5 & 0,793 & 0,005 & 16 & $a b$ \\
\hline & $\mathrm{Fu}$ & & 6 & 0,793 & 0,008 & 16 & ac \\
\hline & $\mathrm{Fu}$ & & 7 & 0,793 & 0,005 & 16 & $a b$ \\
\hline & Fu & & 8 & 0,793 & 0,004 & 16 & $a b$ \\
\hline & $\mathrm{So}{ }^{*} \mathrm{Fu}$ & $P$ & 1 & 0,780 & 0,009 & 8 & $\mathrm{c}$ \\
\hline & So*Fu & $P$ & 2 & 0,787 & 0,006 & 8 & bc \\
\hline & So*Fu & $P$ & 3 & 0,793 & 0,003 & 8 & ac \\
\hline & So*Fu & $P$ & 4 & 0,800 & 0,005 & 8 & $\mathrm{a}$ \\
\hline & So*Fu & $P$ & 5 & 0,793 & 0,003 & 8 & ac \\
\hline & $\mathrm{So}^{*} \mathrm{Fu}$ & $P$ & 6 & 0,796 & 0,009 & 8 & $a b$ \\
\hline & So*Fu & $P$ & 7 & 0,790 & 0,006 & 8 & ac \\
\hline & So*Fu & $P$ & 8 & 0,790 & 0,005 & 8 & ac \\
\hline & So*Fu & V & 1 & 0,789 & 0,006 & 8 & $a$ \\
\hline & $\mathrm{So}^{*} \mathrm{Fu}$ & $\mathrm{V}$ & 2 & 0,792 & 0,007 & 8 & $a$ \\
\hline & $\mathrm{So}^{\star} \mathrm{Fu}$ & $\mathrm{V}$ & 3 & 0,799 & 0,002 & 8 & $a$ \\
\hline & So*Fu & $\mathrm{V}$ & 4 & 0,796 & 0,008 & 8 & $a$ \\
\hline & So*Fu & V & 5 & 0,793 & 0,007 & 8 & $a$ \\
\hline & So*Fu & V & 6 & 0,789 & 0,008 & 8 & $a$ \\
\hline & So*Fu & V & 7 & 0,795 & 0,003 & 8 & $a$ \\
\hline & So* Fu & $\mathrm{V}$ & 8 & 0,797 & 0,003 & 8 & a \\
\hline & $\mathrm{Di}^{\star} \mathrm{Fu}$ & 30 & 1 & 0,778 & 0,009 & 8 & b \\
\hline & $\mathrm{Di}^{\star} \mathrm{Fu}$ & 30 & 2 & 0,787 & 0,009 & 8 & $a b$ \\
\hline & $\mathrm{Di}^{\star} \mathrm{Fu}$ & 30 & 3 & 0,794 & 0,002 & 8 & $a$ \\
\hline & $\mathrm{Di}{ }^{\star} \mathrm{Fu}$ & 30 & 4 & 0,799 & 0,006 & 8 & a \\
\hline & $\mathrm{Di}{ }^{\star} \mathrm{Fu}$ & 30 & 5 & 0,794 & 0,005 & 8 & $a$ \\
\hline & $\mathrm{Di}^{\star} \mathrm{Fu}$ & 30 & 6 & 0,792 & 0,009 & 8 & $a$ \\
\hline & $\mathrm{Di}{ }^{\star} \mathrm{Fu}$ & 30 & 7 & 0,791 & 0,006 & 8 & $a b$ \\
\hline & $\mathrm{Di}^{\star} \mathrm{Fu}$ & 30 & 8 & 0,788 & 0,001 & 8 & $a b$ \\
\hline & $\mathrm{Di}{ }^{\star} \mathrm{Fu}$ & 60 & 1 & 0,792 & 0,007 & 8 & $a$ \\
\hline & $\mathrm{Di}^{\star} \mathrm{Fu}$ & 60 & 2 & 0,791 & 0,004 & 8 & $a$ \\
\hline & $\mathrm{Di}^{\star} \mathrm{Fu}$ & 60 & 3 & 0,798 & 0,003 & 8 & $a$ \\
\hline & $\mathrm{Di}^{\star} \mathrm{Fu}$ & 60 & 4 & 0,797 & 0,007 & 8 & $a$ \\
\hline & $\mathrm{Di}{ }^{\star} \mathrm{Fu}$ & 60 & 5 & 0,793 & 0,005 & 8 & $a$ \\
\hline & $\mathrm{Di}^{\star} \mathrm{Fu}$ & 60 & 6 & 0,793 & 0,008 & 8 & $a$ \\
\hline & $\mathrm{Di}{ }^{*} \mathrm{Fu}$ & 60 & 7 & 0,794 & 0,003 & 8 & $a$ \\
\hline & $\mathrm{Di}^{*} \mathrm{Fu}$ & 60 & 8 & 0,799 & 0,005 & $-\frac{8}{-}$ & a \\
\hline Grünfärbung des & So & $P$ & & 0,758 & 0,007 & 64 & $\mathrm{~b}$ \\
\hline Pflanzenbestandes & So & $\mathrm{V}$ & & 0,772 & 0,006 & 64 & a \\
\hline in BBCH 79 & $\mathrm{Di}$ & 30 & & 0,757 & 0,008 & 64 & b \\
\hline (NDVI_A1) & $\mathrm{Di}$ & 60 & & 0,773 & 0,005 & 64 & a \\
\hline
\end{tabular}




\begin{tabular}{|c|c|c|c|c|c|c|c|}
\hline & $\mathrm{Fu}$ & & 1 & 0,737 & 0,006 & 16 & e \\
\hline & $\mathrm{Fu}$ & & 2 & 0,750 & 0,008 & 16 & $d$ \\
\hline & $\mathrm{Fu}$ & & 3 & 0,768 & 0,007 & 16 & $c$ \\
\hline & $\mathrm{Fu}$ & & 4 & 0,783 & 0,007 & 16 & $a b$ \\
\hline & $\mathrm{Fu}$ & & 5 & 0,778 & 0,006 & 16 & $b$ \\
\hline & $\mathrm{Fu}$ & & 6 & 0,790 & 0,007 & 16 & $a$ \\
\hline & $\mathrm{Fu}$ & & 7 & 0,757 & 0,008 & 16 & $d$ \\
\hline & Fu & & 8. & 0,754 & 0,004 & 16 & d \\
\hline & So* $\mathrm{Fu}$ & $P$ & 1 & 0,730 & 0,007 & 8 & e \\
\hline & $\mathrm{So}^{\star} \mathrm{Fu}$ & $P$ & 2 & 0,740 & 0,008 & 8 & de \\
\hline & $\mathrm{So}^{\star} \mathrm{Fu}$ & $P$ & 3 & 0,757 & 0,009 & 8 & $c$ \\
\hline & So* $\mathrm{Fu}$ & $P$ & 4 & 0,779 & 0,009 & 8 & $a b$ \\
\hline & $\mathrm{So}^{*} \mathrm{Fu}$ & $P$ & 5 & 0,772 & 0,004 & 8 & $b$ \\
\hline & $\mathrm{So}^{*} \mathrm{Fu}$ & $P$ & 6 & 0,792 & 0,007 & 8 & $a$ \\
\hline & $\mathrm{So}^{\star} \mathrm{Fu}$ & $P$ & 7 & 0,748 & 0,008 & 8 & $\mathrm{~cd}$ \\
\hline & So* $\mathrm{Fu}$ & $P$ & 8 & 0,744 & 0,005 & 8 & ce \\
\hline & $\mathrm{So}^{\star} \mathrm{Fu}$ & $\mathrm{V}$ & 1 & 0,745 & 0,003 & 8 & $d$ \\
\hline & So* $\mathrm{Fu}$ & $\mathrm{V}$ & 2 & 0,761 & 0,008 & 8 & $c$ \\
\hline & $\mathrm{So}^{\star} \mathrm{Fu}$ & $\mathrm{V}$ & 3 & 0,780 & 0,005 & 8 & $a b$ \\
\hline & So*Fu & $\mathrm{V}$ & 4 & 0,787 & 0,006 & 8 & $a$ \\
\hline & $\mathrm{So}^{\star} \mathrm{Fu}$ & $\mathrm{V}$ & 5 & 0,784 & 0,008 & 8 & $a$ \\
\hline & So* $\mathrm{Fu}$ & $\mathrm{V}$ & 6 & 0,789 & 0,008 & 8 & $a$ \\
\hline & $\mathrm{So}^{*} \mathrm{Fu}$ & V & 7 & 0,765 & 0,009 & 8 & $c$ \\
\hline & $\mathrm{So}^{*} \mathrm{Fu}$ & $\mathrm{V}$ & 8 & 0,765 & 0,004 & 8 & $b c$ \\
\hline & $\mathrm{Di}^{\star} \mathrm{Fu}$ & 30 & 1 & 0,723 & 0,003 & 8 & d \\
\hline & $\mathrm{Di}^{\star} \mathrm{Fu}$ & 30 & 2 & 0,738 & 0,010 & 8 & $\mathrm{~cd}$ \\
\hline & $\mathrm{Di}^{\star} \mathrm{Fu}$ & 30 & 3 & 0,760 & 0,007 & 8 & $b$ \\
\hline & $\mathrm{Di}^{\star} \mathrm{Fu}$ & 30 & 4 & 0,775 & 0,010 & 8 & $a$ \\
\hline & $\mathrm{Di}{ }^{\star} \mathrm{Fu}$ & 30 & 5 & 0,775 & 0,007 & 8 & $a$ \\
\hline & $\mathrm{Di}{ }^{\star} \mathrm{Fu}$ & 30 & 6 & 0,784 & 0,009 & 8 & $a$ \\
\hline & $\mathrm{Di}{ }^{*} \mathrm{Fu}$ & 30 & 7 & 0,751 & 0,011 & 8 & $b c$ \\
\hline & $\mathrm{Di}{ }^{\star} \mathrm{Fu}$ & 30 & 8 & 0,746 & 0,005 & 8 & $b c$ \\
\hline & $\mathrm{Di}^{\star} \mathrm{Fu}$ & 60 & 1 & 0,751 & 0,007 & 8 & $d$ \\
\hline & $\mathrm{Di}{ }^{\star} \mathrm{Fu}$ & 60 & 2 & 0,762 & 0,005 & 8 & $d$ \\
\hline & $\mathrm{Di}{ }^{\star} \mathrm{Fu}$ & 60 & 3 & 0,777 & 0,007 & 8 & $b c$ \\
\hline & $\mathrm{Di}{ }^{\star} \mathrm{Fu}$ & 60 & 4 & 0,791 & 0,003 & 8 & $a b$ \\
\hline & $\mathrm{Di}{ }^{\star} \mathrm{Fu}$ & 60 & 5 & 0,781 & 0,005 & 8 & $b$ \\
\hline & $\mathrm{Di}{ }^{\star} \mathrm{Fu}$ & 60 & 6 & 0,797 & 0,006 & 8 & a \\
\hline & $\mathrm{Di}{ }^{\star} \mathrm{Fu}$ & 60 & 7 & 0,763 & 0,004 & 8 & $\mathrm{~cd}$ \\
\hline & $\underline{D i} i^{*} \underline{u}$. & -60 & -8 & 0,763 & 0,004 & -8 & cd \\
\hline Grünfärbung des & $\mathrm{Di}$ & 30 & & 0,645 & 0,015 & 64 & b \\
\hline Pflanzenbestandes & $\mathrm{Di}$ & 60 & & 0,659 & 0,012 & 64 & $\mathrm{a}$ \\
\hline
\end{tabular}




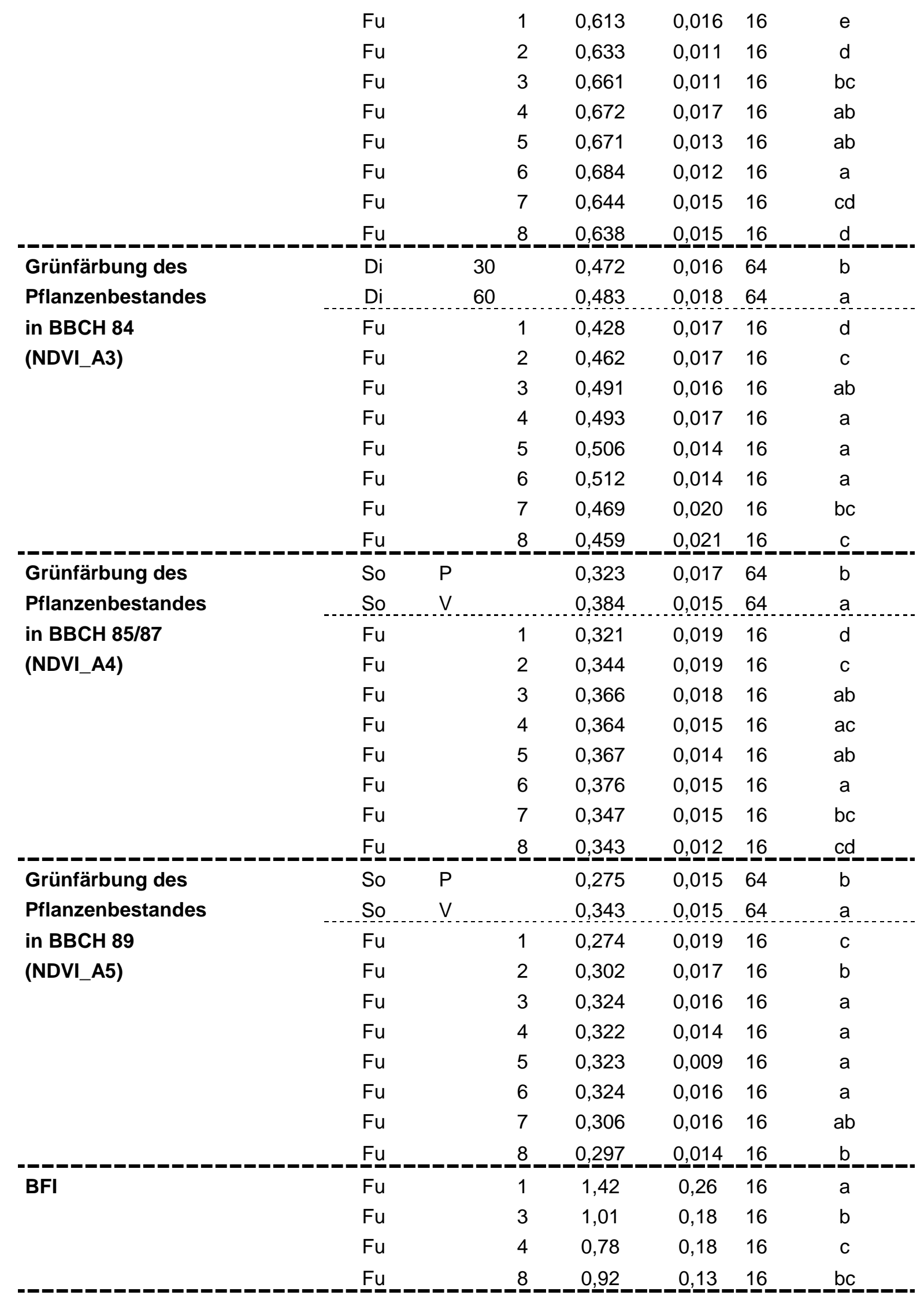




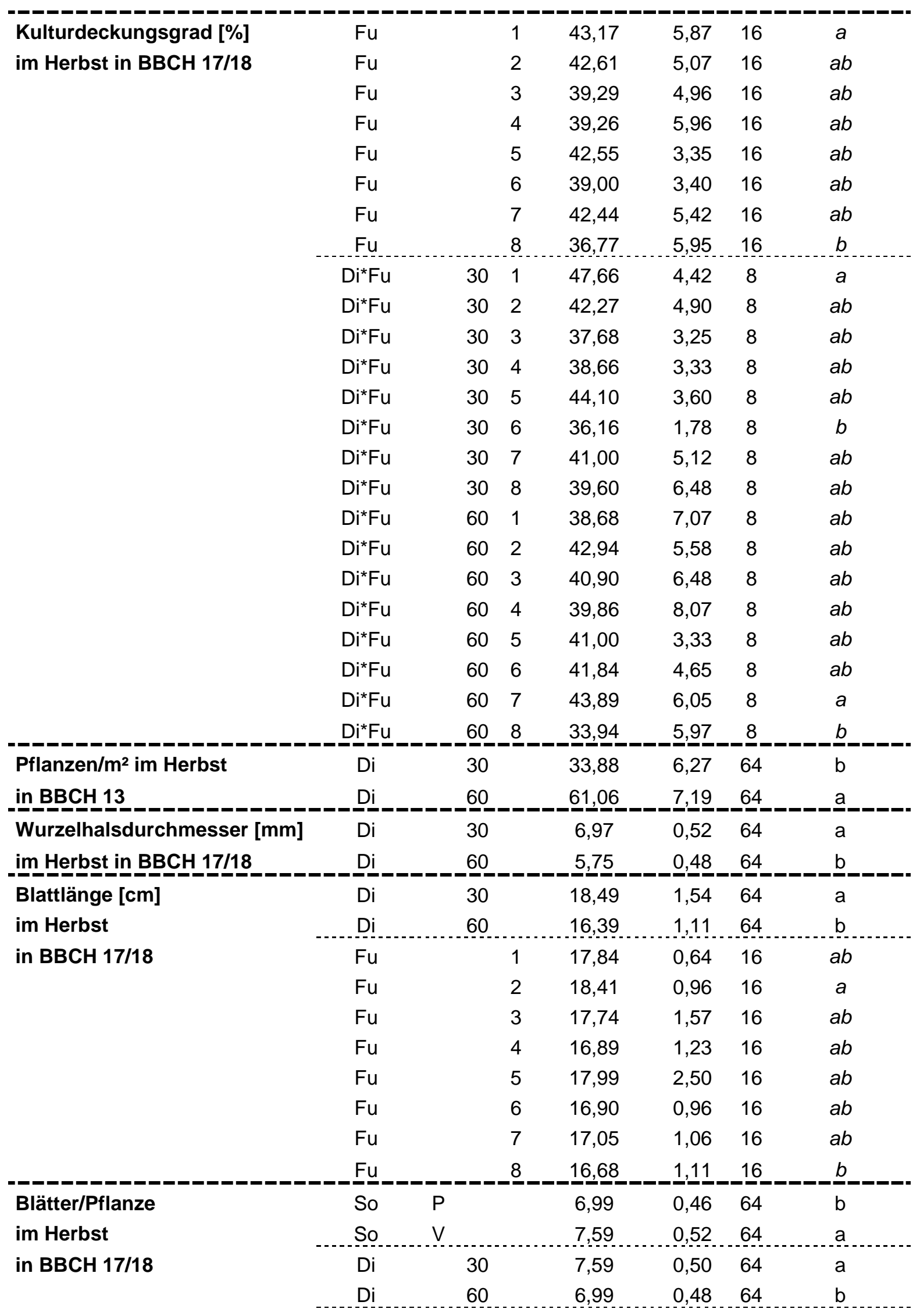




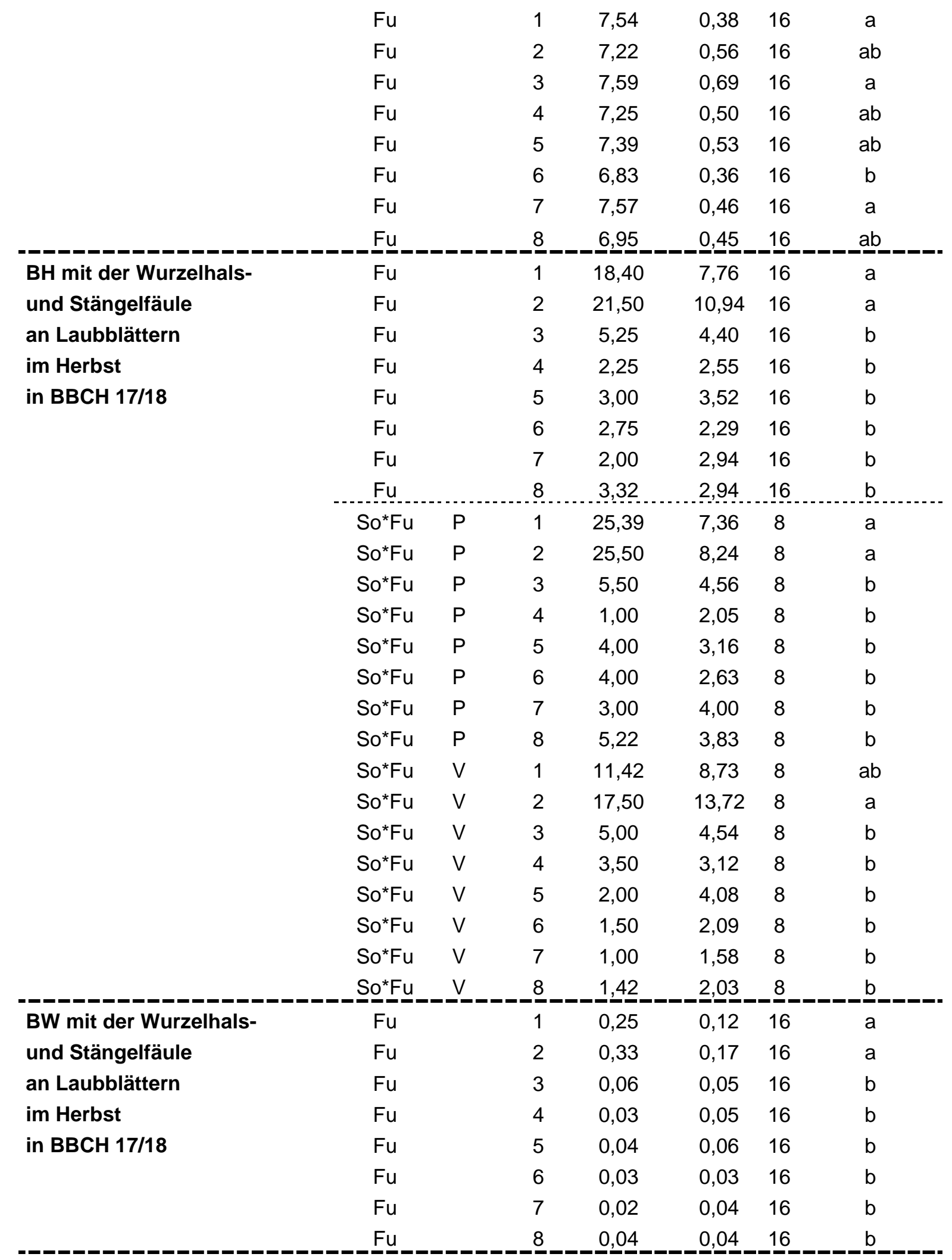




\begin{tabular}{|c|c|c|c|c|c|c|c|}
\hline BH mit der Wurzelhals- & $\mathrm{Fu}$ & & 1 & 23,57 & 13,21 & 16 & a \\
\hline und Stängelfäule am & $\mathrm{Fu}$ & & 2 & 21,25 & 9,17 & 16 & $a b$ \\
\hline unteren Stängel & $\mathrm{Fu}$ & & 3 & 11,75 & 5,46 & 16 & bc \\
\hline im Frühjahr & $\mathrm{Fu}$ & & 4 & 10,50 & 5,72 & 16 & $c$ \\
\hline \multirow[t]{4}{*}{ in $\mathrm{BBCH} 80 / 81$} & $\mathrm{Fu}$ & & 5 & 9,75 & 5,06 & 16 & $c$ \\
\hline & $\mathrm{Fu}$ & & 6 & 10,75 & 7,58 & 16 & $c$ \\
\hline & $\mathrm{Fu}$ & & 7 & 15,00 & 7,39 & 16 & $\mathrm{ac}$ \\
\hline & Fu‥ & & -8 & $-17,24$ & $-6, \underline{6}$ & 16 & ac \\
\hline BW mit der Wurzelhals- & $\mathrm{Di}$ & 30 & & 1,33 & 0,18 & 64 & a \\
\hline und Stängelfäule am & Di & $6 \underline{6}$. & & 1,22 & 0,14 & 64 & $-\underline{b}$ \\
\hline unteren Stängel & $\mathrm{Fu}$ & & 1 & 1,39 & 0,22 & 16 & a \\
\hline im Frühjahr & $\mathrm{Fu}$ & & 2 & 1,36 & 0,21 & 16 & $\mathrm{ac}$ \\
\hline \multirow[t]{6}{*}{ in $\mathrm{BBCH} 80 / 81$} & $\mathrm{Fu}$ & & 3 & 1,25 & 0,13 & 16 & $\mathrm{ac}$ \\
\hline & $\mathrm{Fu}$ & & 4 & 1,18 & 0,14 & 16 & $\mathrm{ac}$ \\
\hline & $\mathrm{Fu}$ & & 5 & 1,17 & 0,09 & 16 & $\mathrm{bc}$ \\
\hline & $\mathrm{Fu}$ & & 6 & 1,15 & 0,10 & 16 & c \\
\hline & $\mathrm{Fu}$ & & 7 & 1,33 & 0,22 & 16 & $\mathrm{ac}$ \\
\hline & $\underline{F} \underline{u}$. & & -8. & 1,37 & $\underline{0,1} \underline{16}$ & 16 & _ab \\
\hline BH mit der Wurzelhals- & $\mathrm{Fu}$ & & 1 & 37,20 & 9,02 & 16 & $a b$ \\
\hline und Stängelfäule am & $\mathrm{Fu}$ & & 2 & 39,75 & 7,56 & 16 & a \\
\hline Wurzelhals & $\mathrm{Fu}$ & & 3 & 29,75 & 8,12 & 16 & $a b$ \\
\hline im Frühjahr & $\mathrm{Fu}$ & & 4 & 25,50 & 12,09 & 16 & $\mathrm{~b}$ \\
\hline \multirow[t]{4}{*}{ in $\mathrm{BBCH} 80 / 81$} & $\mathrm{Fu}$ & & 5 & 28,25 & 11,12 & 16 & $a b$ \\
\hline & $\mathrm{Fu}$ & & 6 & 27,00 & 10,93 & 16 & $b$ \\
\hline & $\mathrm{Fu}$ & & 7 & 33,75 & 7,38 & 16 & $a b$ \\
\hline & Fu & & -8 & 40,70 & 11,98 & 16 & _a \\
\hline BW mit der Wurzelhals- & So & $P$ & & 1,76 & 0,26 & 64 & a \\
\hline und Stängelfäule am & So & $\mathrm{V}$ & & 1,59 & 0,18 & 64 & b \\
\hline Wurzelhals & $\mathrm{Fu}$ & & 1 & 1,79 & 0,20 & 16 & $a b$ \\
\hline im Frühjahr & $\mathrm{Fu}$ & & 2 & 1,82 & 0,21 & 16 & $a b$ \\
\hline \multirow{14}{*}{ in $\mathrm{BBCH} 80 / 81$} & $\mathrm{Fu}$ & & 3 & 1,62 & 0,18 & 16 & $\mathrm{bc}$ \\
\hline & $\mathrm{Fu}$ & & 4 & 1,42 & 0,16 & 16 & c \\
\hline & $\mathrm{Fu}$ & & 5 & 1,57 & 0,25 & 16 & $\mathrm{bc}$ \\
\hline & $\mathrm{Fu}$ & & 6 & 1,43 & 0,18 & 16 & c \\
\hline & $\mathrm{Fu}$ & & 7 & 1,73 & 0,28 & 16 & $b$ \\
\hline & $\mathrm{Fu}$ & & 8 & 2,03 & 0,33 & 16 & $a$ \\
\hline & $\mathrm{Di}^{\star} \mathrm{Fu}$ & 30 & 1 & 1,76 & 0,17 & 8 & $b$ \\
\hline & $\mathrm{Di}^{\star} \mathrm{Fu}$ & 30 & 2 & 1,76 & 0,22 & 8 & $b$ \\
\hline & $\mathrm{Di}{ }^{\star} \mathrm{Fu}$ & 30 & 3 & 1,63 & 0,16 & 8 & b \\
\hline & $\mathrm{Di}^{\star} \mathrm{Fu}$ & 30 & 4 & 1,48 & 0,11 & 8 & b \\
\hline & $\mathrm{Di}^{\star} \mathrm{Fu}$ & 30 & 5 & 1,54 & 0,08 & 8 & b \\
\hline & $\mathrm{Di}{ }^{\star} \mathrm{Fu}$ & 30 & 6 & 1,42 & 0,16 & 8 & b \\
\hline & $\mathrm{Di}^{\star} \mathrm{Fu}$ & 30 & 7 & 1,71 & 0,33 & 8 & b \\
\hline & $\mathrm{Di}^{\star} \mathrm{Fu}$ & 30 & 8 & 2,33 & 0,16 & 8 & a \\
\hline
\end{tabular}




\begin{tabular}{lllllll}
$\mathrm{Di}{ }^{*} \mathrm{Fu}$ & 60 & 1 & 1,82 & 0,22 & 8 & $\mathrm{ab}$ \\
$\mathrm{Di} \mathrm{Fu}$ & 60 & 2 & 1,88 & 0,21 & 8 & $\mathrm{a}$ \\
$\mathrm{Di} \mathrm{Fu}$ & 60 & 3 & 1,61 & 0,21 & 8 & $\mathrm{ab}$ \\
$\mathrm{Di} \mathrm{Fu}$ & 60 & 4 & 1,37 & 0,21 & 8 & $\mathrm{~b}$ \\
$\mathrm{Di} \mathrm{Fu}$ & 60 & 5 & 1,60 & 0,36 & 8 & $\mathrm{ab}$ \\
$\mathrm{Di} \mathrm{Fu}$ & 60 & 6 & 1,44 & 0,21 & 8 & $\mathrm{ab}$ \\
$\mathrm{Di}$ & 60 & 7 & 1,76 & 0,24 & 8 & $\mathrm{ab}$ \\
$\mathrm{Di}$ & 60 & 8 & 1,74 & 0,42 & 8 & $\mathrm{ab}$ \\
\hline
\end{tabular}




\section{Daten aus SAS zu multiplen Regressionen mit der Ausgangszielvariablen Kornertrag im Jahr 2010/11}

Tab. 28A: Prädiktoren für die Zielvariable Kornertrag im Jahr 2010/11, Signifikanzniveau: $p \leq 0,05$. Für weitere Betrachtungen wurden nur die ersten beiden Prädiktoren berücksichtigt. Daten aus SAS. Als Datengrundlage dienten alle Parameter außer OE und El.

\begin{tabular}{|c|c|c|c|c|c|c|}
\hline Schritt & Variable eingegeben & Variable entfernt & Partielles R-Quadrat & Modell R-Quadrat & F-Statistik & $\operatorname{Pr}>\mathrm{F}$ \\
\hline 1 & PAR_B4 & & 0,4374 & 0,4374 & 90,18 & $<, 0001$ \\
\hline 2 & NDVI_B4 & & 0,0663 & 0,5037 & 15,37 & 0,0002 \\
\hline 3 & WHD_He & & 0,0449 & 0,5486 & 11,34 & 0,0010 \\
\hline 4 & BH_Wh_Fj & & 0,0211 & 0,5698 & 5,55 & 0,0202 \\
\hline 5 & SBME & & 0,0214 & 0,5911 & 5,86 & 0,0171 \\
\hline 6 & abs_00 & & 0,0186 & 0,6097 & 5,29 & 0,0234 \\
\hline
\end{tabular}

Tab. 29A: Parameterschätzungen zum vorherigen Modell mit der Zielvariablen Kornertrag. Die Daten sind der Größe nach absteigend für den standardisierten Schätzer sortiert. VIF = Variance Inflation Factor, Daten aus SAS. Daten aus SAS. Als Datengrundlage dienten alle Parameter außer OE und El. $(\mathrm{DF}=$ Degree of freedom = Freiheitsgrade $)$

\begin{tabular}{|c|c|c|c|c|c|c|c|c|}
\hline Variable & DF & Parameterschätzer & Standardfehler & t-Wert & $\operatorname{Pr}>|t|$ & Standardisierter Schätzer & Toleranz & VIF \\
\hline Intercept & 1 & $-3,56592$ & 2,14130 & $-1,67$ & 0,0987 & 0 & , & 0 \\
\hline NDVI_B4 & 1 & 10,35342 & 2,66186 & 3,89 & 0,0002 & 0,26490 & 0,75801 & 1,31924 \\
\hline BH_Wh_Fj & 1 & 0,01595 & 0,00564 & 2,83 & 0,0055 & 0,17868 & 0,88160 & 1,13431 \\
\hline SBME & 1 & 0,11267 & 0,04397 & 2,56 & 0,0117 & 0,16152 & 0,88471 & 1,13032 \\
\hline abs_00 & 1 & $-0,01258$ & 0,00547 & $-2,30$ & 0,0234 & $-0,14193$ & 0,92253 & 1,08398 \\
\hline WHD_He & 1 & $-0,12414$ & 0,04284 & $-2,90$ & 0,0045 & $-0,17483$ & 0,96585 & 1,03536 \\
\hline PAR_B4 & 1 & $-0,07181$ & 0,00993 & $-7,23$ & $<, 0001$ & $-0,51356$ & 0,69754 & 1,43361 \\
\hline
\end{tabular}


Tab. 30A: Prädiktoren für die Zielvariable Anteil an PAR am Boden in BBCH 75 (PAR_B4) im Jahr 2010/11. Signifikanzniveau: $p \leq 0,05$. Daten aus SAS. Als Datengrundlage dienten alle Parameter außer OE und El.

\begin{tabular}{ccccccc}
\hline Schritt & Variable eingegeben & Variable entfernt & Partielles R-Quadrat & Modell R-Quadrat & F-Statistik & Pr > F \\
\hline 1 & PAR_M4 & & 0,7845 & 0,7845 & 426,03 & $<, 0001$ \\
2 & NDVI_B4 & & 0,0224 & 0,8069 & 13,43 \\
3 & NDVI_B1 & 0,0147 & 0,0004 \\
4 & TKM & & 0,0117 & 0,8216 & 9,49 \\
5 & NDVI_Dauer & & 0,0157 & 0,8333 & 7,98 & 0,0056 \\
6 & & NDVI_B1 & 0,0002 & 0,8490 & 11,76 & 0,0008 \\
7 & BpP & & 0,0122 & 0,8488 & 0,19 & 0,6663 \\
\hline
\end{tabular}

Tab. 31A: Parameterschätzungen zum vorherigen Modell mit der Zielvariablen Anteil an PAR am Boden in BBCH 75 (PAR_B4). Die Daten sind der Größe nach absteigend für den standardisierten Schätzer sortiert. VIF = Variance Inflation Factor, Daten aus SAS. Datengrundlage: nur nicht abgeleitete Parameter. $(\mathrm{DF}=$ Degree of freedom $=$ Freiheitsgrade $)$

\begin{tabular}{ccccccccc}
\hline Variable & DF & Parameterschätzer & Standardfehler & t-Wert & Pr $>|\mathbf{t}|$ & Standardisierter Schätzer & Toleranz & VIF \\
\hline Intercept & 1 & 42,40333 & 9,77521 & 4,34 & $<, 0001$ & 0 & 0 \\
PAR_M4 & 1 & 0,53011 & 0,03028 & 17,51 & $<, 0001$ & 0,74552 &, & 0,67833 \\
TKM & 1 & 2,57525 & 0,53129 & 4,85 & $<, 0001$ & 0,22227 & 1,47421 \\
NDVI_B4 & 1 & $-24,78114$ & 11,05452 & $-2,24$ & 0,0269 & $-0,08852$ & 0,58510 & 1,70912 \\
BpP & 1 & $-1,09649$ & 0,34784 & $-3,15$ & 0,0021 & $-0,11585$ & 0,78903 & 1,26737 \\
NDVI_Dauer & 1 & $-0,79063$ & 0,15196 & $-5,20$ & $<, 0001$ & $-0,20816$ & 0,91094 & 1,09777 \\
\hline
\end{tabular}


Tab. 32A: Prädiktoren für die Zielvariable Anteil an PAR unter den Schoten in BBCH 75 (PAR_M4) im Jahr 2010/11. Signifikanzniveau: $p \leq 0,05$. Daten aus SAS. Als Datengrundlage dienten alle Parameter außer OE und El. Wegen Messwiederholungen wurden alle weiteren Parameter von PAR_M und PAR_B ausgeschlossen.

\begin{tabular}{|c|c|c|c|c|c|}
\hline Schritt & Variable eingegeben & Partielles R-Quadrat & Modell R-Quadrat & F-Statistik & $\operatorname{Pr}>\mathrm{F}$ \\
\hline 1 & KDG_Fj & 0,4058 & 0,4058 & 79,91 & $<, 0001$ \\
\hline 2 & abs_01 & 0,0575 & 0,4633 & 12,43 & 0,0006 \\
\hline 3 & Sah_4 & 0,0295 & 0,4928 & 6,69 & 0,0109 \\
\hline 4 & BW_Wh_Fj & 0,0268 & 0,5197 & 6,37 & 0,0130 \\
\hline
\end{tabular}

Tab. 33A: Parameterschätzungen zum vorherigen Modell mit der Zielvariablen Anteil an PAR unter den Schoten in BBCH 75 (PAR_M4). Die Daten sind der Größe nach absteigend für den standardisierten Schätzer sortiert. VIF = Variance Inflation Factor, Daten aus SAS. Als Datengrundlage dienten alle Parameter außer OE und El. Wegen Messwiederholungen wurden alle weiteren Parameter von PAR_M und PAR_B ausgeschlossen. (DF = Degree of freedom $=$ Freiheitsgrade)

\begin{tabular}{|c|c|c|c|c|c|c|c|c|}
\hline Variable & DF & Parameterschätzer & Standardfehler & t-Wert & $\operatorname{Pr}>|t|$ & Standardisierter Schätzer & Toleranz & VIF \\
\hline Intercept & 1 & 25,83400 & 4,02109 & 6,42 & $<, 0001$ & 0 & , & 0 \\
\hline abs_01 & 1 & 0,15925 & 0,04478 & 3,56 & 0,0005 & 0,24530 & 0,88573 & 1,12901 \\
\hline BW_Wh_Fj & 1 & 1,24778 & 0,49450 & 2,52 & 0,0130 & 0,20108 & 0,66349 & 1,50718 \\
\hline Sah_4 & 1 & $-0,18419$ & 0,05488 & $-3,36$ & 0,0011 & $-0,28063$ & 0,60262 & 1,65943 \\
\hline KDG_Fj & 1 & $-0,12476$ & 0,04101 & $-3,04$ & 0,0029 & $-0,29913$ & 0,43572 & 2,29504 \\
\hline
\end{tabular}


Tab. 34A: Prädiktoren für die Zielvariable Grünanteil des Pflanzenbestandes in BBCH 71/73 (NDVI_B4) im Jahr 2010/11. Signifikanzniveau: $p \leq 0,05$. Daten aus SAS. Als Datengrundlage dienten alle Parameter außer OE und El. Wegen Messwiederholungen wurden alle weiteren Parameter von NDVI_B ausgeschlossen. PAR_B4 wurde nicht berücksichtigt, da eine Hierarchieebene vorher, die Abhängigkeit von NDVI_B4 und PAR_B4 festgestellt wurde.

\begin{tabular}{|c|c|c|c|c|c|c|}
\hline Schritt & Variable eingegeben & Variable entfernt & Partielles R-Quadrat & Modell R-Quadrat & F-Statistik & $\mathrm{Pr}>\mathrm{F}$ \\
\hline 1 & WHD_Fj & & 0,2929 & 0,2929 & 48,47 & $<, 0001$ \\
\hline 2 & BW_Wh_Fj & & 0,0387 & 0,3317 & 6,72 & 0,0108 \\
\hline 3 & Schi_3 & & 0,0289 & 0,3606 & 5,21 & 0,0243 \\
\hline 4 & rel_02 & & 0,0324 & 0,3930 & 6,08 & 0,0152 \\
\hline 5 & BW_St_Fj & & 0,0242 & 0,4172 & 4,69 & 0,0325 \\
\hline
\end{tabular}

Tab. 35A: Parameterschätzungen zum vorherigen Modell mit der Zielvariablen Grünanteil des Pflanzenbestandes in BBCH 71/73 (NDVI_B4). Die Daten sind der Größe nach absteigend für den standardisierten Schätzer sortiert. VIF = Variance Inflation Factor, Daten aus SAS. Als Datengrundlage dienten alle Parameter außer OE und EI. Wegen Messwiederholungen wurden alle weiteren Parameter von NDVI_B ausgeschlossen. PAR_B4 wurde nicht berücksichtigt, da eine Hierarchieebene vorher, die Abhängigkeit von NDVI_B4 und PAR_B4 festgestellt wurde. (DF = Degree of freedom = Freiheitsgrade)

\begin{tabular}{|c|c|c|c|c|c|c|c|c|}
\hline Variable & DF & Parameterschätzer & Standardfehler & t-Wert & $\operatorname{Pr}>|t|$ & Standardisierter Schätzer & Toleranz & VIF \\
\hline Intercept & 1 & 0,73729 & 0,02307 & 31,95 & $<, 0001$ & 0 & , & 0 \\
\hline Schi_3 & 1 & 0,00082590 & 0,00031445 & 2,63 & 0,0098 & 0,22145 & 0,72560 & 1,37817 \\
\hline BW_St_Fj & 1 & 0,00341 & 0,00157 & 2,17 & 0,0325 & 0,18242 & 0,72674 & 1,37600 \\
\hline rel_02 & 1 & $-0,00111$ & 0,00039109 & $-2,83$ & 0,0055 & $-0,21400$ & 0,90200 & 1,10865 \\
\hline WHD_Fj & 1 & $-0,00204$ & 0,00073237 & $-2,79$ & 0,0062 & $-0,27503$ & 0,53116 & 1,88268 \\
\hline BW_Wh_Fj & 1 & $-0,00651$ & 0,00158 & $-4,12$ & $<, 0001$ & $-0,41280$ & 0,51322 & 1,94847 \\
\hline
\end{tabular}


Tab. 36A: Prädiktoren für die Zielvariable Wurzelhalsdurchmesser im Frühjahr (WHD_Fj) in BBCH 83/84 im Jahr 2010/11 Signifikanzniveau: $p \leq 0,05$. Daten aus SAS. Als Datengrundlage dienten alle Parameter außer OE und El.

\begin{tabular}{|c|c|c|c|c|c|c|}
\hline Schritt & Variable eingegeben & Variable entfernt & Partielles R-Quadrat & Modell R-Quadrat & F-Statistik & $\operatorname{Pr}>F$ \\
\hline 1 & DI_He & & 0,5630 & 0,5630 & 150,75 & $<, 0001$ \\
\hline 2 & Schi_3 & & 0,0811 & 0,6441 & 26,42 & $<, 0001$ \\
\hline 3 & Sah_2 & & 0,0520 & 0,6961 & 19,68 & $<, 0001$ \\
\hline 4 & DI_Fj & & 0,0531 & 0,7492 & 24,11 & $<, 0001$ \\
\hline 5 & PAR_B2 & & 0,0241 & 0,7732 & 12,00 & 0,0008 \\
\hline 6 & NDVI_A5 & & 0,0112 & 0,7844 & 5,82 & 0,0174 \\
\hline 7 & $\mathrm{KpS}$ & & 0,0116 & 0,7961 & 6,34 & 0,0132 \\
\hline 8 & BW_St_Fj & & 0,0102 & 0,8063 & 5,81 & 0,0176 \\
\hline
\end{tabular}

Tab. 37A: Parameterschätzungen zum vorherigen Modell mit der Zielvariablen Wurzelhalsdurchmesser im Frühjahr in BBCH 83/84 (WHD_FJ). Die Daten sind der Größe nach absteigend für den standardisierten Schätzer sortiert. VIF = Variance Inflation Factor, Daten aus SAS. Als Datengrundlage dienten alle Parameter außer OE und EI. (DF = Degree of freedom = Freiheitsgrade)

\begin{tabular}{ccccccccc}
\hline Variable & DF & Parameterschätzer & Standardfehler & t-Wert & Pr $>|\mathbf{t}|$ & Standardisierter Schätzer & Toleranz & VIF \\
\hline Intercept & 1 & 10,21296 & 2,83718 & 3,60 & 0,0005 & 0 & 0 & 0 \\
Sah_2 & 1 & 0,08363 & 0,01472 & 5,68 & $<, 0001$ & 0,38809 & 0,37724 & 2,65081 \\
PAR_B2 & 1 & 0,12437 & 0,03562 & 3,49 & 0,0007 & 0,20261 & 0,52297 & 1,91217 \\
NDVI_A5 & 1 & 12,93156 & 4,80392 & 2,69 & 0,0082 & 0,18807 & 0,36074 & 2,77212 \\
KpS & 1 & 0,13083 & 0,04243 & 3,08 & 0,0026 & 0,15488 & 0,69805 & 1,43256 \\
BW_St_Fj & 1 & 0,27651 & 0,11470 & 2,41 & 0,0176 & 0,10996 & 0,84637 & 1,18152 \\
DI_He & 1 & $-0,02612$ & 0,01105 & $-2,36$ & 0,0198 & $-0,19903$ & 0,24834 \\
Schi_3 & 1 & $-0,12954$ & 0,02242 & $-5,78$ & $<, 0001$ & $-0,25814$ & 4,02669 \\
DI_Fj & 1 & $-0,04210$ & 0,01126 & $-3,74$ & 0,0003 & $-0,32512$ & 0,88214 & 1,13360 \\
\hline & & & & & & & 0,23299 & 4,29205 \\
\hline
\end{tabular}


Tab. 38A: Prädiktoren für die Zielvariable Befallswert mit der Wurzelhals- und Stängelfäule am Wurzelhals im Frühjahr in BBCH 83/84 (BW_WH_Fj) im Jahr 2010/11 Signifikanzniveau: $p \leq 0,05$. Daten aus SAS. Als Datengrundlage dienten alle Parameter außer OE und El.

\begin{tabular}{|c|c|c|c|c|c|c|}
\hline Schritt & Variable eingegeben & Variable entfernt & Partielles R-Quadrat & Modell R-Quadrat & F-Statistik & $\mathrm{Pr}>\mathrm{F}$ \\
\hline 1 & DI_Fj & & 0,3249 & 0,3249 & 56,30 & $<, 0001$ \\
\hline 2 & BW_St_Fj & & 0,2090 & 0,5339 & 52,03 & $<, 0001$ \\
\hline 3 & BH_Wh_Fj & & 0,0471 & 0,5810 & 12,92 & 0,0005 \\
\hline 4 & Hoe2 & & 0,0404 & 0,6213 & 12,15 & 0,0007 \\
\hline 5 & NDVI_B4 & & 0,0284 & 0,6498 & 9,18 & 0,0030 \\
\hline 6 & BW_He & & 0,0198 & 0,6696 & 6,72 & 0,0108 \\
\hline 7 & rel_02 & & 0,0281 & 0,6977 & 10,33 & 0,0017 \\
\hline 8 & $\mathrm{BpP}$ & & 0,0172 & 0,7149 & 6,65 & 0,0112 \\
\hline
\end{tabular}

Tab. 39A: Parameterschätzungen zum vorherigen Modell mit der Zielvariablen Befallswert mit der Wurzelhals- und Stängelfäule am Wurzelhals im Frühjahr (BW_WH_Fj, BBCH 83/84). Die Daten sind der Größe nach absteigend für den standardisierten Schätzer sortiert. VIF = Variance Inflation Factor, Daten aus SAS. Als Datengrundlage dienten alle Parameter außer OE und El. (DF = Degree of freedom = Freiheitsgrade)

\begin{tabular}{ccccccccc}
\hline Variable & DF & Parameterschätzer & Standardfehler & t-Wert & Pr > |t| & Standardisierter Schätzer & Toleranz & VIF \\
\hline Intercept & 1 & 10,25151 & 3,09834 & 3,31 & 0,0013 & 0 & 0 \\
BW_St_Fj & 1 & 0,33391 & 0,07050 & 4,74 & $<, 0001$ & 0,28159 & 0,73315 \\
BW_He & 1 & 0,14038 & 0,03496 & 4,02 & 0,0001 & 0,23928 & 1,36397 \\
BH_Wh_Fj & 1 & 0,03368 & 0,00900 & 3,74 & 0,0003 & 0,23246 & 0,72963 & 1,37056 \\
Hoe_2 & 1 & 0,01800 & 0,00601 & 3,00 & 0,0034 & 0,17632 & 0,67131 & 1,48963 \\
BpP & 1 & $-0,31214$ & 0,12106 & $-2,58$ & 0,0112 & $-0,14551$ & 0,74777 & 1,33731 \\
rel_02 & 1 & $-0,05945$ & 0,01834 & $-3,24$ & 0,0016 & $-0,18116$ & 0,81364 \\
NDVI_B4 & 1 & $-12,77398$ & 3,70602 & $-3,45$ & 0,0008 & $-0,20133$ & 1,22905 \\
DI_Fj & 1 & $-0,02189$ & 0,00400 & $-5,47$ & $<, 0001$ & $-0,35847$ & 0,82925 & 1,20591 \\
\hline & & & & & & & &
\end{tabular}


Tab. 40A: Prädiktoren für die Zielvariable Kulturdeckungsgrad im Frühjahr (KDG_Fj) im Jahr 2010/2011. Signifikanzniveau: $p \leq 0,05$. Daten aus SAS. Als Datengrundlage dienten alle Parameter außer OE und El. (zusätzlich berechnet)

\begin{tabular}{|c|c|c|c|c|c|c|}
\hline Schritt & Variable eingegeben & Variable entfernt & Partielles R-Quadrat & Modell R-Quadrat & F-Statistik & $\operatorname{Pr}>\mathrm{F}$ \\
\hline 1 & DI_Fj & & 0,6559 & 0,6559 & 221,11 & $<, 0001$ \\
\hline 2 & Hoe_1 & & 0,1033 & 0,7592 & 49,31 & $<, 0001$ \\
\hline 3 & PAR_B2 & & 0,0205 & 0,7797 & 10,60 & 0,0015 \\
\hline 4 & rel_01 & & 0,0136 & 0,7933 & 7,45 & 0,0074 \\
\hline 5 & NDVI_A1 & & 0,0117 & 0,8050 & 6,73 & 0,0107 \\
\hline 6 & Schi_4 & & 0,0094 & 0,8144 & 5,61 & 0,0195 \\
\hline 7 & BH_Wh_Fj & & 0,0076 & 0,8220 & 4,68 & 0,0326 \\
\hline
\end{tabular}

Tab. 41A: Parameterschätzungen zum vorherigen Modell mit der Zielvariablen Kulturdeckungsgrad im Frühjahr (KDG_Fj). Die Daten sind der Größe nach absteigend für den standardisierten Schätzer sortiert. VIF = Variance Inflation Factor, Daten aus SAS. Als Datengrundlage dienten alle Parameter außer OE und El. (DF = Degree of freedom = Freiheitsgrade), (zusätzlich berechnet)

\begin{tabular}{|c|c|c|c|c|c|c|c|c|}
\hline Variable & DF & Parameterschätzer & Standardfehler & t-Wert & $\operatorname{Pr}>|t|$ & Standardisierter Schätzer & Toleranz & VIF \\
\hline Intercept & 1 & $-90,65445$ & 30,06490 & $-3,02$ & 0,0032 & 0 & & 0 \\
\hline DI_Fj & 1 & 0,47631 & 0,04862 & 9,80 & $<, 0001$ & 0,52228 & 0,56947 & 1,75603 \\
\hline Hoe_1 & 1 & 0,45531 & 0,07216 & 6,31 & $<, 0001$ & 0,30894 & 0,67505 & 1,48137 \\
\hline rel_01 & 1 & 0,56915 & 0,19407 & 2,93 & 0,0041 & 0,11963 & 0,97251 & 1,02826 \\
\hline NDVI_A1 & 1 & 90,11406 & 33,00399 & 2,73 & 0,0074 & 0,11438 & 0,92224 & 1,08432 \\
\hline Schi_4 & 1 & 0,40285 & 0,17238 & 2,34 & 0,0212 & 0,09801 & 0,92012 & 1,08682 \\
\hline BH_Wh_Fj & 1 & $-0,20926$ & 0,09668 & $-2,16$ & 0,0326 & $-0,09705$ & 0,80487 & 1,24243 \\
\hline PAR_B2 & 1 & $-0,65475$ & 0,24178 & $-2,71$ & 0,0079 & $-0,15171$ & 0,51561 & 1,93947 \\
\hline
\end{tabular}


Daten aus SAS zu multiplen Regressionen mit der Ausgangszielvariablen Befallswert mit der Wurzelhals- und Stängelfäule am Wurzelhals im Frühjahr in BBCH 83/84 (BW_WH_Fj) im Jahr 2010/11.

Tab. 42A: Prädiktoren für die Zielvariable Befallswert mit der Wurzelhals- und Stängelfäule am Wurzelhals im Frühjahr in BBCH 83/84 (BW_WH_Fj) im Jahr 2010/11. Signifikanzniveau: $p \leq 0,05$. Für weitere Betrachtungen wurden nur die ersten beiden Prädiktoren berücksichtigt. Daten aus SAS. Als Datengrundlage dienten alle Bestandes- und Befallsparameter sowie Di_Fj und He_Fj. NDVI_A4 wurde wegen Multikollinearität ausgeschlossen.

\begin{tabular}{ccccccc}
\hline Schritt & Variable eingegeben & Variable entfernt & Partielles R-Quadrat & Modell R-Quadrat & F-Statistik & Pr $>$ F \\
\hline 1 & DI_Fj & 0,3271 & 0,3271 & 57,37 & $<0,0001$ \\
2 & BW_St_Fj & 0,2088 & 0,5360 & 52,66 & $<0,0001$ \\
3 & BH_Wh_Fj & 0,0468 & 0,5828 & 13,02 & 0,0005 \\
4 & Hoe_2 & 0,0400 & 0,6227 & 12,18 & 0,0007 \\
5 & NDVI_B4 & 0,0286 & 0,6513 & 0,34 & 0,0028 \\
6 & BW_He & 0,0192 & 0,6705 & 0,0116 \\
7 & rel_02 & 0,0279 & 0,6984 & 0,35 & 0,0017 \\
8 & BpP & 0,0169 & 0,7153 & & 6,59 \\
\hline
\end{tabular}


Tab. 43A: Parameterschätzungen zum vorherigen Modell mit der Zielvariablen Befallswert mit der Wurzelhals- und Stängelfäule am Wurzelhals im Frühjahr in BBCH 83/84 (BW_WH_Fj). Die Daten sind der Größe nach absteigend für den standardisierten Schätzer sortiert. VIF = Variance Inflation Factor, Signifikanzniveau: $p \leq 0,05$. Daten aus SAS. Als Datengrundlage dienten alle Bestandes- und Befallsparameter sowie Di_Fj und He_Fj. NDVI_A4 wurde wegen Multikollinearität ausgeschlossen. (DF = Degree of freedom = Freiheitsgrade).

\begin{tabular}{ccccccccc}
\hline Variable & DF & Parameterschätzer & Standardfehler & t-Wert & Pr $>|\mathbf{t}|$ & Standardisierter Schätzer & Toleranz & VIF \\
\hline Intercept & 1 & 9,96592 & 3,05388 & 3,26 & 0,0015 & 0 & 0 \\
BW_St_Fj & 1 & 0,33691 & 0,07013 & 4,80 & $<0,0001$ & 0,28393 & 0, \\
BW_He & 1 & 0,13761 & 0,03457 & 3,98 & 0,0001 & 0,23492 & 0,73451 & 0,73661 \\
BH_Wh_Fj & 1 & 0,03392 & 0,00897 & 3,78 & 0,0003 & 0,23372 & 1,35756 \\
Hoe_2 & 1 & 0,01829 & 0,00597 & 3,06 & 0,0028 & 0,17976 & 0,67192 & 1,48827 \\
BpP & 1 & $-0,30965$ & 0,12065 & $-2,57$ & 0,0116 & $-0,14424$ & 0,74383 & 1,34440 \\
rel_02 & 1 & $-0,05927$ & 0,01829 & $-3,24$ & 0,0016 & $-0,18022$ & 0,81213 \\
NDVI_B4 & 1 & $-12,49895$ & 3,66790 & $-3,41$ & 0,0009 & $-0,20006$ & 0,82945 \\
DI_Fj & 1 & $-0,02171$ & 0,00398 & $-5,45$ & $<0,0001$ & $-0,35957$ & 0,74425 \\
\hline
\end{tabular}


Tab. 44A: Prädiktoren für die Zielvariable Pflanzen/m² im Frühjahr in $\mathrm{BBCH}$ 16/18 (Di_Fj) im Jahr 2010/11. Signifikanzniveau: $p \leq 0,05$. Für weitere Betrachtungen wurden nur die ersten beiden Prädiktoren berücksichtigt. Daten aus SAS. Als Datengrundlage dienten alle Bestandes- und Befallsparameter sowie Di_He. BG_Fj und WHD_Fj wurden wegen Multikollinearität nicht berücksichtigt.

\begin{tabular}{ccccccc}
\hline Schritt & Variable eingegeben & Variable entfernt & Partielles R-Quadrat & Modell R-Quadrat & F-Statistik & Pr $>$ F \\
\hline 1 & DI_He & & 0,7188 & 0,7188 & 301,64 & $<0,0001$ \\
2 & Hoe_4 & 0,0434 & 0,7622 & 21,33 & $<0,0001$ \\
3 & BW_Wh_Fj & 0,0246 & 0,7868 & 13,37 & 0,0004 \\
4 & abs_02 & 0,0118 & 0,7986 & 6,74 & 0,0107 \\
5 & PAR_M2 & 0,0099 & 0,8085 & 5,90 & 0,0167 \\
\hline
\end{tabular}

Tab. 45A: Parameterschätzungen zum vorherigen Modell mit der Zielvariablen Pflanzen $/ \mathrm{m}^{2}$ im Frühjahr in BBCH 16/18 (Di_Fj). Die Daten sind der Größe nach absteigend für den standardisierten Schätzer sortiert. VIF = Variance Inflation Factor, Signifikanzniveau: $p \leq 0,05$. Daten aus SAS Datengrundlage dienten alle Bestandes- und Befallsparameter sowie Di_He. BG_Fj und WHD_Fj wurden wegen Multikollinearität nicht berücksichtigt. (DF = Degree of freedom $=$ Freiheitsgrade) .

\begin{tabular}{ccccccccc}
\hline Variable & DF & Parameterschätzer & Standardfehler & t-Wert & Pr $>|\mathbf{t}|$ & Standardisierter Schätzer & Toleranz & VIF \\
\hline Intercept & 1 & 0,90175 & 13,34452 & 0,07 & 0,9462 & 0 & 0 \\
DI_He & 1 & 0,54535 & 0,06316 & 8,63 & $<0,0001$ & 0,53954 & 0,43029 & 2,32400 \\
Hoe_4 & 1 & 0,31157 & 0,08514 & 3,66 & 0,0004 & 0,18432 & 0,66229 & 1,50991 \\
abs_02 & 1 & $-0,18476$ & 0,07201 & $-2,57$ & 0,0116 & $-0,11893$ & 0,78189 & 1,27895 \\
PAR_M2 & 1 & $-0,22452$ & 0,09245 & $-2,43$ & 0,0167 & $-0,14249$ & 0,48801 & 2,04916 \\
BW_Wh_Fj & 1 & $-3,23175$ & 0,82046 & $-3,94$ & 0,0001 & $-0,19513$ & 0,68462 & 1,46067 \\
\hline
\end{tabular}


Tab. 46A: Prädiktoren für die Zielvariable Bestandeshöhe in BBCH 75 (Hoe_4) im Jahr 2010/11. Signifikanzniveau: $p \leq 0,05$. Für weitere Betrachtungen wurden nur die ersten beiden Prädiktoren berücksichtigt. Daten aus SAS. Als Datengrundlage dienten alle Bestandes- und Befallsparameter sowie Di_Fj und Di_He. Die Parameter Hoe1-4 wurden wegen Multikollinearität ausgeschlossen.

\begin{tabular}{|c|c|c|c|c|c|c|}
\hline Schritt & Variable eingegeben & Variable entfernt & Partielles R-Quadrat & Modell R-Quadrat & F-Statistik & $\operatorname{Pr}>\mathrm{F}$ \\
\hline 1 & Sah_4 & & 0,8642 & 0,8642 & 744,58 & $<0,0001$ \\
\hline 2 & Schi 4 & & 0,1358 & 1,0000 & Unend & $<0,0001$ \\
\hline
\end{tabular}

Tab. 47A: Parameterschätzungen zum vorherigen Modell mit der Zielvariablen Bestandeshöhe in BBCH 75 (Hoe_4). Die Daten sind der Größe nach absteigend für den standardisierten Schätzer sortiert. VIF $=$ Variance Inflation Factor, Signifikanzniveau: $p \leq 0,05$. Daten aus SAS. Als Datengrundlage dienten alle Bestandes- und Befallsparameter sowie Di_Fj und Di_He. Die Parameter Hoe1-4 wurden wegen Multikollinearität ausgeschlossen. (DF = Degree of freedom $=$ Freiheitsgrade)

\begin{tabular}{ccccccccc}
\hline Variable & DF & Parameterschätzer & Standardfehler & t-Wert & $\operatorname{Pr}>|\mathbf{t}|$ & Standardisierter Schätzer & Toleranz & VIF \\
\hline Intercept & 1 & $-2,8159 E-12$ & 0 & Unend & $<, 0001$ & 0 & 0 \\
Sah_4 & 1 & 1,00000 & 0 & Unend & $<, 0001$ & 0,96652 &, \\
Schi_4 & 1 & 1,00000 & 0 & Unend & $<, 0001$ & 0,37035 & 0,99007 & 1,01003 \\
\hline
\end{tabular}


Tab. 48A: Prädiktoren für die Zielvariable Befallswert mit der Wurzelhals- und Stängelfäule am unteren Stängel im Frühjahr in BBCH 83/84 (BW_St_Fj) im Jahr 2010/11. Signifikanzniveau: $p \leq 0,05$. Für weitere Betrachtungen wurden nur die ersten beiden Prädiktoren berücksichtigt. Daten aus SAS. Als Datengrundlage dienten alle Bestandes- und Befallsparameter sowie Di_Fj und Di_He. Wegen Multikollinearität wurden die Parameter NDVI_A1-A5 ausgeschlossen.

\begin{tabular}{ccccccc}
\hline Schritt & Variable eingegeben & Variable entfernt & Partielles R-Quadrat & Modell R-Quadrat & F-Statistik & Pr $>$ F \\
\hline 1 & BH_St_Fj & & 0,3172 & 0,3172 & 54,35 & $<, 0001$ \\
2 & Hoe_3 & 0,2209 & 0,5381 & 55,48 & $<, 0001$ \\
3 & NDVI & 0,0600 & 0,5981 & 17,16 & $<, 0001$ \\
4 & PAR_M3 & 0,0182 & 0,6162 & 5,39 & 0,0220 \\
5 & PAR_B4 & 0,0189 & 0,6351 & 5,85 & 0,0172 \\
\hline
\end{tabular}

Tab. 49A: Parameterschätzungen zum vorherigen Modell mit der Zielvariablen Befallswert mit der Wurzelhals- und Stängelfäule am unteren Stängel im Frühjahr in BBCH 83/84 (BW_St_Fj). Die Daten sind der Größe nach absteigend für den standardisierten Schätzer sortiert. VIF = Variance Inflation Factor, Signifikanzniveau: $p \leq 0,05$. Daten aus SAS. Daten aus SAS. Als Datengrundlage dienten alle Bestandes- und Befallsparameter sowie Di_Fj und Di_He. Wegen Multikollinearität wurden die Parameter NDVI_A1-A5 ausgeschlossen. (DF = Degree of freedom = Freiheitsgrade).

\begin{tabular}{ccccccccc}
\hline Variable & DF & Parameterschätzer & Standardfehler & $\mathbf{t}$-Wert & $\operatorname{Pr}>|\mathbf{t}|$ & Standardisierter Schätzer & Toleranz & VIF \\
\hline Intercept & 1 & 8,83004 & 2,99881 & 2,94 & 0,0039 & 0 & 0 \\
BH_St_Fj & 1 & 0,03818 & 0,00327 & 11,67 & $<, 0001$ & 0,76573 & 0,75035 & 1,33271 \\
Hoe_3 & 1 & 0,02235 & 0,00684 & 3,27 & 0,0014 & 0,26975 & 0,47316 & 2,11344 \\
PAR_M3 & 1 & 0,01812 & 0,00594 & 3,05 & 0,0029 & 0,19933 & 0,75552 & 1,32359 \\
PAR_B4 & 1 & $-0,03570$ & 0,01476 & $-2,42$ & 0,0172 & $-0,18681$ & 0,54128 & 1,84746 \\
NDVI & 1 & $-0,27227$ & 0,05584 & $-4,88$ & $<, 0001$ & $-0,37507$ & 0,54565 & 1,83267 \\
\hline
\end{tabular}


Tab. 50A: Prädiktoren für die Zielvariable Befallshäufigkeit mit der Wurzelhals- und Stängelfäule am unteren Stängel im Frühjahr in BBCH 83/84 (BH_St_Fj) im Jahr 2010/11. Signifikanzniveau: $p \leq 0,05$. Daten aus SAS. Als Datengrundlage dienten alle Bestandes- und Befallsparameter sowie Di_Fj und Di_He. Wegen Multikollinearität wurden die Parameter Sah_1-3, PAR_B1-B4, NDVI_B1-B4 und NDVI_A1-A5 ausgeschlossen.

\begin{tabular}{|c|c|c|c|c|c|c|}
\hline Schritt & Variable eingegeben & Variable entfernt & Partielles R-Quadrat & Modell R-Quadrat & F-Statistik & $\operatorname{Pr}>\mathrm{F}$ \\
\hline 1 & BH_Wh_Fj & & 0,3639 & 0,3639 & 66,94 & $<0,0001$ \\
\hline 2 & $\mathrm{BH} \_\mathrm{He}$ & & 0,0640 & 0,4279 & 12,98 & 0,0005 \\
\hline 3 & Sah_4 & & 0,0804 & 0,5083 & 18,80 & $<0,0001$ \\
\hline 4 & WHD_Fj & & 0,0451 & 0,5535 & 11,52 & 0,0009 \\
\hline 5 & Schi_1 & & 0,0377 & 0,5912 & 10,42 & 0,0016 \\
\hline 6 & WHD_He & & 0,0260 & 0,6172 & 7,60 & 0,0068 \\
\hline
\end{tabular}

Tab. 51A: Parameterschätzungen zum vorherigen Modell mit der Zielvariablen Befallshäufigkeit mit der Wurzelhals- und Stängelfäule am unteren Stängel im Frühjahr in BBCH 83/84 (BH_St_Fj). Die Daten sind der Größe nach absteigend für den standardisierten Schätzer sortiert. VIF = Variance Inflation Factor, Signifikanzniveau: $p \leq 0,05$. Daten aus SAS. Als Datengrundlage dienten alle Bestandes- und Befallsparameter sowie Di_Fj und Di_He. Wegen Multikollinearität wurden die Parameter Sah_1-3, PAR_B1-B4, NDVI_B1-B4 und NDVI_A1-A5 ausgeschlossen. (DF = Degree of freedom = Freiheitsgrade).

\begin{tabular}{ccccccccc}
\hline Variable & DF & Parameterschätzer & Standardfehler & t-Wert & Pr $>|\mathbf{t}|$ & Standardisierter Schätzer & Toleranz & VIF \\
\hline Intercept & 1 & $-29,83827$ & 19,55569 & $-1,53$ & 0,1299 & 0 & 0 \\
BH_Wh_Fj & 1 & 0,91262 & 0,16084 & 5,67 & $<0,0001$ & 0,37251 & 0,79312 & 1,26084 \\
WHD_Fj & 1 & 2,43341 & 0,50774 & 4,79 & $<0,0001$ & 0,30515 & 0,84321 & 1,18594 \\
BH_He & 1 & 0,25735 & 0,05185 & 4,96 & $<0,0001$ & 0,30395 & 0,91133 \\
Schi_1 & 1 & 0,67151 & 0,21851 & 3,07 & 0,0027 & 0,20220 & 0,78962 & 1,26644 \\
WHD_He & 1 & $-3,50919$ & 1,27284 & $-2,76$ & 0,0068 & $-0,18017$ & 0,80038 \\
Sah_4 & 1 & $-0,57590$ & 0,12812 & $-4,50$ & $<0,0001$ & $-0,32195$ & 1,24940 \\
\hline
\end{tabular}


Tab. 52A: Prädiktoren für die Zielvariable Bestandeshöhe in BBCH 73/74 (Hoe_3) im Jahr 2010/11. Signifikanzniveau: $p \leq 0,05$. Daten aus SAS. Als Datengrundlage dienten alle Bestandes- und Befallsparameter sowie Di_Fj und Di_He. Die Parameter Hoe_1-4, Sah_1,2 und 4 sowie Schi_1,2 und 4 wurden wegen Multikollinearität ausgeschlossen.

\begin{tabular}{ccccccc}
\hline Schritt & Variable eingegeben & Variable entfernt & Partielles R-Quadrat & Modell R-Quadrat & F-Statistik & Pr $>$ F \\
\hline 1 & Sah_3 & & 0,8291 & 0,8291 & 567,74 & $<0,0001$ \\
2 & Schi_3 & & 0,1709 & 1,0000 & Unend & $<0,0001$ \\
\hline
\end{tabular}

Tab. 53A: Parameterschätzungen zum vorherigen Modell mit der Zielvariablen Bestandeshöhe in BBCH 73/74 (Hoe_3). Die Daten sind der Größe nach absteigend für den standardisierten Schätzer sortiert. VIF = Variance Inflation Factor, Signifikanzniveau: $p \leq 0,05$. Daten aus SAS. Als Datengrundlage dienten alle Bestandes- und Befallsparameter sowie Di_Fj und Di_He. Die Parameter Hoe_1-4, Sah_1,2 und 4 sowie Schi_1,2 und 4 wurden wegen Multikollinearität ausgeschlossen. (DF = Degree of freedom = Freiheitsgrade)

\begin{tabular}{ccccccccc}
\hline Variable & DF & Parameterschätzer & Standardfehler & t-Wert & $\operatorname{Pr}>|\mathbf{t}|$ & Standardisierter Schätzer & Toleranz & VIF \\
\hline Intercept & 1 & $-1,3847 \mathrm{E}-12$ & 0 & Unend & $<0,0001$ & 0 & 0 \\
Sah_3 & 1 & 1,00000 & 0 & Unend & $<0,0001$ & 0,94954 & 0,99119 & 1,00889 \\
Schi_3 & 1 & 1,00000 & 0 & Unend & $<0,0001$ & 0,41519 & 0,99119 & 1,00889 \\
\hline
\end{tabular}




\section{Daten aus SAS zu multiplen Regressionen mit der Ausgangszielvariablen Kornertrag im Jahr 2012/13.}

Tab. 54A: Prädiktoren für die Zielvariable Kornertrag im Jahr 2012/13, Signifikanzniveau: $p \leq 0,05$. Für weitere Betrachtungen wurden nur die ersten beiden Prädiktoren berücksichtigt. Daten aus SAS. Als Datengrundlage dienten alle Parameter außer SBME, OE und El.

\begin{tabular}{|c|c|c|c|c|c|c|}
\hline Schritt & Variable eingegeben & Variable entfernt & Partielles R-Quadrat & Modell R-Quadrat & F-Statistik & $\operatorname{Pr}>\mathrm{F}$ \\
\hline 1 & Sah_4 & & 0,3060 & 0,3060 & 53,36 & $<, 0001$ \\
\hline 2 & NDVI_A5 & & 0,1661 & 0,4721 & 37,75 & $<, 0001$ \\
\hline 3 & WHD_He & & 0,0751 & 0,5472 & 19,73 & $<, 0001$ \\
\hline 4 & PAR_B1 & & 0,0297 & 0,5769 & 8,30 & 0,0047 \\
\hline 5 & rel_04 & & 0,0237 & 0,6006 & 6,95 & 0,0095 \\
\hline 6 & rel_01 & & 0,0228 & 0,6234 & 7,01 & 0,0092 \\
\hline 7 & abs_02 & & 0,0290 & 0,6524 & 9,58 & 0,0025 \\
\hline
\end{tabular}

Tab. 55A: Parameterschätzungen zum vorherigen Modell mit der Zielvariablen Kornertrag. Die Daten sind der Größe nach absteigend für den standardisierten Schätzer sortiert. Signifikanzniveau: $p \leq 0,05$. VIF = Variance Inflation Factor, Daten aus SAS. Als Datengrundlage dienten alle Parameter außer SBME, OE und El. (DF = Degree of freedom = Freiheitsgrade)

\begin{tabular}{|c|c|c|c|c|c|c|c|c|}
\hline Variable & DF & Parameterschätzer & Standardfehler & t-Wert & $\operatorname{Pr}>|t|$ & Standardisierter Schätzer & Toleranz & VIF \\
\hline Intercept & 1 & 1,85948 & 0,39334 & 4,73 & $<, 0001$ & 0 & & 0 \\
\hline Sah_4 & 1 & 0,02140 & 0,00221 & 9,67 & $<, 0001$ & 0,75541 & 0,49542 & 2,01849 \\
\hline NDVI_A5 & 1 & 4,28890 & 0,66761 & 6,42 & $<, 0001$ & 0,46433 & 0,57862 & 1,72825 \\
\hline rel_01 & 1 & 0,05837 & 0,01443 & 4,04 & $<, 0001$ & 0,31029 & 0,51347 & 1,94752 \\
\hline abs_02 & 1 & 0,02265 & 0,00732 & 3,10 & 0,0025 & 0,24861 & 0,46864 & 2,13383 \\
\hline rel_04 & 1 & 0,03581 & 0,01277 & 2,80 & 0,0059 & 0,16365 & 0,88764 & 1,12659 \\
\hline PAR_B1 & 1 & $-0,16039$ & 0,04428 & $-3,62$ & 0,0004 & $-0,20971$ & 0,90189 & 1,10878 \\
\hline WHD_He & 1 & $-0,11295$ & 0,02996 & $-3,77$ & 0,0003 & $-0,24339$ & 0,72527 & 1,37879 \\
\hline
\end{tabular}


Tab. 56A: Prädiktoren für die Zielvariable Schotenansatzhöhe in BBCH 75 (Sah_4) im Jahr 2012/13. Signifikanzniveau: $p \leq 0,05$. Für weitere Betrachtungen wurden nur die ersten beiden Prädiktoren berücksichtigt. Daten aus SAS. Als Datengrundlage dienten alle Parameter außer SBME, OE und El. Weiterhin wurden für die Berechnung alle Parameter von der Schotenansatzhöhe (Sah_1-4) wegen Messwiederholungen und alle Parameter von der Bestandeshöhe (Hoe_2-4) bis auf die Bestandeshöhe in BBCH 65/67 (Hoe_1), sowie alle Parameter von der Schotenschichtdicke (Schi_2-4) bis auf die Schotenschichtdicke in BBCH 65/67 (Schi_1) wegen Multikollinearität ausgeschlossen.

\begin{tabular}{|c|c|c|c|c|c|c|}
\hline Schritt & Variable eingegeben & Variable entfernt & Partielles R-Quadrat & Modell R-Quadrat & F-Statistik & $\mathrm{Pr}>\mathrm{F}$ \\
\hline 1 & Hoe_1 & & 0,9620 & 0,9620 & 3064,49 & $<, 0001$ \\
\hline 2 & Schi_1 & & 0,0167 & 0,9787 & 93,90 & $<, 0001$ \\
\hline 3 & rel_02 & & 0,0011 & 0,9798 & 6,42 & 0,0126 \\
\hline
\end{tabular}

Tab. 57A: Parameterschätzungen zum vorherigen Modell mit der Zielvariablen Schotenansatzhöhe in BBCH 75 (Sah4). Die Daten sind der Größe nach absteigend für den standardisierten Schätzer sortiert. VIF = Variance Inflation Factor, Signifikanzniveau: $p \leq 0,05$. Daten aus SAS. Als Datengrundlage dienten alle Parameter außer SBME, OE und El. Weiterhin wurden für die Berechnung alle Parameter von der Schotenansatzhöhe (Sah_1-4) wegen Messwiederholungen und alle Parameter von der Bestandeshöhe (Hoe_2-4) bis auf die Bestandeshöhe in BBCH 65/67 (Hoe_1), sowie alle Parameter von der Schotenschichtdicke (Schi_2-4) bis auf die Schotenschichtdicke in BBCH 65/67 (Schi_1) wegen Multikollinearität ausgeschlossen. (DF = Degree of freedom $=$ Freiheitsgrade)

\begin{tabular}{|c|c|c|c|c|c|c|c|c|}
\hline Variable & DF & Parameterschätzer & Standardfehler & t-Wert & $\operatorname{Pr}>|t|$ & Standardisierter Schätzer & Toleranz & VIF \\
\hline Intercept & 1 & $-15,81861$ & 3,18473 & $-4,97$ & $<, 0001$ & 0 & & 0 \\
\hline Hoe_1 & 1 & 0,97607 & 0,01325 & 73,64 & $<, 0001$ & 1,01180 & 0,90006 & 1,11104 \\
\hline rel_02 & 1 & 0,23377 & 0,09224 & 2,53 & 0,0126 & 0,03350 & 0,97276 & 1,02800 \\
\hline Schi 1 & 1 & $-0,59970$ & 0,06147 & $-9,76$ & $<, 0001$ & $-0,13240$ & 0,92253 & 1,08398 \\
\hline
\end{tabular}


Tab. 58A: Prädiktoren für die Zielvariable Bestandeshöhe in BBCH 65/67 (Hoe_1) im Jahr 2012/13. Signifikanzniveau: $p \leq 0,05$. Für weitere Betrachtungen wurden nur die ersten beiden Prädiktoren berücksichtigt. Daten aus SAS. Als Datengrundlage dienten alle Parameter außer SBME, OE und El. Weiterhin wurden für die Berechnung alle Parameter von der Bestandeshöhe (Hoe_1-4) wegen Messwiederholungen und alle Parameter von der Schotenansatzhöhe (Hoe_2-4) bis auf die Schotenansatzhöhe in BBCH 65/67 (Sah_1), sowie alle Parameter von der Schotenschichtdicke (Schi_2-4) bis auf die Schotenschichtdicke in BBCH 65/67 (Schi_1) wegen Multikollinearität ausgeschlossen.

\begin{tabular}{|c|c|c|c|c|c|c|}
\hline Schritt & Variable eingegeben & Variable entfernt & Partielles R-Quadrat & Modell R-Quadrat & F-Statistik & $\operatorname{Pr}>\mathrm{F}$ \\
\hline 1 & Sah_1 & & 0,9548 & 0.9548 & 2557.00 & $<, 0001$ \\
\hline 2 & Schi_1 & & 0,0452 & 1,0000 & Unend & $<, 0001$ \\
\hline
\end{tabular}

Tab. 59A: Parameterschätzungen zum vorherigen Modell mit der Zielvariablen Bestandeshöhe in BBCH 65/67 (Hoe_1). Die Daten sind der Größe nach absteigend für den standardisierten Schätzer sortiert. VIF = Variance Inflation Factor, Signifikanzniveau: $p \leq 0,05$. Daten aus SAS. Als Datengrundlage dienten alle Parameter außer SBME, OE und EI. Weiterhin wurden für die Berechnung alle Parameter von der Bestandeshöhe (Hoe_1-4) wegen Messwiederholungen und alle Parameter von der Schotenansatzhöhe (Hoe_2-4) bis auf die Schotenansatzhöhe in BBCH 65/67 (Sah_1), sowie alle Parameter von der Schotenschichtdicke (Schi_2-4) bis auf die Schotenschichtdicke in BBCH 65/67 (Schi_1) wegen Multikollinearität ausgeschlossen. (DF $=$ Degree of freedom $=$ Freiheitsgrade)

\begin{tabular}{ccccccccc}
\hline Variable & DF & Parameterschätzer & Standardfehler & t-Wert & Pr $>|\mathbf{t}|$ & Standardisierter Schätzer & Toleranz & VIF \\
\hline Intercept & 1 & $-2,1332 \mathrm{E}-12$ & 0 & Unend & $<, 0001$ & 0 & 0 \\
Sah_1 & 1 & 1,00000 & 0 & Unend & $<, 0001$ & 0,96377 & 0,99606 & 1,00396 \\
Schi_1 & 1 & 1,00000 & 0 & Unend & $<, 0001$ & 0,21298 & 0,99606 & 1,00396 \\
\hline
\end{tabular}


Tab. 60A: Prädiktoren für die Zielvariable Schotenschichtdicke in BBCH 65/67 (Schi_1) im Jahr 2012/13. Signifikanzniveau: $p \leq 0,05$. Für weitere Betrachtungen wurden nur die ersten beiden Prädiktoren berücksichtigt. Daten aus SAS. Als Datengrundlage dienten alle Parameter außer SBME, OE und El. Weiterhin wurden für die Berechnung alle Parameter von der Schotenschichtdicke (Schi_2-4) wegen Messwiederholungen und alle Parameter der Bestandeshöhe (Hoe_1-4), sowie der Schotenansatzhöhe (Sah_1-4) wegen Multikollinearität ausgeschlossen. Der Parameter TKM wurde nicht berücksichtigt, da dieser wie der Strohbiomasseertrag oder der Kornertrag eher eine abhängige als eine erklärende Variable darstellt!

\begin{tabular}{|c|c|c|c|c|c|c|}
\hline Schritt & Variable eingegeben & Variable entfernt & Partielles R-Quadrat & Modell R-Quadrat & F-Statistik & $\mathrm{Pr}>\mathrm{F}$ \\
\hline 1 & NDVI_B2 & & 0,1657 & 0,1657 & 24,03 & $<, 0001$ \\
\hline 2 & BH_St_Fj & & 0,0363 & 0,2020 & 5,47 & 0,0210 \\
\hline 3 & $\mathrm{DI} \mathrm{He}$ & & 0,0289 & 0,2309 & 4,47 & 0,0365 \\
\hline
\end{tabular}

Tab. 61A: Parameterschätzungen zum vorherigen Modell mit der Zielvariablen Schotenschichtdicke in BBCH 65/67 (Schi_1). Die Daten sind der Größe nach absteigend für den standardisierten Schätzer sortiert. VIF = Variance Inflation Factor, Signifikanzniveau: $p \leq 0,05$. Daten aus SAS. Als Datengrundlage dienten alle Parameter außer SBME, OE und El. Weiterhin wurden für die Berechnung alle Parameter von der Schotenschichtdicke (Schi_2-4) wegen Messwiederholungen und alle Parameter der Bestandeshöhe (Hoe_1-4), sowie der Schotenansatzhöhe (Sah_1-4) wegen Multikollinearität ausgeschlossen. Der Parameter TKM wurde nicht berücksichtigt, da dieser wie der Strohbiomasseertrag oder der Kornertrag eher eine abhängige als eine erklärende Variable darstellt! (DF = Degree of freedom = Freiheitsgrade)

\begin{tabular}{|c|c|c|c|c|c|c|c|c|}
\hline Variable & DF & Parameterschätzer & Standardfehler & t-Wert & $\operatorname{Pr}>|t|$ & Standardisierter Schätzer & Toleranz & VIF \\
\hline Intercept & 1 & 63,55480 & 2,63039 & 24,16 & $<, 0001$ & 0 & & 0 \\
\hline BH_St_Fj & 1 & 0,07273 & 0,02594 & $-2,80$ & 0,0059 & 0,23268 & 0,93875 & 1,06524 \\
\hline DI_He & 1 & $-0,03626$ & 0,01714 & $-2,11$ & 0,0365 & $-0,17504$ & 0,94344 & 1,05995 \\
\hline NDVI_B2 & 1 & $-28,83132$ & 6,04819 & $-4,77$ & $<, 0001$ & $-0,38473$ & 0,99219 & 1,00787 \\
\hline
\end{tabular}


Tab. 62A: Prädiktoren für die Zielvariable Grünfärbung des Pflanzenbestandes in BBCH 89 (NDVI_A5) im Jahr 2012/13. Signifikanzniveau: $p \leq 0,05$. Für weitere Betrachtungen wurden nur die ersten beiden Prädiktoren berücksichtigt. Daten aus SAS. Als Datengrundlage dienten alle Parameter außer SBME, OE und EI. Weiterhin wurden für die Berechnung alle Parameter von der Grünfärbung des Pflanzenbestandes (NDVI's) ausgeschlossen sowie der Parameter TKM.

\begin{tabular}{|c|c|c|c|c|c|c|}
\hline Schritt & Variable eingegeben & Variable entfernt & Partielles R-Quadrat & Modell R-Quadrat & F-Statistik & $\operatorname{Pr}>\mathrm{F}$ \\
\hline 1 & Hoe_3 & & 0,4599 & 0,4599 & 103,01 & $<0,0001$ \\
\hline 2 & Schi_3 & & 0,0626 & 0,5225 & 15,73 & 0,0001 \\
\hline 3 & WHD_He & & 0,0440 & 0,5665 & 12,08 & 0,0007 \\
\hline 4 & PAR_B3 & & 0,0243 & 0,5908 & 7,85 & 0,0060 \\
\hline
\end{tabular}

Tab. 63A: Parameterschätzungen zum vorherigen Modell mit der Zielvariablen Grünfärbung des Pflanzenbestandes in BBCH 89 (NDVI_A5). Die Daten sind der Größe nach absteigend für den standardisierten Schätzer sortiert. VIF = Variance Inflation Factor, Signifikanzniveau: $p \leq 0,05$. Daten aus SAS. Als Datengrundlage dienten alle Parameter außer SBME, OE und El. Weiterhin wurden für die Berechnung alle Parameter von der Grünfärbung des Pflanzenbestandes (NDVI's) ausgeschlossen sowie der Parameter TKM. (DF = Degree of freedom = Freiheitsgrade)

\begin{tabular}{ccccccccc}
\hline Variable & DF & Parameterschätzer & Standardfehler & $\mathbf{t}$-Wert & Pr $>|\mathbf{t}|$ & Standardisierter Schätzer & Toleranz & VIF \\
\hline Intercept & 1 & 0,62059 & 0,04632 & 13,40 & $<0,0001$ & 0 & 0 \\
WHD_He & 1 & 0,01236 & 0,00298 & 4,14 & $<0,0001$ & 0,24602 & 0,13966 \\
PAR_B3 & 1 & $-0,01158$ & 0,00414 & $-2,80$ & 0,0060 & $-0,15977$ & 0,87746 & 0,95119 \\
Schi_3 & 1 & $-0,00319$ & 0,00080 & $-4,00$ & 0,0001 & $-0,24886$ & 1,05132 \\
Hoe_3 & 1 & $-0,00219$ & 0,00019 & $-11,25$ & $<0,0001$ & $-0,75028$ & 0,80145 & 1,24774 \\
\hline
\end{tabular}


Tab. 64A: Prädiktoren für die Zielvariable Bestandeshöhe in BBCH 73/74 (Hoe_3) im Jahr 2012/13. Signifikanzniveau: $p \leq 0,05$. Für weitere Betrachtungen wurden nur die ersten beiden Prädiktoren berücksichtigt. Daten aus SAS. Als Datengrundlage dienten alle Parameter außer SBME, OE und El. Weiterhin wurden für die Berechnung alle Parameter von der Bestandeshöhe (Hoe_1-4) wegen Messwiederholungen und alle Parameter von der Schotenansatzhöhe (Sah_1, 2, 4) bis auf die Schotenansatzhöhe in BBCH 73/74 (Sah_3) sowie alle Parameter von der Schotenschichtdicke (Schi_1, 2, 4) bis auf die Schotenschichtdicke in BBCH 73/74 (Schi_3) wegen Multikollinearität ausgeschlossen.

\begin{tabular}{|c|c|c|c|c|c|c|}
\hline Schritt & Variable eingegeben & Variable entfernt & Partielles R-Quadrat & Modell R-Quadrat & F-Statistik & $\mathrm{Pr}>\mathrm{F}$ \\
\hline 1 & Sah_3 & & 0,9491 & 0,9491 & 2255,76 & $<, 0001$ \\
\hline 2 & Schi_3 & & 0,0509 & 1,0000 & Unend & $<, 0001$ \\
\hline
\end{tabular}

Tab. 65A: Parameterschätzungen zum vorherigen Modell mit der Zielvariablen Bestandeshöhe in BBCH 73/74 (Hoe_3). Die Daten sind der Größe nach absteigend für den standardisierten Schätzer sortiert. VIF $=$ Variance Inflation Factor, Signifikanzniveau: $p \leq 0,05$. Daten aus SAS. Als Datengrundlage dienten alle Parameter außer SBME, OE und El. Weiterhin wurden für die Berechnung alle Parameter von der Bestandeshöhe (Hoe_1-4) wegen Messwiederholungen und alle Parameter von der Schotenansatzhöhe (Hoe_1, 2, 4) bis auf die Schotenansatzhöhe in BBCH 73/74 (Sah_3) sowie alle Parameter von der Schotenschichtdicke (Schi_1, 2, 4) bis auf die Schotenschichtdicke in BBCH 73/74 (Schi_3) wegen Multikollinearität ausgeschlossen. (DF $=$ Degree of freedom $=$ Freiheitsgrade)

\begin{tabular}{ccccccccc}
\hline Variable & DF & Parameterschätzer & Standardfehler & t-Wert & Pr $>|\mathbf{t}|$ & Standardisierter Schätzer & Toleranz & VIF \\
\hline Intercept & 1 & $-9,5103 \mathrm{E}-13$ & 0 & Unend & $<, 0001$ & 0 & 0 \\
Sah3 & 1 & 1,00000 & 0 & Unend & $<, 0001$ & 0,94909 &, \\
Schi3 & 1 & 1,00000 & 0 & Unend & $<, 0001$ & 0,22703 & 0,98775 & 1,01240 \\
\hline
\end{tabular}


Tab. 66A: Prädiktoren für die Zielvariable Schotenschichtdicke in BBCH 73/74 (Schi_3) im Jahr 2012/13. Signifikanzniveau: $p \leq 0,05$. Für weitere Betrachtungen wurden nur die ersten beiden Prädiktoren berücksichtigt. Daten aus SAS. Als Datengrundlage dienten alle Parameter außer SBME, OE und El. Weiterhin wurden für die Berechnung alle Parameter von der Schotenschichtdicke (Schi_1-4) wegen Messwiederholungen, alle Parameter von der Bestandeshöhe (Hoe_1-4), alle Parameter von der Schotenansatzhöhe (Sah_1, 2, 4) bis auf die Schotenansatzhöhe in BBCH 73/74 (Sah_3), alle Parameter von PAR unter den Schoten bzw. am Boden (PAR_M bzw. PAR_B) sowie alle Parameter von der Grünfärbung des Pflanzenbestandes (NDVI's) bis auf NDVI_B2 wegen Multikollinearität ausgeschlossen.

\begin{tabular}{|c|c|c|c|c|c|c|}
\hline Schritt & Variable eingegeben & Variable entfernt & Partielles R-Quadrat & Modell R-Quadrat & F-Statistik & $\operatorname{Pr}>\mathrm{F}$ \\
\hline 1 & NDVI_B2 & & 0,2909 & 0,2909 & 49,64 & $<0,0001$ \\
\hline 2 & Sah_3 & & 0,0556 & 0,3465 & 10,21 & 0,0018 \\
\hline 3 & $\mathrm{BpP}$ & & 0,0465 & 0,3930 & 9,67 & 0,0023 \\
\hline 4 & WHD $\mathrm{He}$ & & 0,0392 & 0,4322 & 7,59 & 0,0068 \\
\hline
\end{tabular}

Tab.67A: Parameterschätzungen zum vorherigen Modell mit der Zielvariablen Schotenschichtdicke in BBCH 73/74 (Schi_3). Die Daten sind der Größe nach absteigend für den standardisierten Schätzer sortiert. VIF = Variance Inflation Factor, Signifikanzniveau: $p \leq 0,05$. Daten aus SAS. Als Datengrundlage dienten alle Parameter außer SBME, OE und El. Weiterhin wurden für die Berechnung alle Parameter von der Schotenschichtdicke (Schi_1-4) wegen Messwiederholungen, alle Parameter von der Bestandeshöhe (Hoe_1-4), alle Parameter von der Schotenansatzhöhe (Sah_1, 2, 4) bis auf die Schotenansatzhöhe in BBCH 73/74 (Sah_3), alle Parameter von PAR unter den Schoten bzw. am Boden (PAR_M bzw. PAR_B) sowie alle Parameter von der Grünfärbung des Pflanzenbestandes (NDVI's) bis auf NDVI_B2 wegen Multikollinearität ausgeschlossen. (DF = Degree of freedom = Freiheitsgrade)

\begin{tabular}{ccccccccc}
\hline Variable & DF & Parameterschätzer & Standardfehler & t-Wert & Pr $>|\mathbf{t}|$ & Standardisierter Schätzer & Toleranz & VIF \\
\hline Intercept & 1 & 74,34058 & 4,47816 & 16,60 & $<, 0001$ & 0 & 0 \\
WHD_He & 1 & 1,47956 & 0,35501 & 4,17 & $<, 0001$ & 0,37778 & 0 \\
BpP & 1 & $-1,33243$ & 0,42849 & $-3,11$ & 0,0023 & $-0,28767$ & 0,58564 & 1,70753 \\
Sah_3 & 1 & $-0,06939$ & 0,02028 & $-3,42$ & 0,0009 & $-0,29010$ & 0,56227 & 1,77852 \\
NDVI_B2 & 1 & $-45,08383$ & 7,54934 & $-5,97$ & $<, 0001$ & $-0,55559$ & 0,66972 & 1,49317 \\
\hline
\end{tabular}


Tab. 68A: Gerundete Faktorladungen (Eigenvektoren) für die 1. und 2. Hauptkomponente (HK), ermittelt in der Hauptkomponentenanalyse (PCA). Die Faktorladungen sind getrennt nach den Versuchsjahren 2010/11 und 2012/13 jeweils für die 1. und 2. HK dargestellt. Fett hervorgehoben, sind die höchsten negativen bzw. positiven Faktorladungen für die 1. und 2. HK. *Die Erklärungen der einzelnen Parameterabkürzungen befinden sich am Ende von Tab. 22A.

\begin{tabular}{|c|c|c|c|c|c|}
\hline & & \multicolumn{4}{|c|}{ Faktorladungen } \\
\hline \multicolumn{2}{|c|}{ Abkürzungen für Parameter ${ }^{\star}$} & \multicolumn{2}{|c|}{ 2010/11 } & \multicolumn{2}{|c|}{ 2012/13 } \\
\hline in Biplots & in anderen Abb. und Tab. & 1. HK & 2. HK & 1. HK & 2. HK \\
\hline$Y d$ & Yield (Ertrag) & $-0,130$ & $-0,160$ & 0,078 & $-0,144$ \\
\hline DM & SBME & $-0,071$ & $-0,129$ & 0,067 & $-0,128$ \\
\hline OG & OG & 0,045 & $-0,193$ & 0,003 & 0,073 \\
\hline $\mathrm{OE}$ & OE & $-0,121$ & $-0,182$ & 0,071 & $-0,111$ \\
\hline $\mathrm{El}$ & $\mathrm{El}$ & $-0,075$ & $-0,049$ & $-0,019$ & 0,027 \\
\hline D_2 & DI_Fj & $-0,176$ & $-0,084$ & $-0,083$ & $-0,218$ \\
\hline SP & SpP & 0,162 & 0,111 & 0,082 & 0,211 \\
\hline TKG & TKG & 0,158 & $-0,031$ & $-0,091$ & 0,021 \\
\hline KS & KpS & 0,021 & 0,193 & 0,123 & 0,018 \\
\hline Sm2 & Spm2 & $-0,143$ & $-0,026$ & $-0,027$ & $-0,055$ \\
\hline KP & $\mathrm{KpP}$ & 0,150 & 0,137 & 0,091 & 0,215 \\
\hline $\mathrm{KD}$ & Korn_Di & $-0,140$ & 0,029 & 0,005 & $-0,046$ \\
\hline StP & StpP & 0,151 & 0,117 & 0,056 & 0,220 \\
\hline BG_2 & KDG_Fj & $-0,187$ & $-0,040$ & $-0,050$ & $-0,178$ \\
\hline WD_2 & WHD_Fj & 0,115 & 0,193 & 0,082 & 0,196 \\
\hline Sh1 & Sah1 & $-0,139$ & 0,180 & 0,205 & $-0,098$ \\
\hline Sh2 & Sah2 & $-0,130$ & 0,191 & 0,205 & $-0,096$ \\
\hline Sh3 & Sah3 & $-0,121$ & 0,204 & 0,204 & $-0,098$ \\
\hline Sh4 & Sah4 & $-0,148$ & 0,168 & 0,204 & $-0,098$ \\
\hline H_1 & Hoe1 & $-0,149$ & 0,151 & 0,208 & $-0,089$ \\
\hline H_2 & Hoe2 & $-0,129$ & 0,185 & 0,208 & $-0,089$ \\
\hline H_3 & Hoe3 & $-0,142$ & 0,171 & 0,207 & $-0,088$ \\
\hline $\mathrm{H}_{-} 4$ & Hoe4 & $-0,160$ & 0,142 & 0,209 & $-0,082$ \\
\hline Si1 & Schi1 & $-0,082$ & $-0,018$ & 0,091 & 0,044 \\
\hline $\mathrm{Si} 2$ & Schi2 & 0,027 & $-0,051$ & 0,081 & 0,030 \\
\hline $\mathrm{Si} 3$ & Schi3 & $-0,093$ & $-0,122$ & 0,090 & 0,020 \\
\hline $\mathrm{Si} 4$ & Schi4 & $-0,071$ & $-0,118$ & 0,105 & 0,037 \\
\hline r_o & rel_00 & $-0,123$ & $-0,118$ & $-0,112$ & $-0,192$ \\
\hline$r_{-} 1$ & rel_01 & $-0,012$ & $-0,082$ & $-0,058$ & $-0,215$ \\
\hline r_2 & rel_02 & $-0,072$ & 0,039 & $-0,032$ & $-0,227$ \\
\hline r_3 & rel_03 & $-0,156$ & $-0,034$ & 0,039 & $-0,190$ \\
\hline r_4 & rel_04 & $-0,157$ & $-0,009$ & 0,112 & $-0,029$ \\
\hline
\end{tabular}




\begin{tabular}{|c|c|c|c|c|c|}
\hline a_0 & abs_00 & 0,080 & 0,050 & 0,012 & 0,198 \\
\hline a_1 & abs_01 & 0,147 & 0,063 & 0,111 & 0,179 \\
\hline a_2 & abs_02 & 0,109 & 0,116 & 0,114 & 0,191 \\
\hline a_3 & abs_03 & 0,108 & 0,123 & 0,113 & 0,193 \\
\hline a_4 & abs_04 & 0,099 & 0,146 & 0,116 & 0,202 \\
\hline P_M1 & PAR_M1 & 0,119 & $-0,056$ & $-0,087$ & $-0,010$ \\
\hline P_M2 & PAR_M2 & 0,173 & 0,018 & $-0,009$ & $-0,008$ \\
\hline P_M3 & PAR_M3 & 0,135 & 0,092 & $-0,014$ & 0,005 \\
\hline P_M4 & PAR_M4 & 0,175 & 0,039 & 0,040 & $-0,032$ \\
\hline P_B1 & PAR_B1 & 0,175 & $-0,043$ & 0,047 & 0,132 \\
\hline P_B2 & PAR_B2 & 0,177 & 0,052 & $-0,010$ & 0,040 \\
\hline P_B3 & PAR_B3 & 0,143 & 0,098 & $-0,033$ & 0,042 \\
\hline P_B4 & PAR_B4 & 0,179 & 0,073 & 0,023 & 0,023 \\
\hline N_B1 & NDVI_B1 & 0,054 & $-0,117$ & $-0,121$ & 0,119 \\
\hline N_B2 & NDVI_B2 & 0,091 & 0,011 & $-0,144$ & 0,042 \\
\hline N_B3 & NDVI_B3 & 0,080 & $-0,065$ & $-0,052$ & $-0,067$ \\
\hline N_B4 & NDVI_B4 & $-0,096$ & $-0,165$ & $-0,142$ & $-0,020$ \\
\hline N_A1 & NDVI_A1 & 0,009 & $-0,152$ & $-0,214$ & 0,015 \\
\hline N_A2 & NDVI_A2 & 0,076 & $-0,101$ & $-0,203$ & 0,043 \\
\hline N_A3 & NDVI_A3 & 0,083 & $-0,228$ & $-0,191$ & 0,066 \\
\hline N_A4 & NDVI_A4 & 0,131 & $-0,187$ & $-0,174$ & 0,090 \\
\hline N_A5 & NDVI_A5 & 0,173 & $-0,090$ & $-0,162$ & 0,098 \\
\hline $\mathrm{NI}$ & NDVI & 0,113 & $-0,197$ & $-0,213$ & 0,057 \\
\hline BG_1 & KDG_He & \multicolumn{2}{|c|}{ nicht ermittelt 2010/11 } & 0,041 & 0,016 \\
\hline D_1 & DI_He & $-0,164$ & $-0,119$ & $-0,089$ & $-0,214$ \\
\hline WD_1 & WHD_He & $-0,030$ & 0,213 & 0,128 & 0,171 \\
\hline BIL & SprLae & $-0,119$ & 0,172 & 0,115 & 0,140 \\
\hline BP & $\mathrm{BpP}$ & $-0,120$ & 0,039 & 0,027 & 0,137 \\
\hline PW_S & BW_St_Fj & $-0,001$ & 0,131 & 0,148 & 0,032 \\
\hline $\mathrm{PH} \_\mathrm{S}$ & BH_St_Fj & 0,117 & $-0,004$ & 0,118 & 0,031 \\
\hline PW_2 & BW_Wh_Fj & 0,099 & 0,148 & 0,158 & $-0,061$ \\
\hline PH_2 & BH_Wh_Fj & 0,131 & $-0,021$ & 0,148 & $-0,056$ \\
\hline PW_P & BW_He & $-0,029$ & 0,109 & 0,143 & $-0,018$ \\
\hline $\mathrm{PH} \_\mathrm{P}$ & $\mathrm{BH} \_\mathrm{He}$ & $-0,022$ & 0,092 & 0,149 & $-0,024$ \\
\hline PW_1 & BW_Wh_He & $-0,033$ & $-0,030$ & $-0,056$ & 0,122 \\
\hline PH_1 & BH_Wh_He & $-0,043$ & 0,016 & $-0,053$ & 0,113 \\
\hline KFH_2 & $\mathrm{BH} \_\mathrm{KF} \_\mathrm{Fj}$ & 0,141 & $-0,010$ & $-0,005$ & 0,173 \\
\hline KFH_1 & BH_KF_He & 0,049 & 0,013 & \multicolumn{2}{|c|}{ nicht ermittelt $2012 / 13$} \\
\hline
\end{tabular}


Tab. 69A: Kennzahlen der einfachen, linearen Regressionsrechnungen, die zwischen allen Ertragsfaktoren (Pflanzen $/ \mathrm{m}^{2}$, Schoten/Pflanze etc.) durchgeführt wurden. Alle Parameter wurden im Jahr 2010/11 und 2012/13 im Feldversuch am Standort Göttingen untersucht. Getrennt nach Jahren sind dargestellt: die Anzahl der Werte (n) die in jede Berechnung eingeflossen sind, der Korrelationskoeffizient nach Spearman $\left(r_{s}\right)$ und Pearson $\left(r_{p}\right)$, das Bestimmtheitsmaß nach Spearman $\left(R_{s}{ }^{2}\right)$ und Pearson $\left(R_{p}{ }^{2}\right)$ und die Überschreitungswahrscheinlichkeiten ( $p$-Wert) für die jeweiligen Spearman- $\left(p_{s}\right)$ bzw. Pearson-Korrelationen $\left(p_{p}\right)$. Korrelationskoeffizienten und Bestimmtheitsmaße sind signifikant bei einem Wert $p \leq 0,05$ (hoch signifikant bei $p \leq 0,01$, höchst signifikant bei $p \leq 0,001)$. Ergebnisse, die einmal zu einer Korrelation/Regression erwähnt wurden (z.B. Di_Fj mit SpP), werden bei der nächsten entsprechenden $x$-Variablen (z.B. SpP) nicht noch einmal wiederholt. Signifikante Effekte sind fett hervorgehoben.

\begin{tabular}{|c|c|c|c|c|c|c|c|c|c|}
\hline Jahr & $\mathrm{x}$-Variable & -Variable & $\mathbf{n}$ & $r_{p}$ & $\mathbf{R}_{\mathbf{p}}^{2}$ & $p_{p}$ & $r_{s}$ & $\mathbf{R}_{\mathrm{s}}^{2}$ & $p_{s}$ \\
\hline \multirow[t]{7}{*}{2011} & DI_FJ & $\mathrm{SpP}$ & 120 & $-0,676$ & 0,457 & $<0,001$ & $-0,702$ & 0,493 & $<0,001$ \\
\hline & & $\mathrm{KpS}$ & 120 & $-0,261$ & 0,068 & 0,0039 & $-0,271$ & 0,074 & 0,0026 \\
\hline & & TKM & 120 & $-0,646$ & 0,418 & $<0,001$ & $-0,653$ & 0,426 & $<0,001$ \\
\hline & & Spm2 & 120 & 0,711 & 0,505 & $<0,001$ & 0,724 & 0,525 & $<0,001$ \\
\hline & & $\mathrm{KpP}$ & 120 & $-0,663$ & 0,440 & $<0,001$ & $-0,685$ & 0,470 & $<0,001$ \\
\hline & & Korn_Di & 120 & 0,624 & 0,389 & $<0,001$ & 0,614 & 0,377 & $<0,001$ \\
\hline & & StpP & 120 & $-0,654$ & 0,428 & $<0,001$ & $-0,678$ & 0,459 & $<0,001$ \\
\hline \multirow[t]{6}{*}{2013} & DI_FJ & $\mathrm{SpP}$ & 123 & $-0,686$ & 0,470 & $<0,001$ & $-0,728$ & 0,530 & $<0,001$ \\
\hline & & KpS & 124 & $-0,069$ & 0,005 & 0,4498 & $-0,077$ & 0,006 & 0,3975 \\
\hline & & TKM & 124 & 0,042 & 0,002 & 0,6467 & 0,060 & 0,004 & 0,5062 \\
\hline & & Spm2 & 123 & 0,326 & 0,106 & 0,0002 & 0,343 & 0,118 & 0,0001 \\
\hline & & $\mathrm{KpP}$ & 124 & $-0,687$ & 0,472 & $<0,001$ & $-0,721$ & 0,519 & $<0,001$ \\
\hline & & Korn_Di & 124 & 0,281 & 0,079 & 0,0015 & 0,297 & 0,088 & 0,0008 \\
\hline \multirow[t]{6}{*}{$\overline{201 \overline{1}}$} & $\mathrm{SpP}$ & $\frac{\text { StpP }}{\mathrm{KpS}}$ & $\frac{124}{120}$ & $-\frac{-0,640}{0,333}=$ & $\frac{0,409}{0,111}$ & $\begin{array}{l}<0,001 \\
0,0002\end{array}$ & $=\frac{-0,648}{0,349}$ & $\frac{0,420}{0,122}$ & $\begin{array}{l}<0,001 \\
-0,0001\end{array}$ \\
\hline & & TKM & 120 & 0,440 & 0,193 & $<0,001$ & 0,362 & 0,131 & $<0,001$ \\
\hline & & Spm2 & 120 & $-0,025$ & 0,001 & 0,7837 & $-0,074$ & 0,006 & 0,4201 \\
\hline & & KpP & 120 & 0,964 & 0,929 & $<0,001$ & 0,961 & 0,923 & $<0,001$ \\
\hline & & Korn_Di & 120 & 0,062 & 0,004 & 0,5052 & 0,044 & 0,002 & 0,6321 \\
\hline & & StpP & 120 & 0,8183 & 0,670 & $<0,001$ & 0,8354 & 0,698 & $<0,001$ \\
\hline \multirow[t]{6}{*}{2013} & SpP & $\mathrm{KpS}$ & 123 & 0,070 & 0,005 & 0,4395 & 0,082 & 0,007 & 0,3698 \\
\hline & & TKM & 123 & $-0,073$ & 0,005 & 0,4253 & $-0,048$ & 0,002 & 0,5978 \\
\hline & & Spm2 & 123 & 0,409 & 0,168 & $<0,001$ & 0,358 & 0,128 & $<0,001$ \\
\hline & & $\mathrm{KpP}$ & 123 & 0,977 & 0,954 & $<0,001$ & 0,973 & 0,946 & $<0,001$ \\
\hline & & Korn_Di & 123 & 0,411 & 0,169 & $<0,001$ & 0,365 & 0,133 & $<0,001$ \\
\hline & & StpP & 123 & $0,864$. & $\underline{0,746}$ & $<0,001$ & $\underline{0,883}$ & 0,780 & $<0,001$ \\
\hline
\end{tabular}




\begin{tabular}{|c|c|c|c|c|c|c|c|c|c|}
\hline Jahr & $\mathrm{x}$-Variable & $y$-Variable & $\mathbf{n}$ & $r_{p}$ & $\mathbf{R}_{\mathbf{p}}^{2}$ & $p_{p}$ & $r_{s}$ & $\mathbf{R}_{\mathrm{s}}{ }^{2}$ & $p_{s}$ \\
\hline \multirow[t]{5}{*}{2011} & KpS & TKM & 120 & $-0,080$ & 0,006 & 0,3838 & $-0,104$ & 0,011 & 0,2597 \\
\hline & & Spm2 & 120 & $-0,041$ & 0,002 & 0,6546 & $-0,048$ & 0,002 & 0,6038 \\
\hline & & $\mathrm{KpP}$ & 120 & 0,562 & 0,316 & $<0,001$ & 0,580 & 0,336 & $<0,001$ \\
\hline & & Korn_Di & 120 & 0,230 & 0,053 & 0,0112 & 0,246 & 0,060 & 0,0066 \\
\hline & & StpP & 120 & 0,3774 & 0,142 & $<0,001$ & 0,3847 & 0,148 & $<0,001$ \\
\hline \multirow[t]{5}{*}{2013} & $\mathrm{KpS}$ & TKM & 124 & 0,123 & 0,015 & 0,1738 & 0,111 & 0,012 & 0,2210 \\
\hline & & Spm2 & 123 & 0,000 & 0,000 & 0,9971 & $-0,032$ & 0,001 & 0,7270 \\
\hline & & $\mathrm{KpP}$ & 124 & 0,211 & 0,044 & 0,0186 & 0,266 & 0,071 & 0,0027 \\
\hline & & Korn_Di & 124 & 0,271 & 0,074 & 0,0022 & 0,229 & 0,052 & 0,0103 \\
\hline & $\overline{\mathrm{TKM}} \overline{-}$ & $\frac{\text { StpP }}{\text { Spm2 }}$ & $\frac{124}{120}$ & $-\frac{0,056}{-0,545}$ & $\frac{0,003}{0,297}$ & $\begin{array}{r}-0,5405 \\
<0,001\end{array}$ & $\frac{0,041}{-0,565}$ & $\frac{0,002}{0,319}$ & $\begin{array}{l}0,6503 \\
-<0,001\end{array}$ \\
\hline \multirow{3}{*}{2011} & & $\mathrm{KpP}$ & 120 & 0,373 & 0,139 & $<0,001$ & 0,292 & 0,085 & 0,0012 \\
\hline & & Korn_Di & 120 & $-0,555$ & 0,308 & $<0,001$ & $-0,582$ & 0,339 & $<0,001$ \\
\hline & & StpP & 120 & 0,329 & 0,109 & 0,0002 & 0,310 & 0,096 & 0,0005 \\
\hline \multirow[t]{4}{*}{2013} & TKM & Spm2 & 123 & 0,043 & 0,002 & 0,6398 & 0,065 & 0,004 & 0,4754 \\
\hline & & $\mathrm{KpP}$ & 124 & $-0,022$ & 0,000 & 0,8115 & $-0,022$ & 0,000 & 0,8085 \\
\hline & & Korn_Di & 124 & 0,075 & 0,006 & 0,4107 & 0,093 & 0,009 & 0,3043 \\
\hline & & $-\frac{S t p P}{K p P}-$ & $\frac{124}{120}$ & $-\frac{-0,138}{-0,044}$ & $\frac{0,019}{0,002}$ & $-\frac{0,1269}{0,6330}$ & $\begin{array}{l}-0,149 \\
-\overline{-0,082}\end{array}$ & $\frac{0,022}{0,007}$ & $\begin{array}{l}0,0991 \\
-0,3764\end{array}$ \\
\hline \multirow{2}{*}{2011} & & Korn_Di & 120 & 0,959 & 0,920 & $<0,001$ & 0,945 & 0,894 & $<0,001$ \\
\hline & & StpP & 120 & $-0,117$ & 0,014 & 0,2037 & $-0,158$ & 0,025 & 0,0845 \\
\hline \multirow[t]{3}{*}{2013} & Spm2 & $\mathrm{KpP}$ & 123 & 0,394 & 0,155 & $<0,001$ & 0,345 & 0,119 & $<0,001$ \\
\hline & & Korn_Di & 123 & 0,959 & 0,920 & $<0,001$ & 0,955 & 0,912 & $<0,001$ \\
\hline & $\mathrm{KpP}$ & $-\frac{\text { StpP }}{\text { Korn_Di }}$ & $\frac{123}{120}$ & $-\frac{0,364}{0,106}$ & $\frac{0,132}{0,011}$ & $-\frac{\mathbf{0}, 001}{0,2505}$ & $\frac{0,332}{0,105}-$ & $\frac{0,110}{0,011}$ & $\begin{array}{l}<0,001 \\
-0,2540\end{array}$ \\
\hline 2011 & & StpP & 120 & 0,809 & 0,655 & $<0,001$ & 0,830 & 0,688 & $<0,001$ \\
\hline \multirow[t]{2}{*}{2013} & $\mathrm{KpP}$ & Korn_Di & 124 & 0,428 & 0,183 & $<0,001$ & 0,412 & 0,170 & $<0,001$ \\
\hline & $\overline{\text { Korn_Di }}-\overline{\mathrm{Di}}$ & $-\frac{\text { StpP }}{\text { StpP }}-$ & $\frac{124}{120}$ & $-\frac{0,848}{-0,013}=$ & $\frac{0,720}{0,000}$ & $-\frac{\mathbf{0 , 0 0 1}}{0,8873}$ & $-\frac{0,869}{-0,034}$ & $\frac{0,756}{0,001}$ & $\begin{array}{r}<0,001 \\
-0,7130\end{array}$ \\
\hline 2013 & Korn_Di & StpP & 124 & 0,366 & 0,134 & $<0,001$ & 0,346 & 0,120 & $<0,001$ \\
\hline
\end{tabular}

*Erklärung der Parameterabkürzungen: Di_Fj = Pflanzen $/ \mathrm{m}^{2}$ im Frühjahr; $\mathrm{SpP}=$ Schoten pro Pflanze; KpS = Körner pro Schote; TKM = Tausendkornmasse [g]; Spm2 = Schoten pro m²; KpP = Körner pro Pflanze; Korn_Di = Korndichte; StpP = Seitentriebe pro Pflanze 


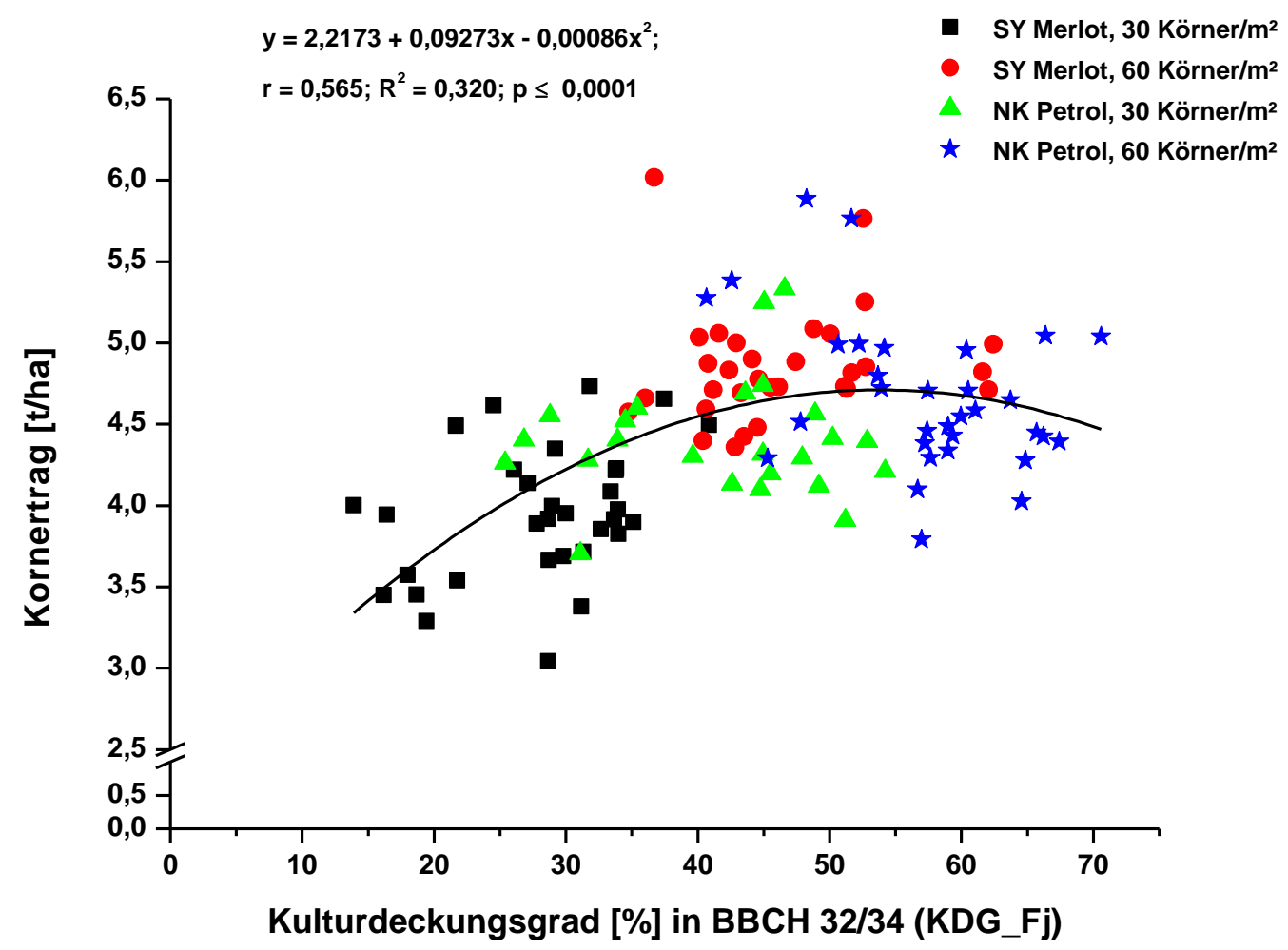

Abb. 19A: Quadratische Regression zwischen dem Kulturdeckungsgrad [\%] in $\mathrm{BBCH} 32 / 34$ (KDG_Fj) und dem Kornertrag [t/ha], berechnet aus den Daten, die im Versuchsjahr 2010/11 im Feldversuch am Standort Göttingen erhoben wurden. Zur Ermittlung des $p$-Wertes wurde der globale F-Test verwendet $(p \leq 0,05)$. $\left(r=\right.$ Korrelationskoeffizient, $R^{2}=$ Bestimmtheitsma $\left.B, n=120\right)$ 


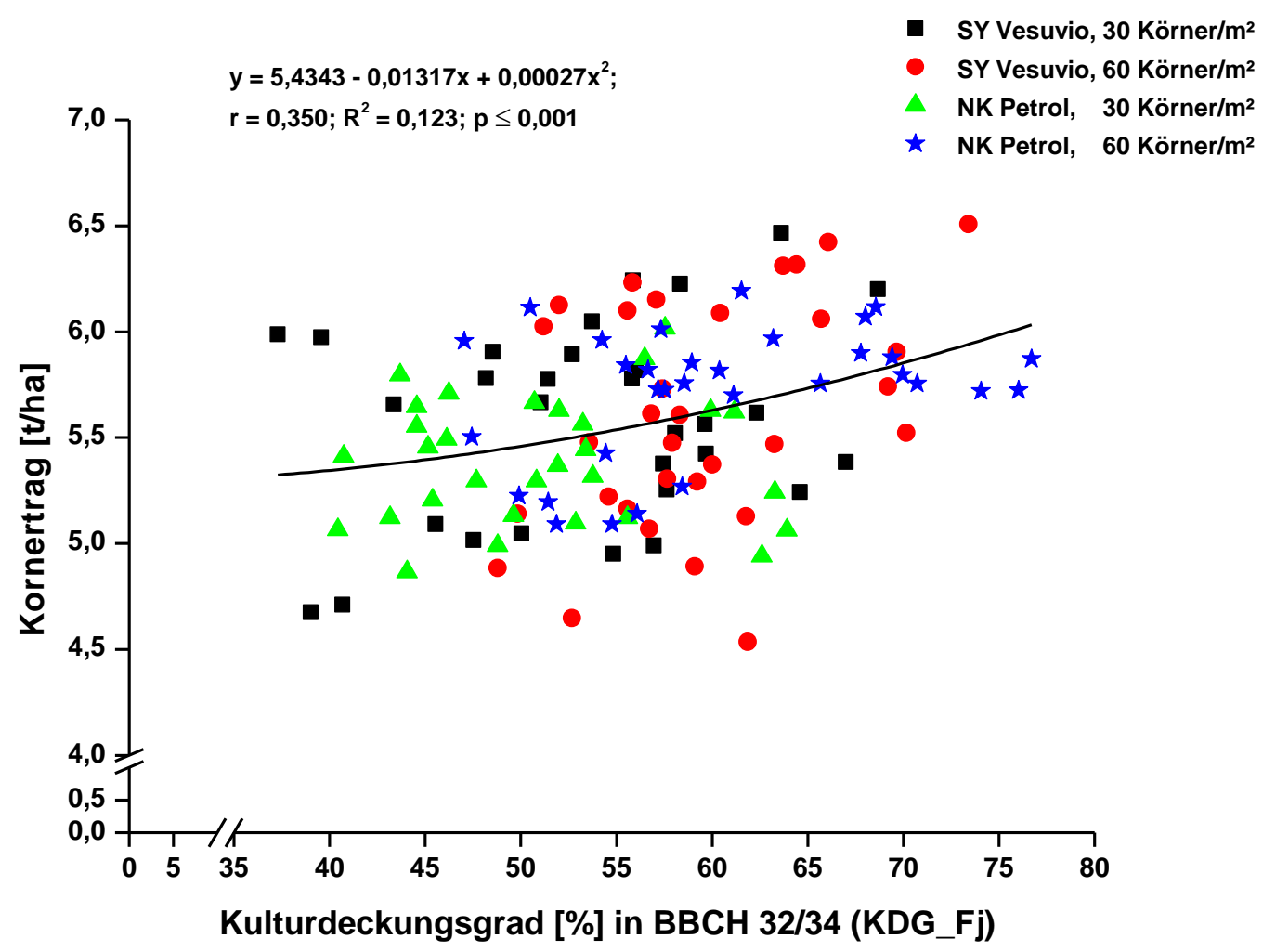

Abb. 20A: Quadratische Regression zwischen dem Kulturdeckungsgrad [\%] in $\mathrm{BBCH} 32 / 34$ (KDG_Fj) und dem Kornertrag [t/ha], berechnet aus den Daten, die im Versuchsjahr 2012/13 im Feldversuch am Standort Göttingen erhoben wurden. Zur Ermittlung des $p$-Wertes wurde der globale F-Test verwendet $(p \leq 0,05)$. $\left(r=\right.$ Korrelationskoeffizient, $R^{2}=$ Bestimmtheitsma $\left.B, n=124\right)$ 
Tab. 70A: Signifikante, einfache, lineare Regressionen zwischen der Schotenansatzhöhe bzw. der Bestandeshöhe von verschiedenen Messterminen und der Zielvariablen Strohbiomasseertrag (Feldversuch Göttingen 2012/13). Dargestellt ist die Anzahl der Werte (n), die in jede Regressionsrechnung eingeflossen sind, der Korrelationskoeffizient nach Pearson $\left(r_{p}\right)$, das Bestimmtheitsmaß nach Pearson $\left(R_{p}{ }^{2}\right)$ und die Überschreitungswahrscheinlichkeit ( $p$-Wert) für die Pearson-Korrelation $\left(p_{p}\right)$. Korrelationen bzw. Bestimmtheitsmaße sind signifikant bei einem Wert $p_{p} \leq 0,05$ (hoch signifikant bei $p_{p} \leq 0,01$, höchst signifikant bei $p_{p} \leq 0,001$ ).

\begin{tabular}{ccccc}
\hline Parameter & $\mathbf{n}$ & $\mathbf{r}_{\mathbf{p}}$ & $\mathbf{R}_{\mathbf{p}}{ }^{2}$ & $\mathbf{p}_{\mathbf{p}}$ \\
\hline Schotenansatzhöhe in BBCH 65/67 & 124 & 0,380 & 0,145 & $\leq 0,0001$ \\
Schotenansatzhöhe in BBCH 67/69 & 124 & 0,381 & 0,145 & $\leq 0,0001$ \\
Schotenansatzhöhe in BBCH 73/74 & 124 & 0,392 & 0,153 & $\leq 0,0001$ \\
Schotenansatzhöhe in BBCH 75 & 124 & 0,394 & 0,155 & $\leq 0,0001$ \\
Bestandeshöhe in BBCH 65/67 & 124 & 0,360 & 0,129 & $\leq 0,0001$ \\
Bestandeshöhe in BBCH 67/69 & 124 & 0,351 & 0,123 & $\leq 0,0001$ \\
Bestandeshöhe in BBCH 73/74 & 124 & 0,350 & 0,123 & $\leq 0,0001$ \\
Bestandeshöhe in BBCH 75 & 124 & 0,324 & 0,105 & 0,0002 \\
\hline
\end{tabular}

Tab. 71A: Signifikante, einfache, lineare Regressionen zwischen der Schotenansatzhöhe bzw. der Bestandeshöhe von verschiedenen Messterminen und der Zielvariablen Strohbiomasseertrag (Feldversuch Göttingen 2010/11). Dargestellt sind die Anzahl der Werte (n) die in jede Regressionsrechnung eingeflossen sind, der Korrelationskoeffizient nach Pearson $\left(r_{p}\right)$, das Bestimmtheitsmaß nach Pearson $\left(R_{p}{ }^{2}\right)$ und die Überschreitungswahrscheinlichkeit ( $p$-Wert) für die Pearson-Korrelation $\left(p_{p}\right)$. Korrelationen bzw. Bestimmtheitsmaße sind signifikant bei einem Wert $p_{p}$ $\leq 0,05$ (hoch signifikant bei $p_{p} \leq 0,01$, höchst signifikant bei $p_{p} \leq 0,001$ ).

\begin{tabular}{ccccc}
\hline Parameter & $\mathbf{n}$ & $\mathbf{r}_{\mathbf{p}}$ & $\mathbf{R}_{\mathbf{p}}{ }^{2}$ & $\mathbf{p}_{\mathbf{p}}$ \\
\hline Schotenansatzhöhe in BBCH 65 & 120 & $-0,007$ & 0,00004 & 0,943 \\
Schotenansatzhöhe in BBCH 67/69 & 120 & $-0,017$ & 0,0002 & 0,856 \\
Schotenansatzhöhe in BBCH 73/74 & 120 & $-0,012$ & 0,0001 & 0,894 \\
Schotenansatzhöhe in BBCH 75 & 120 & 0,032 & 0,001 & 0,726 \\
Bestandeshöhe in BBCH 65/67 & 120 & 0,154 & 0,023 & 0,092 \\
Bestandeshöhe in BBCH 67/69 & 120 & 0,118 & 0,014 & 0,198 \\
Bestandeshöhe in BBCH 73/74 & 120 & 0,094 & 0,009 & 0,307 \\
Bestandeshöhe in BBCH 75 & 120 & 0,143 & 0,021 & 0,117 \\
\hline
\end{tabular}


Tab. 72A: Mittlere Pflanzendichte im Herbst und Frühjahr, getrennt nach Versuchsjahr für die Interaktion aus Sorte und Saatstärke dargestellt.

\begin{tabular}{ccccc}
\hline Versuchsjahr & Sorte & Saatstärke & \multicolumn{2}{c}{ Pflanzen $/ \mathrm{m}^{2}$} \\
& & & Herbst & Frühjahr \\
\hline \multirow{2}{*}{$2010 / 11$} & SY Merlot & $30 \mathrm{Körner} / \mathrm{m}^{2}$ & 28,8 & 19,5 \\
& & $60 \mathrm{Körner} / \mathrm{m}^{2}$ & 51,8 & 42,3 \\
& NK Petrol & $30 \mathrm{Körner} / \mathrm{m}^{2}$ & 36,6 & 29,0 \\
& & $60 \mathrm{Körner} / \mathrm{m}^{2}$ & 59,3 & 52,5 \\
\hline \multirow{2}{*}{$2012 / 13$} & SY Vesuvio & $30 \mathrm{Körner} / \mathrm{m}^{2}$ & 35,6 & 31,8 \\
& & $60 \mathrm{Körner} / \mathrm{m}^{2}$ & 58,4 & 49,4 \\
& NK Petrol & $30 \mathrm{Körner} / \mathrm{m}^{2}$ & 32,6 & 27,7 \\
& & $60 \mathrm{Körner} / \mathrm{m}^{2}$ & 63,7 & 54,0 \\
\hline
\end{tabular}

Tab. 73A: Mittelwerte der einzelnen primären Ertragsfaktoren sowie von Schotendichte und Seitentriebe/Pflanze über alle Parzellen getrennt nach Versuchsjahr.

\begin{tabular}{ccc}
\hline Ertragsfaktor & \multicolumn{2}{c}{ Versuchsjahr } \\
\hline Pflanzen/m² & $\mathbf{2 0 1 0 / 1 1}$ & $\mathbf{2 0 1 2 / 1 3}$ \\
Schoten/Pflanze & 36 & 41 \\
Körner/Schote & 257,0 & 175,2 \\
TKM & 22,7 & 24,2 \\
Schotendichte (Schoten $\left./ \mathrm{m}^{2}\right)$ & 5,46 & 4,42 \\
Seitentriebe/Pflanze & 8579,1 & 6664,6 \\
\end{tabular}




\section{Danksagung}

Ich möchte mich ganz besonders bei Herrn Prof. Dr. Andreas von Tiedemann für die Überlassung des Themas, die Diskussions- und Hilfsbereitschaft sowie die gewährte Freiheit bei der Bearbeitung des Projektes bedanken.

Bei Prof. Dr. Heiko Becker und Prof. Dr. Rolf Rauber bedanke ich mich für die Übernahme des Korreferats und die Teilnahme am Prüfungskomitee.

Herrn Dr. Birger Koopmann danke ich für seine stete Hilfsbereitschaft bei Fragen jeglicher Art.

Für ihre tatkräftige Unterstützung in Labor, Gewächshaus und insbesondere im Feld danke ich Dagmar Tacke, Evelin Vorbeck, Jutta Schaper, Eugen Hodyl, Maik Knobel und Hubertus Reintke. Ohne ihre vielen Tipps und ihre Hilfe wäre Vieles nicht möglich gewesen.

Für die technische Unterstützung jeglicher Art und das unkomplizierte, flexible Handeln danke ich Mark Fiebrich und insbesondere Frank Gremmes.

Bei Evelin Kistner, Bianke Gürntke und insbesondere Martina Bode möchte ich mich für die pragmatische und unbürokratische Hilfe in allen administrativen Angelegenheiten bedanken.

Mein Dank gilt weiterhin meinen beiden Büronachbarn Dr. Nazanin Zamani-Noor und Messan N'Ditisi sowie Kerstin Höch, Geoffrey Onaga und Hendrik Hanekamp für die angenehme Arbeitsatmosphäre, die stete Hilfsbereitschaft, viele anregende Diskussionen und die entgegengebrachte Freundschaft.

Ganz besonders bedanke ich mich bei meinen studentischen Hilfskräften und weiteren freiwilligen Helfern: Stefanie Retz, Kerstin Höch, Lena Steckelberg, Ann-Kathrin Lichtner, Claudia Nordmann, Christian Rikels, David Frische, Alexander Pfaff, Andreas Rahlves, Malik Farooq, Daniel Lopisso, Daniel Kretzschmar und Robert Knoll. Ohne ihre unermüdliche Unterstützung bei der Erhebung der verschiedenen Bestandesparameter und den Bonituren im Gewächshaus wäre der Arbeitsanfall nicht zu bewältigen gewesen.

Der Abteilung Pflanzenzüchtung und hierbei insbesondere Herrn Haiko Brandes gilt mein Dank für die Durchführung der Ölgehaltsanalysen von den Ernteproben.

Sehr herzlich bedanke ich mich bei Dr. Christian Kluth für die dreijährige, kompetente und produktive statistische Beratung. Besonders zum Ende der Arbeit hat mir Herr Dr. Kluth mit großer Geduld bei der Auswertung meines Feldversuches zur Seite gestanden. 
Dr. Anke Sirrenberg, Dr. Mark Winter, Dr. Heinz Josef Kochs und meinem Bruder Martin danke ich vielmals für die kritische Durchsicht der Manuskripte und den fachlichen Austausch.

Bei der Syngenta Agro GmbH bedanke ich mich für die Finanzierung des Projektes Crop Enhancement Oilseed Rape. Für die konstruktive und angenehme Betreuung des Projektes seitens Syngenta möchte ich mich herzlich bei Frau Dr. Ute Achenbach, Herrn Dr. Willy Rueegg, Herrn Dr. Johannes Henke und Herrn Dr. Michael Käsbohrer bedanken. Generell bedanke ich mich bei allen Kolleginnen und Kollegen, die ich während meiner Zeit in der Abteilung Allgemeine Pflanzenpathologie und Pflanzenschutz kennengelernt habe, für das tolle Arbeitsklima und die immer währende Hilfsbereitschaft.

Mein größter Dank gilt meinen Eltern, die mir das Studium und die Promotion ermöglicht haben sowie meiner Frau für ihre Unterstützung und Geduld. 


\section{Erklärungen}

1. Hiermit erkläre ich, dass diese Arbeit weder in gleicher noch in ähnlicher Form bereits anderen Prüfungsbehörden vorgelegen hat.

Weiter erkläre ich, dass ich mich an keiner anderen Hochschule um einen Doktorgrad beworben habe.

Göttingen, den

(Unterschrift)

2. Hiermit erkläre ich eidesstattlich, dass diese Dissertation selbständig und ohne unerlaubte Hilfe angefertigt wurde.

Göttingen, den

(Unterschrift) 


\section{Lebenslauf}

Persönliche Daten

Name

Christian Comberg

Geburtsdatum/ort

18.04.1985/Mettmann

Familienstand

verheiratet

\section{Beruflicher Werdegang}

seit 06.2014

Pfeifer \& Langen GmbH \& Co. KG,

Landwirtschaftlicher Informationsdienst Zuckerrübe

\section{Hochschulausbildung}

$11.2010-01.2014$

Promotion an der Georg-August-Universität Göttingen,

Department für Nutzpflanzenwissenschaften,

Abteilung Allgemeine Pflanzenpathologie und

Pflanzenschutz, Projekt: Crop Enhancement Oilseed Rape

$07.2009-07.2010$

Diplomarbeit bei der Bayer CropScience AG, Monheim

Titel der Arbeit: Wirksamkeit von fungiziden Beizen gegen-

über Microdochium nivale; Abschluss: Diplom-Agraringenieur

$10.2005-07.2010$

Studium der Agrarwissenschaften an der Rheinischen

Friedrich-Wilhelms-Universität Bonn,

Studienschwerpunkt: Pflanzenwissenschaften

$09.2004-08.2005$

Landwirtschaftliches Praktikum zur Vorbereitung des

Studiums mit anschließender Praktikantenprüfung an der LWK NRW

\section{Schulausbildung}

$08.2001-06.2004$

Städtisches Gymnasium Wülfrath; Abschluss Abitur

$08.1995-06.2001$

Theodor-Heuss-Realschule, Wülfrath

$08.1991-06.1995$

Grundschule Rohdenhaus, Wülfrath 